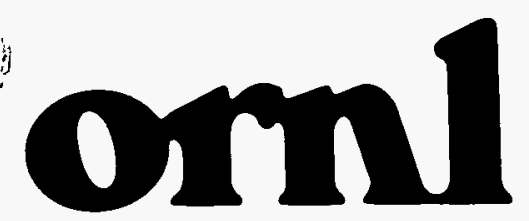

OAK RIDGE

NATIONAL LABORATORY

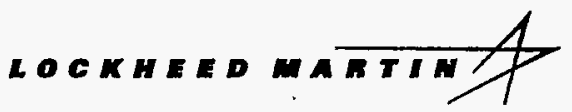

REOEVIVE

JAH 291997

O STI

\section{User's Manual for the SOURCE1 and SOURCE2 Computer Codes: Models for Evaluating Low-Level Radioactive Waste Disposal Facility Source Terms (Version 2.0)}

Alan S. Icenhour

M. Lynn Tharp
MISTRATHE: GF THE, DOCUMENT IS UNLIMITED<smiles>C1=C[As]1</smiles> 
This report has been reproduced directly from the best available copy.

Available to DOE and DOE contractors from the Office of Scientific and Technical Information, P.O.Box 62, Oak Ridge, TN 37831; prices available from (423) 576-8401, FTS 626-8401.

Available to the public from the National Technical Information Service, U.S. Department of Commerce, 5285 Port Royal Rd., Springfield, VA 22161

This report was prepared a an account of work sponsored by an agency of the United States Govemment. Neither the United States Government nor any agency thereof, nor any of their employees, makes any warranty, express or implied, or assumes any legal liability or responsibility for the accuracy. completeness, or usefulness of any information, apparatus, product, or process disclosed, or represents that its use would not infringe privately owned rights. Reference herein to any specific commercial product, process, or service by trade name, trademark, manufacturer, or otherwise, does not necessarily constitule or imply its endorsement, recommendation, or favoring by the United States Government or any agency thereof. The view and opinions of authors expressed herein do not necessarily slate or reflect those of the UnitedStatesGovernment or any agency thereof.

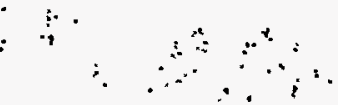


User's Manual for the SOURCE1 and SOURCE2 Computer Codes: Models for Evaluating Low-Level Radioactive Waste Disposal Facility Source Terms (Version 2.0)

Alan S. Icenhour

M. Lynn Tharp

Date Published: August 1996

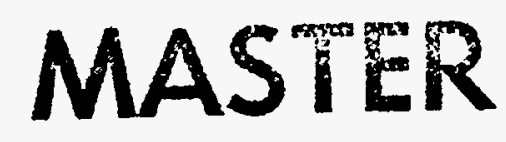

Prepared by the

OAK RIDGE NATIONAL LABORATORY

Oak Ridge, Tennessee 37831-6495

managed by

LOCKHEED MARTIN ENERGY RESEARCH CORP.

for the

U.S. DEPARTMENT OF ENERGY

under contract DE-AC05-96OR22464 


\section{DISCLAIMER}

Portions of this document may be illegible in electronic image products. Images are produced from the best available original document. 


\section{CONTENTS}

Page

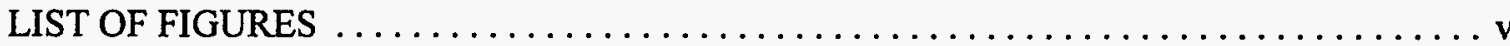

LIST OF TABLES $\ldots \ldots \ldots \ldots \ldots \ldots \ldots \ldots \ldots \ldots \ldots \ldots \ldots \ldots \ldots \ldots \ldots \ldots \ldots \ldots$

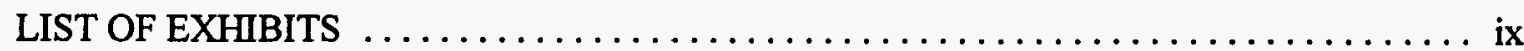

LIST OF ABBREVIATIONS, ACRONYMS, AND INITIALISMS $\ldots \ldots \ldots \ldots \ldots \ldots \ldots$ xi

LIST OF SYMBOLS $\ldots \ldots \ldots \ldots \ldots \ldots \ldots \ldots \ldots \ldots \ldots \ldots \ldots \ldots \ldots \ldots \ldots \ldots \ldots \ldots \ldots \ldots$

ACKNOWLEDGMENTS $\ldots \ldots \ldots \ldots \ldots \ldots \ldots \ldots \ldots \ldots \ldots \ldots \ldots \ldots \ldots \ldots \ldots \ldots \ldots \ldots$

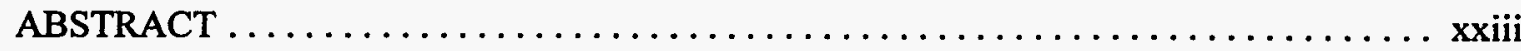

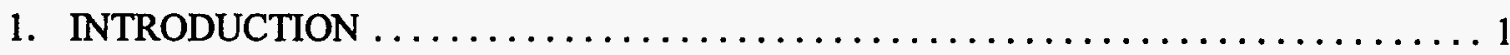

1.1 BACKGROUND $\ldots \ldots \ldots \ldots \ldots \ldots \ldots \ldots \ldots \ldots \ldots \ldots \ldots \ldots \ldots$

1.2 SUMMARY OF MAJOR REVISIONS TO THE SOURCE1 AND

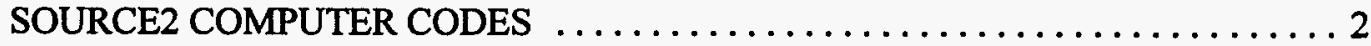

1.2.1 New Advective Transport Model ........................ 2

1.2.2 Degradation Models for Concrete Pad and

Leachate Collection System $\ldots \ldots \ldots \ldots \ldots \ldots \ldots \ldots \ldots \ldots \ldots \ldots \ldots \ldots \ldots \ldots$

1.2.2.1 Concrete Pad Degradation Model .................... 3

1.2.2.2 Leachate Collection System Degradation Model ............ 5

1.2.3 Variation of Water Infiltration Input $\ldots \ldots \ldots \ldots \ldots \ldots \ldots \ldots \ldots \ldots \ldots \ldots \ldots \ldots \ldots$

1.2.4 Variation of Radionuclide Inventory Input $\ldots \ldots \ldots \ldots \ldots \ldots \ldots \ldots$

1.2.5 Addition of Output Files . . . . . . . . . . . . . . . . . . . . . 7

2. COMPUTER CODE OVERVIEW $\ldots \ldots \ldots \ldots \ldots \ldots \ldots \ldots \ldots \ldots \ldots \ldots \ldots \ldots$

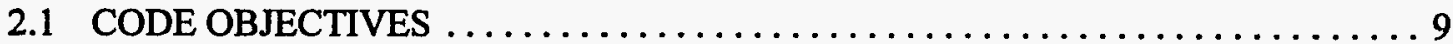

2.2 CONCEPTUAL MODEL SUMMARY $\ldots \ldots \ldots \ldots \ldots \ldots \ldots \ldots \ldots \ldots \ldots$

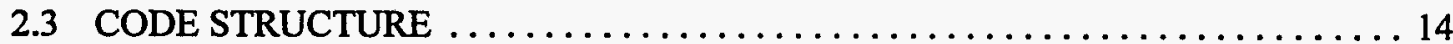

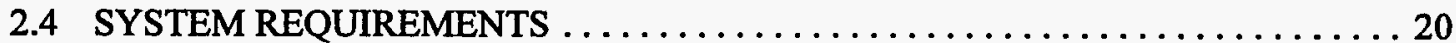

3. CONCEPTUAL AND MATHEMATICAL MODELING METHODOLOGY $\ldots \ldots \ldots 21$

3.1 CONCRETE DEGRADATION MODELING $\ldots \ldots \ldots \ldots \ldots \ldots \ldots \ldots \ldots \ldots \ldots \ldots$

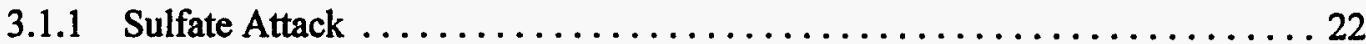

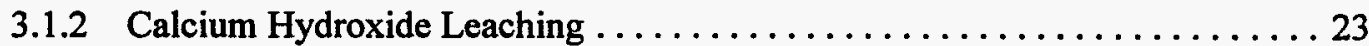

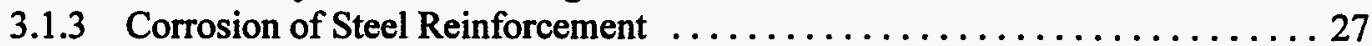


3.2 CONCRETE STRUCTURAL AND CRACKING ANAYSES $\ldots \ldots \ldots \ldots \ldots \ldots$

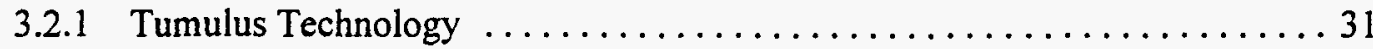

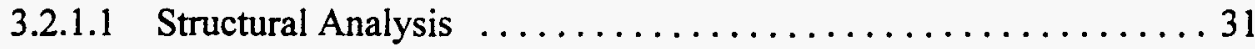

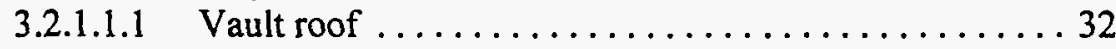

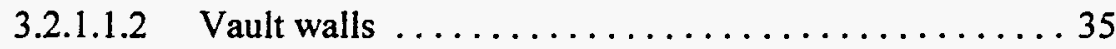

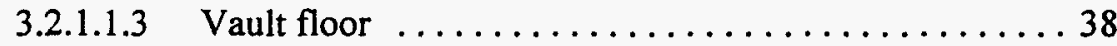

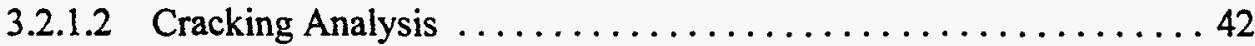

3.2.1.3 Concrete Pad Degradation Model ................. 53

3.2.1.4 Leachate Collection System Degradation Model ............ 55

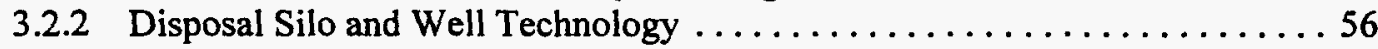

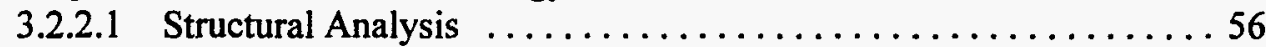

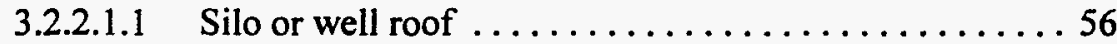

3.2.2.1.2 Silo or well wall $\ldots \ldots \ldots \ldots \ldots \ldots \ldots \ldots \ldots \ldots \ldots$

3.2.2.1.3 Silo or well floor $\ldots \ldots \ldots \ldots \ldots \ldots \ldots \ldots \ldots \ldots \ldots \ldots$

3.2.2.2 Cracking Analyses . . . . . . . . . . . . . . . . . . 64

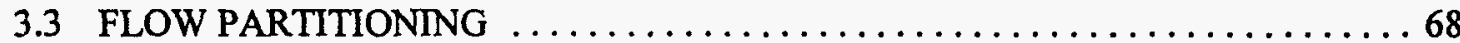

3.4 RADIONUCLIDE RELEASE MODELING $\ldots \ldots \ldots \ldots \ldots \ldots \ldots \ldots \ldots \ldots \ldots \ldots \ldots \ldots$

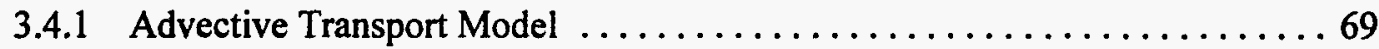

3.4 .2 Diffusion Transport Model .......................... 70

3.4.3 Calculation of Total Radionuclide Release $\ldots \ldots \ldots \ldots \ldots \ldots \ldots \ldots$

4. DESCRIPTION OF THE SOURCE CODES INPUT AND OUTPUT FILES $\ldots \ldots \ldots 75$

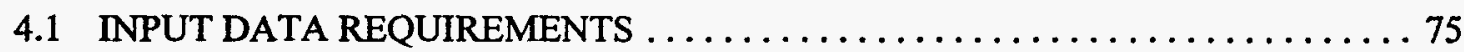

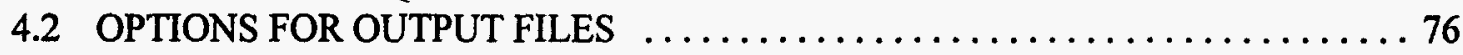

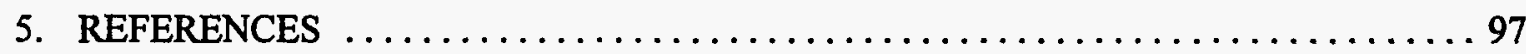

APPENDIX A. THE FLOTHRU COMPUTER PROGRAM $\ldots \ldots \ldots \ldots \ldots \ldots \ldots \ldots 1$

APPENDIX B. GLOSSARY OF SOURCE-CODE PARAMETERS $\ldots \ldots \ldots \ldots \ldots \ldots 121$

APPENDIX C. SAMPLE INPUT AND OUTPUT FILES FOR THE

SOURCE1 AND SOURCE2 COMPUTER CODES $\ldots \ldots \ldots \ldots \ldots \ldots 133$

APPENDIX D. COMPUTER CODE LISTINGS FOR SOURCE1 AND SOURCE2 . . . . 169 


\section{LIST OF FIGURES}

Figure

Page

2.1 Representative tumulus-type disposal facility modeled by SOURCE1 $\ldots \ldots \ldots 10$

2.2 Representative silo-type disposal facility modeled by SOURCE2 $\ldots \ldots \ldots \ldots \ldots 11$

2.3 Logic flow of the SOURCE computer codes $\ldots \ldots \ldots \ldots \ldots \ldots \ldots \ldots \ldots$

2.4 Logic flow of the concrete-degradation and -cracking subroutines $\ldots \ldots \ldots \ldots 15$

2.5 SOURCE1 code hierarchy for modeling tumulus-type disposal facilities $\ldots \ldots \ldots 16$

2.6 SOURCE2 code hierarchy for modeling disposal silos and wells $\ldots \ldots \ldots \ldots \ldots 17$

3.1 Schematic diagram of floor geometry used in the calculation

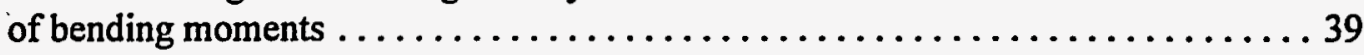

3.2 Schematic diagram of steel and concrete geometry used in calculating stress resulting from corrosion of steel reinforcement $\ldots \ldots \ldots \ldots \ldots \ldots \ldots 1$

3.3 Representation of the system modeled by the FLOTHRU computer code $\ldots \ldots \ldots 71$

A.1 Roots of the transcendental equation (dots) for $D_{2} / D_{1}=1 \ldots \ldots \ldots \ldots \ldots \ldots$

A.2 Roots of the transcendental equation (dots) for $D_{2} / D_{1}=0.5 \ldots \ldots \ldots \ldots \ldots$

A.3 Roots of the transcendental equation (dots) for $\mathrm{D}_{2} / \mathrm{D}_{1}=10 \ldots \ldots \ldots \ldots \ldots \ldots$ 


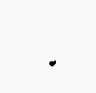




\section{LIST OF TABLES}

Table

Page

2.1 SOURCE1 and SOURCE2 program module description $\ldots \ldots \ldots \ldots \ldots \ldots \ldots 18$

4.1 Input data format for the SOURCE1 computer code $\ldots \ldots \ldots \ldots \ldots \ldots \ldots$

4.2 Input data format for the SOURCE2 computer code $\ldots \ldots \ldots \ldots \ldots \ldots \ldots$

4.3 Input data format for the SOURCE computer codes infiltration values . . . . . . 94

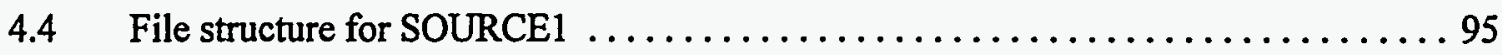

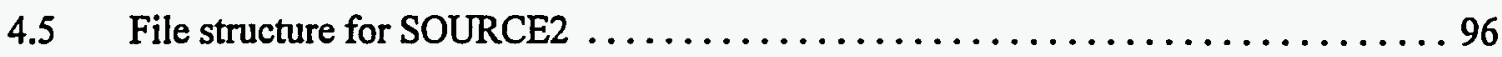

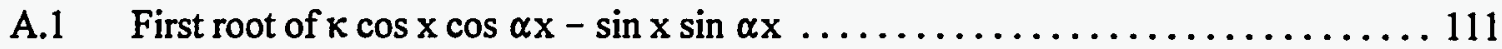

A.2 Comparison of series and alternate solutions $\ldots \ldots \ldots \ldots \ldots \ldots \ldots \ldots \ldots \ldots$ 


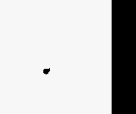




\section{LIST OF EXHIBITS}

\section{Exhibit}

C.1 Sample SOURCE1 input file for ${ }^{137} \mathrm{Cs}$ in a tumulus-type facility with a concrete pad (filename.inp)

C.2 Sample water infiltration input data (the name for this file is specified

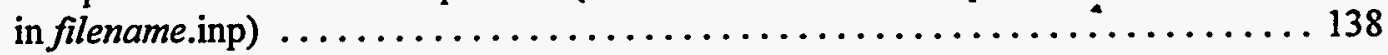

C.3 Sample SOURCE1 output file for input data summary and concrete analyses (filename.con)

C.4 Sample SOURCE1 output of water infiltration input data (filename.h2o) . . . . . 144

C.5 Sample SOURCE1 output of recharge release component (filename.rch) $\ldots \ldots \ldots 145$

C.6 Sample SOURCE1 output of lateral release component (filename.lat) $\ldots \ldots \ldots 146$

C.7 Sample SOURCE1 output of leaching summary (filename.sum) $\ldots \ldots \ldots \ldots \ldots 147$

C.8 Sample SOURCE1 output of advective and diffusive release rates

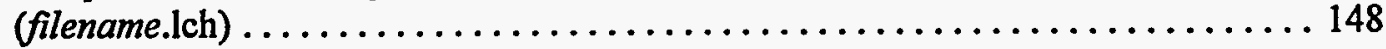

C.9 Sample SOURCE1 output summary for intact vaults (filename.vt1) $\ldots \ldots \ldots \ldots 149$

C.10 Sample SOURCE1 output summary for cracked vaults (filename.vt2) $\ldots \ldots \ldots \ldots 150$

C.11 Sample SOURCE1 input file for ${ }^{137} \mathrm{Cs}$ in a tumulus-type facility without

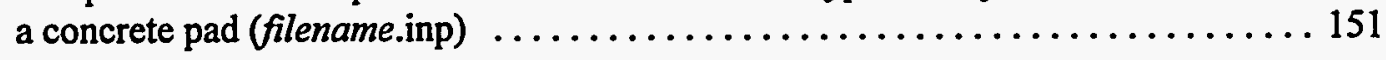

C.12 Sample SOURCE2 input file for ${ }^{238} \mathrm{U}$ in a silo-type facility (filename.inp) $\ldots \ldots \ldots 152$

C.13 Sample SOURCE2 output file for input data summary and concrete

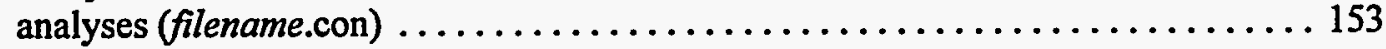

C.14 Sample SOURCE2 output of water infiltration input data (filename.h2o) $\ldots \ldots \ldots 161$

C.15 Sample SOURCE2 output of recharge release component (filename.rch) $\ldots \ldots \ldots 162$

C.16 Sample SOURCE2 output of lateral release component (filename.lat) $\ldots \ldots \ldots 163$

C.17 Sample SOURCE2 output of leaching summary (filename.sum) $\ldots \ldots \ldots \ldots \ldots 164$

C.18 Sample SOURCE2 output of advective and diffusive release

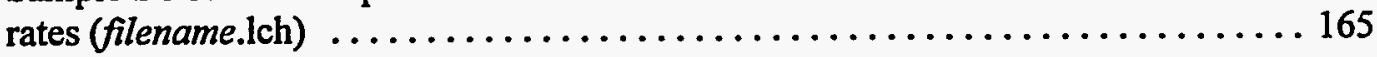

C.19 Sample SOURCE2 input file for ${ }^{137} \mathrm{Cs}$ in a well-type facility (filename.inp) . . . . 166 
C.20 Sample SOURCE2 input file for ${ }^{137} \mathrm{Cs}$ in a well-in-silo-type facility

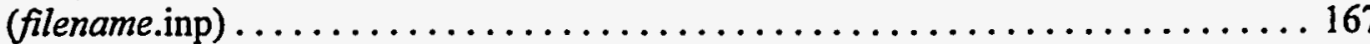

C.21 Sample SOURCE2 input file for ${ }^{137} \mathrm{Cs}$ in a trench-type facility (filename.inp) $\ldots 168$

D.1 Computer Code Listing for SOURCE1 $\ldots \ldots \ldots \ldots \ldots \ldots \ldots \ldots \ldots \ldots \ldots \ldots$

D.2 Computer Code Listing for SOURCE2 $\ldots \ldots \ldots \ldots \ldots \ldots \ldots \ldots \ldots \ldots \ldots \ldots \ldots \ldots \ldots \ldots$ 


\section{LIST OF ABBREVIATIONS, ACRONYMS, INITIALISMS, AND CHEMICAL NOTATIONS}

ANSI

CIIDF

$\mathrm{Ca}(\mathrm{OH})_{2}$

C-S-H

$\mathrm{CO}_{2}$

FLOTHRU

$\mathrm{KOH}$

LLW

$\mathrm{NaOH}$

ORNL

ORR

SOURCE

SWSA 6

\begin{abstract}
American National Standards Institute, Inc.
\end{abstract}
Class II Disposal Facility

Calcium hydroxide

Calcium-silicate-hydrate

Carbon dioxide

Subroutine in SOURCE1 and SOURCE2 that calculates radionuclide releases as a result of diffusion

Potassium hydroxide

Low-level radioactive waste

Sodium hydroxide

Oak Ridge National Laboratory

Oak Ridge Reservation

Used when referring to both the SOURCE1 and SOURCE2 computer codes

Solid Waste Storage Area 6 



\section{LIST OF SYMBOLS}

\section{English}

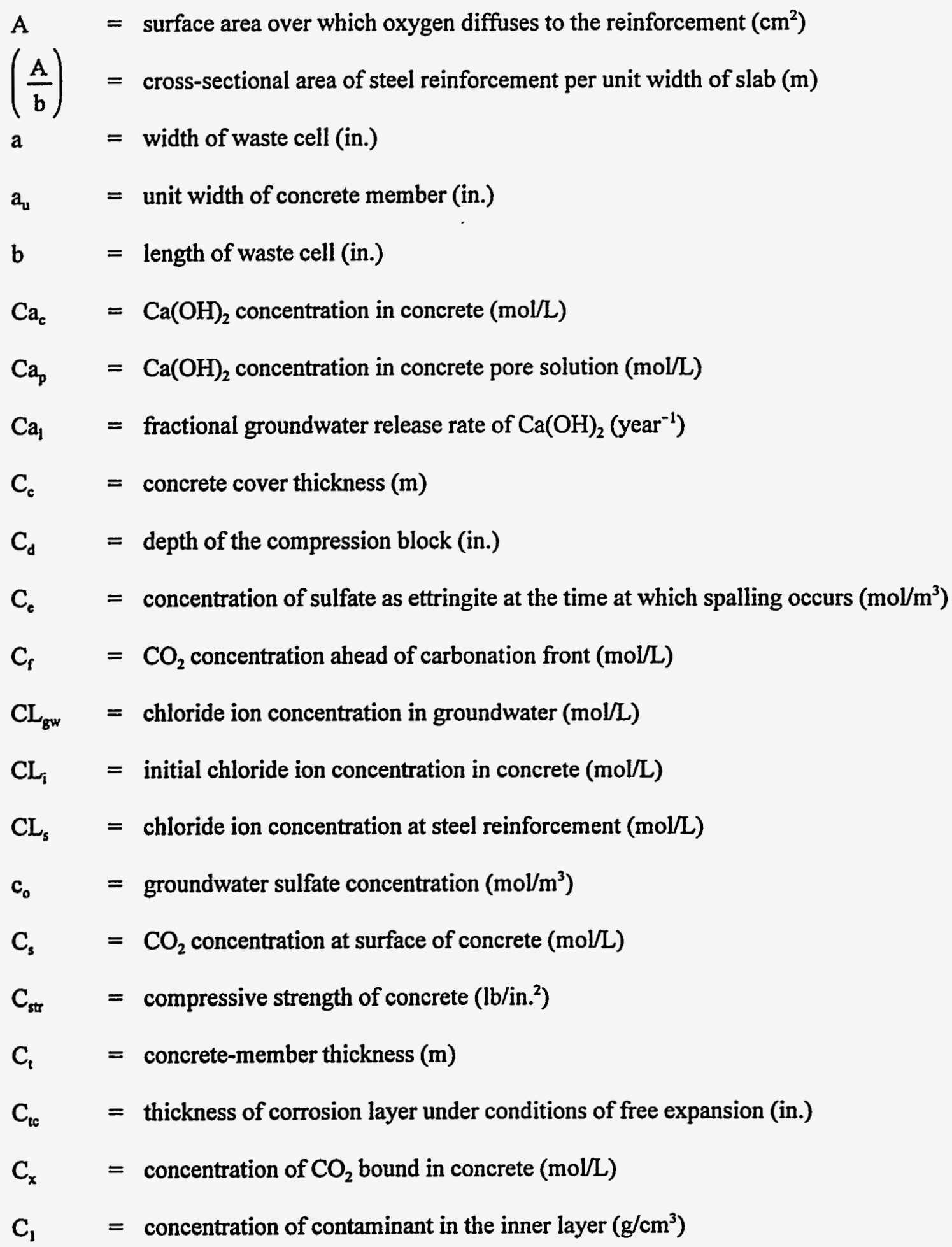




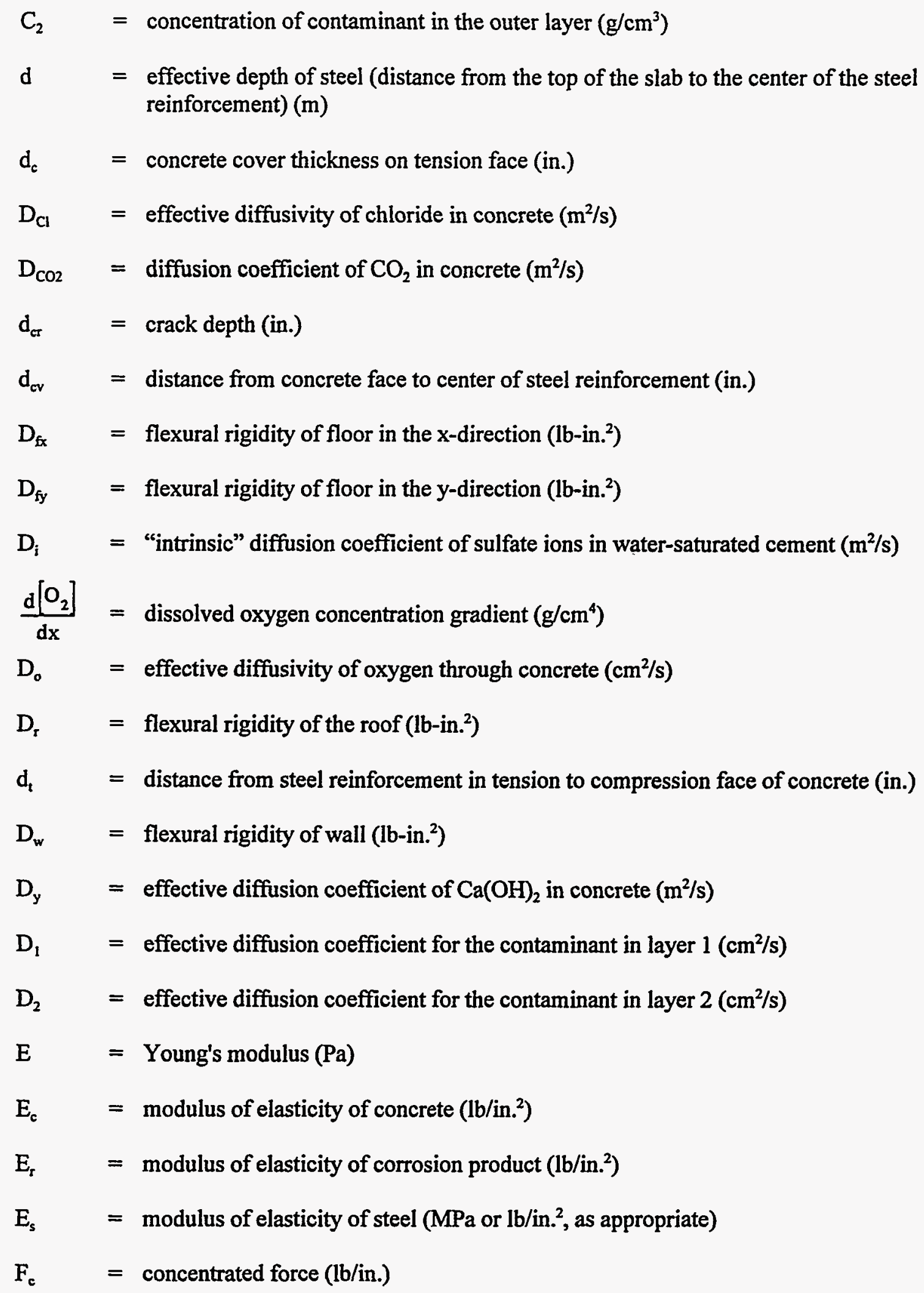




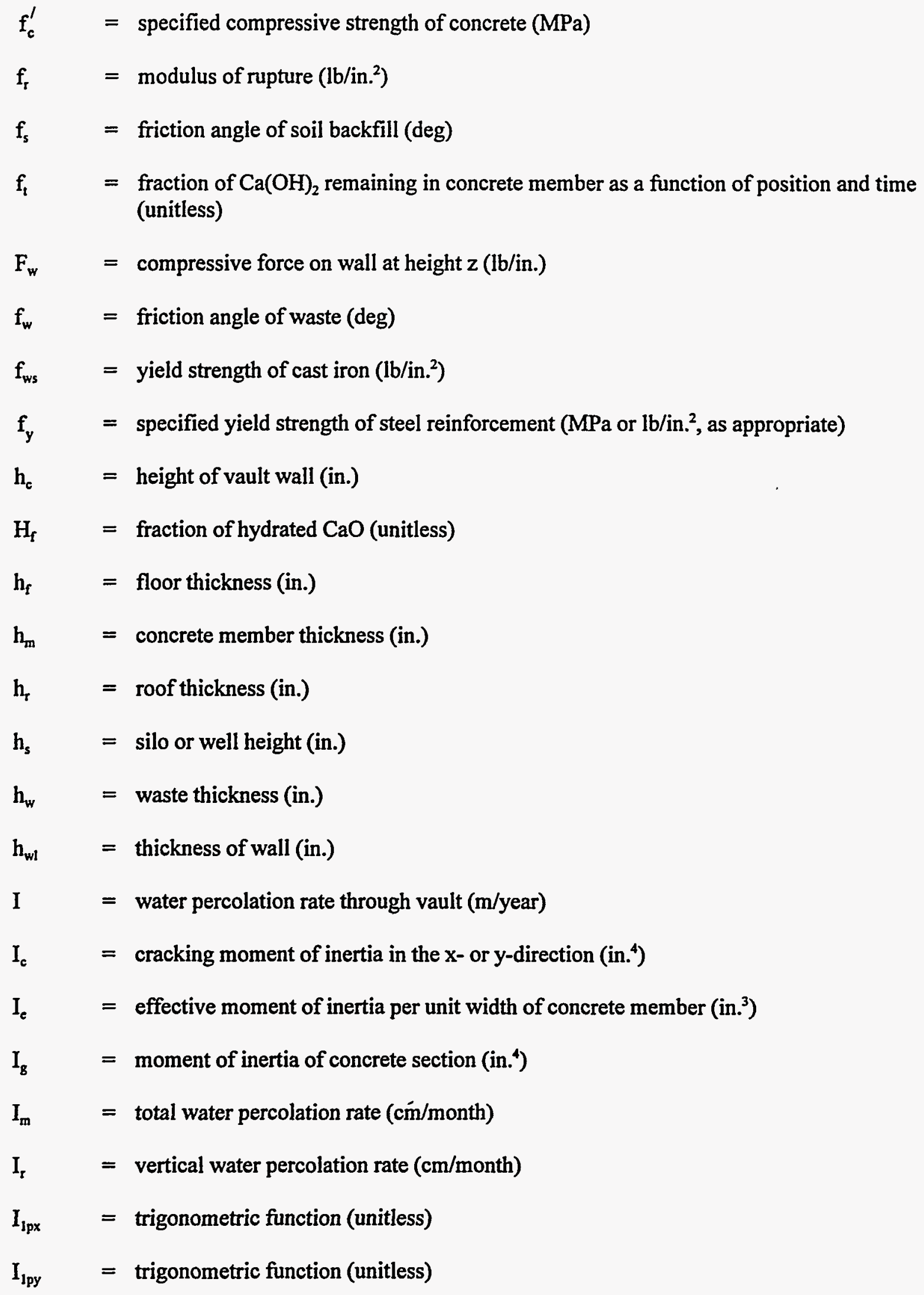




$$
\begin{aligned}
& \mathrm{I}_{2 \mathrm{px}} \quad=\text { trigonometric function (unitless) } \\
& I_{2 p y} \quad=\text { trigonometric function (unitless) } \\
& \mathrm{J}_{\mathrm{o}} \quad=\text { oxygen flux at the steel reinforcement }(\mathrm{g} / \mathrm{s}) \\
& \mathrm{k}=\text { carbonation coefficient }\left(\mathrm{m} / \mathrm{s}^{0.5}\right) \\
& \tilde{\mathrm{k}}=\text { modulus of the subgrade reaction }\left(\mathrm{lb} / \mathrm{in}^{3}{ }^{3}\right) \\
& \mathrm{K}_{\mathrm{d}} \quad=\text { distribution coefficient }(\mathrm{mL} / \mathrm{g}) \\
& \mathrm{L}=\text { mass of radionuclide leached because of advection (g) } \\
& \mathrm{L}_{\mathrm{cm}} \quad=\text { thickness of corrugated steel liner on compression face (in.) } \\
& l_{\mathfrak{f}} \quad=\text { length of floor (in.) } \\
& \mathrm{L}_{\mathrm{t}} \quad=\text { thickness of corrugted steel liner on tension face (in.) } \\
& \mathrm{M} \text { = bending moment due to uniform loading in } \mathrm{x} \text { or } \mathrm{y} \text { direction (lb-in./in.) } \\
& \mathrm{M}_{\mathrm{cr}} \quad=\text { cracking moment per unit width }\left(\frac{\mathrm{lb}-\mathrm{in} .}{\text { in. }}\right) \text {. } \\
& \mathrm{M}_{\mathrm{my}} \quad=\text { modified moment }(\mathrm{lb} \text {-in.) } \\
& \mathrm{M}_{\mathrm{r}} \quad=\text { radial component of bending moment ( } \mathrm{lb} \text {-in./in.) } \\
& \mathrm{M}_{\mathrm{t}} \quad=\text { tangential component of bending moment (lb-in./in.) } \\
& \mathrm{M}_{\mathrm{u}} \quad \text { = ultimate flexural strength (lb-in./in.) } \\
& \mathrm{M}_{\mathrm{uc}} \quad \text { = ultimate strength of the wall in compression (lb/in.) } \\
& \mathrm{M}_{\mathrm{x}} \quad \text { = bending moment resulting from uniform loading in the } \mathrm{x} \text {-direction parallel to width } \\
& \text { of floor or roof (lb-in./in.) } \\
& \mathrm{M}_{\mathrm{xh}} \quad \text { = bending moment resulting from hydrostatic pressures in the x-direction parallel to the }
\end{aligned}
$$




$$
\begin{aligned}
& \mathrm{N}_{a \mathrm{c}}=\text { ultimate strength or critical buckling strength under axial compression (lb/in.) } \\
& \mathrm{N}_{\mathrm{rc}} \quad=\text { ultimate strength or critical buckling strength under ring compression (lb/in.) } \\
& \left.\mathrm{N}_{\theta} \quad=\text { ring compression force (lb/in. }{ }^{2}\right) \\
& \mathrm{P} \quad=\text { maximum hydrostatic pressure }\left(\mathrm{lb} / \mathrm{in}^{2}{ }^{2}\right) \\
& \left.\mathrm{P}_{\mathrm{i}} \quad=\text { internal pressure due to corrosion (lb/in. }{ }^{2}\right) \\
& \mathrm{P}_{\mathrm{x}} \quad=\text { applied concentrated load caused by wall in } \mathrm{x} \text {-direction (lb/in.) } \\
& \mathrm{P}_{\mathrm{y}} \quad=\text { applied concentrated load caused by wall in } \mathrm{y} \text {-direction (lb/in.) } \\
& \text { Q = shear force on roof of well or silo (lb/in.) } \\
& \mathrm{q}=\text { water infiltration rate }(\mathrm{cm} / \mathrm{s}) \\
& \mathrm{Q}_{\max }=\text { maximum shear force on floor (lb/in.) } \\
& \mathrm{Q}_{0} \quad=\quad \text { initial mass of radionuclide in the waste }(\mathrm{g}) \\
& \mathrm{Q}_{\mathrm{r}} \quad=\text { radionuclide release entering recharge component }(\mathrm{g} / \mathrm{month}) \\
& \text { qs = uniform load on vault, silo, or well roof }\left(\mathrm{lb} / \mathrm{in} .{ }^{2}\right) \\
& \text { Q } \quad=\text { total radionuclide release from disposal facility ( } g / \text { month) } \\
& \mathrm{q}_{\mathrm{w}} \quad=\text { uniform load on vault, silo, or well wall (lb/in. }{ }^{2} \text { ) } \\
& \mathrm{Q}_{\mathrm{x}} \quad=\text { shear force resulting from uniform loading in } \mathrm{x} \text {-direction (lb/in.) } \\
& \mathrm{Q}_{\mathrm{xh}} \quad=\text { shear force resulting from hydrostatic loading in the } \mathrm{x} \text {-direction (lb/in.) } \\
& \mathrm{Q}_{\mathrm{y}} \quad=\text { shear force resulting from uniform loading in } \mathrm{y} \text {-direction (lb/in.) } \\
& \mathrm{Q}_{\mathrm{yh}} \quad=\text { shear force resulting from hydrostatic loading in the } y \text {-direction (lb/in.) } \\
& \mathrm{R}=\text { degradation } \mathrm{rate}(\mathrm{m} / \mathrm{s}) \\
& \mathrm{r} \quad=\text { distance from center of silo or well roof (in.) } \\
& \mathrm{R}_{\mathrm{d}} \quad=\text { retardation factor (dimensionless) } \\
& r_{\varepsilon} \quad=\text { radius of remaining steel reinforcement (in.) } \\
& \mathbf{R}_{\mathrm{f}} \quad=\text { retardation factor for } \mathrm{Ca}(\mathrm{OH})_{2} \text { in concrete (unitless) }
\end{aligned}
$$




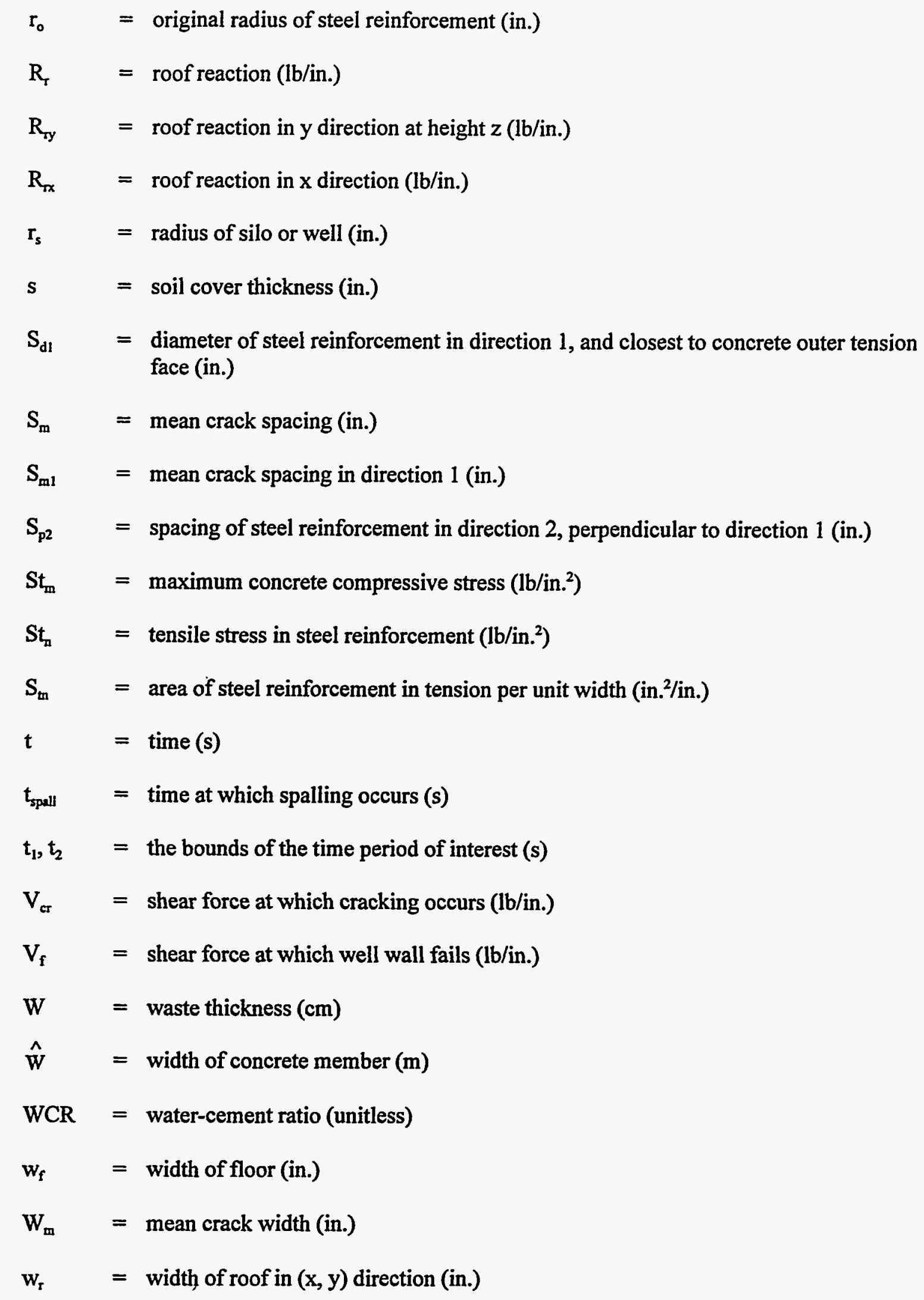




$$
\begin{array}{ll}
\mathrm{W}(\mathrm{x}, \mathrm{y}) & =\text { deflection of roof at location }(\mathrm{x}, \mathrm{y}) \text { (in.) } \\
\mathrm{X} & =\text { depth of carbonation }(\mathrm{m}) \\
\mathrm{x} & =\text { spatial position }(\mathrm{cm}) \\
\mathrm{X}_{\text {spall }} & =\text { reaction zone thickness at which spalling occurs }(\mathrm{m}) \\
\mathrm{y} & =\text { distance from centerline }(\mathrm{m}) \\
\mathrm{y}_{\mathrm{t}} & =\text { distance from the centroidal axis to the tensile face of the concrete (in.) } \\
\mathrm{z} & =\text { wall height (in.) }
\end{array}
$$

\section{Greek}

$\alpha \quad=$ roughness factor for fracture path (unitless)

$\beta=$ linear strain caused by a mole of sulfate reacted in $1 \mathrm{~m}^{3}\left(\mathrm{~m}^{3} / \mathrm{mol}\right)$

$\beta_{1}=$ a factor used in the equivalent rectangular stress diagram for concrete at the ultimate load (dimensionless)

$\Delta \quad=$ thickness of the free expansion layer (in.)

$\epsilon_{\mathrm{c}} \quad=$ concrete porosity (dimensionless)

$\epsilon_{\mathrm{c}}^{\prime} \quad=$ ultimate concrete strain (dimensionless)

$\epsilon_{\mathrm{sh}}=$ shrinkage strain of concrete (in./in.)

$\epsilon_{\mathrm{y}} \quad=$ yield strain of steel (dimensionless)

$\gamma=$ fracture surface energy of concrete $\left(\mathrm{J} / \mathrm{m}^{2}\right)$

$\kappa=\sqrt{D_{2} / D_{1}}$ (dimensionless)

$\lambda_{\mathrm{d}} \quad=$ radioactive decay constant $\left(\mathrm{s}^{-1}\right)$

$\lambda_{\mathrm{L}} \quad=$ leach rate constant $\left(\mathrm{s}^{-1}\right)$,

$\lambda_{\mathrm{x}} \quad=\left[\frac{\tilde{\mathrm{kl}} \mathrm{f}}{4 \mathrm{D}_{\mathrm{fx}}}\right]^{0.25}$ (in. $\left.{ }^{-1}\right)$ 


$$
\begin{aligned}
& \lambda_{\mathrm{y}} \quad=\left[\frac{\tilde{\mathrm{kw}}_{\mathrm{f}}}{4 \mathrm{D}_{\mathrm{fy}}}\right]^{0.25}\left(\text { in. }^{-1}\right) \\
& \mu_{c} \quad=\text { Poisson's ratio for concrete (unitless) } \\
& \mu_{\mathrm{r}} \quad=\text { Poisson's ratio of corrosion product (unitless) } \\
& \phi \quad=\text { strength reduction factor (unitless) } \\
& \rho \quad=\text { reinforcement ratio (dimensionless) } \\
& \rho_{b} \quad=\text { bulk density of waste }\left(\mathrm{g} / \mathrm{cm}^{3}\right) \\
& \rho_{\mathrm{c}} \quad=\text { density of reinforced concrete }\left(\mathrm{lb} / \mathrm{in} .{ }^{3}\right) \\
& \rho_{\mathrm{lim}} \quad=\text { limiting reinforcement ratio (dimensionless) } \\
& \rho_{\mathrm{s}} \quad=\text { density of soil cover }\left(\mathrm{lb} / \mathrm{in}^{3}\right) \\
& \rho_{\mathrm{w}} \quad=\text { density of waste }\left(\mathrm{lb} / \mathrm{in}^{3}{ }^{3}\right) \\
& \left.\sigma_{\mathrm{x}}=\text { stress at surface of concrete (lb/in. }{ }^{2}\right) \\
& \left.\sigma_{\theta E} \quad=\text { maximum tangent stress (lb/in. }{ }^{2}\right) \\
& \sigma_{\theta Q}=\text { tangent stress at point } \mathrm{Q}\left(\mathrm{lb} / \mathrm{in} .^{2}\right) \\
& \theta \quad=\text { relative saturation (i.e., volume of water in waste/volume of waste) (dimensionless) }
\end{aligned}
$$




\section{ACKNOWLEDGMENTS}

Version 1.0 of the SOURCE1 and SOURCE2 computer codes was developed by Rob Shuman, N. Chau, and E. A. Jennrich of Rogers \& Associates Engineering Corporation. The authors are especially grateful to Rob Shuman for his many helpful comments and his advice during the development of Version 2.0. At the Oak Ridge National Laboratory, Steve Storch and Royes Salmon provided excellent critical review and comment. Martin Tull, Don Lee, Herschel Godbee, and Jerry Klein were outstanding sources of support for this work. Ralph Sharpe and Catherine Shappert both provided insightful and timely editorial review. Finally, Sue McDaniel's expert word processing skills and advice resulted in the preparation of this report. 


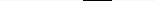




\begin{abstract}
The SOURCE1 and SOURCE2 computer codes (collectively called the SOURCE computer codes) calculate source terms (i.e., radionuclide release rates) for performance assessments of lowlevel radioactive waste (LLW) disposal facilities. SOURCE1 is used to simulate radionuclide releases from tumulus-type facilities. SOURCE2 is used to simulate releases from silo-, well-, well-in-silo-, and trench-type disposal facilities. The SOURCE codes (a) simulate the degradation of engineered barriers (e.g., concrete and metal containers) and (b) provide an estimate of the source term for LLW disposal facilities.

The SOURCE computer codes were originally developed by Rogers \& Associates Engineering Corporation for the Oak Ridge National Laboratory (ORNL). These codes have been used in the radiological performance assessments of the Solid Waste Storage Area 6 (SWSA 6) and Class II LLW disposal sites. Both sites are located on the Oak Ridge Reservation. Numerous disposal technologies have been used at SWSA 6, including tumulus, silos, wells, wells-in-silos, and trenches. The Class II disposal facility is designed to use tumulus-type disposal technology.

This manual summarizes the major changes that have been effected since the codes were originally developed. These revisions include incorporation of a new advective transport model into SOURCE1 and SOURCE2, development of a new model for SOURCE1 that calculates the degradation and failure of a tumulus-type concrete pad and leachate collection system, improvement of routines for controlling water infiltration and radionuclide inventory inputs, and expansion of options for obtaining output summaries. An overview of both SOURCE1 and SOURCE2 is presented. This overview includes objectives, conceptual model summary, code structure, and computing system requirements. A detailed description of the mathematical models used to implement the conceptual model is provided. Input data requirements and output options are also summarized. A description of the FLOTHRU computer program, a subroutine in both SOURCE1 and SOURCE2 that calculates radionuclide releases as a result of diffusion, is presented in Appendix $A$. Also included in the appendixes are a glossary of code variables, sample input data files and corresponding output files, and listings for both computer codes.
\end{abstract}

xxiii 


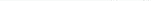




\section{INTRODUCTION}

\subsection{BACKGROUND}

The SOURCE1 and SOURCE2 computer codes (collectively called the SOURCE computer codes) were originally developed by Rogers \& Associates Engineering Corporation for the Oak Ridge National Laboratory (ORNL). ${ }^{1}$ These codes have been used in the radiological performance assessments of the Solid Waste Storage Area 6(SWSA 6) ${ }^{2}$ and Class II Low-Level Radioactive Waste (LLW) disposal sites. Both disposal sites are located on the Oak Ridge Reservation (ORR). Numerous disposal technologies have been used at SWSA 6, including tumulus, silos, wells-in-silos, wells, and trenches. The Class II disposal facility (CIIDF) is designed to use tumulus-type disposal technology.

The SOURCE computer codes were developed to use in the performance assessments of the various types of disposal technologies used at ORNL. SOURCE1 is applicable to tumulus-type facilities, while SOURCE2 can be applied to silo, well-in-silo, well, and trench-type facilities. The SOURCE codes (a) simulate the degradation of engineered barriers (e.g., concrete and metal containers) and (b) provide an estimate of the source term (i.e., radionuclide release rate) for LLW disposal facilities.

The original version (Version 1.0) of the SOURCE codes was modified by ORNL. These modifications were made to improve conceptual models, to increase flexibility of the computer codes, and to correct discrepancies identified during the SOURCE code verification process. The modifications to the SOURCE codes resulted in Version 2.0, which is documented in this user's manual. The following paragraphs provide a brief presentation of major changes that have been made to the SOURCE codes. Section 2 provides an overview of the SOURCE1 and SOURCE2 computer codes, including objectives, conceptual model summary, code structure, and computing system requirements. The conceptual and mathematical models used in the SOURCE codes are discussed in Sect. 3. Detailed information required to construct input data sets and a description of output files are given in Sect. 4. Appendix A provides a description of the algorithm for FLOTHRU, a subroutine in both SOURCE1 and SOURCE2, which calculates the release of radionuclides as a result of diffusion. Appendix B contains a glossary of the variables used in the codes. Sample input data files and corresponding output files are provided in Appendix C. Appendix D contains listings of the SOURCE1 and SOURCE2 computer codes. 


\subsection{SUMMARY OF MAJOR REVISIONS TO THE SOURCE1 AND SOURCE2 COMPUTER CODES}

Several revisions have been incorporated into Version 2.0 of the SOURCE codes. Major revisions are summarized in this section to highlight the differences between Versions 1.0 and 2.0. Numerous minor revisions to the codes and code documentation have also been made. These minor revisions have been incorporated throughout this document. Major revisions include incorporation of a new advective transport model into SOURCE1 and SOURCE2, development of a new model for SOURCE1 that calculates the degradation and failure of a tumulus-type concrete pad and leachate collection system, improvement of routines for controlling water infiltration and radionuclide inventory inputs, and expansion of options for obtaining output summaries.

\subsubsection{New Advective Transport Model}

A new advective transport model was incorporated into the SOURCE codes to improve the simulation of the time dependence of the radionuclide inventory in the disposal facility. This analytical model was developed based on work presented in ref. 3 . A detailed derivation of the model can be found in ref. 4 .

The total radionuclide release during a time-step is calculated by the following formula:

$$
L=\frac{\lambda_{L}}{\lambda_{L}+\lambda_{d}} Q_{0}\left[e^{-\left(\lambda_{L}+\lambda_{d}\right) t_{1}}-e^{-\left(\lambda_{L}+\lambda_{d}\right) t_{L}}\right],
$$

where

$\mathrm{L}=$ mass of radionuclide leached because of advection (g),

$\lambda_{\mathrm{L}} \quad=$ leach rate constant $\left(\mathrm{s}^{-1}\right)$,

$\lambda_{\mathrm{d}} \quad=$ radioactive decay constant $\left(\mathrm{s}^{-1}\right)$,

$\mathrm{Q}_{0} \quad=$ initial mass of radionuclide in the waste $(\mathrm{g})$, and

$t_{1}, t_{2}=$ the bounds of the time period of interest (s).

The leach rate constant, $\lambda_{\mathrm{L}}$, is given by

$$
\lambda_{\mathrm{L}}=\frac{\mathrm{q}}{\mathrm{w} \theta \mathrm{R}_{\mathrm{d}}}
$$


where

$$
\begin{aligned}
& \mathrm{q}=\text { water infiltration rate }(\mathrm{cm} / \mathrm{s}), \\
& \mathrm{W}=\text { waste thickness }(\mathrm{cm}), \\
& \theta \quad=\text { relative saturation(i.e., volume of water in waste/volume of waste) (dimensionless), and } \\
& \mathrm{R}_{\mathrm{d}} \quad=\text { retardation factor (dimensionless). }
\end{aligned}
$$

Finally, the retardation factor, $R_{d}$, can be calculated by the following equation:

$$
R_{d}=1+\frac{\rho_{b}}{\theta} K_{d}
$$

where

$$
\begin{aligned}
& \rho_{\mathrm{b}} \quad=\text { bulk density of waste }\left(\mathrm{g} / \mathrm{cm}^{3}\right) \text { and } \\
& \mathrm{K}_{\mathrm{d}} \quad=\text { distribution coefficient }(\mathrm{mL} / \mathrm{g}) .
\end{aligned}
$$

In ref. 4 , comparisons were made between the new advective transport model and the original model in the SOURCE codes. To perform these comparisons, a number of simulations were conducted using the SOURCE1 and SOURCE2 codes. These simulations allowed for examination of various radionuclides, half-lives, distribution coefficients, radionuclide inventories, and types of disposal. In general, the two advective models produced similar results although the original model predicted a slightly higher cumulative radionuclide release than the new model. A detailed description of the advective model comparisons can be found in ref. 4 .

\subsubsection{Degradation Models for Concrete Pad and Leachate Collection System}

The tumulus-type disposal facility in use at ORNL has a steel-reinforced pad on which disposal vaults are placed and a leachate collection system, which collects water that infiltrates through the waste and reaches the concrete pad. Hence, as long as the pad and collection system are intact and perform correctly, any radionuclide releases from the waste should be captured and not released to the environment. Routines that simulate the degradation and failure of the concrete pad and the leachate collection system have been developed and incorporated into the SOURCE1 code.

\subsubsection{Concrete Pad Degradation Model}

The SOURCE1 code predicts the performance of concrete vaults in a tumulus-type disposal facility. However, the original version of SOURCE1 did not account for the presence of a reinforced 
concrete pad under the vaults. This pad, while intact, should divert water to the leachate collection system. To incorporate the performance of the concrete pad into SOURCE1, a compressive failure model was assumed. Failure was estimated by calculating the reinforcement ratio. ${ }^{5}$ The reinforcement ratio is defined by

$$
\rho=\left(\frac{A}{b}\right) \frac{1}{d},
$$

where

$\rho \quad=$ reinforcement ratio (dimensionless),

$\left(\frac{A}{b}\right)=$ cross-sectional area of steel reinforcement per unit width of slab $(m)$, and

d = effective depth of steel (distance from the top of the slab to the center of the steel reinforcement) (m)

The reinforcement ratio at which compressive failure may occur is called the limiting reinforcement ratio and is given by

$$
\rho_{\lim }=\frac{\epsilon_{c}^{\prime}}{\epsilon_{c}^{\prime}+\epsilon_{y}} 0.85 \beta_{1} \frac{f_{c}^{\prime}}{f_{y}}
$$

where

$\rho_{\text {lim }}=$ limiting reinforcement ratio (dimensionless),

$\epsilon_{\mathrm{c}}^{\prime}=$ ultimate concrete strain (for this application, taken as 0.003 ) (dimensionless),

$\epsilon_{y}=$ yield strain of steel (dimensionless),

$\beta_{1}=$ a factor used in the equivalent rectangular stress diagram for concrete at the ultimate load (dimensionless),

$\mathrm{f}_{\mathrm{c}}^{\prime} \quad=$ specified compressive strength of concrete (MPa), and

$f_{y} \quad=$ specified yield strength of steel reinforcement $(\mathrm{MPa})$.

The yield strain of the steel reinforcement can be calculated by

$$
\epsilon_{y}=\frac{f_{y}}{E_{s}}
$$


where

$\mathrm{E}_{\mathrm{s}}=$ modulus of elasticity of steel reinforcement (for this application, taken as $200,000 \mathrm{MPa})(\mathrm{MPa})$.

The value of $\beta_{1}$ is determined as follows:

$$
\begin{aligned}
& \beta_{1}=0.85 \text { for } \mathrm{f}_{\mathrm{c}}^{\prime} \leq 30 \mathrm{MPa} \text { or } \\
& \beta_{1}=0.85-0.08\left(\frac{\mathrm{f}_{c}^{\prime}-30}{10}\right) \text { for } \mathrm{f}_{c}^{\prime}>30 \mathrm{MPa} .
\end{aligned}
$$

The values of the reinforcement ratio and the limiting reinforcement ratio are evaluated at annual time steps in SOURCE1. These two values are compared; when the reinforcement ratio exceeds the limiting value, the pad is said to have failed hydraulically. Failure of the pad will allow leachate to be released to the environment. Values of both $\rho$ and $\rho_{\text {lim }}$ will change because of the degradation of the concrete. The concrete is simulated to degrade by using the sulfate attack and calcium hydroxide leaching subroutines in SOURCE1. Corrosion of reinforcing steel was not considered because the rates of sulfate attack and calcium hydroxide leaching were judged to greatly exceed the rate of degradation resulting from corrosion. Sulfate attack results in the spalling off of the concrete cover on the reinforcing steel. Hence, as the effective depth of the steel decreases, the reinforcement ratio increases. Leaching of calcium hydroxide from the concrete pad results in reduced concrete strength. Therefore, as the compressive strength of the concrete decreases, the limiting reinforcement ratio decreases. Both of the concrete degradation mechanisms result in a decrease of the margin between the reinforcement ratio and the limiting reinforcement ratio, ultimately resulting in pad failure.

\subsubsection{Leachate Collection System Degradation Model}

Water that reaches an intact concrete pad of a tumulus-type facility will be diverted to a leachate collection system. This system consists of piping, valves, collection sumps, and monitoring equipment. Ideally, with a properly functioning system, all leachate will be collected, and no release of radionuclides to the environment will occur.

As with the concrete pad, the original version of the SOURCE1 code did not simulate the performance and degradation of the leachate collection system. A model has subsequently been developed that describes the functionality fraction of the collection system as a function of time. 
The functionality fraction is defined as the ratio of the amount of radionuclide in the collected leachate to the total radionuclide release from the disposal vaults and can vary from 0 to 1 . With a value of 1 , the leachate collection system is fully functional, and no radionuclides are released to the environment. A zero value indicates a completely degraded system which allows all leached radionuclides to be released to the environment.

The initial functionality fraction and the length of the institutional control period are input parameters to the SOURCE1 code. The functionality fraction degrades linearly to zero from the beginning of the simulation until the end of the institutional control period. The degradation of the collection system is assumed to result from piping and valve leaks or failures, flow obstructions within the system, leakage or overflow of collection sumps, degraded monitoring equipment, etc. At the end of the institutional control period, no maintenance of the collection system is assumed to occur. Hence, no credit is taken for the collection system after the end of institutional control. Additionally, if the concrete pad is predicted to fail hydraulically before the end of institutional control, the functionality fraction is set to zero at the time of pad failure.

\subsubsection{Variation of Water Infiltration Input}

In the original version of the SOURCE codes, only one set of water infiltration values could be input. This set consisted of 12 values of water infiltration data ( 1 value for each month in the year) which were used for each year of the simulation. Because simulations are typically performed for periods of 1000 years or greater, water infiltration would certainly vary with time. The SOURCE codes were modified to allow for variation of water infiltration data. The one set of infiltration values in the input data file was replaced with the name of a file which contains multiple sets of infiltration data. Each set corresponds to a defined time period during the disposal facility performance simulation. For example, six such periods have been defined by ORNL for tumulus-type disposal facilities: (1) the active-use period, during which vaults are placed on the tumulus pad; (2) the capping period, during which the facility is covered with an engineered cap; (3) the cap-decline period, during which the cap weathers and degrades; (4) the grass-cover period, during which the facility is covered with grass and vegetation; (5) the forest-succession period, during which small trees and bushes begin to grow on top of the facility; and (6) the forest-cover period, during which the disposal facility becomes completely covered by trees. Representative water infiltration values can be developed for each of these periods, and with the modifications to the SOURCE codes, these values can be applied during the appropriate time period. 


\subsubsection{Variation of Radionuclide Inventory Input}

In the original version of the SOURCE codes, only one value of radionuclide inventory (for each radionuclide being simulated) could be input. This input represented a disposal at the beginning of the simulation (i.e., "time zero") with no further disposals. However, at many sites, waste disposal may have occurred over a number of years. For example, disposal operations at the SWSA 6 site occurred over a period of more than 20 years. The input to the SOURCE codes was changed to allow simulation of variable disposal of a radionuclide over a period of years. The code user defines the time periods of disposal and provides the amount disposed during each time period. Additionally, some disposal sites may have multiple disposal facilities that began disposal operations at different times. To address this situation, the user supplies a reference year for beginning the simulation, which will ensure that (a) all simulations start at the same point in time and (b) the time dependence of the waste disposal is properly represented.

\subsubsection{Addition of Output Files}

Version 1.0 of the SOURCE codes contained three output files. One file provided a summary of input data and of engineered barrier degradation. Another file provided, as a function of time, calculated radionuclide releases that recharge to groundwater. The third file provided, also as a function of time, calculated radionuclide releases that flow laterally in the shallow storm-flow region. To provide more information from each simulation, five new output files were created for SOURCE1, and three new output files were created for SOURCE2. Summaries of the input and output file structures for SOURCE1 and SOURCE2 are presented in Sect. 4.

The output files now available for the SOURCE codes provide a wide variety of data from a source term simulation. Additionally, the output files have been structured to allow for use of the output data by both spreadsheet and graphing software. These types of software applications aid in quality assurance checks and interpretation of simulation results. 


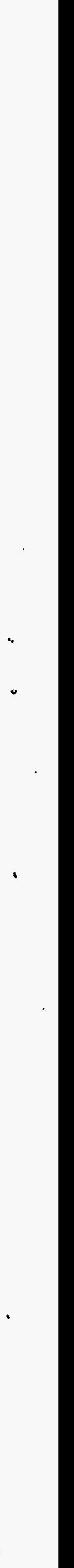




\section{COMPUTER CODE OVERVIEW}

The modeling methodology used in simulating the long-term performance of LLW disposal facilities at the SWSA 6 and CIIDF sites has been incorporated into two separate computer codes. The SOURCE1 code models the performance of tumulus-type technology used at Tumulus I and II, the Interim Waste Management Facility (IWMF), and the CIIDF (Fig. 2.1). The SOURCE2 computer code models the performance of disposal silos (Fig. 2.2), wells-in-silos, wells, and trenches. The code objectives, a brief conceptual model summary, and computing system requirements are presented in the following subsections.

\subsection{CODE OBJECTIVES}

The SOURCE computer codes are used in the evaluation of source terms for LLW disposal facilities. Four major objectives for the SOURCE codes are to:

- Provide for the simulation of the long-term performance and degradation of engineered barriers used in LLW disposal facilities.

- Provide for the simulation of radionuclide releases from LLW disposal facilities. These simulations should include the mechanisms of advection and diffusion and should account for radioactive decay and sorption of radionuclides.

- Provide for the coupling of calculations of engineered barrier degradation with calculations of radionuclide releases.

- Provide sufficient output data to evaluate simulation results and for use in subsequent performance assessment calculations.

\subsection{CONCEPTUAL MODEL SUMMARY}

The routines of the SOURCE codes have four primary functions: structural analysis, simulation of concrete and metal barrier degradation, cracking analyses, and nuclide-leaching calculations. The structural analysis routine establishes initial bending moments and shear forces. The concrete and metal barrier degradation routines simulate the deterioration of engineered barriers with time. The cracking analyses routines calculate moments and shears required for concrete cracking and compare these values with the moments and shears evaluated in the structural analysis. 
ORNL DWG 93-863

TYPICAL CROSS SECTION

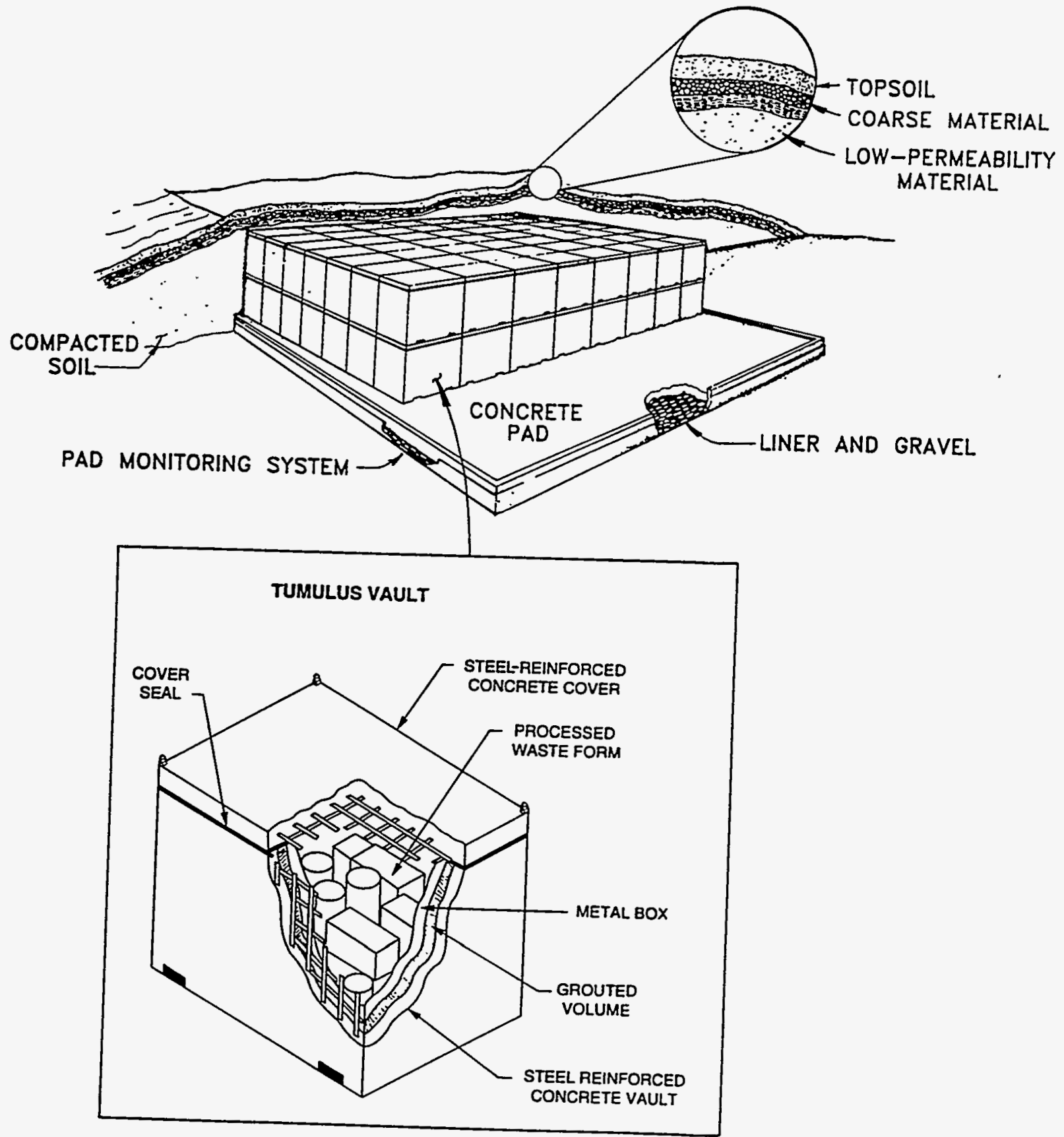

Fig. 2.1. Representative tumulus-type disposal facility modeled by SOURCE1. 


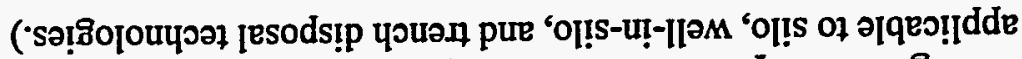

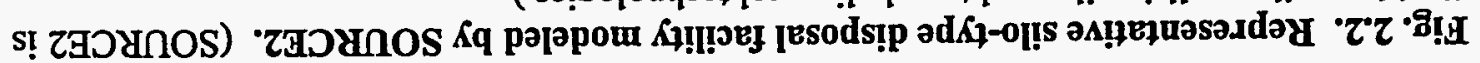

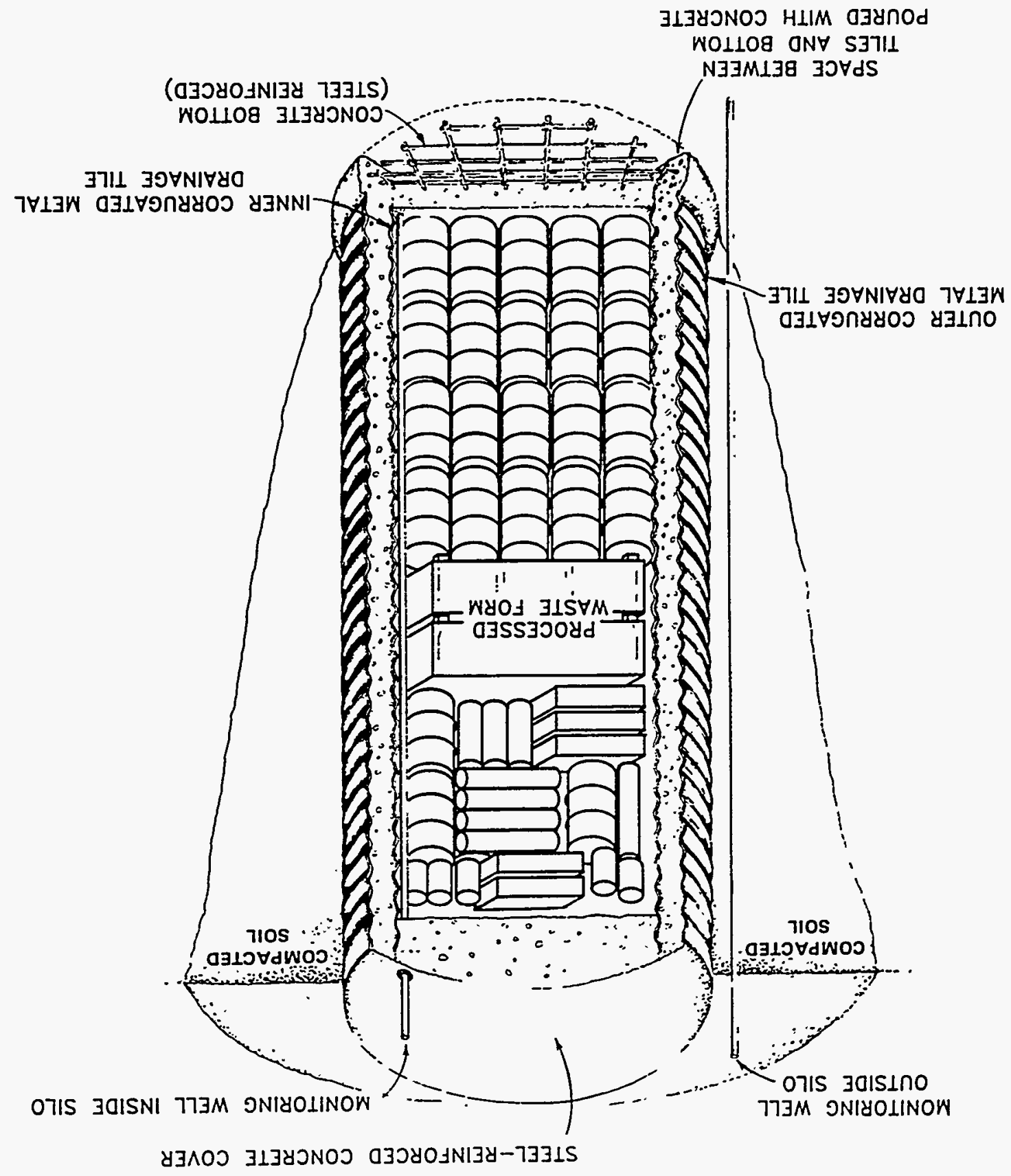

$\neg 98-\varepsilon 6$ פMO TNYO 
Moments and shears required for cracking vary as the engineered facility degrades. The leaching routines calculate the release rate of nuclides to the environment. A detailed illustration of the logic flow used in the SOURCE computer codes to model the aforementioned processes is provided in Fig. 2.3. The structural analysis is performed once at the beginning of a simulation. The concrete and metal barrier degradation and cracking analyses are performed each year by using annual time-steps. Nuclide release rates are calculated by using monthly time-steps.

Before the annual simulation begins, a structural analysis of the disposal facility is conducted to establish the moments and forces placed on the various structural components. For the roof, walls, and floor, the SOURCE codes calculate the uniform load, bending moments resulting from uniform loading, and shear and compressive forces. The walls are subjected also to hydrostatic pressures caused by the backfill and the waste. Bending moments and shear forces are calculated for the walls based on these hydrostatic pressures. The bending moments and shear forces attributed to hydrostatic pressures are added to the bending moments and shear forces for the uniform load to give total bending moments and shear forces for the walls.

Following the structural analysis, the computer codes enter an annual loop in which chemical and physical deterioration of the concrete and steel barriers used in the disposal facility is modeled. Properties of the structural members of the facility are updated to reflect degradation and are used in cracking analyses of the roof, walls, and floor of the disposal facility to assess the structure's ability to bear the loads placed upon it. The deterioration of the concrete barriers is simulated with respect to the removal of calcium hydroxide from the cement matrix, sulfate attack of the concrete, and corrosion of steel reinforcement. Concrete component properties, including strength, thickness, and $\mathrm{pH}$, are updated for each year of the simulation to reflect projected rates of deterioration. Failure rates of iron and steel (used as liners, wells, containers, etc.) are determined by using a linear failure model.

As the engineered structure is weakened by chemical and physical attack, a point is reached at which time the structure is no longer able to bear the loads placed upon it. Under these conditions, the engineered barriers will crack or, otherwise, fail. Failure is judged in terms of the capability of the facility to isolate the waste from water percolating through the disposal site. When the disposal facility is no longer hydraulically intact, the engineered barriers are assumed to offer no benefit. The cracking analyses are performed if hydraulic failure of the disposal facility has not occurred. The cracking moment, cracking shear, and ultimate strength are each calculated for the roof, walls, and floor and compared with the moments and forces calculated in the structural analysis. If the 
ORNL DWG 93A-738

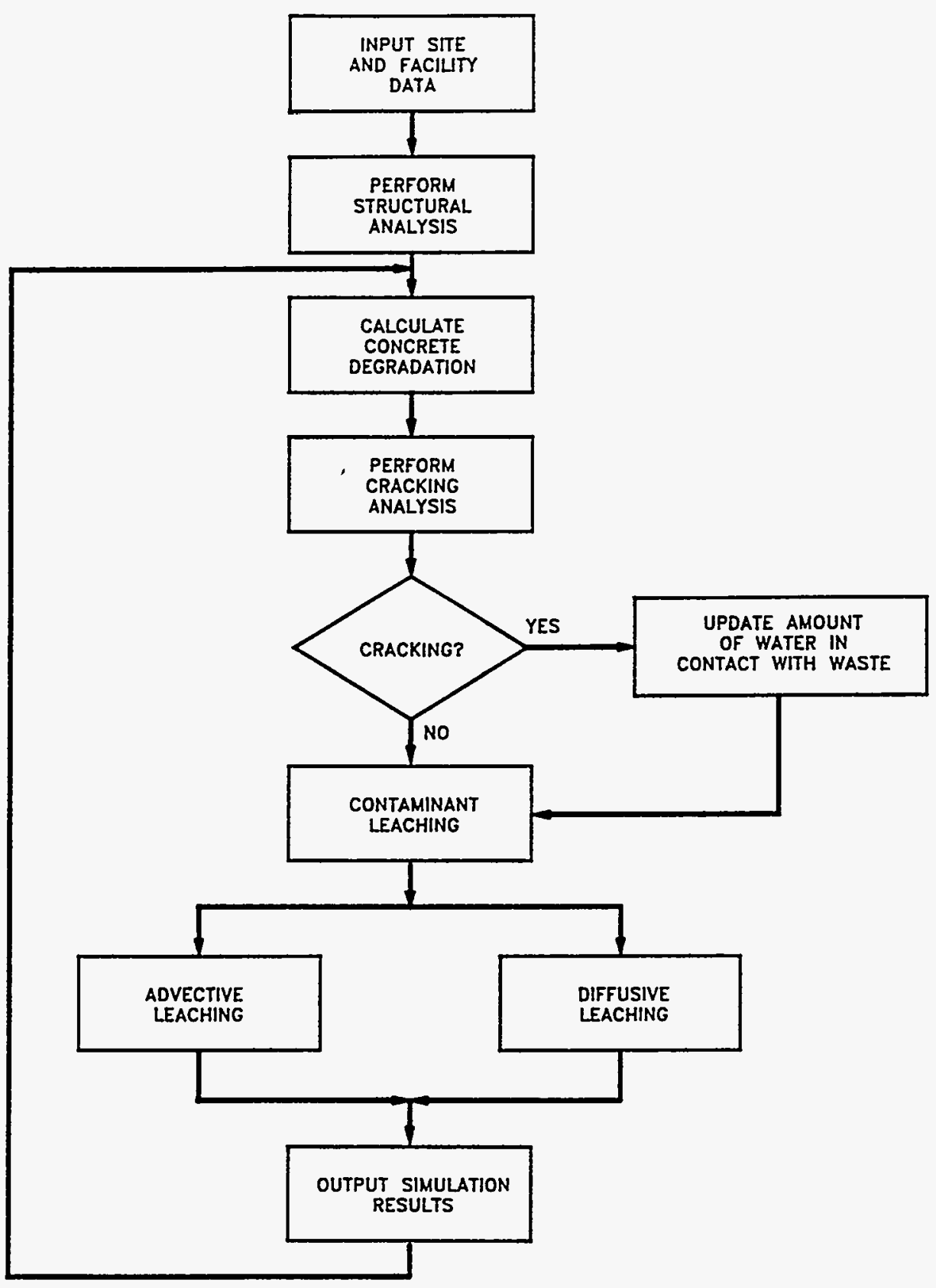

Fig. 2.3. Logic flow of the SOURCE computer codes. 
calculated moments or shears exceed the cracking moments or shear forces, the structural member is projected to crack. Fracture characteristics, including depth, spacing, and width, are calculated with the onset of cracking. Cracking or spalling of concrete members of the disposal facility may result from corrosion of the steel reinforcement. In the event of the former, fracture characteristics are calculated. Concrete-member thicknesses are updated in the event that spalling of the concrete surface occurs. Figure 2.4 demonstrates the logic flow of the structural and cracking analyses that are performed to estimate the time of failure of the disposal facility.

Radionuclide release rates from waste disposal facilities are a function of the integrity of the waste (or waste form) and the engineered barriers used in construction of the facility (e.g., concrete and metal containers). When intact, these barriers minimize the contact of water with the waste, thereby minimizing releases of radionuclides. As the barriers deteriorate, over time, water can more readily contact the waste and mobilize radionuclides, thus accelerating releases to the environment.

The SOURCE computer codes consider two mechanisms through which waste radionuclides are released into the environment: advection (bulk flow driven by hydraulic pressure differences) and diffusion (nuclide movement driven by concentration differences). The calculated total release rate resulting from advection and diffusion is compared with the rate of release dictated by the solubility limit of the nuclide in water. If the solubility limit is exceeded, the release rate is adjusted to the solubility-limited rate. As a disposal facility degrades, the percolation rate of water through the waste increases. Thus, except for cases constrained by solubility, advective releases will increase with degradation and, in general, dominate the total release. The total release is divided into two components: one that recharges to groundwater and a second that flows laterally in the shallowsubsurface flow region of the site.

\subsection{CODE STRUCTURE}

The SOURCE1 code consists of the main program, 18 subroutines, and 3 functions; the SOURCE2 code consists of the main program, 20 subroutines, and 3 functions. The code hierarchy of the SOURCE1 and SOURCE2 code is illustrated in Figs. 2.5 and 2.6, respectively. A brief description of the functions performed by the program modules is provided in Table 2.1.

The SOURCE codes require keyboard input to specify the name of the primary input file. This file contains data describing the disposal site and features of the disposal facility under consideration and nuclide-specific information. Also, the name of the file containing site-specific water infiltration 
ORNL DWG 93A-73?

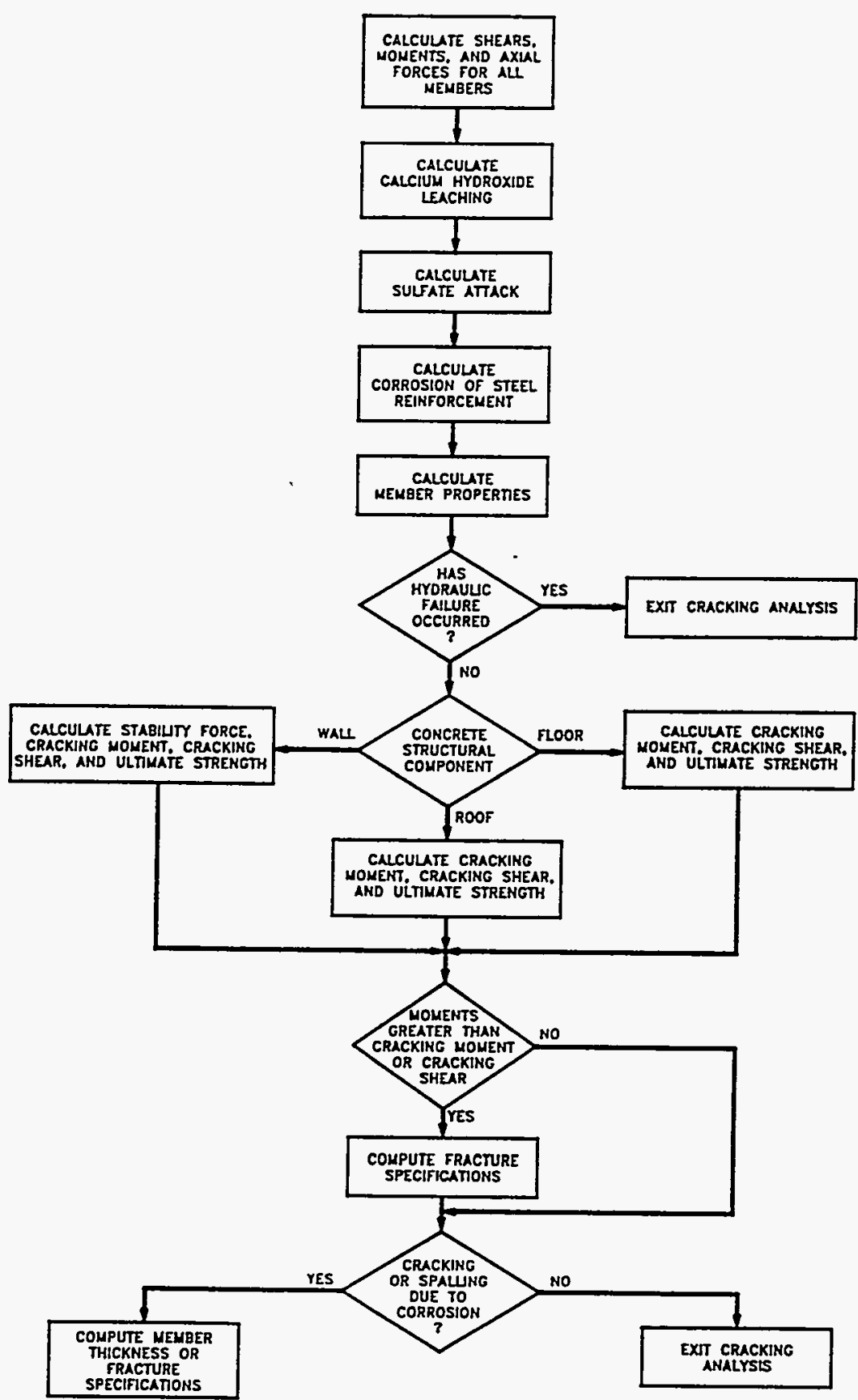

Fig. 2.4. Logic flow of the concrete-degradation and -cracking subroutines. 
ORNL DWG 96-4996

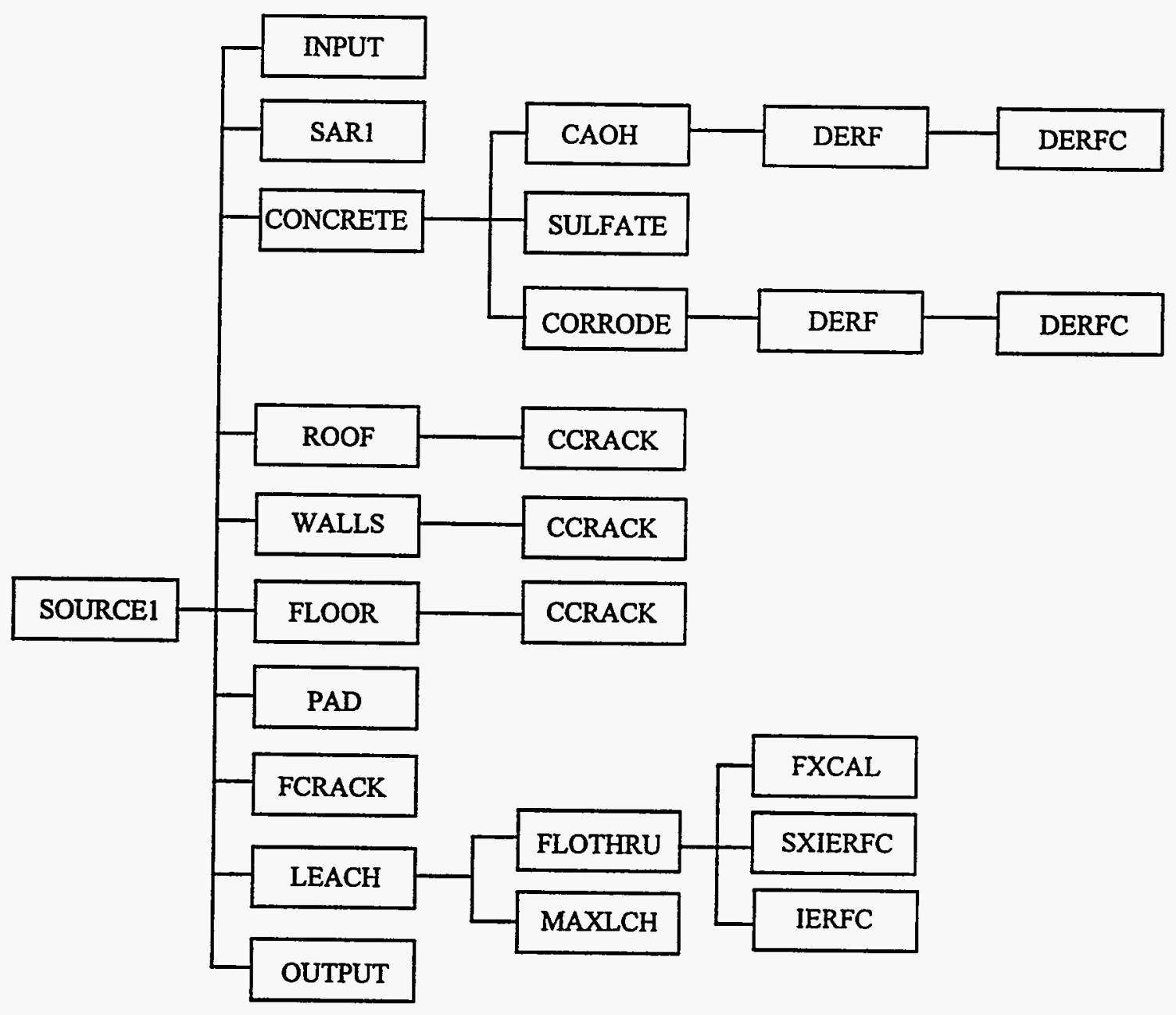

Fig. 2.5. SOURCE1 code hierarchy for modeling tumulus-type disposal facilities. 
ORNL DWG 96-4997

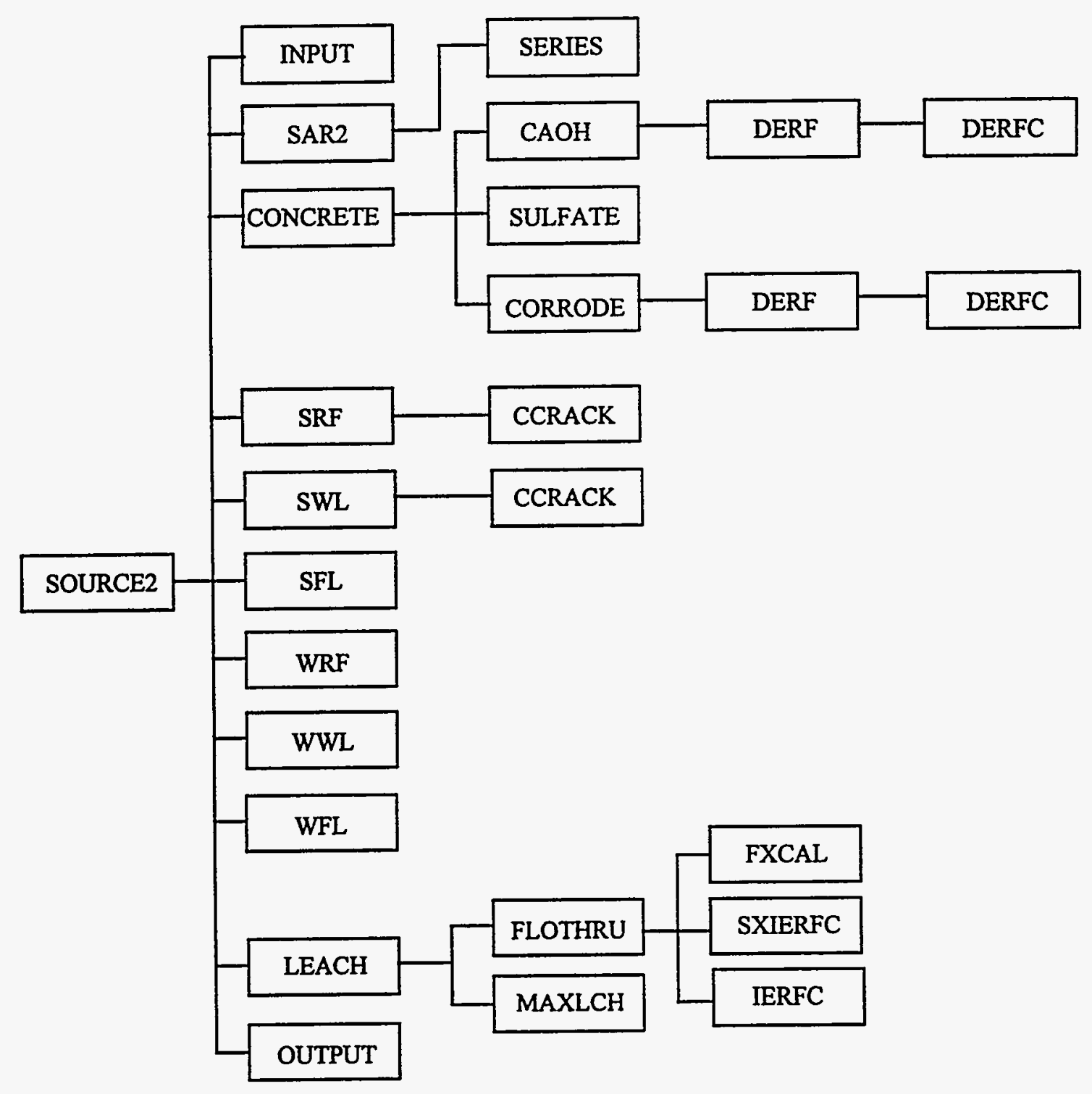

Fig. 2.6. SOURCE2 code hierarchy for modeling disposal silos and wells. 
Table 2.1. SOURCE1 and SOURCE2 program module description

\begin{tabular}{ll}
\hline Module & \multicolumn{1}{c}{ Purpose } \\
\hline SOURCE & Main program, coordinates subroutine calls \\
$\mathrm{CAOH}$ & $\begin{array}{l}\text { Calculates changes in concrete member strength and } \mathrm{pH} \text { resulting from leaching of calcium } \\
\text { hydroxide }\end{array}$
\end{tabular}

CCRACK Performs cracking analysis for cracking resulting from corrosion

CONCRETE Coordinates calls to concrete degradation subroutines

CORRODE Calculates initiation and propagation of corrosion of steel reinforcement

DERF Calculates the error function [erf(z)]

DERFC Calculates the complimentary error function [erfc(z)]

FCRACK Calculates number of vaults that have undergone cracking

FLOOR Performs cracking analysis for vault floor

FLOTHRU Calculates radionuclide releases as a result of diffusion

FXCAL Solves transcendental equation used in calculating releases as a result of diffusion

IERFC Performs the recursive computation of the repeated integrals of the complimentary error function

INPUT $\quad$ Reads input data file and performs preliminary calculations

LEACH Coordinates leaching calculations and calculates radionuclide releases resulting from advection

MAXLCH Calculates solubility limits on radionuclide leaching

OUTPUT Prints summaries of input information, concrete analyses, inventory, and radionuclide release rates

PAD Predicts the performance of the reinforced concrete pad under the vaults

ROOF Performs cracking analysis for vault roof

SAR1 Performs structural analysis for vault roof, walls, and floor

SAR2 Performs structural analysis for silo and well roof, wall, and floor

SERIES Approximates a series used in calculating the maximum shear force on a silo or well floor

SFL Performs cracking analysis for silo floor 
Table 2.1. (continued)

\begin{tabular}{ll}
\hline \multicolumn{1}{c}{ Module } & \\
\hline SRF & Performs cracking analysis for silo roof \\
SULFATE & Calculates change in concrete member thickness resulting from sulfate attack \\
SWL & Performs cracking analysis for silo wall \\
SXIERFC & Function used in calculating releases as a result of diffusion \\
WALLS & Performs cracking analysis for vault walls \\
WFL & Performs cracking analysis for well floor \\
WRF & Performs cracking analysis for well roof \\
WWL & Performs cracking analysis for well wall \\
\hline
\end{tabular}


data is provided in this file. The water infiltration data are composed of multiple sets of monthly infiltration values; each of these sets corresponds to defined time periods during the disposal facility performance simulation.

The SOURCE1 code has seven output options for summarizing the results of the simulation, and the SOURCE2 code has five options for summarizing the results. Both SOURCE1 and SOURCE2 have options for providing a summary of the input data, concrete analyses, remaining inventories, leach rates, cumulative amounts leached, leach rates attributed to advection and diffusion, and the leach rates partitioned to the recharge and lateral components. In addition, SOURCE1 summarizes the inventory and leach rate for advection and diffusion for intact and cracked vaults. A detailed discussion of the structure of the input and output files can be found in Sect. 4 .

\subsection{SYSTEM REQUIREMENTS}

The SOURCE computer codes conform to the American National Standards Institute, Inc. (ANSI), FORTRAN Programming Language standard X3.9-1978. The codes have been executed on UNIX workstations and IBMTM-compatible personal computers. 


\section{CONCEPTUAL AND MATHEMATICAL MODELING METHODOLOGY}

The conceptual and mathematical modeling methodology used in the SOURCE computer codes is discussed in the following subsections. This discussion considers the approaches taken in (1) modeling concrete degradation, (2) performing the structural and cracking analyses for the disposal structures, (3) partitioning water through the disposal facility, and (4) modeling advective and diffusive releases of radionuclides from waste.

At this point, a note on the units used in this manual is in order. The reader will notice that a mixture of metric and English units is used in the definitions presented in this and other sections. This mixture is a carryover from the original versions of the SOURCE1 and SOURCE2 codes. ${ }^{1}$ The use of two unit systems stems primarily from the structural analysis and cracking calculations being performed using English units while the degradation and leaching calculations are performed using metric units. Although working with two sets of units is somewhat inconvenient, it was determined that the cost of converting SOURCE1 and SOURCE2 entirely to metric units was not justified. Therefore, the user is strongly cautioned to observe the unit requirements for each input parameter. Specific unit requirements for each input variable are presented in Sect. 4.

\subsection{CONCRETE DEGRADATION MODELING}

Modes of concrete degradation are considered in terms of surface- and bulk-attack mechanisms. Surface-attack mechanisms are initiated at the surface of the concrete component and progress inward, over time. Bulk-attack mechanisms modify the properties of the entire concrete component uniformly.

Sulfate attack is generally considered the most significant surface attack mechanism in the context of waste repositories. ${ }^{6}$ In areas characterized by cold winters, freeze-thaw cycling may also represent a serious threat to concrete in disposal facilities. In terms of the bulk-attack processes, the most notable degradation processes are likely to be calcium hydroxide leaching and alkali-aggregate attack.

Corrosion of reinforced steel may also undermine the ability of engineered disposal facilities to isolate waste therein from the environment. This process differs from the surface- and bulk-attack processes noted previously because it does not directly alter the properties of the concrete.

The models used in simulating concrete degradation are discussed in Sects. 3.1.1 through 3.1.3. The deterioration processes considered in the SOURCE computer codes include sulfate attack, calcium hydroxide leaching, and corrosion of steel reinforcement. 


\subsubsection{Sulfate Attack}

Sulfate attack generally manifests itself in the form of expansion and, ultimately, cracking of concrete. It may also result in a progressive loss of strength and mass resulting from deterioration in the cohesiveness of the cement hydration products.

Three steps are recognized in the deterioration of concrete as a result of sulfate attack: ${ }^{7}$

- Sulfate ions from the environment penetrate into the concrete, usually by diffusion.

- Sulfate ions react expansively with certain aluminum-containing phases in the concrete to form ettringite.

- The resulting internal expansion causes stress, cracking, and exfoliation of the concrete surface.

These aspects of the degradation process are incorporated into the sulfate attack model used in the SOURCE computer codes.

The sulfate attack model is based on the work of Atkinson and Hearne. ${ }^{7}$ In this model, the reaction zone is assumed to spall out when it reaches a critical thickness given by

$$
X_{\text {spall }}=\frac{2 \alpha \gamma\left(1-\mu_{c}\right)}{E\left(\beta C_{c}\right)^{2}} \text {, }
$$

where

$$
\begin{aligned}
& \mathrm{X}_{\text {spall }}=\text { reaction zone thickness at which spalling occurs }(\mathrm{m}), \\
& \alpha \quad=\text { roughness factor for fracture path (unitless), } \\
& \gamma \quad=\text { fracture surface energy of concrete }\left(\mathrm{J} / \mathrm{m}^{2}\right), \\
& \mu_{\mathrm{c}} \quad=\text { Poisson's ratio for concrete (unitless), } \\
& \mathrm{E} \quad=\text { Young's modulus }(\mathrm{Pa}), \\
& \beta \quad=\text { linear strain caused by a mole of sulfate reacted in } 1 \mathrm{~m}^{3}\left(\mathrm{~m}^{3} / \mathrm{mol}\right), \text { and } \\
& C_{e} \quad=\text { concentration of sulfate as ettringite at the time at which spalling occurs }\left(\mathrm{mol} / \mathrm{m}^{3}\right) .
\end{aligned}
$$


This critical thickness is achieved at a time

$$
t_{\text {spell }}=\frac{X_{s p e l l}^{2} C_{c}}{2 D_{i} c_{o}} \text {, }
$$

where

$$
\begin{aligned}
& t_{\text {spall }}=\text { time at which spalling occurs }(\mathrm{s}) \\
& D_{i}=\text { "intrinsic" diffusion coefficient of sulfate ions in water-saturated cement }\left(\mathrm{m}^{2} / \mathrm{s}\right) \text {, and } \\
& c_{0} \quad=\text { groundwater sulfate concentration }\left(\mathrm{mol} / \mathrm{m}^{3}\right) .
\end{aligned}
$$

The rate of degradation, $R$, is defined as $X_{\text {spall }} / t_{\text {spall }}(m / s)$. Then, based on Eqs. (3.1) and (3.2), $R$ is given by

$$
R=\frac{E \beta^{2} c_{0} C_{c} D_{i}}{\alpha \gamma\left(1-\mu_{c}\right)}
$$

As sulfate attack progresses into the concrete member, it is assumed that the affected layers spall off, thus effectively reducing the thickness of the concrete member.

It is necessary to use an iterative method to determine the concentration of sulfate as ettringite, $\mathrm{C}_{\mathrm{e}}$, and the degradation rate caused by sulfate attack. The starting approximation for $\mathrm{C}_{\mathrm{e}}$ is calculated assuming that the alumina has been completely converted to ettringite in the reacted zone. ${ }^{7}$ Zero-order values of the $X_{\text {spall, }}, t_{\text {spell, }}$ and $R$ are calculated on this basis, and $t_{\text {ppell }}$ is compared with the time required for the reaction to go to completion. If $t_{\text {spell }}$ is not great enough to permit complete reaction, $t_{\text {spall }}$ and $\mathrm{C}_{\mathrm{e}}$ are iterated to self-consistency using the reaction kinetics expression described in ref. 7.

\subsubsection{Calcium Hydroxide Leaching}

Calcium hydroxide $\left[\mathrm{Ca}(\mathrm{OH})_{2}\right]$ leaching results in a loss of strength in the concrete as well as a lowering of the $\mathrm{pH}$ of the material. A loss of strength will affect the concrete structure's ability to withstand the loads placed upon it. Declines in the $\mathrm{pH}$ of the concrete may lead to depassivation of the steel reinforcement, thereby promoting corrosion of the steel. 
$\mathrm{Ca}(\mathrm{OH})_{2}$ may be leached from the concrete because of diffusion and advection. The loss of $\mathrm{Ca}(\mathrm{OH})_{2}$ from concrete members from diffusion is calculated by solving the following equation:

$$
\frac{d f_{t}}{d t}=-D_{y} \frac{d^{2} f_{t}}{d y^{2}}
$$

where

$f_{t}=$ fraction of $\mathrm{Ca}(\mathrm{OH})_{2}$ remaining in concrete member as a function of position and time (unitless),

$\mathrm{t} \quad=$ time (s),

$D_{y}=$ effective diffusion coefficient of $\mathrm{Ca}(\mathrm{OH})_{2}$ in concrete $\left(\mathrm{m}^{2} / \mathrm{s}\right)$, and

$\mathrm{y} \quad=$ distance from centerline $(\mathrm{m})$.

The initial conditions that apply are

$$
f_{t}(y, t=0)=\left\{\begin{array}{l}
1 \text { for }|y|<\frac{\hat{W}}{2} \\
0 \text { for }|y|>\frac{\hat{W}}{2}
\end{array}\right. \text {, }
$$

where

$$
\hat{\mathbf{W}}=\text { width of concrete member }(\mathrm{m}) \text {. }
$$

The equation for $\mathrm{f}_{\mathrm{t}}$ is given by

$$
f_{t}=0.5 \operatorname{erf} \frac{(y+\hat{W} / 2) R_{f}}{2\left(D_{y} t\right)^{0.5}}-0.5 \operatorname{erf} \frac{(y-\hat{W} / 2) R_{f}}{2\left(D_{y} t\right)^{0.5}},
$$

where

$$
\mathrm{R}_{\mathrm{f}}=\text { retardation factor for } \mathrm{Ca}(\mathrm{OH})_{2} \text { in concrete (unitless). }
$$


The $\mathrm{Ca}(\mathrm{OH})_{2}$ retardation factor, $\mathrm{R}_{\mathrm{f}}$, is given by

$$
R_{f}=1+\frac{C a_{c}}{\epsilon_{c} C a_{p}},
$$

where

$\mathrm{Ca}_{c}=\mathrm{Ca}(\mathrm{OH})_{2}$ concentration in concrete $(\mathrm{mol} / \mathrm{L})$,

$\epsilon_{c} \quad=$ concrete porosity (dimensionless), and

$\mathrm{Ca}_{\mathrm{p}}=\mathrm{Ca}(\mathrm{OH})_{2}$ concentration in concrete pore solution $(\mathrm{mol} / \mathrm{L})$.

The potential for leaching of $\mathrm{Ca}(\mathrm{OH})_{2}$ through advective mechanisms will depend upon the nature of the groundwater. If the groundwater is saturated or supersaturated with calcium carbonate, no dissolution of $\mathrm{Ca}(\mathrm{OH})_{2}$ will occur. Groundwater which is not saturated with calcium carbonate may leach $\mathrm{Ca}(\mathrm{OH})_{2}$ as the groundwater passes through the concrete.

Langelier ${ }^{8}$ has developed the calcium carbonate saturation (or Langelier) index as a means of characterizing the degree of calcium carbonate saturation of groundwater. The index takes into account the effects of temperature, total dissolved solids, total alkalinity, $\mathrm{pH}$, and calcium content on the saturation characteristics of the groundwater. A negative value for the Langelier index denotes a groundwater which is not saturated with calcium carbonate [i.e., one capable of leaching $\mathrm{Ca}(\mathrm{OH})_{2}$ from concrete]. Index values equal to or greater than zero indicate calcium carbonate saturation.

Data taken from Langelier ${ }^{8}$ are used in a regression to estimate the saturation index as a function of the total dissolved solids and temperature of the groundwater. When predicted values of the index are positive, losses of $\mathrm{Ca}(\mathrm{OH})_{2}$ are modeled to occur as a result of diffusion only. When the groundwater is not saturated with calcium carbonate (i.e., the Langelier index is negative), advective leaching of $\mathrm{Ca}(\mathrm{OH})_{2}$ is calculated using ${ }^{9}$

$$
C a_{1}=I \frac{C a_{p}}{C_{t} C a_{c}} \text {, }
$$

where

$$
\begin{aligned}
& \mathrm{Ca}_{1}=\text { fractional groundwater release rate of } \mathrm{Ca}(\mathrm{OH})_{2}\left(\text { year }^{-1}\right), \\
& \mathrm{I}=\text { water percolation rate through vault }(\mathrm{m} / \mathrm{year}), \text { and } \\
& \mathrm{C}_{\mathrm{t}} \quad=\text { concrete-member thickness }(\mathrm{m}) .
\end{aligned}
$$


The presence of other ions in the groundwater may influence the rate at which $\mathrm{Ca}(\mathrm{OH})_{2}$ is leached from the concrete. Atkinson ${ }^{9}$ reports that magnesium and carbonate are among the species most likely to speed the loss of $\mathrm{Ca}(\mathrm{OH})_{2}$. The effect of these species is modeled using Eq. (3.8), replacing the pore solution concentration of $\mathrm{Ca}(\mathrm{OH})_{2}, \mathrm{Ca}_{\mathrm{p}}$, with the sum of this concentration and the groundwater concentrations of magnesium and carbonates.

The quantities of $\mathrm{Ca}(\mathrm{OH})_{2}$ lost from the concrete member by diffusion and advection are summed to determine the total amount of the constituent leached from the concrete. The concentration of $\mathrm{Ca}(\mathrm{OH})_{2}$ in the concrete is adjusted downward to reflect these losses. $\mathrm{All} \mathrm{Ca}(\mathrm{OH})_{2}$ leached from the concrete is assumed to be drawn from the calcium-silicate-hydrate (C-S-H) system of the concrete. The calcium incorporated into the relatively less-soluble phases of the concrete is not considered.

Changes in the $\mathrm{pH}$ of concrete as a result of the loss of $\mathrm{Ca}(\mathrm{OH})_{2}$ have been well documented.' The $\mathrm{pH}$ of the concrete is maintained at levels greater than approximately 12.5 in the presence of alkalis, $\mathrm{NaOH}$, and $\mathrm{KOH}$. As these highly soluble species are lost because of leaching, the $\mathrm{pH}$ declines until it reaches 12.5 , at which point the $\mathrm{pH}$ of the concrete is controlled primarily by the $\mathrm{Ca}(\mathrm{OH})_{2}$ content of the concrete.

Changes in the $\mathrm{pH}$ of the concrete are modeled as alkalis and $\mathrm{Ca}(\mathrm{OH})_{2}$ are leached from the concrete. Based on the data of Greenberg and Chang, ${ }^{10}$ the $\mathrm{pH}$ is modeled to decline linearly from the initial $\mathrm{pH}$ of the concrete, as specified by the user, to 12.5 in direct proportion to the reduction in $\mathrm{NaOH}$ and $\mathrm{KOH}$ in the concrete. The rates of loss of these species from leaching by diffusion and advection are calculated using Eqs. (3.6) and (3.8), respectively.

Following the complete loss of $\mathrm{NaOH}$ and $\mathrm{KOH}$ from the concrete, changes in the $\mathrm{pH}$ of the concrete are modeled as a function of the $\mathrm{Ca}(\mathrm{OH})_{2}$ content. Using data from the work of Greenberg and Chang, ${ }^{10}$ concrete $\mathrm{pH}$ was regressed on the Ca:Si ratio of the material. $\mathrm{As} \mathrm{Ca}(\mathrm{OH})_{2}$ is leached from the concrete, the $\mathrm{Ca}: \mathrm{Si}$ ratio is updated, and the $\mathrm{pH}$ of the concrete is estimated using this regression.

In addition to the $\mathrm{pH}$ effects noted, the loss of $\mathrm{Ca}(\mathrm{OH})_{2}$ will result also in a reduction in the strength of the concrete. The loss in strength has been estimated to be approximately $1.5 \%$ for every $1.0 \%$ of the $\mathrm{Ca}(\mathrm{OH})_{2}$ leached from the concrete. ${ }^{11}$ Based on this relationship, the compressive strengths of the concrete members are updated to reflect losses of $\mathrm{Ca}(\mathrm{OH})_{2}$. 


\subsubsection{Corrosion of Steel Reinforcement}

The damage to concrete resulting from the corrosion of steel reinforcement manifests itself in expansion, cracking, and spalling of the concrete member. The reinforced concrete member may suffer structural damage because of (a) the loss of the bond between the steel and concrete and (b) the loss of reinforcement cross-sectional area.

Steel reinforcement is generally passivated because of the alkaline nature of the liquid phase in the concrete pores and, hence, does not undergo corrosion. The passive layer on the steel may be destroyed through a direct lowering of the $\mathrm{pH}$ of the concrete via carbonation or because of chloride ion penetration to the steel. Both mechanisms of depassivation are considered in the SOURCE computer codes.

Carbonation of the concrete occurs as a result of the diffusion of carbon dioxide $\left(\mathrm{CO}_{2}\right)$ into the material. The depth of carbonation is given by ${ }^{12}$

$$
\mathrm{X}=\mathbf{k t}{ }^{0.5}
$$

where

$\mathrm{X}=$ depth of carbonation $(\mathrm{m})$ and

$\mathrm{k}=$ carbonation coefficient $\left(\mathrm{m} / \mathrm{s}^{0.5}\right)$.

Given the value of $k$, the depth of penetration of the carbonation front into the concrete can be determined for any specified time.

The carbonation coefficient is calculated using ${ }^{12}$

$$
\frac{C_{x}-C_{8}}{g\left(k / 2 D_{C 02}^{0.5}\right)}+C_{x}-C_{f}=0
$$

where

$$
\begin{array}{ll}
C_{x} & =\text { concentration of } \mathrm{CO}_{2} \text { bound in concrete }(\mathrm{mol} / \mathrm{L}), \\
C_{s} & \mathrm{CO}_{2} \text { concentration at surface of concrete }(\mathrm{mol} / \mathrm{L}), \\
C_{\mathrm{f}} & \mathrm{CO}_{2} \text { concentration ahead of carbonation front }(\mathrm{mol} / \mathrm{L}), \text { and } \\
g\left(\mathrm{k} / 2 \mathrm{D}_{\mathrm{CO2}}^{0.5}\right)= & \text { function, where } \\
& D_{\mathrm{CO} 2}=\text { diffusion coefficient of } \mathrm{CO}_{2} \text { in concrete }\left(\mathrm{m}^{2} / \mathrm{s}\right)
\end{array}
$$


The function $g\left(k / 2 D_{\mathrm{cO} 2}^{0.5}\right)$ is given by

$$
g\left(k / 2 D_{\mathrm{co2}}^{0.5}\right)=\pi^{0.5} \frac{k}{2 D_{\mathrm{co2}}^{0.5}} \exp \left(\frac{k^{2}}{4 D_{\mathrm{co} 2}}\right) \operatorname{erf}\left(\frac{k}{2 D_{\mathrm{cO} 2}^{0.5}}\right)
$$

Equations (3.10) and (3.11) are combined to arrive at a solution for $k$, the carbonation coefficient. Assuming that the concentration of $\mathrm{CO}_{2}$ ahead of the carbonation front is zero (i.e., that the carbonation front is discontinuous), this solution can be simplified to yield

$$
k^{2}=\frac{4 D_{\operatorname{co} 2}}{\pi^{0.5}}\left(\frac{C_{s}}{C_{x}}-1\right)
$$

When using Eq. (3.12) to evaluate $k$, the model takes into account that a portion of the $\mathrm{CO}_{2}$ diffusing into the concrete is bound by concrete constituents and does not penetrate to the steel reinforcement. This bound $\mathrm{CO}_{2}$ plays no role in depassivation. The amount of $\mathrm{CO}_{2}$ bound in the concrete is set equal to amount of hydrated lime in the concrete. ${ }^{12}$ The quantity of hydrated lime is calculated as the product of the $\mathrm{CaO}$ content in the concrete and the degree of hydration. The degree of hydration, estimated based on the water/cement ratio for Portland cements, ${ }^{12}$ is given by

$$
\mathrm{H}_{\mathrm{f}}=0.4+0.5(\mathrm{WCR}) \text {, }
$$

where

$\mathrm{H}_{\mathrm{f}} \quad=$ fraction of hydrated $\mathrm{CaO}$ (unitless) and

$\mathrm{WCR}=$ water-cement ratio (unitless).

Given the carbonation coefficient, $k$, the depth of carbonation is calculated using Eq. (3.9). As stated previously, this solution assumes that the carbonation front is discontinuous. At that time when the front has penetrated to the depth of the steel reinforcement, depassivation of the steel is assumed to occur, and corrosion is thus initiated. 
Steel reinforcement may also be depassivated as a result of the penetration of chloride ions to the steel surface. Using a standard solution to Fick's first law of diffusion, the chloride ion concentration at the steel is calculated as

$$
C L_{s}=C L_{i}+\left(C L_{g w}-C L_{i}\right)\left[1-\operatorname{erf}\left(\frac{C_{c}}{2\left(D_{c l}\right)^{0.5}}\right)\right] \text {, }
$$

where

$\mathrm{CL}_{s}=$ chloride ion concentration at steel reinforcement $(\mathrm{mol} / \mathrm{L})$,

$\mathrm{CL}_{\mathrm{i}}=$ initial chloride ion concentration in concrete $(\mathrm{mol} / \mathrm{L})$,

$\mathrm{CL}_{\mathrm{gw}}=$ chloride ion concentration in groundwater $(\mathrm{mol} / \mathrm{L})$,

$\mathrm{C}_{\mathrm{c}} \quad=$ concrete cover thickness $(\mathrm{m})$, and

$D_{\mathrm{Cl}}=$ effective diffusivity of chloride in concrete $\left(\mathrm{m}^{2} / \mathrm{s}\right)$.

The concentration of chloride ions at the steel reinforcement required to depassivate the steel has been considered by numerous investigators. Hausmann ${ }^{13}$ found that the $\mathrm{pH}$ of the concrete had an effect on the level of chloride ions required to initiate corrosion. In studies carried out using $\mathrm{NaOH}$ and $\mathrm{Ca}(\mathrm{OH})_{2}$ solutions, it was found that a chloride ion to hydroxide ion concentration ratio of 0.61 was sufficient to depassivate the steel.

Using the results of Hausmann, a chloride-ion-to-hydroxide-ion ratio of 0.61 is assumed to result in depassivation of the steel. The hydroxide ion concentration used in calculating this ratio is determined using the modeled concrete $\mathrm{pH}$. As discussed in Sect. 3.1.2, the $\mathrm{pH}$ of the concrete changes with time as $\mathrm{NaOH}, \mathrm{KOH}$, and $\mathrm{Ca}(\mathrm{OH})_{2}$ are leached from the material.

Upon depassivation of the steel reinforcement by either carbonation or chloride penetration, corrosion is modeled to occur at a rate determined by the rate of diffusion of oxygen to the steel. The molar flow of oxygen to the surface of the steel reinforcement is modeled using Fick's first law of diffusion:

$$
J_{0}=-D_{0} A \frac{d\left[O_{2}\right]}{d x}
$$


where

$\mathrm{J}_{\mathrm{o}} \quad=$ oxygen flux at the steel reinforcement $(\mathrm{g} / \mathrm{s})$,

$\mathrm{D}_{\mathrm{o}} \quad=$ effective diffusivity of oxygen through concrete $\left(\mathrm{cm}^{2} / \mathrm{s}\right)$,

A = surface area over which oxygen diffuses to the reinforcement $\left(\mathrm{cm}^{2}\right)$, and

$\frac{\mathrm{d}\left[\mathrm{O}_{2}\right]}{\mathrm{dx}}=$ dissolved oxygen concentration gradient $\left(\mathrm{g} / \mathrm{cm}^{4}\right)$.

The rate of oxygen consumption by the corrosion reaction is assumed to be greater than the rate of oxygen diffusion to the reaction surface. Under these conditions, the corrosion rate is limited by the flux of oxygen at the steel reinforcement.

The use of epoxy-coated steel reinforcement may delay the onset of corrosion by isolating the steel from aggressive ions and oxygen. The use of epoxy coating is not assumed to delay the time of depassivation of the reinforcement. However, upon depassivation, the coating is assumed to prevent corrosion as long as it remains intact.

The effectiveness of epoxy coating on steel reinforcement is modeled using a linear failure function. Using the time at which failure of the coating begins and the time required for all epoxy coating to fail, a fraction of the reinforcement coating which has failed is calculated. This failure fraction is used to linearly adjust the projected rate of corrosion downward.

Corrosion of components other than steel reinforcement will also affect the long-term performance of LLW disposal facilities. For example, the metal boxes placed inside tumulus vaults, the corrugated steel liners used in the construction of disposal silos, and the cast iron pipes used in well construction will all eventually fail as a result of corrosion.

Corrosion of steel and iron barriers used in the tumulus, silo, well-in-silo, and well disposal technologies is considered in the SOURCE computer codes. Failure rates of these barriers are modeled using linear failure functions. The user specifies the time at which corrosion of the metal component begins and the number of years required, following this time, for the member to fail completely. Using these input data, a failure fraction is calculated for each year of the simulation.

\subsection{CONCRETE STRUCTURAL AND CRACKING ANALYSES}

The structural and cracking analyses serve two distinct purposes in modeling the long-term performance of LLW facilities. The structural analysis considers the loads placed on the disposal facility to determine the bending moments, shears, axial tension, and compressive forces placed on 
the various structural components. Because these loads vary with the structural component under consideration, this analysis is carried out for the roof, walls, and floor of each disposal facility.

The cracking analyses are concerned with the ability of the disposal facility to bear the loads placed upon it. Bending moments, shears, axial tensions, and compressive forces calculated as part of the structural analysis are compared with loads and forces at which structural failure will occur to determine the structural integrity of the disposal facility. The cracking analyses must account for the changes in concrete properties projected to occur because of physical and chemical attack. As such, it is conducted for each year of the simulation, or until hydraulic failure of the disposal facility is complete.

The structural and cracking analyses must address the structural features of each disposal facility. Even though the disposal silos and wells share a number of common features, both of these technologies differ significantly from the tumulus technology. Consequently, the following discussion considers the silos and wells, and tumulus separately.

The models used in the structural and cracking analyses are generally applicable to performance analysis of concrete, steel, and iron structural components. However, the manner in which some of these models are applied is specific to the disposal technologies in use at SWSA 6 and planned for L-II. Consequently, general application of the SOURCE computer codes to other disposal configurations requires extreme caution.

\subsubsection{Tumulus Technology}

The long-term performance of a tumulus disposal facility is a function of the performance of the individual vaults of which it is composed. The structural and cracking analyses performed to model the behavior of these vaults are discussed in Sects. 3.2.1.1 and 3.2.1.2, respectively. Additionally, models for the degradation and failure of the tumulus pad and leachate collection system are presented in Sects. 3.2.1.3 and 3.2.1.4.

\subsubsection{Structural Analysis}

Each structural component of the vaults has unique loading conditions placed upon it. As such, separate structural analyses are conducted for the roof or lid, walls, and floor of the vaults. A description of these analyses follows. 
3.2.1.1.1. Vault roof. The roof is analyzed structurally as a simply supported, or hinged, slab. The uniform load on the roof of a vault in layer $i$ of the tumulus disposal facility is calculated as

$$
q_{r}=s \rho_{s}+i h_{s} \rho_{c}+(i-1)\left[h_{w} \rho_{w}+\left(h_{f}+h_{r}\right) \rho_{c}\right]
$$

where

$\mathrm{q}_{\mathrm{r}} \quad=$ uniform load on vault roof in layer $\mathrm{i}\left(\mathrm{lb} / \mathrm{in}^{2}{ }^{2}\right)$,

s = soil cover thickness (in.),

$\rho_{\mathrm{s}} \quad=$ density of soil cover (lb/in. $\left.{ }^{3}\right)$,

i = layer number (unitless),

$h_{\mathrm{r}} \quad=$ roof thickness (in.),

$\rho_{\mathrm{c}} \quad=$ density of reinforced concrete $\left(\mathrm{lb} / \mathrm{in}^{3}{ }^{3}\right)$,

$\mathrm{h}_{\mathrm{w}} \quad=$ waste thickness (in.),

$\rho_{\mathrm{w}} \quad=$ density of waste $\left(\mathrm{lb} / \mathrm{in} .{ }^{3}\right)$, and

$\mathrm{h}_{\mathrm{f}} \quad=$ floor thickness (in.).

Thermal loads on the vaults are not considered because the insulating properties of the cover material minimize thermal gradients across the concrete structural components.

The deflection of the simply supported rectangular roof resulting from the uniform load is given by

$$
W(x, y)=\frac{16 q_{r} W_{r}}{\pi^{6} D_{r}} \sum_{m=1}^{\infty} \sum_{n=1}^{\infty} \frac{\sin \frac{m \pi x}{a} \sin \frac{n \pi y}{b}}{m n\left(\frac{m^{2}}{a^{2}}+\frac{n^{2}}{b^{2}}\right)^{2}},
$$

where

$W(x, y)=$ deflection of roof at location $(x, y)$ (in.),

$w_{s} \quad=$ width of roof in $(x, y)$ direction (in.),

$\mathrm{m}, \mathrm{n}=1,3,5, \ldots$,

a = width of waste cell (in.),

b = length of waste cell (in.), and

$\mathrm{D}_{\mathrm{r}} \quad$ = flexural rigidity of the roof (lb-in. $\left.{ }^{2}\right)$. 
The flexural rigidity of the roof is calculated using

$$
D_{r}=\frac{E_{c} h_{r}^{3} w_{r}}{12\left(1-\mu_{c}^{2}\right)} \text {, }
$$

where

$\mathrm{E}_{\mathrm{c}} \quad=$ modulus of elasticity of concrete (lb/in. $\left.{ }^{2}\right)$.

Based on Eqs. (3.17) and (3.18), the bending moments resulting from uniform loading as a function of location on the roof are calculated as

$$
\begin{aligned}
M_{x} & =q_{z} a^{2}\left[\frac{16}{\pi^{4}} \sum_{m=1}^{\infty} \sum_{n=1}^{\infty} \frac{\sin \frac{m \pi x}{a} \sin \frac{n \pi y}{b}}{\left.m m^{2}+\frac{n^{2}}{\left(\frac{b}{a}\right)^{2}}\right)^{2}}\right. \\
& \left.+\mu_{c} \frac{\sin \frac{m \pi x}{a} \sin \frac{n \pi y}{b}}{\left(\frac{b}{a}\right)^{2}\left(\frac{m}{n}\right)\left(m^{2}+\frac{n^{2}}{\left(\frac{b}{a}\right)^{2}}\right)^{2}}\right]
\end{aligned}
$$

and 


$$
\begin{gathered}
M_{y}=q_{z} b^{2}\left[\frac{16}{\pi^{4}} \sum_{m=1}^{\infty} \sum_{n=1}^{\infty} \frac{\sin \frac{m \pi x}{a} \sin \frac{n \pi y}{b}}{\frac{m}{n}\left(\frac{m^{2}}{\left(\frac{a}{b}\right)^{2}}+n^{2}\right)^{2}}\right. \\
\left.+\mu_{c} \frac{\sin \frac{m \pi x}{a} \sin \frac{n \pi y}{b}}{\left(\frac{a}{b}\right)^{2}\left(\frac{n}{m}\right)\left(\frac{m^{2}}{\left(\frac{a}{b}\right)^{2}}+n^{2}\right)^{2}}\right]
\end{gathered}
$$

where

$$
\begin{aligned}
\mathrm{M}_{x}= & \text { bending moment resulting from uniform loading in the x-direction parallel to width of } \\
& \text { roof (lb-in./in.) and } \\
M_{y}= & \text { bending moment resulting from uniform loading in the } y \text {-direction parallel to length of } \\
& \text { roof (lb-in./in.). }
\end{aligned}
$$

Uniform loads on the vault roof result in shear forces upon that component as well. These forces are calculated as

$$
\begin{aligned}
Q_{x}= & q_{x} a\left\{\frac{16}{\pi^{3}} \sum_{m=1}^{\infty} \sum_{n=1}^{\infty} \cos \frac{m \pi x}{a} \cdot \sin \frac{n \pi y}{b}\right. \\
& {\left.\left[\frac{m^{2}}{n\left(m^{2}+n^{2}\left(\frac{a}{b}\right)^{2}\right)^{2}}+\frac{n}{\left(m^{2}\left(\frac{b}{a}\right)+n^{2}\left(\frac{a}{b}\right)\right)^{2}}\right]\right\} }
\end{aligned}
$$

and 


$$
\begin{aligned}
Q_{y}= & q_{r} b\left\{\frac{16}{\pi^{3}} \sum_{m=1}^{\infty} \sum_{n=1}^{\infty} \sin \frac{m \pi x}{a} \cos \frac{n \pi y}{b}\right. \\
& {\left.\left[\frac{m}{\left(m^{2}\left(\frac{b}{a}\right)+n^{2}\left(\frac{a}{b}\right)\right)^{2}}+\frac{n^{2}}{m\left(m^{2}\left(\frac{b}{a}\right)^{2}+n^{2}\right)^{2}}\right]\right\}, }
\end{aligned}
$$

where

$\mathrm{Q}_{\mathrm{x}} \quad=$ shear force resulting from uniform loading in the $\mathrm{x}$-direction (lb/in.) and

$\mathrm{Q}_{\mathrm{y}} \quad$ = shear force resulting from uniform loading in the $y$-direction (lb/in.).

3.2.1.1.2. Vault walls. The vault walls are subject to vertical, or uniform, loads and hydrostatic pressures. The uniform loads are calculated for a vault in layer $i$ of the tumulus disposal facility using

$$
q_{w}=\rho_{s}\left(\frac{h_{r}}{2} i+\left(h_{f}+h_{w}\right)(i-1)+s\right)\left(1-\sin f_{s}\right),
$$

where

$\mathrm{q}_{\mathrm{w}}=$ uniform load on vault wall in layer $\mathrm{i}\left(\mathrm{lb} / \mathrm{in} .{ }^{2}\right)$ and

$f_{s} \quad=$ friction angle of soil backfill around tumulus (deg).

Hydrostatic pressures on the vault walls are a result of lateral soil pressures from the soil backfill and from the waste and grout inside the vault. This pressure is calculated as

$$
P=\rho_{s}\left(h_{w}+\frac{h_{s}+h_{f}}{2}\right)\left(h-\sin f_{s}\right)-\rho_{w}\left(h_{w}+\frac{h_{r}+h_{f}}{2}\right)\left(1-\sin f_{w}\right),
$$


where

$$
\begin{aligned}
& \left.\mathrm{P} \quad=\text { maximum hydrostatic pressure (lb/in. }{ }^{2}\right) \text { and } \\
& f_{w} \quad=\text { friction angle of waste }(\mathrm{deg}) .
\end{aligned}
$$

Bending moment calculations for the vault walls must account for the uniform loads and hydrostatic pressures on the structural components. Bending moments resulting from the uniform load are calculated using Eqs. (3.19) and (3.20), substituting the uniform load on the wall for the uniform load on the roof and changing roof dimensions to those of the wall. Bending moments caused by hydrostatic pressures are calculated using

$$
\begin{aligned}
M_{x h} & =P^{2} \sum_{m=1}^{\infty}(m \pi)^{2}\left[\frac{2(-1)^{m+1}}{\pi^{5} m^{5}}+\left[\left(1-\mu_{c}\right) A_{m}-2 \mu_{c} B_{m}\right] \cosh \left(\frac{m \pi y}{a}\right)\right. \\
& \left.+\left(1-\mu_{c}\right) B_{m}\left(\frac{m \pi}{a}\right) y \sinh \left(\frac{m \pi y}{a}\right)\right] \sin \frac{m \pi x}{a}
\end{aligned}
$$

and

$$
\begin{aligned}
M_{y h} & =P_{a}^{2} \sum_{m=1}^{\infty}(m \pi)^{2}\left[\frac{2(-1)^{m+1}}{\pi^{5} m^{5}} \mu_{c}+\left[\left(\mu_{c}-1\right) A_{m}-2 B_{m}\right] \cosh \left(\frac{m \pi y}{a}\right)\right. \\
& \left.+\left(\mu_{c}-1\right) B_{m}\left(\frac{m \pi}{a}\right) y \sinh \left(\frac{m \pi y}{a}\right)\right] \sin \frac{m \pi x}{a},
\end{aligned}
$$

where

$\mathrm{M}_{\mathrm{xh}}$ = bending moment resulting from hydrostatic pressures in the x-direction parallel to the width of the wall (lb-in./in.) and

$\mathrm{M}_{\mathrm{yh}}$ = bending moment resulting from hydrostatic pressures in the $y$-direction parallel to the length of the wall (lb-in./in.). 
The quantities $A_{m}$ and $B_{m}$ are given, respectively, by

$$
A_{m}=-\frac{\left(2+\alpha_{m} \tanh \alpha_{m}\right)(-1)^{m+1}}{\pi^{5} m^{5} \cosh \alpha_{m}}
$$

and

$$
B_{m}=\frac{(-1)^{m+1}}{\pi^{5} m^{5} \cosh \alpha_{m}}
$$

where

$$
\alpha_{m}=\frac{m \pi b}{2 a}
$$

Bending moments calculated for the uniform load and hydrostatic pressure on the wall are summed to arrive at the final bending moments for the wall as a function of location. The calculations of the bending moments are repeated for each wall geometry comprising the disposal vault.

Shear forces caused by hydrostatic pressures on the vault walls are calculated as

$$
Q_{x h}=2 P a \sum_{m=1}^{\infty}(m \pi)^{3}\left[\frac{(-1)^{m+1}}{\pi^{5} m^{5}}-B_{m} \cosh \left(\frac{m \pi y}{a}\right)\right] \cos \left(\frac{m \pi x}{a}\right)
$$

and

$$
Q_{y h}=-2 P a \sum_{m=1}^{\infty}(m \pi)^{3} B_{m} \sinh \left(\frac{m \pi y}{a}\right) \sin \left(\frac{m \pi x}{a}\right),
$$

where

$\mathrm{Q}_{\mathrm{xh}}=$ shear force resulting from hydrostatic loading in the $\mathrm{x}$-direction (lb/in.) and

$\mathrm{Q}_{\mathrm{yh}}=$ shear force resulting from hydrostatic loading in the $y$-direction (lb/in.). 
The shear forces on vault walls resulting from uniform loads are calculated using Eqs. (3.21) and (3.22) and substituting appropriate parameters for the wall. Shear forces caused by uniform and hydrostatic loads are summed for each wall location. Calculations of shear forces are performed for each wall geometry comprising the vault.

The walls of the vaults are subject to compressive forces from the roof reaction and the weight of the walls. The compressive force, calculated as a function of height on the wall, is given by

$$
F_{w}=R_{r y}+h_{w 1} z \rho_{c}
$$

where

$$
\begin{aligned}
& F_{w}=\text { compressive force on wall at height } z \text { (lb/in.), } \\
& R_{r y}=\text { roof reaction in y direction at height } z \text { (lb/in.), } \\
& h_{w l}=\text { thickness of wall (in.), and } \\
& z \quad=\text { wall height (in.) }
\end{aligned}
$$

3.2.1.1.3. Vault floor. The floor of a given vault must bear loads from the walls, including the wall weight and loads transmitted to the walls from the roof, and loads from the waste within the vault. Based on the floor geometry illustrated in Fig. 3.1, the bending moments in the region $x$ (or $y$ ) $\leq a$ of the beam subjected to a concentrated force and moment are calculated as

$$
M_{x}=\frac{P_{x} I_{1 p x}}{2 \lambda_{x}\left[\sinh ^{2}\left(\lambda_{x} w_{f}\right)-\sin ^{2}\left(\lambda_{x} w_{f}\right)\right]}
$$

and

$$
M_{y}=\frac{P_{y} I_{1 p y}}{2 \lambda_{y}\left[\sinh ^{2}\left(\lambda_{y} 1_{f}\right)-\sin ^{2}\left(\lambda_{y} 1_{f}\right)\right]},
$$

where

$\mathrm{M}_{\mathrm{x}}$ = bending moment in $\mathrm{x}$-direction parallel to width of floor (lb-in./in.),

$\mathbf{P}_{\mathbf{x}} \quad=$ applied concentrated load caused by wall in $\mathrm{x}$-direction (lb/in.), 


$$
\begin{aligned}
& I_{\mathrm{lpx}}=\text { trigonometric function (unitless), } \\
& \lambda_{x}=\left[\frac{\tilde{k l}_{f}}{4 D_{f x}}\right]^{0.25}\left(\text { in. }^{-1}\right), \\
& \tilde{\mathrm{k}} \quad=\text { modulus of the subgrade reaction }\left(\mathrm{lb} / \mathrm{in} .^{3}\right) \text {, } \\
& \mathrm{l}_{\mathrm{f}} \quad=\text { length of floor (in.), } \\
& D_{\mathrm{b}}=\text { flexural rigidity of floor in the x-direction (lb-in. }{ }^{2} \text { ), } \\
& w_{f}=\text { width of floor (in.), } \\
& \mathrm{M}_{\mathrm{y}} \text { = bending moment in y-direction parallel to length of floor (lb-in_/in.), } \\
& \mathrm{P}_{\mathrm{y}} \quad=\text { applied concentrated load caused by wall in } \mathrm{y} \text {-direction (lb/in.), } \\
& I_{\text {lpy }} \quad \text { trigonometric function (unitless), } \\
& \lambda_{y}=\left[\frac{\tilde{k}_{f}}{4 D_{f y}}\right]^{0.2 s}\left(\text { in. }^{-1}\right) \text {, and } \\
& D_{f y}=\text { flexural rigidity of floor in the } y \text {-direction (lb-in. }{ }^{2} \text { ). }
\end{aligned}
$$

ORNL-DWG 84.5975

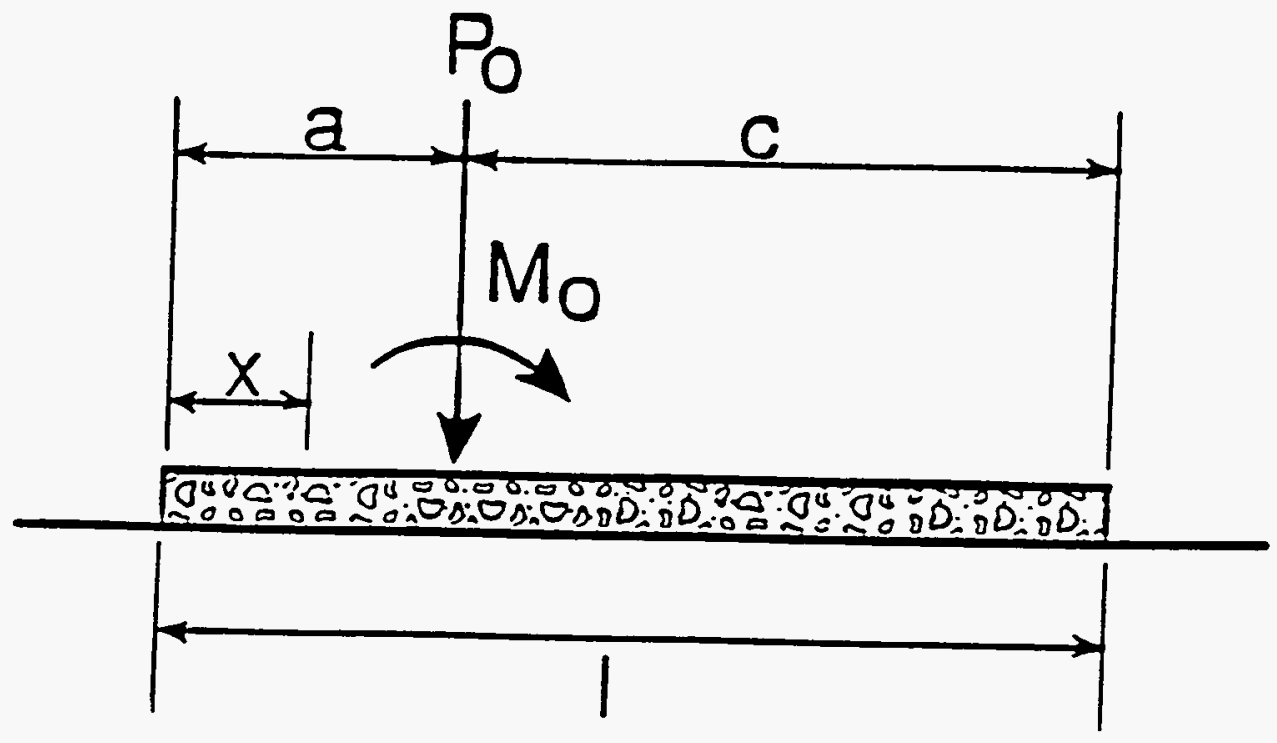

Fig. 3.1. Schematic diagram of floor geometry used in the calculation of bending moments. 
Applied moments caused by the wall are not considered in the bending moment calculations because it is assumed that the floor and walls are hinged.

The concentrated load on the floor, $\mathrm{P}_{\mathrm{x}}$ or $\mathrm{P}_{\mathrm{y}}$, is calculated as a function of location using

$$
P_{x}=R_{i x}+h_{w 1}\left(h_{w}+\frac{h_{r}+h_{f}}{2}\right)\left(\rho_{c}-\rho_{w}\right)
$$

and

$$
P_{y}=R_{r y}+h_{w l}\left(h_{w}+\frac{h_{r}+h_{f}}{2}\right)\left(\rho_{c}-\rho_{w}\right),
$$

where

$$
R_{x x}=\text { roof reaction in } x \text {-direction (lb/in.). }
$$

The flexural rigidity of the floor is calculated using Eq. (3.18). To calculate the quantity $D_{\mathrm{fx}}$ the thickness and width of the floor are substituted for $h_{r}$ and $w_{p}$ respectively. The thickness and length of the floor are substituted for $h_{r}$ and $w_{p}$, respectively, to calculate $D_{f y}$.

The parameters $I_{1 \mathrm{px}}$ and $I_{\mathrm{Ipy}}$ are complex trigonometric functions of $\lambda_{x}, \lambda_{y}$, and the geometry of the structural member and are given by

$$
\begin{aligned}
I_{1 p x}= & 2 \sinh \left(\lambda_{x} x\right) \sin \left(\lambda_{x} x\right)\left[\sinh \left(\lambda_{x} w_{f}\right) \cos \left(\lambda_{x} a\right) \cosh \left(\lambda_{x} c\right)\right. \\
& \left.-\sin \left(\lambda_{x} w_{f}\right) \cosh \left(\lambda_{x} a\right) \cos \left(\lambda_{x} c\right)\right]-\left[\sinh \left(\lambda_{x} x\right) \cos \left(\lambda_{x} x\right)\right. \\
& \left.-\cosh \left(\lambda_{x} x\right) \sin \left(\lambda_{x} x\right)\right]\left[\operatorname { s i n h } ( \lambda _ { x } w _ { f } ) \left\{\sin \left(\lambda_{x} a\right) \cosh \left(\lambda_{x} c\right)\right.\right. \\
& \left.-\cos \left(\lambda_{x} a\right) \sinh \left(\lambda_{x} c\right)\right\}+\sin \left(\lambda_{x} w_{f}\right)\left\{\sinh \left(\lambda_{x} a\right) \cos \left(\lambda_{x} c\right)\right. \\
& \left.\left.-\cosh \left(\lambda_{x} a\right) \sin \left(\lambda_{x} c\right)\right\}\right]
\end{aligned}
$$

and 


$$
\begin{aligned}
I_{1 p y}= & 2 \sinh \left(\lambda_{y} y\right) \sin \left(\lambda_{y} y\right)\left[\sinh \left(\lambda_{y} I_{f}\right) \cos \left(\lambda_{y} a\right) \cosh \left(\lambda_{y} c\right)\right. \\
& \left.-\sin \left(\lambda_{y} l_{f}\right) \cosh \left(\lambda_{y} a\right) \cos \left(\lambda_{y} c\right)\right]-\left[\sinh \left(\lambda_{y} y\right) \cos \left(\lambda_{y} y\right)\right. \\
& \left.-\cosh \left(\lambda_{y} y\right) \sin \left(\lambda_{y} y\right)\right]\left[\operatorname { s i n h } ( \lambda _ { y } l _ { f } ) \left\{\sin \left(\lambda_{y} a\right) \cosh \left(\lambda_{y} c\right)\right.\right. \\
& \left.-\cos \left(\lambda_{y} a\right) \sinh \left(\lambda_{y} c\right)\right\}+\sin \left(\lambda_{y} l_{f}\right)\left\{\sinh \left(\lambda_{y} a\right) \cos \left(\lambda_{y} c\right)\right. \\
& \left.\left.-\cosh \left(\lambda_{y} a\right) \sin \left(\lambda_{y} c\right)\right\}\right]
\end{aligned}
$$

where the parameters $a$ and $c$ are indicated in Fig. 3.1.

Shear forces on the floor of the vault are calculated as a function of location using

$$
Q_{x}=\frac{P_{x} I_{2 p x}}{\left[\sinh ^{2}\left(\lambda_{x} w_{f}\right)-\sin ^{2}\left(\lambda_{x} w_{f}\right)\right]}
$$

and

$$
Q_{y}=\frac{p_{y} I_{2 p y}}{\left[\sinh ^{2}\left(\lambda_{y} 1_{f}\right)-\sin ^{2}\left(\lambda_{y} 1_{f}\right)\right]} \text {, }
$$

where

$$
\begin{aligned}
& I_{2 p x}=\text { trigonometric function (unitless) and } \\
& I_{2 p y}=\text { trigonometric function (unitless). }
\end{aligned}
$$

The parameters $I_{2 p x}$ and $I_{2 p y}$ are functions of $\lambda_{x}, \lambda_{y}$, and the geometry of the structural member and are given by 


$$
\begin{aligned}
I_{2 p x}= & {\left[\cosh \left(\lambda_{x} x\right) \sin \left(\lambda_{x} x\right)+\sinh \left(\lambda_{x} x\right) \cos \left(\lambda_{x} x\right)\right]\left[\sinh \left(\lambda_{x} w_{f}\right)\right.} \\
& \left.\cos \left(\lambda_{x} a\right) \cosh \left(\lambda_{x} c\right) \sin \left(\lambda_{x} w_{f}\right) \cosh \left(\lambda_{x} a\right) \cos \left(\lambda_{x} c\right)\right] \\
& +\sinh \left(\lambda_{x} x\right) \sin \left(\lambda_{x} s\right)\left[\operatorname { s i n h } ( \lambda _ { x } w _ { f } ) \left\{\sin \left(\lambda_{x} a\right) \cosh \left(\lambda_{x} c\right)\right.\right. \\
& \left.-\cos \left(\lambda_{x} a\right) \sinh \left(\lambda_{x} c\right)\right\}+\sin \left(\lambda_{x} w_{f}\right)\left\{\sinh \left(\lambda_{x} a\right) \cos \left(\lambda_{x} c\right)\right. \\
& \left.\left.-\cosh \left(\lambda_{x} a\right) \sin \left(\lambda_{x} c\right)\right\}\right]
\end{aligned}
$$

and

$$
\begin{aligned}
& I_{2 p y}=\left[\cosh \left(\lambda_{s} y\right) \sin \left(\lambda_{y} y\right)+\sinh \left(\lambda_{y} y\right) \cos \left(\lambda_{y} y\right)\right]\left[\sinh \left(\lambda_{y} w_{f}\right)\right. \\
& \left.\cos \left(\lambda_{y} a\right) \cosh \left(\lambda_{y} c\right) \sin \left(\lambda_{y} l_{f}\right) \cosh \left(\lambda_{y} a\right) \cos \left(\lambda_{y} c\right)\right] \\
& +\sinh \left(\lambda_{y} y\right) \sin \left(\lambda_{y} s\right)\left[\operatorname { s i n h } ( \lambda _ { y } l _ { f } ) \left\{\sin \left(\lambda_{y} a\right) \cosh \left(\lambda_{y} c\right)\right.\right. \\
& \left.-\cos \left(\lambda_{y} a\right) \sinh \left(\lambda_{y} c\right)\right\}+\sin \left(\lambda_{y} l_{f}\right)\left\{\sinh \left(\lambda_{y} a\right) \cos \left(\lambda_{y} c\right)\right. \\
& \left.\left.-\cosh \left(\lambda_{y} a\right) \sin \left(\lambda_{y} c\right)\right\}\right]
\end{aligned}
$$

\subsubsection{Cracking Analyses}

The cracking analyses are performed to assess the ability of the structural components of each vault to bear the loads placed upon it. In the event that the roof, wall(s), or floor of a vault cannot bear these loads, cracking will occur. Cracking of these components may occur as a result of shear forces or bending; cracking of the vault walls may also result from compressive loads on the structure. The manner in which these modes of cracking are modeled is discussed in the following.

Shear cracking will occur if the shear force on a concrete member exceeds the cracking shear of the member. The cracking shears for the roof, floor, and wall in the horizontal direction are calculated as the minimum of

$$
V_{c r}=d_{t}\left(1.9 C_{s t r}^{0.5}+2500 S_{t m} Q_{x} / M_{x}\right)
$$


or

$$
V_{c r}=3.5 C_{s t r}^{0.5} d_{t}
$$

where

$\mathrm{V}_{\mathrm{cr}}=$ shear force at which cracking occurs (lb/in.),

$\mathrm{d}_{\mathrm{t}}=$ distance from steel reinforcement in tension to compression face of concrete (in.),

$\mathrm{C}_{\mathrm{str}}=$ compressive strength of concrete $\left(\mathrm{lb} / \mathrm{in} .^{2}\right)$, and

$\mathrm{S}_{\mathrm{m}}=$ area of steel reinforcement in tension per unit width (in. ${ }^{2} / \mathrm{in}$.).

The cracking shear for the wall in the vertical direction is the minimum of Eqs. (3.43) and (3.45).

$$
V_{c r}=3.5 C_{s t r}^{0.5} d_{1}\left(1 .+F_{w} /\left(500 h_{w 1}\right)\right)^{0.5}
$$

In the event of cracking caused by shear failure, crack characteristics are determined. The depth of the single crack is the thickness of the concrete member, and the crack width is 0.013 in.

Cracking caused by bending will be initiated if the bending moments calculated for a given concrete member exceed the cracking moment for that structural component. The cracking moment is given by

$$
M_{c x}=\frac{I_{g} f_{r}}{y_{t} a_{u}}
$$

where

$$
\begin{aligned}
& M_{c r} \quad=\text { cracking moment per unit width }\left(\frac{\mathrm{lb}-\mathrm{in} .}{\mathrm{in.}}\right), \\
& \left.\mathrm{I}_{\mathrm{B}} \quad=\text { moment of inertia of concrete section (in. }{ }^{4}\right), \\
& f_{\mathrm{r}} \quad=\text { modulus of rupture }\left(\mathrm{lb} / \mathrm{in}^{2}\right), \\
& y_{t} \quad=\text { distance from the centroidal axis to the tensile face of the concrete (in.), and } \\
& \mathrm{a}_{\mathrm{u}} \quad=\text { unit width of concrete member. }
\end{aligned}
$$


For a rectangular slab

$$
I_{g}=\frac{a_{n} h_{m}^{3}}{12},
$$

where

$\mathrm{h}_{\mathrm{m}} \quad=$ concrete member thickness (in.).

The value of $y_{t}$ is given by

$$
y_{t}=\frac{h_{m}}{2}
$$

Axial compression force is conservatively neglected in the roof and floor.

If the bending moments exceed the cracking moment but do not exceed the ultimate strength of the concrete member, cracks will not propagate through the entire member. If, however, the bending moments exceed the ultimate strength of the structural component, cracks will span the thickness of the member. The ultimate flexural strength of a member without compressive steel is approximated using

$$
M_{v}=\phi S_{t w} f_{y}\left(d_{t}-\frac{C_{d}}{2}\right),
$$

where

$\mathrm{M}_{\mathrm{u}} \quad$ = ultimate flexural strength (lb-in./in.),

$\phi \quad=$ strength reduction factor (unitless),

$\mathrm{f}_{\mathrm{y}} \quad=$ yield strength of steel reinforcement $\left(\mathrm{lb} / \mathrm{in}^{2}{ }^{2}\right)$, and

$C_{\mathrm{d}} \quad=$ depth of the compression block (in.).

The depth of the compression block is calculated using

$$
C_{d}=\frac{S_{\text {tm }} f_{y}}{0.85 C_{s t r}}
$$


If all reinforcement has been lost because of corrosion, the ultimate strength is equal to the cracking moment.

Crack characteristics are calculated as fractures due to loading and propagate through a given structural component. The depth of cracking caused by bending is calculated as the distance from the surface of the concrete to the neutral axis. Crack depth is computed using the strain compatibility relation wherein the tensile crack depth is given by

$$
d_{c x}=\frac{d_{l}}{\frac{S t_{n}}{E g}+\frac{S t_{m}}{E_{c}}}\left[\frac{S t_{p}}{E_{s}}+\epsilon_{s h}\right]+d_{c},
$$

where

$\mathrm{d}_{\mathrm{cr}} \quad=$ crack depth (in.),

$\epsilon_{\mathrm{sh}}=$ shrinkage strain of concrete (in./in.),

$\mathrm{d}_{\mathrm{c}}=$ concrete cover thickness on tension face (in.),

$\mathrm{St}_{\mathrm{n}}=$ tensile stress in steel reinforcement $\left(\mathrm{lb} / \mathrm{in}^{2}{ }^{2}\right)$,

$\mathrm{St}_{\mathrm{m}} \quad=$ maximum concrete compressive stress $\left(\mathrm{lb} / \mathrm{in}^{2}{ }^{2}\right)$, and

$\mathrm{E}_{\mathrm{s}}=$ modulus of elasticity of steel reinforcement (for this application, taken as $200,000 \mathrm{MPa}$ ) (MPa).

The tensile stress in steel reinforcement is calculated using

$$
S t_{n}=\left(\frac{E_{s}}{E_{c}}\right) M\left(\frac{d_{1}-R_{z}}{I_{c}}\right),
$$

where

$\mathrm{M}$ = bending moment due to uniform loading in $\mathrm{x}$ or $\mathrm{y}$ direction (lb-in./in.) and

$\mathrm{I}_{\mathrm{e}} \quad=$ effective moment of inertia per unit width of concrete member (in. ${ }^{3}$ ). 
The quantity $R_{t}$ (in.) is given by

$$
R_{t}=\frac{-\left(\hat{\beta}_{1}+\hat{\beta}_{2}\right)+\left[\left(\hat{\beta}_{1}+\hat{\beta}_{2}\right)^{2}-4 \alpha\left(C_{c} \hat{\beta}_{1}-d_{t} \hat{\beta}_{2}\right)\right]^{0.5}}{2 \alpha_{1}} .
$$

The quantities $\alpha_{1}$ (unitless), $\hat{\beta}_{1}$ (in.), and $\hat{\beta}_{2}$ (in.) are calculated by

$$
\begin{gathered}
\alpha_{1}=0.5, \\
\hat{\beta}_{1}=\left(\frac{\pi}{S_{p 2}}\right)\left(\frac{S_{d 1}}{2}\right)^{2}\left(\frac{E_{z}}{E_{c}}-1\right),
\end{gathered}
$$

and

$$
\hat{\beta}_{2}=\left(\frac{\pi}{S_{p 2}}\right)\left(\frac{S_{d 1}}{2}\right)^{2}\left(\frac{E_{s}}{E_{c}}\right) \text {, }
$$

where

$\mathrm{S}_{\mathrm{d} 1}=$ diameter of steel reinforcement in direction 1 , and closest to concrete outer tension face (in.) and

$\mathrm{S}_{\mathrm{p} 2}=$ spacing of steel reinforcement in direction 2, perpendicular to direction 1 (in.). 
The quantity $I_{c}$ is given by

$$
I_{e}=\left(\frac{1}{a_{v}}\right)\left[\left(\frac{M_{c r}}{M}\right)^{3} I_{B}+\left(1-\left(\frac{M_{c r}}{M}\right)^{3}\right) I_{c}\right]
$$

where

$I_{c}=$ cracking moment of inertia in the $x$ - or $y$-direction (in. ${ }^{4}$ ).

The cracking moment of inertia is calculated using the following equation:

$$
I_{c}=a_{a}\left[0.333 R_{t}^{3}+\hat{\beta}_{1}\left(R_{t}-C_{c}\right)^{2}+\hat{\beta}_{2}\left(d_{t}-R_{t}\right)^{2}\right]
$$

The maximum concrete compressive stress is given by

$$
S t_{m}=M\left(\frac{R_{t}}{I_{e}}\right)
$$

In modeling the water flow characteristics of failed concrete, it is assumed that cracks achieving a depth equal to three-fourths of the remaining slab thickness functionally penetrate the slab. Prior to this, flow through the concrete is the same as that through intact concrete. If the bending moment exceeds the ultimate strength of the concrete slab, cracks penetrate immediately through the slab.

Numerous equations have been proposed for the prediction of crack spacing and width in flexural members. Nawy ${ }^{14}$ developed a formula for calculating mean crack spacing for a two-way concrete slab: 


$$
\mathrm{S}_{\mathrm{m} 1}=0.5 \mathrm{~K}\left(\frac{\mathrm{S}_{\mathrm{d} 1} \mathrm{~S}_{\mathrm{p} 2}}{\mathrm{Q}_{\mathrm{d}}}\right)^{0.5} \text {, }
$$

where

$\mathrm{S}_{\mathrm{m} 1}=$ mean crack spacing in direction 1 (in.).

The variables $K_{n}$ and $Q_{d}$ are given by

$$
\mathrm{K}_{\mathrm{n}}=\left[1.6+2.4\left(\frac{\mathrm{a}}{\mathrm{b}}-0.5\right)\right] 0.29
$$

and

$$
Q_{d}=\frac{S_{t a}}{24 d_{c}}
$$

If the bending moment exceeds the cracking moment, but not the ultimate strength of the concrete member, the mean crack width is given by

$$
W_{m}=S_{m}\left(\beta_{r} \frac{S t_{n}}{E_{s}}+\epsilon_{s h}\right),
$$

where

$$
\begin{aligned}
& \mathrm{W}_{\mathrm{m}}=\text { mean crack width (in.) and } \\
& \mathrm{S}_{\mathrm{m}}=\text { mean crack spacing (in.). }
\end{aligned}
$$


The quantity $\beta_{r}$ is given by

$$
\beta_{r}=\frac{d_{c r}}{d_{c r}-d_{c}}
$$

If the bending moment exceeds the ultimate strength of the concrete member, the crack width is calculated as

$$
W_{m}=S_{m}\left(\frac{f_{y}}{E_{z}}+\epsilon_{s h}\right)
$$

If the compressive forces on the wall exceed the ultimate strength of the wall in compression, cracking will occur. The ultimate strength of the wall in compression is calculated as

$$
M_{v e}=0.39 h_{w 1} C_{s t r}\left[1 .-\left(\frac{h_{c}}{32 h_{w 1}}\right)^{2}\right] \text {, }
$$

where

$$
\begin{aligned}
& M_{u c}=\text { ultimate strength of the wall in compression (lb/in.) and } \\
& h_{c} \quad=\text { height of vault wall (in.). }
\end{aligned}
$$

Cracking because of compression results in a single crack extending through the concrete member; the crack width is one-tenth of the height of the wall section under consideration.

Cracking of a reinforced concrete member may occur also as a result of corrosion of the steel reinforcement. As the concrete surrounding the reinforcement prevents free expansion, the steelcorrosion products will exert pressure within the concrete. Based on elasticity theory, ${ }^{15}$ the magnitude of this internal pressure is approximated using 


$$
P_{i}=\frac{\Delta}{r_{0}} \frac{1}{\left[\frac{1-\mu_{r}}{E_{r}}+\frac{\left(1-\mu_{c}\right) r_{0}^{2}+\left(1+\mu_{c}\right) d_{c v}^{2}}{E_{c}\left(d_{c v}-r_{0}^{2}\right)}\right]},
$$

where

$$
\begin{aligned}
& \mathrm{P}_{\mathrm{i}} \quad \text { = internal pressure due to corrosion (lb/in. }{ }^{2} \text { ), } \\
& \Delta \quad=\text { thickness of the free expansion layer (in.), } \\
& r_{0} \quad=\text { original radius of steel reinforcement (in.), } \\
& \mu_{r} \quad=\text { Poisson's ratio of corrosion product (unitless), } \\
& d_{c v} \quad=\text { distance from concrete face to center of steel reinforcement (in.), and } \\
& \left.E_{r} \quad=\text { modulus of elasticity of corrosion product (lb/in. }{ }^{2}\right) .
\end{aligned}
$$

The thickness of the free expansion layer is given by

$$
\Delta=r_{e}+C_{t c}-r_{0},
$$

where

$$
\begin{aligned}
& r_{e} \quad=\text { radius of remaining steel reinforcement (in.) and } \\
& \mathrm{C}_{\mathfrak{t} c} \quad=\text { thickness of corrosion layer under conditions of free expansion (in.). }
\end{aligned}
$$

A general series form of the stress function in bipolar coordinates was given by Jeffrey. ${ }^{16}$ This function has been applied to the situation of a semi-infinite region with a circular hole under a uniform radius pressure (Fig. 3.2). Based on this work, the stress on the surface of the concrete is given by

$$
\sigma_{x}=-4 P_{i} \frac{r_{0}^{2}\left(x^{2}-d_{c v}^{2}+r_{0}^{2}\right)}{\left(x^{2}+d_{c v}^{2}-r_{0}^{2}\right)^{2}},
$$


where

$\sigma_{\mathrm{x}} \quad=$ stress at surface of concrete (lb/in. $\left.{ }^{2}\right)$ and

$\mathrm{x}=$ distance from point $\mathrm{A}$ (Fig. 3.2) along the surface of the concrete (in.).

ORNL-DWG 94-5976

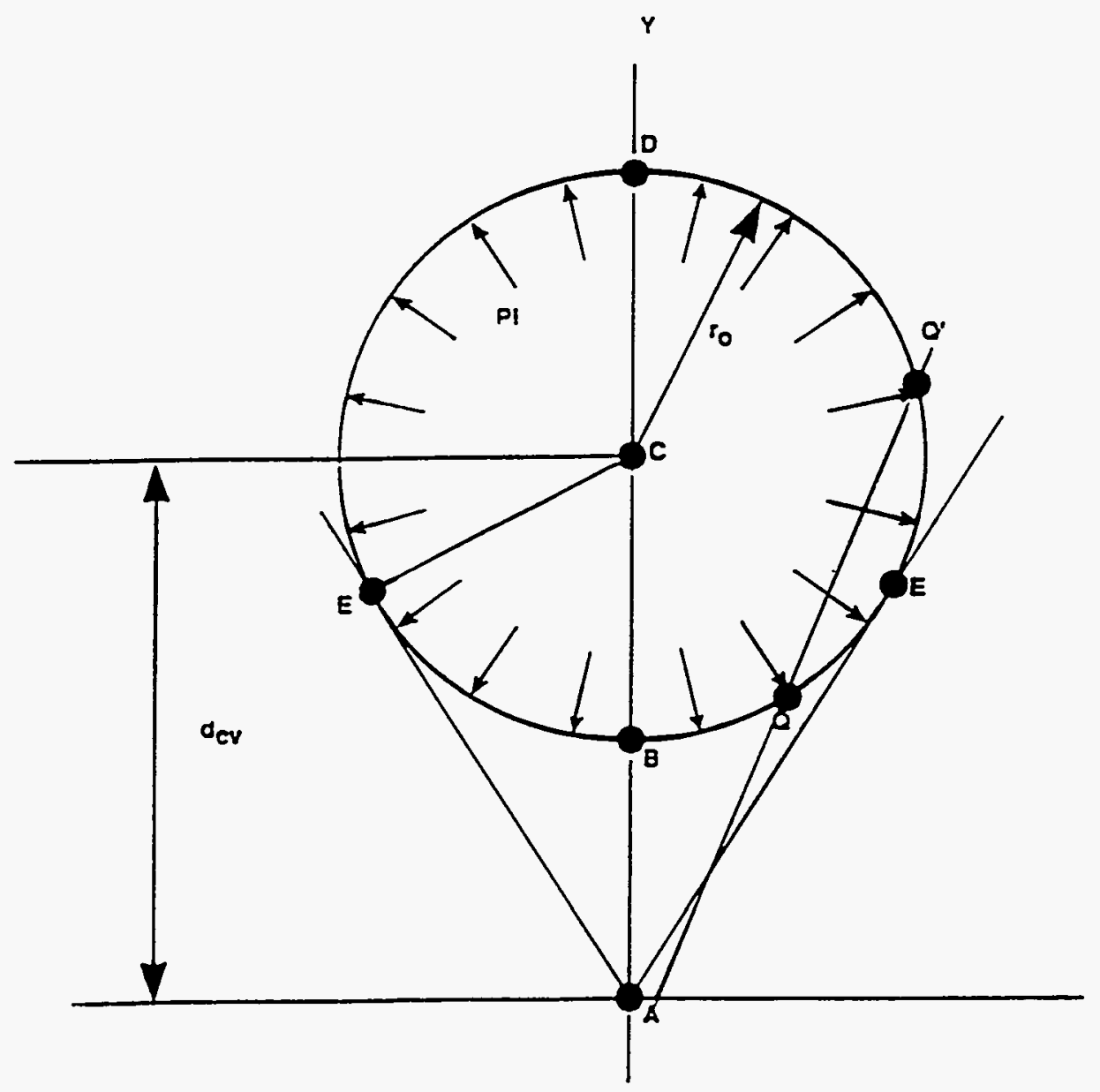

Fig. 3.2. Schematic diagram of steel and concrete geometry used in calculating stress resulting from corrosion of steel reinforcement. 
The point of maximum stress occurs at point A (Fig. 3.2), where $x=0$. For this case, Eq. (3.69) reduces to

$$
\sigma_{x A}=\frac{4 P_{i} r_{0}^{2}}{\left(d_{c v}^{2}-r_{0}^{2}\right)} \text {. }
$$

The tangent stress at any point, $\mathrm{Q}$ or $\mathrm{Q}^{\prime}$, around the circular hole is given by

$$
\sigma_{\theta Q}=P_{i}\left(1+2 \tan ^{2} \phi\right)
$$

where

$$
\sigma_{\theta Q}=\text { tangent stress at point } \mathrm{Q}\left(\mathrm{lb} / \mathrm{in}^{2}{ }^{2}\right) \text {. }
$$

This relationship exhibits a maximum tangent stress at point $E$ and is calculated using

$$
\sigma_{\theta \mathrm{E}}=P_{i} \frac{d_{c v}^{2}+r_{0}^{2}}{d_{c v}^{2}-r_{0}^{2}},
$$

where

$$
\sigma_{\theta E}=\text { maximum tangent stress }\left(\mathrm{lb} / \mathrm{in}^{2}{ }^{2}\right) \text {. }
$$

The magnitude of the maximum stress around the circular hole is a function of the ratio of the concrete cover thickness and the radius of the remaining steel reinforcement. The following dependencies are noted:

$$
\begin{array}{ll}
\text { if } d_{c v}<1.73 r, & \sigma_{x A}>\sigma_{\theta E}>2 P_{i} ; \\
\text { if } d_{c v}=1.73 r, & \sigma_{x A}=\sigma_{\theta E}=2 P_{i} ; \\
\text { if } d_{c v}>1.73 r, & \sigma_{x A}<\sigma_{\theta E}<2 P_{i}
\end{array}
$$

These relationships provide a simple method for determining where cracking from corrosion will begin. 
When the concrete cover thickness is greater than three times the diameter of the reinforcing steel, the tensile stresses around the circular boundary will approach the applied pressure $P_{i}$. Plain concrete has minimal tensile strength to resist these stresses-only 6 to $8 \%$ of the specified compressive strength of concrete. Consequently, the maximum tension stress can readily exceed the tensile strength of concrete, at which point cracking begins.

Cracking from corrosion is typically initiated internally, along the circular boundary, as the ratio of concrete cover thickness to the original radius of the steel is usually greater than $1.73 .{ }^{16}$ As corrosion progresses, accompanied by the deterioration of the concrete cover, cracking will propagate toward the surface of the concrete slab. When the tension stress at the concrete surface equals or exceeds the tensile strength of the concrete, the cracking will penetrate the concrete cover. This cracking will occur along the length of the steel reinforcement.

Spalling out of the concrete will occur if the concrete cover over the steel reinforcement is small $\left(d_{c v} \leq 1.73 r_{0}\right)$. Under these conditions, the stresses at the concrete surface exceed both the stresses at the steel surface and the tensile strength of concrete and spalling along the reinforcement occurs.

\subsubsection{Concrete Pad Degradation Model}

Tumulus-type disposal facilities may use a steel-reinforced concrete pad upon which disposal vaults are placed. This pad, while intact, should divert water to the leachate collection system. To incorporate the performance of the concrete pad into SOURCE1, a compressive failure model is assumed. Failure is estimated by calculating the reinforcement ratio, ${ }^{5}$ which is defined by

$$
\rho=\left(\frac{A}{b}\right) \frac{1}{d},
$$

where

$\rho=$ reinforcement ratio (dimensionless),

$\left(\frac{A}{b}\right)=$ cross-sectional area of steel reinforcement per unit width of slab $(m)$, and

d = effective depth of steel (distance from the top of the slab to the center of the steel reinforcement) (m). 
The reinforcement ratio at which compressive failure may occur is called the limiting reinforcement ratio and is given by ${ }^{5}$

$$
\rho_{\mathrm{lim}}=\frac{\epsilon_{\mathrm{c}}^{\prime}}{\epsilon_{\mathrm{c}}^{\prime}+\epsilon_{\mathrm{y}}} 0.85 \beta_{1} \frac{\mathrm{f}_{\mathrm{c}}^{\prime}}{\mathrm{f}_{\mathrm{y}}},
$$

where

$$
\begin{aligned}
\rho_{\text {lim }}= & \text { limiting reinforcement ratio (dimensionless), } \\
\epsilon_{\mathrm{c}}^{\prime}= & \text { ultimate concrete strain (for this application, taken as } 0.003 \text { ) (dimensionless), } \\
\epsilon_{\mathrm{y}}= & \text { yield strain of steel (dimensionless), } \\
\beta_{1}= & \text { a factor used in the equivalent rectangular stress diagram for concrete at the ultimate } \\
& \text { load (dimensionless), } \\
\mathrm{f}_{\mathrm{c}}^{\prime}= & \text { specified compressive strength of concrete (MPa), and } \\
f_{y}= & \text { specified yield strength of steel reinforcement (MPa). }
\end{aligned}
$$

The yield strain of the steel reinforcement can be calculated by

$$
\epsilon_{y}=\frac{f_{y}}{E_{s}}
$$

where

$\mathrm{E}_{\mathrm{s}}=$ modulus of elasticity of steel reinforcement (for this application, taken as 200,000 $\mathrm{MPa})(\mathrm{MPa})$.

The value of $\beta_{1}$ is determined as follows:

$$
\beta_{1}=0.85 \text { for } f_{c}^{\prime} \leq 30 \mathrm{MPa}
$$


or

$$
\beta_{1}=0.85-0.08\left(\frac{f_{c}^{\prime}-30}{10}\right) \text { for } f_{c}^{\prime}>30 \mathrm{MPa}
$$

The values of the reinforcement ratio and the limiting reinforcement ratio are evaluated at annual time steps in SOURCE1. These two values are compared, and when the reinforcement ratio exceeds the limiting value, the pad is said to have failed hydraulically. Pad failure allows leachate to pass through it. Values of both $\rho$ and $\rho_{\text {lim }}$ will change because of the degradation of the concrete. The concrete is simulated to degrade by using the sulfate attack and calcium hydroxide leaching subroutines in SOURCE1. Sulfate attack results in the spalling off of the concrete cover on the reinforcing steel. Hence, as the effective depth of the steel decreases, the reinforcement ratio increases. Leaching of calcium hydroxide from the concrete pad results in reduced concrete strength. Therefore, as the compressive strength of the concrete decreases, the limiting reinforcement ratio decreases. Both of the concrete degradation mechanisms result in a decrease of the margin between the reinforcement ratio and the limiting reinforcement ratio, ultimately resulting in pad failure.

\subsubsection{Leachate Collection System Degradation Model}

Water that reaches an intact concrete pad of a tumulus-type facility will be diverted to a leachate collection system. This system consists of piping, valves, collection sumps, and monitoring equipment. Ideally, with a properly functioning system, all leachate will be collected, and no release of radionuclides to the environment will occur.

The leachate collection system degradation model describes the functionality fraction of the collection system as a function of time. The functionality fraction is defined as the ratio of the amount of radionuclide in the collected leachate to the total radionuclide release from the disposal vaults and can vary from 0 to 1 . With a value of 1 , the leachate collection system is fully functional, and no radionuclides are released to the environment. A zero value indicates a fully degraded system that allows all leached radionuclides to be released to the environment.

The initial functionality fraction and the length of the institutional control period are input parameters to the SOURCE1 code. The functionality fraction degrades linearly to zero from the 
beginning of the simulation until the end of the institutional control period. The degradation of the collection system is assumed to result from piping and valve leaks or failures, flow obstructions within the system, leakage or overflow of collection sumps, degraded monitoring equipment, etc. At the end of the institutional control period, no maintenance of the collection system is assumed to occur. Hence, no credit is taken for the collection system after the end of institutional control. Additionally, if the concrete pad is predicted to fail hydraulically before the end of institutional control, the functionality fraction is set to zero at the time of pad failure.

\subsubsection{Disposal Silo and Well Technology}

The structural and cracking analyses of the disposal silos, wells, and wells-in-silos are discussed in Sects. 3.2.2.1 through 3.2.2.2. Even though these analyses are similar in many respects to the analyses conducted for the tumulus disposal technology, features unique to these disposal units require additional modeling considerations.

\subsubsection{Structural Analysis}

The structural analysis of the silo and well disposal technologies considers the three structural components of each-loosely referred to as the roof, wall, and floor. These analyses differ depending upon whether the silo or well configuration is being considered. For the analysis of wells-in-silos, structural analyses of both the silo and well are performed.

3.2.2.1.1 Silo or well roof. A polar coordinate system is used in the structural analysis of the roof of the silo or well disposal unit. The roof is modeled as a simply supported circular plate under uniform loading. The load upon the roof is calculated as

$$
q_{r}=h_{r} p_{c}+s p_{s}
$$

where

$\mathrm{q}_{\mathrm{r}}=$ uniform load on silo or well roof (lb/in. $\left.{ }^{2}\right)$.

The final bending moments on the roof caused by the uniform load consist of radial and tangential components, which are given by 


$$
M_{r}=\frac{q_{r}}{16}\left(3+\mu_{c}\right)\left(r_{3}^{2}-r^{2}\right)
$$

and

$$
M_{t}=\frac{q_{r}}{16}\left[r_{s}^{2}\left(3+\mu_{c}\right)-r^{2}\left(1+3 \mu_{c}\right)\right] \text {, }
$$

where

$M_{r}$ = radial component of bending moment (lb-in./in.),

$\mathrm{M}_{\mathrm{t}}$ = tangential component of bending moment (lb-in./in.),

$r_{s} \quad=$ radius of silo or well (in.), and

$r \quad=$ distance from center of silo or well roof (in.).

These components are summed to arrive at the total bending moment at location $(\theta, r)$, namely

$$
M_{x}=M_{r} \cos ^{2} \theta+M_{t} \sin ^{2} \theta
$$

and

$$
M_{y}=M_{r} \sin ^{2} \theta+M_{t} \cos ^{2} \theta
$$

The shear force on the roof at distance $d_{t}$ from the interior face of the wall is calculated using

$$
Q=\frac{q_{r}\left(r_{8}-\frac{h_{w 1}}{2}-d_{t}\right)}{2},
$$


where

$\mathrm{Q} \quad=$ shear force on roof of well or silo (lb/in.).

3.2.2.1.2 Silo or well wall. The wall of the silo or well is subject to uniform and hydrostatic pressures. Setting the origin of the coordinate system at the mid-height of the wall, the uniform pressure or load is calculated as

$$
q_{w}=\rho_{s}\left(s+\frac{h_{z}}{2}+\frac{h_{3}}{2}\right)\left(1-\sin f_{s}\right)-\frac{h_{3}}{2} \rho_{w}\left(1-\sin f_{w}\right),
$$

where

$\mathrm{q}_{\mathrm{w}}=$ uniform load on silo or well wall (lb/in. ${ }^{2}$ ),

$h_{s} \quad=$ silo or well height (in.),

$f_{s} \quad=$ friction angle of soil backfill around silo or well (deg), and

$f_{w} \quad=$ friction angle of waste inside silo or well (deg).

The corresponding maximum antisymmetrical hydrostatic pressure on the wall is calculated using

$$
P=\frac{h}{2}\left(\rho_{s}\left(1-\sin f_{s}\right)-\rho_{w}\left(1-\sin f_{w}\right)\right)
$$

Bending moments and shear forces due to uniform pressure are calculated for the silo or well wall using

$$
\begin{aligned}
M_{y} & =\frac{q_{w} h_{z}^{2}}{4 \alpha^{2}}\left(\frac{\sin \alpha \sinh \alpha}{\cos 2 \alpha+\cosh 2 \alpha} \cos \beta y \cosh \beta y\right. \\
& \left.-\frac{\cos \alpha \cosh \alpha}{\cos 2 \alpha+\cosh 2 \alpha} \sin \beta y \sinh \beta y\right)
\end{aligned}
$$


and

$$
\begin{aligned}
Q_{y} & =\frac{q_{w} h_{s}}{2 \alpha}\left[\frac{\sin \alpha \sinh \alpha}{\cos 2 \alpha+\cosh 2 \alpha}(\cos \beta y \sinh \beta y-\sin \beta y \cosh \beta y)\right. \\
& \left.-\frac{\cos \alpha \cosh \alpha}{\cos 2 \alpha+\cosh 2 \alpha}(\cos \beta y \sinh \beta y+\sin \beta y \cosh \beta y)\right],
\end{aligned}
$$

where

$$
\begin{aligned}
& M_{y} \quad \text { = bending moment resulting from uniform loading in the } y \text {-direction (lb-in./in.) and } \\
& Q_{y} \quad=\text { shear force resulting from uniform loading in the } y \text {-direction (lb/in.). }
\end{aligned}
$$

The quantities $\alpha$ and $\beta$ are given by

$$
\alpha=\frac{\beta h_{s}}{2}
$$

and

$$
\beta=\left[\frac{3\left(1-\mu_{c}^{2}\right)}{r_{s}^{2} h_{w 1}^{2}}\right]^{0.25} .
$$

The silo and well walls are also subject to axial and ring compression forces. The axial compressive force on the silo wall is calculated using Eq. (3.32). This same equation is used for the well-wall calculation by substituting the density of the cast iron for the density of concrete. The ring compression force resulting from a uniform load is calculated as 


$$
\begin{aligned}
N_{\theta} & =q_{w_{s}} r_{s}-\frac{2 \sin \alpha \sinh \alpha}{\cos 2 \alpha+\cosh 2 \alpha} \sin \beta y \sinh \beta y \\
& \left.-\frac{2 \cos \alpha \cosh \alpha}{\cos 2 \alpha+\cosh 2 \alpha} \cos \beta y \cosh \beta y\right]
\end{aligned}
$$

where

$$
\left.\mathrm{N}_{\theta} \quad \text { = ring compression force (lb/in. }{ }^{2}\right) \text {. }
$$

The bending moments and shear forces resulting from antisymmetrical hydrostatic pressure are calculated using

$$
\begin{aligned}
M_{y} & =\frac{P_{z}^{2}}{4 \alpha^{2}}\left(\frac{\sin \alpha \cosh \alpha}{\cosh 2 \alpha-\cos 2 \alpha} \cos \beta y \sinh \beta y\right. \\
& \left.-\frac{\cos \alpha \sinh \alpha}{\cosh 2 \alpha-\cos 2 \alpha} \sin \beta y \cosh \beta y\right)
\end{aligned}
$$

and

$$
\begin{aligned}
Q_{y} & =\frac{P h_{s}}{2 \alpha}\left[\frac{\sin \alpha \cosh \alpha}{\cosh 2 \alpha-\cos 2 \alpha}(\cos \beta y \cosh \beta y-\sin \beta y \sinh \beta y)\right. \\
& \left.-\frac{\cos \alpha \sinh \alpha}{\cosh 2 \alpha-\cos 2 \alpha}(\cos \beta y \cosh \beta y+\sin \beta y \sinh \beta y)\right]
\end{aligned}
$$

The ring compression force caused by hydrostatic pressure is calculated using 


$$
\begin{aligned}
N_{\theta}= & -2 \mathrm{Pr}_{\mathrm{z}}\left[\frac{\mathrm{y}}{\mathrm{h}_{\mathrm{z}}}-\frac{\sin \alpha \cosh \alpha}{\cosh 2 \alpha-\cos 2 \alpha} \sin \beta \mathrm{y} \cosh \beta \mathrm{y}\right. \\
& \left.-\frac{\cos \alpha \sinh \alpha}{\cosh 2 \alpha-\cos 2 \alpha} \cos \beta \mathrm{y} \sinh \beta \mathrm{y}\right] .
\end{aligned}
$$

Bending moments, shear forces, and ring compression forces calculated for the uniform and antisymmetrical hydrostatic pressures are summed at each location on the wall to arrive at the final values.

3.2.2.1.3 Silo or well floor. The circular floor plate is subjected to a distributed line load, or concentrated force, along its perimeter. This concentrated force is calculated as

$$
F_{c}=R_{r}+h_{w 1} h_{s}\left(\rho_{c}-\rho_{w}\right),
$$

where

$$
\begin{aligned}
& \mathrm{F}_{\mathrm{c}} \quad=\text { concentrated force }(\mathrm{lb} / \mathrm{in} .) \text { and } \\
& \mathrm{R}_{\mathrm{T}} \quad=\text { roof reaction }(\mathrm{lb} / \mathrm{in} .) .
\end{aligned}
$$

The radial and tangential components of the bending moments for the circular floor are given by

$$
M_{r}=-\frac{D}{L_{D K}^{2}}\left[C_{1} Z_{2 r}-C_{2} Z_{1 r}-\frac{L_{D X}}{T}\left(1-\mu_{c}\right)\left(C_{1} Z_{1 r}^{\prime}+C_{2} Z_{2 r}^{\prime}\right)\right]
$$

and

$$
M_{t}=-\frac{D}{L_{D K}^{2}}\left[\mu_{c}\left(C_{1} Z_{2 r}-C_{2} Z_{1 r}\right)+\frac{L_{D K}}{r}\left(1-\mu_{c}\right)\left(C_{1} z_{1 r}^{\prime}+C_{2} z_{2 r}^{\prime}\right)\right] .
$$


The final bending moments are calculated using Eqs. (3.81) and (3.82).

The maximum shear force on the floor is calculated using

$$
Q_{\max }=-\frac{D}{L_{D K}^{3}}\left[C_{1} Z_{2 r}^{\prime}-C_{2} Z_{1 r}^{\prime}\right]
$$

where

$$
\mathrm{Q}_{\max }=\text { maximum shear force on floor (lb/in.). }
$$

The quantities $\mathrm{D}, \mathrm{C}_{1}, \mathrm{C}_{2}$, and $\mathrm{L}_{\mathrm{DK}}$ are calculated, respectively, as

$$
\begin{gathered}
D=\frac{E_{c} h_{f}^{3}}{12\left(1-\mu_{c}^{2}\right)}, \\
C_{1}=-\frac{F_{c}}{\tilde{k} L_{D K} \psi}\left[Z_{1 x}+\frac{L_{D K}}{r_{s}}\left(1-\mu_{c}\right) Z_{2 r}^{\prime}\right], \\
C_{2}=-\frac{F_{c}}{\tilde{k} L_{D K} \psi}\left[Z_{2 r}-\frac{L_{D K}}{r_{s}}\left(1-\mu_{c}\right) Z_{1 r}^{\prime}\right],
\end{gathered}
$$

and

$$
\mathrm{L}_{\mathrm{DK}}=\left(\frac{\mathrm{D}}{\tilde{\mathrm{k}}}\right)^{0.25}
$$


The quantities $Z_{1 r}, Z_{2 r}, Z_{1 r}^{\prime}$, and $Z_{2 r}^{\prime}$ are calculated using the following equations.

$$
\begin{aligned}
& Z_{15}=1+\sum_{n=1}^{\infty}(-1)^{n} \frac{\left(\frac{r / L_{D K}}{2}\right)^{4 n}}{((2 n) !)^{2}}, \\
& Z_{2 r}=\sum_{n=1}^{\infty}(-1)^{n} \frac{\left(\frac{r / L_{D K}}{2}\right)^{4 n-2}}{((2 n-1) !)^{2}}, \\
& Z_{1 r}^{\prime}=\sum_{n=1}^{\infty}(-1)^{n} \frac{2 n\left(\frac{r / L_{D K}}{2}\right)^{4 n-1}}{((2 n) !)^{2}},
\end{aligned}
$$

and

$$
Z_{2 r}^{\prime}=\sum_{n=1}^{\infty}(-1)^{n} \frac{(2 n-1)\left(\frac{r / L_{D K}}{2}\right)^{4 n-3}}{((2 n-1) !)^{2}},
$$

where

$$
\mathrm{n} \quad=1,2,3 \ldots .
$$

The variable $\psi$, used in Eqs. (3.99) and (3.100), is calculated as

$$
\psi=Z_{1 r} z_{2 r}^{\prime}-z_{1 r}^{\prime} Z_{2 r}+\frac{L_{D K}}{r_{s}}\left(1-\mu_{c}\right)\left(z_{1 r}^{\prime 2}+z_{2 r}^{\prime 2}\right) .
$$


The quantities $Z_{1 r}, Z_{2 r}, Z_{1 r}^{\prime}$, and $z_{2 r}^{\prime}$ are calculated using Eqs. (3.102) through (3.105), substituting the silo or well rádius, $r_{s}$, for the parameter $r$.

\subsubsection{Cracking Analyses}

Cracking or failure of the disposal silos, wells, and wells-in-silos occurs at the point at which the structural components can no longer bear the loads placed upon them. Cracking of the roof, wall, and floor of the silo or well may occur as a result of shear forces or bending. Cracking of the wall may occur as a result of compressive forces on the structure.

The cracking analyses for the disposal silos are similar to that performed for tumulus-type facilities in that these analyses model the initiation and propagation of cracks in concrete barriers and calculate fracture characteristics. In contrast, the cracking analyses for the wells simply determine when the roof, wall, or floor undergoes initial failure and does not calculate fracture characteristics.

Shear cracking of a silo or well occurs if the shear force on the structural member exceeds the cracking shear of the member. The cracking shears for the roof and floor in the silo and well are calculated using Eqs. (3.43) and (3.44).

The cracking shear for the silo wall in the vertical direction is the minimum of

$$
V_{c r}=h_{w 1}\left(1.9 C_{s t r}^{0.5}+2500 S_{t w} Q_{x} / M_{m y}\right)
$$

and

$$
V_{c r}=3.5 C_{s t r}^{0.5} h_{w l}\left(1 .+F_{w} /\left(500 h_{w 1}\right)\right)^{0.5},
$$

where

$$
M_{m y}=\text { modified moment (lb-in.). }
$$

The modified moment, $M_{\text {my }}$ is given by

$$
M_{m y}=M_{y}-0.38 F_{w} h_{w l}
$$


$F_{w}$ is determined from Eq. (3.32).

A single fracture will extend through the entire concrete member because of shear cracking. The width of the fracture is $0.013 \mathrm{in}$. The shear force at which failure of the cast iron wall of the well occurs is given as

$$
v_{f}=0.7 h_{w 1} f_{w s},
$$

where

$V_{f}=$ shear force at which well wall fails (lb/in.) and

$f_{w s}=$ yield strength of cast iron (lb/in. $\left.{ }^{2}\right)$.

The roof and floor of the silos and wells crack if the bending moment at a given location exceeds the cracking moment. The cracking moment is calculated using Eq. (3.46). Cracks will not extend through the entire member unless the bending moments exceed the uitimate strength of the member. The ultimate flexural strength of the roof and floor is calculated using Eq. (3.49). The ultimate strength for the silo wall is calculated using

$$
\begin{aligned}
M_{v} & =\phi\left[S_{m} f_{y}\left(d_{t}-\frac{C_{d}}{2}\right)+L_{m} f_{y}\left(h_{w 1}+\frac{L_{t m}}{2}-\frac{C_{d}}{2}\right)\right. \\
& \left.+L_{c m} f_{y}\left(\frac{C_{d}}{2}+\frac{L_{c m}}{2}\right)\right],
\end{aligned}
$$

where

$$
\begin{aligned}
& L_{t n}=\text { thickness of corrugated steel liner on tension face (in.) and } \\
& L_{c m}=\text { thickness of corrugated steel liner on compression face (in.). }
\end{aligned}
$$

The depth of the compression block is given by 


$$
C_{d}=\frac{f_{y}\left(S_{m}+L_{m}-L_{c m}\right)}{.85 C_{s t r}}
$$

Fracture depth, spacing, and width are calculated as cracks initiate and propagate in concrete members comprising the silos and wells-in-silos. These characteristics are calculated using the approach discussed for the tumulus-type facility (Sect. 3.2.1.2).

The wall of the silo or well may fail from axial or ring compression. In terms of the former, the silo wall will crack if the axial compression force on the member exceeds the ultimate strength of the wall in compression or critical buckling strength. The strength of the wall in axial compression is calculated as the minimum of

$$
\mathrm{N}_{\mathrm{ac}}=0.39 \mathrm{~h}_{\mathrm{w} 1} \mathrm{C}_{\mathrm{str}}
$$

and

$$
N_{u c}=\frac{D_{w}}{w_{f} h_{s}^{2}} m^{2} \pi^{2}+E_{c} h_{w 1} \frac{h_{s}^{2}}{r_{s}^{2}} m^{2} \pi^{2},
$$

where

$$
\begin{aligned}
& N_{a c}=\text { ultimate strength or critical buckling strength under axial compression (lb/in.), } \\
& D_{w}=\text { flexural rigidity of wall }\left(\mathrm{lb} / \mathrm{in}^{2}\right) \text {, and } \\
& m \quad=1,2,3 \ldots .
\end{aligned}
$$

The flexural rigidity of the wall is calculated using Eq. (3.18), substituting the thickness and unit width of the wall for $h_{r}$ and $w_{r}$ respectively.

If the ring compression force on the silo exceeds the ultimate or buckling strength of the wall, cracking will occur. The strength of the wall subject to ring compression is given by the minimum value calculated using 


$$
N_{r c}=\frac{D_{w}}{w_{f} r_{s}^{2}}\left(n^{2}-1+\frac{2 n^{2}-1-\mu_{c}}{1+A}\right)+\frac{E h_{w l}}{\left(n^{2}-1\right)(1+A)^{2}},
$$

where

$\mathrm{N}_{\mathrm{rc}}=$ ultimate strength or critical buckling strength under ring compression (lb/in.) and

$\mathrm{n} \quad=2,3,4 \ldots$.

The parameter $A$ is calculated using

$$
A=\left(\frac{n h_{8}}{\pi r_{8}}\right)^{2}
$$

Compressive forces and bending moments on the wall of the disposal well may result in failure of the well. If the combined stresses on the wall exceed the yield strength of the cast iron, failure will occur. The combined stresses are calculated as

$$
N_{a c}=\frac{F_{w 1}}{h_{w 1}}+\frac{6 M_{y}}{h_{w 1}^{2}}
$$

The wall will also fail if the ring compression force on the well wall exceeds the buckling strength of the wall. The ultimate strength of the wall subject to ring compression is the minimum of

$$
N_{r c}=2 h_{w 1}\left(2 \times 10^{6} \frac{h_{w 1}}{r_{s}}\right)\left|\left(1-33.3 \frac{h_{w 1}}{r_{s}}\right)\right|
$$


and

$$
\mathrm{N}_{\mathrm{rc}}=3 \times 10^{4} \mathrm{~h}_{\mathrm{wl}}
$$

Cracking of reinforced concrete resulting from the corrosion of the steel reinforcement is modeled using the same methodology developed for the tumulus disposal unit. This portion of the cracking analyses is performed for the roof and floor of the disposal silo only. The walls of the silo and the roof and floor of the well do not contain steel reinforcement.

\subsection{FLOW PARTITIONING}

A benefit of the concrete engineered barriers used in the tumulus, silo, and well disposal facilities is the material's low hydraulic conductivity. When intact, the concrete largely prevents water from contacting the disposed waste. As the concrete members deteriorate with time, cracks form and greater amounts of water may contact the waste. Eventually, the conductivity of the concrete will be no better than that of the soil backfill around the disposal facility.

To calculate radionuclide releases as a result of advection, it is necessary to estimate the amount of water percolating through the waste. The water entering a disposal area is divided into two components: a component which flows around the disposal facility and a component which contacts the waste.

The flow partitioning scheme used in the SOURCE computer codes is based on the assumption of a saturated steady-state system under a unit hydraulic gradient. Under these conditions, the amount of water percolating through the intact vaults, silos, and wells is equal to the saturated hydraulic conductivity of the concrete. As the concrete members deteriorate and crack, preferential flow of water through the fractures occurs at much greater rates.

Preliminary analyses conducted with the SOURCE computer codes have indicated that much of the ability of a disposal facility to exclude water is lost when fractures penetrate through one or more concrete members. Based on these observations, the amount of water percolating through the waste is set equal to the amount of water entering the disposal area when fractures first penetrate the disposal facility. From this point on, the amount of water contacting the waste is solely a function of the hydraulic characteristics of the site soils and soil backfill. 


\subsection{RADIONUCLIDE RELEASE MODELING}

The SOURCE codes incorporate two mass-transport mechanisms (advection and diffusion) that are modeled in one dimension. The concentration that is calculated to be released by these two mechanisms cannot exceed the solubility limit of the assumed chemical form of a nuclide. Rates of release from disposal facilities which have not undergone significant structural failure will generally be low-that is, below detection limits. These releases are dependent largely on the relative water saturation of the waste and concrete and, for the most part, are the result of diffusion. As a facility deteriorates and undergoes cracking, water may percolate more easily through the waste. Under these conditions, leaching of radionuclides by advection can accelerate and may overshadow leaching by diffusion.

Leaching of radionuclides by advection is directly proportional to the amount of water contacting the waste and inversely proportional to the degree to which radionuclides are sorbed by the waste matrix. An analytical expression in which the radionuclide inventory is updated at preset time-steps is used to evaluate advective leaching. Leaching by diffusion is calculated using the FLOTHRU computer program (a subroutine in the SOURCE codes). ${ }^{2}$ A description of these two leaching mechanisms is provided in the following sections and in Appendix A.

\subsubsection{Advective Transport Model}

The analytical model for advective transport is based on work presented in ref. 3. A detailed derivation of the model can be found in ref. 4.

The total radionuclide release during a time-step is calculated by the following formula:

$$
L=\frac{\lambda_{L}}{\lambda_{L}+\lambda_{d}} Q_{0}\left[e^{-\left(\lambda_{L}+\lambda_{d}\right) t_{L}}-e^{-\left(\lambda_{L}+\lambda_{d}\right) t_{L}}\right],
$$

where

$\mathrm{L} \quad=$ mass of radionuclide leached because of advection (g),

$\lambda_{\mathrm{L}}=$ leach rate constant $\left(\mathrm{s}^{-1}\right)$,

$\lambda_{\mathrm{d}}=$ radioactive decay constant $\left(\mathrm{s}^{-1}\right)$,

$\mathrm{Q}_{0} \quad=$ initial mass of radionuclide in the waste $(\mathrm{g})$, and

$t_{1}, t_{2}=$ the bounds of the time period of interest (s). 
The leach constant, $\lambda_{\mathrm{L}}$, is given by

$$
\lambda_{\mathrm{L}}=\frac{\mathrm{q}}{\mathrm{W} \theta \mathrm{R}_{\mathrm{d}}} \text {, }
$$

where

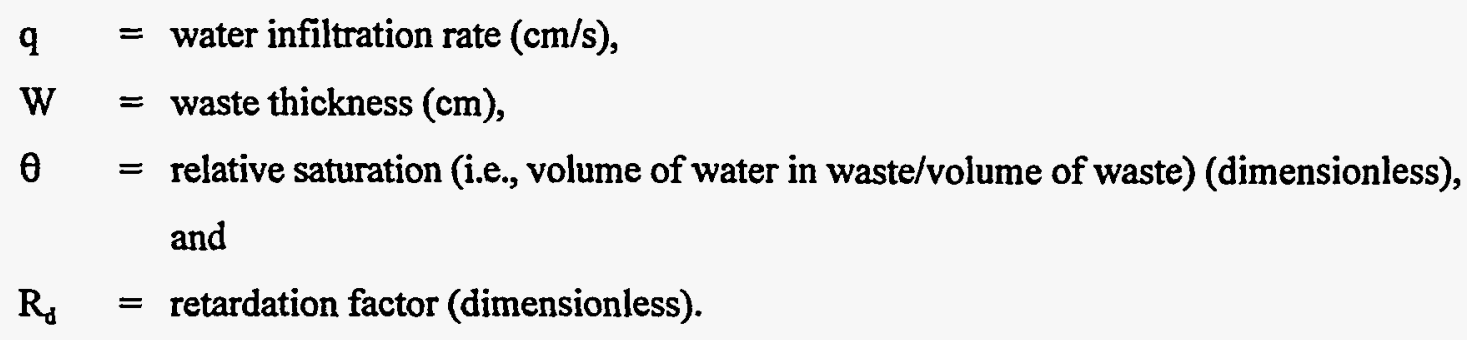

Finally, the retardation factor, $R_{d}$, can be calculated by the following equation:

$$
\mathrm{R}_{\mathrm{d}}=1+\frac{\rho_{\mathrm{b}}}{\theta} \mathrm{K}_{\mathrm{d}}
$$

where

$$
\begin{aligned}
& \rho_{\mathrm{b}} \quad=\text { bulk density of waste }\left(\mathrm{g} / \mathrm{cm}^{3}\right) \text { and } \\
& \mathrm{K}_{\mathrm{d}} \quad=\text { distribution coefficient }(\mathrm{mL} / \mathrm{g}) .
\end{aligned}
$$

\subsubsection{Diffusion Transport Model}

The diffusive transport model that is outlined in this section is a résumé of the work by Nestor presented in ref. 2. Nestor's detailed derivation of this model is presented in Appendix A.

Consider the two-layer slab representation of a waste disposal unit presented in Fig. 3.3. The inner layer, which is of half-thickness a, initially contains a contaminant with concentration $C_{0}$. The outer layer, which has thickness $b-a$, is initially uncontaminated. This situation is analogous to the grouted waste initially placed inside an uncontaminated concrete vault (e.g., tumulus-type disposal). If there is little bulk fluid flow through this system, then diffusion will be the dominant transport mechanism. Diffusion equations can then be written for the inner and outer layers of the disposal unit. The concentration of contaminant in the inner layer is denoted by $C_{l}$, while that in the outer layer is denoted by $\mathrm{C}_{2}$. 
ORNL DWG 96-5013

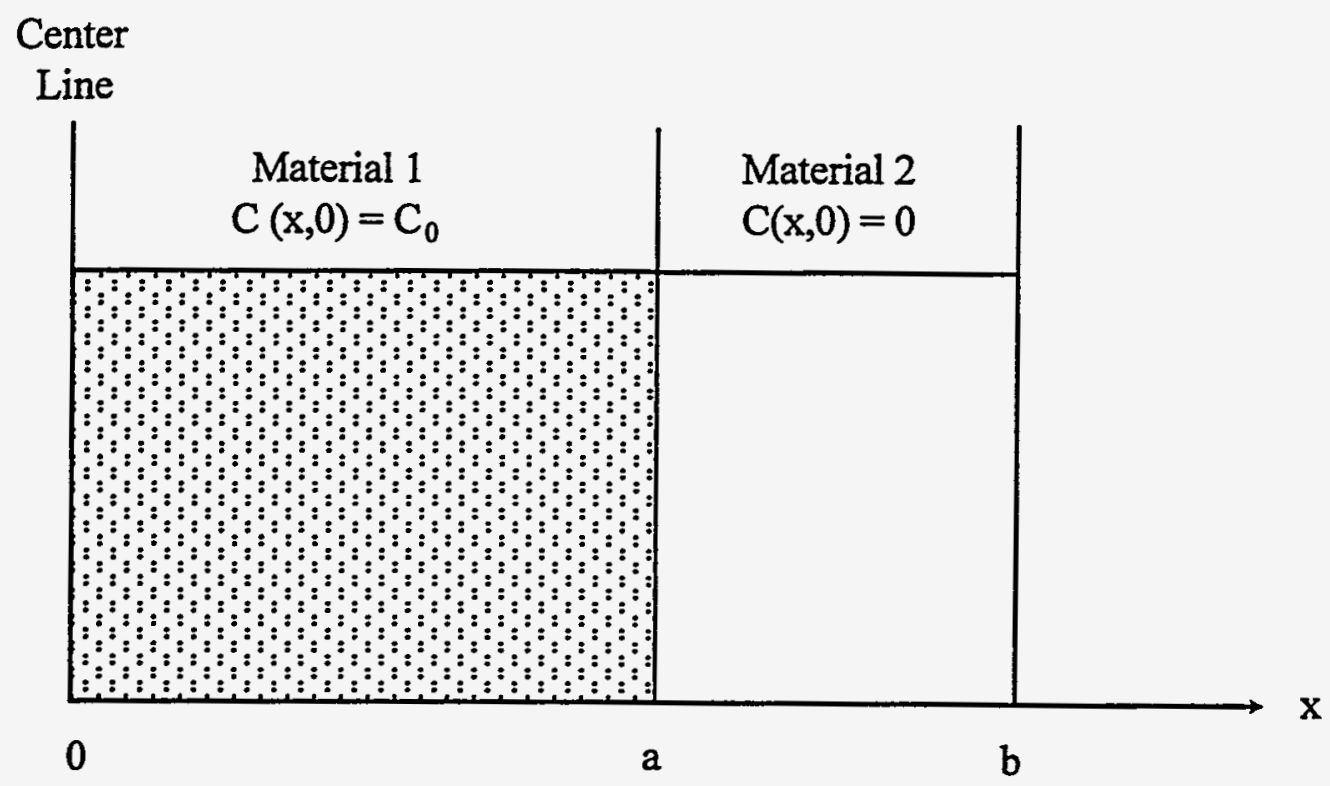

Fig. 3.3. Represeritation of the system modeled by the FLOTHRU computer code.

The diffusion equation for the inner layer is

$$
\frac{\partial C_{1}}{\partial t}=D_{1} \frac{\partial^{2} C_{1}}{\partial x^{2}}-\lambda_{d} C_{1}
$$

where

$\mathrm{C}_{1}=$ concentration of contaminant in the inner layer $\left(\mathrm{g} / \mathrm{cm}^{3}\right)$,

$\mathrm{D}_{1}=$ effective diffusion coefficient for the contaminant in layer $1\left(\mathrm{~cm}^{2} / \mathrm{s}\right)$, and

$\mathrm{x} \quad=$ spatial position $(\mathrm{cm})$. 
Similarly, a diffusion equation can be written for the outer layer:

$$
\frac{\partial \mathrm{C}_{2}}{\partial \mathrm{t}}=\mathrm{D}_{2} \frac{\partial^{2} \mathrm{C}_{2}}{\partial \mathrm{x}^{2}}-\lambda_{\mathrm{d}} \mathrm{C}_{2}
$$

where

$$
\begin{aligned}
& C_{2}=\text { concentration of contaminant in the outer layer }\left(\mathrm{g} / \mathrm{cm}^{3}\right) \text { and } \\
& D_{2}=\text { effective diffusion coefficient for the contaminant in layer } 2\left(\mathrm{~cm}^{2} / \mathrm{s}\right) .
\end{aligned}
$$

Equations (3.123) and (3.124) can be solved with appropriate initial and boundary conditions. In this case, the initial conditions are

$$
C_{1}(x, 0)=C_{0} \text { for } 0 \leq x<a
$$

and

$$
C_{2}(x, 0)=0 \text { for } a \leq x<b \quad \text {. }
$$

The boundary conditions are

$$
\begin{aligned}
& \left.\frac{\partial C_{1}}{\partial x}\right|_{x=0}=0, \\
& C_{2}(b, t)=0, \\
& C_{1}(a, t)=C_{2}(a, t),
\end{aligned}
$$


and

$$
\left.\mathrm{D}_{1} \frac{\partial \mathrm{C}_{1}}{\partial \mathrm{x}}\right|_{\mathrm{x}=\mathrm{z}}=\left.\mathrm{D}_{2} \frac{\partial \mathrm{C}_{2}}{\partial \mathrm{x}}\right|_{x=\mathrm{z}}
$$

The solution to Eqs. (3.123) through (3.130) is implemented using the FLOTHRU computer code, as described in ref. 2 and Appendix A. This code is incorporated as a subroutine into the SOURCE codes.

\subsubsection{Calculation of Total Radionuclide Release}

In order to calculate the total amount of radionuclide leaching from a disposal facility using the SOURCE codes, the advective and diffusive components are determined separately. These two components are then added together to calculate the total release. This calculated total is compared with the solubility limit of the radionuclide for the amount of water flowing through the facility. If this limit is exceeded, then the release is limited to the amount determined by solubility.

Radionuclides leached from the waste will be transported away from the disposal facility with the water percolating through the disposal facility. Two flow components are observed on the ORR. A vertical component represents recharge to the underlying aquifer at the site, while a lateral subsurface component discharges to surface waters.

Radionuclide releases from the disposal facilities are partitioned between the recharge and lateral flow components in proportion to the vertical and lateral fluxes. The amount of water which flows vertically to the aquifer is calculated as the minimum of the amount of water percolating through the disposal facility and the saturated hydraulic conductivity of the site soils. Water in excess of the saturated hydraulic conductivity is modeled as lateral sub-surface flow.

Based on the assumption that radionuclide concentrations are equal in each flow component, the amount of material entering the recharge component in a given month is given as

$$
Q_{r}=Q_{t} \frac{I_{r}}{I_{m}} \text {, }
$$


where

$\mathrm{Q}_{\mathbf{r}} \quad=$ radionuclide release entering recharge flow component $(\mathrm{g} / \mathrm{month})$,

$\mathrm{Q}_{\mathrm{t}} \quad$ = total radionuclide release from disposal facility ( $\mathrm{g} / \mathrm{month}$ ),

$\mathrm{I}_{\mathrm{r}} \quad=$ vertical water percolation rate $(\mathrm{cm} / \mathrm{month})$, and

$\mathrm{I}_{\mathrm{m}} \quad=$ total water percolation rate $(\mathrm{cm} /$ month).

The mass of material entering the lateral flow component is simply the difference of the total release and the mass of material transported to the aquifer. Annual releases for each flow component are calculated by summing the monthly releases. 


\section{DESCRIPTION OF THE SOURCE CODES INPUT AND OUTPUT FILES}

This section provides a description of the input files required to execute the SOURCE codes and the output files created during a simulation. Sample input files and the corresponding output files are found in Appendix C.

\subsection{INPUT DATA REQUIREMENTS}

The input requirements for the SOURCE codes consist of (1) keyboard input, which provides the name of the primary input file; (2) the primary input file itself, which initializes approximately 115 variables required to conduct a model simulation; and (3) a secondary file, named in the primary file, which contains monthly water infiltration values.

Only the filename of the primary file should be entered at the interactive prompt (e.g., filename), and the number of characters should not exceed sixteen. The SOURCE codes will concatenate the extension of .inp to the user-supplied filename to open filename.inp as the primary input file. If the current operating system allows for the redirection of standard input, the keyboard input to the SOURCE codes can be redirected so that the filename is input from a file.

The primary input file sets the length of the simulation and print options, provides dimensions and design specifications of the waste disposal facility, establishes physicochemical properties for the facility and groundwater, defines nuclide-specific parameters, initializes a reference year for the simulation, and provides radionuclide inventories disposed of during specified time periods. There are two options for providing radionuclide inventories. If a positive value is input for QCASK on record 23 for SOURCE1 or QSW on record 27 for SOURCE2, this inventory will be used for the simulation, and no additional inventories will be provided. If QCASK is negative or zero, a reference year and a year of disposal with an associated inventory will be read. The variable BGNDUMP on record 25 should equal the year of disposal. Since it is assumed that a pad in a tumulus-type disposal facility will be filled during a year, SOURCE1 does not allow for multiple inventory disposals, but a reference year can be associated with the output summaries of the simulation. If the input value for QSW is negative or zero, a reference year for the simulation and radionuclide inventories disposed of during specified time periods will be read. The reference year for SOURCE1 and SOURCE2 is initialized to the earliest year of a radionuclide disposal at the waste facility. Because disposal times for specific radionuclide inventories may vary, this option provides the capability of ensuring that the simulations of all radionuclide releases at the facility represent the same time period. The output files 
summarizing the recharge and lateral leach rates will show leach rates of zero until a radionuclide disposal has occurred. For SOURCE2, the time periods for radionuclide disposal can be defined for a year or a range of years. For an interval of 1 year, the inventory in the input file will be added to the current inventory at the appropriate year of the simulation. If a range of years is specified, the corresponding inventory will be added to the disposed inventory during each year of the range. The last time period of disposal should specify an inventory of zero to be disposed of for the remainder of the simulation, and the value of ENDDUMP should be set to 9999999 to terminate the reading of multiple disposals. Table 4.1 provides the input variables and data formats for SOURCE1. For SOURCE2, the input variables and data formats are found in Table 4.2.

The SOURCE1 and the SOURCE2 codes are designed to update the water infiltration values from the monthly infiltration file as changes in the infiltration rates occur at the waste disposal facility. Water infiltration values can be updated annually or held constant for a range of years; the updated values are read when the year of the simulation exceeds the end year of the previous time period. A description of the parameters initialized in the infiltration file is found in Table 4.3.

The SOURCE codes are designed to model leach rates for multiple radionuclides. The number of nuclides which will be simulated is determined by the value of the variable, NONCLD, on record 22 of the SOURCE1 primary input file and record 26 of the SOURCE2 primary input file. The source codes currently allow a maximum number of ten nuclides.

\subsection{OPTIONS FOR OUTPUT FILES}

The SOURCE1 code has options for generating seven output files, and the SOURCE2 code has options for generating five output files. The two additional SOURCE1 files provide summary information for intact and cracked vaults. The names of the output files are the filename of the primary input file concatenated with default extensions set by the SOURCE codes. Table 4.4 shows the file structure of the SOURCE1 code, and Table 4.5 gives the file structure for the SOURCE2 code. The print options for selecting the output files are read on record 2 of the primary input file. A zero or missing value (a blank field) for an option will generate the output file, and the years for printing the simulation results are controlled by the associated frequency option. If a print option is requested and the associated frequency option is not specified, the simulation results will print every year.

The SOURCE codes have the option of providing an input data summary of the waste facility and concrete design parameters, chemical exposure values, and radionuclide-specific parameters in filename.con. This same option will create an input data summary of the monthly water infiltration 
values in filename.h2o. If the appropriate print option is selected, filename.con will also contain the disposal facility performance summary at selected time intervals, such as rates of concrete degradation and cracking analyses. The annual radionuclide releases into the groundwater recharge, along with the associated water volume, are summarized in filename.rch, and the radionuclide releases to the lateral sub-surface flow region and the associated water volume are summarized in filename.lat.

For the SOURCE1 code, the leach rate summaries in filename.rch, filename.lat, and filename.sum and the inventory summary in filename.sum represent leaching from the total number of vaults at the waste disposal facility. A per-vault summary of the advective leach rate, diffusive leach rate, and the total leach rate is found in filename.lch. The two additional output files of the SOURCE1 code provide per-vault summaries for intact and cracked vaults. The inventory and radionuclide release rates by advection and diffusion for intact vaults are summarized in filename.vt1. A similar summary is provided for cracked vaults in filename.vt2. For the SOURCE2 code, the leach-rate summaries in filename.rch, filename.lat, filename.sum, and filename.lch and the inventory summary in filename.sum are per silo, well, well-in-silo, or trench. 
Table 4.1. Input data format for the SOURCE1 computer code

\begin{tabular}{|c|c|c|c|}
\hline Column No. & Parameter & Description & \\
\hline \multicolumn{3}{|c|}{ Record 1: Format (A80) } & \\
\hline $1-80$ & TITLE & Title of simulation & . \\
\hline \multicolumn{4}{|c|}{ Record 2: Format (2I10,12,7(12,15)) } \\
\hline $1-10$ & NYEARS & Length of simulation (year) & \\
\hline $11-20$ & INTCTRL & End of institutional control (year) & \\
\hline $21-22$ & IPRINT & $\begin{array}{l}\text { Option for input data summary } \\
\begin{aligned} 0 & =\text { Input data summary is printed } \\
1 & =\text { No input data summary is printed }\end{aligned}\end{array}$ & \\
\hline $23-24$ & IPRN1 & $\begin{array}{l}\text { Option for recharge summary } \\
\begin{aligned} 0 & =\text { Recharge summary is printed } \\
1 & =\text { No recharge summary is printed }\end{aligned}\end{array}$ & \\
\hline $25-29$ & IFRQ1 & Option for frequency of printing recharge summary (year) & \\
\hline $30-31$ & IPRN2 & $\begin{array}{l}\text { Option for lateral summary } \\
\begin{aligned} 0 & =\text { Lateral summary is printed } \\
1 & =\text { No lateral summary is printed }\end{aligned}\end{array}$ & \\
\hline $32-36$ & IFRQ2 & Option for frequency of printing lateral summary (year) & \\
\hline $37-38$ & IPRN3 & $\begin{array}{l}\text { Option for concrete analyses summary } \\
\begin{aligned} 0 & =\text { Concrete analyses summary is printed } \\
1 & =\text { No concrete analyses summary is printed }\end{aligned}\end{array}$ & \\
\hline $39-43$ & IFRQ3 & $\begin{array}{l}\text { Option for frequency of printing concrete analyses summary } \\
\text { (year) }\end{array}$ & \\
\hline $44-45$ & IPRN4 & $\begin{array}{l}\text { Option for inventory, leach rate, and cumulative leached } \\
\text { summary } \\
\begin{array}{l}0=\text { Inventory, leach rate, and cumulative leached } \\
\text { summary is printed } \\
1=\text { No inventory, leach rate, and cumulative leached } \\
\text { summary is printed }\end{array}\end{array}$ & \\
\hline $46-50$ & IFRQ4 & $\begin{array}{l}\text { Option for frequency of printing inventory, leach rate, and } \\
\text { cumulative leached summary (year) }\end{array}$ & \\
\hline
\end{tabular}


Table 4.1. (continued)

\begin{tabular}{|c|c|c|}
\hline Column No. & Parameter & Description \\
\hline \multicolumn{3}{|c|}{ Record 2 (continued) } \\
\hline $51-52$ & IPRN5 & $\begin{array}{l}\text { Option for advection, diffusion, and leach rate summary } \\
0=\text { Advection, diffusion, and leach rate summary is } \\
\text { printed } \\
1=\text { No advection, diffusion, and leach rate summary is } \\
\text { printed }\end{array}$ \\
\hline $53-57$ & IFRQ5 & $\begin{array}{l}\text { Option for frequency of printing advection, diffusion, and } \\
\text { leach rate summary (year) }\end{array}$ \\
\hline $58-59$ & IPRN6 & $\begin{array}{l}\text { Option for inventory, advection, and diffusion for intact vaults } \\
\text { summary } \\
\begin{array}{l}0= \\
\text { Inventory, advection, and diffusion for intact vaults } \\
\text { summary is printed } \\
1=\text { No inventory, advection, and diffusion for intact vaults } \\
\text { summary is printed }\end{array}\end{array}$ \\
\hline $60-64$ & IFRQ6 & $\begin{array}{l}\text { Option for frequency of printing inventory, advection, and } \\
\text { diffusion for intact vaults summary (year) }\end{array}$ \\
\hline $65-66$ & IPRN7 & $\begin{array}{l}\text { Option for inventory, advection, and diffusion for cracked } \\
\text { vaults summary } \\
\begin{aligned} 0= & \text { Inventory, advection, and diffusion for cracked vaults } \\
& \text { summary is printed } \\
1= & \text { No inventory, advection, and diffusion for cracked } \\
& \text { vaults summary is printed }\end{aligned}\end{array}$ \\
\hline $67-71$ & IFRQ7 & $\begin{array}{l}\text { Option for frequency of printing inventory, advection, and } \\
\text { diffusion for cracked vaults summary (year) }\end{array}$ \\
\hline
\end{tabular}

\section{Record 3: Format (415)}

1-5 LYR Number of layers of vaults in tumulus

6-10 NUMWID

11-15 NUMLTH

16-20 NMEMBER

Number of vaults along width of tumulus

Number of vaults along length of tumulus

Number of concrete members to be modeled $(=3$ if pad is not modeled, $=4$ if pad is modeled)

\section{Record 4: Format (3E10.3)}

1-10 CLWID

Vault width measured from centerline of opposite walls (in.) 
Table 4.1. (continued)

\begin{tabular}{|c|c|c|}
\hline Column No. & Parameter & Description \\
\hline \multicolumn{3}{|c|}{ Record 4 (continued) } \\
\hline $11-20$ & CLLTH & Vault length measured from centerline of opposite walls (in.) \\
\hline $21-30$ & CLHGHT & $\begin{array}{l}\text { Vault height measured from centerline of roof to centerline of } \\
\text { floor (in.) }\end{array}$ \\
\hline \multicolumn{3}{|c|}{ Record 5: Format (3E10.3) } \\
\hline $1-10$ & CMTHK(1) & Thickness of roof (in.) \\
\hline $11-20$ & CMTHK(2) & Thickness of wall (in.) \\
\hline $21-30$ & CMTHK(3) & Thickness of floor (in.) \\
\hline \multicolumn{3}{|c|}{ Record 6: Format (6E10.3) } \\
\hline $1-10$ & TENCVX(1) & $\begin{array}{l}\text { Concrete cover thickness on tension face of concrete roof in } \\
\text { x-direction (in.) }\end{array}$ \\
\hline $11-20$ & TENCVY(1) & $\begin{array}{l}\text { Concrete cover thickness on tension face of concrete roof in } \\
\text { y-direction (in.) }\end{array}$ \\
\hline $21-30$ & TENCVX(2) & $\begin{array}{l}\text { Concrete cover thickness on tension face of concrete wall in } \\
\text { x-direction (in.) }\end{array}$ \\
\hline $31-40$ & TENCVY(2) & $\begin{array}{l}\text { Concrete cover thickness on tension face of concrete wall in } \\
\text { y-direction (in.) }\end{array}$ \\
\hline $41-50$ & TENCVX(3) & $\begin{array}{l}\text { Concrete cover thickness on tension face of concrete floor in } \\
\text { x-direction (in.) }\end{array}$ \\
\hline $51-60$ & TENCVY(3) & $\begin{array}{l}\text { Concrete cover thickness on tension face of concrete floor in } \\
\text { y-direction (in.) }\end{array}$ \\
\hline
\end{tabular}

Record 7: Format (6E10.3)

$1-10$

STLRAD(1)

Radius of steel reinforcement in roof (in.)

$11-20$

STLSPC(1)

Spacing of steel reinforcement in roof (in.)

$21-30$

STLRAD(2)

Radius of steel reinforcement in wall (in.)

$31-40$

STLSPC(2)

Spacing of steel reinforcement in wall (in.) 
Table 4.1. (continued)

\begin{tabular}{|c|c|c|}
\hline Column No. & Parameter & Description \\
\hline \multicolumn{3}{|c|}{ Record 7 (continued) } \\
\hline $41-50$ & STLRAD(3) & Radius of steel reinforcement in floor (in.) \\
\hline $51-60$ & STLSPC(3) & Spacing of steel reinforcement in floor (in.) \\
\hline \multicolumn{3}{|c|}{ Record 8: Format (4E10.3) } \\
\hline $1-10$ & SUBMOD & Modulus of elasticity of the subgrade reaction ( $\mathrm{lb} / \mathrm{in}^{3}{ }^{3}$ ) \\
\hline $11-20$ & FLANGL & Friction angle of waste/grout in vault (deg) \\
\hline $21-30$ & SLDNS & Density of soil backfill around tumulus $\left(\mathrm{g} / \mathrm{cm}^{3}\right)$ \\
\hline $31-40$ & SLANGL & Friction angle of soil backfill around tumulus (deg) \\
\hline \multicolumn{3}{|c|}{ Record 9: Format (4E10.3) } \\
\hline $1-10$ & CVRTHK & Thickness of earthen cover (in.) \\
\hline $11-20$ & CVRDNS & Density of earthen cover $\left(\mathrm{g} / \mathrm{cm}^{3}\right)$ \\
\hline $21-30$ & WSTDNS & Density of waste $\left(\mathrm{g} / \mathrm{cm}^{3}\right)$ \\
\hline $31-40$ & WSTHT & Relative saturation of waste \\
\hline \multicolumn{3}{|c|}{ Record 10: Format (7E10.3) } \\
\hline $1-10$ & CCDNS & Density of concrete $\left(\mathrm{g} / \mathrm{cm}^{3}\right)$ \\
\hline $11-20$ & CCPOR & Porosity of concrete \\
\hline $21-30$ & CONPSN & Poisson's ratio for concrete \\
\hline $31-40$ & COM28D & Compressive strength of concrete at $28 \mathrm{~d}\left(\mathrm{lb} / \mathrm{in.}^{2}\right)$ \\
\hline $41-50$ & WCR & Water-cement ratio \\
\hline $51-60$ & PHBEG & Initial $\mathrm{pH}$ of concrete \\
\hline $61-70$ & WTCMNT & Cement content of concrete $\left(\mathrm{kg} / \mathrm{m}^{3}\right)$ \\
\hline
\end{tabular}


Table 4.1. (continued)

\begin{tabular}{|c|c|c|}
\hline Column No. & Parameter & Description \\
\hline \multicolumn{3}{|c|}{ Record 11: Format (4E10.3) } \\
\hline $1-10$ & CLCON & Concentration of free chloride in concrete (mol/L) \\
\hline $11-20$ & CCON & Concentration of $\mathrm{CaO}$ in concrete $(\mathrm{mol} / \mathrm{L})$ \\
\hline $21-30$ & CFA & Coefficient used in compressive strength function \\
\hline $31-40$ & CFB & Coefficient used in compressive strength function \\
\hline \multicolumn{3}{|c|}{ Record 12: Format (3E10.3) } \\
\hline $1-10$ & STLMOD & Modulus of elasticity of steel reinforcement (lb/in..$\left.^{2}\right)$ \\
\hline $11-20$ & STLYLD & Yield strength of steel reinforcement $\left(\mathrm{lb} / \mathrm{in}^{2}{ }^{2}\right)$ \\
\hline $21-30$ & YNGMOD & Young's modulus of elasticity for concrete $(\mathrm{Pa})$ \\
\hline \multicolumn{3}{|c|}{ Record 13: Format (3E10.3) } \\
\hline $1-10$ & CACON & Concentration of calcium in C-S-H system (mol/L) \\
\hline $11-20$ & CAP & $\begin{array}{l}\text { Concentration of calcium hydroxide in concrete pore solution } \\
(\mathrm{mol} / \mathrm{L})\end{array}$ \\
\hline $21-30$ & SI & Concentration of silica in C-S-H system (mol/L) \\
\hline \multicolumn{3}{|c|}{ Enter Record 14 if NMEMBER $=4$} \\
\hline \multicolumn{3}{|c|}{ Record 14: Format (F8.4,8E9.2) } \\
\hline $1-8$ & PSTLRAD & Radius of pad steel reinforcement (in.) \\
\hline $9-17$ & CMTHK(4) & Concrete pad thickness (in.) \\
\hline $18-26$ & PSTLMOD & Modulus of elasticity of steel reinforcement (lb/in. $\left.{ }^{2}\right)$ \\
\hline $27-35$ & PSTLYLD & Yield strength of steel reinforcement $\left(\mathrm{lb} / \mathrm{in}^{2}{ }^{2}\right)$ \\
\hline $36-44$ & PCONSTR & Compressive strength of pad concrete (lb/in. $\left.{ }^{2}\right)$ \\
\hline $45-53$ & PSTLSPC & Spacing between steel reinforcing rods (in.) \\
\hline
\end{tabular}


Table 4.1. (continued)

\begin{tabular}{lll}
\hline Column No. & Parameter & Description \\
\hline $54-62$ & PBOTCOV & $\begin{array}{l}\text { Concrete cover thickness from the center of the bottom row of } \\
\text { steel reinforcing rods to the bottom of the pad (in.) }\end{array}$ \\
$63-71$ & PWTCMNT & Weight of pad cement per unit volume concrete $\left(\mathrm{kg} / \mathrm{m}^{3}\right)$ \\
$72-80$ & PIFF & Pad initial functionality fraction
\end{tabular}

Record 15: Format (8E10.3)

$1-10$

CAGW

Concentration of calcium in groundwater $(\mathrm{mol} / \mathrm{L})$

$11-20$

CL

Concentration of chloride in groundwater ( $\mathrm{mol} / \mathrm{L}$ )

$21-30$

$\mathrm{CO} 2$

Concentration of carbon dioxide outside tumulus ( $\mathrm{mol} / \mathrm{L}$ )

$31-40$

$\mathrm{CO} 3$

Concentration of carbonate in groundwater (mol/L)

$41-50$

XMG2

Concentration of magnesium in groundwater $(\mathrm{mol} / \mathrm{L})$

$51-60$

$\mathrm{O} 2$

Concentration of oxygen at tumulus surface $(\mathrm{mol} / \mathrm{L})$

$61-70$

SO4I

Concentration of sulfate inside vault $(\mathrm{mol} / \mathrm{L})$

$71-80$

SO4O

Concentration of sulfate outside vault (mol/L)

Record 16: Format (6E10.3)

$1-10$

$11-20$

$21-30$

$31-40$

$41-50$

$51-60$

$1-10$
DFALK

DFCAOH

DFCL

DFCO2

DFO2

DFSO4

\section{Record 17: Format (3E10.3)}

PHGW
Groundwater $\mathrm{pH}$
Effective diffusivity of alkalis in concrete $\left(\mathrm{m}^{2} / \mathrm{s}\right)$

Effective diffusivity of calcium hydroxide in concrete $\left(\mathrm{m}^{2} / \mathrm{s}\right)$

Effective diffusivity of chloride in concrete $\left(\mathrm{m}^{2} / \mathrm{s}\right)$

Effective diffusivity of carbon dioxide in concrete $\left(\mathrm{m}^{2} / \mathrm{s}\right)$

Effective diffusivity of oxygen in concrete $\left(\mathrm{m}^{2} / \mathrm{s}\right)$

Effective diffusivity of sulfate in concrete $\left(\mathrm{m}^{2} / \mathrm{s}\right)$ 
Table 4.1. (continued)

\begin{tabular}{|c|c|c|}
\hline Column No. & Parameter & Description \\
\hline \multicolumn{3}{|c|}{ Record 17 (continued) } \\
\hline $11-20$ & TDS & Total dissolved solids in groundwater (ppm) \\
\hline $21-30$ & TEMP & Groundwater temperature $\left({ }^{\circ} \mathrm{C}\right)$ \\
\hline \multicolumn{3}{|c|}{ Record 18: Format (3E10.3) } \\
\hline $1-10$ & CASOL & Solubility of calcium in groundwater $(\mathrm{mol} / \mathrm{L})$ \\
\hline $11-20$ & CRBSOL & Solubility of carbonate in groundwater (mol/L) \\
\hline $21-30$ & XMGSOL & Solubility of magnesium in groundwater $(\mathrm{mol} / \mathrm{L})$ \\
\hline \multicolumn{3}{|c|}{ Record 19: Format (4E10.3) } \\
\hline $1-10$ & CFT1 & Time at which waste containers begin to corrode (year) \\
\hline $11-20$ & DCFT & Time required for complete corrosion of waste containers (year) \\
\hline $21-30$ & EFT1 & Time at which epoxy-coating begins to fail (year) \\
\hline $31-40$ & DEFT & Time required for complete failure of epoxy-coating (year) \\
\hline \multicolumn{3}{|c|}{ Record 20: Format (4E10.3) } \\
\hline $1-10$ & SITARA & Containment area per unit $\left(\mathrm{m}^{2}\right)$ \\
\hline $11-20$ & SLKR & $\begin{array}{l}\text { Saturated hydraulic conductivity of the soil under the tumulus } \\
(\mathrm{cm} / \mathrm{s})\end{array}$ \\
\hline $21-30$ & SLK & $\begin{array}{l}\text { Saturated hydraulic conductivity of soil backfill around } \\
\text { tumulus }(\mathrm{cm} / \mathrm{s})\end{array}$ \\
\hline $31-40$ & CCK & Saturated hydraulic conductivity of concrete $(\mathrm{cm} / \mathrm{s})$ \\
\hline
\end{tabular}

Record 21: Format (A60)

1-60 WAT_INP

File name containing monthly infiltration values

Record 22: Format (I5)

1-5 NONCLD Number of radionuclides considered in the simulation 
Table 4.1. (continued)

\begin{tabular}{|c|c|c|}
\hline Column No. & Parameter & Description \\
\hline \multicolumn{3}{|c|}{ Record 23: Format $(A 8,7 E 10.3)$} \\
\hline $1-8$ & NUCLID & Radionuclide name \\
\hline $9-18$ & $\mathrm{AM}$ & Atomic mass of radionuclide \\
\hline $19-28$ & HLIFE & Radionuclide half-life (year) \\
\hline $29-38$ & SOL & Radionuclide solubility limit $(\mathrm{mol} / \mathrm{L})$ \\
\hline $39-48$ & XKD & Radionuclide distribution coefficient (mL/g) \\
\hline $49-58$ & QCASK & Radionuclide inventory in vault $(\mathrm{g})$ \\
\hline $59-68$ & DFWST & Waste diffusion coefficient $\left(\mathrm{m}^{2} / \mathrm{s}\right)$ \\
\hline $69-78$ & DFCON & Concrete diffusion coefficient $\left(\mathrm{m}^{2} / \mathrm{s}\right)$ \\
\hline \multicolumn{3}{|c|}{ Record 24: Format (I10) } \\
\hline $1-10$ & REFYEAR & Reference year for simulation \\
\hline \multicolumn{3}{|c|}{ Record 25: Format (110,10E10.3) } \\
\hline $1-10$ & BGNDUMP & Beginning year for inventory disposal \\
\hline $11-20$ & QCASK & Inventory in vault $(\mathrm{g})$ for first radionuclide \\
\hline $21-30$ & QCASK & Inventory in vault $(\mathrm{g})$ for second radionuclide \\
\hline $\begin{array}{c}\downarrow \\
101-110\end{array}$ & $\begin{array}{c}\downarrow \\
\text { QCASK }\end{array}$ & Inventory in vault $(\mathrm{g})$ for tenth radionuclide \\
\hline
\end{tabular}


Table 4.2. Input data format for the SOURCE2 computer code

\begin{tabular}{|c|c|c|c|}
\hline Column No. & Parameter & Description & \\
\hline \multicolumn{4}{|c|}{ Record 1: Format (A80) } \\
\hline $1-80$ & TITLE & Title of simulation & \\
\hline \multicolumn{4}{|c|}{ Record 2: Format $(110,15,12,5(12,15))$} \\
\hline $1-10$ & NYEARS & Length of simulation (year) & \\
\hline $11-15$ & IDFLAG & $\begin{array}{l}\text { Disposal unit identification flag } \\
\qquad \begin{aligned} 1 & =\text { silo } \\
2 & =\text { well } \\
3 & =\text { well-in-silo }\end{aligned}\end{array}$ & \\
\hline $16-17$ & IPRINT & $\begin{array}{l}\text { Option for input data summary } \\
\begin{array}{l}0=\text { Input data summary is printed } \\
1=\text { No input data summary is printed }\end{array}\end{array}$ & \\
\hline $18-19$ & IPRN1 & $\begin{array}{l}\text { Option for recharge summary } \\
\begin{array}{l}0=\text { Recharge summary is printed } \\
1=\text { No recharge summary is printed }\end{array}\end{array}$ & . \\
\hline $20-24$ & IFRQ1 & Option for frequency of printing recharge summary (year) & \\
\hline $25-26$ & IPRN2 & $\begin{array}{l}\text { Option for lateral summary } \\
\begin{array}{l}0=\text { Lateral summary is printed } \\
1=\text { No lateral summary is printed }\end{array}\end{array}$ & \\
\hline $27-31$ & IFRQ2 & Option for frequency of printing lateral summary (year) & \\
\hline $32-33$ & IPRN3 & $\begin{array}{l}\text { Option for concrete analyses summary } \\
\begin{aligned} 0 & =\text { Concrete analyses summary is printed } \\
1 & =\text { No concrete analyses summary is printed }\end{aligned}\end{array}$ & \\
\hline $34-38$ & IFRQ3 & $\begin{array}{l}\text { Option for frequency of printing concrete analyses summary } \\
\text { (year) }\end{array}$ & \\
\hline $39-40$ & IPRN4 & $\begin{array}{l}\text { Option for inventory, leach rate, and cumulative leached } \\
\text { summary } \\
0=\text { Inventory, leach rate, and cumulative leached } \\
\text { summary is printed } \\
1=\text { No inventory, leach rate, and cumulative leached } \\
\text { summary is printed }\end{array}$ & \\
\hline $41-45$ & IFRQ4 & $\begin{array}{l}\text { Option for frequency of printing inventory, leach rate, and } \\
\text { cumulative leached summary (year) }\end{array}$ & \\
\hline
\end{tabular}


Table 4.2. (continued)

\begin{tabular}{|c|c|c|}
\hline Column No. & Parameter & Description \\
\hline \multicolumn{3}{|c|}{ Record 2 (continued) } \\
\hline $46-47$ & IPRN5 & $\begin{array}{l}\text { Option for advection, diffusion, and leach rate summary } \\
\begin{aligned} 0= & \text { Advection, diffusion, and leach rate summary is } \\
& \text { printed } \\
1 & =\text { No advection, diffusion, and leach rate summary is } \\
& \text { printed }\end{aligned}\end{array}$ \\
\hline $48-52$ & IFRQ5 & $\begin{array}{l}\text { Option for frequency of printing advection, diffusion, and } \\
\text { leach rate summary (year) }\end{array}$ \\
\hline \multicolumn{3}{|c|}{ Enter Records 3 through 7 if DFLAG $=1$ or 3} \\
\hline \multicolumn{3}{|c|}{ Record 3: Format (2E10.3) } \\
\hline $1-10$ & SLHGHT & $\begin{array}{l}\text { Height of silo measured from centerline of roof to centerline } \\
\text { of floor (in.) }\end{array}$ \\
\hline $11-20$ & SILRAD & Radius of silo measured to centerline of wall (in.) \\
\hline \multicolumn{3}{|c|}{ Record 4: Format (3E10.3) } \\
\hline $1-10$ & CMTHK $(1,1)$ & Thickness of silo roof (in.) \\
\hline $11-20$ & CMTHK $(1,2)$ & Thickness of silo wall (in.) \\
\hline $21-30$ & $\operatorname{CMTHK}(1,3)$ & Thickness of silo floor (in.) \\
\hline \multicolumn{3}{|c|}{ Record 5: Format (6E10.3) } \\
\hline $1-10$ & $\operatorname{TENCVX}(1,1)$ & $\begin{array}{l}\text { Concrete cover thickness on tension face of silo roof in } \\
\text { x-direction (in.) }\end{array}$ \\
\hline $11-20$ & $\operatorname{TENCVY}(1,1)$ & $\begin{array}{l}\text { Concrete cover thickness on tension face of silo roof in } \\
\text { y-direction (in.) }\end{array}$ \\
\hline $21-30$ & TENCVX $(1,2)$ & $\begin{array}{l}\text { Concrete cover thickness on tension face of silo wall in } \\
\text { x-direction (in.) }\end{array}$ \\
\hline $31-40$ & $\operatorname{TENCVY}(1,2)$ & $\begin{array}{l}\text { Concrete cover thickness on tension face of silo wall in } \\
y \text {-direction (in.) }\end{array}$ \\
\hline $41-50$ & $\operatorname{TENCVX}(1,3)$ & $\begin{array}{l}\text { Concrete cover thickness on tension face of silo floor in } \\
x \text {-direction (in.) }\end{array}$ \\
\hline
\end{tabular}


Table 4.2. (continued)

\begin{tabular}{|c|c|c|}
\hline Column No. & Parameter & Description \\
\hline \multicolumn{3}{|c|}{ Record 5 (continued) } \\
\hline \multirow[t]{3}{*}{$51-60$} & $\operatorname{TENCVY}(1,3)$ & $\begin{array}{l}\text { Concrete cover thickness on tension face of silo floor in } \\
y \text {-direction (in.) }\end{array}$ \\
\hline & & ' \\
\hline & \multicolumn{2}{|c|}{ Record 6: Format (2E10.3) } \\
\hline $1-10$ & STTKCM & $\begin{array}{l}\text { Thickness of corrugated steel liner on compression face of silo } \\
\text { wall (in.) }\end{array}$ \\
\hline $11-20$ & STTKTN & $\begin{array}{l}\text { Thickness of corrugated steel liner on tension face of silo wall } \\
\text { (in.) }\end{array}$ \\
\hline \multicolumn{3}{|c|}{ Record 7: Format (6E10.3) } \\
\hline $1-10$ & STLRAD(1) & Radius of steel reinforcement in silo roof (in.) \\
\hline $11-20$ & STLSPC(1) & Spacing of steel reinforcement in silo roof (in.) \\
\hline $21-30$ & STLRAD(2) & Radius of steel reinforcement in silo wall (in.) \\
\hline $31-40$ & STLSPC(2) & Spacing of steel reinforcement in silo wall (in.) \\
\hline $41-50$ & STLRAD(3) & Radius of steel reinforcement in silo floor (in.) \\
\hline $51-60$ & STLSPC(3) & Spacing of steel reinforcement in silo floor (in.) \\
\hline \multicolumn{3}{|c|}{ Enter Records 8 through 11 if IDFLAG $=2$ or 3} \\
\hline \multicolumn{3}{|c|}{ Record 8: Format (2E10.3) } \\
\hline $1-10$ & WLHGHT & $\begin{array}{l}\text { Height of well measured from centerline of roof to centerline } \\
\text { of floor (in.) }\end{array}$ \\
\hline $11-20$ & WLRAD & Radius of well measured to centerline of wall (in.) \\
\hline \multicolumn{3}{|c|}{ Record 9: Format (3E10.3) } \\
\hline $1-10$ & CMTHK(2,1) & Thickness of well roof (in.) \\
\hline $11-20$ & CMTHK $(2,2)$ & Thickness of well wall (in.) \\
\hline $21-30$ & $\operatorname{CMTHK}(2,3)$ & Thickness of well floor (in.) \\
\hline
\end{tabular}


Table 4.2. (continued)

\begin{tabular}{|c|c|c|}
\hline Column No. & Parameter & Description \\
\hline \multicolumn{3}{|c|}{ Record 10: Format (6E10.3) } \\
\hline $1-10$ & $\operatorname{TENCVX}(2,1)$ & $\begin{array}{l}\text { Concrete cover thickness on tension face of well roof in } \\
\text { x-direction (in.) }\end{array}$ \\
\hline $11-20$ & $\operatorname{TENCVY}(2,1)$ & $\begin{array}{l}\text { Concrete cover thickness on tension face of well roof in } \\
y \text {-direction (in.) }\end{array}$ \\
\hline $21-30$ & $\operatorname{TENCVX}(2,2)$ & $\begin{array}{l}\text { Concrete cover thickness on tension face of well wall in } \\
\text { x-direction (in.) }\end{array}$ \\
\hline $31-40$ & $\operatorname{TENCVY}(2,2)$ & $\begin{array}{l}\text { Concrete cover thickness on tension face of well wall in } \\
y \text {-direction (in.) }\end{array}$ \\
\hline $41-50$ & $\operatorname{TENCVX}(2,3)$ & $\begin{array}{l}\text { Concrete cover thickness on tension face of well floor in } \\
\text { x-direction (in.) }\end{array}$ \\
\hline $51-60$ & $\operatorname{TENCVY}(2,3)$ & $\begin{array}{l}\text { Concrete cover thickness on tension face of well floor in } \\
y \text {-direction (in.) }\end{array}$ \\
\hline
\end{tabular}

\section{Record 11: Format (3E10.3)}

$1-10$

WLSTR

Yield strength of cast iron pipe (lb/in. $\left.{ }^{2}\right)$

$11-20$

STLPSN

Poisson's ratio for cast iron

$21-30$

STLDNS

Density of cast iron used in well $\left(\mathrm{g} / \mathrm{cm}^{3}\right)$

\section{Record 12: Format (4E10.3)}

$1-10$

SUBMOD

$11-20$

$21-30$

$31-40$

1-10

$11-20$

$21-30$
FLANGL

SLDNS

SLANGL
CVRTHK

CVRDNS
Modulus of elasticity of the subgrade reaction (lb/in. $\left.{ }^{3}\right)$

Friction angle of waste/grout in silo or well (deg)

Density of soil backfill around silo or well $\left(\mathrm{g} / \mathrm{cm}^{3}\right)$

Friction angle of soil backfill around silo or well(deg)

\section{Record 13: Format (4E10.3)}

Thickness of earthen cover (in.)

Density of earthen cover $\left(\mathrm{g} / \mathrm{cm}^{3}\right)$

Density of waste $\left(\mathrm{g} / \mathrm{cm}^{3}\right)$ 
Table 4.2. (continued)

\begin{tabular}{|c|c|c|c|}
\hline Column No. & Parameter & Description & \\
\hline & & ord 13 (continued) & \\
\hline \multirow{2}{*}{$31-40$} & WSTHT & Relative saturation of waste & \\
\hline & & 14: Format (7E10.3) & \\
\hline $1-10$ & CCDNS & Density of concrete $\left(\mathrm{g} / \mathrm{cm}^{3}\right)$ & \\
\hline $11-20$ & CCPOR & Porosity of concrete & \\
\hline $21-30$ & CONPSN & Poisson's ratio for concrete & \\
\hline $31-40$ & COM28D & Compressive strength of concrete at $28 \mathrm{~d}\left(\mathrm{lb} / \mathrm{in}^{2}{ }^{2}\right)$ & \\
\hline $41-50$ & WCR & Water-cement ratio & \\
\hline $51-60$ & PHBEG & Initial $\mathrm{pH}$ of concrete & \\
\hline \multirow[t]{2}{*}{$61-70$} & WTCMNT & Cement content of concrete $\left(\mathrm{kg} / \mathrm{m}^{3}\right)$ & \\
\hline & & 15: Format (4E10.3) & \\
\hline $1-10$ & CLCON & Concentration of free chloride in concrete (mol/L) & \\
\hline $11-20$ & $\mathrm{CCON}$ & Concentration of $\mathrm{CaO}$ in concrete $(\mathrm{mol} / \mathrm{L})$ & \\
\hline $21-30$ & CFA & Coefficient used in compressive strength function & \\
\hline \multirow[t]{2}{*}{$31-40$} & CFB & Coefficient used in compressive strength function & \\
\hline & & 16: Format (3E10.3) & \\
\hline $1-10$ & STLMOD & Modulus of elasticity of steel reinforcement (lb/in. $\left.{ }^{2}\right)$ & \\
\hline $11-20$ & STLYLD & Yield strength of steel reinforcement (lb/in. $\left.{ }^{2}\right)$ & \\
\hline \multirow[t]{2}{*}{$21-30$} & YNGMOD & Young's modulus of elasticity for concrete $(\mathrm{Pa})$ & \\
\hline & & 17: Format (3E10.3) & \\
\hline $1-10$ & CACON & Concentration of calcium in C-S-H system $(\mathrm{mol} / \mathrm{L})$ & \\
\hline $11-20$ & CAP & $\begin{array}{l}\text { Concentration of calcium hydroxide in concrete pore solution } \\
(\mathrm{mol} / \mathrm{L})\end{array}$ & • \\
\hline
\end{tabular}


Table 4.2. (continued)

\begin{tabular}{|c|c|c|}
\hline Column No. & Parameter & Description \\
\hline \multicolumn{3}{|c|}{ Record 17 (continued) } \\
\hline $21-30$ & SI & Concentration of silica in C-S-H system (mol/L) \\
\hline \multicolumn{3}{|c|}{ Record 18: Format (8E10.3) } \\
\hline $1-10$ & CAGW & Concentration of calcium in groundwater $(\mathrm{mol} / \mathrm{L})$ \\
\hline $11-20$ & $\mathrm{CL}$ & Concentration of chloride in groundwater $(\mathrm{mol} / \mathrm{L})$ \\
\hline $21-30$ & $\mathrm{CO} 2$ & Concentration of carbon dioxide outside tumulus ( $\mathrm{mol} / \mathrm{L}$ ) \\
\hline $31-40$ & $\mathrm{CO} 3$ & Concentration of carbonate in groundwater $(\mathrm{mol} / \mathrm{L})$ \\
\hline $41-50$ & XMG2 & Concentration of magnesium in groundwater $(\mathrm{mol} / \mathrm{L})$ \\
\hline $51-60$ & $\mathrm{O} 2$ & Concentration of oxygen at tumulus surface (mol/L) \\
\hline $61-70$ & SO4I & Concentration of sulfate inside cask ( $\mathrm{mol} / \mathrm{L})$ \\
\hline $71-80$ & SO4O & Concentration of sulfate outside cask (mol/L) \\
\hline \multicolumn{3}{|c|}{ Record 19: Format (6E10.3) } \\
\hline $1-10$ & DFALK & Effective diffusivity of alkalis in concrete $\left(\mathrm{m}^{2} / \mathrm{s}\right)$ \\
\hline $11-20$ & $\mathrm{DFCAOH}$ & Effective diffusivity of calcium hydroxide in concrete $\left(\mathrm{m}^{2} / \mathrm{s}\right)$ \\
\hline $21-30$ & DFCL & Effective diffusivity of chloride in concrete $\left(\mathrm{m}^{2} / \mathrm{s}\right)$ \\
\hline $31-40$ & $\mathrm{DFCO} 2$ & Effective diffusivity of carbon dioxide in concrete $\left(\mathrm{m}^{2} / \mathrm{s}\right)$ \\
\hline $41-50$ & $\mathrm{DFO} 2$ & Effective diffusivity of oxygen in concrete $\left(\mathrm{m}^{2} / \mathrm{s}\right)$ \\
\hline $51-60$ & DFSO4 & Effective diffusivity of sulfate in concrete $\left(\mathrm{m}^{2} / \mathrm{s}\right)$ \\
\hline \multicolumn{3}{|c|}{ Record 20: Format (3E10.3) } \\
\hline $1-10$ & PHGW & Groundwater $\mathrm{pH}$ \\
\hline $11-20$ & TDS & Total dissolved solids in groundwater (ppm) \\
\hline $21-30$ & TEMP & Groundwater temperature $\left({ }^{\circ} \mathrm{C}\right)$ \\
\hline
\end{tabular}


Table 4.2. (continued)

\begin{tabular}{lll} 
Column No. & Parameter & \multicolumn{1}{c}{ Description } \\
\hline $1-10$ & Record 21: Format (3E10.3) \\
$11-20$ & CRSOL & Solubility of calcium in groundwater (mol/L) \\
$21-30$ & XMGSOL & Solubility of carbonate in groundwater (mol/L) \\
& & Solubility of magnesium in groundwater (mol/L) \\
& & Enter Record 22 if IDFLAG = 1 or 3 \\
$1-10$ & EFT1 & Time at which epoxy-coating begins to fail (year) \\
$11-20$ & DEFT & Time required for complete failure of epoxy-coating (year) \\
$21-30$ & XLT1 & Time at which corrugated steel liners begin to corrode (year) \\
$31-40$ & DLFT & Time required for complete corrosion of corrugated steel \\
& & liners (year)
\end{tabular}

Enter Record 23 if IDFLAG $=2$ or 3

Record 23: Format (2E10.3)

$1-10$

$11-20$

1-10

$11-20$

$21-30$

$31-40$

$1-60$
WFT1

DWFT

SITARA

SLKR

SLK

CCK

WAT_INP
Time at which cast iron pipe begins to corrode (year)

Time required for complete corrosion of cast iron pipe (year)

\section{Record 24: Format (4E10.3)}

Containment area per unit $\left(\mathrm{m}^{2}\right)$

Saturated hydraulic conductivity of the soil under the waste unit $(\mathrm{cm} / \mathrm{s})$

Saturated hydraulic conductivity of soil backfill around the waste unit $(\mathrm{cm} / \mathrm{s})$

Saturated hydraulic conductivity of concrete $(\mathrm{cm} / \mathrm{s})$

\section{Record 25: Format (A60)}

File name containing monthly infiltration values 
Table 4.2. (continued)

\begin{tabular}{|c|c|c|}
\hline Column No. & Parameter & Description \\
\hline \multicolumn{3}{|c|}{ Record 26: Format (IS) } \\
\hline $1-5$ & NONCLD & Number of radionuclides considered in the simulation \\
\hline \multicolumn{3}{|c|}{ Record 27: Format (A8,7E10.3) } \\
\hline $1-8$ & NUCLID & Radionuclide name \\
\hline $9-18$ & AM & Atomic mass of radionuclide \\
\hline $19-28$ & HLIFE & Radionuclide half-life (year) \\
\hline $29-38$ & SOL & Radionuclide solubility limit (mol/L) \\
\hline $39-48$ & XKD & Radionuclide distribution coefficient (mL/g) \\
\hline $49-58$ & QSW & Radionuclide inventory in silo, well, well-in-silo, or trench (g) \\
\hline $59-68$ & DFWST & Waste diffusion coefficient $\left(\mathrm{m}^{2} / \mathrm{s}\right)$ \\
\hline $69-78$ & DFCON & Concrete diffusion coefficient $\left(\mathrm{m}^{2} / \mathrm{s}\right)$ \\
\hline \multicolumn{3}{|c|}{ Record 28: Format (I10) } \\
\hline $1-10$ & REFYEAR & Reference year for simulation \\
\hline \multicolumn{3}{|c|}{ Repeat Record 29 as required to describe the inventory disposal periods } \\
\hline \multicolumn{3}{|c|}{ Record 29: Format $(2110,10 E 10.3)$} \\
\hline $1-10$ & BGNDUMP & Beginning year for inventory disposal \\
\hline $11-20$ & ENDDUMP & Ending year for inventory disposal \\
\hline $21-30$ & QSW & Inventory in silo, well, or well-in-silo (g) for first radionuclide \\
\hline$\underset{111-120}{\downarrow}$ & $\begin{array}{c}\downarrow \\
\text { QSW }\end{array}$ & $\begin{array}{l}\text { Inventory in silo, well, or well-in-silo (g) for tenth } \\
\text { radionuclide }\end{array}$ \\
\hline
\end{tabular}


Table 4.3. Input data format for the SOURCE computer codes infiltration values

\begin{tabular}{|c|c|c|}
\hline Column No. & Parameter & Description \\
\hline \multicolumn{3}{|c|}{ Repeat Record 1 as required to describe infiltration scenario for waste unit } \\
\hline \multicolumn{3}{|c|}{ Record 1: Format $(2110,12 F 5.2)$} \\
\hline $1-10$ & IYRI & Beginning year for using WATER(1) - WATER(12) \\
\hline $11-20$ & IYR2 & Last year for using WATER(1) - WATER(12) \\
\hline $21-25$ & WATER(1) & Water infiltration rate for first month of year $(\mathrm{cm})$ \\
\hline $26-30$ & WATER(2) & Water infiltration rate for second month of year $(\mathrm{cm})$ \\
\hline $31-35$ & WATER(3) & Water infiltration rate for third month of year $(\mathrm{cm})$ \\
\hline $36-40$ & WATER(4) & Water infiltration rate for fourth month of year $(\mathrm{cm})$ \\
\hline $41-45$ & WATER(5) & Water infiltration rate for fifth month of year $(\mathrm{cm})$ \\
\hline $46-50$ & WATER(6) & Water infiltration rate for sixth month of year $(\mathrm{cm})$ \\
\hline $51-55$ & WATER(7) & Water infiltration rate for seventh month of year $(\mathrm{cm})$ \\
\hline $56-60$ & WATER(8) & Water infiltration rate for eighth month of year $(\mathrm{cm})$ \\
\hline $61-65$ & WATER(9) & Water infiltration rate for ninth month of year $(\mathrm{cm})$ \\
\hline $66-70$ & WATER(10) & Water infiltration rate for tenth month of year $(\mathrm{cm})$ \\
\hline $71-75$ & WATER(11) & Water infiltration rate for eleventh month of year $(\mathrm{cm})$ \\
\hline $76-80$ & WATER(12) & Water infiltration rate for twelfth month of year $(\mathrm{cm})$ \\
\hline
\end{tabular}


Table 4.4. File structure for SOURCE1

\begin{tabular}{|c|c|c|c|}
\hline Name & Function & Output control variables & Unit \\
\hline filename.inp & Input: Model parameters & & 1 \\
\hline $\begin{array}{l}\text { Specified in } \\
\text { filename.inp } \\
\text { Example: } \\
\text { water_tum1.dat }\end{array}$ & Input: Infiltration values & & 4 \\
\hline filename.con & $\begin{array}{l}\text { Output: Summary of input information and } \\
\text { concrete analyses }\end{array}$ & iprint, ipm3, ifrq3 & 7 \\
\hline filename.h2o & $\begin{array}{l}\text { Output: Beginning year, ending year, } \\
\text { monthly infiltration values }\end{array}$ & jprint & 12 \\
\hline filename.rch & Output: Year, flow, recharge & ipml, ifrql & 2 \\
\hline filename.lat & Output: Year, flow, lateral & iprn2, ifrq2 & 3 \\
\hline filename.sum & $\begin{array}{l}\text { Output: Year, inventory, leach rate, } \\
\text { cumulative leached }\end{array}$ & ipm4, ifrq4 & 10 \\
\hline filename.lch & $\begin{array}{l}\text { Output: Year, advection, diffusion, leach } \\
\text { rate }\end{array}$ & ipm5, ifrq5 & 11 \\
\hline filename.vtl & $\begin{array}{l}\text { Output: Year, inventory, advection, } \\
\text { diffusion }\end{array}$ & iprn6, ifrq6 & 14 \\
\hline filename.vt2 & $\begin{array}{l}\text { Output: Year, inventory, advection, } \\
\text { diffusion }\end{array}$ & ipm7, ifrq7 & 15 \\
\hline
\end{tabular}


Table 4.5. File structure for SOURCE2

\begin{tabular}{|c|c|c|c|}
\hline Name & Function & Output control variables & Unit \\
\hline filename.inp & Input: Model parameters & & 1 \\
\hline $\begin{array}{l}\text { Specified in } \\
\text { filename.inp } \\
\text { Example: } \\
\text { water_th.dat }\end{array}$ & Input: Infiltration values & & 4 \\
\hline filename.con & $\begin{array}{l}\text { Output: Summary of input information and } \\
\text { concrete analyses }\end{array}$ & iprint, ipm3, ifrq3 & 7 \\
\hline filename.h2o & $\begin{array}{l}\text { Output: Beginning year, ending year, } \\
\text { monthly infiltration values }\end{array}$ & iprint & 12 \\
\hline filename.rch & Output: Year, flow, recharge & ipm1, ifrq1 & 2 \\
\hline filename.lat & Output: Year, flow, lateral & iprn2, ifrq2 & 3 \\
\hline filename.sum & $\begin{array}{l}\text { Output: Year, inventory, leach rate, } \\
\text { cumulative leached }\end{array}$ & iprn4, ifrq4 & 10 \\
\hline filename.lch & $\begin{array}{l}\text { Output: Year, advection, diffusion, leach } \\
\text { rate }\end{array}$ & iprn5, ifrq5 & 11 \\
\hline
\end{tabular}




\section{REFERENCES}

1. R. Shuman, N. Chau, and E. A. Jennrich, The SOURCE Computer Codes: Models for Evaluating the Long-Term Performance of SWSA 6 Disposal Units, Version 1.0: User's Manual, RAE-9005/8-1, Rogers \& Associates Engineering Corporation, Salt Lake City, Utah, April 1992.

2. D. W. Lee et al., Performance Assessment for Continuing and Future Operations at Solid Waste Storage Area 6, ORNL-6783, Martin Marietta Energy Systems, Inc., Oak Ridge National Laboratory, Oak Ridge, Tennessee, February 1994.

3. C.F. Baes and R. D. Sharp, "A Proposal for Estimation of Soil Leaching and Leaching Constants for Use in Assessment Models," J. Environ. Qual. 12(1), 17-28 (1983).

4. A. S. Icenhour, Analysis of Source Term Modeling for Low-Level Radioactive Waste Performance Assessments, ORNL/TM-12908, Martin Marietta Energy Systems, Inc., Oak Ridge National Laboratory, Oak Ridge, Tennessee, March 1995.

5. H. J. Cowan, Design of Reinforced Concrete Structures, Prentice-Hall, Inc., Englewood Cliffs, New Jersey, 1982.

6. A. Atkinson and J. A. Hearne, An Assessment of the Long-Term Durability of Concrete in Radioactive Waste Repositories, AERE-R11465, Harwell Laboratory, Oxfordshire, England, October 1984.

7. A. Atkinson and J. A. Hearne, "Mechanistic Model for the Durability of Concrete Barriers Exposed to Sulphate-Bearing Groundwaters," Mat. Res. Soc. Symp. Proc. 176, 149-156 (1990).

8. W. F. Langelier, "The Analytical Control of Anti-Corrosion Water Treatment," J. Amer. Water Works Assoc. 28(10), 1500-1521 (1936).

9. A. Atkinson, The Time Dependence of pH Within a Repository for Radioactive Waste Disposal, AERE-R11777, Harwell Laboratory, Oxfordshire, England, April 1985.

10. S. A. Greenberg and T.N. Chang, "Investigation of the Colloidal Hydrated Calcium Silicates. II. Solubility Relationships in the Calcium Oxide-Silica-Water System at 25 D," J. Phys. Chem. 69, 182 (1965).

11. F. M. Lea, The Chemistry of Cement and Concrete, 3rd ed., Edward Amold, Ltd., London, 1970.

12. K. Tuutti, Corrosion of Steel in Concrete, Swedish Cement and Concrete Research Institute, Stockholm, Sweden, 1982.

13. D. A. Hausmann, "Steel Corrosion in Concrete," Materials Protection, November, 19-23 (1967)

14. E. D. Nawy, "Crack Width Control in Welded Fabric Reinforced Centrally Loaded Two-Way Concrete Slabs," presentation at 62nd ACI Annual Convention in Philadelphia, March 1966. 
15. A. S. Saada, Elasticity Theory and Application, Pergamon Press, Inc., New York, 1974.

16. G. B. Jeffrey, Plane Stress and Plane Strain in Bipolar Coordinates, 1920. 
APPENDIX A

THE FLOTHRU COMPUTER PROGRAM 



\section{A. THE FLOTHRU COMPUTER PROGRAM}

This appendix presents a derivation of the algorithms used in the FLOTHRU computer program, a subroutine in both SOURCE1 and SOURCE2. This derivation was developed by W. Nestor and was originally included in ref. 2 . It is included in this appendix for completeness.

The FLOTHRU computer code calculates releases of radionuclides as a result of diffusion. This code represents the diffusion of contamination from grouted waste materials to the outside surface of a disposal facility. The disposal facility is modeled as a two-slab system. The inner slab-representing the grouted waste-is initially uniformly contaminated; the outer slab-representing the concrete components of vaults, silos, or wells-is initially uncontaminated.

Assume that we have a two-layer slab with the inner layer of half-thickness a, initially containing a contaminate with concentration $C_{o}$ and decay constant $\lambda_{d}$ and with the outer layer of thickness $b-a$, initially uncontaminated. We will write $C_{1}$ for the concentration in the inner layer and $C_{2}$ for the concentration in the outer layer.

The diffusion equation for the inner layer is

$$
\frac{\partial C_{1}}{\partial t}=D_{1} \frac{\partial^{2} C_{1}}{\partial x^{2}}-\lambda_{d} C_{1}
$$

where

$\mathrm{C}_{1}=$ concentration of contaminant in the inner layer $\left(\mathrm{g} / \mathrm{cm}^{3}\right)$,

$t=$ time $(s)$,

$D_{1}=$ effective diffusion coefficient for the contaminant in layer $1\left(\mathrm{~cm}^{2} / \mathrm{s}\right)$,

$\mathrm{x}=$ spatial position $(\mathrm{cm})$, and

$\lambda_{\mathrm{d}} \quad=$ radioactive decay constant $\left(\mathrm{s}^{-1}\right)$.

Similarly, a diffusion equation can be written for the outer layer:

$$
\frac{\partial C_{2}}{\partial t}=D_{2} \frac{\partial^{2} C_{2}}{\partial x^{2}}-\lambda_{d} C_{2}
$$


where

$\mathrm{C}_{2}=$ concentration of contaminant in the outer layer $\left(\mathrm{g} / \mathrm{cm}^{3}\right)$ and

$\mathrm{D}_{2}=$ effective diffusion coefficient for the contaminant in layer $2\left(\mathrm{~cm}^{2} / \mathrm{s}\right)$.

Equations (A.1) and (A.2) can be solved with appropriate initial and boundary conditions. In this case, the initial conditions are

$$
C_{1}(x, 0)=C_{0} \text { for } 0 \leq x<a
$$

and

$$
C_{2}(x, 0)=0 \text { for } a \leq x<b \text {. }
$$

The boundary conditions are

$$
\begin{aligned}
& \left.\frac{\partial C_{1}}{\partial x}\right|_{x=0}=0, \\
& c_{2}(b, t)=0, \\
& c_{1}(a, t)=c_{2}(a, t),
\end{aligned}
$$

and

$$
\left.D_{1} \frac{\partial C_{1}}{\partial x}\right|_{x=2}=\left.D_{2} \frac{\partial C_{2}}{\partial x}\right|_{x=a}
$$


Taking the Laplace transform of the differential equations [i.e., Eqs. (A.1) and (A.2)], we obtain

$$
D_{1} \frac{d^{2} \overline{C_{1}}}{d x^{2}}-\lambda_{d} \overline{C_{1}}=s \overline{C_{1}}-C_{0}
$$

and

$$
D_{2} \frac{d^{2} \overline{C_{2}}}{d x^{2}}-\lambda_{d} \overline{C_{2}}=s \overline{C_{2}}
$$

Solutions to the ordinary differential equations are

$$
\overline{C_{1}}(x)=A_{1}(s) \cosh \left(x \sqrt{\frac{s+\lambda_{d}}{D_{1}}}\right)+\frac{C_{0}}{s+\lambda_{d}}
$$

and.

$$
\overline{C_{2}}(x)=A_{2}(s) \sinh \left[(b-x) \sqrt{\frac{s+\lambda_{d}}{D_{2}}}\right]
$$

Note that these solutions satisfy the transformed boundary conditions

$$
\left.\frac{d \overline{C_{1}}}{d x}\right|_{x=0}=0
$$


and

$$
\overline{C_{2}}(b)=0
$$

Applying the transformed boundary conditions at $x=a$, we obtain

$$
\frac{C_{0}}{s+\lambda_{d}}+A_{1}(s) \cosh \left(\sqrt[a]{\frac{s+\lambda_{d}}{D_{1}}}\right)=A_{2}(s) \sinh \left[(b-a) \sqrt{\frac{s+\lambda_{d}}{D_{2}}}\right]
$$

and

$$
D_{1} A_{1}(s) \sqrt{\frac{s+\lambda_{d}}{D_{1}}} \sinh \left(\sqrt[a]{\frac{s+\lambda_{d}}{D_{1}}}\right)=-D_{2} A_{2}(s) \sqrt{\frac{s+\lambda_{d}}{D_{2}}} \cosh \left[(b-a) \sqrt{\frac{s+\lambda_{d}}{D_{2}}}\right] .
$$

Since we wish to find the transform of the release rate $a t x=b$, we solve the second equation for $A_{1}(s)$ in terms of $A_{2}(s)$, and substitute the result in the first equation to solve for $A_{2}(s)$. Let

$$
P_{1}=\sqrt{\frac{s+\lambda_{d}}{D_{1}}}
$$

and

$$
P_{2}=\sqrt{\frac{s+\lambda_{d}}{D_{2}}}
$$


We then obtain

$$
A_{2}(s)=\frac{C_{0}}{s+\lambda_{d}} \frac{\sinh \left(a p_{1}\right)}{\sinh \left[(b-a) p_{2}\right] \sinh \left(a p_{1}\right)+\sqrt{D_{2} / D_{1}} \cosh \left[(b-a) p_{2}\right] \cosh \left(a p_{1}\right)} .
$$

The transformed release rate at $x=b$ is

$$
\bar{q}(s)=-\left.D_{2} \frac{d \overrightarrow{C_{2}}}{d x}\right|_{x=b}=D_{2} \sqrt{\frac{s+\lambda_{d}}{D_{2}}} A_{2}(s)
$$

or

$$
\bar{q}(s)=\frac{C_{0}}{P_{2}} \frac{\sinh \left(a p_{1}\right)}{\sinh \left[(b-a) p_{2}\right] \sinh \left(a p_{1}\right)+\sqrt{D_{2} / D_{1}} \cosh \left[(b-a) p_{2}\right] \cosh \left(a p_{1}\right)},
$$

so that

$$
q(t)=C_{0} e^{-\lambda_{d} t} g(t)
$$


with

$$
\bar{g}(s)=\frac{\sinh \left(a \sqrt{s / D_{1}}\right) / \sqrt{s / D_{2}}}{\sinh \left[(b-a) \sqrt{s / D_{2}}\right] \sinh \left(a \sqrt{s / D_{1}}\right)+\kappa \cosh \left[(b-a) \sqrt{s / D_{2}}\right] \cosh \left(a \sqrt{s / D_{1}}\right)}
$$

where $k=\sqrt{D_{2} / D_{1}}$.

The zeros of the denominator are all on the imaginary axis; thus, we write

$$
\begin{gathered}
a \sqrt{s_{n} / D_{1}}=i x_{n}, \\
(b-a) \sqrt{s_{n} / D_{1}}=i \alpha x_{n},
\end{gathered}
$$

so that

$$
\alpha=\frac{b-a}{\kappa a}
$$

We then need to solve the transcendental equation

$$
f(x)=k \cos (x) \cos (\alpha x)-\sin (x) \sin (\alpha x)=0 .
$$


The derivatives of $f(x)$ are

$$
\begin{gathered}
f^{\prime}(x)=-(k+\alpha) \sin (x) \cos (\alpha x)-(1+\kappa \alpha) \cos (x) \sin (\alpha x) \\
f^{\prime \prime}(x)=\left(\alpha^{2}+2 \alpha \kappa+1\right) \sin (x) \sin (\alpha x)-\left[\left(\alpha^{2}+1\right) k+2 \alpha\right] \cos (x) \cos (\alpha x), \\
f^{\prime \prime \prime}(x)=C_{1} \cos (x) \sin (\alpha x)+C_{2} \sin (x) \cos (\alpha x),
\end{gathered}
$$

where

$$
C_{1}=\alpha^{3} k+3 \alpha^{2}+3 \alpha \kappa+1
$$

and

$$
C_{2}=\alpha^{3}+3 \alpha^{2} \kappa+3 \alpha+\kappa
$$

We have plotted $f(x)$ for a few values of $a, b, D_{1}$, and $D_{2}$ in Figs. A.1 through A.3. We note that the first part of the curves is similar to a cosine curve; we approximate

$$
\begin{aligned}
f(x) & =\kappa \cos (\gamma x), \\
f^{\prime \prime}(x) & =-\gamma^{2} \kappa \cos (\gamma x),
\end{aligned}
$$

and 


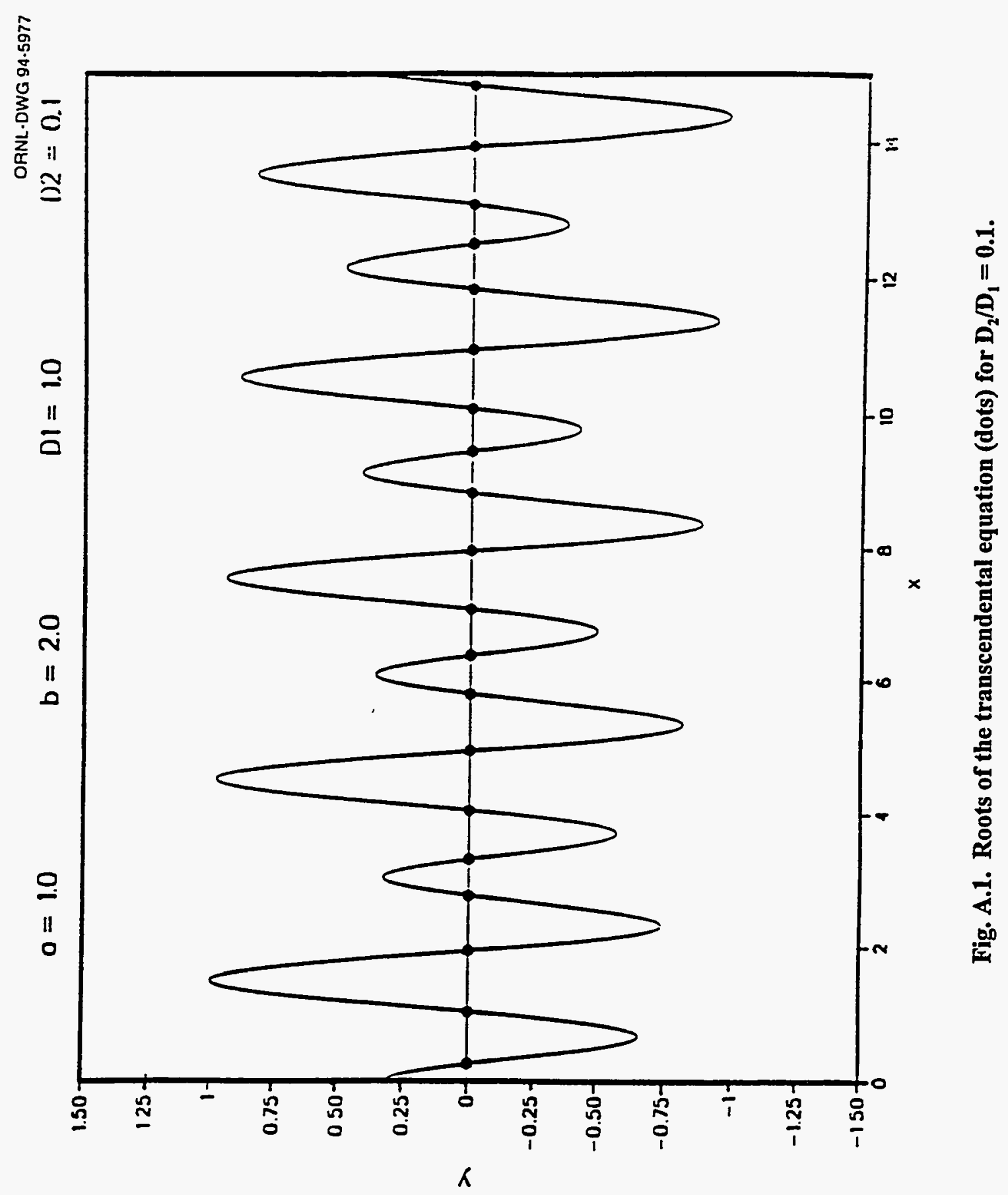




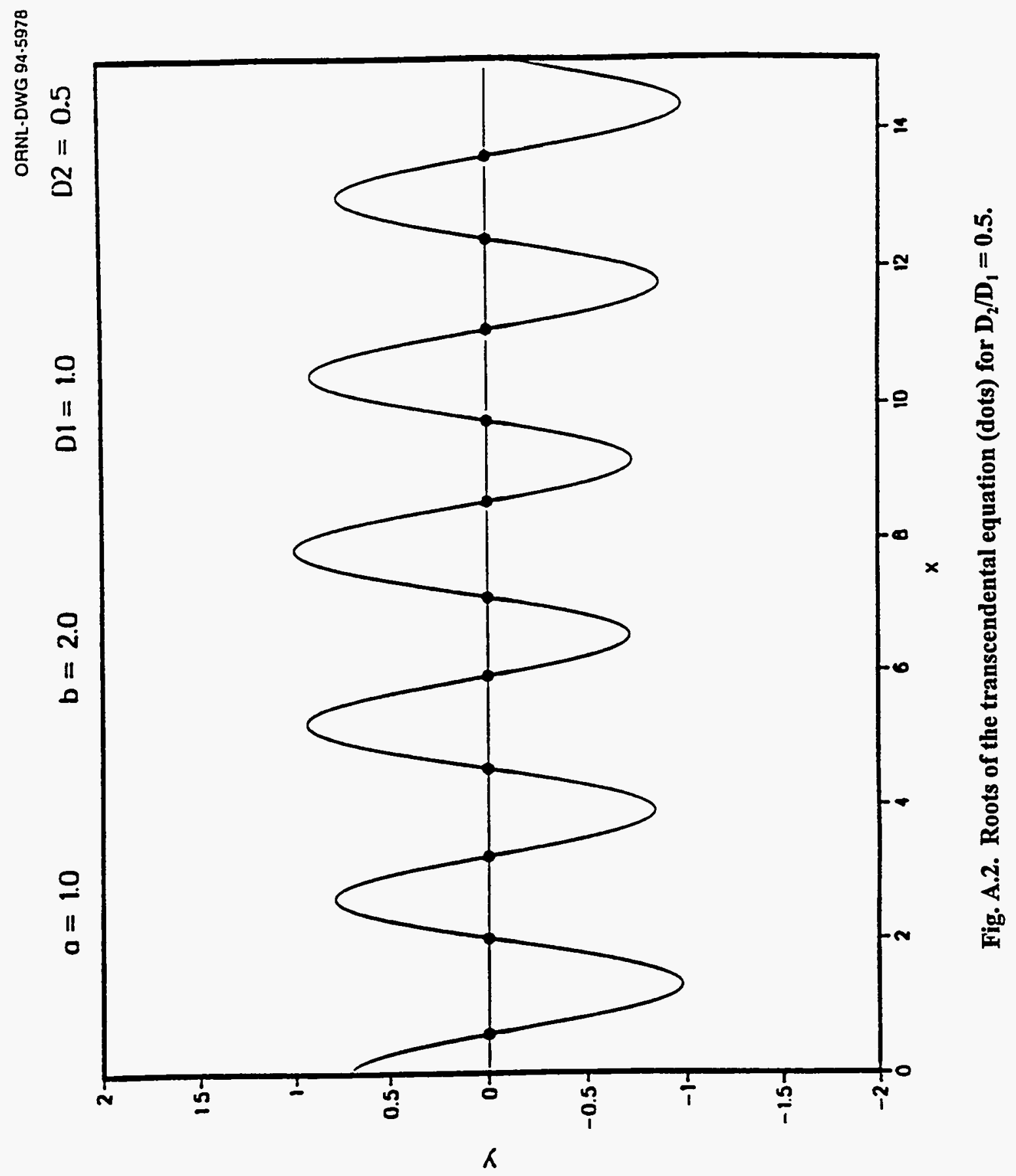




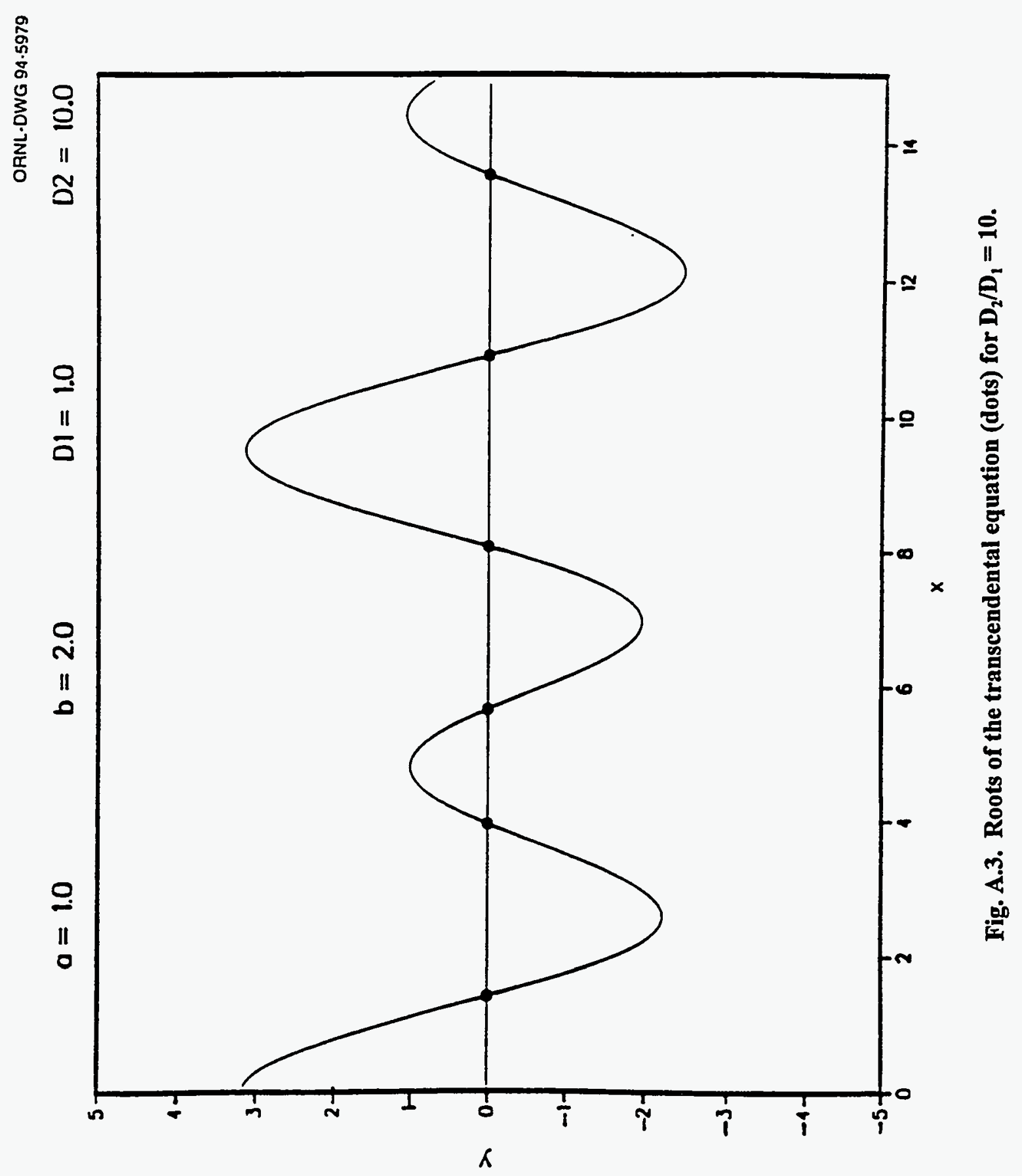




$$
\gamma=\sqrt{\frac{-f^{\prime \prime}(0)}{f(0)}}=\sqrt{\frac{\left(\alpha^{2}+1\right) \kappa+2 \alpha}{k}},
$$

and, for a starting estimate for the first root, we use $x_{1}=\pi / 2 \gamma$. We show a few values of the first root and the number of Newton-Raphson iterations needed to reduce the relative error to $5 \times 10^{-9}$ in Table A.1. Between successive higher roots, the curves resemble sine curves. We approximate

$$
\begin{gathered}
f(x)=A \sin (\gamma x), \\
f^{\prime}(x)=\gamma A \cos (\gamma x),
\end{gathered}
$$

and

$$
f^{\prime \prime \prime}(x)=-\gamma^{3} A \cos (\gamma x)
$$

\begin{tabular}{|c|c|c|c|c|c|c|c|c|}
\hline \multirow{2}{*}{$\kappa$} & \multicolumn{8}{|c|}{$\alpha$} \\
\hline & 0.05 & & 0.10 & & 0.15 & & 0.20 & \\
\hline 0.1 & 1.076583 & 3 & 0.859559 & 4 & 0.734800 & 4 & 0.651694 & 4 \\
\hline 0.2 & 1.264279 & 3 & 1.075710 & 3 & 0.949012 & 4 & 0.857237 & 4 \\
\hline 0.5 & 1.428653 & 3 & 1.312642 & 3 & 1.217087 & 3 & 1.137256 & 3 \\
\hline 1.0 & 1.495997 & 1 & 1.427997 & 1 & 1.365910 & 1 & 1.308997 & 1 \\
\hline 2.0 & 1.532429 & 2 & 1.495596 & 3 & 1.459970 & 3 & 1.425310 & 3 \\
\hline 5.0 & 1.555214 & 3 & 1.539765 & 3 & 1.524287 & 3 & 1.508631 & 3 \\
\hline 10.0 & 1.562966 & 3 & 1.555120 & 3 & 1.547167 & 3 & 1.539016 & 3 \\
\hline
\end{tabular}

Table A.1. First root of $x \cos x \cos \alpha x-\sin x \sin \alpha x^{2}$

'The integer to the right of each root entry is the number of Newton-Raphson iterations required. 
If $x_{n}$ is a root, we evaluate

$$
\gamma=\sqrt{\frac{-f^{\prime \prime \prime}\left(x_{n}\right)}{f^{\prime}\left(x_{n}\right)}},
$$

and for a starting estimate of the next root, we use

$$
\mathrm{x}_{\mathrm{n}+1}=\mathrm{x}_{\mathrm{n}}+\frac{\pi}{\gamma}
$$

Typically, three or four Newton-Raphson iterations are sufficient to obtain convergence to a relative error of $10^{-8}$.

The function $\overline{\mathrm{g}}(\mathrm{s})$ is of the form

$$
\overline{\mathbf{g}}(\mathbf{s})=\frac{P(\mathbf{s})}{\mathrm{Q}(\mathbf{s})}
$$

with

$$
P(s)=\frac{\sinh \left(a \sqrt{s / D_{1}}\right)}{\sqrt{s / D_{2}}}
$$

and

$$
Q(s)=\sinh \left[(b-a) \sqrt{s / D_{2}}\right] \sinh \left(a \sqrt{s / D_{1}}\right)+\kappa \cosh \left[(b-a) \sqrt{s / D_{2}}\right] \cosh \left(a \sqrt{s / D_{1}}\right) .
$$


The inverse transform is then

$$
g(t)=\sum_{n=1}^{\infty} \frac{P\left(s_{n}\right)}{Q^{\prime}\left(s_{n}\right)} e^{-s_{n} t},
$$

where the $s_{n}$ are the roots (i.e., $\left.x_{n}\right)$ of $Q(s)$. Carrying out the differentiation of $Q(s)$ and substituting the values of $s_{n}$, we obtain

$$
g(t)=2 D_{1} \kappa a \sum_{n=1}^{\infty} \frac{\sin \left(x_{n}\right) e^{-D_{1} x_{a}^{2} t / z^{2}}}{\left[\frac{a(b-a)}{k}+\kappa a^{2}\right] \cos \left(\alpha x_{n}\right) \sin \left(x_{n}\right)+a b \sin \left(\alpha x_{n}\right) \cos \left(x_{n}\right)} .
$$

The cumulative amount released remaining at time $t$ is

$$
R(t)=\int_{0}^{t} q(\tau) e^{-\lambda_{d}(t-\tau)} d \tau
$$

Since $q(\tau)=C_{0} e^{-\lambda_{d} \tau} g(\tau)$,

$$
R(t)=2 \mathrm{KaC}_{0} e^{-\lambda_{a^{2}}} \sum_{n=1}^{\infty} \frac{\left(1-e^{-D_{1} x_{2}^{2} t / n^{2}}\right) \sin \left(x_{n}\right)}{x_{n}^{2}\left[(\alpha+\kappa) \cos \left(\alpha x_{n}\right) \sin \left(x_{n}\right)+\frac{b}{a} \sin \left(\alpha x_{n}\right) \cos \left(x_{n}\right)\right]}
$$


When $\lambda_{d}=0, \lim _{t \rightarrow \infty} \frac{R(t)}{a C_{0}}=1$, so that

$$
\sum_{n=1}^{\infty} \frac{\sin \left(x_{n}\right)}{x_{n}^{2}\left[(\alpha+\kappa) \cos \left(\alpha x_{n}\right) \sin \left(x_{n}\right)+\frac{b}{a} \sin \left(\alpha x_{n}\right) \cos \left(x_{n}\right)\right]}=\frac{1}{2 k}
$$

$$
\frac{R(t)}{a C_{0}}=e^{-\lambda_{d} s^{2}}\left[1-2 \kappa \sum_{n=1}^{\infty} \frac{e^{-D_{1} x_{n}^{2} / a^{2}} \sin \left(x_{n}\right)}{x_{n}^{2}\left[(\alpha+K) \cos \left(\alpha x_{n}\right) \sin \left(x_{n}\right)+\frac{b}{a} \sin \left(\alpha x_{n}\right) \cos \left(x_{n}\right)\right]}\right] .
$$

At small t, Eq. (A.49) has two serious computational defects. The series is slowly convergent, and the sum is nearly equal to $1(2 \kappa)$, so that serious loss of significant figures will occur in the subtraction. To develop an alternative expression for small time, we note that

$$
\bar{R}(s)=\frac{\bar{q}(s)}{s+\lambda_{d}}
$$

and

$$
R(t)=C_{0} e^{-\lambda_{d}{ }^{2}} h(t),
$$


where

$$
\bar{h}(s)=\frac{\sqrt{D_{2}} \sinh \left(a \sqrt[s / D_{1}]{ }\right)}{s^{3 / 2}\left\{\sinh \left[(b-a) \sqrt{s / D_{2}}\right] \sinh \left(a \sqrt{s / D_{1}}\right)+\kappa \cosh \left[(b-a) \sqrt{s / D_{2}}\right] \cosh \left(a \sqrt{s / D_{1}}\right)\right\}}
$$

If we express all hyperbolic functions in Eq. (A.52) as exponentials and multiply numerator and denominator by

$$
\exp \left(-a \sqrt{s / D_{1}}\right) \exp \left[-(b-a) \sqrt{s / D_{2}}\right]
$$

we obtain, to first order,

$$
\bar{h}(s) \propto \frac{2 \sqrt{D_{2}}}{1+K} \frac{e^{-(b-a) \sqrt{3 / D_{2}}}}{s^{3 / 2}},
$$

so that

$$
\frac{R(t)}{a C_{0}} \propto \frac{4}{a(1+k)} \sqrt{D_{2} t} \operatorname{ierfc}\left(\frac{b-a}{2 \sqrt{D_{2} t}}\right)
$$

where ierfc $(x)$ is the integrated complementary error function. ${ }^{1}$ To compare the two solutions we show in Table A.2 the first 19 roots of the transcendental equation with the calculated values of $f(x)$ 
and $f^{\prime}(x)$; the column headed IT shows the number of Newton-Raphson iterations required. In the footnotes of the table, we have listed the sum of the first 19 terms of the series at $t=0$, which should have the value $1(2 \kappa)$. The time, $T$, makes the argument of the integrated complementary error function equal to unity.

Table A.2. Comparison of series and alternate solutions ${ }^{a, b}$

\begin{tabular}{|c|c|c|c|c|}
\hline $\mathbf{n}$ & $\mathrm{IT}^{c}$ & $x_{n}$ & $f\left(x_{n}\right)$ & $f^{\prime}\left(x_{n}\right)$ \\
\hline 1 & 2 & $4.18879 \times 10^{0}$ & $2.47794 \times 10^{-16}$ & $1.12500 \times 10^{0}$ \\
\hline 2 & 2 & $6.98132 \times 10^{0}$ & $-5.54298 \times 10^{-16}$ & $-1.12500 \times 10^{0}$ \\
\hline 3 & 2 & $9.77384 \times 10^{0}$ & $6.49762 \times 10^{-16}$ & $1.12500 \times 10^{0}$ \\
\hline 4 & 1 & $1.25664 \times 10^{1}$ & $2.74089 \times 10^{-9}$ & $-1.12500 \times 10^{0}$ \\
\hline 5 & 0 & $1.53589 \times 10^{1}$ & $-2.74098 \times 10^{-9}$ & $1.12500 \times 10^{0}$ \\
\hline 6 & 1 & $1.81514 \times 10^{1}$ & $2.74088 \times 10^{-9}$ & $-1.12500 \times 10^{0}$ \\
\hline 7 & 1 & $2.09440 \times 10^{1}$ & $-1.21669 \times 10^{-7}$ & $1.12500 \times 10^{0}$ \\
\hline 8 & 2 & $2.37365 \times 10^{1}$ & $1.36664 \times 10^{-16}$ & $-1.12500 \times 10^{0}$ \\
\hline 9 & 2 & $2.65290 \times 10^{1}$ & $1.63999 \times 10^{-16}$ & $1.12500 \times 10^{0}$ \\
\hline 10 & 2 & $2.93215 \times 10^{1}$ & $-4.80844 \times 10^{-17}$ & $-1.12500 \times 10^{0}$ \\
\hline 11 & 2 & $3.21141 \times 10^{1}$ & $3.93766 \times 10^{-15}$ & $1.12500 \times 10^{0}$ \\
\hline 12 & 1 & $3.49066 \times 10^{1}$ & $1.21669 \times 10^{-7}$ & $-1.12500 \times 10^{0}$ \\
\hline 13 & 1 & $3.76991 \times 10^{1}$ & $-2.74040 \times 10^{-9}$ & $1.12500 \times 10^{0}$ \\
\hline 14 & 0 & $4.04916 \times 10^{1}$ & $2.74040 \times 10^{-9}$ & $-1.12500 \times 10^{0}$ \\
\hline 15 & 1 & $4.32842 \times 10^{1}$ & $-2.74088 \times 10^{-9}$ & $1.12500 \times 10^{0}$ \\
\hline 16 & 1 & $4.60767 \times 10^{1}$ & $1.21669 \times 10^{-7}$ & $-1.12500 \times 10^{0}$ \\
\hline 17 & 2 & $4.88692 \times 10^{1}$ & $-2.13521 \times 10^{-15}$ & $1.12500 \times 10^{0}$ \\
\hline 18 & 2 & $5.16617 \times 10^{1}$ & $-2.18182 \times 10^{-15}$ & $-1.12500 \times 10^{0}$ \\
\hline 19 & 2 & $5.44543 \times 10^{1}$ & $-2.33385 \times 10^{-15}$ & $1.12500 \times 10^{0}$ \\
\hline
\end{tabular}

$a_{a}=121.92 \mathrm{~cm}, \mathrm{~b}-\mathrm{a}=15.24 \mathrm{~cm}, \mathrm{D}_{1}=\mathrm{D}_{2}=1.10 \times 10^{-6} \mathrm{~cm}^{2} / \mathrm{s}, \mathrm{k}=1, \alpha=0.125$.

${ }^{b}$ Sum of series [Eq. (A.48)] at $t=0: 5.00330 \times 10^{-1}, 1 /(2 \mathrm{~K})=5.00000 \times 10^{-1}$. Sum of series in Eq. (A.49) at $t=\mathrm{T}: 4.96859 \times 10^{-1}$ with last term retained: $2.42018 \times 10^{-9}, \mathrm{~T}=(\mathrm{b}-\mathrm{a})^{2} / 4 \mathrm{D}_{2}$. Calculated release (series method) [Eq. (A.49)]: $6.28182 \times 10^{-3}$. Calculated release (short-time method) [Eq. (A.55)]: $6.28182 \times 10^{-3}$.

$\mathrm{c}_{\mathrm{IT}}$ is the number of Newton-Raphson iterations required for convergence to the root, $x_{n}$. 
In some cases, we will need more than the first term. Assuming that we can neglect the terms involving $D_{1}$, the series is of the form

$$
\bar{h}(s) \propto \frac{2 \sqrt{D_{2}}}{(1+\kappa) s^{3 / 2}} \sum_{n=0}^{\infty} e^{-(2 n+1)(b-z) \sqrt{s / D_{2}}}\left(\frac{1-k}{1+K}\right)^{D},
$$

so that

$$
h(t) \propto \frac{4 \sqrt{D_{2} t}}{(1+k)} \sum_{n=0}^{\infty}\left(\frac{1-k}{1+K}\right)^{n} \operatorname{ierfc}\left[\frac{(2 n+1)(b-a)}{2 \sqrt{D_{2} t}}\right] .
$$

Since ierfc $(10) \approx 10^{-44}$, we sum the series until the relative error is $5 \times 10^{-9}$, or until the argument of the integrated complementary error function is greater than 10 . If more than three terms are required, we use the Aitken delta-squared process to accelerate the convergence.

\section{REFERENCE}

1. J. Crank, The Mathematics of Diffusion, 2d ed., Oxford University Press, Inc., New York, 1993. 


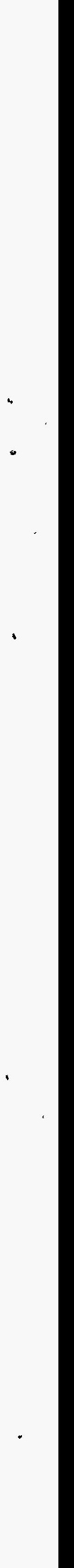


APPENDIX B

GLOSSARY OF SOURCE-CODE PARAMETERS 
,

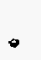

, 


\section{B. GLOSSARY OF SOURCE-CODE PARAMETERS}

The following glossary defines the major terms used in the SOURCE computer codes. Included are variables, arrays and parameter constants as implemented in the main program, functions, and subroutines.

ACOEF Inner slab layer half-thickness (cm)

ALKLCH Fraction of alkalis removed from concrete

AM Radionuclide atomic mass ( $\mathrm{g} / \mathrm{mol})$

ANNPRC Percolation rate in intact concrete (cm/year)

APER Average fracture aperture in concrete members of silo (cm)

ATTK Fraction of original concrete member strength

BCOEF Outer slab layer thickness $(\mathrm{cm})$

BGNDUMP Beginning year for inventory disposal

C1 Carbon dioxide concentration at concrete surface ( $\mathrm{mol} / \mathrm{L})$

CA Calcium content in C-S-H system ( $\mathrm{mol} / \mathrm{L})$

CACON Calcium concentration in C-S-H system (mol/L)

CAGW Calcium concentration in groundwater ( $\mathrm{mol} / \mathrm{L}$ )

$\mathrm{CALCH} \quad$ Fraction of calcium remaining in C-S-H system

CAP Calcium hydroxide concentration in pore solution of concrete $(\mathrm{mol} / \mathrm{L})$

CA_SI Calcium-to-silica ratio in C-S-H system

CASOL Solubility of calcium in groundwater ( $\mathrm{mol} / \mathrm{L})$

CCDNS Density of concrete $\left(\mathrm{g} / \mathrm{cm}^{3}\right)$

CCK Saturated hydraulic conductivity of intact concrete $(\mathrm{cm} / \mathrm{s})$

$\mathrm{CCON} \quad$ Average $\mathrm{CaO}$ concentration in concrete $(\mathrm{mol} / \mathrm{L})$

CCPOR Concrete porosity

CDTSTR Direct tensile strength of concrete (lb/in. $\left.{ }^{2}\right)$

CFA Coefficient used in compressive strength equation

CFB Coefficient used in compressive strength equation

CFF Container failure fraction

CFT1 Year in which steel boxes begin to corrode

CL Chloride concentration in groundwater $(\mathrm{mol} / \mathrm{L})$ 


\begin{tabular}{|c|c|}
\hline CLCON & Concentration of free chloride in concrete $(\mathrm{mol} / \mathrm{L})$ \\
\hline CLHGHT & Vault height (in.) \\
\hline CLLTH & Vault length (in.) \\
\hline CLSTL & Chloride concentration at steel reinforcement $(\mathrm{mol} / \mathrm{L})$ \\
\hline CLWID & Vault width (in.) \\
\hline CMTHK & Concrete member thickness (in.) \\
\hline CNCFRC & Concentrated force on floor of silo or well (lb-in./in.) \\
\hline CNCFRX & Concentrated force on vault floor in $\mathrm{x}$-direction (lb/in.) \\
\hline CNCFRY & Concentrated force on vault floor in y-direction (lb/in.) \\
\hline CNMNTI & Concrete moment of inertia (in. ${ }^{4}$ ) \\
\hline $\mathrm{CO} 2$ & Environmental concentration of carbon dioxide $(\mathrm{mol} / \mathrm{L})$ \\
\hline $\mathrm{CO} 3$ & Carbonate concentration in groundwater $(\mathrm{mol} / \mathrm{L})$ \\
\hline COM28D & Compressive strength of concrete at 28 days $\left(\mathrm{lb} / \mathrm{in}^{2}{ }^{2}\right)$ \\
\hline COMCVX & Concrete cover thickness on compression face in $\mathrm{x}$-direction (in.) \\
\hline COMCVY & Concrete cover thickness on compression face in y-direction (in.) \\
\hline COMSTR & Time-dependent compressive strength of concrete (lb/in. $\left.{ }^{2}\right)$ \\
\hline CONMOD & Modulus of elasticity for concrete $\left(\mathrm{lb} / \mathrm{in}^{2}{ }^{2}\right)$ \\
\hline CONPSN & Poisson's ratio for concrete \\
\hline CONSTR & Concrete strength $\left(\mathrm{lb} / \mathrm{in}^{2}{ }^{2}\right)$ \\
\hline CORVOL & Volume of corrosion product (in. ${ }^{3}$ ) \\
\hline CRBCOF & Carbonation coefficient \\
\hline CRBSOL & Solubility of carbonates in groundwater ( $\mathrm{mol} / \mathrm{L})$ \\
\hline CRFRAC & Fraction of concrete member composed of fractures due to corrosion cracking \\
\hline CRFRCD & Depth of fractures due to corrosion cracking (in.) \\
\hline CRFRCS & Fracture spacing due to corrosion cracking (in.) \\
\hline CRFRCW & Width of fractures due to corrosion cracking \\
\hline CRKMNT & Cracking moment for walls in y-direction (lb-in./in.) \\
\hline CRKMTF & Cracking moment for floor (lb-in./in.) \\
\hline CRKMTR & Cracking moment for roof (lb-in./in.) \\
\hline CRKMTW & Cracking moment for walls in $\mathrm{x}$-direction (lb-in./in.) \\
\hline CRMTIX & Cracking moment of inertia for $\mathrm{x}$-direction (in. ${ }^{4}$ ) \\
\hline CRMTIY & Cracking moment of inertia for $y$-direction (in. ${ }^{4}$ ) \\
\hline
\end{tabular}




\begin{tabular}{|c|c|}
\hline CRPCOF & Creep coefficient \\
\hline CSKSA & Vault surface area $\left(\mathrm{m}^{2}\right)$ \\
\hline CSKVOL & Vault volume $\left(\mathrm{m}^{3}\right)$ \\
\hline CSSTRN & Shrinkage strain of concrete \\
\hline CSSTRS & Stress in steel reinforcement in compression $\left(\mathrm{lb} / \mathrm{in} .^{2}\right)$ \\
\hline CTSTRS & Maximum tangent stress on concrete surface $\left(\mathrm{lb} / \mathrm{in} .{ }^{2}\right)$ \\
\hline CVRDNS & Density of earthen cover $\left(\mathrm{g} / \mathrm{cm}^{3}\right)$ \\
\hline CVRTHK & Thickness of earthen cover (in.) \\
\hline DCFT & Time required for complete corrosion of steel boxes (year) \\
\hline DECAY & Radioactive decay correction factor \\
\hline DEFT & Time required for complete failure of epoxy coating (year) \\
\hline DFALK & Effective diffusivity of alkalis in concrete $\left(\mathrm{m}^{2} / \mathrm{s}\right)$ \\
\hline DFCAOH & Effective diffusivity of calcium hydroxide in concrete $\left(\mathrm{m}^{2} / \mathrm{s}\right)$ \\
\hline $\mathrm{DFCL}$ & Effective diffusivity of chloride ions in concrete $\left(\mathrm{m}^{2} / \mathrm{s}\right)$ \\
\hline $\mathrm{DFCO} 2$ & Effective diffusivity of carbon dioxide in concrete $\left(\mathrm{m}^{2} / \mathrm{s}\right)$ \\
\hline DFCON & Effective diffusivity of radionuclide in concrete $\left(\mathrm{m}^{2} / \mathrm{s}\right)$ \\
\hline DFO2 & Effective diffusivity of oxygen in concrete $\left(\mathrm{m}^{2} / \mathrm{s}\right)$ \\
\hline DFSO4 & Effective diffusivity of sulfate ions in concrete $\left(\mathrm{m}^{2} / \mathrm{s}\right)$ \\
\hline DFWST & Effective diffusivity of radionuclide in waste $\left(\mathrm{m}^{2} / \mathrm{s}\right)$ \\
\hline DHYDR & Fraction of hydration of Portland cement \\
\hline DLFT & Time required for complete corrosion of corrugated steel liners (year) \\
\hline DPCRB & Depth of carbonation (cm) \\
\hline DPM & Number of days per month \\
\hline DWFT & Time required for complete corrosion of well wall (year) \\
\hline EFT1 & Year in which epoxy coating on steel reinforcement begins to fail \\
\hline EMOLE & Moles of radioactive element available for leaching \\
\hline ENDDUMP & Ending year for inventory disposal \\
\hline FCASK & Fraction of vaults that have undergone cracking \\
\hline FILENAM & Name of input and output files \\
\hline FLANGL & Friction angle of waste (deg) \\
\hline FLAPER & Average fracture aperture in floor $(\mathrm{cm})$ \\
\hline
\end{tabular}


FLDSTX Distance from steel reinforcement in tension to compression surface of concrete in floor in $\mathrm{x}$-direction (in.)

FLDSTY Distance from steel reinforcement in tension to compression surface of concrete in floor in y-direction (in.)

FLFDPX Depth of fractures due to bending in floor $\mathrm{x}$-direction (in.)

FLFDPY Depth of fractures due to bending in floor $y$-direction (in.)

FLFRAC Fraction of floor that consists of fractures

FLFSPX Spacing of fractures due to bending in floor in $\mathrm{x}$-direction (in.)

FLFSPY Spacing of fractures due to bending in floor in y-direction (in.)

FLSHR Maximum shear force in silo floor (lb/in.)

FLUSTX Ultimate strength of floor in $\mathrm{x}$-direction (lb/in. ${ }^{2}$ )

FLUSTY Ultimate strength of floor in $y$-direction (lb/in. ${ }^{2}$ )

FLWSHR Maximum shear force in well floor (lb/in.)

FLXMNT Bending moment for vault or silo floor in $\mathrm{x}$-direction (lb-in./in.)

FLXSHR Shear force for vault floor in $\mathrm{x}$-direction (lb/in.)

FLYMNT Bending moment for vault or silo floor in $y$-direction (lb-in./in.)

FLYSHR Shear force for vault floor in y-direction (lb/in.)

FNAME First extension name of input and output files

FRAC Fraction of concrete member in silo that consists of fractures

FRCWDX Fracture width of cracks due to bending in the $\mathrm{x}$-direction (in.)

FRCWDY Fracture width of cracks due to bending in the y-direction (in.)

FWXMNT Bending moment for well floor in x-direction (lb-in./in.)

FWYMNT Bending moment for well floor in y-direction (lb-in./in.)

HLIFE Radionuclide half-life (year)

HYDRLD Hydrostatic pressure on wall of disposal unit (lb/in. $\left.{ }^{2}\right)$

ICL Corrosion initiation time for concrete member due to chloride penetration (year)

$\mathrm{ICO} 2$ Corrosion initiation time for concrete member due to carbonation (year)

ICRACK Flag indicating that concrete member has cracked

ICRFLG Flag indicating steel reinforcement depassivation

IDFLAG Disposal unit identification flag

IFAIL Flag indicating that structural member of well has failed

IFLAGS Flag indicating that solubility constraints were exceeded in silo or well 
IFLAGS1 Flag indicating that solubility constraints were exceeded in intact vaults

IFLAGS2 Flag indicating that solubility constraints were exceeded in cracked vaults

IFRQ1 Option for frequency of printing recharge summary (year)

IFRQ2 Option for frequency of printing lateral summary (year)

IFRQ3 Option for frequency of printing concrete analyses summary (year)

IFRQ4 Option for frequency of printing inventory, leach rate, and cumulative leached summary (year)

IFRQ5 Option for frequency of printing advection, diffusion, and leach rate summary (year)

IFRQ6 Option for frequency of printing inventory, advection, and diffusion for intact vaults summary (year)

IFRQ7 Option for frequency of printing inventory, advection, and diffusion for cracked vaults summary (year)

INTCTRL Year institutional control period ends

IPRINT Option to print input data summary

IPRN1 Option to print recharge summary

IPRN2 Option to print lateral summary

IPRN3 Option to print concrete analyses summary

IPRN4 Option to print inventory, leach rate, and cumulative leached summary

IPRN5 Option to print advection, diffusion, and leach rate summary

IPRN6 Option to print inventory, advection, and diffusion for intact vaults summary

IPRN7 Option to print inventory, advection, and diffusion for cracked vaults summary

ISAVE Flag indicating number of concrete members of vaults which have cracked

ISAVE1 Flag indicating number of concrete members of silo which have cracked

ISAVE2 Flag indicating number of structural members of well which have failed

ISPL Flag indicating concrete member has spalled due to corrosion

LYR Number of layers of vaults in tumulus

MAXNUC Maximum number of nuclides that can be considered

MAXYR Maximum number of years that can be simulated

NCCASK Number of vaults which have undergone cracking

NMEMBER Number of structural members to be considered

NOCLX Scale factor for calculating floor overhang in $\mathrm{X}$-direction

NOCLY Scale factor for calculating floor overhang in $y$-direction 
NONCLD Number of radionuclides considered in simulation

NUCLID Radionuclide name

NUMCSK Number of vaults in tumulus

NUMLTH Number of vaults along length of tumulus

NUMWID Number of vaults along width of tumulus

NYEARS Length of simulation (year)

$\mathrm{O} 2$ Oxygen concentration in groundwater $(\mathrm{mol} / \mathrm{L})$

O2FLUX Oxygen flux at steel reinforcement (mol/year)

O2GRD Oxygen concentration gradient across concrete cover $\left(\mathrm{mol} / \mathrm{m}^{4}\right)$

$\mathrm{OH} \quad$ Hydroxide ion concentration in concrete pore solution ( $\mathrm{mol} / \mathrm{L}$ )

OMMTHK Initial concrete member thickness (in.)

OSTLRD Initial steel reinforcement radius (in.)

OSTTKC Initial thickness of corrugated steel liner on compression face of silo wall (in.)

OSTTKT Initial thickness of corrugated steel liner on tension face of silo wall (in.)

OTNCVX Initial concrete cover on tension face in $\mathrm{x}$-direction (in.)

OTNCVY Initial concrete cover on tension face in y-direction (in.)

OVRHNG Floor overhang measured from centerline of wall (in.)

PADCRK Flag indicating concrete pad has failed

PBOTCOV Concrete cover thickness from the center of the bottom row of steel reinforcing rods to the bottom of the pad (in.)

PCONSTR Compressive strength of pad concrete (lb/in. ${ }^{2}$ )

$\mathrm{PH} \quad$ Concrete $\mathrm{pH}$

PHBEG Initial concrete $\mathrm{pH}$

PHGW Groundwater pH

PHS Groundwater $\mathrm{pH}$ at calcium carbonate saturation

PIFF Pad initial functionality fraction (unitless)

PIPSHR Allowable shear in well wall (lb/in. ${ }^{2}$ )

PSTL Internal pressure on concrete due to corrosion (lb/in. $\left.{ }^{2}\right)$

PSTLMOD Modulus of elasticity of steel reinforcement (lb/in. ${ }^{2}$ )

PSTLRAD Radius of pad steel reinforcement (in.)

PSTLSPC Spacing between steel reinforcing rods in pad (in.)

PSTLYLD Yield strength of steel reinforcement (lb/in. ${ }^{2}$ ) 
PUSRC Buckling strength of well wall (lb/in.)

PUSTR Ultimate strength of well wall (lb/in. ${ }^{2}$ )

PWTCMNT Weight of pad cement per unit volume concrete $\left(\mathrm{kg} / \mathrm{m}^{3}\right)$

Q Radionuclide inventory available for leaching (g)

QCASK Initial radionuclide inventory ( $\mathrm{g} / \mathrm{vault}$ )

QCASK1 Radionuclide inventory in intact vaults ( $g$ /intact vault)

QCASK2 Radionuclide inventory in cracked vaults (g/cracked vault)

QK1 Radionuclide inventory available for leaching from intact vaults (g)

QK2 Radionuclide inventory available for leaching from cracked vaults (g)

QSW Radionuclide inventory in silo or well $(\mathrm{g})$

RATMOD Ratio of modulus of elasticity of steel and modulus of elasticity of concrete

REFYEAR Reference year for beginning the simulation

REL Monthly leach rate due to diffusion ( $\mathrm{g} / \mathrm{month}$ )

RFAPER Average fracture aperture in roof $(\mathrm{cm})$

RFDSTX Distance from steel reinforcement in tension to compression surface of concrete in roof in X-direction (in.)

RFDSTY Distance from steel reinforcement in tension to compression surface of concrete in roof in $y$-direction (in.)

RFFDPX Depth of fractures due to bending in roof $\mathrm{x}$-direction (in.)

RFFDPY Depth of fractures due to bending in roof $y$-direction (in.)

RFFRAC Fraction of roof that consists of fractures

RFFSPX Spacing of fractures due to bending in roof in $x$-direction (in.)

RFFSPY Spacing of fractures due to bending in roof in y-direction (in.)

RFSHR Maximum shear force in silo roof (lb/in.)

RFUSTX Ultimate strength of roof in X-direction (lb/in. ${ }^{2}$ )

RFUSTY Ultimate strength of roof in y-direction (lb/in. ${ }^{2}$ )

RFWSHR Maximum shear force in well roof (lb/in.)

RFXMNT Bending moment for vault or silo roof in $\mathrm{x}$-direction (lb-in./in.)

RFXRXN Roof reaction in $\mathrm{x}$-direction (lb/in.)

RFXSHR Shear force for vault roof in $x$-direction (lb/in.)

RFYMNT Bending moment for vault or silo roof in y-direction (lb-in./in.)

RFYRXN Roof reaction in y-direction (lb/in.) 
RFYSHR Shear force for vault roof in y-direction (lb/in.)

$\mathrm{RLCH} \quad$ Radionuclide release to recharge component (g)

RUPMOD Modulus of rupture of concrete (lb/in. $\left.{ }^{2}\right)$

RWXMNT bending moment for well roof in $\mathrm{x}$-direction (lb-in./in.)

RWYMNT Bending moment for well roof in y-direction (lb-in./in.)

SFRCDX Depth of fractures due to shear cracking in x-direction (in.)

SFRCDY Depth of fractures due to shear cracking in $y$-direction (in.)

SFRCSX Spacing of fractures due to shear cracking in $x$-direction (in.)

SFRCSY Spacing of fractures due to shear cracking in $y$-direction (in.)

SFRCWX Width of fractures due to shear cracking in $x$-direction (in.)

SFRCWY Width of fractures due to shear cracking in y-direction (in.)

SHRSTR Shear strength (lb/in. $\left.{ }^{2}\right)$

SI Silica concentration in C-S-H system $(\mathrm{mol} / \mathrm{L})$

SILRAD Radius of silo (in.)

SITARA Disposal facility drainage area $\left(\mathrm{m}^{2}\right)$

SLANGL Friction angle of soil backfill around disposal facility (deg)

SLDNS Density of soil backfill around disposal facility $\left(\mathrm{g} / \mathrm{cm}^{3}\right)$

SLFI Concrete loss from inside of disposal facility due to sulfate attack $(\mathrm{cm})$

SLFO Concrete loss from outside of disposal facility due to sulfate attack $(\mathrm{cm})$

SLHGHT Height of silo (in.)

SLK Saturated hydraulic conductivity of soil backfill around disposal facility $(\mathrm{cm} / \mathrm{s})$

SLKR Saturated hydraulic conductivity of the soil under the disposal facility $(\mathrm{cm} / \mathrm{s})$

SO4I Sulfate ion concentration in groundwater inside disposal facility $(\mathrm{mol} / \mathrm{L})$

SO4O Sulfate ion concentration in groundwater outside disposal facility $(\mathrm{mol} / \mathrm{L})$

SOL Radionuclide solubility (mol/L)

SSTRED Strength reduction factor for silo wall

STARCM Area of steel reinforcement in compression (in. ${ }^{2}$ )

STARTN Area of steel reinforcement in tension (in. ${ }^{2} / \mathrm{in}$.)

STLARA Area of steel reinforcement subject to corrosive attack $\left(\mathrm{m}^{2}\right)$

STLCOR Thickness of corrosion layer around steel reinforcement (in.)

STLDNS Density of cast iron used in well construction $\left(\mathrm{g} / \mathrm{cm}^{3}\right)$

STLMOD Modulus of elasticity of steel reinforcement (lb/in. $\left.{ }^{2}\right)$ 
STLPSN Poisson's ratio for cast iron

STLRAD Radius of steel reinforcement (in.)

STLSPC Spacing of steel reinforcement (in.)

STLYLD Yield strength of steel reinforcement (lb/in. $\left.{ }^{2}\right)$

STRRED Strength reduction factor

STSTRS Tangent stress upon concrete at surface of steel reinforcement (lb/in. $\left.{ }^{2}\right)$

STTKCM Thickness of corrugated steel liner on compression face of silo wall (in.)

STTKTN Thickness of corrugated steel liner on tension face of silo wall (in.)

SUBMOD Modulus of the subgrade reaction (lb/in. ${ }^{3}$ )

TDS Total dissolved solids in groundwater (ppm)

TEMP Groundwater temperature $\left({ }^{\circ} \mathrm{C}\right)$

TENCVX Concrete cover thickness on tension face in $\mathrm{X}$-direction (in.)

TENCVY Concrete cover thickness on tension face in y-direction (in.)

TITLE Title of simulation

TLEACH1 Leach rate from intact vaults (g/year)

TLEACH2 Leach rate from cracked vaults (g/year)

TTLWAT Volume of water percolating through the disposal facility $\left(\mathrm{m}^{3}\right)$

UNFLD Uniform load on wall of disposal facility (lb/in. $\left.{ }^{2}\right)$

VCR Cracking shear (lb/in. ${ }^{2}$ )

VOLFE Volume of iron (in. ${ }^{3}$ )

W1APER Average fracture aperture in vault wall $1(\mathrm{~cm})$

W1CMFY Compressive force on vault wall 1 in $y$-direction (lb/in.)

W1FDPX Wall 1 crack depth in $x$-direction (in.)

W1FDPY Wall 1 crack depth in y-direction (in.)

W1FRAC Fraction of vault wall 1 that consists of fractures

W1FSPX Wall 1 crack spacing in $x$-direction (in.)

W1FSPY Wall 1 crack spacing in y-direction (in.)

W1XMNT Bending moment for vault wall 1 in $\mathrm{x}$-direction (lb-in./in.)

W1XSHR Shear force for vault wall 1 in $\mathrm{x}$-direction (lb/in.)

W1YMNT Bending moment for vault wall 1 in $y$-direction (lb-in./in.)

WIYSHR Shear force for vault wall 1 in y-direction (lb/in.)

W2APER Average fracture aperture in vault wall $2(\mathrm{~cm})$ 
W2CMFY Compressive force on vault wall 2 in $y$-direction (lb/in.)

W2FDPX Wall 2 crack depth in $\mathrm{x}$-direction (in.)

W2FDPY Wall 2 crack depth in y-direction (in.)

W2FRAC Fraction of vault wall 2 that consists of fractures

W2FSPX Wall 2 crack spacing in $\mathrm{x}$-direction (in.)

W2FSPY Wall 2 crack spacing in y-direction (in.)

W2XMNT Bending moment for vault wall 2 in $\mathrm{X}$-direction (lb-in./in.)

W2XSHR Shear force for vault wall 2 in $\mathrm{x}$-direction (lb/in.)

W2YMNT Bending moment for vault wall 2 in y-direction (lb-in./in.)

W2YSHR Shear force for vault wall 2 in y-direction (lb/in.)

WATER Infiltration rate of water into the disposal facility $(\mathrm{cm} / \mathrm{month})$

WAT_INP File name containing monthly infiltration values

WCR Water-cement ratio of concrete

WFT1 Year in which corrosion of well wall begins

WLCMFR Silo compressive forces due to the roof reaction and weight of the walls (lb/in.)

WLDSTX Distance from steel reinforcement in tension to compression surface of concrete in walls in X-direction (in.)

WLDSTY Distance from steel reinforcement in tension to compression surface of concrete in walls in $y$-direction (in.)

WLFDPX Depth of fractures due to bending in wall in x-direction (in.)

WLFDPY Depth of fractures due to bending in wall in y-direction (in.)

WLFSPX Spacing of fractures due to bending in $\mathrm{x}$-direction (in.)

WLFSPY Spacing of fractures due to bending in y-direction (in.)

WLHGHT Well height (in.)

WLRAD Radius of well (in.)

WLSTR Yield strength of steel in well wall (lb/in. ${ }^{2}$ )

WLUSTX Ultimate strength of wall in $\mathrm{x}$-direction (lb/in. ${ }^{2}$ )

WLUSTY Ultimate strength of wall in y-direction (lb/in. ${ }^{2}$ )

WLWXRC Well ring compression force due to a uniform load (lb/in.)

WLXRC Silo ring compression force due to hydrostatic pressure (lb/in.)

WLYMNT Bending moment for silo wall in y-direction (lb-in./in.)

WLYSHR Shear force in silo wall (lb/in.) 


\begin{tabular}{|c|c|}
\hline WSTDNS & Density of waste $\left(\mathrm{g} / \mathrm{cm}^{3}\right)$ \\
\hline WSTHK & Thickness of waste in disposal facility $(\mathrm{cm})$ \\
\hline WSTHT & Relative saturation of waste \\
\hline WSTRED & Strength reduction factor for well \\
\hline WTCMNT & Cement content of concrete $\left(\mathrm{kg} / \mathrm{m}^{3}\right)$ \\
\hline WWCMFR & Well compressive forces due to the roof reaction and weight of the walls (lb/in.) \\
\hline WWYMNT & Bending moment for well wall in y-direction (lb-in./in.) \\
\hline WWYSHR & Shear force in well wall (lb-in./in.) \\
\hline XIM & Trigonometric function used in floor structural analysis \\
\hline XIIM & Trigonometric function used in floor structural analysis \\
\hline XIP & Trigonometric function used in floor structural analysis \\
\hline XIIP & Trigonometric function used in floor structural analysis \\
\hline XKD & Radionuclide distribution coefficient in waste $(\mathrm{mL} / \mathrm{g})$ \\
\hline XLEACH & Total radionuclide release (g/year) \\
\hline XIFF & Corrugated steel liner failure fraction \\
\hline XLFT1 & Year in which corrugated steel liners begin to corrode \\
\hline XLI & Langelier index \\
\hline $\mathrm{XLLCH}$ & Annual radionuclide release to lateral flow component (g) \\
\hline XLOAD & Uniform load on roof of disposal facility (lb/in. ${ }^{2}$ ) \\
\hline $\mathrm{XMG} 2$ & Magnesium ion concentration in groundwater $(\mathrm{mol} / \mathrm{L})$ \\
\hline XMGSOL & Solubility of magnesium in groundwater $(\mathrm{mol} / \mathrm{L})$ \\
\hline XMOLE & Moles of iron in steel reinforcement \\
\hline XPERC & Percolation rate through intact and cracked concrete $(\mathrm{cm} / \mathrm{month})$ \\
\hline YIM & Trigonometric function used in floor structural analysis \\
\hline YIIM & Ttrigonometric function used in floor structural analysis \\
\hline YIP & Trigonometric function used in floor structural analysis \\
\hline YIIP & Trigonometric function used in floor structural analysis \\
\hline YNGMOD & Young's modulus $(\mathrm{Pa})$ \\
\hline
\end{tabular}





\section{APPENDIX C \\ SAMPLE INPUT AND OUTPUT FILES \\ FOR THE SOURCE1 AND SOURCE2 COMPUTER CODES}




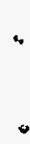




\section{SAMPLE INPUT AND OUTPUT FILES FOR THE SOURCE1 AND SOURCE2 COMPUTER CODES}

Sample input and output data files for SOURCE1 and SOURCE2 are presented in Exhibits C.1 through C.21. With the exception of the radionuclide inventories, values used in the input files were taken from ref. 2. A unit inventory was used in each of the input files, except for the ${ }^{238} U$ file, which has a higher inventory to demonstrate solubility-limited releases. Note that in the caption of each exhibit, the filename extension associated with the file is indicated in parentheses. For purposes of these examples, a generic filename (e.g., filename.con) is used to demonstrate the file-naming convention. Output files that correspond to the input files are provided for one of the SOURCE1 samples and one of the SOURCE2 samples. Similar output files would be obtained for the other sample input files. The output frequency was selected to conserve space. Format requirements for the input files are presented in Tables 4.1 through 4.3 of Sect. 4. A summary of information presented in each of the output files is presented in Tables 4.4 and 4.5 in Sect. 4.

Exhibit C.I provides a sample input file for ${ }^{137} \mathrm{C}$ in a tumulus-type facility. Note that this file requires the water infiltration input file water.dat. A generic example of a water infiltration input file is presented as Exhibit C.2. To use this file with the sample in Exhibit C.1, the water infiltration file should be named water.dat. Associated output files for the input files shown in Exhibits C.1 and C.2 are provided in Exhibits C.3 through C.10. For a performance assessment, the recharge and lateral-release output files (Exhibits C.5 and C.6, respectively) would be used in subsequent radionuclide transport calculations and probably would be written at an annual frequency. Exhibit C.11 is also an input file for ${ }^{137} \mathrm{Cs}$ in a tumulus-type disposal facility. This file differs from Exhibit $\mathrm{C} .1$ in that there is no concrete pad.

Exhibit $\mathrm{C} .12$ is a sample input file for ${ }^{238} \mathrm{U}$ in a silo-type facility. This file demonstrates the use of a reference year and radionuclide disposal over a range of years. Additionally, the radionuclide inventory was selected to demonstrate solubility-limited releases. Output files that correspond to a SOURCE2 simulation for ${ }^{238} \mathrm{U}$ in a silo (using Exhibits C.2 and C.12) are provided in Exhibits C.13 through C.18.

Additional sample SOURCE2 input files are presented in Exhibits C.19 through C.21. Exhibit C.19 is for ${ }^{137} \mathrm{Cs}$ in a well-type facility. Exhibit C.20 is for ${ }^{137} \mathrm{Cs}$ in a well-in-silo-type facility. Finally, Exhibit C.21 is for ${ }^{137} \mathrm{Cs}$ in a trench-type facility. The trench is modeled as a silo without barriers by using an equivalent surface-to-volume ratio. Concrete parameters are selected 
to result in silo (i.e., the equivalent of a trench) failure during the first year of the simulation. The trench then effectively has no engineered barriers. 
Exhibit C.1. Sample SOURCE1 input file for ${ }^{137} \mathrm{Cs}$ in a tumulus-type facility with a concrete pad (filename.inp)

Sample run of Cs-137 in a tumulus-type disposal facility (with concrete pad) $3 \quad 10 \quad 11 \quad 4$

$6.000 E+01 \quad 8.700 \mathrm{E}+01 \quad 6.500 \mathrm{E}+01$

$7.000 \mathrm{E}+007.000 \mathrm{E}+00 \quad 7.000 \mathrm{E}+00$

$\begin{array}{llllll}3.060 E+00 & 3.690 \mathrm{E}+00 & 3.250 \mathrm{E}+00 \quad 3.750 \mathrm{E}+00 \quad 2.000 \mathrm{E}+00 \quad 2.500 \mathrm{E}+00\end{array}$

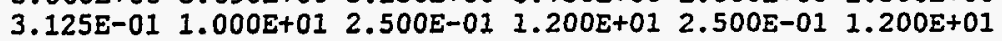

$2.000 \mathrm{E}+03 \quad 4.000 \mathrm{E}+01 \quad 1.760 \mathrm{E}+00 \quad 3.000 \mathrm{E}+01$

$7.200 \mathrm{E}+01 \quad 1.760 \mathrm{E}+00 \quad 1.760 \mathrm{E}+00 \quad 3.500 \mathrm{E}-01$

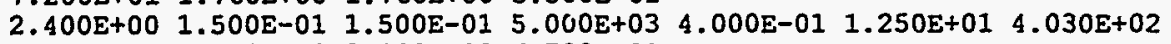

$1.000 \mathrm{E}-02 \quad 2.110 \mathrm{E}+00 \quad 8.000 \mathrm{E}+00 \quad 6.700 \mathrm{E}-01$

$2.900 E+07 \quad 6.000 E+04 \quad 2.000 E+10$

$1.750 \mathrm{E}+002.000 \mathrm{E}-02 \quad 7.100 \mathrm{E}-01$

$\begin{array}{lllllll}0.4375 & 1.50 \mathrm{E}+01 & 2.90 \mathrm{E}+07 \quad 6.00 \mathrm{E}+04 & 4.00 \mathrm{E}+03 & 6.00 \mathrm{E}+00 & 6.00 \mathrm{E}+00 & 3.30 \mathrm{E}+02 \quad 8.00 \mathrm{E}-01\end{array}$

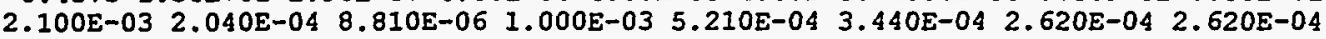

$2.120 \mathrm{E}-11$ 1.820E-11 5.080E-11 $1.920 \mathrm{E}-10 \quad 2.100 \mathrm{E}-10 \quad 1.060 \mathrm{E}-11$

$6.750 E+00 \quad 3.490 E+02 \quad 1.500 E+01$

2.000E-02 $1.200 \mathrm{E}-03$ 1.200E-03

$\begin{array}{lll}0.000 \mathrm{E}+00 & 6.000 \mathrm{E}+01 & 0.000 \mathrm{E}+00 \quad 2.000 \mathrm{E}+01\end{array}$

$4.990 \mathrm{E}+02 \quad 5.800 \mathrm{E}-07 \quad 3.500 \mathrm{E}-03 \quad 1.000 \mathrm{E}-10$

water.dat

1

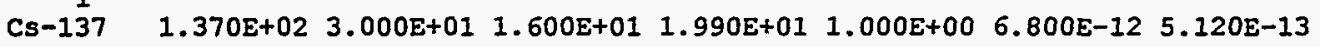


Exhibit C.2. Sample water infiltration input data (the name for this file is specified in filename.inp)

$2212.4212 .4211 .6810 .9215 .75 \quad 8.4823 .44 \quad 6.20 \quad 8.00 \quad 6.38 \quad 5.5415 .98$ $\begin{array}{lllllllllllllll}32 & 0.03 & 0.38 & 1.12 & 1.12 & 0.77 & 0.34 & 0.16 & 0.08 & 0.04 & 0.02 & 0.01 & 0.01\end{array}$ $\begin{array}{llllllllllllll}33 & 0.91 & 1.24 & 2.04 & 1.71 & 1.83 & 0.60 & 0.29 & 0.23 & 0.19 & 0.16 & 0.13 & 0.09\end{array}$ $\begin{array}{llllllllllllll}34 & 1.80 & 2.10 & 2.96 & 2.30 & 2.89 & 0.86 & 0.42 & 0.38 & 0.33 & 0.30 & 0.26 & 0.16\end{array}$ $\begin{array}{lllllllllllll}35 & 2.68 & 2.96 & 3.88 & 2.88 & 3.95 & 1.12 & 0.55 & 0.52 & 0.48 & 0.44 & 0.38 & 0.24\end{array}$ $\begin{array}{llllllllllllll}36 & 3.56 & 3.82 & 4.80 & 3.47 & 5.01 & 1.38 & 0.68 & 0.67 & 0.63 & 0.58 & 0.50 & 0.32\end{array}$ $\begin{array}{llllllllllllll}37 & 4.44 & 4.68 & 5.72 & 4.06 & 6.07 & 1.64 & 0.81 & 0.82 & 0.77 & 0.72 & 0.62 & 0.39\end{array}$ $\begin{array}{llllllllllllll}38 & 5.33 & 5.55 & 6.65 & 4.65 & 7.14 & 1.91 & 0.93 & 0.97 & 0.92 & 0.85 & 0.75 & 0.47\end{array}$ $\begin{array}{lllllllllllllll}39 & 6.21 & 6.41 & 7.57 & 5.24 & 8.20 & 2.17 & 1.06 & 1.12 & 1.06 & 0.99 & 0.87 & 0.54\end{array}$ $\begin{array}{llllllllllllll}40 & 7.09 & 7.27 & 8.49 & 5.83 & 9.26 & 2.43 & 1.19 & 1.27 & 1.21 & 1.13 & 0.99 & 0.62\end{array}$ $\begin{array}{llllllllllllll}41 & 7.97 & 8.13 & 9.41 & 6.4110 .32 & 2.69 & 1.32 & 1.41 & 1.36 & 1.27 & 1.11 & 0.70\end{array}$ $\begin{array}{llllllllllll}42 & 8.86 & 8.9910 .33 & 7.0011 .38 & 2.95 & 1.45 & 1.56 & 1.50 & 1.41 & 1.24 & 0.77\end{array}$ $9999999 \quad 9.74 \quad 9.8511 .25 \quad 7.5912 .44 \quad 3.21 \quad 1.58 \quad 1.71 \quad 1.651 .55 \quad 1.36 \quad 0.85$ 
Exhibit C.3. Sample SOURCE1 output file for input data summary and concrete analyses (filename.con)

Sample run of Cs-137 in a tumulus-type disposal facility (with concrete pad)

Input Data Sumary:

Simulation length

Output edit frequency

300 years

150 years

Disposal unit area

Total dissolved solids

Groundwater temperature

Groundwater $\mathrm{pH}$

$4.99 \mathrm{E}+02 \mathrm{~m} \star \star 2$

$3.49 \mathrm{E}+02 \mathrm{ppm}$

$1.50 E+01$ deg $C$

$6.75 E+00$

Saturated hydraulic conductivity:

Recharge

Soil backfill

Concrete

$5.80 \mathrm{E}-07 \mathrm{~cm} / \mathrm{s}$

$3.50 \mathrm{E}-03 \mathrm{~cm} / \mathrm{s}$

$1.00 \mathrm{E}-10 \mathrm{~cm} / \mathrm{s}$

Groundwater constituent concentrations:
$\mathrm{Ca}++$
Cl-
CO3--
$\mathrm{Mg++}$
SO4--
02

Constituent solubilities:

$\mathrm{Ca}(\mathrm{OH}) 2$

$\mathrm{CO} 3-$

$\mathrm{Mg}++$

Concrete constituent concentrations:

Calcium concentration in $\mathrm{C}-\mathrm{S}-\mathrm{H}$ system

Calcium concentration in pore fluid

Cao content in cement

Free Cl-

Silica concentration in $\mathrm{C}-\mathrm{S}-\mathrm{H}$ system

Concrete design specifications:

Compressive strength at 28 days

Poisson's ratio of concrete

Modulus of elasticity of steel

Yield strength of steel

Modulus of subgrade reaction

Young's modulus of elasticity

Concrete water/cement ratio

Concrete density

Concrete porosity

Cement content

Initial pH

Concrete pad failure model parameters:

Radius of pad steel reinforcement

Concrete pad thickness

Modulus of elasticity of steel reinforcement

Yield strength of steel reinforcement

Compressive strength of pad concrete

Spacing between steel reinforcing rods

Concrete cover thickness from the center

of the bottom row of steel reinforcing rods

to the bottom of the pad

Weight of pad cement per unit

volume concrete
2.10E-03 mole/L

2.04E-04 mole/I

$1.00 \mathrm{E}-03 \mathrm{~mole} / \mathrm{L}$

$5.21 \mathrm{E}-04 \mathrm{~mole} / \mathrm{I}$

2.62E-04 mole/L

3.44E-04 mole/I

2.00E-02 mole/L

$1.20 \mathrm{E}-03 \mathrm{~mole} / \mathrm{L}$

1.20E-03 mole/L

1.75E+00 mole/L

$2.00 \mathrm{E}-02 \mathrm{~mole} / \mathrm{L}$

$2.11 E+00 \mathrm{~mole} / \mathrm{L}$

$1.00 \mathrm{E}-02 \mathrm{~mole} / \mathrm{L}$

$7.10 \mathrm{E}-01 \mathrm{~mole} / \mathrm{L}$

$3.52 \mathrm{E}+02 \mathrm{~kg} / \mathrm{cm}^{\star \star 2}$

$1.50 \mathrm{E}-01$

$2.04 \mathrm{E}+06 \mathrm{~kg} / \mathrm{cm}^{\star \star} 2$

$4.22 E+03 \mathrm{~kg} / \mathrm{cm} \star \star 2$

$1.41 \mathrm{E}+02 \mathrm{~kg} / \mathrm{cm}^{\star} * 2$

$2.04 \mathrm{E}+05 \mathrm{~kg} / \mathrm{cm} \star \star 2$

$4.00 \mathrm{E}-01$

$2.40 \mathrm{E}+00 \mathrm{~g} / \mathrm{cm} \star \star 3$

$1.50 \mathrm{E}-01$

$4.03 \mathrm{E}+02 \mathrm{~kg} / \mathrm{m}^{\star \star 3}$

$1.25 E+01$

$1.11 \mathrm{E}+00 \mathrm{~cm}$

3.81E+0I Cm

$2.04 \mathrm{E}+06 \mathrm{~kg} / \mathrm{cm}^{\star \star} 2$

$4.22 \mathrm{E}+03 \mathrm{~kg} / \mathrm{cm} * \star 2$

$2.82 \mathrm{E}+02 \mathrm{~kg} / \mathrm{cm}^{\star \star} 2$

$1.52 \mathrm{E}+01 \mathrm{~cm}$

$1.52 \mathrm{E}+01 \mathrm{~cm}$

$3.30 \mathrm{E}+02 \mathrm{~kg} / \mathrm{m} \star \star 3$ 
Pad initial functionality fraction

Diffusion coefficients in concrete:

$\mathrm{NaOH}, \mathrm{KOH}$

$\mathrm{Ca}(\mathrm{OH}) 2$

Ci-

$\mathrm{CO} 2$

02

SO4--

Tumulus design specifications:

Layers of vaults

Number of vaults wide

Number of vaults long

Vault dimensions:

Width

Iength

Height

Concrete member thickness:

Roof

Halls

Floor

Pad

Steel reinforcement radius:

Roof

Walls

Floor

Spacing of steel reinforcement:

Roof

Walls

Floor

Concrete cover thickness on tension face: Roof:

$\mathrm{x}$-direction

Y-direction

Halls :

Horizontal direction

Vertical direction

Floor:

$\mathrm{X}$-direction

$\mathrm{Y}$-direction

Static load:

Vault layer 1

Vault layer 2

vault layer 3

Soil and waste properties:

Earthen cover thickness

Earthen cover density

Friction angle of waste backfill

Friction angle of soil backfill

Density of soil backfill

Waste density

Relative saturation of waste

Concrete and waste package failure rates:

Waste container:

start of failure

Time to complete failure

Epoxy coating:

start of failure

Time to complete failure
$8.00 \mathrm{E}-01$

$2.12 \mathrm{E}-11 \mathrm{~m} * \star 2 / \mathrm{s}$

1. $82 \mathrm{E}-11 \mathrm{~m} \mathrm{~m}^{\star *} 2 / \mathrm{s}$

$5.08 \mathrm{E}-11 \mathrm{~m} * * 2 / \mathrm{s}$

$1.92 \mathrm{E}-10 \mathrm{~m} * \star 2 / \mathrm{s}$

$2.10 \mathrm{E}-10 \mathrm{~m} \star \star 2 / \mathrm{s}$

$1.06 \mathrm{E}-11 \mathrm{~m} \mathrm{~m}^{\star \star 2} / \mathrm{s}$

3

11

$1.52 \mathrm{E}+00 \mathrm{~m}$

$2.21 \mathrm{E}+00 \mathrm{~m}$

$1.65 \mathrm{E}+00 \mathrm{~m}$

$1.78 \mathrm{E}+01 \mathrm{~cm}$

$1.78 \mathrm{E}+01 \mathrm{~cm}$

$1.78 \mathrm{E}+01 \mathrm{~cm}$

$3.81 \mathrm{E}+01 \mathrm{~cm}$

$7.94 \mathrm{E}-01 \mathrm{~cm}$

$6.35 \mathrm{E}-01 \mathrm{~cm}$

$6.35 \mathrm{E}-01 \mathrm{~cm}$

$2.54 \mathrm{E}+01 \mathrm{~cm}$

$3.05 \mathrm{E}+01 \mathrm{~cm}$

$3.05 \mathrm{E}+01 \mathrm{~cm}$

$7.77 \mathrm{E}+00 \mathrm{~cm}$

9. $37 \mathrm{E}+00 \mathrm{~cm}$

$8.26 \mathrm{E}+00 \mathrm{~cm}$

$9.52 \mathrm{E}+00 \mathrm{~cm}$

$5.08 \mathrm{E}+00 \mathrm{~cm}$

$6.35 \mathrm{E}+00 \mathrm{~cm}$

3. $65 \mathrm{E}-01 \mathrm{~kg} / \mathrm{cm}^{\star *} 2$

$7.10 \mathrm{E}-01 \mathrm{~kg} / \mathrm{cm} \star \star 2$

$1.05 \mathrm{E}+00 \mathrm{~kg} / \mathrm{cm}^{\star *} 2$

1. $83 \mathrm{E}+00 \mathrm{~m}$

$1.76 \mathrm{E}+00 \mathrm{~g} / \mathrm{cm} \star * 3$

4.00E+01 deg

$3.00 \mathrm{E}+01 \mathrm{deg}$

$1.76 \mathrm{E}+00 \mathrm{~g} / \mathrm{Cm} * \star 3$

$1.76 \mathrm{E}+00 \mathrm{~g} / \mathrm{cm} \star \star 3$

$3.50 \mathrm{E}-01$

$0.00 E+00$ years $6.00 \mathrm{E}+01$ years

$0.00 \mathrm{E}+00$ years $2.00 \mathrm{E}+01$ years 
Nuclide-specific parameters:

\begin{tabular}{|c|c|c|c|c|c|c|}
\hline \multirow[b]{2}{*}{ Nuclide } & \multirow[b]{2}{*}{$\begin{array}{c}\text { Half-life } \\
\text { (yr) }\end{array}$} & \multirow[b]{2}{*}{$\begin{array}{c}\text { Solubility } \\
\text { (mole/L) }\end{array}$} & \multirow[b]{2}{*}{$\begin{array}{c}\text { Waste } \\
\mathrm{Kd} \\
(\mathrm{ml} / \mathrm{g})\end{array}$} & \multicolumn{2}{|c|}{ Diffusion coefficient } & \multirow[b]{2}{*}{$\begin{array}{c}\text { Initial } \\
\text { Inventory } \\
\text { (g) }\end{array}$} \\
\hline & & & & $\begin{array}{c}\text { Haste } \\
(m * \approx 2 / s)\end{array}$ & $\begin{array}{l}\text { Concrete } \\
(m \star \star 2 / s)\end{array}$ & \\
\hline$C_{s-}$ & $3.00 \mathrm{E}+01$ & $1.60 E+01$ & $1.99 \mathrm{E}+01$ & $6.80 \mathrm{E}-12$ & $5.12 \mathrm{E}-13$ & $1.00 \mathrm{E}+00$ \\
\hline
\end{tabular}

Output summary:

Output sumary:

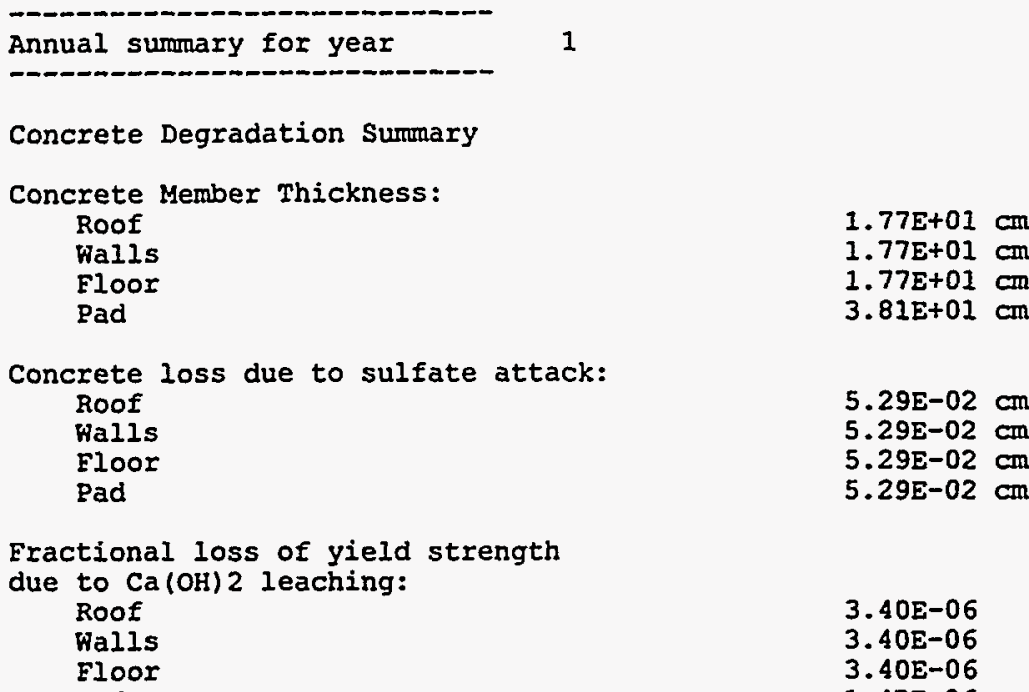

$5.29 \mathrm{E}-02 \mathrm{~cm}$

Fractional loss of yield strength due to $\mathrm{Ca}(\mathrm{OH}) 2$ leaching:

Roof

Walls

Eloor

3. $40 \mathrm{E}-06$

3. $40 \mathrm{E}-06$

$3.40 \mathrm{E}-06$ $5.29 \mathrm{E}-02 \mathrm{~cm}$

Pad

$1.43 \mathrm{E}-06$

Corrosion results:

Time to onset of corrosion: Roof

Walls

Floor

0 years

Corrosion product layer thickness: Roof

Walls

Floor

$0.00 \mathrm{E}+00 \mathrm{~cm}$ $0.00 \mathrm{E}+00 \mathrm{~cm}$ $0.00 \mathrm{E}+00 \mathrm{~cm}$

Remaining steel reinforcement:

Roof

Walls

Floor

$7.94 \mathrm{E}-01 \mathrm{~cm}$ $6.35 \mathrm{E}-01 \mathrm{~cm}$ $6.35 \mathrm{E}-01 \mathrm{~cm}$

Concrete Cracking Analysis

Cracking due to corrosion of steel:

Cask roof

Cask walls

Cask floor

Cracking due to loading and shear:

Cask roof

Cask walls

None

Cask floor

None 
Annual summary for year

Concrete Degradation Summary

Concrete Member Thickness: Roof

Walls

Floor

Pad

Concrete loss due to sulfate attack: Roof

Walls

Floor

Pad

Fractional loss of yield strength

due to $\mathrm{Ca}(\mathrm{OH}) 2$ leaching:

Roof

WaIls

Floor

Pad

Corrosion results:

Time to onset of corrosion: Roof

Falls

Floor

Corrosion product layer thickness:

Roof

Falls

Floor

Remaining steel reinforcement:

Roof

Halls

Floor

Concrete Cracking Analysis

Cracking due to corrosion of steel:

Cask roof

Cask walls

Cask floor

Cracking due to loading and shear:

Cask roof

Cask walls

Cask floor

Concrete crack characteristics:

\begin{tabular}{llr}
\multicolumn{3}{c}{ Layer of casks } \\
\hline Upper layer middle layer lower Iayer \\
& & \\
$0.00 \mathrm{E}+00$ & $1.30 \mathrm{E}-02$ & $2.92 \mathrm{E}-02$ \\
$0.00 \mathrm{E}+00$ & $3.48 \mathrm{E}-04$ & $7.22 \mathrm{E}-04$ \\
& & \\
$0.00 \mathrm{E}+00$ & $7.46 \mathrm{E}-03$ & $2.86 \mathrm{E}-02$ \\
$0.00 \mathrm{E}+00$ & $2.80 \mathrm{E}-04$ & $8.51 \mathrm{E}-04$
\end{tabular}

$9.85 \mathrm{E}+00 \mathrm{~cm}$ $9.85 \mathrm{E}+00 \mathrm{~cm}$ $9.85 \mathrm{E}+00 \mathrm{~cm}$ $3.47 \mathrm{E}+01 \mathrm{~cm}$

7. $93 \mathrm{E}+00 \mathrm{~cm}$ $7.93 \mathrm{E}+00 \mathrm{~cm}$ $7.93 \mathrm{E}+00 \mathrm{~cm}$ $7.93 \mathrm{E}+00 \mathrm{~cm}$

$7.32 E-02$ $7.32 \mathrm{E}-02$ $3.07 \mathrm{E}-02$ $7.32 \mathrm{E}-02$

$0.00 \mathrm{E}+00 \mathrm{~cm}$ $0.00 \mathrm{E}+00 \mathrm{~cm}$ $0.00 \mathrm{E}+00 \mathrm{~cm}$

$7.94 \mathrm{E}-01 \mathrm{~cm}$ $6.35 \mathrm{E}-01 \mathrm{~cm}$ $6.35 \mathrm{E}-01 \mathrm{~cm}$

None

None

None

0 years

0 years

0 years

Cracked

Cracked

Cracked
Cask roof
Average crack width $(\mathrm{cm})$
Fractional volume of cracks
$0.00 E+00$
1.30E-02
2. $92 \mathrm{E}-02$
Cask floor
Average crack width $(\mathrm{cm})$
Fractional volume of cracks
$0.00 \mathrm{E}+00$
$0.00 \mathrm{E}+00$
$7.46 \mathrm{E}-03$
$8.51 E-04$ 


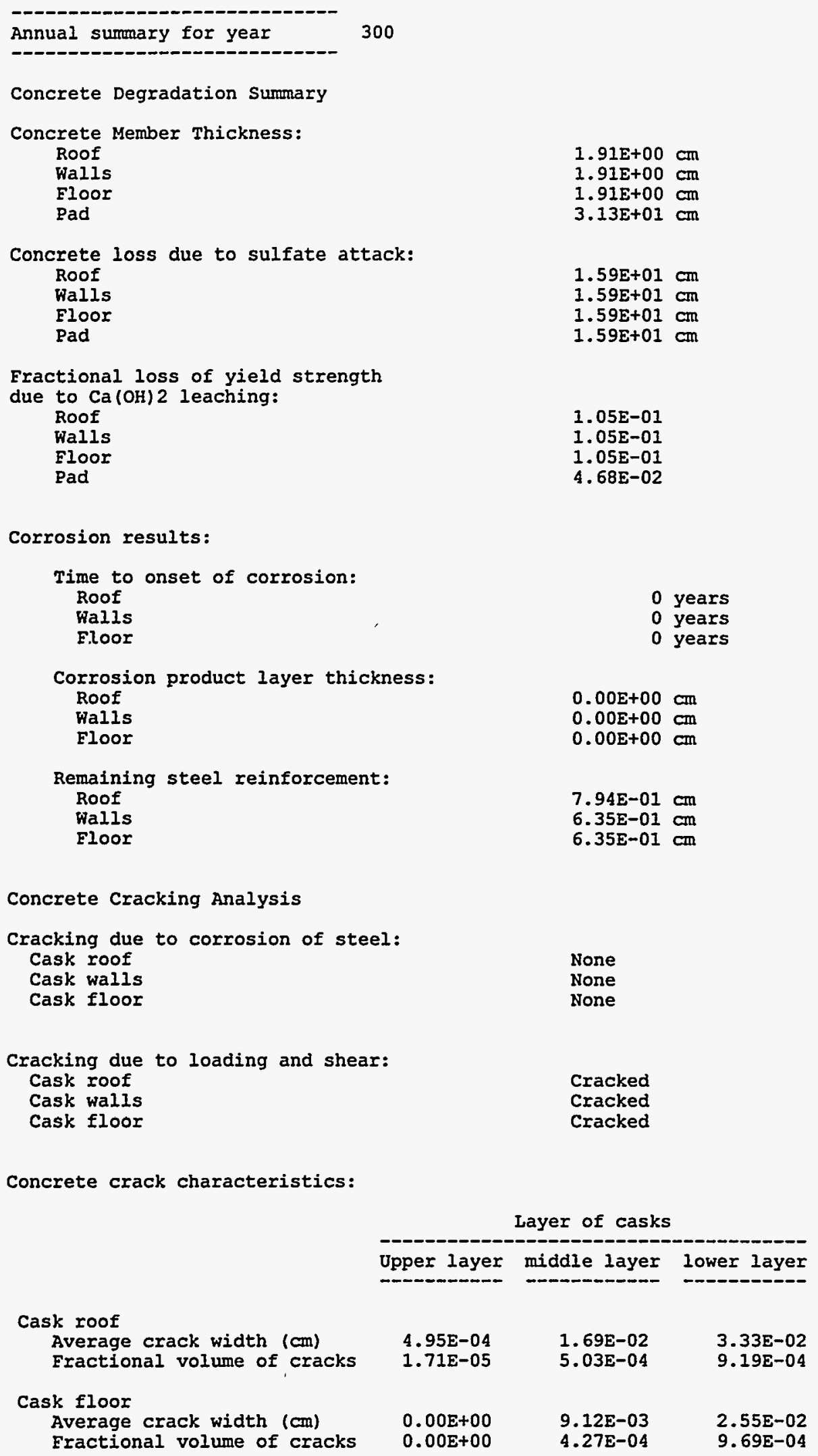


Exhibit C.4. Sample SOURCE1 output of water infiltration input data (filename.h2o)

Sumary of Infiltration Data

Sample run of $\mathrm{Cs}-137$ in a tumulus-type disposal facility (with concrete pad)

\begin{tabular}{|c|c|c|c|c|c|c|c|c|c|c|c|c|c|}
\hline earl & Year2 & Jan & Feb & Mar & Apr & May & Jun & JuI & Aug & Sep & oct & Nov & Dec \\
\hline $\begin{array}{l}1 \\
23 \\
33 \\
34 \\
35 \\
36 \\
37 \\
38 \\
39 \\
40 \\
41 \\
42 \\
43\end{array}$ & $\begin{array}{r}22 \\
32 \\
33 \\
34 \\
35 \\
36 \\
37 \\
38 \\
39 \\
40 \\
41 \\
42 \\
9999999\end{array}$ & $\begin{array}{r}12.42 \\
0.03 \\
0.91 \\
1.80 \\
2.68 \\
3.56 \\
4.44 \\
5.33 \\
6.21 \\
7.09 \\
7.97 \\
8.86 \\
9.74\end{array}$ & $\begin{array}{r}12.42 \\
0.38 \\
1.24 \\
2.10 \\
2.96 \\
3.82 \\
4.68 \\
5.55 \\
6.41 \\
7.27 \\
8.13 \\
8.99 \\
9.85\end{array}$ & $\begin{array}{r}11.68 \\
1.12 \\
2.04 \\
2.96 \\
3.88 \\
4.80 \\
5.72 \\
6.65 \\
7.57 \\
8.49 \\
9.41 \\
10.33 \\
11.25\end{array}$ & $\begin{array}{r}10.92 \\
1.12 \\
1.71 \\
2.30 \\
2.88 \\
3.47 \\
4.06 \\
4.65 \\
5.24 \\
5.83 \\
6.41 \\
7.00 \\
7.59\end{array}$ & $\begin{array}{r}15.75 \\
0.77 \\
1.83 \\
2.89 \\
3.95 \\
5.01 \\
6.07 \\
7.14 \\
8.20 \\
9.26 \\
10.32 \\
11.38 \\
12.44\end{array}$ & $\begin{array}{l}8.48 \\
0.34 \\
0.60 \\
0.86 \\
1.12 \\
1.38 \\
1.64 \\
1.91 \\
2.17 \\
2.43 \\
2.69 \\
2.95 \\
3.21\end{array}$ & $\begin{array}{r}23.44 \\
0.16 \\
0.29 \\
0.42 \\
0.55 \\
0.68 \\
0.81 \\
0.93 \\
1.06 \\
1.19 \\
1.32 \\
1.45 \\
1.58\end{array}$ & $\begin{array}{l}6.20 \\
0.08 \\
0.23 \\
0.38 \\
0.52 \\
0.67 \\
0.82 \\
0.97 \\
1.12 \\
1.27 \\
1.41 \\
1.56 \\
1.71\end{array}$ & $\begin{array}{l}8.00 \\
0.04 \\
0.19 \\
0.33 \\
0.48 \\
0.63 \\
0.77 \\
0.92 \\
1.06 \\
1.21 \\
1.36 \\
1.50 \\
1.65\end{array}$ & $\begin{array}{l}6.38 \\
0.02 \\
0.16 \\
0.30 \\
0.44 \\
0.58 \\
0.72 \\
0.85 \\
0.99 \\
1.13 \\
1.27 \\
1.41 \\
1.55\end{array}$ & $\begin{array}{l}5.54 \\
0.01 \\
0.13 \\
0.26 \\
0.38 \\
0.50 \\
0.62 \\
0.75 \\
0.87 \\
0.99 \\
1.11 \\
1.24 \\
1.36\end{array}$ & $\begin{array}{r}15.98 \\
0.01 \\
0.09 \\
0.16 \\
0.24 \\
0.32 \\
0.39 \\
0.47 \\
0.54 \\
0.62 \\
0.70 \\
0.77 \\
0.85\end{array}$ \\
\hline
\end{tabular}


Exhibit C.5. Sample SOURCE1 output of recharge release component (filename.rch)

Sample run of cs-137 in a tumulus-type disposal facility (with concrete pad)

Water and total grams in recharge component

\begin{tabular}{crc} 
& \multicolumn{3}{c}{ Cs-137 } \\
Year & Water infiltration $(\mathrm{cm})$ & Recharge $(\mathrm{g})$ \\
10 & $1.83034096 \mathrm{E}+01$ & $1.12228406 \mathrm{E}-06$ \\
20 & $1.83034096 \mathrm{E}+01$ & $2.29051579 \mathrm{E}-06$ \\
30 & $4.08000040 \mathrm{E}+00$ & $2.10606104 \mathrm{E}-05$ \\
40 & $1.54928007 \mathrm{E}+01$ & $1.69660725 \mathrm{E}-05$ \\
50 & $1.74531059 \mathrm{E}+01$ & $5.13803437 \mathrm{E}-02$ \\
60 & $1.74531059 \mathrm{E}+01$ & $4.98911142 \mathrm{E}-02$ \\
70 & $1.74531059 \mathrm{E}+01$ & $3.94661352 \mathrm{E}-02$ \\
80 & $1.74531059 \mathrm{E}+01$ & $3.09160128 \mathrm{E}-02$ \\
90 & $1.7431059 \mathrm{E}+01$ & $2.40589995 \mathrm{E}-02$ \\
100 & $1.74531059 \mathrm{E}+01$ & $5.09368926 \mathrm{E}-02$ \\
110 & $1.74531059 \mathrm{E}+01$ & $3.61716822 \mathrm{E}-02$ \\
120 & $1.74531059 \mathrm{E}+01$ & $2.57364567 \mathrm{E}-02$ \\
130 & $1.74531059 \mathrm{E}+01$ & $1.83554757 \mathrm{E}-02$ \\
140 & $1.7431059 \mathrm{E}+01$ & $1.31286727 \mathrm{E}-02$ \\
150 & $1.74531059 \mathrm{E}+01$ & $9.42158233 \mathrm{E}-03$ \\
160 & $1.74531059 \mathrm{E}+01$ & $6.78717392 \mathrm{E}-03$ \\
170 & $1.74531059 \mathrm{E}+01$ & $1.08960224 \mathrm{E}-02$ \\
180 & $1.74531059 \mathrm{E}+01$ & $7.71504967 \mathrm{E}-03$ \\
190 & $1.74531059 \mathrm{E}+01$ & $5.45583107 \mathrm{E}-03$ \\
200 & $1.74531059 \mathrm{E}+01$ & $3.85183073 \mathrm{E}-03$ \\
210 & $1.74531059 \mathrm{E}+01$ & $2.71384884 \mathrm{E}-03$ \\
220 & $1.74531059 \mathrm{E}+01$ & $1.90740335 \mathrm{E}-03$ \\
230 & $1.74531059 \mathrm{E}+01$ & $1.33679295 \mathrm{E}-03$ \\
240 & $1.74531059 \mathrm{E}+01$ & $9.33853618 \mathrm{E}-04$ \\
250 & $1.74531059 \mathrm{E}+01$ & $6.50006987 \mathrm{E}-04$ \\
260 & $1.74531059 \mathrm{E}+01$ & $4.50627762 \mathrm{E}-04$ \\
270 & $1.74531059 \mathrm{E}+01$ & $3.11042415 \mathrm{E}-04$ \\
280 & $1.7451059 \mathrm{E}+01$ & $2.13683088 \mathrm{E}-04$ \\
290 & $1.74531059 \mathrm{E}+01$ & $1.46057093 \mathrm{E}-04$ \\
300 & $1.74531059 \mathrm{E}+01$ & $9.92971109 \mathrm{E}-05$
\end{tabular}


Exhibit C.6. Sample SOURCE1 output of lateral release component (filename. lat)

Sample run of Cs-137 in a tumulus-type disposal facility (with concrete pad)

Water and total grams in lateral component

Cs -137

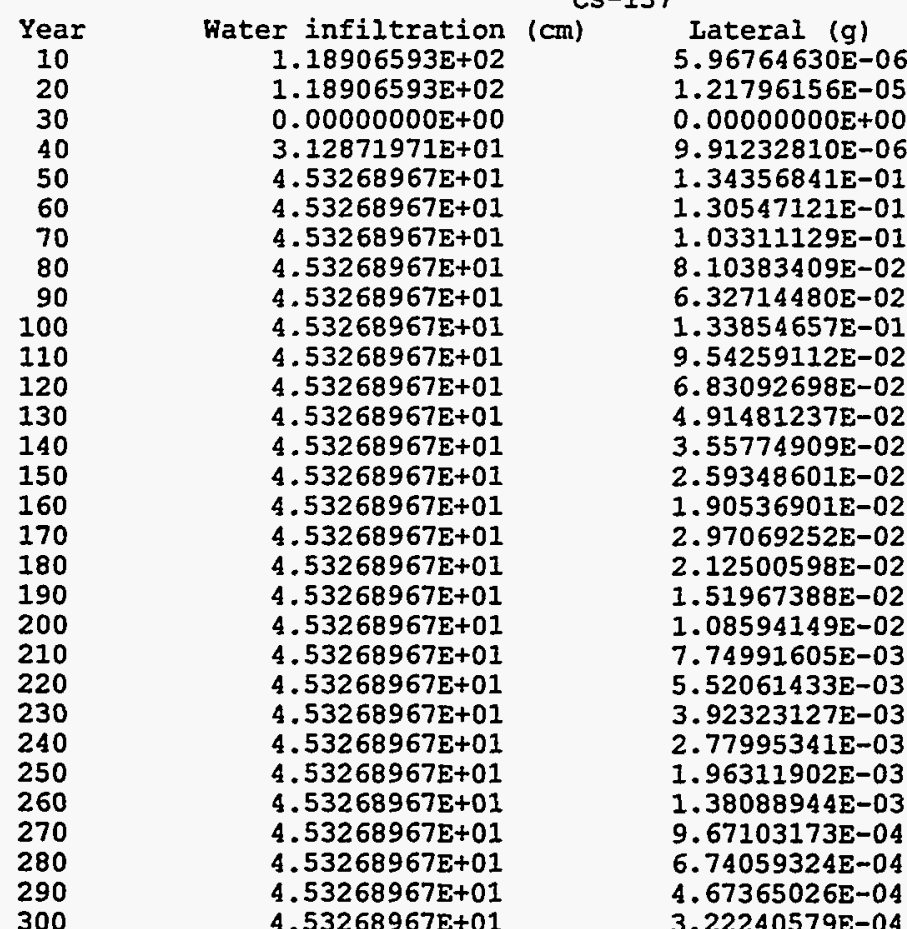

$300 \quad 4.53268967 \mathrm{E}+01 \quad 3.22240579 \mathrm{E}-04$ 
Exhibit C.7. Sample SOURCE1 output of leaching summary (filename.sum)

Sample run of Cs-137 in a tumulus-type disposal facility (with concrete pad)

Nuclide-specific parameters:

\begin{tabular}{ccccccc} 
Nuclide & Half-life Solubility & $\begin{array}{c}\text { Waste } \\
\mathrm{Kd} \\
(\mathrm{ml} / \mathrm{g})\end{array}$ & $\begin{array}{c}\text { Diffusion coefficient } \\
\text { Waste } \\
\left(\mathrm{m}^{\star \star 2} 2 / \mathrm{s}\right)\end{array}$ & $\begin{array}{c}\text { Concrete } \\
\left(\mathrm{m}^{\star \star 2} \mathrm{~s}\right)\end{array}$ & $\begin{array}{c}\text { Inventory } \\
\text { In })\end{array}$ \\
\hline $\mathrm{Cs}-137$ & $3.00 \mathrm{E}+01$ & $1.60 \mathrm{E}+01$ & $1.99 \mathrm{E}+01$ & $6.80 \mathrm{E}-12$ & $5.12 \mathrm{E}-13$ & $1.00 \mathrm{E}+00$
\end{tabular}

Output sumary total for all vaults:

Cs -137

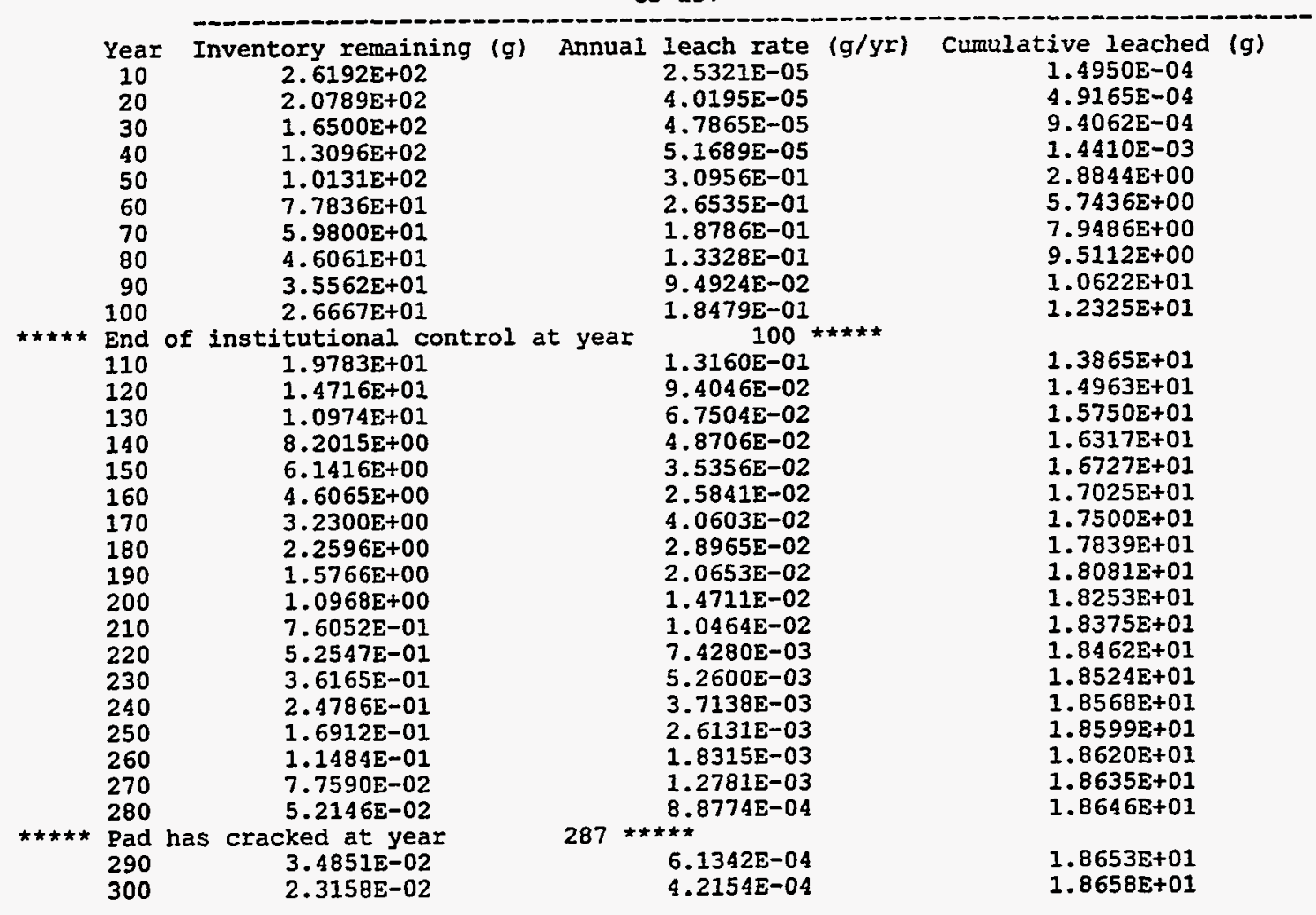

The solubility constraints were not exceeded for cs-137 
Exhibit C.8. Sample SOURCE1 output of advective and diffusive release rates (filename. Ich)

Sample run of Cs-137 in a tumulus-type disposal facility (with concrete pad)

Nuclide-specific parameters:

\begin{tabular}{|c|c|c|c|c|c|c|}
\hline \multirow[b]{2}{*}{ Nuclide } & \multirow[b]{2}{*}{$\begin{array}{c}\text { Half-life } \\
\text { (yr) }\end{array}$} & \multirow[b]{2}{*}{$\begin{array}{l}\text { Solubility } \\
\text { (mole/L) }\end{array}$} & \multirow[b]{2}{*}{$\begin{array}{l}\text { Waste } \\
\mathrm{Kd} \\
(\mathrm{ml} / \mathrm{g})\end{array}$} & \multicolumn{2}{|c|}{ Diffusion coefficient } & \multirow[b]{2}{*}{$\begin{array}{l}\text { Initial } \\
\text { Inventory } \\
\text { (g) }\end{array}$} \\
\hline & & & & $\begin{array}{c}\text { Waste } \\
(m * \star 2 / s)\end{array}$ & $\begin{array}{l}\text { Concrete } \\
\left(m^{\star \star} 2 / \mathrm{s}\right)\end{array}$ & \\
\hline Cs- & $3.00 E+01$ & $1.60 E+01$ & $1.99 E+01$ & $6.80 E-12$ & $5.12 \mathrm{E}-13$ & $1.00 E+00$ \\
\hline
\end{tabular}

Output summary per total number of vaults:

Cs -137

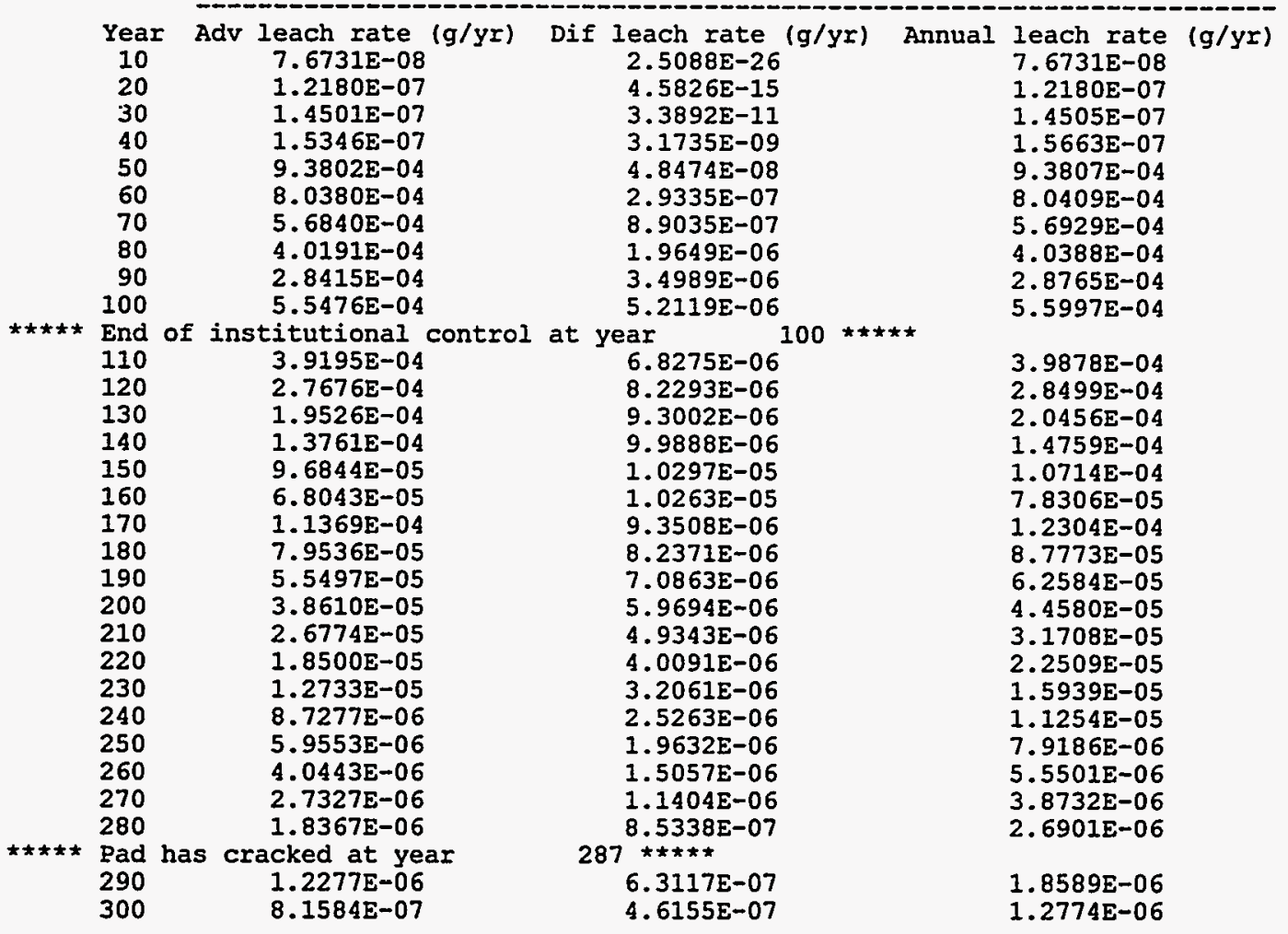

The solubility constraints were not exceeded for cs-137 
Exhibit C.9. Sample SOURCE1 output summary for intact vaults (filename.vt1)

Sample run of cs-137 in a tumulus-type disposal facility (with concrete pad)

sample run of cs-137 in a temulus teype disposal facility (with concrete pad)

Nuclide-specific parameters:

\begin{tabular}{|c|c|c|c|c|c|c|}
\hline Nuclide & $\begin{array}{c}\text { Half-life } \\
\text { (yr) }\end{array}$ & $\begin{array}{l}\text { Solubility } \\
\text { (mole/I) }\end{array}$ & $\begin{array}{c}\text { Haste } \\
\text { Kd } \\
\text { (ml/g) }\end{array}$ & $\begin{array}{c}\text { Diffusion } \\
\text { Maste } \\
\left(\mathrm{m}^{\star} \star 2 / \mathrm{s}\right)\end{array}$ & $\begin{array}{c}\text { coefficient } \\
\text { Concrete } \\
\left(\mathrm{m}^{\star \star 2} / \mathrm{s}\right)\end{array}$ & $\begin{array}{c}\text { Initial } \\
\text { Inventory } \\
\text { (g) }\end{array}$ \\
\hline $\operatorname{cs}-137$ & $3.00 \mathrm{E}+01$ & 1. $60 \mathrm{E}+01$ & $1.99 E+01$ & $6.80 \mathrm{E}-12$ & $5.12 \mathrm{E}-13$ & $1.00 E+00$ \\
\hline
\end{tabular}

Output summary per number of intact vaults:

Cs -137

$\begin{array}{cccc}\text { Year } & \text { Inventory remaining }(g) & \begin{array}{c}\text { Adv leach rate } \\ 1.6 / y r)\end{array} & \begin{array}{c}\text { Dif } \\ 10\end{array} \\ 7.9370 \mathrm{E}-01 & 1.6731 \mathrm{E}-08 & 2.5088 \mathrm{~g}-26 \\ 20 & 6.2996 \mathrm{E}-01 & 1.2180 \mathrm{E}-07 & 4.5826 \mathrm{E}-15 \\ 30 & 5.0000 \mathrm{E}-01 & 1.4501 \mathrm{E}-07 & 3.3892 \mathrm{E}-1 \mathrm{I} \\ 40 & 3.9685 \mathrm{E}-01 & 1.5346 \mathrm{E}-07 & 3.1735 \mathrm{E}-09 \\ 50 & 3.1498 \mathrm{E}-01 & 1.5225 \mathrm{E}-07 & 4.9602 \mathrm{E}-08 \\ 60 & 2.4999 \mathrm{E}-01 & 1.4501 \mathrm{E}-07 & 3.0997 \mathrm{E}-07 \\ 70 & 1.9841 \mathrm{E}-01 & 1.1509 \mathrm{E}-07 & 9.7205 \mathrm{E}-07 \\ 80 & 1.5746 \mathrm{E}-01 & 9.1338 \mathrm{E}-08 & 2.2107 \mathrm{E}-06 \\ 90 & 1.2495 \mathrm{E}-01 & 7.2478 \mathrm{E}-08 & 4.0468 \mathrm{E}-06 \\ 100 & 9.9124 \mathrm{E}-02 & 5.7497 \mathrm{E}-08 & 6.3514 \mathrm{E}-06 \\ 110 & 7.8604 \mathrm{E}-02 & 4.5595 \mathrm{E}-08 & 8.8959 \mathrm{E}-06 \\ 120 & 6.2294 \mathrm{E}-02 & 3.6135 \mathrm{E}-08 & 1.1427 \mathrm{E}-05 \\ 130 & 4.9328 \mathrm{E}-02 & 2.8613 \mathrm{E}-08 & 1.3717 \mathrm{E}-05 \\ 140 & 3.9017 \mathrm{E}-02 & 2.2633 \mathrm{E}-08 & 1.5597 \mathrm{E}-05 \\ 150 & 3.0819 \mathrm{E}-02 & 1.7878 \mathrm{E}-08 & 1.6965 \mathrm{E}-05 \\ 160 & 2.4303 \mathrm{E}-02 & 1.4098 \mathrm{E}-08 & 1.7783 \mathrm{E}-05 \\ 170 & 0.0000 \mathrm{E}+00 & 0.0000 \mathrm{E}+00 & 0.0000 \mathrm{E}+00 \\ 180 & 0.0000 \mathrm{E}+00 & 0.0000 \mathrm{E}+00 & 0.0000 \mathrm{E}+00 \\ 190 & 0.0000 \mathrm{E}+00 & 0.0000 \mathrm{E}+00 & 0.0000 \mathrm{E}+00 \\ 200 & 0.0000 \mathrm{E}+00 & 0.0000 \mathrm{E}+00 & 0.0000 \mathrm{E}+00 \\ 210 & 0.0000 \mathrm{E}+00 & 0.0000 \mathrm{E}+00 & 0.0000 \mathrm{E}+00 \\ 220 & 0.0000 \mathrm{E}+00 & 0.0000 \mathrm{E}+00 & 0.0000 \mathrm{E}+00 \\ 230 & 0.0000 \mathrm{E}+00 & 0.0000 \mathrm{E}+00 & 0.0000 \mathrm{E}+00 \\ 240 & 0.0000 \mathrm{E}+00 & 0.0000 \mathrm{E}+00 & 0.0000 \mathrm{E}+00 \\ 250 & 0.0000 \mathrm{E}+00 & 0.0000 \mathrm{E}+00 & 0.0000 \mathrm{E}+00 \\ 260 & 0.0000 \mathrm{E}+00 & 0.0000 \mathrm{E}+00 & 0.0000 \mathrm{E}+00 \\ 270 & 0.0000 \mathrm{E}+00 & 0.0000 \mathrm{E}+00 & 0.0000 \mathrm{E}+00 \\ 280 & 0.0000 \mathrm{E}+00 & 0.0000 \mathrm{E}+00 & 0.0000 \mathrm{E}+00 \\ 290 & 0.0000 \mathrm{E}+00 & 0.0000 \mathrm{E}+00 & 0.0000 \mathrm{E}+00 \\ 300 & 0.0000 \mathrm{E}+00 & 0.0000 \mathrm{E}+00 & 0.0000 \mathrm{E}+00\end{array}$


Exhibit C.10. Sample SOURCE1 output summary for cracked vaults (filename.vt2)

Sample run of Cs-137 in a tumulus-type disposal facility (with concrete pad)

Nuclide-specific parameters:

\begin{tabular}{ccccccc} 
Nuclide & Half-life Solubility & $\begin{array}{c}\text { Waste } \\
\mathrm{Kd} \\
(\mathrm{ml} / \mathrm{g})\end{array}$ & $\begin{array}{c}\text { Diffusion coefficient } \\
\text { Waste } \\
(\mathrm{m} \star \star 2 / \mathrm{s})\end{array}$ & $\begin{array}{c}\text { Concrete } \\
\left(\mathrm{m}^{\star} 2 / \mathrm{s}\right)\end{array}$ & $\begin{array}{c}\text { Invitial } \\
\text { (g) }\end{array}$ \\
\hline $\mathrm{Cs}-137$ & $3.00 \mathrm{E}+01$ & $1.60 \mathrm{E}+01$ & $1.99 \mathrm{E}+01$ & $6.80 \mathrm{E}-12$ & $5.12 \mathrm{E}-13$ & $1.00 \mathrm{E}+00$
\end{tabular}

Output summary per number of cracked vaults:

Cs -137

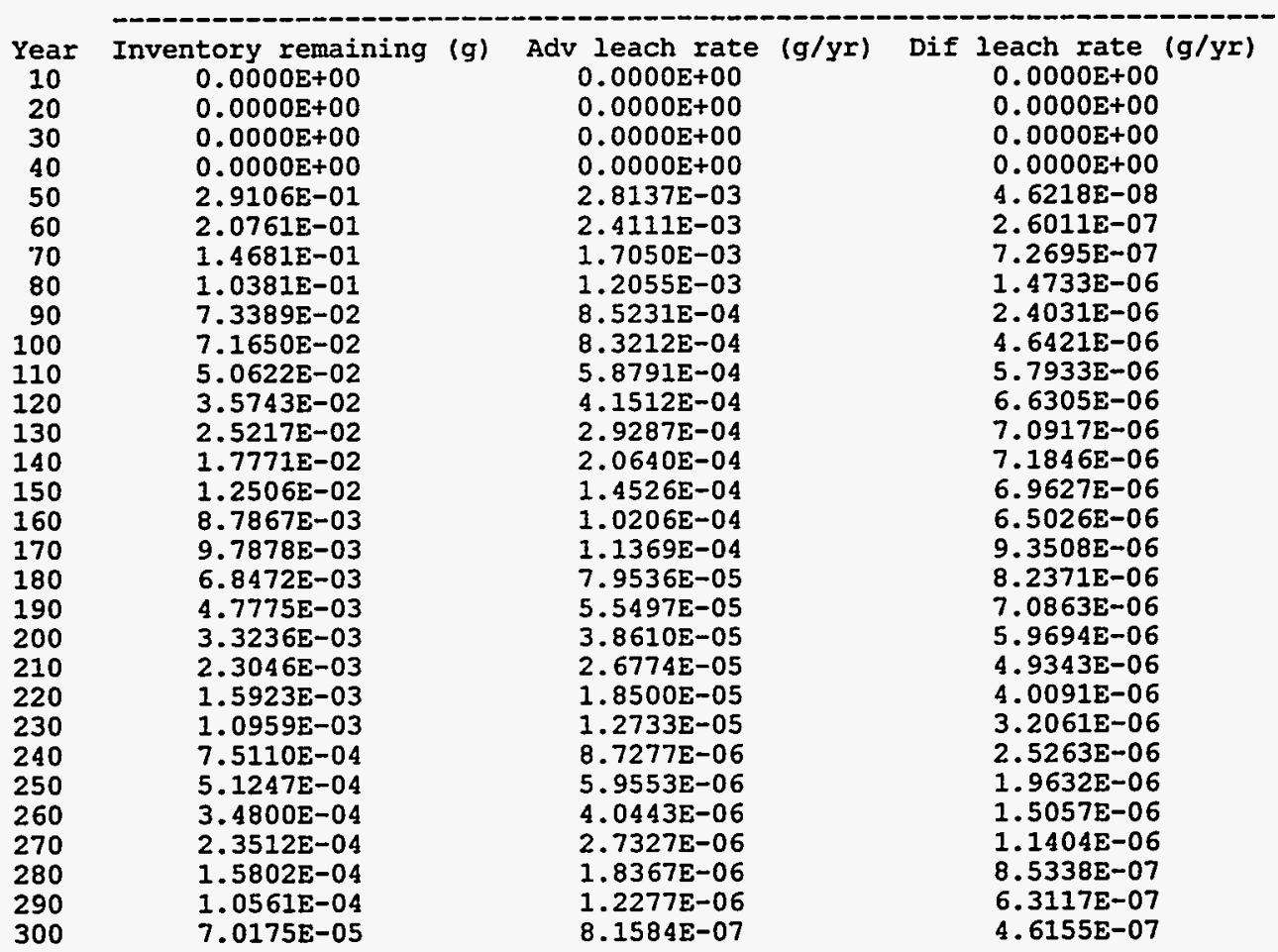


Exhibit C.11. Sample SOURCE1 input file for ${ }^{137} \mathrm{Cs}$ in a tumulus-type facility without a concrete pad (filename.inp)

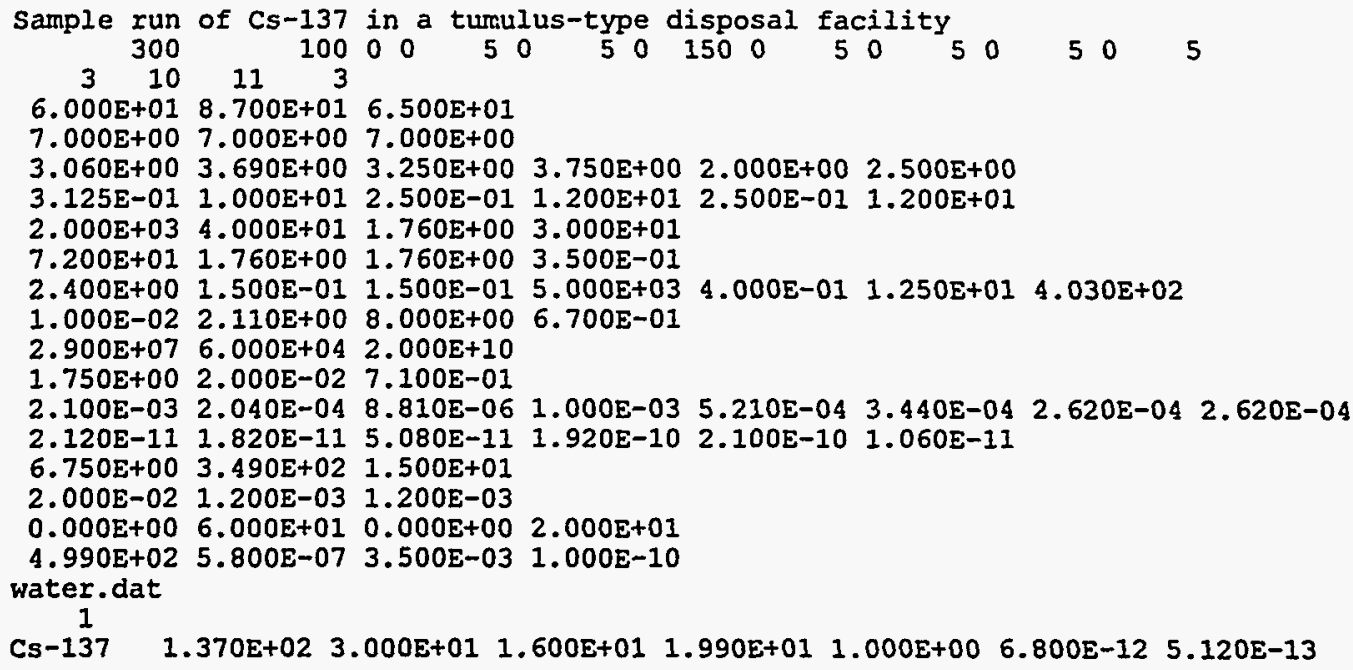


Exhibit C.12. Sample SOURCE2 input file for ${ }^{238} \mathrm{U}$ in a silo-type facility (filename.inp)

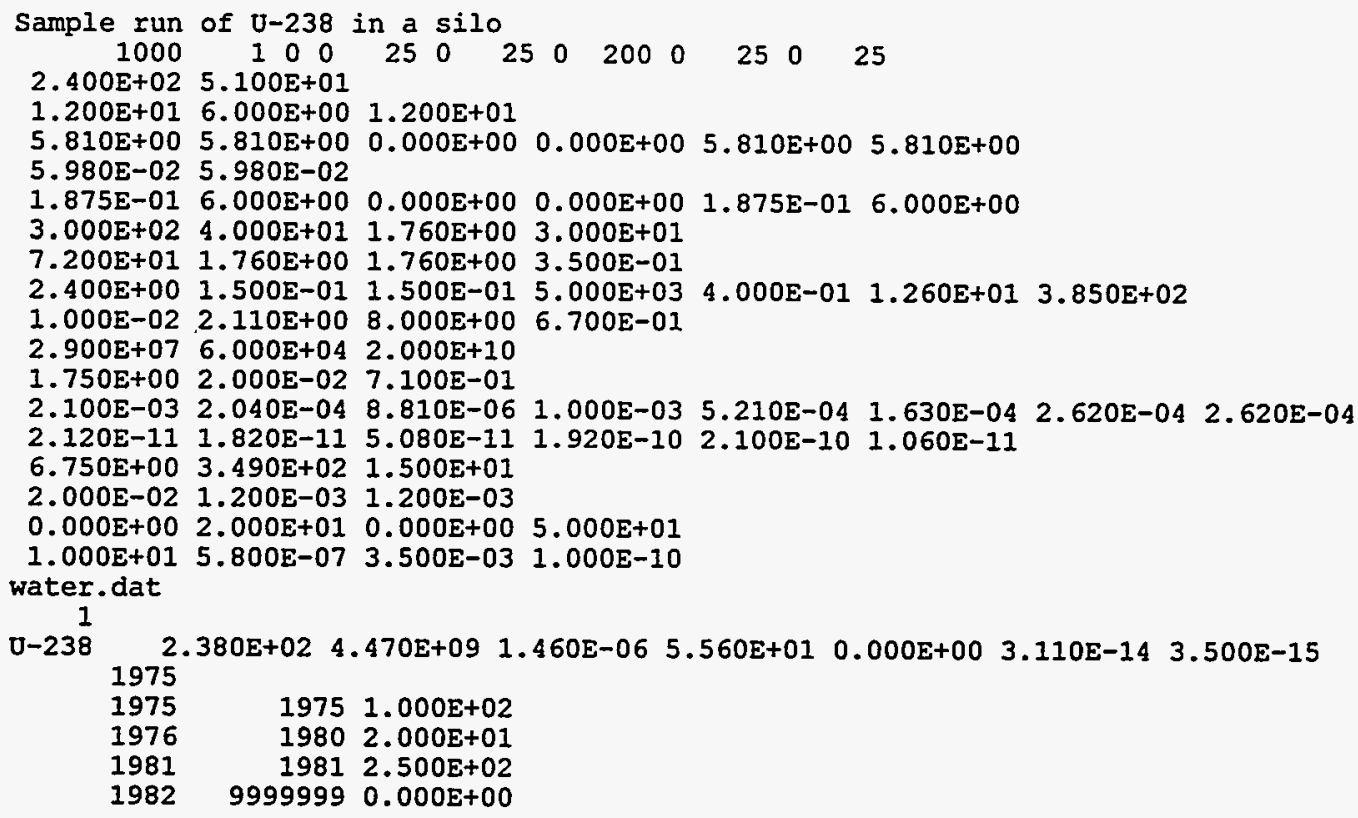


Exhibit C.13. Sample SOURCE2 output file for input data summary and concrete analyses (filename.con)

Sample run of $\mathrm{t}-238$ in a silo

Input Data Summary:

Simulation lengt

Output edit frequency

1000 years

200 years

Disposal technology: silo

Disposal unit area

1. $00 \mathrm{E}+01 \mathrm{~m}^{\star \star * 2}$

Total dissolved solids

Groundwater temperature

Groundwater $\mathrm{pH}$

$3.49 \mathrm{E}+02 \mathrm{ppm}$

1. $50 \mathrm{E}+01 \mathrm{deg} \mathrm{c}$

$6.75 E+00$

Saturated hydraulic conductivity: Recharge

Soil backfill

Concrete

$5.80 \mathrm{E}-07 \mathrm{~cm} / \mathrm{s}$

$3.50 \mathrm{E}-03 \mathrm{~cm} / \mathrm{s}$

$1.00 \mathrm{E}-10 \mathrm{~cm} / \mathrm{s}$

Groundwater constituent concentrations:

$$
\text { Catt }
$$

Cl-

co3--

$\mathrm{Mgt+}$

so4-- (inside silo or well)

SO4-- (outside silo or well)

02

$2.10 \mathrm{E}-03 \mathrm{~mole} / \mathrm{I}$

2.04E-04 mole/L

1. 00E-03 mole/L

5.21E-04 mole/I

2. 62E-04 mole/I

2. 62E-04 mole/I

1. 63E-04 mole/L

Constituent solubilitiès:

$\mathrm{Ca}(\mathrm{OH}) 2$

CO3--

2.00E-02 mole/L

1.20E-03 mole/L

$1.20 \mathrm{E}-03 \mathrm{~mole} / \mathrm{L}$

Concrete constituent concentrations:

Calcium Concentration in $\mathrm{C}-\mathrm{S}-\mathrm{H}$ system

Calcium concentration in pore fluid

Cao content in cement

Free Cl-

Silica concentration in $\mathrm{C}-\mathrm{S}-\mathrm{H}$ system

$1.75 E+00$ mole/I

2.00E-02 mole/I

2.11E+00 mole/I

1.00E-02 mole/L

7.10E-01 mole/L

Concrete design specifications:

Compressive strength at 28 days

Poisson's ratio of concrete

$3.52 E+02 \mathrm{~kg} / \mathrm{cm}^{\star \star} 2$

1.50E-01

2.04E $+06 \mathrm{~kg} / \mathrm{cm}^{\star *} 2$

Modulus of elasticity of steel

Yield strength of steel

Modulus of subgrade reaction

Young's modulus of elasticity

Concrete water/cement ratio

Concrete density

Concrete porosity

Cement content

Initial pH

$4.22 \mathrm{E}+03 \mathrm{~kg} / \mathrm{Cm}^{\star \star * 2}$

$2.11 \mathrm{E}+01 \mathrm{~kg} / \mathrm{cm}^{\star *} 2$

2. 04E $+05 \mathrm{~kg} / \mathrm{cm}^{\star *} 2$

4. $00 \mathrm{E}-01$

$2.40 \mathrm{E}+00 \mathrm{~g} / \mathrm{cm}^{\star \star} 3$

1. 50E-01

$3.85 \mathrm{E}+02 \mathrm{~kg} / \mathrm{m} * \star 3$

$1.26 \mathrm{E}+01$

Diffusion coefficients in concrete: $\mathrm{NaOH}, \mathrm{KOH}$

$\mathrm{Ca}(\mathrm{OH}) 2$

C1-

$\mathrm{CO} 2$

02

SO4--

$2.12 \mathrm{E}-11 \mathrm{~m} * * 2 / \mathrm{s}$

$1.82 \mathrm{E}-11 \mathrm{~m} * * 2 / \mathrm{s}$

5. 08E-11 m**2/s

1. $92 \mathrm{E}-10 \mathrm{~m} * * 2 / \mathrm{s}$

$2.10 \mathrm{~s}-10 \mathrm{~m} * * 2 / \mathrm{s}$

1. $06 \mathrm{E}-11 \mathrm{~m} * * 2 / \mathrm{s}$ 
Silo design specifications:

Silo dimensions:
Radius

Height

$1.30 \mathrm{E}+00 \mathrm{~m}$

$6.10 \mathrm{E}+00 \mathrm{~m}$

Concrete member thickness:

Roof

Walls

Floor

$3.05 \mathrm{E}+01 \mathrm{~cm}$

$1.52 \mathrm{E}+01 \mathrm{~cm}$

$3.05 \mathrm{E}+01 \mathrm{~cm}$

Steel reinforcement radius:

Roof

Walis

Floor

$4.76 \mathrm{E}-01 \mathrm{~cm}$ $0.00 \mathrm{E}+00 \mathrm{~cm}$

$4.76 \mathrm{E}-01 \mathrm{~cm}$

Spacing of steel reinforcement:

Roof

Walls

Floor

$1.52 \mathrm{E}+01 \mathrm{~cm}$

$0.00 \mathrm{E}+00 \mathrm{~cm}$

$1.52 \mathrm{E}+01 \mathrm{~cm}$

$1.52 \mathrm{E}-01 \mathrm{~cm}$

$1.52 \mathrm{E}-01 \mathrm{~cm}$

Compression face

Tension face

Concrete cover thickness on tension face:

Roof:

$\mathrm{X}$-direction

Y-direction

Walls:

Horizontal direction

Vertical direction

Floor:

$\mathrm{X}$-direction

$\mathrm{Y}$-direction

static load

$1.48 \mathrm{E}+01 \mathrm{~cm}$

$1.48 \mathrm{E}+01 \mathrm{~cm}$

$0.00 \mathrm{E}+00 \mathrm{~cm}$

$0.00 \mathrm{E}+00 \mathrm{~cm}$

$1.48 \mathrm{E}+01 \mathrm{~cm}$

$1.48 \mathrm{E}+01 \mathrm{~cm}$

$3.95 \mathrm{E}-01 \mathrm{~kg} / \mathrm{cm}^{\star \star 2}$

$1.83 \mathrm{E}+00 \mathrm{~m}$

$1.76 \mathrm{E}+00 \mathrm{~g} / \mathrm{cm}^{\star \star} 3$

4. $00 \mathrm{E}+01 \mathrm{deg}$

$3.00 E+01$ deg

$1.76 \mathrm{E}+00 \mathrm{~g} / \mathrm{cm} \star * 3$

$1.76 \mathrm{E}+00 \mathrm{~g} / \mathrm{cm} \star \star 3$

$3.50 \mathrm{E}-01$

Waste density

Relative saturation of waste

Concrete and steel failure rates:

Epoxy coating:

start of failure

Time to complete failure

Steel liner:

start of failure

Time to complete failure

$0.00 \mathrm{E}+00$ years

$2.00 \mathrm{E}+01$ years

$0.00 \mathrm{E}+00$ years

$5.00 E+01$ years

Nuclide-specific parameters:

\begin{tabular}{|c|c|c|c|c|c|c|}
\hline Nuc & $\begin{array}{c}\text { Half-life } \\
\text { (yr) }\end{array}$ & $\begin{array}{c}\text { Solubility } \\
\text { (mole/l) }\end{array}$ & $\begin{array}{c}\text { Waste } \\
\mathrm{kd} \\
(\mathrm{ml} / \mathrm{g})\end{array}$ & $\begin{array}{c}\text { Diffusion } \\
\text { Haste } \\
\left(m^{\star \star} 2 / s\right)\end{array}$ & $\begin{array}{c}\text { coefficient } \\
\text { Concrete } \\
(m \star \star 2 / s)\end{array}$ & $\begin{array}{l}\text { Initial } \\
\text { inventory } \\
\text { (g) }\end{array}$ \\
\hline & $1.47 \mathrm{E}+09$ & $1.46 \mathrm{E}-06$ & $.56 E+01$ & $3.11 \mathrm{E}-14$ & $3.50 \mathrm{E}-15$ & $1.00 \mathrm{E}+02$ \\
\hline
\end{tabular}

Annual Summary for Year 1975

Concrete Degradation Summary

Member thickness:

silo roof

$3.04 \mathrm{E}+01 \mathrm{~cm}$

silo wall

$1.52 \mathrm{E}+01 \mathrm{~cm}$ 
Silo floor

Concrete loss due to sulfate attack:

silo roof

silo wall

silo floor

Fractional loss of yield strength

due to $\mathrm{Ca}(\mathrm{OH}) 2$ leaching:

silo roof

Silo wall

silo floor

Corrosion results:

Time to onset of corrosion:

silo roof

silo floor

Corrosion product layer thickness: silo roof Silo floor

Remaining steel reinforcement:

silo roof

Silo floor

Remaining corrugated steel: Compression face

Tension face

Concrete Cracking Analysis

cracking due to corrosion of steel:

\section{silo roof}

Silo wall

Silo floor

Cracking due to loading and shear:

$$
\begin{aligned}
& \text { Silo roof } \\
& \text { Silo wall } \\
& \text { Silo floor }
\end{aligned}
$$

Kd/diffusion controlled leach rates $(g / y r)$
$3.04 E+01 \mathrm{~cm}$

$5.10 \mathrm{E}-02 \mathrm{~cm}$ $5.10 \mathrm{E}-02 \mathrm{~cm}$ 5. $10 \mathrm{E}-02 \mathrm{~cm}$

$0.00 E+00$

$0.00 E+00$

$0.00 \mathrm{E}+00$

0 years

0 years

$0.00 \mathrm{E}+00 \mathrm{~cm}$ $0.00 \mathrm{E}+00 \mathrm{~cm}$

$4.76 \mathrm{E}-01 \mathrm{~cm}$ $4.76 \mathrm{E}-01 \mathrm{~cm}$

$1.49 \mathrm{E}-01 \mathrm{~cm}$ $1.49 \mathrm{E}-01 \mathrm{~cm}$

none

none

none

none

none

none
$2.03 E+01 \mathrm{~cm}$ $5.03 \mathrm{E}+00 \mathrm{~cm}$ 2.03E+01 cm

1. $02 \mathrm{E}+01 \mathrm{~cm}$ $1.02 \mathrm{E}+01 \mathrm{~cm}$ 1. $02 \mathrm{E}+01 \mathrm{~cm}$

$0.00 \mathrm{E}+00$

$0.00 E+00$

$0.00 \mathrm{E}+00$ 
Corrosion results:

Time to onset of corrosion:

silo roof

silo floor

0 years

0 years

Corrosion product layer thickness:

Silo roof

Silo floor

$0.00 \mathrm{E}+00 \mathrm{~cm}$

$0.00 \mathrm{E}+00 \mathrm{~cm}$

Remaining steel reinforcement:

Silo roof

Silo floor

$4.76 \mathrm{E}-01 \mathrm{~cm}$

$4.76 \mathrm{E}-01 \mathrm{~cm}$

Remaining corrugated steel:

Compression face

Tension face

$0.00 \mathrm{E}+00 \mathrm{~cm}$

$0.00 \mathrm{E}+00 \mathrm{~cm}$

Concrete Cracking Analysis

Cracking due to corrosion of steel:

silo roof

Silo wall

Silo floor

none

none

none

Cracking due to loading and shear:

Silo roof

Silo wall

silo floor

none

none

none

Kd/diffusion controlled leach rates $(\mathrm{g} / \mathrm{yr})$

J-238 1.10E-04

Annual Sumnary for Year 2375

Concrete Degradation Sumary

Member thickness:

Silo roof

Silo wall

silo floor

$1.01 \mathrm{E}+01 \mathrm{~cm}$

$0.00 \mathrm{E}+00 \mathrm{~cm}$

$1.01 \mathrm{E}+01 \mathrm{~cm}$

Concrete loss due to sulfate attack:

Silo roof

Silo wall

Silo floor

$2.04 \mathrm{E}+01 \mathrm{~cm}$ $1.52 \mathrm{E}+01 \mathrm{~cm}$ 2.04E+01 cm

Fractional loss of yield strength

due to $\mathrm{Ca}(\mathrm{OH}) 2$ leaching:

silo roof

Silo wall

silo floor

$0.00 \mathrm{E}+00$

$0.00 \mathrm{E}+00$

$0.00 E+00$

Corrosion results:

Time to onset of corrosion:

$$
\text { silo roof }
$$

silo floor

0 years

0 years

Corrosion product layer thickness:

silo roof

silo floor

$0.00 \mathrm{E}+00 \mathrm{~cm}$ $0.00 \mathrm{E}+00 \mathrm{~cm}$

Remaining steel reinforcement:

silo roof

silo floor

$4.76 \mathrm{E}-01 \mathrm{~cm}$

$4.76 \mathrm{E}-01 \mathrm{~cm}$ 
Remaining corrugated steel:

Compression face

Tension face

$0.00 \mathrm{E}+00 \mathrm{~cm}$ $0.00 \mathrm{E}+00 \mathrm{~cm}$

Concrete Cracking Analysis

Cracking due to corrosion of steel:

silo roof

silo wall

silo floor

none

none

none

cracking due to loading and shear:

silo roof

Silo wall

none

cracked

silo floor

none

Concrete crack characteristics:

silo wall

Average crack width (cm)

Fractional volume of cracks

4.24E-01

$2.98 \mathrm{E}-09$

Kd/diffusion controlled leach rates $(\mathrm{g} / \mathrm{yr})$

Annual Summary for Year 2575

Concrete Degradation Summary

Member thickness:

$$
\text { silo roof }
$$

silo wall

silo floor

$0.00 \mathrm{E}+00 \mathrm{~cm}$

$0.00 \mathrm{E}+00 \mathrm{~cm}$

$0.00 \mathrm{E}+00 \mathrm{~cm}$

Concrete loss due to sulfate attack:

silo roof

Silo wall

silo floor

$3.05 \mathrm{E}+01 \mathrm{~cm}$

$1.52 \mathrm{E}+01 \mathrm{~cm}$

$3.05 \mathrm{E}+01 \mathrm{~cm}$

Fractional loss of yield strength

due to $\mathrm{Ca}(\mathrm{OH}) 2$ leaching:

Silo roof

Silo wall

Silo floor

$0.00 \mathrm{E}+00$

$1.00 \mathrm{E}+00$

$0.00 \mathrm{E}+00$

Corrosion results:

Time to onset of corrosion:

Silo roof

silo floor

569 years

569 years

Corrosion product layer thickness: silo roof

silo floor

$6.34 \mathrm{E}-01 \mathrm{CII}$

$6.34 \mathrm{E}-01 \mathrm{~cm}$

Remaining steel reinforcement:

Silo roof

silo floor

$0.00 \mathrm{E}+00 \mathrm{~cm}$

$0.00 \mathrm{E}+00 \mathrm{~cm}$

Remaining corrugated steel:

Compression face

Tension face

$0.00 \mathrm{E}+00 \mathrm{~cm}$

$0.00 \mathrm{E}+00 \mathrm{~cm}$ 
Concrete cracking Analysis

Cracking due to corrosion of steel:

silo roof

Silo wall

none

none

silo floor

none

Cracking due to loading and shear:

$$
\begin{aligned}
& \text { Silo roof } \\
& \text { Silo wall } \\
& \text { Silo floor }
\end{aligned}
$$

Concrete crack characteristics:

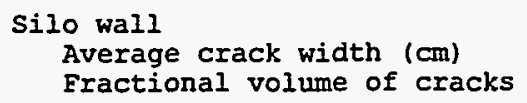

$\mathrm{Kd} / \mathrm{diffusion}$ controlled leach rates $(\mathrm{g} / \mathrm{yr}$ )

Annual Summary for Year 2775

Concrete Degradation Summary

$\begin{array}{ll}\text { Member thickness: } & 0.00 \mathrm{E}+00 \mathrm{~cm} \\ \text { Silo roof } & 0.00 \mathrm{E}+00 \mathrm{~cm} \\ \text { Silo wall } & 0.00 \mathrm{E}+00 \mathrm{~cm} \\ \text { Silo floor } & \\ \text { Concrete loss due to sulfate attack: } & 3.05 \mathrm{E}+01 \mathrm{~cm} \\ \text { Silo roof } & 1.52 \mathrm{E}+01 \mathrm{~cm} \\ \text { Silo wall } & 3.05 \mathrm{E}+01 \mathrm{~cm} \\ \text { Silo floor } & \\ \text { Fractional loss of yield strength } & \\ \text { due to Ca(OH)2 leaching: } & 0.00 \mathrm{E}+00 \\ \text { Silo roof } & 1.00 \mathrm{E}+00 \\ \text { Silo wall } & 0.00 \mathrm{E}+00 \\ \text { Silo floor } & \\ \text { Corrosion results: } & \\ \text { Time to onset of corrosion: } & 569 \mathrm{years} \\ \text { Silo roof } & 569 \mathrm{years} \\ \text { Silo floor } & \\ \text { Corrosion product layer thickness: } & \\ \text { Silo roof } & \\ \text { Silo floor } & 6.34 \mathrm{E}-01 \mathrm{~cm} \\ \text { Remaining steel reinforcement: } & \\ \text { Silo roof } & \\ \text { Silo floor } & 0.00 \mathrm{E}+00 \mathrm{~cm} \\ \text { Remaining corrugated steel: } & 0.00 \mathrm{E}+00 \mathrm{~cm} \\ \text { Compression face } & \\ \text { Tension face } & 0.00 \mathrm{E}+00 \mathrm{~cm} \\ & \end{array}$

Concrete Cracking Analysis

Cracking due to corrosion of steel: 
Silo wall

silo floor

cracking due to loading and shear:

silo roof

silo wall

silo floor

Concrete crack characteristics:

Silo wall

Average crack width (cm)

Fractional volume of cracks

4. 24E-01

2. 98E-09

none

cracked

none

$\mathrm{Kd} / \mathrm{diffusion}$ controlled leach rates $(\mathrm{g} / \mathrm{yr})$

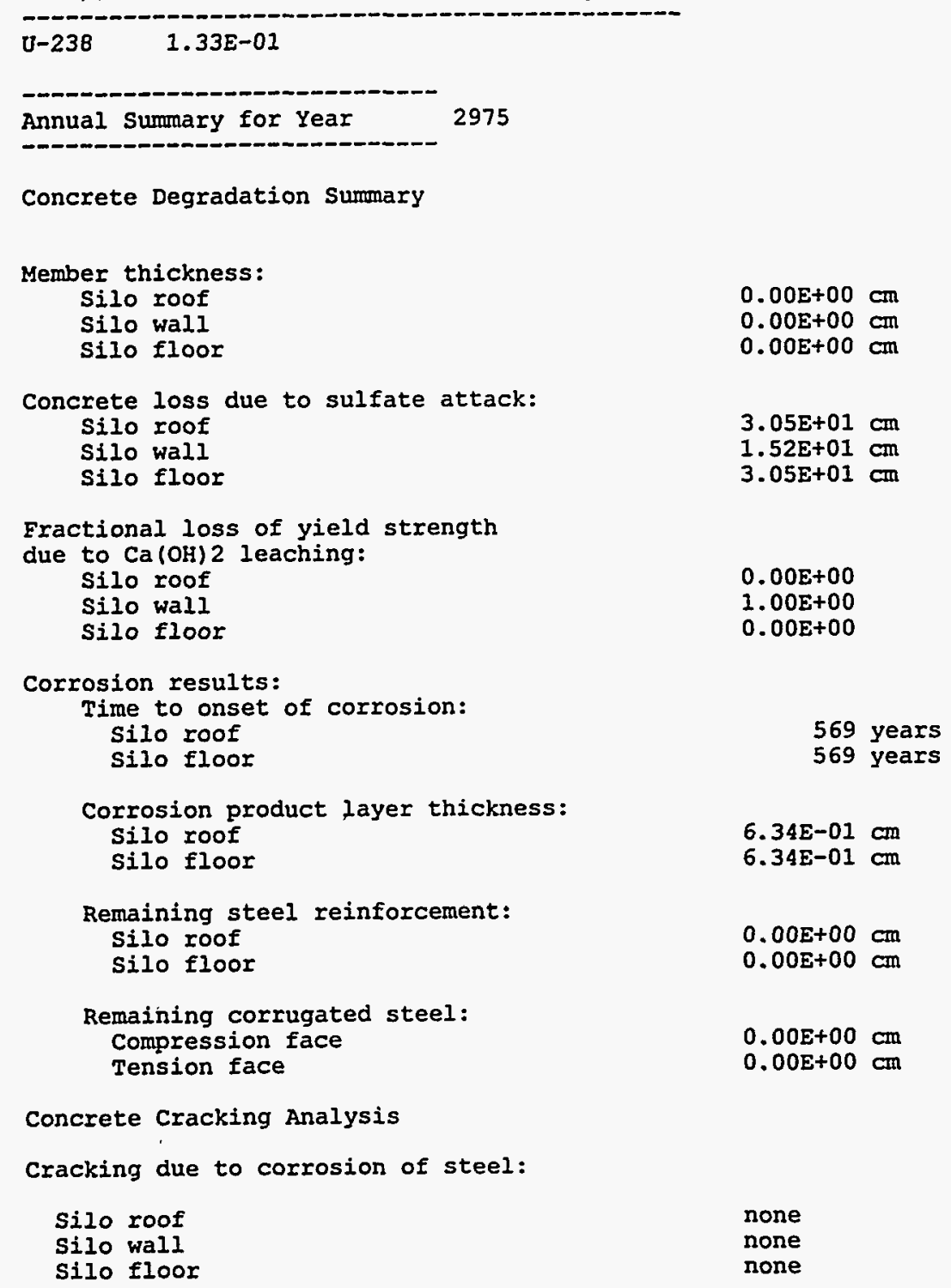

$3.05 \mathrm{E}+01 \mathrm{~cm}$ $1.52 \mathrm{E}+01 \mathrm{~cm}$

$0.00 \mathrm{E}+00$

$1.00 \mathrm{E}+00$

$0.00 \mathrm{E}+00$

569 years

ars

$6.34 \mathrm{E}-01 \mathrm{~cm}$ $6.34 \mathrm{E}-01 \mathrm{~cm}$

$0.00 \mathrm{E}+00 \mathrm{~cm}$

$0.00 \mathrm{E}+00 \mathrm{~cm}$

none 
Cracking due to loading and shear:

Silo roof

Silo wall

cracked

Silo floor

none

Concrete crack characteristics:

Silo wall

Average crack width (cm)

$4.24 \mathrm{E}-01$

Fractional volume of cracks

$2.98 \mathrm{E}-09$

$\mathrm{Kd} / \mathrm{diffusion}$ controlled leach rates $(\mathrm{g} / \mathrm{yr}$ )

U-238 $4.83 \mathrm{E}-02$ 
Exhibit C.14. Sample SOURCE2 output of water infiltration input data (filename.h20)

Summary of Infiltration Data

Sample run of $U-238$ in a silo

\begin{tabular}{|c|c|c|c|c|c|c|c|c|c|c|c|c|c|}
\hline Year1 & Year2 & Jan & Eeb & Mar & Apr & May & Jun & Jul & Aug & Sep & Oct & Nov & Dec \\
\hline $\begin{array}{l}1 \\
23 \\
33 \\
34 \\
35 \\
36 \\
37 \\
38 \\
39 \\
40 \\
41 \\
42 \\
43\end{array}$ & $\begin{array}{r}22 \\
32 \\
33 \\
34 \\
35 \\
36 \\
37 \\
38 \\
39 \\
40 \\
41 \\
42 \\
9999999\end{array}$ & $\begin{array}{r}12.42 \\
0.03 \\
0.91 \\
1.80 \\
2.68 \\
3.56 \\
4.44 \\
5.33 \\
6.21 \\
7.09 \\
7.97 \\
8.86 \\
9.74\end{array}$ & $\begin{array}{r}12.42 \\
0.38 \\
1.24 \\
2.10 \\
2.96 \\
3.82 \\
4.68 \\
5.55 \\
6.41 \\
7.27 \\
8.13 \\
8.99 \\
9.85\end{array}$ & $\begin{array}{r}11.68 \\
1.12 \\
2.04 \\
2.96 \\
3.88 \\
4.80 \\
5.72 \\
6.65 \\
7.57 \\
8.49 \\
9.41 \\
10.33 \\
11.25\end{array}$ & $\begin{array}{r}10.92 \\
1.12 \\
1.71 \\
2.30 \\
2.88 \\
3.47 \\
4.06 \\
4.65 \\
5.24 \\
5.83 \\
6.41 \\
7.00 \\
7.59\end{array}$ & $\begin{array}{r}15.75 \\
0.77 \\
1.83 \\
2.89 \\
3.95 \\
5.01 \\
6.07 \\
7.14 \\
8.20 \\
9.26 \\
10.32 \\
11.38 \\
12.44\end{array}$ & $\begin{array}{l}8.48 \\
0.34 \\
0.60 \\
0.86 \\
1.12 \\
1.38 \\
1.64 \\
1.91 \\
2.17 \\
2.43 \\
2.69 \\
2.95 \\
3.21\end{array}$ & $\begin{array}{r}23.44 \\
0.16 \\
0.29 \\
0.42 \\
0.55 \\
0.68 \\
0.81 \\
0.93 \\
1.06 \\
1.19 \\
1.32 \\
1.45 \\
1.58\end{array}$ & $\begin{array}{l}6.20 \\
0.08 \\
0.23 \\
0.38 \\
0.52 \\
0.67 \\
0.82 \\
0.97 \\
1.12 \\
1.27 \\
1.41 \\
1.56 \\
1.71\end{array}$ & $\begin{array}{l}8.00 \\
0.04 \\
0.19 \\
0.33 \\
0.48 \\
0.63 \\
0.77 \\
0.92 \\
1.06 \\
1.21 \\
1.36 \\
1.50 \\
1.65\end{array}$ & $\begin{array}{l}0 . \\
0 . \\
0 . \\
0 . \\
0 . \\
0 . \\
0 . \\
0 . \\
1 . \\
1 . \\
1 . \\
1 .\end{array}$ & $\begin{array}{l}5.54 \\
0.01 \\
0.13 \\
0.26 \\
0.38 \\
0.50 \\
0.62 \\
0.75 \\
0.87 \\
0.99 \\
1.11 \\
1.24 \\
1.36\end{array}$ & $\begin{array}{r}15.98 \\
0.01 \\
0.09 \\
0.16 \\
0.24 \\
0.32 \\
0.39 \\
0.47 \\
0.54 \\
0.62 \\
0.70 \\
0.77 \\
0.85\end{array}$ \\
\hline
\end{tabular}


Exhibit C.15. Sample SOURCE2 output of recharge release component (filename.rch)

Sample run of $\mathrm{U}-238$ in a silo

Water and total grams in recharge component

Year
1999
2024
2049
2074
2099
2124
2149
2174
2199
2224
2249
2274
2299
2324
2349
2374
2399
2424
2449
2474
2499
2524
2549
2574
2599
2624
2649
2674
2699
2724
2749
2774
2799
2824
2849
2874
2899
2924
2949
2974

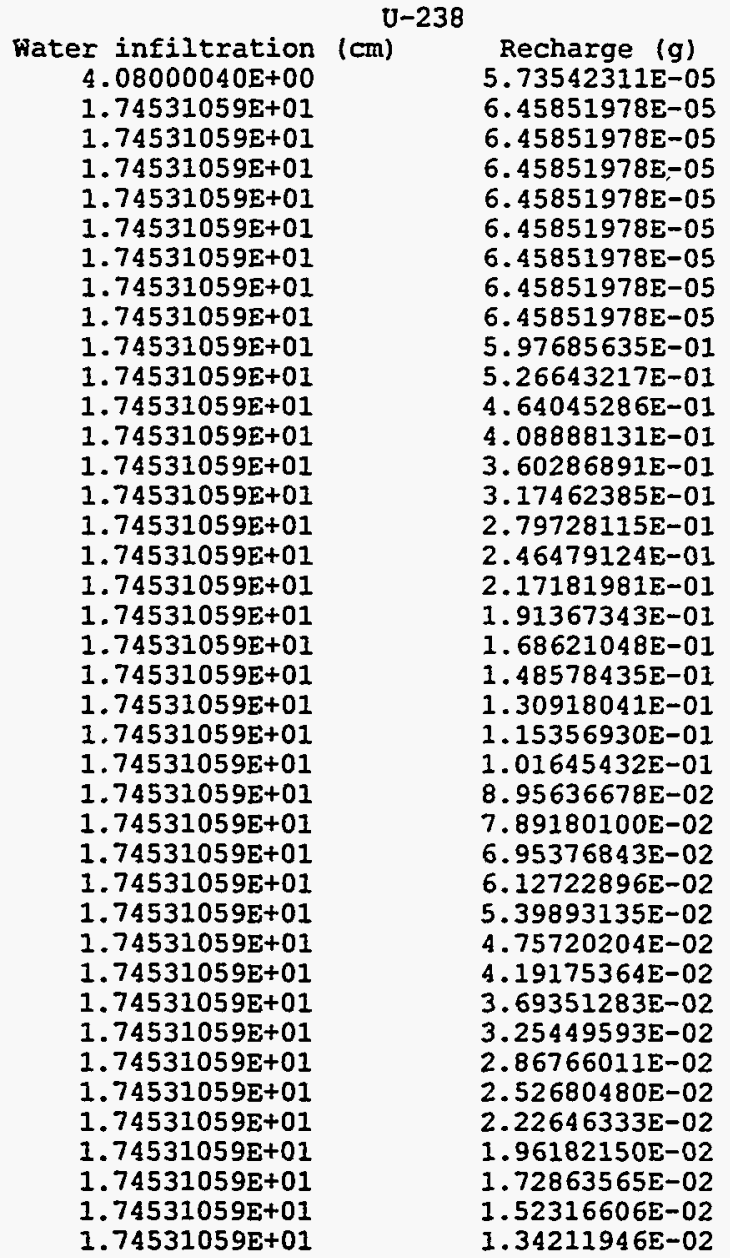


Exhibit C.16. Sample SOURCE2 output of lateral release component (filename.lat)

Sample run of $\mathrm{U}-238$ in a silo

Water and total grams in lateral component

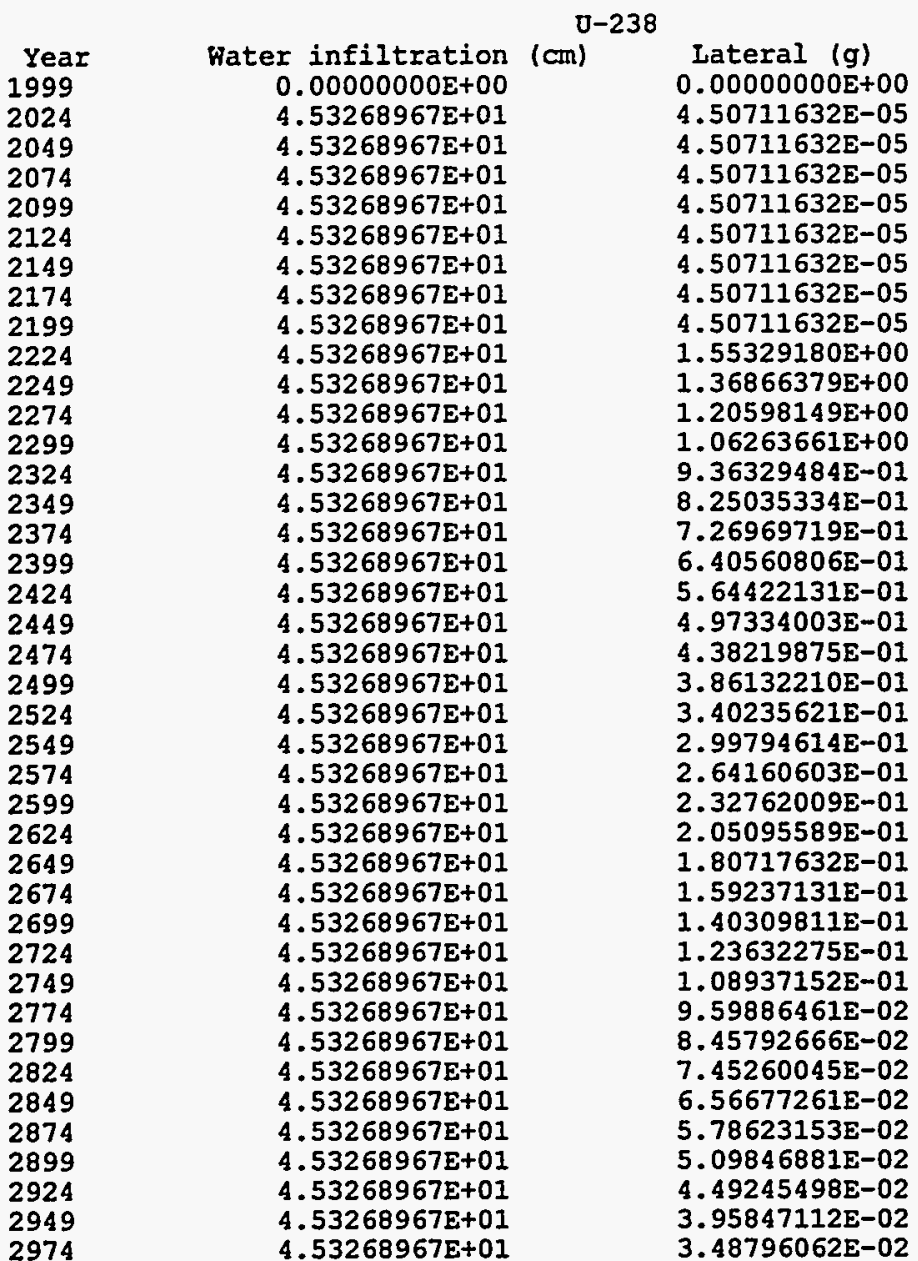


Exhibit C.17. Sample SOURCE2 output of leaching summary (filename.sum)

Sample run of $\mathrm{U}-238$ in a silo

Nuclide-specific parameters:

\begin{tabular}{|c|c|c|c|c|c|c|}
\hline Nuclide & $\begin{array}{l}\text { Half-life } \\
\text { (yr) }\end{array}$ & $\begin{array}{c}\text { Solubility } \\
\text { (mole/1) }\end{array}$ & $\begin{array}{c}\text { Waste } \\
k d \\
(\mathrm{ml} / \mathrm{g})\end{array}$ & 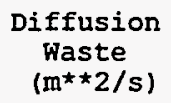 & $\begin{array}{c}\text { coefficient } \\
\text { Concrete } \\
\left(m^{\star \star 2} / \mathrm{s}\right)\end{array}$ & $\begin{array}{c}\text { Initial } \\
\text { inventory } \\
\text { (g) }\end{array}$ \\
\hline $\mathrm{U}-2$ & $1.47 E+09$ & $1.46 \mathrm{E}-06$ & $5.56 \mathrm{E}+01$ & $3.11 \mathrm{E}-14$ & $3.50 E-15$ & $1.00 \mathrm{E}+02$ \\
\hline
\end{tabular}

Output summary:

U-238

\begin{tabular}{|c|c|c|c|c|c|}
\hline $\begin{array}{l}\text { Year } \\
1999 \\
2024 \\
2049 \\
2074 \\
2099 \\
2124 \\
2149 \\
2174 \\
2199 \\
2224 \\
2249 \\
2274 \\
2299 \\
2324 \\
2349 \\
2374 \\
2399 \\
2424 \\
2449 \\
2474 \\
2499 \\
2524 \\
2549 \\
2574 \\
2599 \\
2624 \\
2649 \\
2674 \\
2699 \\
2724 \\
2749 \\
2774 \\
2799 \\
2824 \\
2849 \\
2874 \\
2899 \\
2924 \\
2949 \\
2974\end{array}$ & 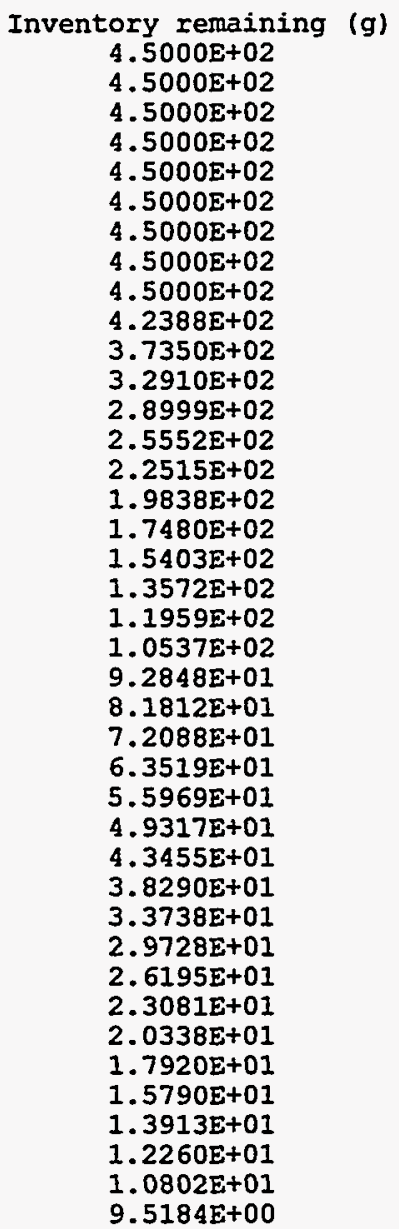 & Annual & $\begin{array}{l}\text { leach rate } \\
5.7354 E-05 \\
1.0966 E-04 \\
1.0966 E-04 \\
1.0966 E-04 \\
1.0966 E-04 \\
1.0966 E-04 \\
1.0966 E-04 \\
1.0966 E-04 \\
1.0966 E-04 \\
2.1510 E+00 \\
1.8953 E+00 \\
1.6700 E+00 \\
1.4715 E+00 \\
1.2966 E+00 \\
1.1425 E+00 \\
1.0067 E+00 \\
8.8704 E-01 \\
7.8160 E-01 \\
6.8870 E-01 \\
6.0684 E-01 \\
5.3471 E-01 \\
4.7115 E-01 \\
4.1515 E-01 \\
3.6581 E-01 \\
3.2233 E-01 \\
2.8401 E-01 \\
2.5026 E-01 \\
2.2051 E-01 \\
1.9430 E-01 \\
1.7120 E-01 \\
1.5085 E-01 \\
1.3292 E-01 \\
1.1712 E-01 \\
1.0320 E-01 \\
9.0936 E-02 \\
8.0127 E-02 \\
7.0603 E-02 \\
6.2211 E-02 \\
5.4816 E-02 \\
4.8301 E-02\end{array}$ & $(g / y r)$ & $\begin{array}{c}\text { Cumulative leached } \\
7.1527 \mathrm{E}-04 \\
2.8865 \mathrm{E}-03 \\
5.6279 \mathrm{E}-03 \\
8.3693 \mathrm{E}-03 \\
1.1111 \mathrm{E}-02 \\
1.3852 \mathrm{E}-02 \\
1.6594 \mathrm{E}-02 \\
1.9335 \mathrm{E}-02 \\
2.2076 \mathrm{E}-02 \\
2.6142 \mathrm{E}+01 \\
7.6525 \mathrm{E}+01 \\
1.2092 \mathrm{E}+02 \\
1.6004 \mathrm{E}+02 \\
1.9451 \mathrm{E}+02 \\
2.2488 \mathrm{E}+02 \\
2.5164 \mathrm{E}+02 \\
2.7522 \mathrm{E}+02 \\
2.9600 \mathrm{E}+02 \\
3.1430 \mathrm{E}+02 \\
3.3044 \mathrm{E}+02 \\
3.4465 \mathrm{E}+02 \\
3.5718 \mathrm{E}+02 \\
3.6821 \mathrm{E}+02 \\
3.7794 \mathrm{E}+02 \\
3.8650 \mathrm{E}+02 \\
3.9405 \mathrm{E}+02 \\
4.0071 \mathrm{E}+02 \\
4.0657 \mathrm{E}+02 \\
4.1173 \mathrm{E}+02 \\
4.1628 \mathrm{E}+02 \\
4.2030 \mathrm{E}+02 \\
4.2383 \mathrm{E}+02 \\
4.2694 \mathrm{E}+02 \\
4.2969 \mathrm{E}+02 \\
4.3210 \mathrm{E}+02 \\
4.3423 \mathrm{E}+02 \\
4.3611 \mathrm{E}+02 \\
4.3776 \mathrm{E}+02 \\
4.3922 \mathrm{E}+02 \\
4.4050 \mathrm{E}+02\end{array}$ \\
\hline
\end{tabular}

The solubility constraints were exceeded for $0-238$ 
Exhibit C.18. Sample SOURCE2 output of advective and diffusive release rates (filename.lch)

Sample run of $\mathrm{U}-238$ in a silo

Nuclide-specific parameters:

\begin{tabular}{|c|c|c|c|c|c|c|}
\hline Nuclide & $\begin{array}{c}\text { Half-life } \\
\text { (yr) }\end{array}$ & $\begin{array}{c}\text { Solubility } \\
\text { (mole/l) }\end{array}$ & $\begin{array}{c}\text { Haste } \\
k d \\
(\mathrm{ml} / \mathrm{g})\end{array}$ & $\begin{array}{l}\text { Diffusion } \\
\text { Waste } \\
(m \star \star 2 / s)\end{array}$ & $\begin{array}{c}\text { coefficient } \\
\text { Concrete } \\
\left(m^{\star \star} 2 / s\right)\end{array}$ & $\begin{array}{l}\text { Initial } \\
\text { inventory } \\
\text { (g) }\end{array}$ \\
\hline & $4.47 E+09$ & $1.46 \mathrm{E}-06$ & $5.56 E+01$ & $3.11 E-14$ & $3.50 E-15$ & $1.00 \mathrm{E}+02$ \\
\hline
\end{tabular}

Output sumary:

$$
\mathrm{U}-238
$$

\begin{tabular}{|c|c|c|c|c|c|c|}
\hline $\begin{array}{l}\text { Year } \\
1999 \\
2024 \\
2049 \\
2074 \\
2099 \\
2124 \\
2149 \\
2174 \\
2199 \\
2224 \\
2249 \\
2274 \\
2299 \\
2324 \\
2349 \\
2374 \\
2399 \\
2424 \\
2449 \\
2474 \\
2499 \\
2524 \\
2549 \\
2574 \\
2599 \\
2624 \\
2649 \\
2674 \\
2699 \\
2724 \\
2749 \\
2774 \\
2799 \\
2824 \\
2849 \\
2874 \\
2899 \\
2924 \\
2949 \\
2974\end{array}$ & $\begin{array}{r}\text { Advach rate } \\
5.7354 \mathrm{E}-05 \\
1.0966 \mathrm{E}-04 \\
1.0966 \mathrm{E}-04 \\
1.0966 \mathrm{E}-04 \\
1.0966 \mathrm{E}-04 \\
1.0966 \mathrm{E}-04 \\
1.0966 \mathrm{E}-04 \\
1.0966 \mathrm{E}-04 \\
1.0966 \mathrm{E}-04 \\
2.1510 \mathrm{E}+00 \\
1.8953 \mathrm{E}+00 \\
1.6700 \mathrm{E}+00 \\
1.4715 \mathrm{E}+00 \\
1.2966 \mathrm{E}+00 \\
1.1425 \mathrm{E}+00 \\
1.0067 \mathrm{E}+00 \\
8.8704 \mathrm{E}-01 \\
7.8160 \mathrm{E}-01 \\
6.8870 \mathrm{E}-01 \\
6.0684 \mathrm{E}-01 \\
5.3471 \mathrm{E}-01 \\
4.7115 \mathrm{E}-01 \\
4.1515 \mathrm{E}-01 \\
3.6581 \mathrm{E}-01 \\
3.2233 \mathrm{E}-01 \\
2.8401 \mathrm{E}-01 \\
2.5026 \mathrm{E}-01 \\
2.2051 \mathrm{E}-01 \\
1.9430 \mathrm{E}-01 \\
1.7120 \mathrm{E}-01 \\
1.5085 \mathrm{E}-01 \\
1.3292 \mathrm{E}-01 \\
1.1712 \mathrm{E}-01 \\
1.0320 \mathrm{E}-01 \\
9.0936 \mathrm{E}-02 \\
8.0127 \mathrm{E}-02 \\
7.0603 \mathrm{E}-02 \\
6.2211 \mathrm{E}-02 \\
5.4816 \mathrm{E}-02 \\
4.8301 \mathrm{E}-02\end{array}$ & (g/yr) & $\begin{array}{r}\text { Dif leach rate } \\
0.0000 \mathrm{E}+00 \\
0.0000 \mathrm{E}+00 \\
0.0000 \mathrm{E}+00 \\
0.0000 \mathrm{E}+00 \\
0.0000 \mathrm{E}+00 \\
0.0000 \mathrm{E}+00 \\
0.0000 \mathrm{E}+00 \\
0.0000 \mathrm{E}+00 \\
0.0000 \mathrm{E}+00 \\
0.0000 \mathrm{E}+00 \\
0.0000 \mathrm{E}+00 \\
0.0000 \mathrm{E}+00 \\
0.0000 \mathrm{E}+00 \\
0.0000 \mathrm{E}+00 \\
0.0000 \mathrm{E}+00 \\
0.0000 \mathrm{E}+00 \\
0.0000 \mathrm{E}+00 \\
0.0000 \mathrm{E}+00 \\
0.0000 \mathrm{E}+00 \\
0.0000 \mathrm{E}+00 \\
0.0000 \mathrm{E}+00 \\
0.0000 \mathrm{E}+00 \\
0.0000 \mathrm{E}+00 \\
0.0000 \mathrm{E}+00 \\
0.0000 \mathrm{E}+00 \\
0.0000 \mathrm{E}+00 \\
0.0000 \mathrm{E}+00 \\
8.7380 \mathrm{E}-37 \\
1.0117 \mathrm{E}-35 \\
9.8592 \mathrm{E}-35 \\
8.2226 \mathrm{E}-34 \\
5.9554 \mathrm{E}-33 \\
3.7943 \mathrm{E}-32 \\
2.1507 \mathrm{E}-31 \\
1.0956 \mathrm{E}-30 \\
5.0601 \mathrm{E}-30 \\
2.1361 \mathrm{E}-29 \\
8.3000 \mathrm{E}-29 \\
2.9877 \mathrm{E}-28 \\
1.0020 \mathrm{E}-27\end{array}$ & 列 & Annual & $\begin{array}{l}\text { leach rate } \\
5.7354 E-05 \\
1.0966 E-04 \\
1.0966 E-04 \\
1.0966 E-04 \\
1.0966 E-04 \\
1.0966 E-04 \\
1.0966 E-04 \\
1.0966 E-04 \\
1.0966 E-04 \\
2.1510 E+00 \\
1.8953 E+00 \\
1.6700 E+00 \\
1.4715 E+00 \\
1.2966 E+00 \\
1.1425 E+00 \\
1.0067 E+00 \\
8.8704 E-01 \\
7.8160 E-01 \\
6.8970 E-01 \\
6.0684 E-01 \\
5.3471 E-01 \\
4.7115 E-01 \\
4.1515 E-01 \\
3.6581 E-01 \\
3.2233 E-01 \\
2.8401 E-01 \\
2.5026 E-01 \\
2.2051 E-01 \\
1.9430 E-01 \\
1.7120 E-01 \\
1.5085 E-01 \\
1.3292 E-01 \\
1.1712 E-01 \\
1.0320 E-01 \\
9.0936 E-02 \\
8.0127 E-02 \\
7.0603 E-02 \\
6.2211 E-02 \\
5.4816 E-02 \\
4.8301 E-02\end{array}$ \\
\hline
\end{tabular}

The solubility constraints were exceeded for U-238 
Exhibit C.19. Sample SOURCE2 input file for ${ }^{137} \mathrm{Cs}$ in a well-type facility (filename.inp)

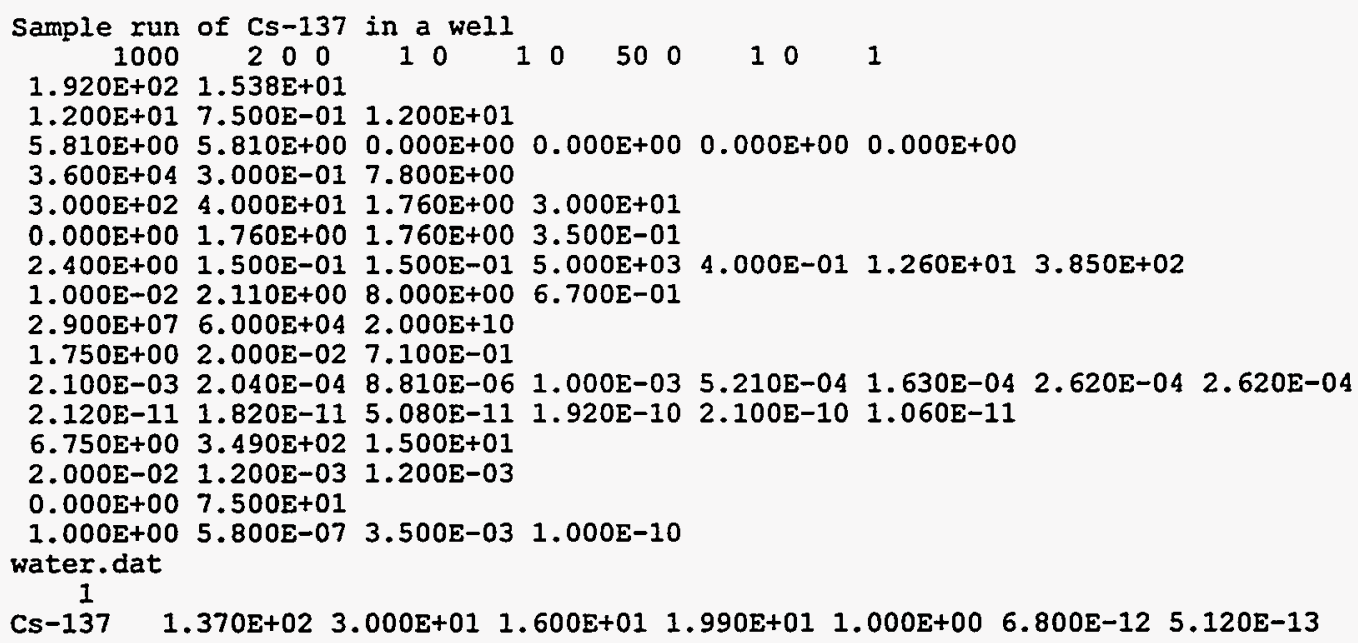


Exhibit C.20. Sample SOURCE2 input file for ${ }^{137} \mathrm{Cs}$ in a well-in-silo-type facility (filename.inp)

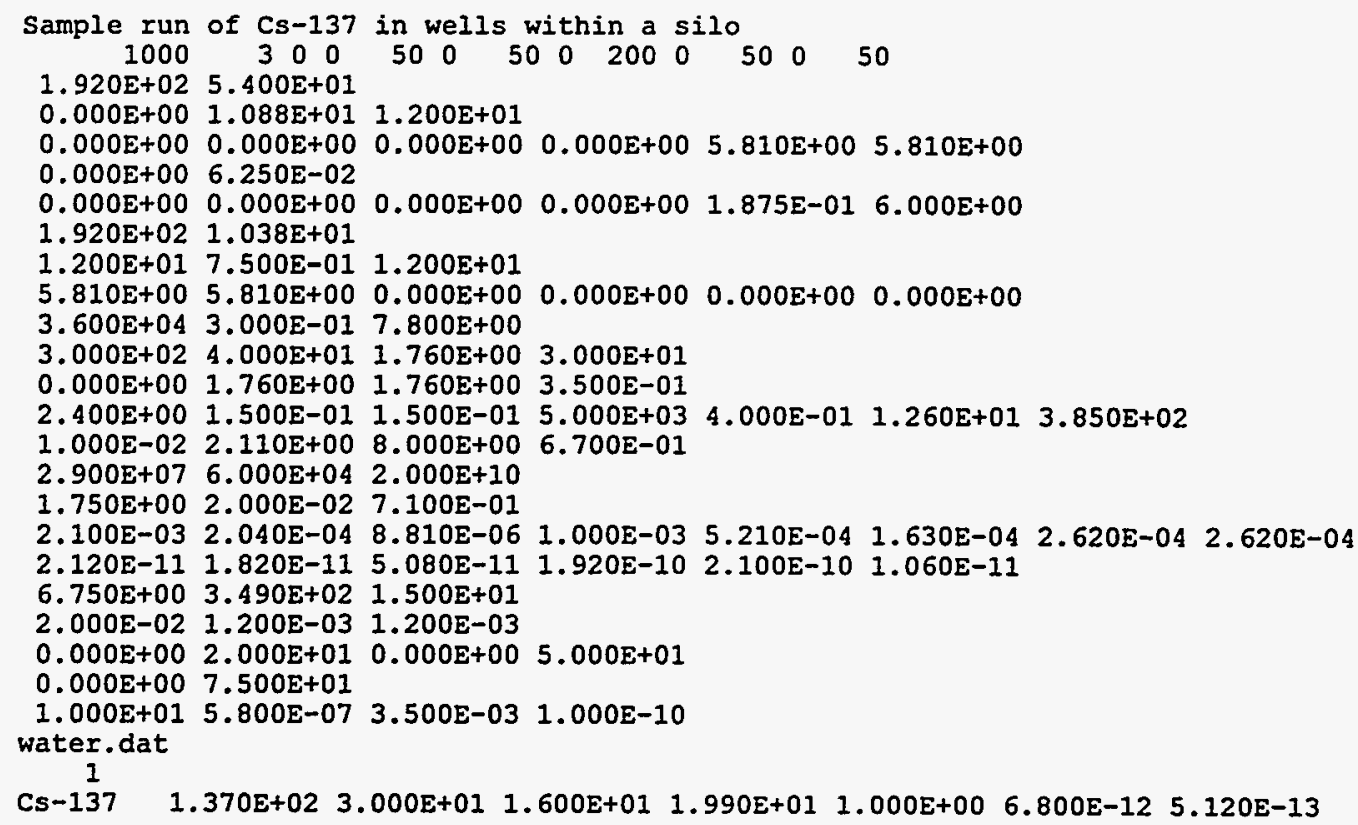


Exhibit C.21. Sample SOURCE2 input file for ${ }^{137} \mathrm{Cs}$ in a trench-type facility (filename.inp)

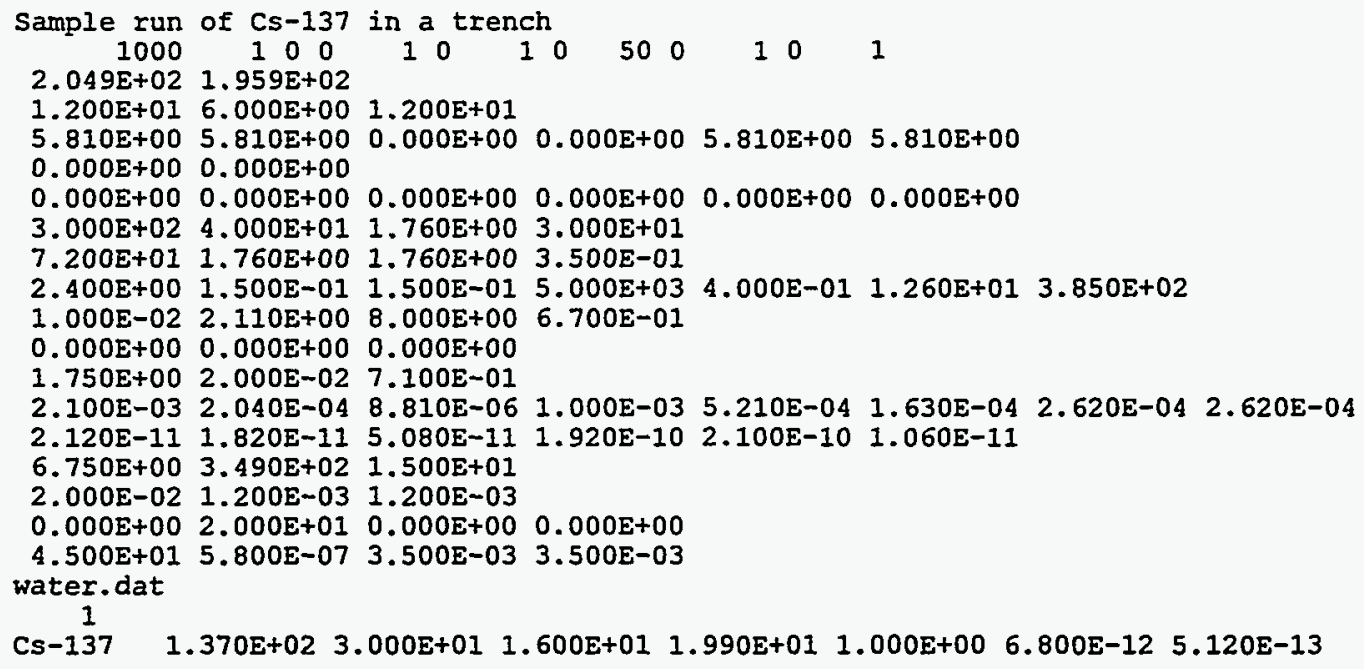


APPENDIX D

COMPUTER CODE LISTINGS FOR SOURCE1 AND SOURCE2 
,

$\checkmark$

,

,

$-$ 
D. COMPUTER CODE LISTINGS FOR SOURCE1 AND SOURCE2

Computer code listings for Version 2.0 of SOURCE1 and SOURCE2 are provided in Exhibits D.1 and D.2, respectively. An illustration of the code hierarchy for the SOURCE codes is presented in Figs. 2.5 and 2.6 of Sect. 2. 


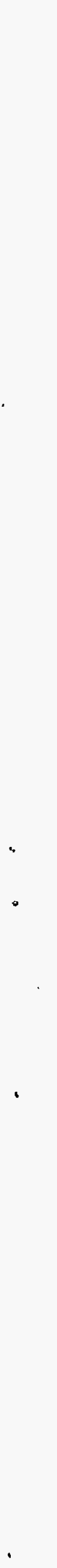


Exhibit D.1. Computer code listing for SOURCE1

program source1

C..... SOURCE1 Version 2.0 .

c.....Reference: Icenhour, A. S. and M. I. Tharp, "User's Manual for c.....the SOURCE1 and SOURCE2 Computer Codes: Models for Evaluating c..... Low-Level Radioactive Waste Disposal Facility Source Terms

c..... (Version 2.0)," ORNL/TM-13035, Oak Ridge National Laboratory, C..... Oak Ridge, TN, 1996.

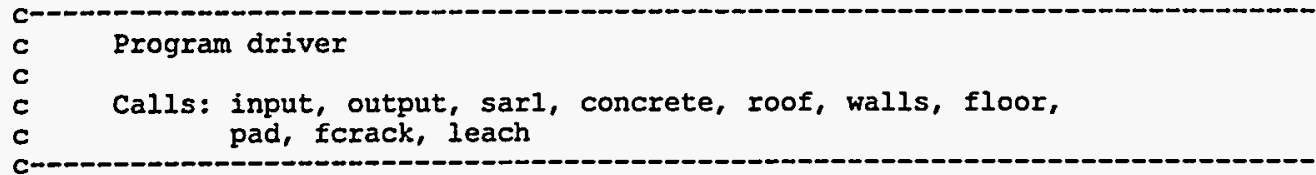

common/cask/clhght, cllth, clwid, cmthk (4), comcvx (3), comcvy (3),

\# evrdns, cvrthk, flangl, noclx, nocly, ommthk (4), ostlrd (3),

\# otnevs (3), otncvy (3), ovrhng, slangl, sldns, stlrad (3),

\# stlspc (3), submod, tencvx (3), tencvy (3), wstans, wsthk, wstht

common/clcult/annprc, attk (4), crfrac (3), crfrcd (3), crfrcs (3),

\# crfrcw (3), crpcof, csstrn, flaper (3), flfrac (3), icl (3), ico2 (3),

\# icrack (3), icrflg(3), ispl (3), ph (4), rfaper (3), rffrac(3),

slfi, slfo, stlcor(3), ttlwat, wlaper $(3,2)$, wlfrac $(3,2)$,

w2aper $(3,2)$, w2 frac $(3,2), x l o a d(3), x p e r c(2)$

common/padc/pstlrad,pstlmod,pstlyld, pconstr,

\# pbotcov, pwtcmnt, pstlspc, padcrk, piff, intctrl

common/tumulus/lyr, numwid, numlth, numcsk, nmember

data fcask $/ 0 . /$

c.... Read input data and perform preliminary calculations for simulation.

call input $(0$, nyears $)$

c..... Opens the files which have been selected to provide summaries

c..... of the simulation results.

call output (fcask, 0, nyears)

c..... Start annual loop.

do 100 iyear $=1$, nyears

c.....Read years when inventories were disposed and associated inventories c..... and updates water infiltration values.

call input (iyear, nyears)

c..... if $(\bmod ($ iyear, 10) .eq. 0$)$ write $(\star, \star)$ 'year: ', iyear

c.....Calculate time-dependent properties of reinforced concrete.

time $=$ iyear $\star 365$.

csstrn $=\operatorname{amax} 1(($ (time-28.) $/($ time+7. $)) * 6.7 \mathrm{e}-4,0.0)$

crpcof $=5.83 e^{-1 *}($ time $* \star 0.6 /(10 .+$ time $* \star 0.6))$

c.....Perform structural analysis for model simulation.

if (iyear .eq. 1) call sar1

c.....Perform concrete deterioration analysis. Analysis results are c..... used in cracking analysis until all casks have at least one c.....cracked or failed member. Degradation analysis is continued for c.....the entire simulation.

call concrete (iyear) 
c.....Perform analysis of cracking due to shear, compression, corrosion, c..... and loading for roof, walls, and floor in succession. Cracking c......analysis is peformed until all casks have at least one cracked c.....member.

if (fcask .lt. 1.) then

$$
\begin{array}{llll}
\text { if (cmthk (1) } & \text { gt. } 0 . \text { ) call roof (iyear) } \\
\text { if (cmthk(2) } & \text {.gt. } 0 . \text { ) call walis (iyear) } \\
\text { if (cmthk(3) } & \text {.gt. } 0 . \text { ) call floor (iyear) }
\end{array}
$$

endif

if (nmember .eq. 4 .and. padcrk .eq. 0.) call pad(iyear)

c..... Determine proportion of casks that have cracked; update advective and c.....diffusive leach rates; provide output at user-specified edit frequency.

if (fcask .1t. 1.) call fcrack(fcask)

call leach (fcask, iyear, nyears)

call output (fcask, iyear, nyears)

100 continue

$$
\text { stop }
$$

end

block data sorbd

common/cask/clinght, cllth, clwid, cmthk (4), comcvx (3), comevy (3),

\# cvrdins, cvrthk, flangl, noclx, nocly, ormthk (4), ostlrd (3).

\# otncrx (3), otncvy (3), ovrhng, slangl, sldns, stlrad (3),

\# stlspc (3), submod, tencvx (3), tencvy (3), wstdns, wsthk, wstht

common/clcult/annprc, attk (4), crfrac (3), crfrcd (3), crfres (3),

\# crfrcw (3), crpcof, csstrn, flaper (3), flfrac (3), icl (3), ico2 (3),

\# icrack (3), icrflg (3), ispl (3), ph (4), rfaper (3), rffrac(3),

\# slfi, slfo, stlcor (3), ttlwat, wlaper $(3,2)$, wlfrac $(3,2)$,

\# w2aper $(3,2)$, w2 frac $(3,2)$, xload $(3), \operatorname{xperc}(2)$

comon/miscel/acoef, bcoef, dpm (12)

data cmthk $/ 4 \div 0.1$

data attk, icrack $/ 4 * 1 . .3 * 0 /$

data icl, ico 2 , icrflg/9*0/

data isp $1 / 3 * 0 /$

data $\mathrm{dpm} / 31,28,25,31,, 30,31,30,, 31,, 31,, 30,, 31,, 30,31 . /$

data annpre, noclx, nocly, ovrhng $/ 0 ., 1,1,0.1$

end

subroutine caoh(iyear)

Called by concrete
$\mathrm{c} \quad$ Calculates loss of concrete strength and reduction in $\mathrm{pH}$ of concrete
$\mathrm{c}$ due to leaching of $\mathrm{Ca}(\mathrm{OH}) 2$.
$\mathrm{c}$

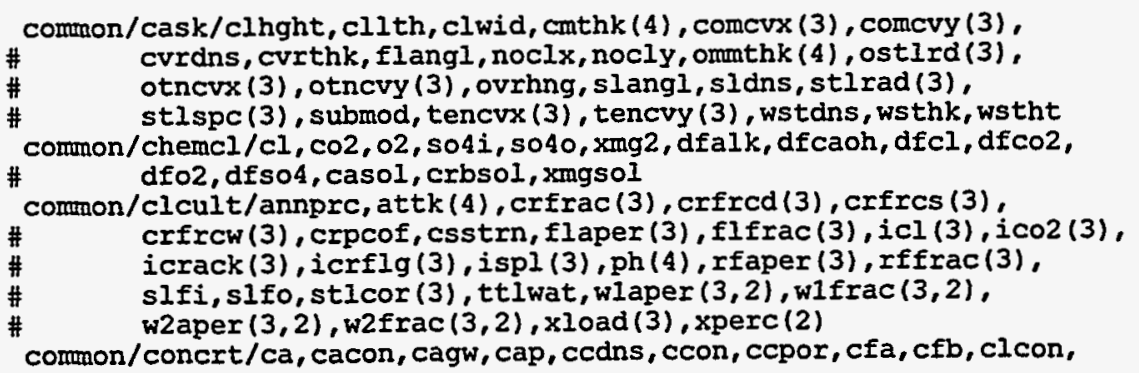




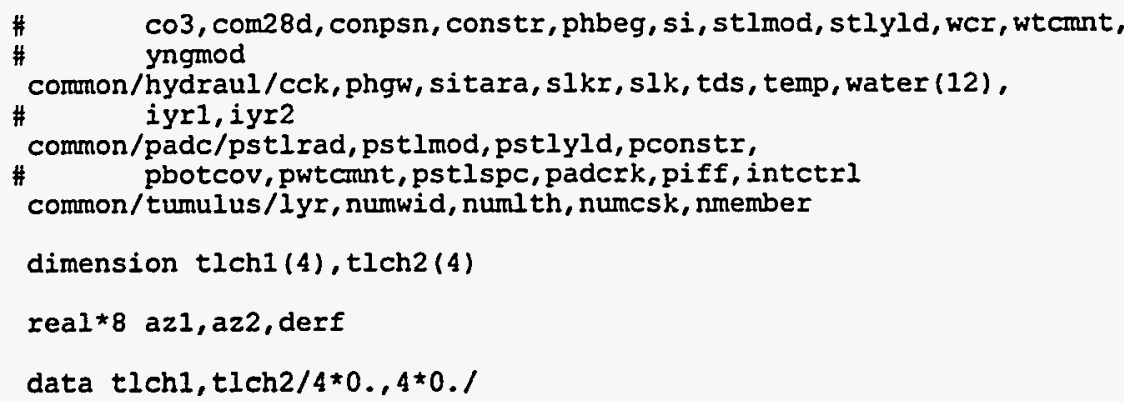

c......Calculate retardation factor for $\mathrm{Ca}(\mathrm{OH}) 2$ leaching by diffusion and c..... initialize Ca content in C-S-H system.

if (iyear .eq. 1) then

If $=1 .+$ ccdns $^{\star}$ cacon/aminl (casol, cap) /ccpor

- c.....calculate Iangelier or calcium carbonate saturation index and ionic c......concentrations of $\mathrm{Ca}(\mathrm{OH}) 2, \mathrm{Mg}++$, and $\mathrm{CO}-$.

xmg2 = aminl (xmg2, xmgsol)

co3 $=\operatorname{aminl}($ co3, crbsol)

cap $=\operatorname{amin} 1($ cap, casol)

casum $=\mathrm{xmg} 2+\mathrm{co} 3+\mathrm{cap}$

$\mathrm{pk}=2.268712-1.122 \mathrm{e}-2 \star$ temp $+3.91 \mathrm{e}-5 \star$ temp $* \star 2+1.007 \mathrm{e}-3 *$ tds -

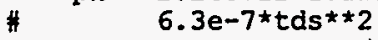

phs $=$ pktalog10 $(1 /$ cagw $)+\operatorname{alog} 10(1 / \operatorname{co} 3)$

$x l i=$ phgw - phs

endif

c..... If initial $\mathrm{pH}$ is greater than 12.5 , calculate rate of loss of NaOH c..... and KOH and consequent decline in pH. Pore liquid and solid conc......centrations are assumed to be equal.

do $3001=1$, nmember

if (ph (1) .gt. 12.5) then

c..... Calculate fraction of alkalis remaining in concrete following c.....leaching by advection.

$\operatorname{tlch} 1(1)=\operatorname{amin} 1(1, . \operatorname{tlch} 1(1)+\operatorname{annprc} / 2.54 / \operatorname{omnthk}(1))$

$x \operatorname{lch} 1=1 .-\operatorname{tgh} 1(1)$

c.....Calculate fraction of alkalis remaining in concrete following c.....leaching by diffusion.

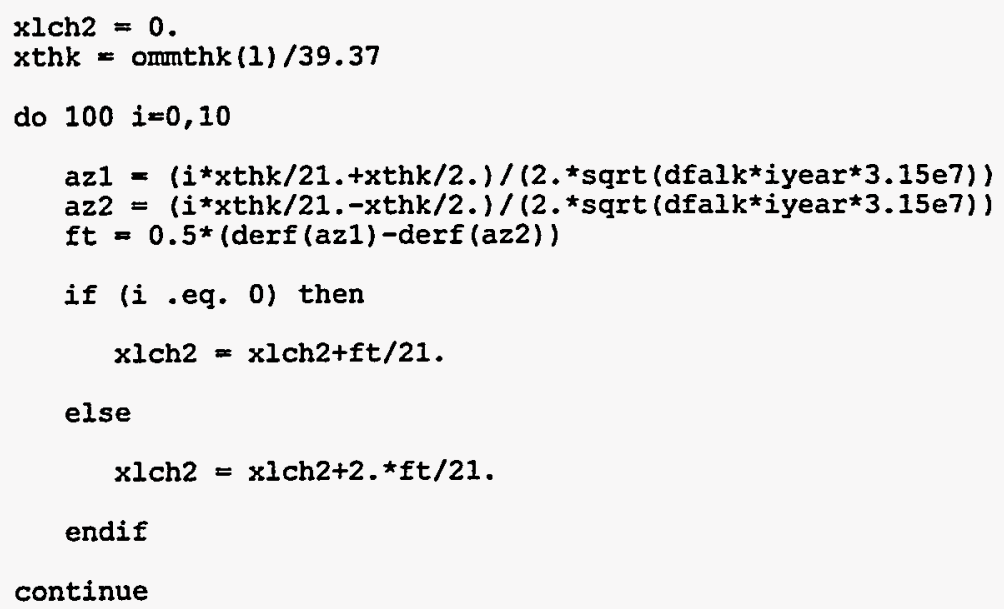


c..... Determine total amount of alkalis lost from concrete.

alklch $=2 .-x l \operatorname{ch} 1-x I c h 2$

$\operatorname{ph}(1)=\operatorname{amax} 1(12.5$, phbeg $-($ phbeg -12.5$) * a 1 k 1 \mathrm{ch})$

else

c...... Calculate fraction of $\mathrm{Ca}(\mathrm{OH}) 2$ remaining in concrete following

c......leaching by advection. Groundwater leaching is assumed only if

c.....the Iangelier index is negative, indicating the water is capable

c..... of dissolving $\mathrm{Ca}(\mathrm{OH}) 2$.

if (xli .It. 0.) then

$\#$

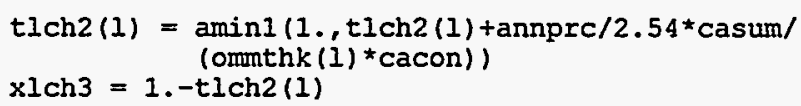

c..... Calculate fraction of $\mathrm{Ca}(\mathrm{OH}) 2$ remaining in concrete following c....leaching by diffusion.

$x \operatorname{lch} 4=0$.

xthk $=$ ommthk (1)/39.37

do $200 i=0,10$

\#

$a z 1=(i \star x \operatorname{thk} / 21 .+x \operatorname{thk} / 2) /.(2 . *$ sqrt (dfcaoh/rf*iyear*3.15e7))

az2 $=(i * x$ thk $/ 21 .-x \operatorname{thk} / 2) /.(2 . *$ sqrt (dfcaoh/rf*iyear*3.15e7))

$\#$

$f t=0.5 *(\operatorname{derf}(a z 1)-\operatorname{derf}(a z 2))$

if ( $i$.eq. 0 ) then

$x l \operatorname{ch} 4=x l \operatorname{ch} 4+f t / 21$.

else

$x \operatorname{lch} 4=x \operatorname{lch} 4+2 . * f t / 21$.

endif

200

continue

c..... Determine total amount of ca lost from concrete.

$\operatorname{calch}=2 .-x l \operatorname{ch} 3-x \operatorname{lch} 4$

c.....Adjust $\mathrm{Ca}$ concentration and recalculate $\mathrm{Ca}: \mathrm{Si}$ ratio.

$$
\begin{aligned}
& \mathrm{ca}=\mathrm{cacon}{ }^{\star}(1 .-\mathrm{cal} \mathrm{ch}) \\
& \mathrm{ca} \_\mathrm{si}=\mathrm{ca} / \mathrm{si}
\end{aligned}
$$

c..... Calculate average $\mathrm{pH}$ for concrete as a function of Ca:Si following c.....the loss of $\mathrm{NaOH}$ and $\mathrm{KOH}$.

$\operatorname{ph}(1)=\operatorname{amin} 1\left(12.5,8.83533+3.143848 * \mathrm{Ca} \_\mathrm{si}-0.6617 * \mathrm{Ca} \_i \star \star 2\right)$

c..... Calculate equivalent depth of $\mathrm{Ca}(\mathrm{OH}) 2$ loss and loss in strength for c.....roof, floor, and internal and external walls.

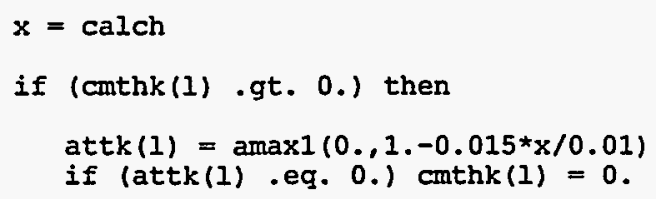


else

$\operatorname{attk}(1)=0$

endif

endif

300 continue

return

end

subroutine $\operatorname{ccrack}(i$, iyear)

called by: sourcel
c
c Calculates cracking due to corrosion of reinforcing steel.
Calls: none

common/cask/clhght, cllth, clwid, cmthk (4), comcvx (3), comcvy (3),

\# cvrdns, cvrthk, flangl, noclx, nocly, ommthk (4), ostlrd (3).

\# otncrx (3), otncvy (3), ovrhng, slangl, sldns, stirad (3),

\# stlspc (3), submod, tencvx (3), tencvy (3), wstdns, wsthk, wstht

common/clcult/annprc,attk (4), crfrac (3), crfrcd (3), crfrcs (3),

\# crfrcw (3), crpcof, csstrn, flaper (3), flfrac (3), icl (3), ico2 (3),

\# $\quad i \operatorname{crack}(3), i \operatorname{crflg}(3), i \operatorname{spl}(3), \operatorname{ph}(4)$, rfaper (3), rffrac (3),

\# slfi,slfo, stlcor(3), ttlwat, wlaper $(3,2)$, wlfrac $(3,2)$,

\# w2aper $(3,2)$, w2 frac $(3,2), x$ load $(3), x p e r c(2)$

common/concrt/ca, cacon, cagw, cap, ccdns, ccon, ccpor, cfa, cfb, clcon,

\# co3, com28d, conpsn, constr,phbeg, si, stlmod, stlyld, wcr, wtcmnt,

\# yngmod

data stipsn/.30/

time $=365 .{ }^{*}$ iyear

comstr $=\operatorname{aminl}\left(\right.$ time $/\left(c f a+c f b{ }^{\star} \text { time }\right)^{\star} \operatorname{com} 28 d^{\star}$ attk(i), constr*attk(i))

cdtstr $=4 .{ }^{\star}$ sqrt (comstr)

crpcof $=5.83 \mathrm{e}-1 \star\left(\right.$ time $\star \star 0.6 /\left(10 .+\right.$ time $\left.\left.e^{\star \star 0} 0.6\right)\right)$

csstrn $=\operatorname{amaxl}(($ (time-28.) $/($ time+7.) $) \star 6.7 e-4,0.0)$

conmod $=5.7 \mathrm{e} 4$ sqrt $($ comstr $) /(1 .+$ crpcof $)$

tmp $=\operatorname{amin} 1($ tencvx $(i), \operatorname{tencvy}(i), \operatorname{comcvx}(i), \operatorname{comcvy}(i))+$ ostlrd $(i)$

if (tmp. le. stlrad(i) + sticor(i)) return

c..... Calculate internal pressure due to corrosion.

pstl $=($ stlrad(i)+stlcor(i)-ostlrd(i)) /ostlrd(i)*l.1

$\# \quad(1 .-$ stlpsn $) /$ st lmod $+((1 .-$ conpsn $) \star 0$ ost lrd $(i) * \star 2+$

$\# \quad(1 .+\operatorname{conpsn}) \star \operatorname{tmp} \star \star 2) /(\operatorname{conmod} *(\operatorname{tmp} \star \star 2-\operatorname{ostlird}(i) \star \star 2)))$

c..... Calculate maximurn stress.

conrad $=$ stlrad $(i)+s t l \operatorname{cor}(i)-p s t l * o s t l r d(i) *(1 .-s t l p s n) / s t l m o d$

ctstrs $=4 .{ }^{*}$ pst $1 *$ conrad $* * 2 /($ tmp $* * 2-\operatorname{conrad} * * 2)$

ststrs $=$ pst $1 *($ tmp $\star \star 2+$ conrad $\star \star 2) /($ tmp $\star \star 2-\operatorname{conrad} \star \star 2)$

xzero $=\operatorname{amax} 1\left(0.5^{\star}\right.$ stlspc(i), sqrt (tmp $\star \star 2-0$ stlrd $\left.\left.(i) \star \star 2\right)\right)$

c..... Determine whether spalling has occurred. if it has, all of the c..... concrete cover is assumed to be destroyed and all steel is exposed.

if (ctstrs.gt.cdtstr . and. ststrs.gt.cdtstr .and.

$\#$ ctstrs.gt.ststrs) then

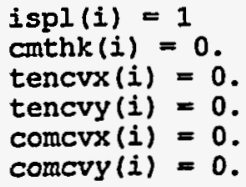


c..... Cracking extends through concrete cover to steel along steel members.

elseif (ctstrs .gt. cdtstr) then

$\operatorname{crfrcd}(i)=\operatorname{cmthk}(i)-2 .{ }^{*} \operatorname{stlrad}(i)$

$\operatorname{crfrcw}(i)=2 . * x z e r o *($ cdtstr/conmod $+\operatorname{csstrn})$

$\operatorname{crfrcs}(i)=\operatorname{stlspc}(i)$

\#

$\operatorname{crfrac}(i)=\operatorname{crfrcw}(i) * \operatorname{crfrcd}(i) *(\operatorname{clwid}+c l l t h) *(\operatorname{clwid}+$ cllth)/crfrcs (i)

c..... Calculate potential for cracking through concrete cover versus

c.....internal cracking only (i.e., not through the entire concrete cover).

elseif (ststrs .gt. catstr) then

rrI $=\operatorname{sqrt}((\operatorname{conrad} \star \star 2 \star t m p \star \star 2 \star p s t 1) /($ cdtstr $*($ tmp $\star \star 2-$ conrad $\star \star 2$ ) -conrad $\star \star 2 \star$ pstl)

if (rrr-conrad .ge. $0.5^{*}($ tmp-conrad)) then

$\operatorname{crfrcd}(i)=\operatorname{crathk}(i)-2 \cdot{ }^{*} \operatorname{stl} \operatorname{rad}(i)$

$\operatorname{crfrcw}(i)=2{ }^{\star}$ xzero ${ }^{\star}($ cdtstr/conmod+csstrn $)$

$\operatorname{crfrcs}(i)=\operatorname{stlspc}(i)$

\#

$\operatorname{crfrac}(i)=\operatorname{crfrcw}(i) * \operatorname{crfrcd}(i) \bullet(\operatorname{clwid}+\operatorname{cllth}) *(\operatorname{clwid}+$ cllth)/crfrcs (i)

endif

endif

return

end

subroutine concrete(iyear)

Called by: sourcel

Calculates degradation of concrete with time.

Calls: caoh, corrode, sulfate

common/failure/cft 1 , dcft, eft 1 , deft

c.....Calculate loss of concrete strength and changes in $\mathrm{pH}$ of concrete

c......structure due to leaching of $\mathrm{Ca}(\mathrm{OH}) 2$.

call caoh(iyear)

c..... Calculate loss of concrete due to sulfate attack.

call sulfate(iyear)

c.....Calculate corrosion of steel reinforcement.

call corrode(iyear)

return

end

subroutine corrode(iyear)

Called by concrete

Calculates rate of corrosion of steel reinforcement in concrete

Calls: none

common/cask/clinght, cllth, clwid, cmthk (4), comcvx (3), comcvy (3),

\# cvrdis, cvrthk, flangl, noclx, nocly, omnthk (4), ostlrd (3), 


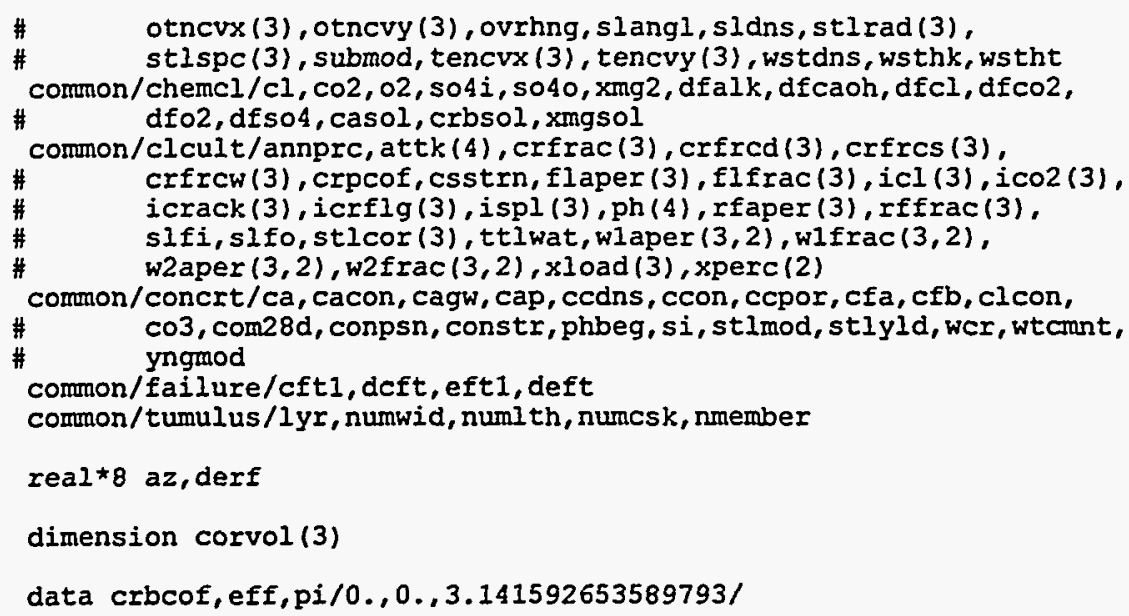

c..... Calculate failure function of epoxy coating on steel reinforcement. c..... If no failure has occurred, corrosion does not occur.

if (deft .gt. 0) then

aux $=$ float (iyear)

if (aux.gt. eft1) then

eff $=\operatorname{amin} 1(1 .,(\operatorname{aux}-\mathrm{eft} 1) / \operatorname{def} t)$

else

return

endif

else

eff $=1$.

endif

c..... Determine depth of concrete carbonation based on Crank formulation.

if (crbcof .eq. 0.) then

dhydr $=0.4+0.5^{\star}$ wCr

ccon $=\operatorname{ccon} *$ dhydr

$\mathrm{cl}=\mathrm{co2}+\mathrm{ccon}$

crbcof $=\operatorname{sqrt}((\mathrm{c} 1 / \mathrm{ccon}-1.) \star 4 . * d f c 02 \star 3.15 \mathrm{e} 7 / \mathrm{sqrt}(\mathrm{pi}))$

endif

dpcrb $=\operatorname{crbcof} \star s q r t(f l o a t($ iyear $))$

c..... Check carbonation depth and concrete cover thickness for structural c...... components.

do $100 i=1$, nmember

$t m p=(\operatorname{aminl}(\operatorname{comcvx}(i), \operatorname{tencvx}(i), \operatorname{comcvy}(i), \operatorname{tencvy}(i))+$

\# ostlrd(i))/39.37

if (dpcrb.ge.tmp .and. icrflg(i).eq.0 .and. eff.gt.0.) then

$i \operatorname{co2}(i)=$ iyear

icrflg(i) $=1$

endif

c..... Calculate $[\mathrm{OH}-]$ in pore solution based on concrete $\mathrm{pH}$. 


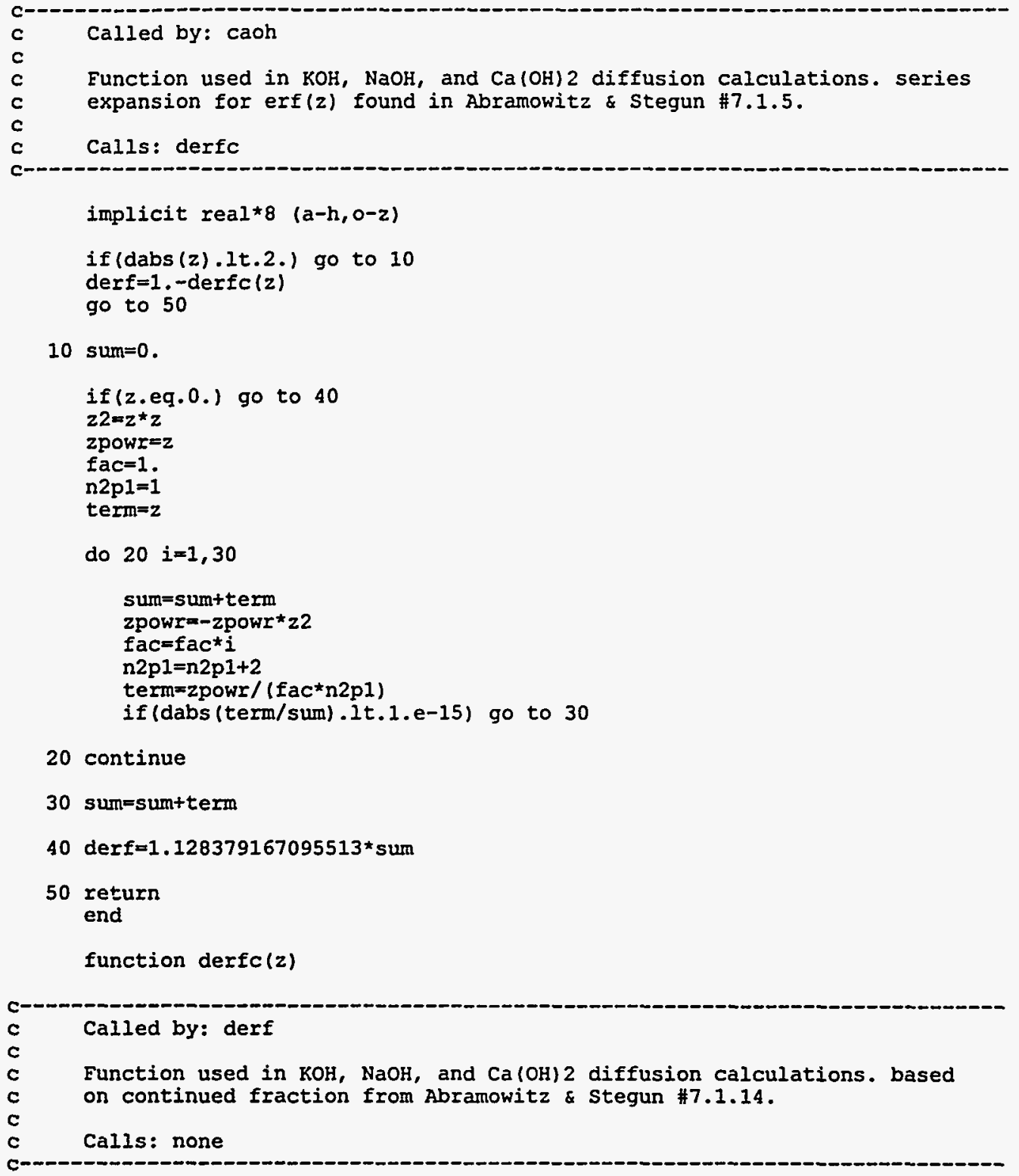

implicit real*8 $(a-h, 0-z)$

if(dabs (z).ge.2.) go to 10

$\operatorname{derfc}=1 .-\operatorname{derf}(z)$

go to 30

10 xnum=20.

$z a b=$ dabs $(z)$

frac $=z a b$

do $20 i=1,40$

frac $=z a b+x n u m / f r a c$

xnum $=x$ num -0.5

20 continue

$\operatorname{der} f c=0$.

if $(z a b . l e .9 .3)$ derfc=dexp $(-z a b * z a b) /(f r a c \star 1.772453850905516)$

if $(z .1 t .0$.$) derfc =2$. $-\operatorname{derfc}$ 
30 return

end

subroutine fcrack(fcask)

c Called by: sourcel
c Determines the number of casks with one or more cracked members.

c Calls: none

c-1-

common/clcult/annprc, attk (4), crfrac (3), crfrcd (3), crfrcs (3),

\# crfrcw (3), crpcof, csstrn, flaper (3), flfrac (3), icl (3), ico2 (3),

\# icrack (3), icrflg (3), ispl (3), ph (4), rfaper(3), rffrac(3),

\# slfi,slfo, stlcor (3), ttlwat, wlaper $(3,2)$, wlfrac $(3,2)$,

\# w2aper $(3,2)$, w2frac $(3,2), \operatorname{xload}(3), \operatorname{xperc}(2)$

common/tumulus/lyx, numwid, numith, numcsk, nmember

c..... Determine the number of casks which have at least one cracked

c.....structural member.

nccask $=0$

do $100 i=1$, lyx

if(rffrac(i).gt.0. .or. flfrac(i).gt.0.) then

nccask $=$ nccask+numcsk/lyr

elseif (w1frac (i,2).gt.0. .or. w2frac $(i, 2) \cdot g t .0$.$) then$

nccask $=$ nccask+numcsk/lyr

else

if $(w 1 \mathrm{frac}(i, 1)$.gt. 0.$)$ nccask $=$ nccask+numwid $* 2$

if $(w 2 f r a c(i, 1) \cdot g t$. 0.$)$ nccask $=$ nccask+numith $* 2$

nccask $=\operatorname{min0}($ rccask, $2 *($ numwid+numlth $)-4)$

endif

100 continue

fcask $=$ float (nccask)/float (numcsk)

return

end

subroutine floor(iyear)

Called by: sourcel

Performs cracking analysis for cask floor.

Calls: ccrack

common/cask/clinght, cllth, clwid, cmthk (4), comcvx (3), comcvy (3), cvrdns, cvrthk, flangl, noclx, nocly, ommthk (4), ostlrd (3). otncvx (3), otncvy (3), ovrhng, slangl, sldns, stlrad (3), stlspe (3), submod, tencrx (3), tencvy (3), wstdns, wsthk, wstht

common/clcult/annprc, attk (4), crfrac (3), crfred (3), crfrcs (3),

\# crfrcw (3), crpcof, csstrn, flaper (3), flfrac (3), icl (3), ico2(3), icrack (3), icrflg (3), ispl (3), ph (4), rfaper (3), Iffrac(3), slfi, slfo, stlcor (3), ttlwat, wlaper $(3,2)$, wlfrac $(3,2)$, w2aper $(3,2)$, w2 frac $(3,2), x$ load $(3), \operatorname{xperc}(2)$

common/concrt/ca, cacon, cagw, cap, ccdns, ccon, ccpor, cfa, cfb, clcon,

\# co3, com28d, conpsn, constr, phbeg, si, stlmod, stlyld, wcr, wtcmnt,

\# yngmod

common/flfrac/flfdpx $(3,11,11)$, flfdpy $(3,11,11), \operatorname{flfspx}(3,11,11)$, 
\# $\quad$ Ilfspy $(3,11,11)$

common/moment/rfxmnt $(3,11,11)$, rfymnt $(3,11,11)$, flxmnt $(3,11,11)$,

\# $\quad$ flymnt $(3,11,11)$, w1xmnt $(3,11,11)$, w2xmnt $(3,11,11)$.

$\# \quad$ w1ymnt $(3,11,11)$, w2ymnt $(3,11,11)$

common/shear/rfxshr $(3,11,11), \operatorname{rfyshr}(3,11,11), \operatorname{flxshr}(3,11,11)$,

\# flyshr $(3,11,11)$, w1xshr $(3,11,11), w 2 x \operatorname{shr}(3,11,11)$,

\# $\quad$ w1yshr $(3,11,11)$, w2yshr $(3,11,11)$

common/tumulus/lyr, numwid, numl th, numcsk, nmember

data pi/3.141592653589793/

data strred/.9/

c.....Calculate time-dependent parameters used in cracking analysis. Steel

c..... running parallel to the cask width is $\mathrm{x}$-direction steel; steel

c.....running perpendicular to cask width is $y$-direction steel.

time $=$ iyear $* 365$

comstr $=\operatorname{amin} 1(t i m e /(c f a+c f b * t i m e) * \operatorname{com} 28 d * a t t k(3)$, constr*attk $(3))$

conmod $=5.7 e 4^{\star} \operatorname{sqrt}($ comstr $) /(1 .+$ crpcof $)$

ratmod $=$ stlmod/conmod

rupmod $=7.5^{*}$ sqrt $($ comstr $)$

fldstx $=$ cmthk (3)-tencux (3)

fldsty $=$ cinthk $(3)-$ tencvy $(3)$

starcm $=0$

startn $=\operatorname{stlrad}(3) * \star 2 \star p i / s t l s p c(3)$

cnmnti $=$ cmthk $(3) * * 3 . / 12$.

crkmtf $=$ cnmti $/(0.5 *$ cmthk $(3)) *$ rupmod

c..... Calculate ultimate strength for floor.

$a=.7225 *$ comstr

$b=.003 *$ stlmod*starcm-startn*stlyld

$c 1=.003 *$ stlmod*starcm*comcvx (3)

$c 2=.003 *$ stlmod*starcm* comcvy $(3)$

$\operatorname{axisn} 1=\left(-b+\operatorname{sgrt}\left(b \star \star 2-4 \star^{*} a * c 1\right)\right) /(2, \star a)$

axisn2 $=\left(-b+\operatorname{sqrt}\left(b * \star 2-4{ }^{*} a * c 2\right)\right) /\left(2,{ }^{*} a\right)$

if (axisnl . le. comcrx (3)) then

cmblk $=$ startn*stlyld $/\left(0.85^{\star}\right.$ comstr $)$

flustx $=\operatorname{amax} 1$ (crkmtf, strred*stlyld*startn*(fldstx-cmblk/2.))

else

csstrs $=($ axisn $1-\operatorname{comcvx}(3)) /$ axisn $1 * .003 *$ stlmod

as2 $=$ starcm $\operatorname{csstrs}_{\text {stlyld }}$

as1 = startn-as2

cmblk $=$ as $1 * s t l y l d /(0.85 *$ comstr $)$

flustx $=\operatorname{amaxl}($ crkmtf, strred* (as1*stlyld* (fldstx-cmblk/2.) +

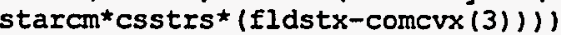

endif

if (axisn2. .le. comcvy(3)) then

cmblk = startn*stlyld/(0.85* comstr $)$

flusty $=\operatorname{amax} 1($ crkmtf, strred*stlyld*startn* (fldsty-cmblk/2.) )

else

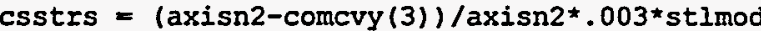

as 2 = starcmcsstrs/stiyld

as1 = startn-as2

cmblk $=$ as $1 *$ stlyld $/(0.85 *$ comstr $)$

flusty $=\operatorname{amax} 1$ (crkmtf, strred* (as1*stlyld* (fldsty-cmblk/2.)+ starcm* csstrs* (fldsty-comcvy (3))))

endif

c..... Calculate cracking moment of inertia for floor for $x$ and $y$ directions.

aa $=0.5$

$\mathrm{bb}=\operatorname{starcm}{ }^{\star}($ ratmod -1.$)+$ startn*ratmod 


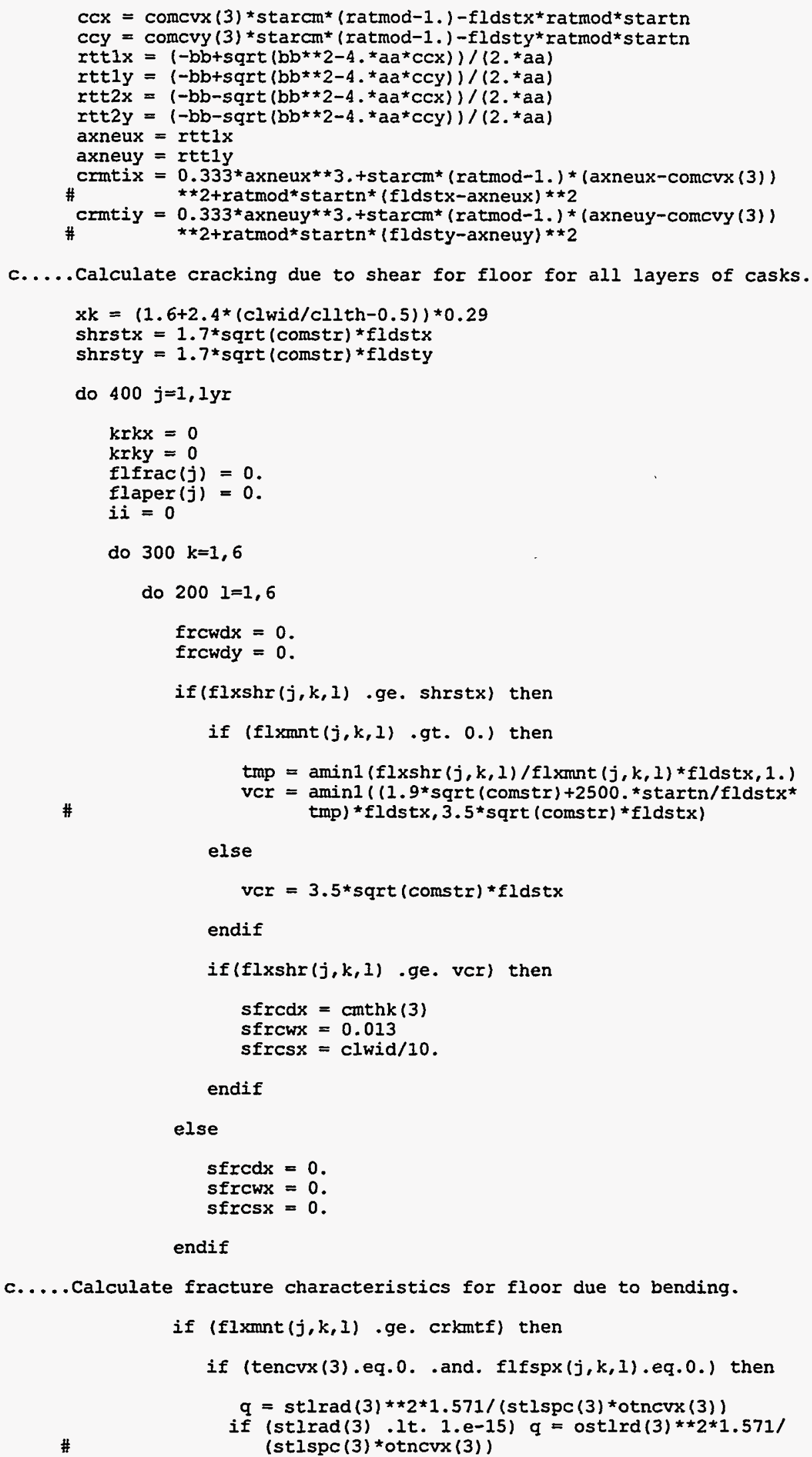


\#

$\#$ elseif (stlrad(3).1t.1.e-15 .and. flfspx $(j, k, 1)$.eg.0.) then

$q=\operatorname{ostlrd}(3) \star \star 2 \star 1.571 /(\operatorname{stlspc}(3) \star \operatorname{tencvx}(3))$

elseif (tencvx(3) .gt. 0 . . and. stlrad (3).ge. 1.e-15) then

$q=\operatorname{stlrad}(3) \star \star 2 \star 1.571 /(\operatorname{stlspc}(3) \star \operatorname{tencvx}(3))$

endif

if (stlrad(3) .ge. 1.e-15) then

frspce $=0.5 * x k^{\star} \operatorname{sqrt}\left(2 .{ }^{\star} \operatorname{stl} \operatorname{rad}(3) \star \operatorname{stlspc}(3) / q\right)$

elseif (stlrad(3).1t.1.e-15 .and. flespx $(j, k, 1)$.eq. 0.$)$ then

frspce $=0.5 * x k \star \operatorname{sqrt}\left(2 .{ }^{*} \operatorname{ostlrd}(3) * \operatorname{stlspc}(3) / q\right)$

endif

if $(f l f \operatorname{spx}(j, k, 1) . e q .0$. or. flfspx $(j, k, 1)$.ge. 2 . $\star$ frspce) flfspx $(j, k, 1)=$ frspce

endif

c.....x-moments exceed cracking moment but not ultimate strength of floor.

$\#$

if (flxmnt $(j, k, l)$.ge.crkmtf and.

flxme $(j, k, 1) .1 t$.flust $x)$ then

efmntx $=($ crkmtf $/ f l \operatorname{xan} t(j, k, 1)) * * 3 .{ }^{*}$ cnmnti+

$(1 .-($ crkmt $f / f l$ xmnt $(j, k, 1)) * \star 3)$.$* crmtix$

\#

strsmx $=$ flxmit $(j, k, 1) *$ axneux/efmntx

stltnx $=$ ratmod*flxmnt $(j, k, 1) \bullet$ (fldstx-axneux) /efmntx

axsnex $=\mathrm{fldstx} /($ stltnx/stlmod+strsmx/conmod) * (stltnx/stlmod+csstrn)+tencux (3)

betax $=$ axsnex $/($ axsnex-tencux (3))

flfdpx $(j, k, 1)=$ axsnex

frcwdx $=f l f \operatorname{spx}(j, k, l) *($ stltnx/stlmod*betax+csstrn $)$

endif

c.....x-moments exceed ultimate strength of floor.

\#

if (flxmnt $(j, k, 1)$.ge.flustx. and.

fifdpx $(j, k, 1)$. It.cmthk(3)) then

flfdpx $(j, k, 1)=$ cmthk (3)

frcwdx $=\operatorname{aminl}(($ stlyld/stlmod+csstrn)*flfspx $(j, k, 1)$. $\left.3 \cdot e-3^{\star} \mp l f \operatorname{spx}(j, k, 1)\right)$

endif

c.....Perform calculations for y (length) direction of floor. Start c......with shear cracking calculations.

if (flyshr $(j, k, 1)$.ge. shrsty) then

if (flymit $(j, k, 1)$.gt. 0.$)$ then

tmp $=\operatorname{aminl}(f l y s h r(j, k, 1) /$ flymnt $(j, k, 1) * f l d s t y, l$.

vor $=\operatorname{amin} 1((1.9 *$ sqrt (comstr) $+2500 *$ startn $/$ fldsty*tmp) *fldsty, 3.5*sqrt (comstr)*fldsty)

else

vcr $=3.5 * \operatorname{sqrt}($ comstr $) *$ fldsty

endif 
if (flyshr $(j, k, 1) \cdot g e$. vcr) then

$$
\begin{aligned}
& \text { sfrcdy }=\text { cmthk }(3) \\
& \text { sfrcwy }=0.013 \\
& \text { sfrcsy }=\text { clith } / 10 .
\end{aligned}
$$

endif

else

sfrcdy $=0$.

sfrcwy $=0$.

sfrcsy $=0$.

endif

c..... Calculate fracture characteristics for $y$ (length) direction.

if (flymnt $(j, k, 1)$.ge. crkmtf) then

if (tencvy (3).eq.0. .and. flfspy $(j, k, I)$.eq.0.) then

$q=\operatorname{stl} \operatorname{rad}(3) * \star 2 \star 1.571 /(\operatorname{stl} \operatorname{spc}(3) * \operatorname{otncvy}(3))$

$\#$

if (stlrad(3) .1t. $\left.1 . e^{-15}\right) \mathrm{q}=\operatorname{ostlrd}(3) \star \star 2 \star 1.571 /$ (stlspc (3) * otncry (3))

$\#$

elseif (stlrad(3).1t.1.e-15 .and. flfspy $(j, k, 1)$, eq.0.) then

$q=\operatorname{ostlrd}(3) \star \star 2 \star 1.571 /(\operatorname{stl} \operatorname{spc}(3) * \operatorname{tencvy}(3))$

$\#$

elseif (tencry (3).gt.0. .and. stlrad(3).ge.1.e-15) then

$q=\operatorname{stl} \operatorname{rad}(3) * \star 2 \star 1.571 /(\operatorname{stlspc}(3) * \operatorname{tencvy}(3))$

endif

if (stlrad(3) .ge. 1.e-15) then

frspce $=0.5^{\star} \times k^{\star} \operatorname{sqrt}\left(2{ }^{*} \operatorname{stl} \operatorname{rad}(3) * \operatorname{stlspc}(3) / q\right)$

$\#$

elseif (stlrad(3).1t.1.e-15 .and. flfspy $(j, k, 1)$.eq.0.) then

frspce $=0.5^{\star} x k^{\star} \operatorname{sgrt}\left(2 .{ }^{\star} \operatorname{ostl} l \mathrm{rd}(3) * \operatorname{stlspc}(3) / \mathrm{q}\right)$

endif

if (flfspy $(j, k, 1)$.eq. 0 . .or.

$\begin{array}{ll}\# & \text { flfspy }(j, k, 1) \cdot g e .2 . * \text { frspce }) \\ \# & \text { flfspy }(j, k, 1)=\text { frspce }\end{array}$

endif

c.....Y-moments exceed cracking moment but not ultimate strength of floor.

$\#$

if ( $f l y m n t(j, k, l)$.ge.crkmtf .and.

flymnt $(j, k, 1) .1 t . f l u s t y)$ then

$\#$

efmnty $=($ crkmtf $/ f l y m n t(j, k, 1)) * 3 . *$ cnmnti+(1.(crkmtf/flymnt $(j, k, 1)) * 3) * c r m t i$.

strsmy $=$ flymnt $(j, k, 1) *$ axneuy/efmnty

stltny $=$ ratmod*flymnt $(j, k, 1) *($ fldsty-axneuy $) /$ efmnty

axsney $=$ fldsty/(stltny/stlmod+strsmy/conmod $)$ * (stltny/stimod+csstrn) +tencvy (3)

betay $=$ axsney $/($ axsney-tencvy (3))

$f l f d p y(j, k, l)=$ axsney

frcwdy $=f l f s p y(j, k, l) *($ stltny/stlmod*betay+csstrn $)$

endif

c..... Y-moments exceed ultimate strength of floor. 
if (flymnt $(j, k, 1)$.ge.flusty.and. flfdpy $(j, k, 1) .1 t$. cmthk (3)) then

flfdpy $(j, k, 1)=\operatorname{cmthk}(3)$

frcwdy $=\operatorname{aminl}($ (stlyld/stlmod+csstrn $) * f l f s p y(j, k, 1)$,

$\#$ $3 . e-3^{\star}$ flfspy $\left.(j, k, 1)\right)$

endif

c.....Calculate cracking due to corrosion once it begins.

$\#$

if (icrflg(3) eq. 1 and. $(j+k+1)$.eq. 3 ) call ccrack $(3$, iyear $)$

c......Calculate average crack characteristics for floor.

if (cmthk(3) .eq. 0.) then

do $100 \mathrm{~m}=1$, Iyr

flaper $(m)=0$.

$\operatorname{flfrac}(m)=0$.

100

continue

return

else

$f \max =.75^{\star} \operatorname{cmthk}(3)$

depth $=\operatorname{amax} 1(\operatorname{flfdpx}(j, k, 1), \operatorname{sfrcd} x, \operatorname{crfrcd}(3))$

if (depth.ge. fmax) then

tmpl $=0$.

tmp2 $=0$.

$\operatorname{tmp} 3=0$.

$k r k x=k r k x+1$

if (flfspx $(j, k, 1)$.gt. 0.$)$

$\#$

tmpl $=\operatorname{clwid} / 10 . /$ flfspx $(j, k, 1)$

if (crfrcs (3) .gt. 0.) tmp2 = clith/10./crfrcs (3)

if (sfrcsx .gt. 0.) tmp $3=$ clwid/10./sfrcsx

tmp $=t m p 1+t m p 2+t m p 3$

flaper $(j)=f l$ aper $(j)+(f r c w d x * t m p l+\operatorname{crfrcw}(3) \star \operatorname{tmp} 2+$ sfrcwX*tmp3)/tmp

flfrac $(j)=$ flfrac $(j)+2{ }^{\star}$ cmthk $(3) \star \operatorname{cllth} / 10 . *$ (frcwdx*tmp $1+$ sfrcw $*$ tmp 3 )

endif

depth $=\operatorname{amax} 1(\operatorname{flfdpy}(j, k, 1), \operatorname{sfrcdy}, \operatorname{crfrcd}(3))$

if (depth.ge. fmax) then

$\operatorname{tmp} 1=0$.

tmp2 $=0$.

tmp3 $=0$.

$k r k y=k r k y+1$

$\#$

if (flfspy $(j, k, 1)$.gt. 0.$)$

tmpl $=\operatorname{cllth} / 10 . /$ flfspy $(j, k, 1)$

if (crfrcs (3) .gt. 0.$)$ tmp2 $=$ clwid/10./crfrcs (3)

if (sfrcsy.gt. 0.) tmp $3=$ cllth/10./sfrcsy

tmp $=$ trop $1+t m p 2+\operatorname{tmp} 3$

flaper $(j)=$ flaper $(j)+($ frcwdy $*$ tmp $1+\operatorname{crfrcw}(3) * \operatorname{tmp} 2+$ sfrcwy*tmp 3$) /$ tmp

flfrac $(j)=$ flfrac $(j)+2 . *$ cmthk $(3) * \operatorname{clwid} / 10 . *$

(frcwdy tmp $1+$ sfrcwy $*$ tmp 3 )

endif

endif 
300

continue

if (flfrac(j).gt. 0.) icrack(3) $=1$

flfrac $(j)=$ flfrac $(j)+\operatorname{crfrac}(3)$

400 continue

do $500 \mathrm{j}=1,1 \mathrm{yr}$

if (flfraclj) .gt. 0.$)$ then

flfrac $(j)=$ flfrac $(j) /($ cmthk $(3) *$ clwid*cllth $)$

flaper $(j)=f l a p e r(j) /(k r k x+k r k y) * 2.54$

endif

500 continue

return

end

subroutine flothru(d1, d2, flam, iyear,m, qzero, rel)

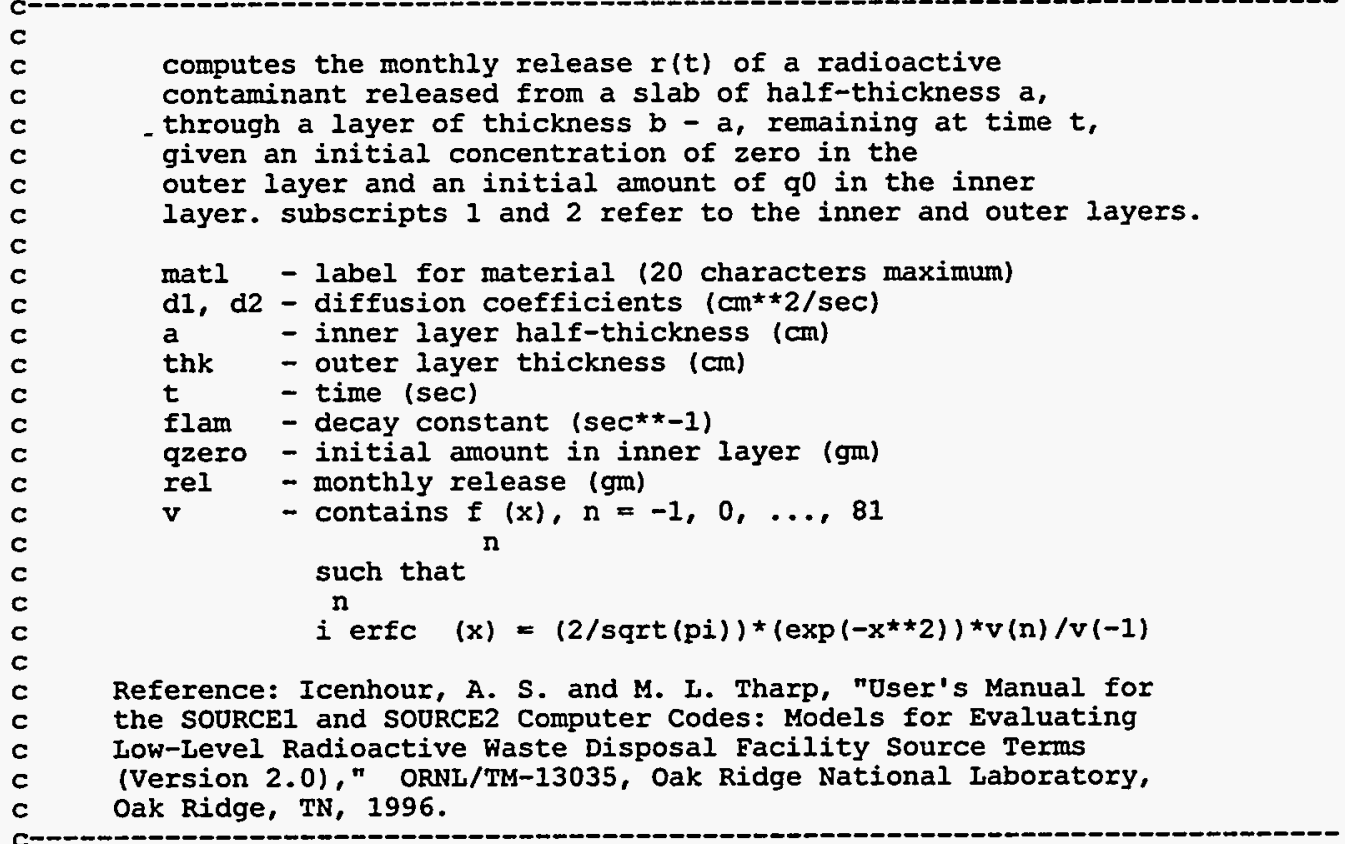

implicit double precision $(a-h, 0-z)$

parameter (maxnuc $=10)$

parameter ( $12=1 . \mathrm{do} / 12 . \mathrm{d} 0$ )

common/miscel/acoef,bcoef, dpm (12)

dimension $v(-1: 81), f f(30), f x 2(30)$, save(3), Iel(maxnuc, 12)

real $\star 4$ acoef, bcoef, dpm, d1, d2, flam, rel

data tosrpi/1.128379167095513do/

data pi/3.141592653589793d0/

data secpyr/3.15576d7/

$a=a c o e f$

thk $=$ bcoef

xkap $=$ dsqrt $(\mathrm{dble}(\mathrm{d} 2 / \mathrm{dl})$

tk $=$ xkap + xkap

alfa $=($ thk $) /($ xkap $* a)$ 
apk $=$ alfa + xkap

$b=a+t h k$

boa $=b / a$

c..... Compute first 30 roots of transcendental equation.

$c 1=((a l f a * x k a p+3 . d 0) * a l f a+(x k a p * 3 . d 0)) * a l f a+1 . d 0$

$c 2=((a l f a+(x k a p * 3 . d 0)) \star a l f a+3 . d 0) \star a l f a+x k a p$

gam $=\operatorname{dsqrt}(((a l f a \star \star 2+1 . d 0) \star x k a p+a l f a+a l f a) / x k a p)$

$\mathrm{x} 1=0.5 \mathrm{~d}^{*} \mathrm{pi} / \mathrm{gam}$

$x=x 1$

do $100 i=1,30$

$\mathrm{n}=0$

50

continue

call fxcal ( $x$, alfa, xkap, $f, f p)$

$\mathrm{x} 2=\mathrm{x}-\mathrm{f} / \mathrm{fp}$

if (abs $((x 2-x) /(x 2)$.gt. $5 . d-9)$ then

$\mathrm{n}=\mathrm{n}+1$

$x=x^{2}$

if $(\mathrm{n} .1 \mathrm{e} .20)$ go to 50

write $\left({ }^{\star}, '(1 x\right.$, a)') 'not converged after 20 iterations'

endif

$f \times 2(i)=d 1 *(x / a) \star \star 2$

$a x=\operatorname{alfa}{ }^{\star} x$

$c=\cos (x)$

$s=\sin (x)$

$c a=\cos (a x)$

$\mathrm{sa}=\sin (\mathrm{ax})$

ff $(i)=s /\left(\left(\right.\right.$ apk $\left.\left.k^{\star} c a^{\star} s+b o a^{\star} s a^{\star} c\right) \star x^{\star \star} 2\right)$

$f 3=c 1{ }^{\star} c^{\star} s a+c 2^{\star} s^{\star} c a$

gam $=-f 3 / f p$

if (gam .lt. 0.do) then

write $\left(*,{ }^{*}\right)$ 'fp and $f 3$ have same sign' return

endif

$x=x+p i / d s q r t(g a m)$

100 continue

c..... Set a few constants.

ropk $=1 . \mathrm{d} 0 /(1 . \mathrm{d} 0+\mathrm{xkap})$

c3 = ropk + ropk

fac1 $=(c 3+c 3) / a$

fxk $=($ xkap $-1 . d 0) *$ ropk

resold $=0 . d 0$

c..... Compute monthly releases for current year.

do 500 n=iyear, iyear

$y x=$ float $(n-1)$

do $400 \mathrm{mo}=1,12$

decay $=0 . \mathrm{do}$

$t=(y r+r 12 *$ float $(m o)) *$ secpyr

to $=($ r12*float (mo $)) *$ secpyr

$\arg =\log (2 . \mathrm{d0}) / f \operatorname{lam} \star t 0$

decay $=\exp (-\arg )$

$\arg 1=a / d \operatorname{sqrt}(d 1 * t)$ 


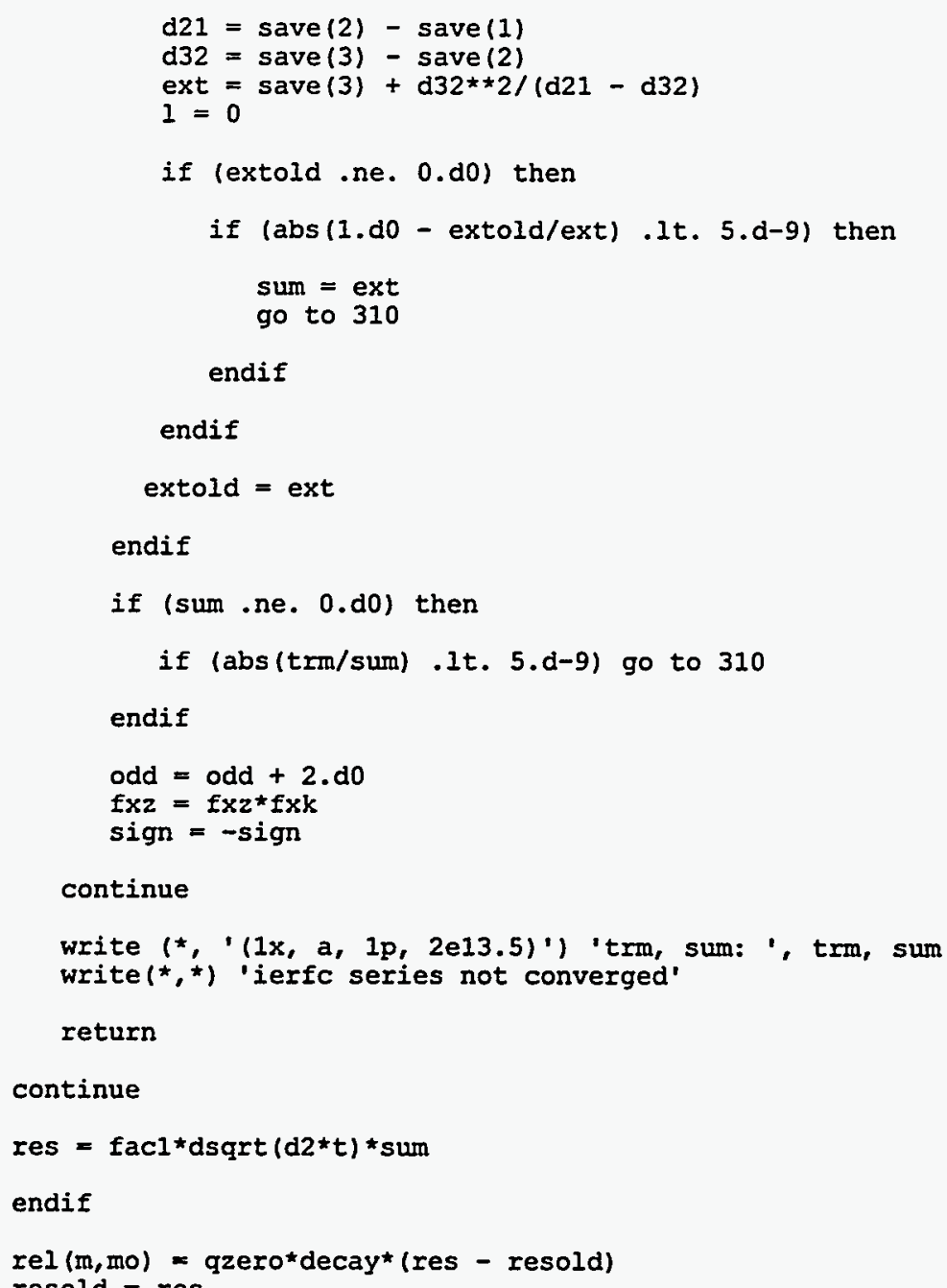


subroutine ierfc $(x, v, n$, tol $)$

\section{Called by: flothru}

Subroutine used in diffusion leaching calculations (2 december 1991).

Calls: none

Compute the repeated integrals of the complementary error $\mathrm{n}$ function $i$ erfc $(x)$ by backward recurrence and normalization. input parameters:

$x$ - argument

$\mathrm{n}$ - maximum value of $\mathrm{n}$

tol - relative exror in $i$ erfc $(x)$

$v$ - double precision aray, dimensioned $(-1: 81)$ in the calling program

output parameters:

$v \quad$ - contains $f(x), n=-1,0, \ldots, 81$

such that

n

$\left.i \operatorname{erfc}(x)=(2 / \operatorname{sgrt}(p i)) \star \exp \left(-x^{\star} \star 2\right)\right) \star v(n) / v(1)$

see W. Gautschi, Recursive computation of the repeated

integrals of the error function, Mathematics of Computation

15, 227-232(1961)

implicit double precision $(a-h, 0-z)$

common/numb/mmax

dimension $v(-1: 81), x t(21)$

$x s q=x \star \star 2$

$1=0$

do $200 \mathrm{~m}=21,81,5$

$$
\begin{aligned}
& v(m)=0 . d 0 \\
& v(m-1)=10 \cdot d 0 \star \star(-20) \\
& x 2=x+x \\
& a=110 a t(m+m) \\
& \text { do } 100 k=m, 1,-1 \\
& v(k-2)=a \star v(k)+x 2 \star v(k-1)
\end{aligned}
$$

c..... Watch growth in backward recurrence. Scale down if needed.

c.....this works for $n=1$ only.

$$
\begin{aligned}
& \text { if }(v(k-2) \cdot g t \cdot 1 \cdot d 20) \text { then } \\
& \text { if (k.gt.1) then } \\
& v(k-1)=v(k-1) / v(k-2) \\
& v(k-2)=1 \cdot d 0 \\
& \text { endif } \\
& a=a-2 . d 0
\end{aligned}
$$

100

continue

$I=1+1$

$x t(1)=v(n) / v(-1)$

if (1.gt. 1) then 
if $(a b s(x t(1) / x t(1-1)-1 . d 0) .1 t$. tol) go to 210

endif

200 continue

write $(*, '(1 x, a, i 2,1 x, a, 1 p, e 11.3) ')$

$m=81$ not enough for $n=1, n, \cdot x=1, x$

$\mathrm{m}=81$

write $\langle *, '(1 x, 1 p, 4 e 15.7) '\rangle(x t(n), n=1,1)$

210 continue

$\max =\mathrm{m}$

return

end

subroutine input (iyear, nyears)

Called by sourcel

Reads and checks input data, prints summary, and performs initial calculations.

Calls: none

parameter (maxnuc $=10$, maxyr $=9999999)$

common/cask/clhght, cllth, clwid, cmthk (4), comcvx (3), comcvy (3),

\# cvrdns, cvrthk, flangl, noclx, nocly, omathk (4), ostlrd (3), otncvx (3), otncvy (3), ovrhng, slangl, sldns, stlrad (3).

stlspc (3), submod, tencrx (3), tencvy (3), wstons, wsthk, wstht

common/chemcl/cl, c02, o2, so4i, so40, xmg2, dfalk, dfcaoh, dfcl, dfco2.

\# dfo2, dfso4, casol, crbsol, xmgsol

common/clcult/annprc, attk (4), crfrac (3), crfrcd (3), crfrcs (3),

\# crfrcw (3), crpcof, csstrn, flaper (3), flfrac (3), icl (3), ico2 (3), icrack (3), icrflg (3), ispl (3), ph (4), rfaper (3), rffrac (3), slfi, slfo, sticor (3), ttlwat, wiaper $(3,2)$, wifrac $(3,2)$, w2aper $(3,2)$, w2 frac $(3,2), x$ load $(3)$, xperc (2)

common/concrt/ca, cacon, cagw, cap, ccdns, ccon, ccpor, cfa, cfb, clcon,

\# co3, com28d, conpsn, constr, phbeg, si, stlmod, stlyld, wer, wtcment,

$\#$ yngmod

common/dump/ndump, refyear

common/failure/cft 1 , deft, eft 1 , deft

comon/files/iprint, fname, iprn1, ifrq1, iprn2, ifrq2, iprn3, ifrq3,

\# iprn4, ifrq4, iprn5, ifrq5, iprn6, ifrq6, iprn7, ifrq7,

\# filenam(9)

common/hydraul/cck, phgw, sitara, slkx, slk, tds, temp, water (12),

\# iyr1, iyr2

common/miscel/acoef, bcoef, dpm (12)

cormon/nuclide/noncld, nuclid (maxnuc), am (maxnuc),

\# dfcon (maxnuc), dfwst (maxnuc).

hlife (maxnuc), xllch (maxnuc):

gcask (maxnuc), rlch (maxnuc), sol (maxnuc). xkd (maxnuc)

common/padc/pstlrad,pstlmod,pstlyld, pconstr,

\# pbotcov, pwtcmnt, pstlspc, padcrk, piff, intctrl

common/pleach/cumlch (maxnuc), xleach (maxnuc), sladv (maxnuc),

\# sldif (maxnuc), qcaskl (maxnuc), saladv1 (maxnuc),

\# sldif1 (maxnuc), qcask2 (maxnuc), saladv2 (maxnuc),

\# sldif2 (maxnuc)

comon/runid/title

common/tumulus/lyr, numwid, numlth, numcsk, nmember

dimension ext (9)

real 8 qcask1, qcask $2, \times l e a c h$

integex refyear, bgndump

character $\star 16$ fname, filenam $\star 20$, ext $\star 4$, wat inp $\star 60$

character 8 nuclid 


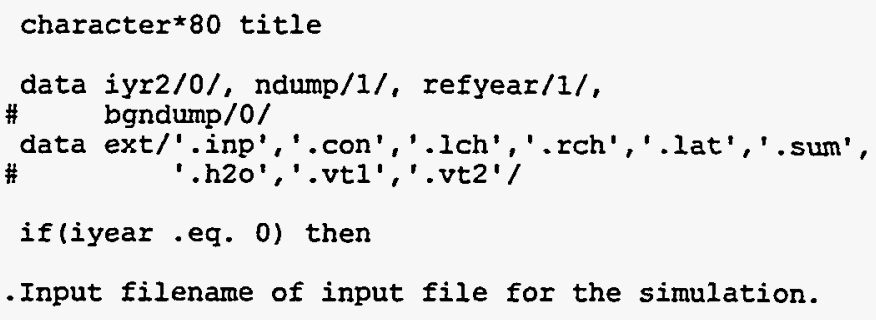

c..... Input filename of input file for the simulation.

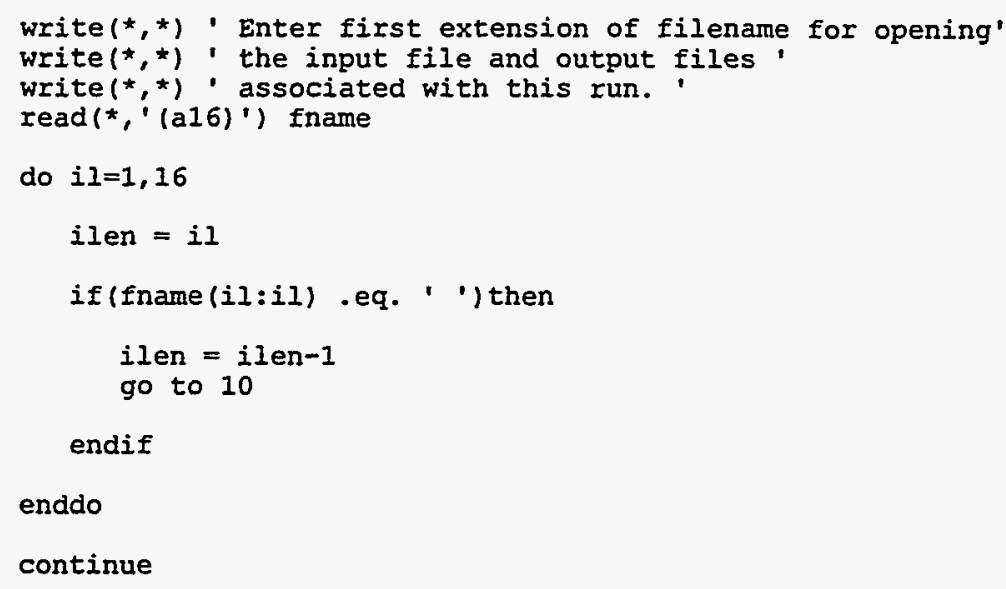

c......Create filenames with extensions for all input and output c.....files.

do ifile $=1,9$

filenam(ifile) $=$ fname $(1: i l e n) / / e x t(i f i l e)$

enddo

c..... Open input file with name "fname".inp.

c..... Open input data set; read title of simulation and simulation options.

open (unit=1, file=filenam(1), status=' old')

read $(1, \cdot(a 80)$ ') title

read $(1, '(2 i 10, i 2,7(i 2, i 5)) ')$ nyears, intctrl, iprint, iprn1, ifrq1, iprn2, ifrq2, iprn3, ifrg3, iprn4, ifrq4, iprn5, ifrq5, iprn6, ifrq6, iprn7, ifrq7

c..... Set default for output files to print every year.

if (iprnI .eq. 0 .and. ifrq1 .eq. 0 ) ifrq $1=1$

if (iprn2 .eq. 0 .and. ifrq2 .eq. 0 ) ifrq2 $=1$

if (iprn3 .eq. 0 .and. ifrq 3 .eq. 0 ) ifrq $3=1$

if (iprn4 .eq. 0 .and. ifrq4 .eq. 0 ) ifrq $4=1$

if (iprn5 .eq. 0 .and. ifrq5 .eq. 0 ) ifrq5 $=1$

if (iprn6 .eq. 0 .and. ifrq6 .eq. 0 ) ifrq $6=1$

if (iprn7 .eq. 0 .and. ifrq7 .eq. 0) ifrq7 $=1$

c......Cask and tumulus dimensions and design specifications.

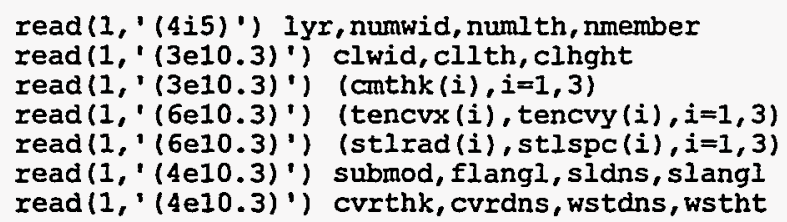

c..... Concrete and steel specifications for vault. 
read (1,' (7e10.3)') ccdns, ccpor, conpsn, com28d, wer, phbeg, wtcmnt read (1,' (4e10.3)') clcon, ccon, cfa, cfb read $(1, '(3 e 10.3)$ ') stlmod, stlyld, yngmod read $(1, '(3 e 10.3)$ ') cacon, cap, si

c.....Pad dimensions and concrete and steel specifications. pstlyld, pconstr,pstlspc, pbotcov, pwtcmnt, piff

c.....Chemical concentrations, diffusion coefficients, groundwater c..... properties, and solubilities.

$\operatorname{read}(1, '(8 \mathrm{e} 10.3) ') \mathrm{cagw}, \mathrm{cl}, \mathrm{co} 2, \mathrm{co3}, \mathrm{xmg} 2,02, \mathrm{so} 4 \mathrm{i}, \mathrm{s040}$ read (1, ' (6e10.3)') dfalk, dfcaoh, dfcl, dfco2, dfo2, dfso read (1,' (3e10.3)') phgw, tds, temp read $(1, '(3 e 10.3)$ ') casol, crbsol, xmgsol

c..... Failure function data for metal containers and epoxy c...... covering on rebar.

$\operatorname{read}(1, '(4 e 10.3) ')$ cftl,dcft, eftl, deft

c......Hydrogeological parameters.

$\operatorname{read}(1, '(4 \mathrm{e} 10.3)$ ') sitara, slkr, slk, cck

c..... Input name of file containing water seepage values.

read $(1, '(a) ')$ wat inp

open (unit=4, file= wat_inp, status $=$ 'old')

c..... Radionuclide-specific data.

read (1,' (i5)') noncld

if (noncld . gt. maxnuc) then

\# write (*, write ${ }^{*}$,

\# ' ("' than the value specified for maxnuc on the' ')')

write $(*$

' ("' parameter statements. Increase the value of'")') write(*, "(" maxnuc." ')') stop

endif

do $100 k=1$, noncld

read $(1, '(a 8,7 e 10,3) ')$ nuclid (k), am (k), hlife (k), sol (k)

$\#$ $x k d(k), q \operatorname{qcask}(k), \operatorname{dfwst}(k), \operatorname{dfcon}(k)$

if (qcask (k) . le. 0.) ndump=0

100

continue

if (ndump.ne. 1) then

read (1,'(i10)') refyear

read (1,' (i10,10e10.3)')

$\#$

bgndump, (qcask (k), k=1, noncld)

ndump = bgndump

endif

c.....Calculate or initialize various parameters for tumulus, start with c..... variables dealing with casks, cask dimensions, and concrete pH.

acoef $=0.5 *($ clwid-cmthk $(2)) / 39.37$ 


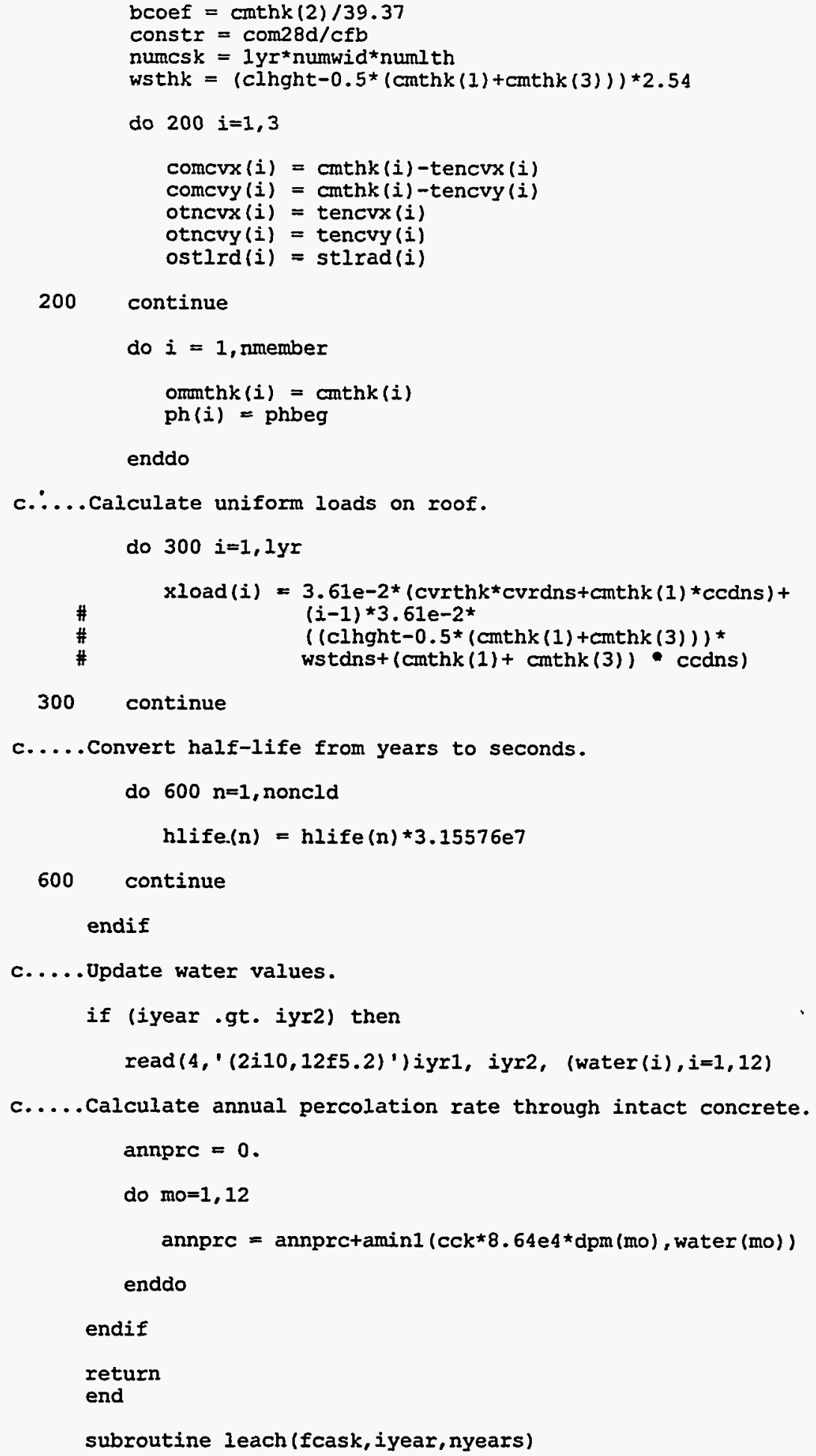

300 continue

c..... Convert half-life from years to seconds.

do $600 \mathrm{n}=1$, noncld

hlife. $(n)=$ hlife $(n) * 3.15576 \mathrm{e} 7$

600

continue

endif

c.... Update water values.

if (iyear.gt. iyr2) then

$\operatorname{read}\left(4, \cdot(2 i 10,12 f 5.2)^{\prime}\right)$ iyr1, iyr2, (water(i), $\left.i=1,12\right)$

c..... Calculate annual percolation rate through intact concrete.

annprc $=0$.

do $\mathrm{mo}=1,12$

annprc $=\operatorname{annprctamin} 1\left(c k^{\star} * 8.64 \mathrm{e} 4 \star \operatorname{dpm}(m o)\right.$, water $\left.(\mathrm{mo})\right)$

enddo

endif

return

end

subroutine leach (fcask, iyear, nyears)

Called by: source 1

Calculates annual radionuclide releases due to advection and diffusion.

Calls: flothru, maxlch 


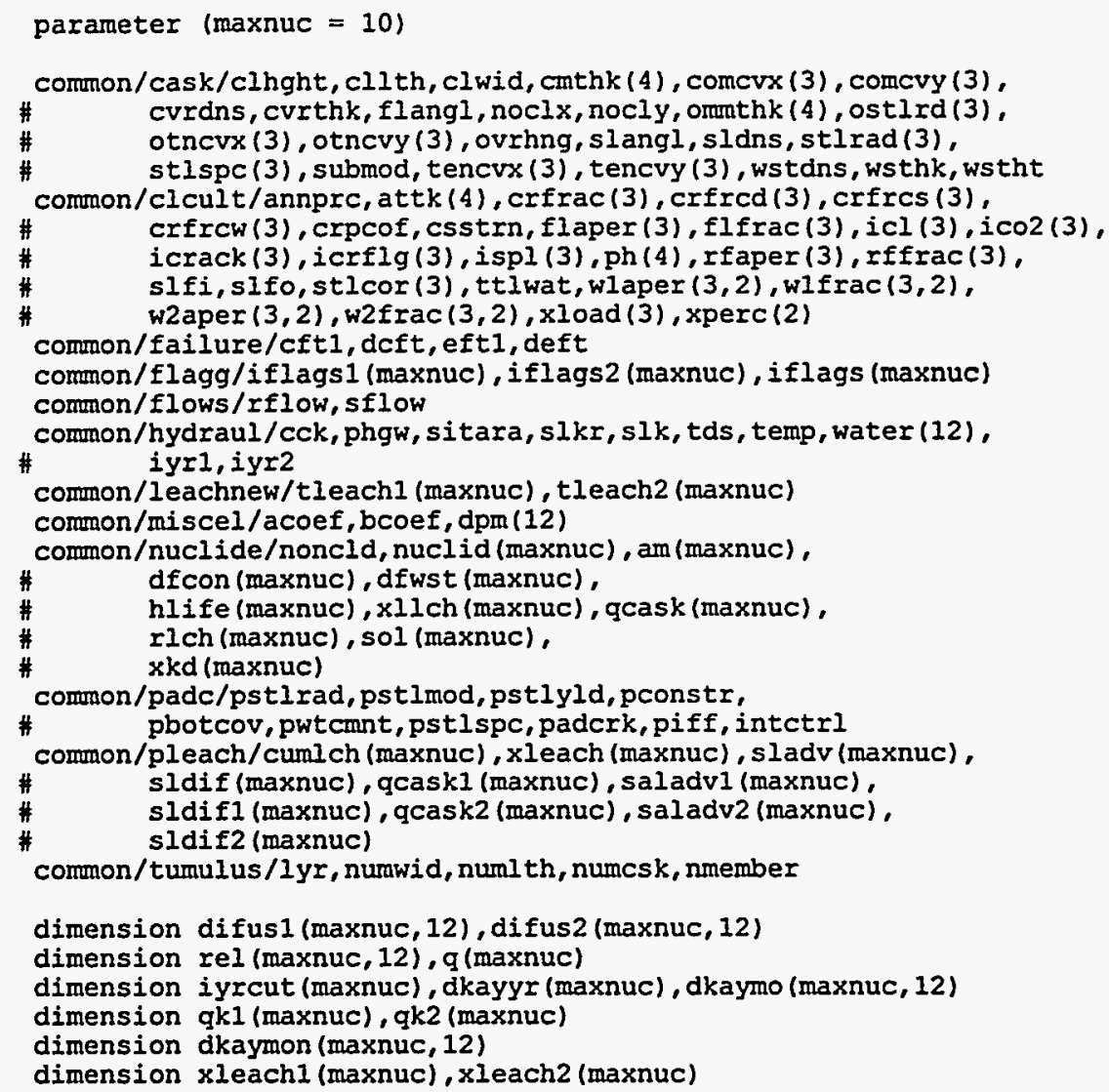

real*8 $q, q k 1, q k 2, q c a s k 1$, qcask2, difus1, difus2

real* 8 xleach, xleach1, xleach2, tleach1, tleach2

real* $8 \mathrm{t} 1, t 2, I$ mbdal (maxnuc), Imbda2 (maxnuc), Imbdad (maxnuc)

character $\star 8$ nuclid

data $\operatorname{cff} / 0 . /$

save iyrcut, dkayyr, dkaymo

save fcskold

c..... Define the local vectors iyrcut, dkayyr, dkaymo on first call. c.....dkaymo $(n, m o)$ - decay constant for first mo months of a year. c.....dkaymon $(n, m o)$ - monthly decay constant

if (iyear.eq.1) then

nyd5p1 = nyears $/ 5+1$

$\mathrm{dcon}=-\log (2) * .3.15576 \mathrm{e} 7$

ccon $=-80 . /$ dcon

do $100 \mathrm{n}=1$, noncld

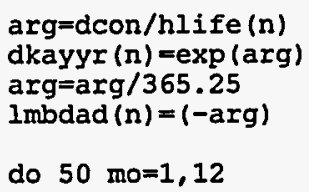

if (mo.eq.12) then

dkaymo $(n, m o)=1$ 


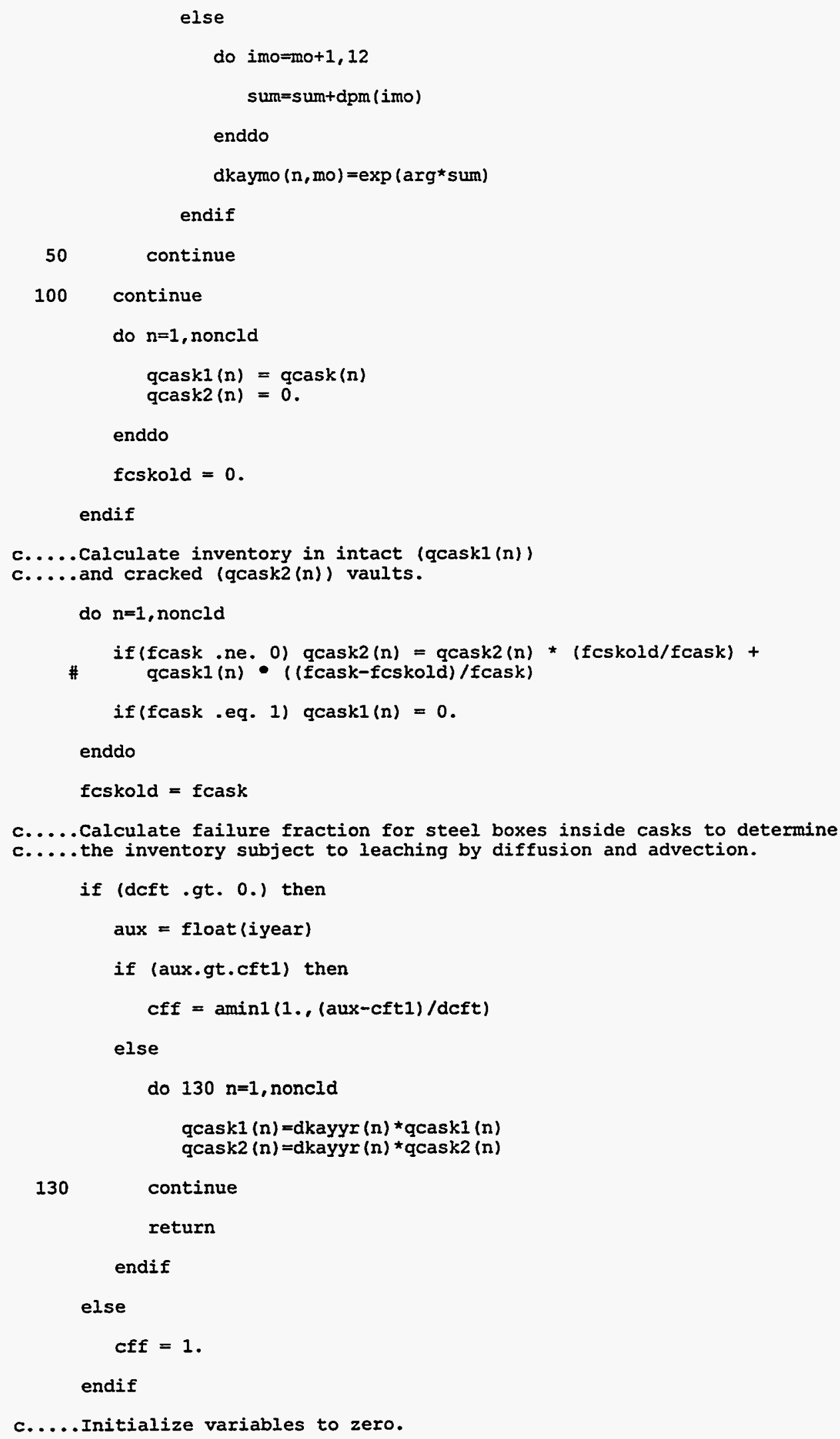


do $150 \mathrm{n}=1$, noncld

$\operatorname{sladv}(n)=0$.

$\operatorname{sldif}(n)=0$.

saladvl $(n)=0$.

$\operatorname{saladv} 2(n)=0$

$\operatorname{sldifI}(n)=0$.

$\operatorname{sldif2}(n)=0$.

do $\mathrm{mo}=1,12$

$\operatorname{difus} 1(n, \mathrm{mo})=0 . \mathrm{do}$

difus $2(n, m o)=0 . d 0$

enddo

150 continue

Iflow $=0$

sflow $=0$.

c..... Set very small inventory values to zero to prevent

c.....numerical problems in the leaching calculations.

do $\mathrm{n}=1$, noncld

if (qcask1 (n) .1t. 1.d-25) qcask1 $(n)=0 . d 0$

if (qcask2 $(n)$.1t. 1.d-25) qcask2(n) $=0 . d 0$

enddo

do mo $=1,12$

do $1=1$, noncld

$\operatorname{rel}(1, \mathrm{mo})=0$

enddo

enddo

c......Begin monthly loop.

$t 1=1$.

do $400 \mathrm{mo}=1,12$

$\mathrm{t} 2=\mathrm{t} 1+\mathrm{dpm}(\mathrm{mo})-1$

ttlwat $=$ water $(\mathrm{mo}) / 100 .{ }^{\star}$ sitara

$\operatorname{xperc}(1)=\operatorname{amin1}\left(\mathrm{cck}^{\star} 8.64 \mathrm{e} 4 * \mathrm{dpm}(\mathrm{mo}), \operatorname{water}(\mathrm{mo})\right)$

$\operatorname{xperc}(2)=\operatorname{aminl}\left(s 1 k^{\star} 8.64 \mathrm{e}^{\star}{ }^{\star} \mathrm{dpm}(\mathrm{mo})\right.$, water $\left.(\mathrm{mo})\right)$

c.....Calculate lateral and recharge flow components.

if (water (mo) .ne.0) then

$\operatorname{tmp}=\operatorname{amin} 1(1, ., s 1 \mathrm{kr} * 8.64 \mathrm{e} 4 * \operatorname{dpm}(\mathrm{mo}) /$ water (mo) $)$

rflow $=$ rflow+tmp*water (mo)

sflow $=$ sflow $(1 .-$ tmp $) \star$ water $($ mo $)$

endif

c begin nuclide loop

do $2001=1$, noncld

c..... Calculate inventory available for leaching from intact and cracked casks.

$q k 1(1)=\operatorname{qcask} 1(1){ }^{*} \operatorname{cff}^{\star}$ numcsk$k^{\star}(1$. -fcask $)$

$q k 2(1)=q \operatorname{qcask} 2(1){ }^{*}$ cff*numcsk* $($ fcask $)$

c......Calculate total inventory available for leaching. 
$q(1)=q k I(I)+q k 2(1)$

c.....Calculate leach rate constant for intact and cracked casks.

$1 \operatorname{mbdal}(1)=\operatorname{xperc}(1) /($ wsthk* (wstht+wstdns*xkd (1)))

lmbda2 (1) $=x \operatorname{perc}(2) /($ wsthk* (wstht+wstdins * xkd (1)))

c..... Calculate advective releases based on percolation rates through c..... intact casks.

\#

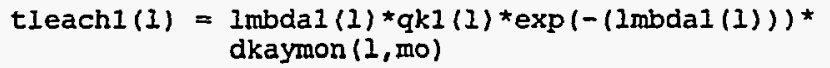

if (mo .eq. 1) then

c..... Calculate monthly leach rates due to diffusion for entire year c.....using the flothru computer code and initialize leach fractions c..... for recharge and lateral flow components.

if $(q(1)$.ne. 0.$)$

\# call flothru(dfwst(1), dfcon(l), hlife(l),

$\operatorname{rlch}(1)=0$. iyear, $1, q(1)$, rel

$\operatorname{xIlch}(1)=0$.

endif

if $(q(1)$.ne. $0 . d 0)$

difusl $(1, \mathrm{mo})=\operatorname{dble}(\operatorname{rel}(1, \mathrm{mo})) * q k l(1) / q(1)$

if $(g(1)$.ne. $0 . d 0)$

$\operatorname{difus} 2(1, m o)=\operatorname{dble}(\operatorname{rel}(1, \mathrm{mo})) * \mathrm{qk} 2(1) / q(1)$

c..... Sum diffusive and advective releases for intact casks to obtain total c....release rate.

$$
\text { tleachl }(1)=\operatorname{tleach} 1(1)+\operatorname{difus} 1(1, \mathrm{mo})
$$

c..... Calculate advective releases for cracked casks.

\#

$\operatorname{tleach} 2(1)=1 \operatorname{mbda} 2(1) * q k 2(1) * \operatorname{dexp}(-(1 \operatorname{mbda} 2(1))) *$ dkaymon $(1$, mo)

c..... Sum diffusive and advective releases for cracked casks to obtain total c.....release rate.

$\operatorname{tleach} 2(1)=\operatorname{tleach} 2(1)+\operatorname{difus} 2(1, \mathrm{mo})$

c..... Sum diffusive releases for intact and cracked casks.

200 continue

c..... Check calculated releases against solubility limits using the total c..... amount of water passing through intact casks.

do $1=1$, noncld

$$
q(1)=q k I(1)
$$

enddo

call maxlch $(q, \operatorname{xperc}(1) / 100 . * \operatorname{sitara}, 1)$

do $1=1$, noncld

c..... Sum advective and diffusive components for intact and cracked casks.

$$
\text { tleach2 (1) = tleach2 (1) +tleachl (1) }
$$

c......sum inventory for intact and cracked casks.

$$
q(1)=q k 1(1)+q k 2(1)
$$

enddo 
c......Check calculated releases against solubility limits using the total c......amount of water passing through casks.

call maxlch (q, xperc(2)/100.*sitara,2)

do $3001=1$, noncld

c..... Calculate total tumulus release and monthly update of inventory.

if (iflagsl (1) eq. 0 ) then

$1 \operatorname{mbdal}(1)=1 \mathrm{mbdal}(1) / \mathrm{dpm}$ (mo)

$\operatorname{xleach} 1(1)=\left(1 \operatorname{mbda} 1(1)^{\star} \mathrm{qk} 1(1)\right) /(1 \operatorname{mbda} 1(1)+1 \operatorname{mbdad}(1))$

* $(\operatorname{dexp}(-t 1 *(1 \operatorname{mbda} 1(1)+1 \operatorname{mbdad}(1)))-$ $\operatorname{dexp}(-t 2 *(1 \operatorname{mbda}(1)+1 \operatorname{mbdad}(1))))+$

$\#$
$\#$
$\#$

else difus $1(1, \mathrm{mo}) * 1$.

$\times \operatorname{xleach} 1(1)=\operatorname{treach} 1(1) \star 1$

endif

if (fcask .ne. 1)

qcask $1(1)=\operatorname{dmax} 1(0 . \mathrm{d} 0,(\mathrm{dkaymon}(1, \mathrm{mo}) *$ qcask $1(1)-$ $x l e a c h l(1) /($ numcsk*(1.-fcask) $))$ )

if (iflags $2(1)$ eq. 0 ) then

$1 \mathrm{mbda} 2(1)=1 \mathrm{mbda} 2(1) / \mathrm{dpm}$ (mo)

$x$ leach $2(1)=(1 \operatorname{mbda} 2(1) * q k 2(1))$

$/(1 \operatorname{mbda2}(1)+1 \operatorname{mbdad}(1))$

* (dexp $(-t 1 *(1 \operatorname{mbda} 2(1)+1 \operatorname{mbdad}(1)))$

$-\operatorname{dexp}(-t 2 *(1 \operatorname{mbda} 2(1)+1 \operatorname{mbdad}(1))))+$

else difus $2(1$, mo $) * 1$.

$x \operatorname{leach} 2(1)=(\operatorname{teach} 2(1)-\operatorname{tleach} 1(1)) * 1$.

endif

if (fcask .ne. 0 )

qcask2 (1) $=\operatorname{dmax} 1(0 . \mathrm{do},($ dkaymon $(1, \mathrm{mo}) *$ qcask2 $(1)-$

xleach2(1)/(numcsk*fcask))

$x$ leach $(1)=x$ leach $1(1)+x$ leach $2(1)$

tleach2 (1) $=$ tleach2 (1)-tleach1 (1)

saladv1 $(1)=\operatorname{saladv} 1(1)+\operatorname{dkaymo}(1, \mathrm{mo})$ *

$\operatorname{dmax} 1(0 . d 0, \times l e a c h l(I)-\operatorname{difus} 1(1, \mathrm{mo}))$

saladv2 $(1)=\operatorname{saladv} 2(1)+\operatorname{dkaymo}(1, \mathrm{mo})$ * $\operatorname{dmax} 1(0 . d 0, x l e a c h 2(1)-\operatorname{difus} 2(1, \mathrm{mo}))$

sldifI $(I)=\operatorname{sidifl}(1)+$ dkaymo $(1, \mathrm{mo})$ *dmin1 $(t$ leach $1(1)$, dble (difus $1(1$, mo) ))

sldif2(1) = sldif2(1) + dkaymo (l,mo) *dmin1 (tleach2 (1), dble (difus2 $(1$, mo) ))

if (mo .eq. 12) then

sladv $(1)=\operatorname{saladv} 1(1)+\operatorname{saladv} 2(1)$

sldif $(1)=\operatorname{sldif1}(1)+\operatorname{sldif} 2(1)$

endif

c.....Partition release into lateral flow and recharge components assuming c.....same contaminant concentration in each component. Decay partitioned c.....releases to end of current year.

$\operatorname{rlch}(1)=\operatorname{rlch}(1)+x l e a c h(1) * t m p *$ dkaymo $(1, \mathrm{mo})$

if (tmp .1t. 1.) xllch(1) $=$ xllch $(1)+x l e a c h(1) *$

\# (1. -tmp) *dkaymo $(1, \mathrm{mo})$

300 continue 
$t 1=t 2+1$

400 continue

do $3101=1$, noncld

c..... Calculate adjusted total inventory per cask.

$q \operatorname{cask}(1)=q \operatorname{cas} k 1(1) *(1 .-$ fcask $)+$

qcask2(1) * fcask

c..... Calculate total annual release.

$x l e a c h(1)=\operatorname{llch}(1)+x l l c h(1)$

c..... Determine cumulative amount leached.

if (iyear.eq.1) then

$\operatorname{cumlch}(1)=x l e a c h(1)$

else

$\operatorname{cumlch}(1)=\operatorname{cumlch}(1)+x l e a c h(1)$

endif

310 continue

c.....Reset negative diffusion values.

do $n=1$, noncld

if $(\operatorname{sldif}(n)$. It. 0$)$ sldif $(n)=-\operatorname{sldif}(n)$

if (sldifl $(n)$. It. 0 ) sldifl $(n)=-\operatorname{sldifl}(n)$

if $($ sldif2 $(n)$. .lt. 0) $\operatorname{sldif2}(n)=-\operatorname{sldif2}(n)$

enddo

do $\mathrm{n}=1$, noncld

if (fcask .ne. 1.) then

c.....Advection and diffusion for intact vaults (per vault).

$\operatorname{saladv} 1(n)=\operatorname{saladv} 1(n) /($ numcsk*$(1 .-f c a s k))$

sldifl $(n)=\operatorname{sldif1}(n) /($ numcsk $*(1$. -fcask $))$

endif

if (fcask .ne. 0.) then

c.....Advection and diffusion for cracked vaults (per vault).

saladv $2(n)=\operatorname{saladv} 2(n) /($ numesk $k$ fcask)

$\operatorname{sldif2}(n)=\operatorname{sidif2}(n) /($ numcsk*fcask)

endif

endido

if (nmember .eq. 4) then

if (padcrk .ne. 1. .and. iyear . It. intctrl) then

do $\mathrm{n}=1$, noncld

c.....Attenuate the releases to the environment based on the c..... functionality of the concrete pad and collection system.

$\operatorname{rlch}(n)=\operatorname{rlch}(n) *(1 .-($ piff-(piff/intctrl $) *$ iyear $))$
$x l l c h(n)=x l l c h(n) *(1 .-($ piff $-($ piff/intctr $) *$ iyear $))$ 


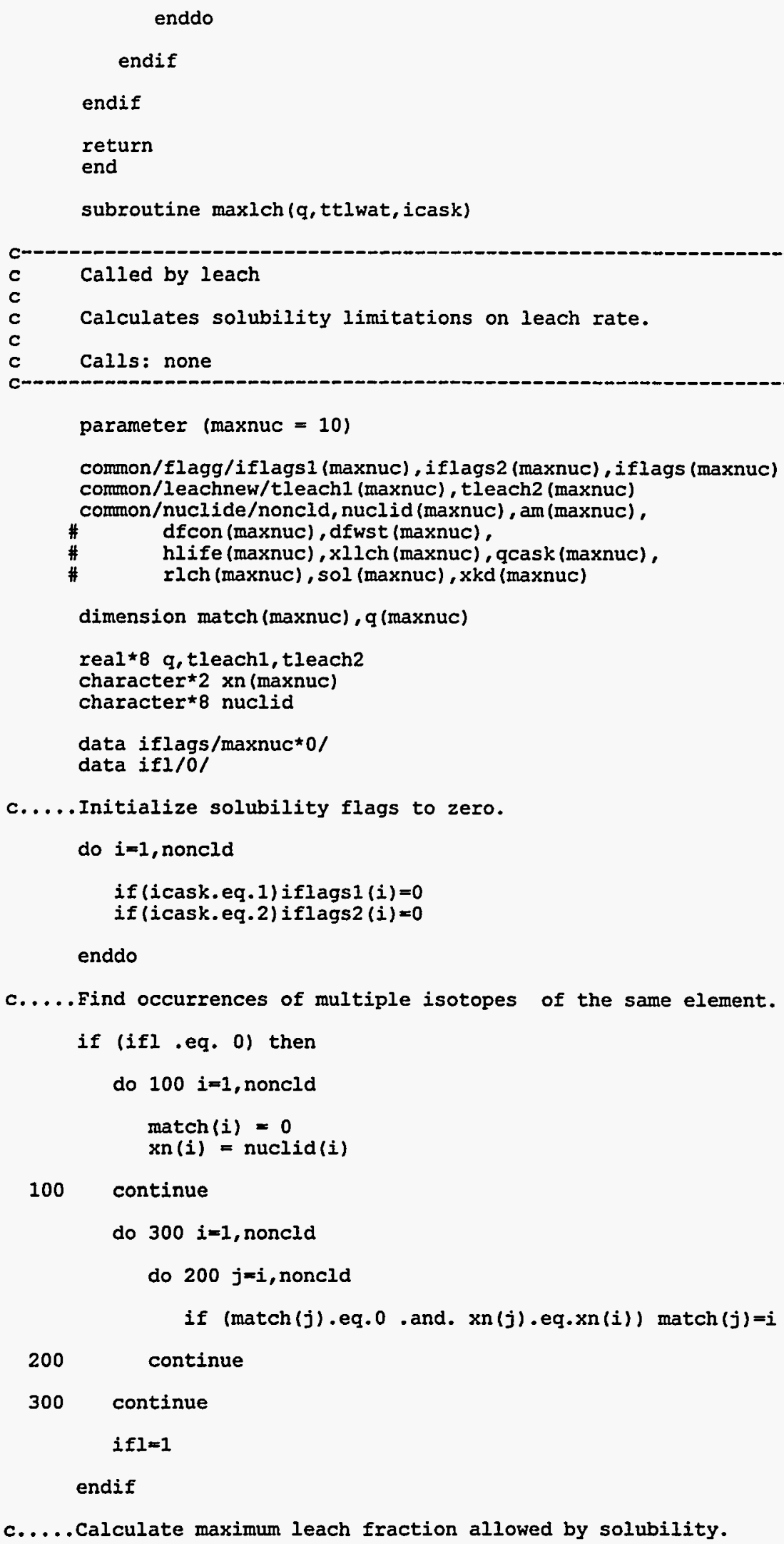


do $600 i=1$, noncld

if(sol(i).eq.0. .or. match(i).lt.i) go to 600 enole $=0$.

do $400 j=1$, noncld

if $(\operatorname{match}(j)$.eq. i) emole=emole+q $(j) / a m(j)$

continue

if (emole .eq. 0.) go to 600

$x I \max =1000$. sol(i) * ttlwat / emole

do $500 j=1$, noncld

if (match $(j)$. eq. $i)$ then

if (icask .eq. 1) then

if $(t$ leach $1(j)$.gt. $(q(j) * x l \max ))$ iflagsl $(j)=1$

tleach $1(j)=\operatorname{dmin} 1(\mathrm{dble}(q(j) * x \max ), \operatorname{tleach} 1(j))$

endif

if (icask .eq. 2) then

if (tleach2 $(j) \cdot g t . \quad(q(j) \star x l$ max $))$ iflags $2(j)=1$ tleach $2(j)=\operatorname{dmin} 1(\operatorname{dble}(q(j) \star x I m a x)$, tleach $2(j))$

endif

endif

if (iflagsl(j) .eq. 1 .or. iflags $2(j)$.eq. 1)

$\#$ iflags $(j)=$ iflags $(j)+1$

500 continue

600 continue

return

end

subroutine output (fcask, iyear, nyears)

c Called by main
c
c Prints results of concrete cracking analyses and leach calculations.
c Calls: none

parameter $($ maxnuc $=10)$

common/cask/clhght, clith, clwid, cmthk (4), comcvx (3), comcvy (3),

\# cvrdns, cvrthk, flangl, noclx, nocly, ommthk (4), ostlrd (3).

\# otncrx (3), otncvy (3), ovrhng, slangl, sldns, stirad (3),

\# stlspc (3), submod, tencvx (3), tencvy (3), wstdns, wsthk, ws tht

common/chemcl/cl, co2, 02, so4i, so40, xmg2, dfalk, dfcaoh, dfcl, dfco2,

\# dfo2, dfso4, casol, crbsol, xmgsol

common/clcult/annprc, attk (4), crfrac (3), crfrcd (3), crfrcs (3),

\# crfrcw (3), crpcof, csstrn, flaper (3), flfrac (3), icl (3), ico2 (3),

\# icrack (3),icrflg(3), ispl (3), ph (4), rfaper (3), rffrac (3),

\# slfi,slfo, stlcor (3), ttlwat, wlaper $(3,2)$, wlfrac $(3,2)$,

\# w2aper $(3,2)$, w2 frac $(3,2), \operatorname{xload}(3), \operatorname{xperc}(2)$

common/concrt/ca, cacon, cagw, cap, ccdns, ccon, ccpor, cfa, cfb, clcon,

\# co3, com28d, conpsn, constr, phbeg, si, stlmod, stlyld, wcr, wtemnt,

\# yngmod

common/dump/ndump, refyear

comon/failure/cftl, deft, eft 1 , deft

common/files/iprint, fname, iprn1, ifrq1, iprn2, ifrq2, iprn3, ifrq3, 
\# iprn4, ifrq4, iprn5, ifrq5, iprn6, ifrq6, iprn7, ifrq7,

\# filenam(9)

common/flagg/iflags1 (maxnuc), iflags2 (maxnuc), iflags (maxnuc)

common/flows/rflow, sflow

common/hydraul/cck, phgw, sitara, slkr, slk, tds, temp, water(12),

$\#$ iyr1, iyr2

common/nuclide/noncld, nuclid (maxnuc), am (maxnuc),

\# dfcon (maxnuc), dfwst (maxnuc),

\# hlife (maxnuc), xllch (maxnuc), qcask (maxnuc),

\# Ilch (maxnuc), sol (maxnuc),

\# xkd (maxnuc)

conmon/padc/pstlrad,pstlmod,pstlyld,pconstr,

\# pbotcov, pwtcmint, pstlspc, padcrk, piff, intctrl

common/pleach/cumlch (maxnuc), xleach (maxnuc), sladv (maxnuc),

\# sldif (maxnuc), qcaskl (maxnuc), saladv1 (maxnuc),

\# sldif1 (maxnuc), qcask2 (maxnuc), saladv2 (maxnuc),

\# sldif2 (maxnuc)

cormon/runid/title

common/tumul us/lyr, numwid, numlth, numcsk, nmember

dimension name(3)

real $\star 8$ qcask 1 , qcask $2, x l e a c h$

integer refyear

character $\$ 8$ nuclid

character $\star 10$ name

character $\star 12$ fname, filenam $* 20$

character $\star 80$ title

character*23 labell (maxnuc) /10*'Inventory remaining $(g) \%$

$\#$

H label2 (maxnuc) $* 24 / 10 *$ Annual leach rate $(g / y r) \%$ label3 (maxnuc) *25/10*' Cumulative leached $(g) /$

character ${ }^{21}$ label4 (maxnuc) $/ 10{ }^{\prime}$ Adv leach rate $(\mathrm{g} / \mathrm{yr}) \%$

\# label5 (maxnuc)/10*'Dif leach rate ( $g / \mathrm{yr}) \%$

character*12 label6 (maxnuc) $/ 10 *$ 'Recharge $(g) \%$

$\#$

character $* 1$ dashs $(76) / 76^{*}-1 /$

data name/'Cask roof', 'Cask walls', 'Cask floor'/

data ictrl/0/, ipcrk/0/

data zero/0./

if(iyear .eq. 0) then

c..... Open file for input data summary and concrete analysis c......with name "fname".con.

if (iprint .eq. 0 .or. iprn3 .eq. 0 )

萧 open (unit=7, file=filenam (2), status='new')

if (iprint .eq. 0) then

write $(7,1000)$ title

write $(7,1025)$

write $(7,1050)$ nyears

write $(7,1060)$ ifrq3

write $(7,1125)$ sitara, tds, temp, phgw, slkr, slk, cck

write $(7,1150)$ cagw, cl, co3, xng 2, so4o, 02

write $(7,1175)$ casol, crbsol, xmgsol

write $(7,1200)$ cacon, cap, ccon, clcon, si

write $(7,1225)$ com28d*7.04e-2, conpsn, stlmod*7.04e-2, stlyld* $7.04 \mathrm{e}-2$, submod $* 7.04 e-2$, yngmod $* 1.02 e-5$, wCr,

\# ccdns, ccpor, wtcmint, phbeg

if (nnember .eq. 4)

write $(7,1240)$ pstl rad $\star 2.54$, cmthk $(4) * 2.54$ pstlmod $\star 7.04 e-2$, pstlyld $\star 7.04 \mathrm{e}-2$, pconstr $\star 7.04 \mathrm{e}-2$, pstlspc 2.54, pbotcov 2.54 pwtcmnt, piff

write $(7,1250)$ dfalk, dfcaoh, dfcl, dfco2, dfo2, dfso4

write $(7,1275$ ) Iyr, numwid, numlth, clwid/39.37,

clith/39.37, clhght/

39.37, (cmthk $(i) * 2.54, i=1,4),(\operatorname{stl} \operatorname{rad}(i) * 2.54$, $i=1,3),(\operatorname{stl} \operatorname{spc}(i) \star 2.54, i=1,3)$ 


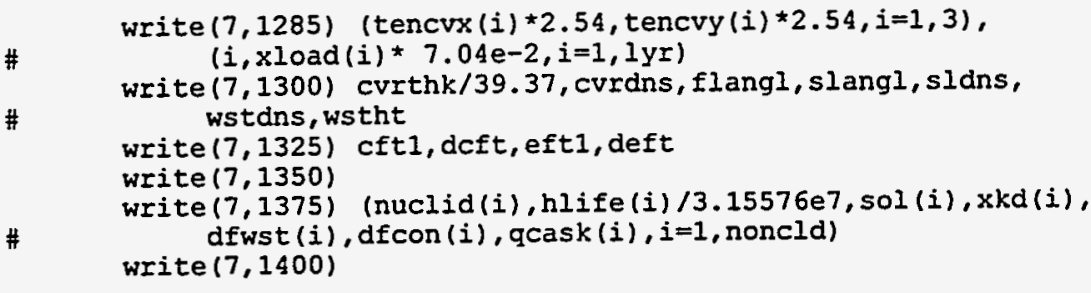

endif

if(iprn1 .eq. 0) then

c..... Open file for recharge components with name "fname".rch.

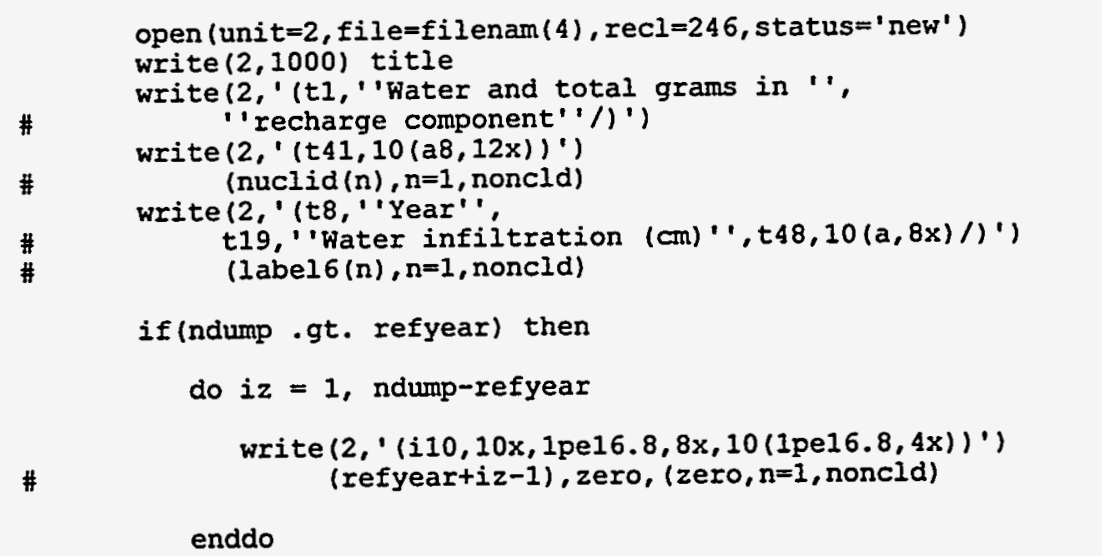

endif

endif

if(iprn2 .eq. 0) then

c..... Open file for lateral flow with name "fname".lat.

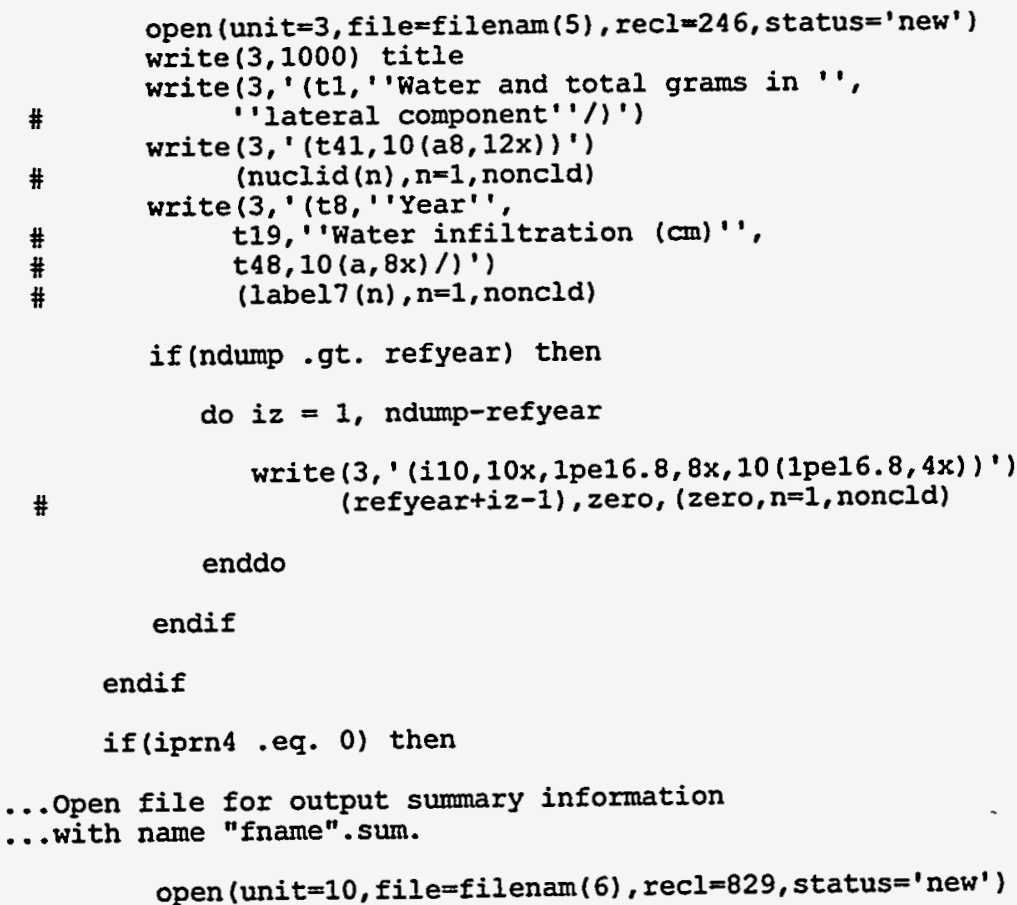




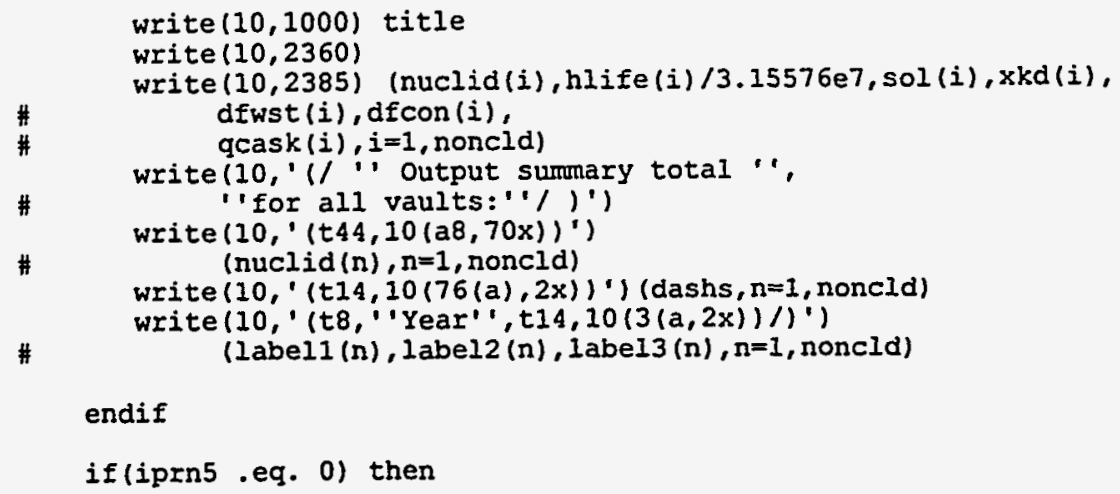

c..... Open file for annual advective loss, diffusive loss, and total loss c......with name "fname".1ch.

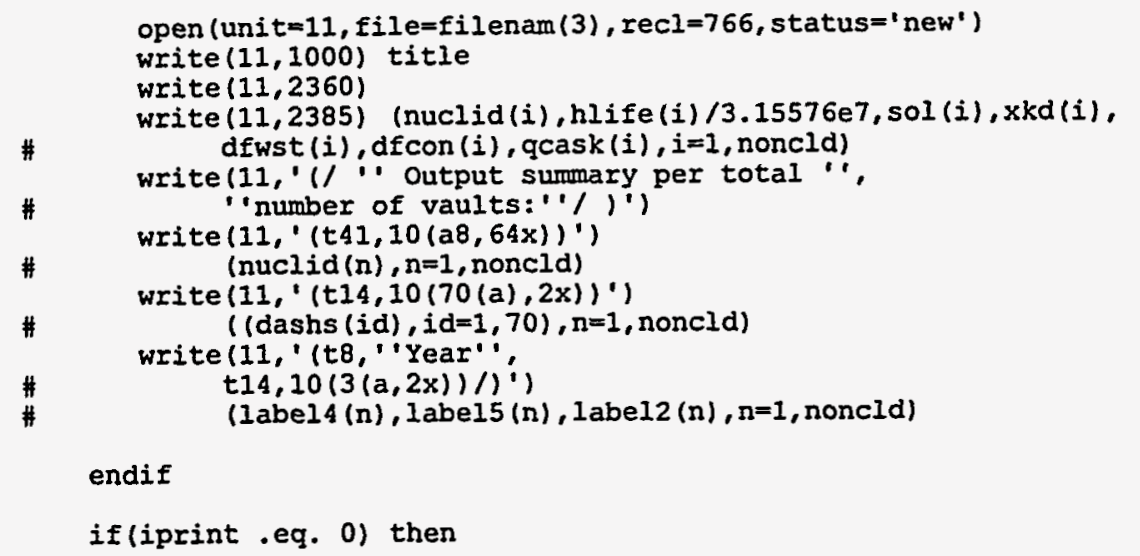

c..... Open file for water infiltration sumary information c...... with name "fname".h2o.

open (unit=12, file=filenam(7), status=' new')

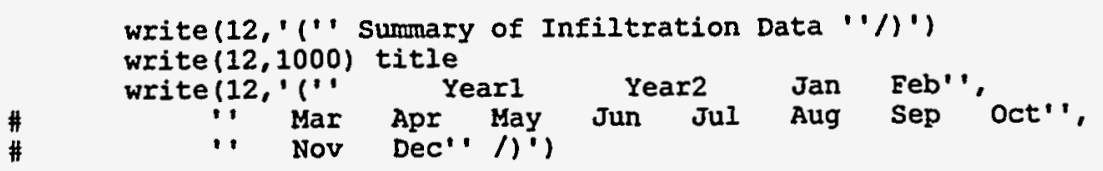

endif

if(iprn6 .eq. 0) then

c..... Open file for intact vault information

c......with name "Ename".vt1.

open (unit $=14$, file $=$ filenam $(8)$, recl $=766$, status $=$ 'new')

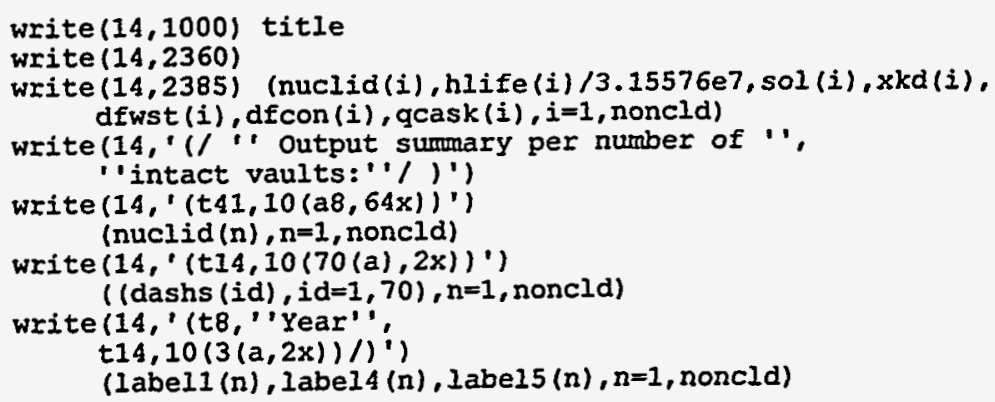


endif

if(iprn7 .eq. 0) then

c..... Open file for cracked vault information

c....... with name "fname". vt2.

open (unit=15, file=filenam ( 9 ), recl=766, status=' new')

write $(15,1000)$ title

write $(15,2360)$

write $(15,2385$ ) (nuclid(i), hlife(i)/3.15576el, sol(i), xkd(i),

\# dfwst (i), dfcon(i), qcask( $i), i=1$, noncld)

write $(15,, / /$ " Output summary per number of ' ,

\# $\quad$ "cracked vaults:' '/,')

write $\left(15,{ }^{\prime}(t 41,10(a 8,64 x)) '\right)$

\# (nuclid ( $n), n=1$, noncld)

write $(15, '(t 14,10(70(a), 2 x)) ')$

\# ((dashs (id), $i d=1,70$ ), n=1, noncld)

\# write $(15, '($ t8, ' Year''

\# (labell (n), label4 (n), label5 (n), $n=1$, noncld)

endif

return

endif

if((iprn3 .eq. 0 .and. iyear .eq. 1) .or.

\# (iprn3 .eq. 0 .and. mod(iyear, ifrq3) .eq. 0)) then

if(iyear .eq. 1) then

write $(7,2000)$ ndump

else

if (ndump .gt. 1) then

write $(7,2000)$ ndump+iyear

else

write $(7,2000)$ iyear

endif

endif

c.....Print concrete degradation.

write $(7,2025)$

write $(7,2050)$ (cmthk (i) $2.54, i=1,4)$, (aminl (omathk (i), i year*

$\#$ $(\operatorname{sifi+slfo})) * 2.54, i=1,4),(1 .-\operatorname{attk}(i), i=1,4)$

write $(7,2075)(\max 0(i c l(i), i \operatorname{co} 2(i)), i=1,3),(s t l \operatorname{cor}(i) * 2.54$, $\# \quad i=1,3),(\operatorname{stl} \operatorname{rad}(i) \star 2.54, i=1,3)$

c.....Print results of cracking analyses.

write $(7,2100)$

write $(7,2125)$

do $100 i=1,3$

if (ispl(i) .eq. 1) then

write $(7,2150)$ name (i)

elseif (crfrcd(i) .gt. .75*cmthk(i)) then 


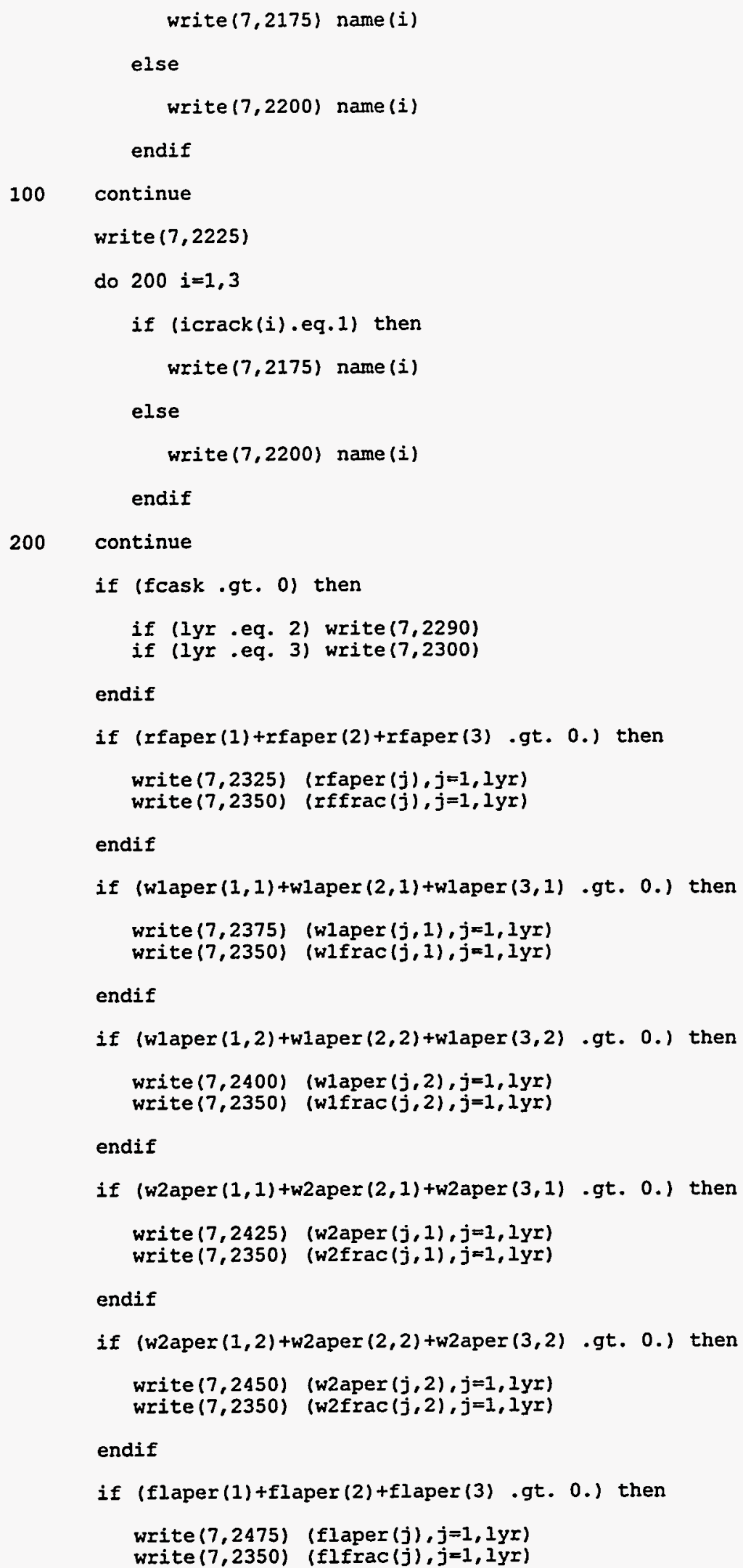




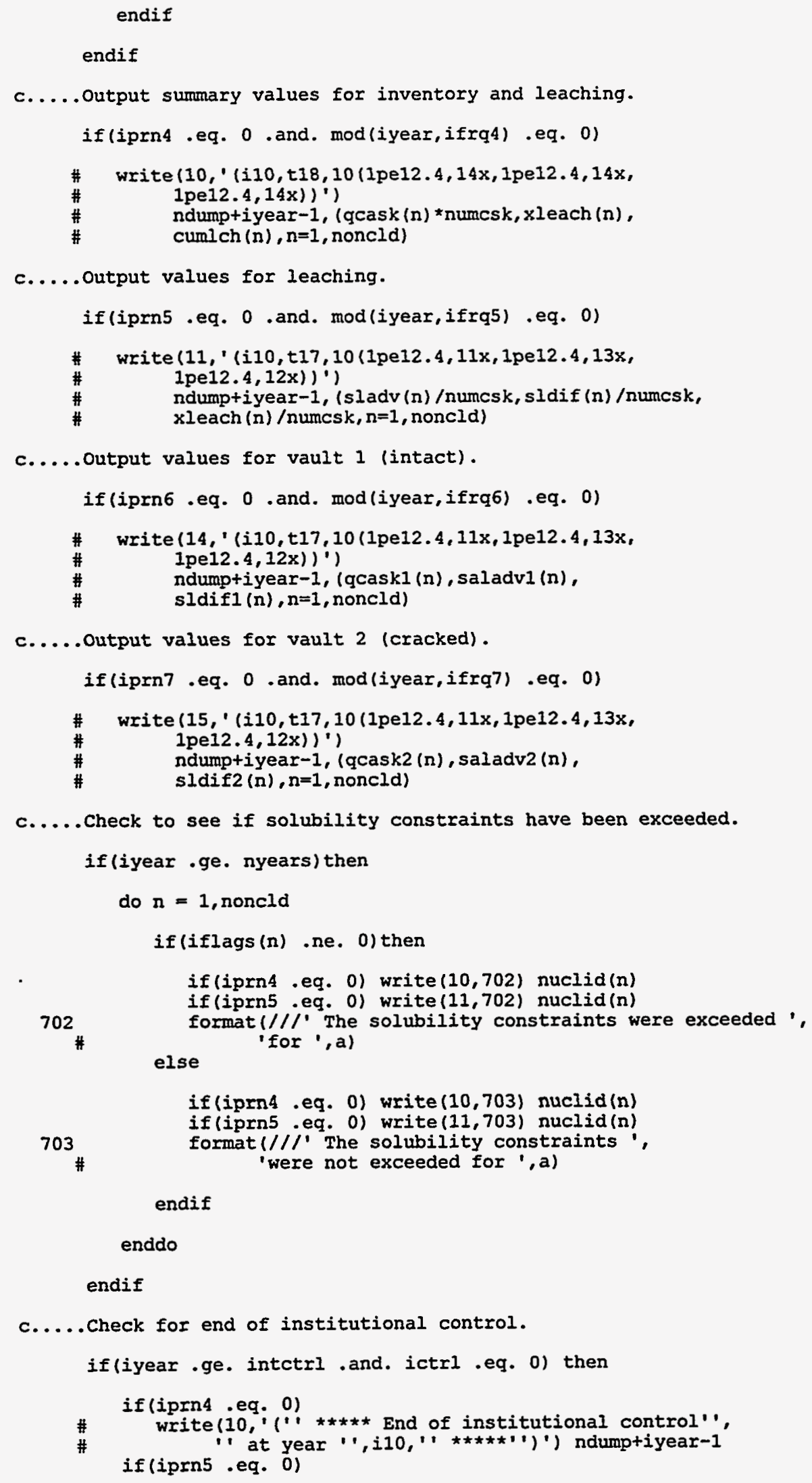


write $(11, '(" * \star \star \star *$ End of institutional control' ',

$i \operatorname{ctrl}=1$

endif

c..... Check if concrete pad has cracked.

if (padcrk .eq. 1. .and. ipcrk .eq. 0) then

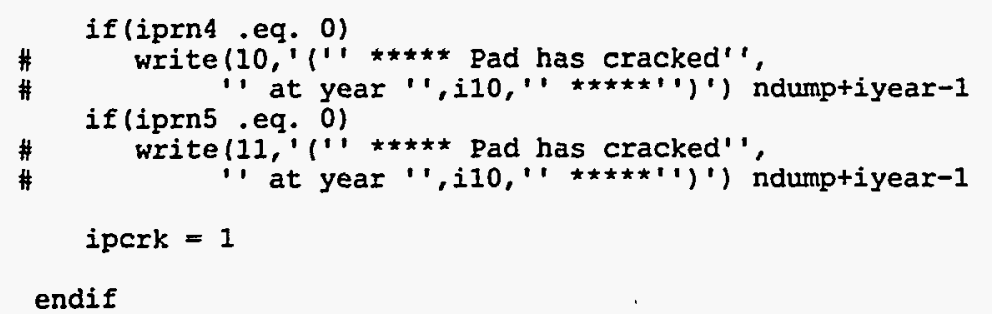

c.....Write annual releases to lateral and recharge component files.

if (iprn1 .eq. 0 .and. mod(iyear, ifrq1) .eq. 0)

\# write $\left(2,{ }^{\prime}(110,10 x, 1\right.$ pe16.8,8x,10(1pe16.8,4x))')

\# ndump+iyear-1, rflow, ( $\mathrm{rlch}(\mathrm{n}), \mathrm{n}=1$, noncld)

if (iprn2 .eq. 0 . and. mod (iyear, ifrq2) .eq. 0$)$
$\# \quad$ write $(3, \cdot(i 10,10 x, 1$ pe16.8, $8 x, 10(1$ pe $16,8,4 x))$
$\# \quad$ ndump+iyear-1, sflow, $(x 11 \operatorname{ch}(n), n=1$, noncld)

if (iyear .eq. iyr2 .or. iyear .eq. nyears) then

if (iprint eq. 0$)$
\#rite $(12, \cdot(1 \mathrm{~h}, i 10,1 x, i 10,3 x, 12 f 6.2) ')$ iyr1, iyr2,
(water(i),i=1,12)

endif

return

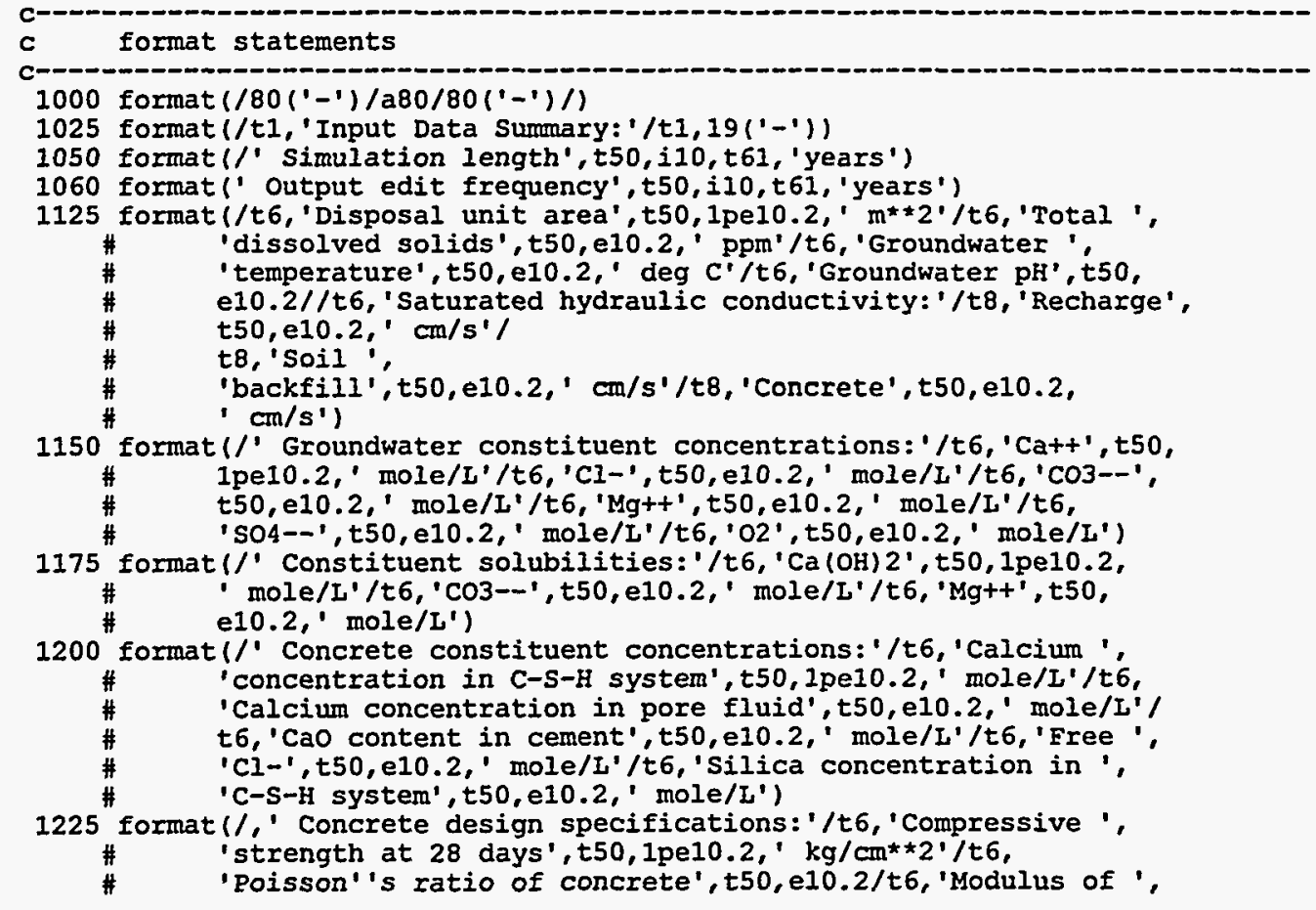


'elasticity of steel',t50,e10.2,' $\mathrm{kg} / \mathrm{cm} * \star 2$ ' $/ \mathrm{t} 6$, 'Yield ', 'strength of steel', t50,e10.2,' $\mathrm{kg} / \mathrm{cm} \star \star 2 ' / \mathrm{t} 6$, 'Modulus of ', 'subgrade reaction', $\mathrm{t50}, \mathrm{e} 10.2$,' $\mathrm{kg} / \mathrm{cm} \star \star 2$ '/t6, 'Young' 's ', 'modulus of elasticity', 550, e10.2,' $\mathrm{kg} / \mathrm{cm} * 2^{\prime} / \mathrm{t} 6$,

'Concrete water/cement ratio', t50,e10.2/t6, 'concrete ', 'density', t50, e10.2,' $\mathrm{g} / \mathrm{cm}^{\star} \star 3 ' / t 6$, 'Concrete porosity', $t 50$, e10.2/t6, 'Cement content', t50,e10.2,' $\mathrm{kg} / \mathrm{m}^{\star} * 3^{\prime} / \mathrm{t} 6$, 'Initial pH', t50, e10.2)

1240 format (/' Concrete pad failure model parameters:'/

$t 6$, 'Radius of pad steel reinforcement', t50,1pe10.2, ' cm'/

$t 6$, 'Concrete pad thickness', t50,1pe10.2,' $\mathrm{cm}$ '/

t6. 'Modulus of elasticity of steel reinforcement', t50, 1pe10.2,' $\mathrm{kg} / \mathrm{cm}^{\star \star 2} 2 /$

t6, 'Yield strength of steel reinforcement',

t50, Ipe10.2,' $\mathrm{kg} / \mathrm{cm}^{\star} \star 2 ' /$

$t 6$, 'Compressive strength of pad concrete',

t50, Ipe $10.2, ' \mathrm{~kg} / \mathrm{cm} * \star 2, /$

t6, 'Spacing between steel reinforcing rods',

t50,1pe10.2,' cm'/t6,

'Concrete cover thickness from the center'

t50, Ipe10.2,' cm'/

$t 6$, 'of the bottom '.

'row of steel reinforcing rods '/

$t 6$, 'to the bottom of the pad'/

$t 6$, 'Weight of pad cement per unit',

t50, 1pe10.2,' $\mathrm{kg} / \mathrm{m}^{\star \star} 3^{\prime} /$

$t 6$, 'volume concrete'/

t6, 'Pad initial functionality fraction',

t50,1pe10.2)

1250 format $(/, '$ Diffusion coefficients in concrete: ', /, t6, 'NaOH, $\mathrm{kOH}$ ',

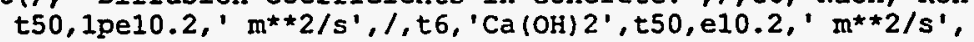
l, t6, ' $\mathrm{Cl}-^{\prime}, \mathrm{t} 50, \mathrm{e} 10.2, \mathrm{\prime}^{\prime} \mathrm{m} * 2 / \mathrm{s}^{\prime}, \mathrm{l}, \mathrm{t} 6, \mathrm{\prime}^{\prime} \mathrm{CO} 2^{\prime}, \mathrm{t50}, \mathrm{e} 10.2$,

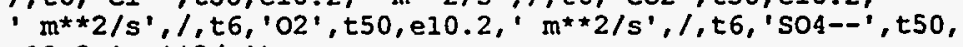
$\left.\mathrm{e} 10.2, \mathrm{~m}^{\prime} \mathrm{m} 2 / \mathrm{s}^{\prime}\right)$

1275 format (/' Tumulus design specifications:'/t6, 'Layers of vaults', $t 50, i 4 / t 6$, 'Number of vaults wide', $t 50, i 4 / t 6$, 'Number of ', 'vaults long', $t 50, i 4 / / t 6$, 'vault dimensions:'/t8, 'Fidth', t50, Ipe10.2,' 'm'/t8, 'Length', t50, e10.2, ' $\mathrm{m}$ '/t8, 'Height', t50, e10.2,' $\mathrm{m}^{\prime} / / \mathrm{t} 6^{\prime}$ Concrete member thickness:'/

$t 8$, 'Roof', $t 50$, el0.2,' cm'/t8, 'Walls', t50,e10.2,' cm'/t8, 'Eloor', t50, e10.2,' cm'/t8, 'Pad', t50,e10.2,' cm'// $t 6$, 'Steel reinforcement radius:'/

$t 8$, 'Roof', $t 50$, el0.2,' cm'/t8, 'Walls', t50, el10.2,' cm'/t8, 'Floor', t50, e10.2,' cm'//t6,' Spacing of steel',

'reinforcement: '/t8, 'Roof', t50, el10.2,' cm'/t8, 'Walls', t50, e10.2,'cin'/t8, 'Floor', t50,e10.2,' cm')

1285 format (/t6' Concrete cover thickness on tension face:'/t8, 'Roof: '/

\# t10,'x-direction', t50, 1pe10.2,' cm'/t10,'Y-directión', $t 50$, e10.2,' $\mathrm{cm}$ '/t8, 'Walls:'/t10,'Horizontal direction', t50, e10.2,' cm'/t10, 'Vertical direction', t50,el0.2,' cm'/t8, 'Floor: '/t10, 'X-direction', t50, e10.2,' $\mathrm{cm} / \mathrm{tl0}$,

'Y-direction', t50, e10.2,' cm'//t6, 'static load:', $31 / \mathrm{t} 8$,

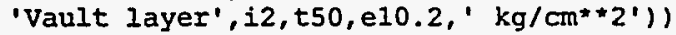

1300 format $(/$ ' Soil and waste properties:'/t6, 'Earthen cover ', 'thickness', t50,1pe10.2,' $\mathrm{m}$ '/t6, 'Earthen cover density' t50,e10.2, ' $\mathrm{g} / \mathrm{cm} \star \star 3 / / t 6$, 'Friction angle of waste backfill', $t 50$, el0.2,' $\operatorname{deg} / \mathrm{t} 6$, 'Eriction angle of soil backfill', t50, e10.2,' deg'/

$t 6$, 'Density of soil backfil1', t50,e10.2,

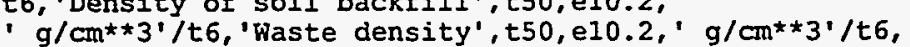
'Relative saturation of waste',t50,e10.2)

1325 format $(/$ ' Concrete and waste package failure rates:'/t6, 'Faste', 'container:'/t8, 'start of failure', $t 50,1$ pel0.2,' years'/ t8, 'Time to complete failure', $t 50, e 10.2$,' years'/t 6 ,

'Epoxy coating:'/t8, 'start of failure', t50,e10.2,' years'/

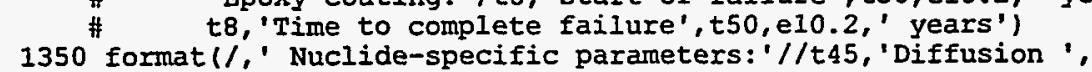
'coefficient'/t2, 'Nuclide', t13, 'Half-life', $t 23$, 'Solubility', t36, 'Waste', t45,' '- ' ' $\mathrm{Kd}$ ', t47, 'Waste' , t57, 'Concrete', t68, 'Inventory'/t15, ' (yr)',

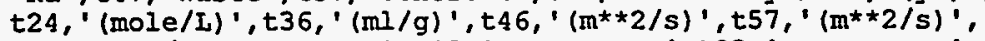
$t 71, '(g) ' / t 2, \cdot-\cdots$,

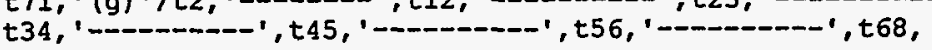




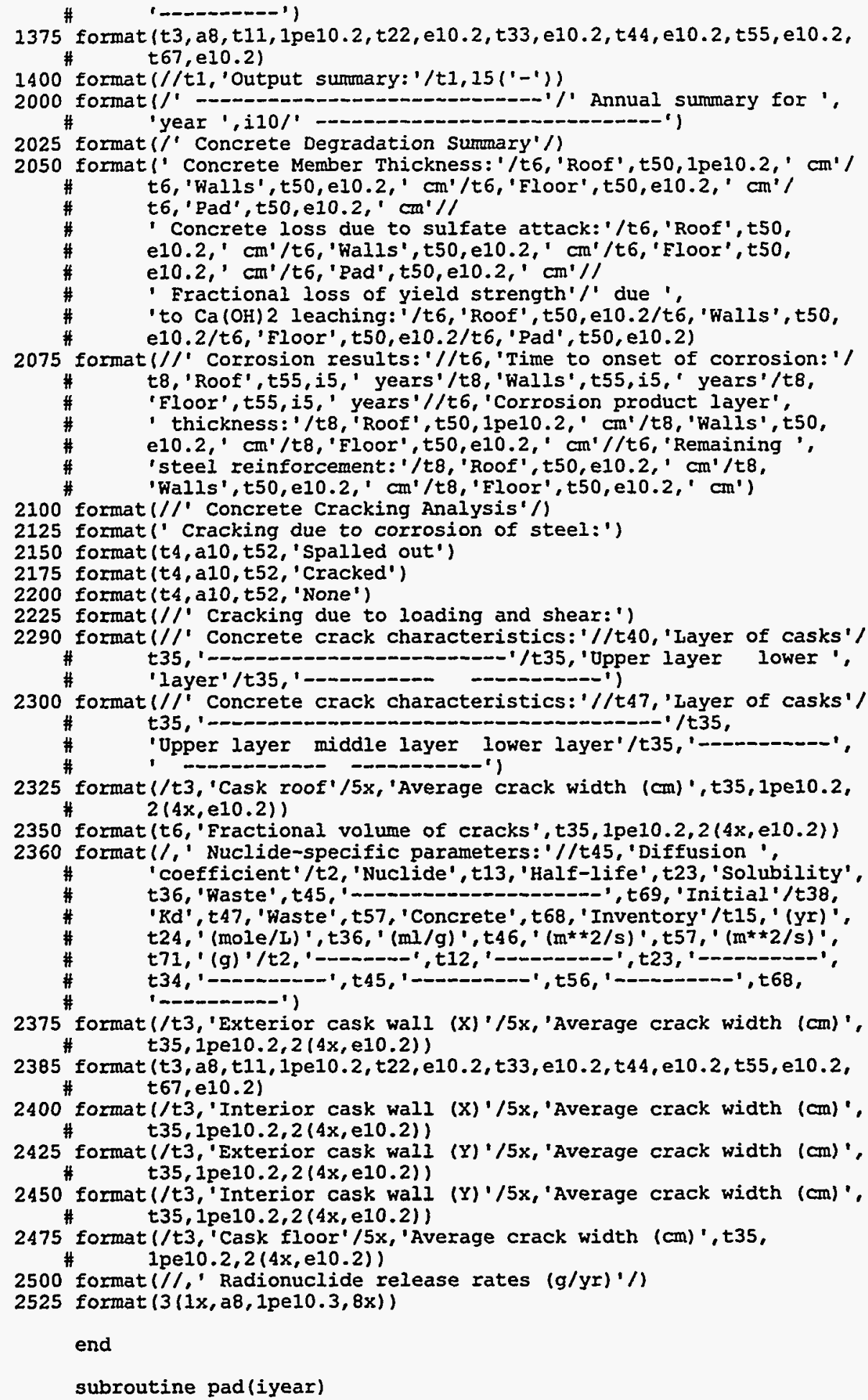




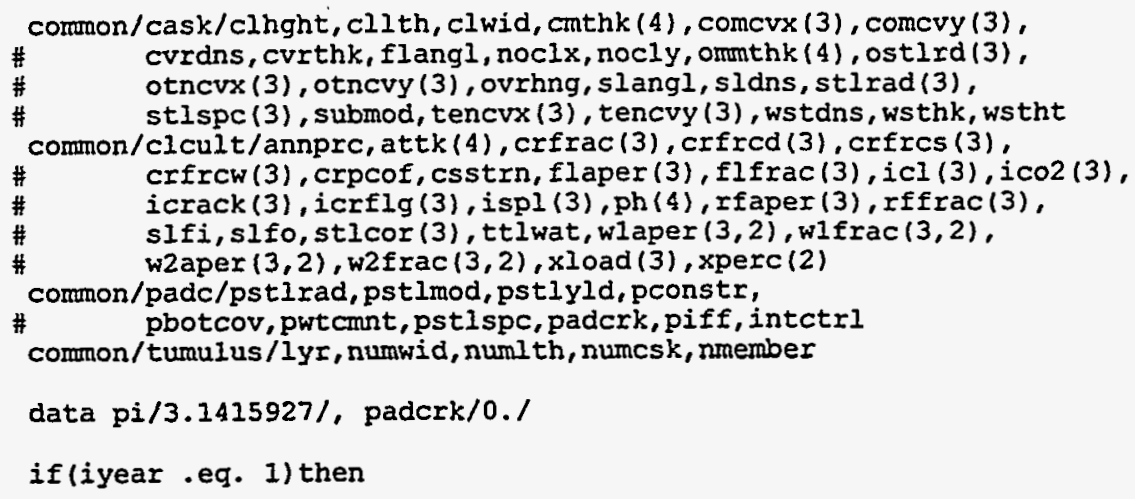

c..... Calculate reinforcement cross-sectional area per unit length.

starpd $=2 . *$ pi $*($ pstlrad $) * * 2 /($ pstlspc $+2 . *$ pstlrad $)$

c..... Calculate yield strain of reinforcement.

epsy $=$ pstlyld $/$ pstlmod

endif

if (pconstr .gt. 30.) then

betal $=0.85-0.08 *($ pconstr $* \operatorname{attk}(4)-30) / 10$.

else

beta1 $=0.85$

endif

c.....Calculate limiting reinforcement ratio for compressive failure.

rratiol $=.003 /(.003+$ epsy $) *(10.85 \bullet$ betal $\bullet$

\# (pconstr * attk(4)) / pstlyld))

c..... Calculate cover thickness at compressive failure (d).

$d=$ starpd / rratiol

if ((cathk (4) - pbotcov) .le. d) padcrk = 1

return

end

subroutine roof (iyear)

$\begin{array}{ll}\text { c } & \text { Called by: sourcel } \\ \text { c } & \text { Performs cracking analysis for cask roof. } \\ \text { c } & \text { Calls: ccrack }\end{array}$

common/cask/clhght, cllth, clwid, cmthk (4), comcvx (3), comcvy (3), \# cvrdns, cvrthk, flangl, noclx, nocly, omathk (4), ostlrd (3), otncvx (3), otncvy (3), ovrhng, slangl, sldns, stlrad (3),

\# otncvx (3), otncvy (3), ovrhng, slangl, sldns, stlrad (3),
\#
stlspc (3), submod, tencvx (3), tencvy (3), wstdns, wsthk, wstht

\# crfrcw (3), crpcof, csstrn, flaper (3), flfrac (3), icl (3), ico2 (3),

\# $\quad$ crfrcw (3), crpcof, csstrn, flaper (3), , ifrac (3), icl (3) (3),

\# slfi,slfo, stlcor(3), ttlwat, wlaper $(3,2)$, wlfrac $(3,2)$. 
\# w2aper $(3,2), \operatorname{werac}(3,2), \operatorname{xload}(3), \operatorname{xperc}(2)$

common/concrt/ca, cacon, cagw, cap, ccdns, ccon, ccpor, cfa, cfb, clcon,

\# co3, com28d, conpsn, constr, phbeg, si, stlmod, stlyld, wcr, wtcmnt, \# yngmod

common/moment/Ifxmnt $(3,11,11)$, rfymnt $(3,11,11)$, flxmnt $(3,11,11)$,

\# flymnt $(3,11,11)$, wlxmnt $(3,11,11)$, w2xmnt $(3,11,11)$.

\# wiymnt $(3,11,11)$, w2ymnt $(3,11,11)$

common/rffrac/rffdpx $(3,11,11), \operatorname{rffdpy}(3,11,11), \operatorname{rffspx}(3,11,11)$ \# rffspy $(3,11,11)$

common/shear/rfxshr $(3,11,11), \operatorname{rfyshr}(3,11,11), \operatorname{flxshr}(3,11,11)$ 。

\# flyshr $(3,11,11), w 1 x \operatorname{shr}(3,11,11), w 2 x \operatorname{xhr}(3,11,11)$.

\# w1yshr $(3,11,11)$, w2yshr $(3,11,11)$

common/tumulus/lyr, numwid, numlth, numcsk, nmember

data pi/3.141592653589793/

data strred/.9/

c..... Calculate time-dependent parameters used in cracking analysis. In c.....roof steel running parallel to the cask width is x-direction steel; c.....steel running perpendicular to cask width is y-direction steel.

time $=$ iyear $\star 365$

comstr $=\operatorname{aminl}($ time $/(c f a+c f b \star t i m e) \star \operatorname{com} 28 d \star a t t k(1)$, constr*attk $(1))$

conmod $=5.7 \mathrm{e} 4 * \operatorname{sqrt}($ comstr $) /(1 .+\mathrm{crpcof})$

ratmod $=$ stlmod/conmod

rupmod $=7.5^{\star}$ sqrt (comstr)

rfdstx $=$ cmthk $(1)-$ tencvx $(1)$

rfdsty $=$ cmthk $(1)-\operatorname{tencvy}(1)$

starcm $=0$.

startn $=\operatorname{stlrad}(1) * * 2 * \mathrm{pi} / \mathrm{st} l \operatorname{spc}(1)$

cnmnti $=$ cmthk $(1) \star \star 3 . / 12$.

crkmtr $=$ cnmnti $/(0.5 *$ cmthk $(1)) *$ rupmod

c..... Calculate ultimate strength for roof.

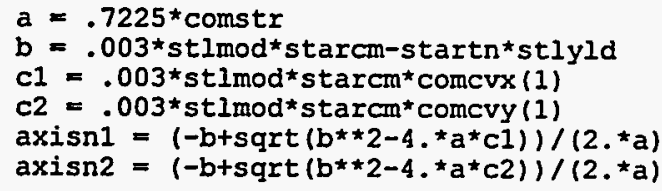

if(axisnl . le. comcrx(1)) then

cmblk = startn*stlyld $/\left(0.85^{\star}\right.$ comst $\left.r\right)$

rfustx = amaxl (crkmtr, strred*stlyld*startn*(rfdstx-cmblk/2.))

else

csstrs $=(\operatorname{axisn} 1-\operatorname{comcvx}(1)) /$ axisn $1 * .003 \star$ stlmod

as2 = starcm*csstrs/stlyid

as1 = startn-as2

cmblk $=$ as $1 * s t l y l d /\left(0.85^{\star}\right.$ comstr $)$

$\#$

rfustx $=$ amaxl (crkmtr, strred* (asl*stlyld* (rfdstx-cmblk/2. )+

endif

if(axisn2 .le. comcry(1)) then

cmblk = startn*stlyld/(0.85* comstr $)$

rfusty $=\operatorname{amaxl}($ crkmtr, strred*stlyld*startn* (rfdsty-cmblk/2.))

else

csstrs $=($ axisn2-comcvy $(1)) /$ axisn2*.003*stlmod

as2 $=$ starcm*csstrs/stlyld

as $1=$ startn-as2

cmblk $=$ as $1{ }^{*}$ stlyld $/\left(0.85^{\star}\right.$ comstr $)$

$\#$

rfusty $=\operatorname{amax} 1$ (crkmtr, strred* (as $1 *$ stlyld* (rfdsty-cmblk/2.)+

endif 
c..... Calculate cracking moment of inertia for roof for $x$ and $y$ directions.

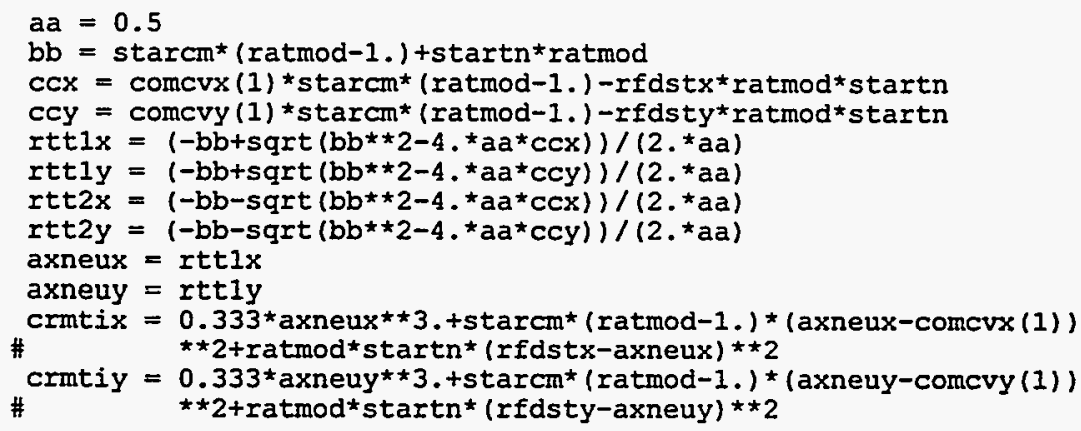

c..... Calculate cracking due to shear for roof for all layers of casks.

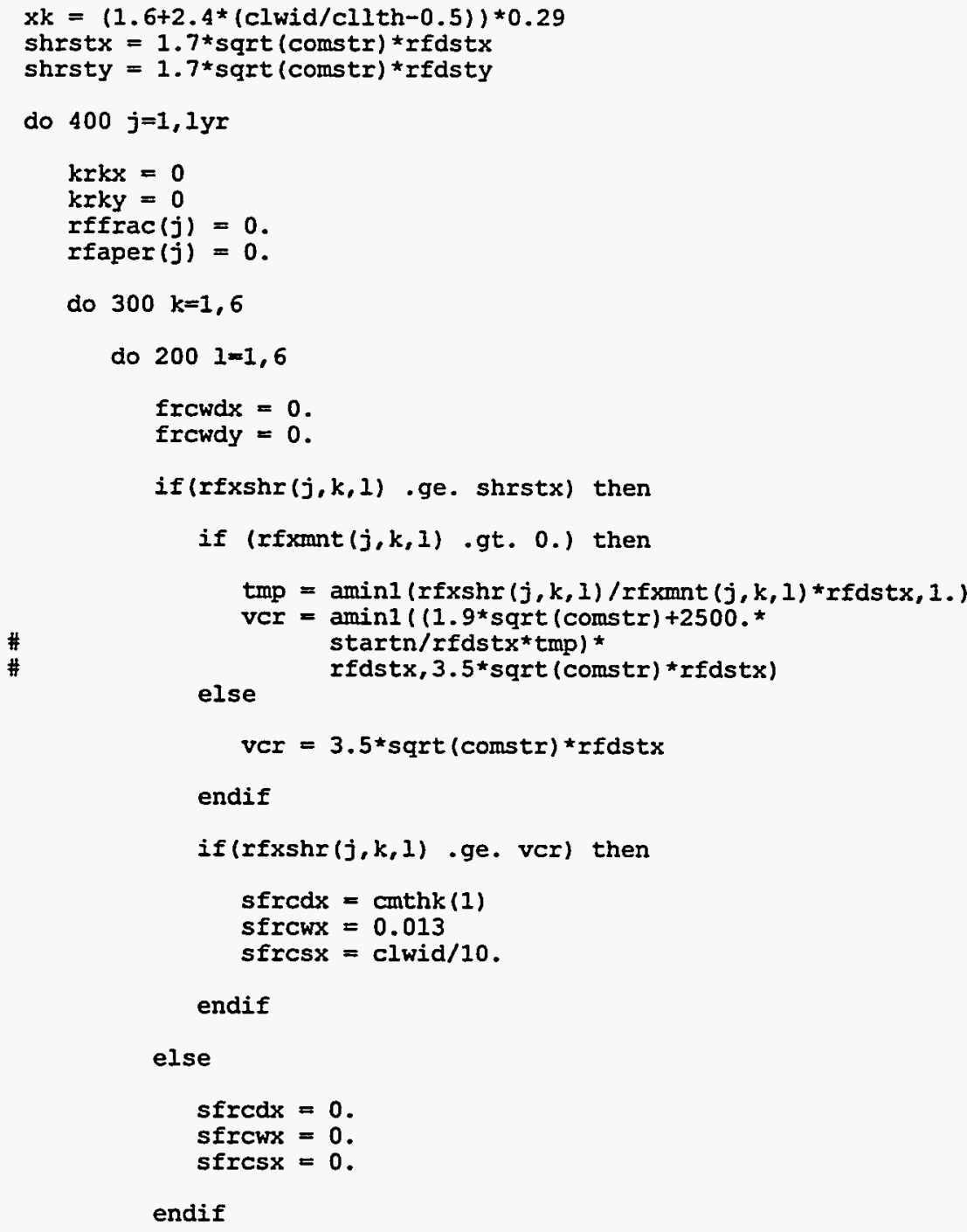


if (stlrad(1) .1t. 1.e-15) then

$q=\operatorname{ostlrd}(1) \star \star 2 \star 1.571 /(\operatorname{stlspc}(1) \star \operatorname{otncvx}(1))$

else

$\mathrm{g}=\operatorname{stl} \operatorname{rad}(1) \star \star 2 \star 1.571 /(\operatorname{stl} \operatorname{spc}(1) \star \operatorname{otncvx}(1))$

endif

\#

elseif (stlrad(1).1t.1.e-15 .and. rffspx $(j, k, 1) . e q .0$.$) then$

$q=\operatorname{ostlrd}(1) \star \star 2 * 1.571 /(\operatorname{stl} \operatorname{spc}(1) * \operatorname{tencvx}(1))$

$\#$

elseif (tencvx(1).gt.0. .and. stlrad(1).ge.1.e-15) then

$q=\operatorname{stl} \operatorname{rad}(1) * \star 2 * 1.571 /(\operatorname{stlspc}(1) \star \operatorname{tencvx}(1))$

endif

if (stlrad(1) .ge. 1.e-15) then

frspce $=0.5^{\star} x^{\star} k^{\star} \operatorname{sqrt}\left(2 .{ }^{\star} \operatorname{stl} \operatorname{rad}(1){ }^{\star} \operatorname{st} 1 \operatorname{spc}(1) / q\right)$

elseif (stlrad(1).1t.1.e-15 .and. $\operatorname{rffspx}(j, k, 1)$.eq. 0.$)$ then

frspce $=0.5^{*} x k^{\star} \operatorname{sqrt}\left(2{ }^{*}\right.$ ostlrd $\left.(1) * \operatorname{stlspc}(1) / q\right)$

endif

if $(\operatorname{rffspx}(j, k, 1)$, eq. 0 . .or. rffspx $(j, k, l) \cdot g e .2 . \star f r s p c e)$ $\operatorname{rffspx}(j, k, l)=$ frspce

endif

c..... X-moments exceed cracking moment but not ultimate strength of roof.

if (rfxmnt $(j, k, 1) . g e . c r k m t r$.and. rfxmnt $(j, k, 1) .1 t . r f u s t x)$ then

efmntx $=(c r k m t r / r f x m i n t(j, k, 1)) * * 3$. *cnminti+(1.-(crkmtr) rfxunt $(j, k, 1)) \star \star 3.1 * \operatorname{crmtix}$ (stltnx/stlmod+csstrn) +tencux (1)

betax $=$ axsnex $/($ axsnex-tencux (l))

$\operatorname{rffdpx}(j, k, 1)=$ axsnex

frcwdx $=\operatorname{rffspx}(j, k, 1) *$ (stltnx/stlmod*betax+csstrn)

endif

c.....x-moments exceed ultimate strength of roof.

if (rfxmnt $(j, k, 1)$.ge.rfustx.and.

$\#$ $\operatorname{rffdpx}(j, k, 1)$. it.cmthk(1)) then

$\operatorname{rffdpx}(j, k, 1)=\operatorname{cmthk}(1)$

frcwdx $=\operatorname{aminl}(($ stlyld $/$ stlmod+csstrn)*

$\#$ $\left.\operatorname{rffspx}(j, k, 1), 3 \cdot e^{-3 \star} \operatorname{rffspx}(j, k, 1)\right)$

endif

c.....Perform calculations for y (length) direction of roof. Start c......with shear cracking calculations.

if (rfyshr $(j, k, 1)$.ge. shrsty) then 


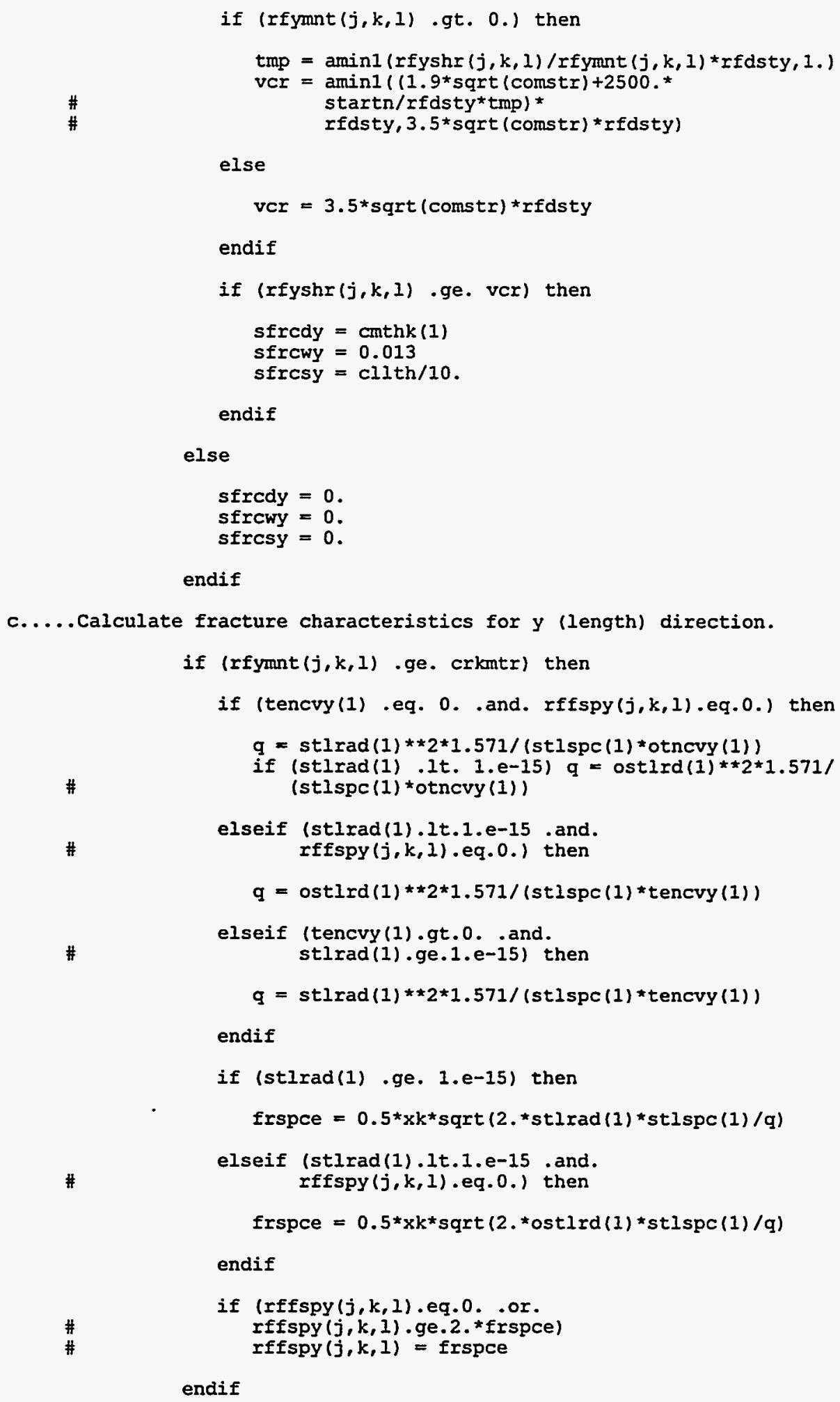

c..... Y-moments exceed cracking moment but not ultimate strength of roof.

if (rfyment $(j, k, 1)$.ge.crkntr .and. rfymit $(j, k, l) .1 t$.rfusty) then 


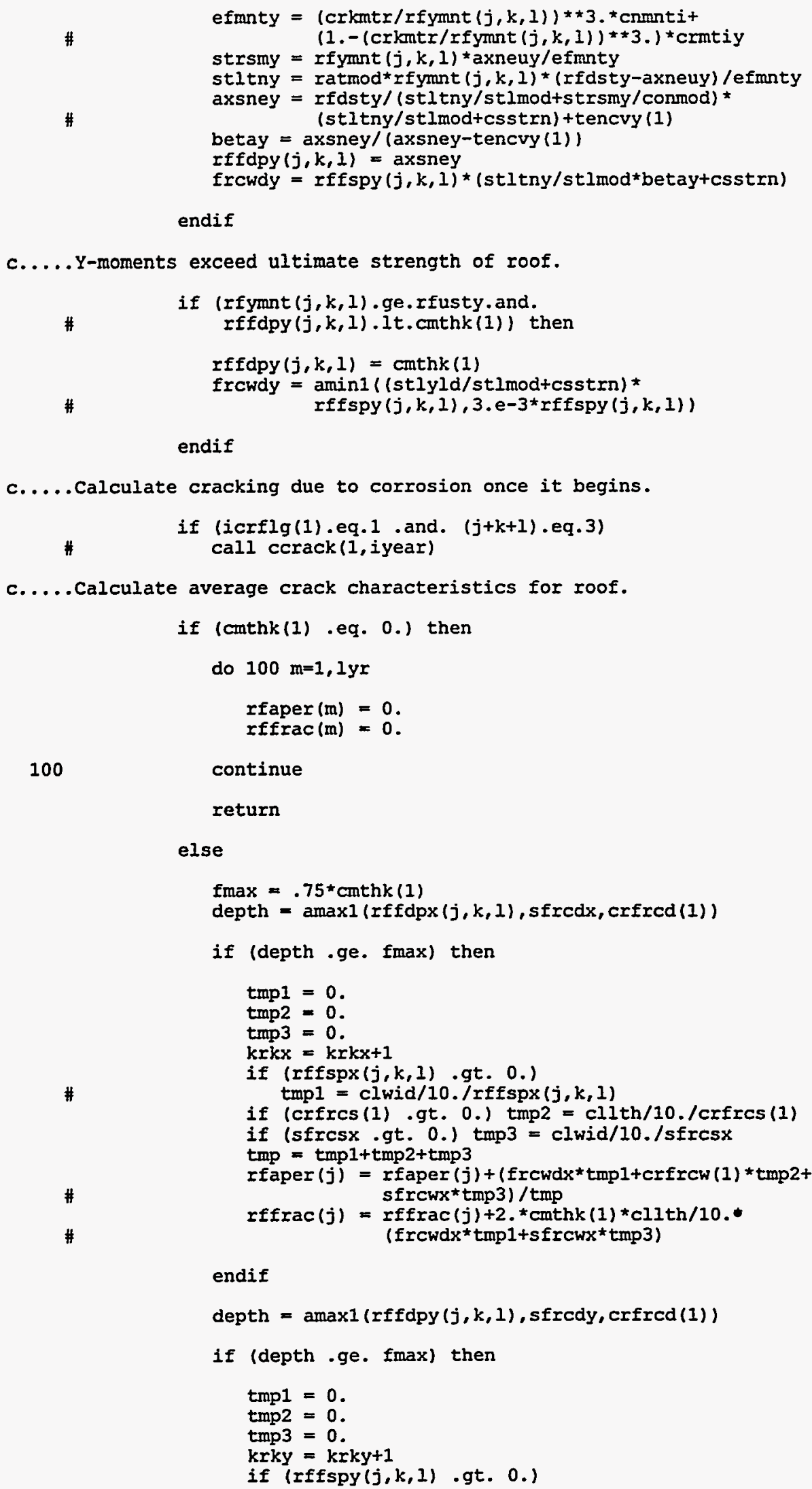


\#

tmpl $=$ cllth/10./rffspy $(j, k, 1)$

if (crfrcs(1) .gt. 0.) tmp2 = clwid/10./crfrcs (1)

if (sfrcsy .gt. 0.) tmp $3=$ cllth/10./sfrcsy

tmp $=t m p 1+t m p 2+t m p 3$

rfaper $(j)=\operatorname{rfaper}(j)+($ frcwdy $t \operatorname{tmp} 1+\operatorname{crfrcw}(1) \star \operatorname{tmp} 2+$ sfrcwy timp 3$) /$ tmp

$\operatorname{rffrac}(j)=\operatorname{rffrac}(j)+2{ }^{*} \operatorname{cmthk}(1) * \operatorname{clwid} / 10 . *$ (frcwdy ${ }^{\star}$ tmp $1+$ sfrcwy $\operatorname{tmp} 3$ )

endif

endif

200

continue

300

continue

if (rffrac(j) .gt. 0.) i.crack $(1)=1$

$\operatorname{rffrac}(j)=\operatorname{rffrac}(j)+\operatorname{crfrac}(1)$

400 continue

do $500 j=1,1 y r$

if (rffrac(j) .gt. 0.$)$ then

$\operatorname{rffrac}(j)=\operatorname{rffrac}(j) /(\operatorname{conthk}(1) \star c l w i d * c l i t h)$

rfaper $(j)=\operatorname{rfaper}(j) /(k r k x+k r k y) \star 2.54$

endif

500 continue

return

end.

subroutine $\operatorname{sar} 1$

Called by sourcel

Performs structural analysis of casks.

Calls: none

common/cask/clhght, cllth, clwid, cmthk (4), comcvx (3), comcvy (3), cvrdns, cvrthk, flangl, noclx, nocly, ommthk (4), ostlrd (3).

\# otncvx (3), otncvy (3), ovrhng, slangl, sldns, stirad (3),

\# stlspc (3), submod, tencvx (3), tencvy (3), wstans, wsthk, wstht

common/clcult/annprc, attk (4), crfrac (3), crfrcd (3), crfrcs (3),

\# crfrcw (3), crpcof, csstrn, flaper (3), flfrac (3), icl (3), ico2 (3),

\# icrack (3),icrflg(3),ispl(3), ph(4), rfaper (3), rffrac(3),

\# slfi,slfo, stlcor (3), ttlwat, wlaper $(3,2)$, wlfrac $(3,2)$,

\# w2aper $(3,2)$, w2frac $(3,2), x l o a d(3), x p e r c(2)$

common/concrt/ca, cacon, cagw, cap, ccdns, ccon, ccpor, cfa, cfb, clcon,

\# co3, com28d, conpsn, constr, phbeg, si, stlmod, stlyld, wcr, wtcmnt,

\# yngmod

common/moment/rfxmnt $(3,11,11), \operatorname{rfymnt}(3,11,11)$, flxmit $(3,11,11)$,

\# flymnt $(3,11,11)$, wixmnt $(3,11,11)$, w2xme $(3,11,11)$,

\# wlymnt $(3,11,11)$, w2yant $(3,11,11)$

common/reactn/rfxrxn $(3,11,11), \operatorname{rfyrxn}(3,11,11)$

common/shear/rfxshr $(3,11,11), \operatorname{rfyshr}(3,11,11), \operatorname{flxshr}(3,11,11)$,

\# $\quad$ flyshr $(3,11,11)$, w1xshr $(3,11,11)$, $2 x \operatorname{xhr}(3,11,11)$,

\# w1yshr $(3,11,11)$, w2yshr $(3,11,11)$

common/tumulus/lyr, numwid, numlth, numcsk, nmember

common/wlforc/wlcmfy $(3,11,11)$, w2 cmfy $(3,11,11)$

dimension $\operatorname{cncfrx}(3,11,11), \operatorname{cncfry}(3,11,11)$

dimension rxnc( 3 ) unfld (3)

dimension wimntx $(11,11)$, wlmnty $(11,11)$

dimension xmnnt $(11,11), y m n n t(11,11), x \operatorname{shrt}(20,20), y \operatorname{shrt}(20,20)$

dimension $x i m(2,12), x i i m(2,12), x i p(2,12), x i i p(2,12), y i m(2,12)$, 
real*4 num1, num2, num3, num4

data pi/3.141592653589793/

c.... Calculate modulus of elasticity of concrete for use in structural c..... analysis of floor.

time $=365$.

comstr $=\operatorname{amin} 1($ time $/(\mathrm{cfa}+c f b \star t i m e) \star c o m 28 \mathrm{~d}$, const $r)$

conmod $=5.7 e 4^{*}$ sqrt $($ comstr $) /(1 .+$ crpcof $)$

c..... Begin roof structural analysis.

c.....Calculate $x$ - and $y$-direction moments for roof of concrete casks. c.... moment curves are discretized into eleven segments, over any one of c..... which the moment is constant.

$j k=12$

do $400 \mathrm{k}=0,5$

$j k=j k-2$

$j I=12$

do $3001=0,5$

$j 1=j 1-2$
coef1 $=0.0$
coef2 $=0.0$
coef3 $=0.0$
coef4 $=0.0$
coef5 $=0.0$
coef6 $=0.0$
coef7 $=0.0$

do $100 \mathrm{~m}=1,15,2$

numl $=\sin \left(p i * m^{\star}(1 * c l w i d / 10.) / c l w i d\right)$

num3 $=\cos \left(p^{*} m^{*}(1 * c l w i d / 10\right.$.$\left.) / clwid \right)$

do $50 \mathrm{n}=1,15,2$

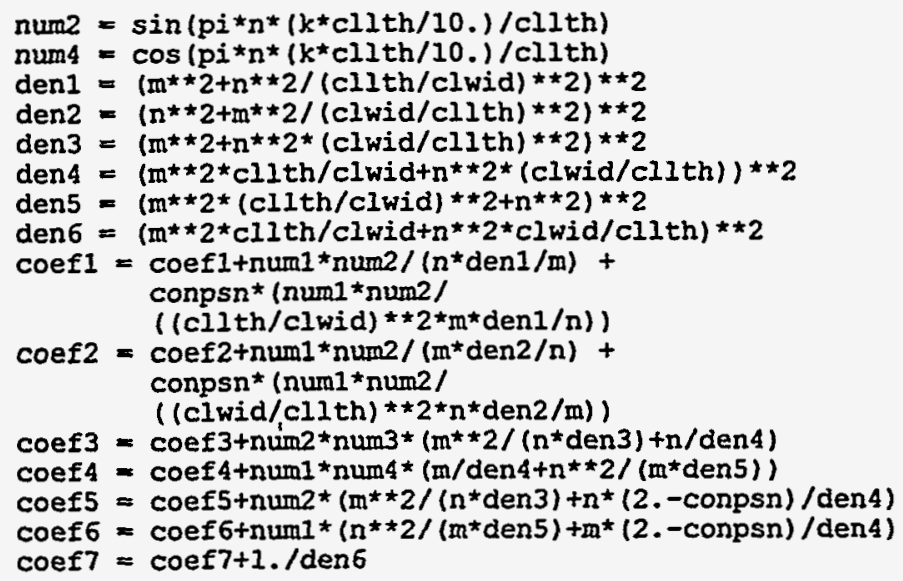

100

continue

do $200 j=1,1 y x$

c...... Calculate bending moments and shears for roof in $x$-direction.

$\operatorname{rfxmnt}(j, k+1,1+1)=\operatorname{abs}\left(16 . / p i * \star 4 .{ }^{\star} \operatorname{coef} 1 *\right.$ 
$\#$

$\#$

$\operatorname{rxshr}(j, k+1+j k, 1+1+j l)=\operatorname{abs}(-\operatorname{rfxshr}(j, k+1,1+1))$
$\operatorname{rxnc}(j)=-32 . \star(1,-\operatorname{conpsn}) / p i \star \star 4 . \star \operatorname{coef} 7 \star x 1$ oad $(j) *$

clwid * cllth/ $(0.5 *$ cmthk $(2)+c l w i d / 10$.

if $(k$. eq. 0 .or. 1. eq. 0$)$ then

rfxmnt $(j, k+1,1+1+j 1)=\operatorname{rfxmnt}(j, k+1,1+1)$

$\operatorname{rfxshr}(j, k+1,1+1+j 1)=\operatorname{abs}(-\operatorname{rfxshr}(j, k+1,1+1))$

$\operatorname{rfxmant}(j, k+1+j k, l+1)=\operatorname{rfxmant}(j, k+1,1+1)$

$\operatorname{rfxshr}(j, k+1+j k, l+1)=\operatorname{abs}(\operatorname{rxxhr}(j, k+1,1+1))$

$\operatorname{rfxmnt}(j, k+1+j k, 1+1+j l)=\operatorname{rfxint}(j, k+1,1+1)$ $\operatorname{xload}(j) \star C l w i d * * 21$

$\operatorname{rfxshr}(j, k+1,1+1)=\operatorname{abs}\left(-16 . / p i \star \star 3 .{ }^{\star} \operatorname{coef} 3 * x l o a d(j) * c l w i d\right)$

c......calculate roof reaction in $x$-direction.

$\operatorname{rfxrxn}(j, k+1,1+1)=16 . / p i * \star 3 . * \operatorname{coef5} * \operatorname{xload}(j) * c l w i d$

if $(k$. eq.0.and.1.eq. 0$)$ rfxrxn $(j, k+1,1+1)=$

$\operatorname{rxxxn}(j, k+1,1+1)+\operatorname{rxnc}(j) / 2$.

$\operatorname{rxxxn}(j, k+1,1+1+j l)=\operatorname{rxx\operatorname {xxn}}(j, k+1,1+1)$

$\operatorname{rfxrxn}(j, k+1+j k, 1+1)=\operatorname{rfxrxn}(j, k+1,1+1)$

$\operatorname{rfxrxn}(j, k+1+j k, 1+1+j 1)=\operatorname{rfxrxn}(j, k+1,1+1)$

endif

c..... Calculate bending moments and shears for roof in $y$-direction.

\#

$\operatorname{rfymint}(j, k+1,1+1)=\operatorname{abs}(16 . / p i \star \star 4 . * \operatorname{coef} 2 *$ xload $(j) * \mathrm{cl}(\mathrm{th} * \star 2)$

$\operatorname{rfyshr}(j, k+1,1+1)=\operatorname{abs}(-16 . / p i * \star 3 . * \operatorname{coef} 4 * x \operatorname{load}(j) * \mathrm{cl} 3$ th $)$

$\operatorname{rfymnt}(j, k+1,1+1+j 1)=\operatorname{rfymnt}(j, k+1,1+1)$

$\operatorname{rfyshr}(j, k+1,1+1+j l)=\operatorname{abs}(\operatorname{Ifyshr}(j, k+1,1+1))$

$\operatorname{rfymant}(j, k+1+j k, 1+1)=\operatorname{rfymnt}(j, k+1,1+1)$

$\operatorname{rfyshr}(j, k+1+j k, j+1)=\operatorname{abs}(-\operatorname{rfyshr}(j, k+1,1+1)$

$\operatorname{rfymnt}(j, k+1+j k, 1+1+j 1)=\operatorname{rfymnt}(j, k+1,1+1)$

$\operatorname{Ifyshr}(j, k+1+j k, 1+1+j 1)=\operatorname{abs}(-\operatorname{rfyshr}(j, k+1,1+1))$

if (k.eq. 0 .or. (k.gt.0.and.l.eq.0)) then

c......Calculate roof reaction in $y$-direction.

$\operatorname{rfyrxn}(j, k+1,1+1)=16 . / \mathrm{pi} * * 3 .{ }^{*} \operatorname{coef} 6 * x \operatorname{load}(j) * \mathrm{cllth}$ if $(k$. eq. 0 .and.1.eq.0) $\operatorname{rfyrxn}(j, k+1,1+1)=$ $\operatorname{rfy} \operatorname{rxn}(j, k+1,1+1)+\operatorname{rxnc}(j) / 2$.

$\#$

$\operatorname{rfyrxn}(j, k+1,1+1+j 1)=\operatorname{rfyrxn}(j, k+1,1+1)$

$\operatorname{rfyrxn}(j, k+1+j k, 1+1)=\operatorname{rfyrxn}(j, k+1,1+1)$

$\operatorname{rfyrxn}(j, k+1+j k, 1+1+j 1)=\operatorname{rfyrxn}(j, k+1,1+1)$

endif

200 continue

300 continue

400 continue

c.....Begin wall structural analysis.

c..... Calculate moments and shears due to uniform load for walls of c......concrete casks. Calculations are discretized into eleven c..... segments, over any one of which the moment or shear is assumed c.....to be constant.

flarg $=1 .-\sin ($ flangl*pi $/ 180$.

slarg $=1 .-\sin ($ slangl $* \mathrm{pi} / 180$.

do $500 i=1,1 \mathrm{yr}$

c.....Calculate the uniform load on the wall.

unfld $(i)=\operatorname{sldns} * 3.61 \mathrm{e}-2 * \operatorname{slarg} *\left(\left(\operatorname{cvrthk}+0.5^{\star} \operatorname{cmthk}(1)\right)+(i-1) *\right.$

$\#$ $(0.5 *($ cmthk $(1)+$ cmthk $(3))+$ clhght $))$

500 continue 
c..... Calculate the maximum hydrostatic pressure.

hydrld $=$ sldns*3.61e-2*clinght*slarg-wstdns*3.61e-2*clhght ${ }^{\star}$ flarg $j k=12$

do $1100 k=0,5$

$$
\begin{aligned}
& j k=j k-2 \\
& j l=12 \\
& \text { do } 10001=0,5 \\
& j 1=j l-2 \\
& \text { coef1 }=0.0 \\
& \text { coef2 }=0.0 \\
& \text { coef } 3=0.0 \\
& \text { coef } 4=0.0
\end{aligned}
$$

do $800 m=1,15,2$

numl $=\sin \left(p^{\star} \mathbb{m}^{\star}\left(11^{\star} \mathrm{clwid} / 10.\right) / c 1 w i d\right)$ num3 $=\cos \left(\mathrm{pi}^{\star} \mathrm{m}^{\star}(1 * \mathrm{clwid} / 10.) / \mathrm{clwid}\right)$

do $700 \mathrm{n}=1,15,2$

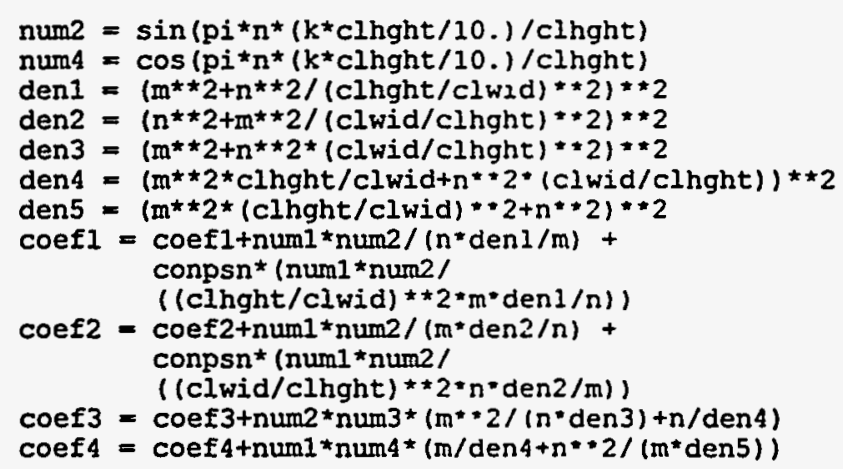

800

do $900 \mathrm{~m}=1,1 \mathrm{yr}$

c...... Calculate the bending moments and shear forces for wall 1 .

wlxmnt $(m, k+1,1+1)=16 . / p i * \star 4 . * \operatorname{coef} l * u n f l d(m) * \mathrm{clwid} * \star 2$ w1xshr $(m, k+1,1+1)=16 . / p i * 3$. coef $3 *$ unfld $(m) * c l w i d$ w1xmnt $(m, k+1,1+1+j 1)=$ w1xmnt $(m, k+1,1+1)$

900

continue

1000

continue

1100 continue

c.....Perform calculations for second wall of cask. 
$j k=12$

do $1600 k=0,5$

$$
\begin{aligned}
& j k=j k-2 \\
& j l=12 \\
& \text { do } 15001=0,5 \\
& j 1=j l-2 \\
& \text { coefl }=0.0 \\
& \text { coef2 }=0.0 \\
& \text { coef3 }=0.0 \\
& \text { coef } 4=0.0
\end{aligned}
$$$$
\text { do } 1300 \mathrm{~m}=1,15,2
$$

numl $=\sin \left(p i \star m^{\star}(1 * c l 1 t h / 10.) / c l l t h\right)$

num3 $=\cos \left(p i \star m^{\star}(I * c 1 l t h / 10.) / c l l t h\right)$

do $1200 n=1,15,2$

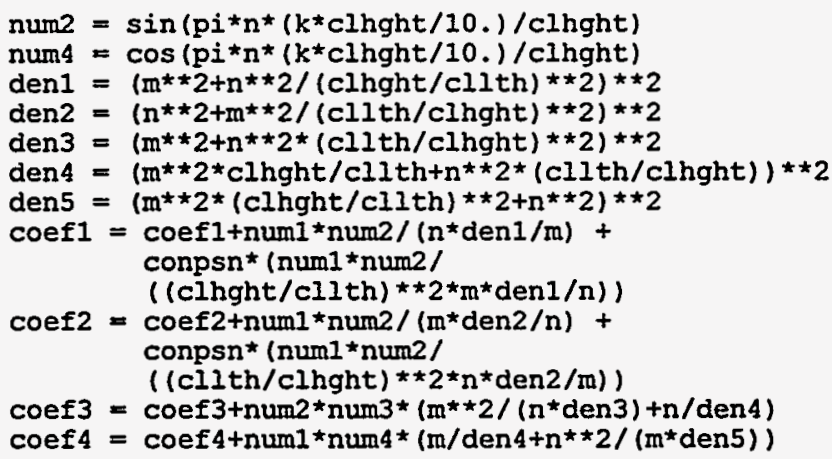

continue

1300

continue

do $1400 \mathrm{~m}=1,1 \mathrm{yr}$

c..... Calculate the bending moments and shear forces for wall 2 .

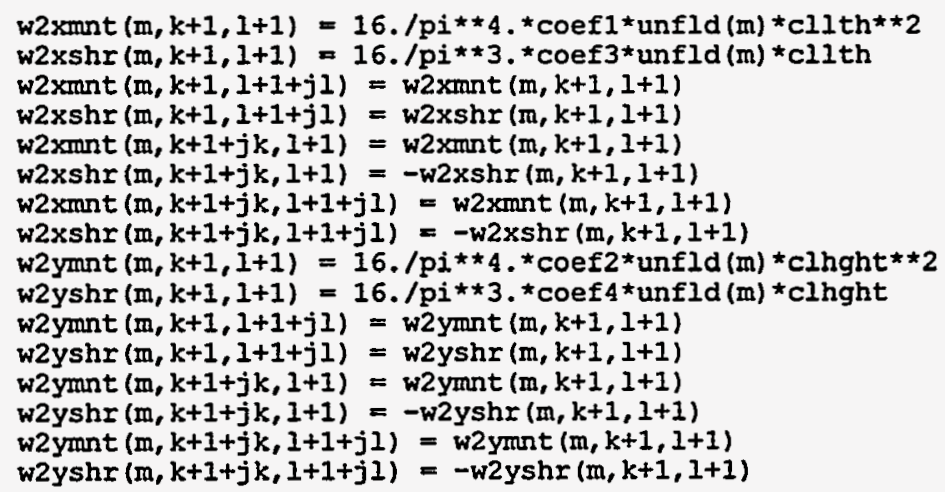


do $2000 k=0,10$

$$
\begin{aligned}
& j 1=12 \\
& \text { do } 19001=0,5 \\
& j 1=j 1-2 \\
& \text { coef1 }=0.0 \\
& \text { coef2 }=0.0 \\
& \text { coef3 }=0.0 \\
& \text { coef } 4=0.0 \\
& \text { do } 1700 \mathrm{~m}=1,12
\end{aligned}
$$

c......Calculate quantities needed to determine the bending moments c.... due to hydrostatic pressures.

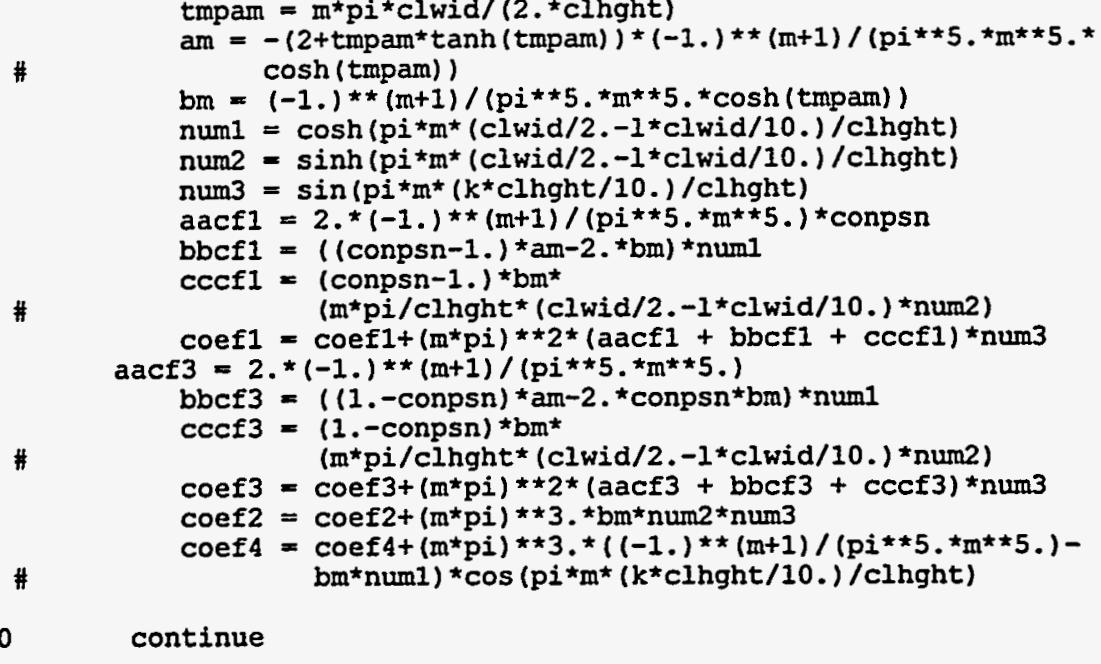

c..... Combine moments and shears for uniform and hydrostatic loads on c..... walls while calculating moments and shears for hydrostatic load.

$$
\begin{aligned}
& \text { tmpl }=\text { hydrld*clhght } * 2^{\star} \text { coef } 1 \\
& \text { tmp2 }=-2 .{ }^{*} \text { hydrld*clhght*coef2 } \\
& \text { tmp3 }=\text { hydrld }{ }^{\star} \text { clhght } * 2^{\star} \text { coef } 3 \\
& \text { tmp4 }=2 \text {. *hydrld*clhght* coef } 4 \\
& \text { do } 1800 \mathrm{~m}=1,1 \mathrm{yr}
\end{aligned}
$$

wlxmnt $(m, k+1,1+1)=\operatorname{abs}(w 1 \times \operatorname{mant}(m, k+1,1+1)+t m p 1)$ w1 xmnt $(m, k+1,1+1+j l)=$ abs (w1xunt (m, $k+1,1+1+j 1)+t$ tmpl) $w 1 \times \operatorname{shr}(m, k+1,1+1)=a b s(w 1 x \operatorname{shr}(m, k+1,1+1)+\operatorname{tmp} 2)$ $w 1 x \operatorname{shr}(m, k+1,1+1+j 1)=\operatorname{abs}(w 1 x \operatorname{shr}(m, k+1,1+1+j 1)-\operatorname{tmp} 2)$ wlymnt $(m, k+1,1+1)=$ abs (klymnt $(m, k+1,1+1)+t m p 3)$ wlyme $(m, k+1,1+1+j l)=\operatorname{abs}(w 1$ ymnt $(m, k+1,1+1+j 1)+t m p 3)$ w1yshr $(m, k+1,1+1)=$ abs (w1yshr $(m, k+1,1+1)+$ tmp 4$)$ wlyshr $(m, k+1,1+1+j l)=$ abs $(w 1 y \operatorname{shr}(m, k+1,1+1+j l)+\operatorname{tmp} 4)$

1800 continue

1900 continue

2000 continue

c.....Perform calculations for hydrostatic pressure for second wall.

do $2400 k=0,10$

$$
\begin{aligned}
& j 1=12 \\
& \text { do } 2300 \quad 1=0,5
\end{aligned}
$$




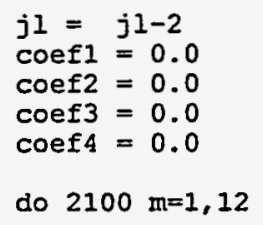

c..... Calculate quantities needed to determine the bending moments c..... due to hydrostatic pressures.

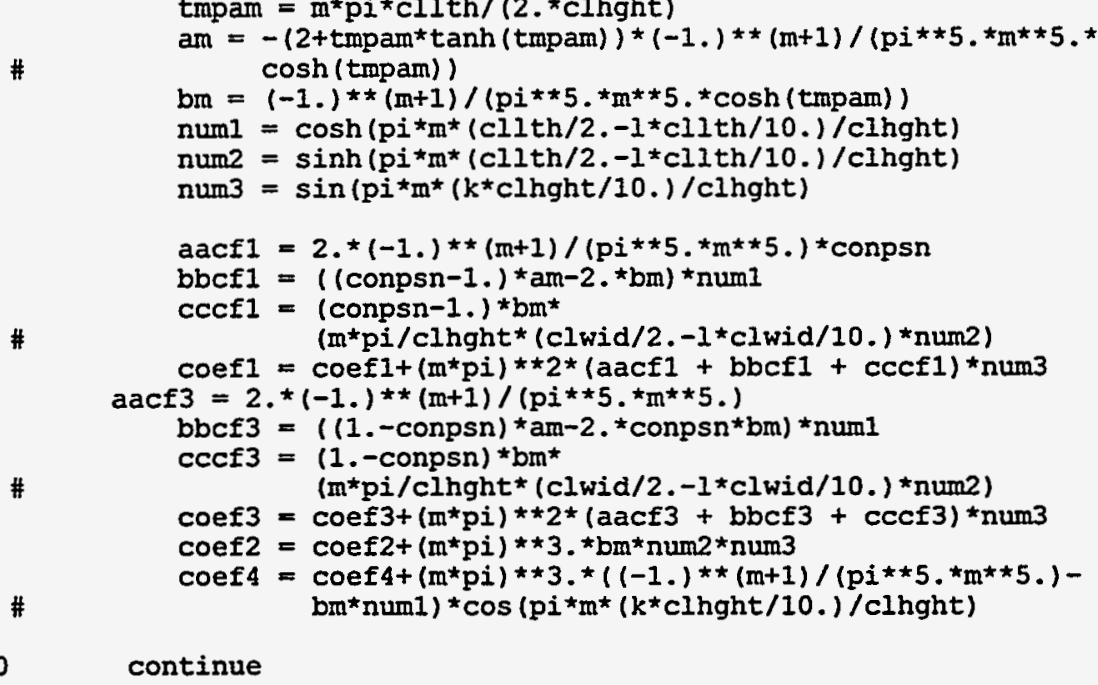

c..... Combine moments and shears for uniform and hydrostatic loads on c.... walls while calculating moments and shears for hydrostatic load.

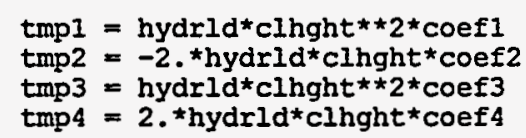




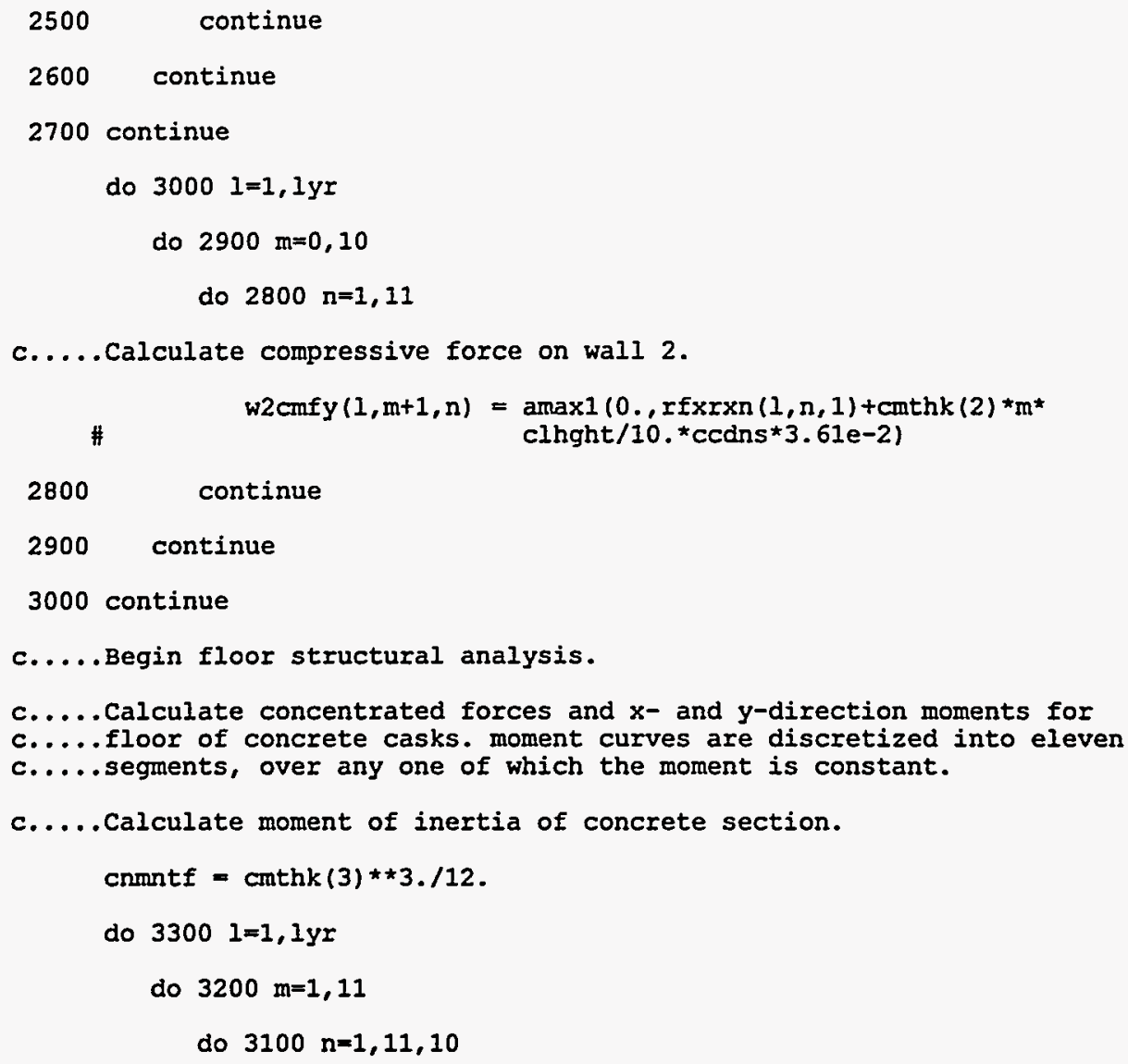


do $3800 \mathrm{~m}=1$, nocl $x+1$

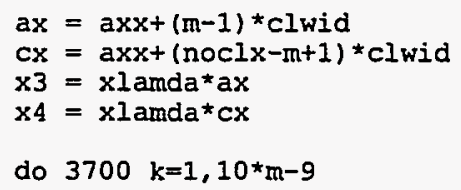

c..... Calculate geometry of the floor for the bending moments c..... and shears in the $x$-direction.

$x 2=x l a m d a *(a x x+(k-1) \star c l w i d / 10$.

$\operatorname{txip} 1=2 .{ }^{\star} \sinh (x 2) * \sin (x 2) \star(\sinh (x 1) * \cos (x 3) * \cosh (x 4)-$

$\#$

$\operatorname{txip} 2=(\sinh (x 2) * \cos (x 2)-\cosh (x 2) \star \sin (x 2))$
$\operatorname{txip} 3=(\sinh (x 1) *(\sin (x 3) * \cosh (x 4)-\cos (x 3) * \sinh (x 4))+$ $\sin (x 1) *(\sinh (x 3) * \cos (x 4)-\cosh (x 3) * \sin (x 4)))$

$\operatorname{xip}(m, k)=\operatorname{txip} 1-\operatorname{txip} 2 * \operatorname{txip} 3$

txiipl $=(\cosh (x 2) * \sin (x 2)+\sinh (x 2) * \cos (x 2)) *(\sinh (x 1) *$ $\cos (x 3) * \cosh (x 4)-\sin (x 1) * \cosh (x 3) * \cos (x 4))$

$\#$

txiip2 $=(\sinh (x 1) *(\sin (x 3) \star \cosh (x 4)-\cos (x 3) * \sinh (x 4))$ $+\sin (x 1) *(\sinh (x 3) * \cos (\times 4)-\cosh (x 3) * \sin (x 4)))$

xiip $(m, k)=\operatorname{txiip} 1+\sinh (x 2) * \sin (x 2) \star \operatorname{txiip} 2$

$\operatorname{tximl}=(\sinh (x 1) *(\cos (x 1) * \sinh (x 4) * \cos (x 4)+\sin (x 3) \star$ $\cosh (x 4))+\sin (x 1) *(\cosh (x I) * \cosh (x 4) * \sin (x 4)$ $+\sinh (x 3) * \cos (x 4))$

$\operatorname{txim} 2^{*}=(\sinh (x 1) \star \cos (x 3) \star \cosh (x 4)+\sin (x 1) \star$ $\cosh (x 3) * \cos (x 4))$

$x \operatorname{im}(m, k)=\sinh (x 2) * \sin (x 2) * t x i m 1+(\sinh (x 2) * \cos (x 2)-$ $\cosh (x 2) * \sin (x 2)) * \operatorname{txim} 2$

$\operatorname{txiim1}=(\cosh (x 2) * \sin (x 2)+\sinh (x 2) * \cos (x 2))$

txiim2 $=(\cos (x 1) * \sinh (x 4) * \cos (x 4)+\sin (x 3) * \cosh (x 4))$

$\operatorname{txiim} 3=(\cosh (x 1) \star \cosh (x 4) \star \sin (x 4)+\sinh (x 3) \star \cos (x 4))$

$\operatorname{txiim} 4=(\sinh (x 1) * \cos (x 3) * \cosh (x 4)+\sin (x 1) *$ $\cosh (x 3) * \cos (x 4))$

$\operatorname{xim}(m, k)=\operatorname{txiim} 1 *(\sinh (x 1) * t x i \min 2+\sin (x 1) *$ $\operatorname{txi} \operatorname{tm} 3)-2 .{ }^{*} \sinh (x 2) * \sin (\times 2) * \operatorname{txiim} 4$

3700

continue

3800 continue

do $4000 j=1$, nocly+1

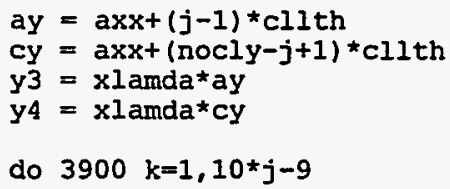

c..... Calculate geometry of the floor for the bending moments c...... and shears in the $y$-direction.

y2 $=x 1$ amda* $(a x x+(k-1) * \operatorname{cllth} / 10$.

tyip $1=(\sinh (y 1) * \cos (y 3) * \cosh (y 4)-\sin (y 1) *$ $\left.\cosh \left(y^{3}\right) * \cos (y 4)\right)$

tyip2 $=(\sinh (y 1) *(\sin (y 3) * \cosh (y 4)-\cos (y 3) * \sinh (y 4))+$ $\sin (y 1) *(\sinh (y 3) * \cos (y 4)-\cosh (y 3) * \sin (y 4)))$

tyiip $1=(\sinh (y 1) * \cos (y 3) * \cosh (y 4)-\sin (y 1) *$ $\left.\cosh \left(y^{3}\right) * \cos \left(y^{4}\right)\right)$

tyiip2 $=\left(\sinh (y I) *\left(\sin \left(y^{3}\right) * \cosh \left(y^{4}\right)-\cos \left(y^{3}\right) * \sinh \left(y^{4}\right)\right)\right.$ $+\sin (y 1) *(\sinh (y 3) * \cos (y 4)-\cosh (y 3) * \sin (y 4)))$ $y i i p(j, k)=(\cosh (y 2) * \sin (y 2)+\sinh (y 2) * \cos (y 2)) \star t y i i p 1+$ $\sinh (y 2) * \sin (y 2) * t y i i p 2$

tyim $1=\left(\cos (y 1) \star \sinh (y 4) * \cos (y 4)+\sin \left(y^{3}\right) \star \cosh (y 4)\right)$

tyim2 $=\left(\cosh \left(y_{1}\right) * \cosh \left(y^{4}\right) * \sin \left(y^{4}\right)+\sinh \left(y^{3}\right) * \cos \left(y^{4}\right)\right)$

tyim3 $=(\sinh (y 2) * \cos (y 2)-\cosh (y 2) * \sin (y 2))$

tyim4 $=\left(\sinh (y 1) * \cos \left(y^{3}\right) * \cosh \left(y^{4}\right)+\sin (y 1) * \cosh (y 3) *\right.$ $\cos (y 4))$ 


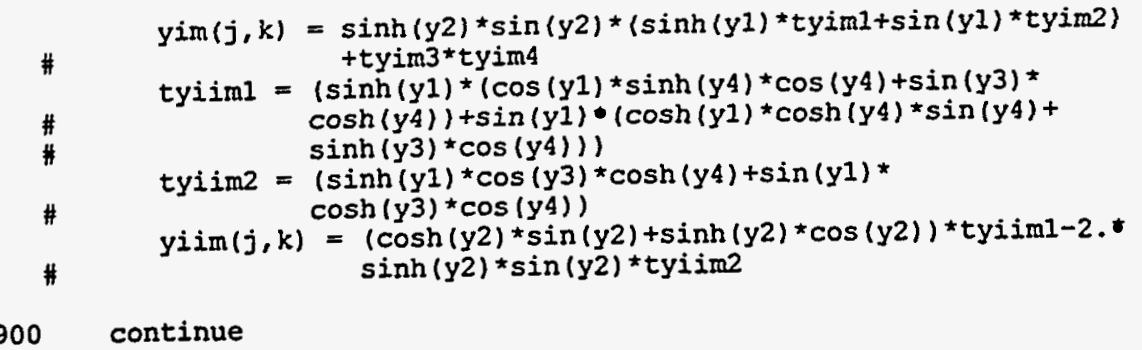

4000 continue

do $4200 k=1$, nocl $x+1$

do $41001=1,10 * k-9$

w1mntx $(x, 1)=0$.

wImnty $(k, 1)=0$.

* $\quad$ xmnnt $(k, 1)=\operatorname{xip}(k, 1) /\left(2, x_{x l a m d a * x c h i)+}+\right.$

$\operatorname{xshrt}(k, 1)=1, / x \operatorname{chi}{ }_{x i j p}(k, 1)+$ wlmntx $(k, 1) \cdot$ $x$ lamda/xchi $\star x i i m(k, 1)$
ymnnt $(k, 1)=y i p(k, 1) /\left(2,{ }^{\star} x\right.$ lamda $\left.{ }^{\star} y c h i\right)+$ wlmnty $(k, 1) / y c h i * y i m(k, 1)$
$\#$

$\#$

$y \operatorname{shrt}(k, 1)=1 . / y c h i \star y i i p(k, 1)+$ wlmnty $(k, 1) \star$

4100 continue xlamda/ychi`yiim $(k, I)$

4200 continue

c.....Calculate bending moments and shear forces in the $x$ and $y$-direction.

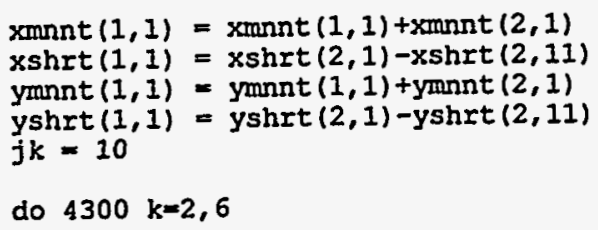

4300 continue

$j k=0$

do $4400 \quad k=7,11$

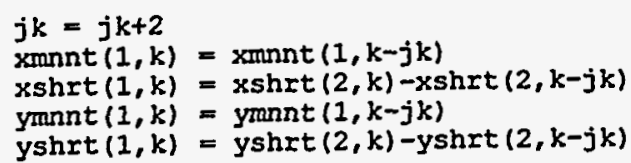

4400 continue

do $4700 \mathrm{~m}=1,1 \mathrm{yr}$

do $46001=1,11$

do $4500 \mathrm{k}=1,11$

flxmnt $(m, l, k)=\operatorname{abs}(x \operatorname{mnnt}(1, k) * \operatorname{cncfrx}(m, 1,1))$

flxshr $(m, 1, k)=\operatorname{abs}(x s h r t(1, k) *(-1). * \operatorname{cncfrx}(m, 1,1))$

flymnt $(m, k, 1)=\operatorname{abs}(\operatorname{ymnnt}(1, k) * \operatorname{cncfry}(m, 1,1)$ )

flyshr $(m, k, 1)=\operatorname{abs}\left(y \operatorname{shrt}(1, k) *(-1 .)^{\star} \operatorname{cncfry}(m, 1,1)\right)$ 
4500 continue
4600 continue
4700 continue
end
subroutine sulfate(iyear)

c Called by concrete

c Calculates loss of concrete thickness due to sulfate attack.

Calls: none

common/cask/clhght, cllth, clwid, cmthk (4), comcvx (3), comcvy (3),

\# cvrdns, cvrthk, flangl, noclx, nocly, ommthk (4), ostlrd (3),

\# otncvx (3), otncvy (3), ovihng, slangl, slans, stirad (3).

\# stlspc (3), submod, tencvx (3), tencvy (3), wstdns, wsthk, wstht

common/chencl/cl, co2, 02, so4i, so4o, xmg2, dfalk, dfcaoh, dfcl, dfco2,

\# dfo2, dfso4, casol, crbsol, xmgsol

common/clcult/annprc, attk (4), crfrac (3), crfrcd (3), crfrcs (3),

\# crfrcw (3), crpcof, csstrn, flaper (3), flfrac (3), icl (3), ico2 (3),

\# icrack (3), icrflg (3), ispl(3), ph (4), rfaper (3), rffrac (3),

\# slfi,slfo,stlcor(3), ttlwat, wlaper $(3,2)$, wlfrac $(3,2)$.

\# w2aper $(3,2)$, w2 $f r a c(3,2), x l o a d(3), x p e r c(2)$

common/concrt/ca, cacon, cagw, cap, ccdns, ccon, ccpor, cfa, cfb, clcon,

\# co3, com28d, conpsn, constr, phbeg, si, stlmod, stlyld, wCr, wtcmnt,

\# yngmod

common/padc/pstlrad,pstlmod,pstlyld,pconstr,

\# pbotcov, pwtconnt,pstlspc,padcrk, piff, intctrl

common/tumulus/lyr, numwid, numlth, numcsk, nmember

c.....Rate of degradation calculated as per Atkinson and Hearne.

if (iyear .eq. 1) then

c.....Begin outside disposal facility calculations.

$\operatorname{tmp}=1.24$

!Atkinson \& Hearne

$5040=5040 \star 1000$

100 continue

c.....Estimate ettringite concentration.

$c e=$ wtconst $\star t m p$

c.....calculate reaction zone thickness at which spalling occurs.

$x \operatorname{spl}=2 . \star 1 . \star 10 . \star(1-\operatorname{conps}) /(\operatorname{yngmod} *(1.8 \mathrm{e}-6 \star c e) \star \star 2)$

c..... Calculate time when spalling occurs.

$\operatorname{tspl}=x \operatorname{spl} \star \star 2 \star c e /\left(2 .{ }^{*} \mathrm{dfso}{ }^{\star}{ }^{*} \mathrm{so} 0 \mathrm{o}\right)$

$t=10 . \star \star(t m p / .32-a \log 10($ so40 $)+a \log 10(3577)+.a \log 10(12.2)$

$\operatorname{tmp}=\operatorname{tmp}^{*} .99$

if(tspl.1t.t) go to 100

c..... Concrete loss from outside of disposal facility.

slfo $=x s p l * 39.37 / \mathrm{tspl} * 3.15 \mathrm{e} 7$

c.....Begin inside disposal facility calculations.

tmp $=1.24$

!Atkinson \& Hearne

so4i $=\operatorname{so4} i \star 1000$. 
200 continue

c..... Estimate ettringite concentration.

$c e=$ wtcmnt*tmp

c......Calculate reaction zone thickness at which spalling occurs.

$x \operatorname{spl}=2 . \star 1 . \star 10 . *(1-\operatorname{conpsn}) /(\operatorname{yngmod} *(1.8 \mathrm{e}-6 \star c e) \star \star 2)$

c..... Calculate time when spalling occurs.

$\operatorname{tspl}=x s p l * \star 2 \star c e /\left(2 . \star \operatorname{dfsO} 4^{\star} \mathrm{SO} 4 i\right)$

$t=10 . \star \star(t m p / .32-a \log 10(\operatorname{so4} i)+a \log 10(3577)+.a \log 10(12.2))$

tmp $=t m p * .99$

if (tspl.1t.t) go to 200

c..... Concrete loss from inside of disposal facility.

slfi $=x s p l * 39.37 / t s p l * 3.15 e 7$

c.....Begin pad calculations.

if (nmember .eq. 4) then

$\operatorname{tmp}=1.24$

!atkinson \& hearne

300

continue

c.....Estimate ettringite concentration.

$c e=$ pwtcmint*tmp

c..... Calculate reaction zone thickness at which spalling occurs.

$x \operatorname{spl}=2 . \star 1 . \star 10 . *(1-\operatorname{conpsn}) /(\operatorname{yngmod} *(1.8 \mathrm{e}-6 \star c e) \star \star 2)$

c..... Calculate time when spalling occurs.

tspl $=x s p l * \star 2 * \mathrm{ce} /(2 . \star$ dfso 4 so 40$)$

$t=10 . \star \star(t m p / .32-a \log 10(5040)+a \log 10(3577)+.\operatorname{alog} 10(12.2))$

tmp $=t m p \star .99$

if(tspl.lt.t) go to 300

c..... Concrete loss from pad.

pslfo $=x s p l * 39.37 / t s p l * 3.15 e 7$

endif

endif

c..... Update total member thicknesses.

do $400 i=1$, nmember

if $(i$.ne. 4$)$ then

$\operatorname{cmthk}(i)=\operatorname{amax} 1(0,, \operatorname{cmthk}(i)-(s l f i+s l f 0))$

else

$\operatorname{cmthk}(i)=\operatorname{amax} 1(0, \ldots \operatorname{cmthk}(i)-p s l f o)$

endif

400 continue

c..... Update cover thickness on compression and tension faces of concrete.

do $500 \quad i=1,3$ 


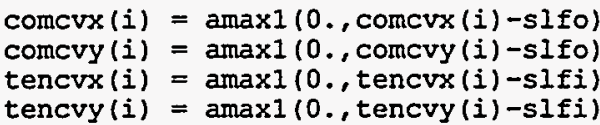

500 continue

return

end

function sxierfe $(x)$

Called by: flothru

Function used in diffusion leaching calculations (2 december 1991).

Calls: none

implicit double precision $(a-h, 0-z)$

common/numb/max

data rstpi / 5.641895835477563d-1/

$x s q=x * \star 2$

u $=\operatorname{rsrpi} * x s q$

sum $=$ rsrpi $-x+u$

$\mathrm{d}=6 . \mathrm{dO}$

$e=9 . d 0$

thm $2 m=-1 . d 0$

do $100 \mathrm{~m}=2,30$

$\max =m$

$\mathrm{u}=\mathrm{u}^{\star} \mathrm{xsq} \mathbf{q}^{\star} \mathrm{thm} 2 \mathrm{~m} / \mathrm{d}$

sum $=$ sum $+u$

if (abs (u/sum) .1t. 5.d-9) go to 110

$d=d+e$

$\mathrm{e}=\mathrm{e}+4 . \mathrm{do}$

$\operatorname{thm} 2 \mathfrak{m}=\operatorname{thm} 2 m-2 . d 0$

100 continue

write $(*, *)$ 'did not converge in sxierfc'

return

110 continue

sxierfc $=$ sum

return

end

subroutine walls (iyear)

Called by: sourcel

Performs cracking analysis for cask walls.

Calls: ccrack

common/cask/clhght, cllth, clwid, cmthk (4), comcvx (3), comcry (3),

curdns, curthk, flangl, noclx, nocly, ommthk (4), ostlrd (3).

\# otncvx (3), otncvy (3), ovrhng, slangl, sldns, stirad (3),

\# $\quad$ stlspc (3), submod, tencrx (3), tencvy (3), wstdns, wsthk, wstht

comon/clcult/annprc, attk (4), crfrac (3), crfrcd (3), crfrcs (3),

\# $\quad$ crfrcw (3), crpcof, csstrn, flaper (3), fifrac (3), icl (3), ico2 (3),

\# $\quad i \operatorname{crack}(3), i \operatorname{crflg}(3), i \operatorname{spl}(3), \mathrm{ph}(4)$, rfaper (3), Iffrac (3), 


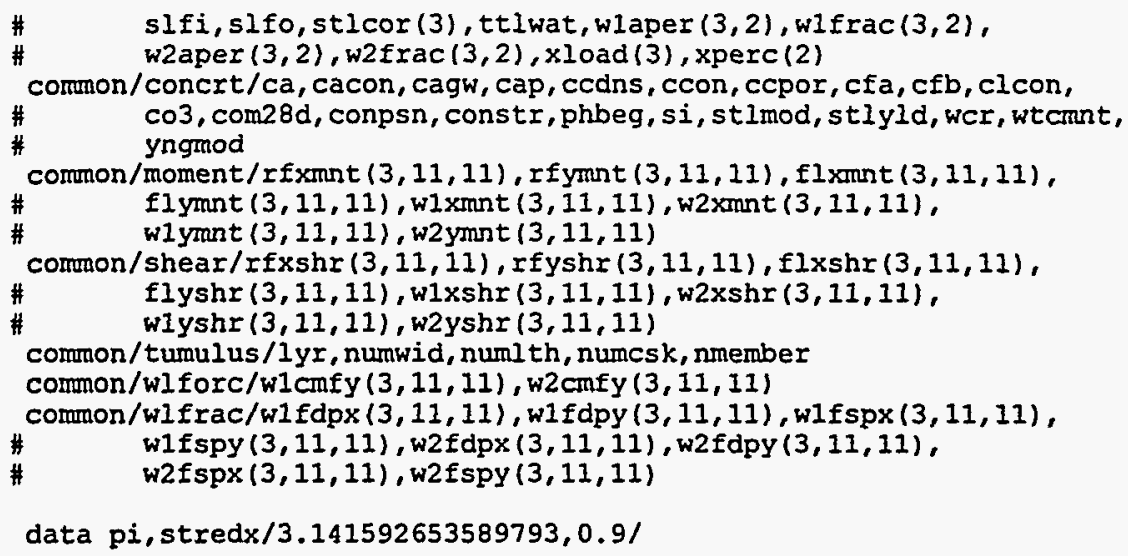

c.....Calculate time-dependent parameters used in cracking analysis.

c.....horizontal steel is $x$-direction steel; vertical steel is $y$-direction c.....steel.

time $=$ iyear $* 365$

comstr $=\operatorname{amin} 1($ time $/(c f a+c f b * t i m e) * \operatorname{com} 28 d * a t t k(2)$, constr*attk $(2)$

conmod $=5.7$ e4*sqrt (comstr) $/(1 .+$ crpcof $)$

ratmod $=$ stlmod/conmod

rupmod $=7.5^{\star}$ sqrt (comstr)

wldstx $=$ cmthk (2)-tencux (2)

wldsty $=$ comthk $(2)$-tencvy $(2)$

starcm $=0$.

startn $=\operatorname{stlrad}(2) \star \star 2 \star p i / s t l s p c(2)$

comnti $=$ cmthk $(2) \star * 3.112$.

crkmtw $=$ cnmnti $/\left(0.5^{\star}\right.$ cmthk $\left.(2)\right) *$ rupmod

c..... Calculate ultimate strength for horizontal $(x)$ direction of walls.

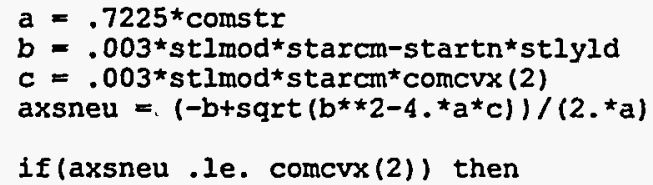

if(axsneu . le. comcrx(2)) then

cmblk = startn*stlyld $/(0.85 *$ comstr $)$

wlustx $=\operatorname{amaxl}(c r k m t w$, stredx*stlyld*startn* (wldstx-cmblk/2.))

else

csstrs $=($ axsneu-comcvx (2)) /axsneu*.003*stlmod

as2 $=$ starcmcsstrs/stlyld

as1 $=$ startn-as2

cmblk = as $1 *$ stlyld $/(0.85 *$ comstr $)$

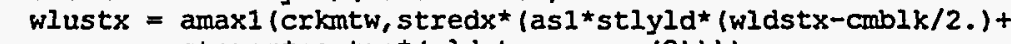

$\sharp$ starcmcsstrs ${ }^{\star}($ wldst $\left.x-\operatorname{comcvx}(2))\right)$ )

endif

c..... Calculate cracking moment of inertia for walls for $x$ and $y$ directions.

$\mathrm{aa}=0.5$

$b b=\operatorname{starcm} *($ ratmod-1. $)+$ startn*ratmod

cCx $=$ comcvx $(2) \star$ starcm ${ }^{*}($ ratmod -1.$)$-wldstx*ratmod*startn

ccy $=$ comcvy $(2) *$ starcm* $($ ratmod-1.) - wldsty* ratmod*startn

$r t t 1 x=(-b b+\operatorname{sqrt}(b b * \star 2-4 . * a a * c c x)) /(2, * a a)$

$\operatorname{rtt} 1 y=(-b b+s q r t(b b * \star 2-4 . * a a * c c y)) /(2 . * a a)$

rtt $2 x=\left(-b b-\operatorname{sgrt}\left(b b * \star 2-4 . * a a^{\star} c c x\right)\right) /(2 . \star a a)$

rtt2y $=(-b b-s q r t(b b * \star 2-4 . * a a * c c y)) /(2 . \star a a)$

axneux $=$ rtt $1 x$

axneuy $=$ rttly

crmtix $=0.333^{*}$ axneux $* 3 .+\operatorname{starcm} *($ ratmod-1.) $)($ axneux-comcrx $(2))$

$\#$ $\star * 2+$ ratmod*startn* (wldstx-axneux) $* * 2$

crmtiy $=0.333 *$ axneuy $\star \star 3 .+\operatorname{starcm} *($ ratmod -1.$) *($ axneuy-comcvy $(2))$ 
\# $\quad \star \star 2+$ ratmod*startn* $($ wIdsty-axneuy $) \star \star 2$

c..... Calculate cracking due to shear for first wall for all layers of casks.

$x k=(1.6+2.4 *($ clwid/cllth -0.5$)) * 0.29$

shrstx $=1.7 *$ sqrt (comstr)*wldstx

cmblk $=87000 . /(87000 .+$ stlyid $) * 0.85 * w l d s t y$

$\mathrm{pb}=0.7 *(0.85 *$ comstr*cmblk-startn*stlyld)

wlustc $=0.55^{\star} 0.7{ }^{\star}$ cmthk $(2) \star$ comstr* $\left(1 .-\left(\right.\right.$ clhght $/\left(32 .{ }^{\star}\right.$ cmthk $\left.\left.\left.(2)\right)\right) \star \star 2\right)$

do $500 j=1,1 \mathrm{yr}$

$\mathrm{krkx}=0$

$k r k y=0$

$\omega 1$ frac $(j, 1)=0$.

$\operatorname{wlfrac}(j, 2)=0$.

wlaper $(j, 1)=0$.

wlaper $(j, 2)=0$.

do $400 \mathrm{k}=1,11$

do $3001=1,11$

frcwdx $=0$.

frcwdy $=0$.

if $(w 1 x \operatorname{shr}(j, k, 1)$.ge. shrstx) then

if (wlxment $(j, k, 1)$.gt. 0.$)$ then

$\operatorname{tmp}=\operatorname{amin} 1(w 1 x \operatorname{shr}(j, k, 1) / w 1 x m n t(j, k, 1) * w l d s t x, 1$.

ver $=\operatorname{aminl}((1.9 * \operatorname{sgrt}($ comstr $)+2500 . *$ startn/wldstx*tmp) *

$\#$ wldstx, 3.5*sqrt (comstr)*wldstx)

else

vcr $=3.5 *$ sqrt $($ comstr $) *$ wldstx

endif

if (wlxshr $(j, k, 1)$.ge. vcr) then

sfrcdx $=$ cmthk (2)

sfrcwx $=0.013$

$\operatorname{sfrcs} x=\operatorname{clwid} / 10$.

endif

else

sfrcdx $=0$.

sfrewx $=0$.

$\operatorname{sfrcs} x=0$.

endif

c..... Calculate fracture characteristics for horizontal $(x)$ direction due to c..... bending.

if (w1xmnt $(j, k, 1)$.ge. crkmtw) then

if (tencrx (2).eq.0. .and. $\operatorname{wlfspx}(j, k, 1)$.eq.0.) then

$\mathrm{q}=\operatorname{stlrad}(2) * \star 2 * 1.571 /(\operatorname{stl} \operatorname{spc}(2) * \operatorname{otncvx}(2))$

\#

if (stlrad (2) .1t. $1 . e-15) q=\operatorname{ostlrd}(2) \star \star 2 * 1.571$ / (stlspc(2)*otncrx (2))

\#

elseif (stirad(2).1t.1.e-15 .and. w1fspx $(j, k, 1)$.eq.0.) then

$q=\operatorname{ostlrd}(2) * \star 2 * 1.571 /(\operatorname{stlspc}(2) * \operatorname{tencvx}(2))$ 
\#

elseif (tencux(2).gt.0. . and.

stlrad(2).ge.1.e-15) then

$q=\operatorname{stlrad}(2) \star \star 2 * 1.571 /(\operatorname{stlspc}(2) * \operatorname{tencvx}(2))$

endif

if (stlrad(2) .ge. 1.e-15) then

frspce $=0.5 * x k \star s q r t\left(2 .{ }^{*} \operatorname{stlrad}(2) \star s t l \operatorname{spc}(2) / q\right)$

elseif (stlrad(2).1t.1.e-15 .and.

wlfspx $(j, k, 1)$.eq.0.) then

frspce $=0.5 * \times k^{\star} \operatorname{sqrt}\left(2 .{ }^{*}\right.$ ostlrd $\left.(2) \star \operatorname{stlspc}(2) / q\right)$

endif

if $(w 1 f \operatorname{spx}(j, k, l)$.eq.0. .or.

$w 1 f \operatorname{spx}(j, k, l), g e .2 . \star f r s p c e)$

$w 1 f \operatorname{spx}(j, k, l)=$ frspce

endif

c.....x-moments exceed cracking moment but not ultimate strength of wall.

if (w1xmnt $(j, k, 1)$.ge.crkmtw .and.

w1xmnt $(j, k, 1) .1 t$.wlustx) then

efmntx $=(\text { crkmtw/wlxmnt }(j, k, 1))^{\star \star} 3 .{ }^{\star}$ comntit

(1. $-($ crkmtw/w1xmnt $(j, k, 1)) \star * 3)$.$* crmtix$

strsmx $=$ wlxmit $(j, k, 1) \star$ axneux/efmntx

stltnx $=$ ratmod*wlxmint $(j, k, l) *($ wldst $x$-axneux $) /$ efmntx

axsnex $=$ wldstx/(stltnx/stlmod+strsmx/conmod $) *$

(stltnx/stlmod+csstrn) +tencvx (2)

betax = axsnex $/(\operatorname{axsnex}-$ tencvx (2))

wlfdpx $(j, k, l)=$ axsnex

frcwdx $=w l f \operatorname{spx}(j, k, l) \bullet($ stl $l \operatorname{tnx} /$ stlmod*betax+csstrn $)$

endif

c.....x-moments exceed ultimate strength of wall.

if (wlxmnt $(j, k, 1)$.ge.wlustx.and.

wlfdpx $(j, k, 1), 1 t$. cmthk (2)) then

wIfdpx $(j, k, 1)=\operatorname{cmthk}(2)$

frcwdx = aminl (stlyld/stlmod+csstrn)*

\# w1fspx $\left.(j, k, 1), 3 . e-3^{*} w 1 f \operatorname{spx}(j, k, 1)\right)$

endif

c.....Perform cracking calculations for first wall in vertical (y) direction. c..... Calculate ultimate strength for vertical (y) direction.

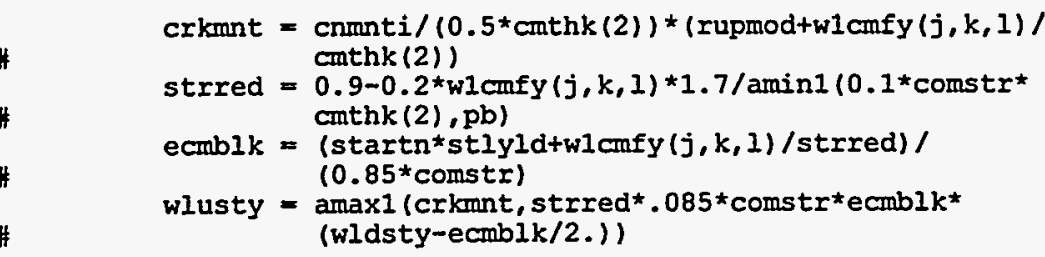

c..... Shear cracking calculations for vertical (y) direction. calculation c..... differs from those for horizontal (x) direction as there is also c...... compressive force.

$\operatorname{mm}=w 1 y \operatorname{mnt}(j, k, 1)-w 1 \operatorname{cmfy}(j, k, 1) *\left(4 .{ }^{\star} \operatorname{cmthk}(2)-w 1\right.$ dsty $) / 8$.

tmp $=3.5^{\star}$ sqrt $($ comstr $){ }^{*}$ wldsty $(1 .+w 1$ cmfy $(j, k, 1) /(500 . *$

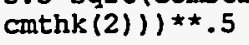

if (mm . gt. 0.) then 
vcr $=\operatorname{aminl}((1.9 *$ sqrt (comstr) $+2500 . *$ startn/wldsty* $\left.\left.w 1 y \operatorname{shr}(j, k, 1){ }^{*} w l d s t y / m m\right) * w l d s t y, t m p\right)$

else

ver $=$ tmp

endif

if (abs (wlyshr $(j, k, 1)$ ).ge. vcr) then

sfrcdy $=$ cmthk $(2)$

sfrcwy $=0.013$

sfrcsy $=$ clhght $/ 10$.

else

sfrcdy $=0$.

sfrcwy $=0$.

sfrcsy $=0$.

endif

c..... Calculate cracking of interior walls due to compression. No cracking c..... due to bending is assumed for these walls. When cracking occurs there c..... is a single (horizontal) crack per section.

if (wlamfy $(j, k, I)$.ge. wlustc) then

cfrcdp $=\operatorname{cmthk}(2)$

cfrcwd $=.003^{\star}$ clhght $/ 10$.

cfrcsp $=$ clhght $/ 10$.

else

cfrcdp $=0$.

cfrcwd $=0$.

cfrcsp $=0$.

endif

c..... Calculate fracture characteristics.

if (wlymnt $(j, k, 1)$.ge. crkmnt) then

if (tencvy (2).eq.0. .and. wlfspy $(j, k, 1)$.eq.0.) then

$q=\operatorname{stlrad}(2) \star \star 2 \star 1.571 /(\operatorname{stlspc}(2) \star \operatorname{otncvy}(2))$

if (stlrad(2) .1t. $1 . e-15) q=\operatorname{ostlrd}(2) \star * 2 \star 1.571 /$

\# (stlspc (2)*otncvy (2))

$\#$

elseif (stlrad(2).1t.1.e-15 .and. w1fspy $(j, k, 1)$.eq. 0.$)$ then

$\mathrm{q}=\operatorname{ostlrd}(2) \star \star 2 \star 1.571 /(\operatorname{stl} \operatorname{spc}(2) * \operatorname{tencvy}(2))$

elseif (tencvy (2).gt.0. .and. stlrad(2).ge.1.e-15) then

$\mathrm{q}=\operatorname{stl} \operatorname{rad}(2) * \star 2 * 1.571 /(\operatorname{stl} \operatorname{spc}(2) * \operatorname{tencvy}(2))$

endif

if (stlrad(2) ge. 1.e-15) then

frspce $=0.5 * x k * \operatorname{sqrt}(2 . * \operatorname{stlrad}(2) * \operatorname{stIspc}(2) / q)$

elseif (stirad(2).1t.1.e-15 .and.

wlfspy $(j, k, 1)$.eq. 0.$)$ then

frspce $=0.5 x^{*} k^{\star} \operatorname{sqrt}\left(2 .{ }^{*} \operatorname{ost} l r d(2) \star \operatorname{st} I s p c(2) / q\right)$

endif 


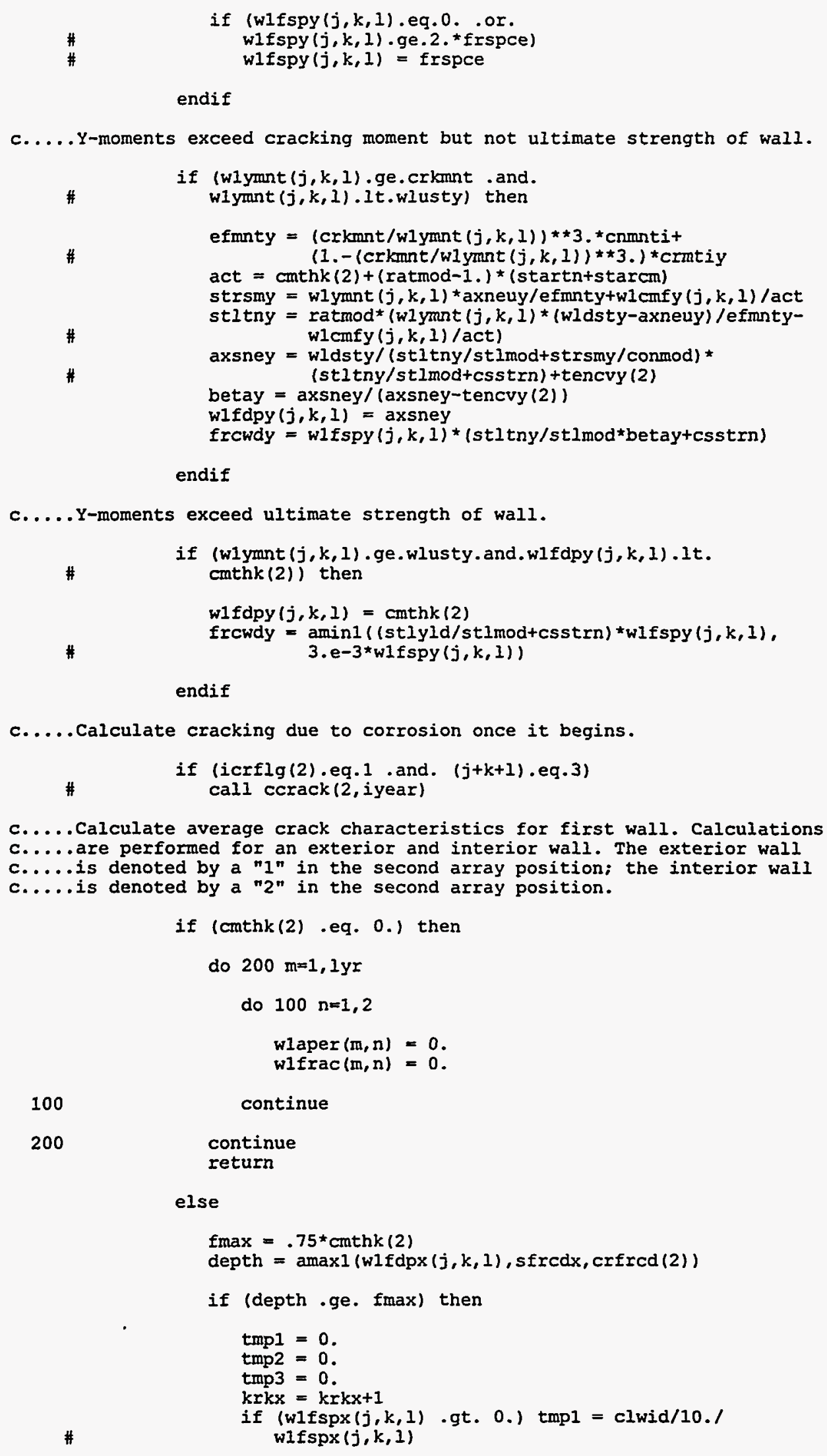

endif

c.....Y-moments exceed cracking moment but not ultimate strength of wall.

if (wlyme $(j, k, 1) \cdot$ ge.crkmnt . and.

\# wlyme $(j, k, l) .1 t$.wlusty) then

efmnty $=(\operatorname{crkmnt} /$ wlymnt $(j, k, 1)) \star * 3 .{ }^{*}$ cramnti+

(1. - (crkmnt/wlymnt $(j, k, 1)) * * 3)$.$* crmtiy$

act $=$ cmthk $(2)+($ ratmod -1.$) *($ startn + starcm $)$

strsmy $=$ wlymnt $(j, k, 1) \star$ axneuy/efmnty+wlcmfy $(j, k, 1) /$ act

stltny $=$ ratmod $*$ (wlymnt $(j, k, 1) *$ (wldsty-axneuy $) /$ efmnty-

$\begin{aligned} & \text { axsney }=\text { wldidsty } /(j, k, 1) / \text { act }) \\ &\text { wlitny/stimod+strsmy/conmod }) *\end{aligned}$

$\#$

(stltny/stlmod+csstrn)+tencvy (2)

betay $=$ axsney $/($ axsney-tencvy $(2))$

w1fdpy $(j, k, 1)=$ axsney

frcwdy $=w 1$ fspy $(j, k, 1) \star(s t l$ tny $/ s t l \bmod \star b e t a y+c s s t r n)$

endif

c.....Y-moments exceed ultimate strength of wall.

$\#$

if (wlymat $(j, k, 1)$.ge.wlusty.and.wlfdpy $(j, k, 1) .1 t$. crnthk (2)) then

wlfdpy $(j, k, 1)=\operatorname{cmthk}(2)$

frcwdy $=\operatorname{aminl}($ (stlyld/stlmod+csstrn) $*$ wlfspy $(j, k, l)$,

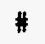

$3 . e^{-3 *}$ w 1 fspy $\left.(j, k, 1)\right)$

endif

c..... Calculate cracking due to corrosion once it begins.

IIf (icrflg(2).eq.1 . and. $(j+k+1) . e q .3)$

\# call $\operatorname{ccrack}(2$, iyear $)$

c..... Calculate average crack characteristics for first wall. Calculations c.... are performed for an exterior and interior wall. The exterior wall

c..... is denoted by a " 1 " in the second array position; the interior wall c..... is denoted by a "2" in the second array position.

if (cmthk (2) .eq. 0.) then

do $200 \mathrm{~m}=1,1 \mathrm{yr}$

do $100 n=1,2$

wlaper $(m, n)=0$.

w1frac $(m, n)=0$.

100

continue

200

continue

return

else

$f \max =.75^{\star}$ crathk (2)

depth $=\operatorname{amaxl}(w 1 f d p x(j, k, 1), \operatorname{sfrcdx}, \operatorname{crfrcd}(2))$

if (depth .ge. fmax) then

tmpl $=0$.

tmp2 $=0$.

$\operatorname{tmp} 3=0$.

$\mathrm{krkx}=\mathrm{krkx}+1$

if $(w 1 f \operatorname{spx}(j, k, 1)$.gt. 0.$)$ tmpl = clwid/10.l

wIfspx $(j, k, 1)$ 
$\#$

$\#$

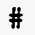

if $(\operatorname{crfrcs}(2)$.gt. 0.$)$ tmp2 $=$ clhght $/ 10 . / \operatorname{crfrcs}(2)$

if $($ sfrcs. gt. 0.$)$ tmp $3=$ clwid/10./sfrcs $x$

tmp $=$ tmp $1+$ tmp $2+t m p 3$

wlaper $(j, 1)=$ wlaper $(j, 1)+(\operatorname{frcwdx} * \operatorname{tmp} 1+\operatorname{crfrcw}(2) *$ tmp2+sfrcwx tmp3)/tmp

wlaper $(j, 2)=$ wlaper $(j, 2)+\operatorname{crfrcw}(2) * \operatorname{tmp} 2$

wifrac $(j, 1)=w 1 \operatorname{wrac}(j, 1)+\operatorname{cmthk}(2) * \operatorname{clhght} / 10$ *

endif

depth $=\operatorname{amax} 1(w 1 f d p y(j, k, 1), \operatorname{sfrcdy}, \operatorname{crfrcd}(2), \operatorname{cfrcdp})$

if (depth.ge. fmax) then

$\operatorname{tmp} 1=0$.

$\operatorname{tmp} 2=0$.

$\operatorname{tmp} 3=0$.

tmp4 $=0$.

$k r k y=k r k y+1$

if $(w 1$ fspy $(j, k, 1)$.gt. 0.$)$ tmpl = clhght/10./ wlfspy $(j, k, 1)$

if (crfrcs (2) .gt. 0.$)$ tmp2 $=$ clwid/10./crfrcs (2)

if (sfrcsy .gt. 0.) tmp $3=$ clhght/10./sfrcsy

if (cfrcsp .gt. 0. ) tmp $4=$ clhght $/ 10 . /$ cfrcsp

$t m p=t m p 1+t m p 2+t m p 3+t m p 4$

wlaper $(j, 1)=\operatorname{wlaper}(j, 1)+\left(f r c w d y^{\star} \operatorname{tmp} 1+\operatorname{crfrcw}(2) *\right.$ tmp2+sfrcwy* tmp $3+c$ frcwd tmp 4$) /$ tmp

if $(\operatorname{tmp} 2+\operatorname{tmp} 4 . g t .0$.$) wlaper (j, 2)=$ w1aper $(j, 2)+$ (crfrcw (2)*tmp2+cfrcwd*tmp4) /(tmp2+tmp4)

$w 1 \operatorname{rac}(j, 1)=w 1 \operatorname{frac}(j, 1)+\operatorname{cmthk}(2) * \operatorname{clwid} / 10$.

(frcwdy*tmp 1+sfrcwy*tmp3+cfrcwd*tmp4)

wifrac $(j, 2)=\operatorname{w1frac}(j, 2)+\operatorname{cmthk}(2) * \operatorname{clwid} / 10 . *$ cfrcwd*tmp4

endif

endif

300 continue

400 continue

if $(w 1 \operatorname{frac}(j, 1) \cdot g t .0$. or. $w 1 \operatorname{frac}(j, 2) \cdot g t .0$.$) icrack(2) =1$

$w 1 \operatorname{frac}(j, 1)=w 1 \operatorname{frac}(j, 1)+\operatorname{crfrac}(2)$

wlfrac $(j, 2)=\operatorname{wlfrac}(j, 2)+\operatorname{crfrac}(2)$

500 continue

do $700 j=1,1 y x$

do $600 i=1,2$

if (w1frac (j,i) .gt. 0.) then

$w 1 \operatorname{frac}(j, i)=w 1 \operatorname{frac}(j, i) /(\operatorname{conthk}(2) * \operatorname{clwid} * \operatorname{clhght})$

wlaper $(j, i)=w 1$ aper $(j, i) /(k r k x+k r k y) \star 2.54$

endif

600 continue

700 continue

c..... Calculate cracking due to shear for second wall for all layers of casks.

do $1200 \mathrm{j}=1$, Iyr

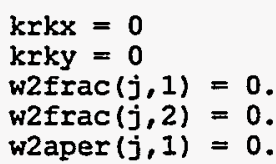




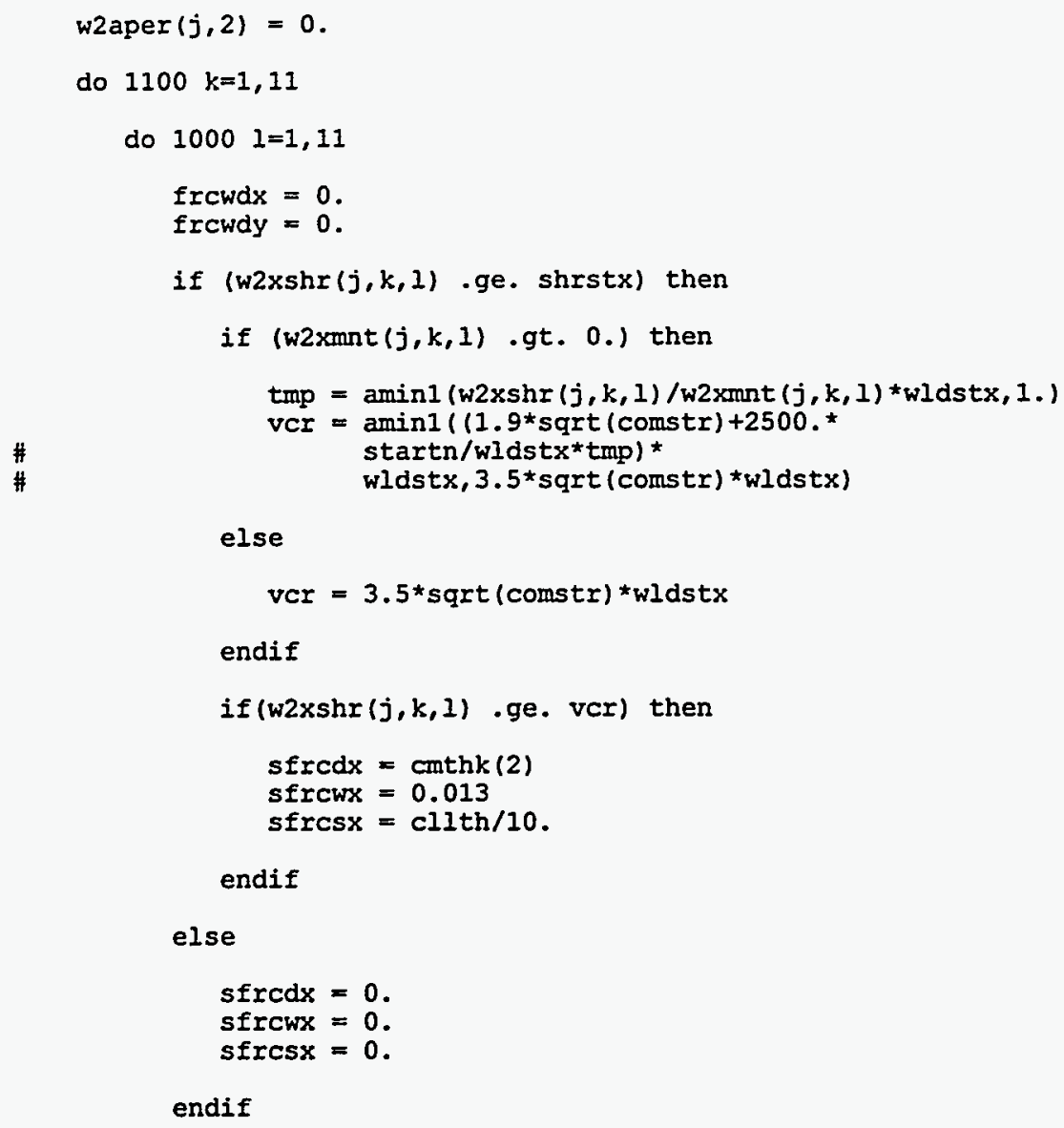


if $(w 2 f \operatorname{spx}(j, k, l)$.eq.0. .or. w2fspx $(j, k, l) . g e$.

2. frspce) $w 2 f \operatorname{spx}(j, k, l)=$ frspce

endif

c....x-moments exceed cracking moment but not ultimate strength of wall.

w $2 x \operatorname{mant}(j, k, 1)$. it.wlustx) then

\#

efmntx $=($ crkmtw $/ w 2 x m n t(j, k, 1)) * * 3 . *$ cnmnt $i+(1 .-$ (crkmtw/w2xmnt $(j, k, 1)) * \star 3). * \operatorname{crmtix}$

strsmx $=$ w2xint $(j, k, l) * a x n e u x / e f m n t x$

stltnx $=\operatorname{ratmod} *$ w $2 x m n t(j, k, l) *($ wldstx-axneux $) /$ efmntx

axsnex $=$ wldstx/(stltnx/stlmod+strsmx/conmod $)$ *

(stltnx/stlmod+csstrn)+tencvx (2)

betax $=$ axsnex $/(\operatorname{axsnex}-\operatorname{tencvx}(2))$

w2 $f d p x(j, k, l)=\operatorname{axsnex}$

frcwdx $=w 2 f \operatorname{spx}(j, k, 1) *($ stltnx/stlmod*betax+csstrn $)$

endif

c..... X-moments exceed ultimate strength of wall.

$\#$

if (w2xmt $(j, k, 1)$.ge.wlustx. and.w2fdpx $(j, k, 1), 1 t$. canthk (2)) then

w2fdpx $(j, k, 1)=\operatorname{cmthk}(2)$

frcwdx $=\operatorname{aminl}($ (stlyld/stlmod+csstrn) *

\#

w2fspx $(j, k, 1), 3 \cdot e^{-3 * w 2 f \operatorname{spx}(j, k, 1))}$

endif

c.....Perform cracking calculations for second wall in vertical (y) direction. c.....Calculate ultimate strength for vertical (y) direction.

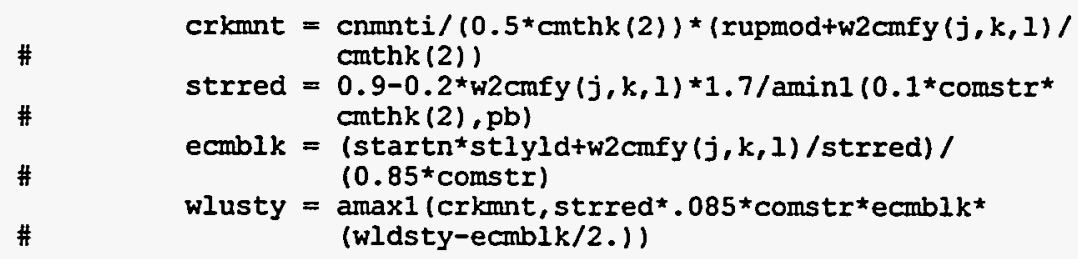

c.....Shear cracking calculations for vertical (y) direction. Calculation c..... differs from those for horizontal $(x)$ direction as there is also c..... compressive force.

$\#$

$\operatorname{mm}=w 2 y \operatorname{mnt}(j, k, 1)-w 2 \operatorname{confy}(j, k, 1) *(4 . * \operatorname{cmthk}(2)-w 1 d s t y) / 8$.

tmp $=3.5^{*}$ sqrt (comstr) *wldsty* $(1 .+w 2 \operatorname{cmfy}(j, k, 1) /(500 . *$ cmthk (2))) ${ }^{\star \star} .5$

if (mm .gt. 0.) then

$\#$

ver $=\operatorname{aminl}\left(\left(1.9^{\star} \operatorname{sqrt}(\right.\right.$ comstr $)+2500{ }^{\star}{ }^{\star}$ startn/wldsty* $w 2 y \operatorname{shr}(j, k, 1) * w l d s t y / m n) * w l d s t y, t m p)$

else

$\mathrm{vcr}=\mathrm{tmp}$

endif

if (abs (w2yshr $(j, k, 1))$.ge. vcr) then

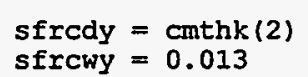

else

sfrcdy $=0$. 
sfrcwy $=0$.

sfrcsy $=0$.

endif

c..... Calculate cracking of interior walls due to compression. No cracking c..... due to bending is assumed for these walls. When cracking occurs there c..... is a single (horizontal) crack per section.

if (w2 cmfy $(j, k, 1)$.ge. wlustc) then

cfrcdp $=$ cmthk $(2)$

cfrcwd $=.003^{\star}$ clhght $/ 10$.

cfrcsp $=$ clhght $/ 10$.

else

cfrcdp $=0$.

cfrcwd $=0$

cfrcsp $=0$.

endif

c..... Calculate fracture characteristics.

if (w2ymant $(j, k, 1) . g e . c r k m n t)$ then

if (tencry (2).eq. 0 . and. w2fspy $(j, k, 1) . e q .0$.$) then$

$q=\operatorname{stlrad}(2) \star * 2 \star 1.571 /(\operatorname{stlspc}(2) \star$ otncvy $(2))$

\#

if (stlrad(2) .It. 1.e-15) $q=$ ostlrd (2) $\star \star 2 \star 1.571 /$

(stlspe (2) *otncry (2))

elseif (stlrad(2),1t.1.e-15 .and.

w2fspy $(j, k, 1)$.eq. 0.$)$ then

\#

$\mathrm{q}=\operatorname{ostlrd}(2) \star \star 2 \star 1.571 /(\operatorname{stlspc}(2) \star \operatorname{tencvy}(2))$

\#

elseif (tencvy (2).gt.0. .and. stlrad(2).ge.1.e-15) then

$q=\operatorname{stlrad}(2) \star \star 2 \star 1.571 /(\operatorname{stlspc}(2) \star \operatorname{tencvy}(2))$

endif

if (stlrad(2) .ge. 1.e-15) then

frspce $=0.5^{\star} x k^{\star} s q r t\left(2{ }^{\star} s t l r a d(2) \star s t l s p c(2) / q\right)$

elseif (stlrad(2).1t.1.e-15 .and. w2fspy $(j, k, 1)$. eq. 0.$)$ then

frspce $=0.5 * x k^{*} \operatorname{sqrt}\left(2 .{ }^{*}\right.$ ost $\left.l \mathrm{rd}(2) * \operatorname{stlspc}(2) / q\right)$

endif

if (w2fspy $(j, k, I)$.eq. 0 . .or. w2fspy $(j, k, 1), g e .2 . \star$ frspce)

$\#$ w2fspy $(j, k, 1)=$ frspce

endif

c..... Y-moments exceed cracking moment but not ultimate strength of wall.

$\#$

\#

\#

if (w2ymnt $(j, k, 1)$.ge.crkmnt .and. w2yme $(j, k, 1)$. It.wlusty) then

efmnty $=($ crkmnt $/ w 2 y \operatorname{mnt}(j, k, 1)) * * 3 . *$ cnmnti+(1.$($ crkmnt/w2ymnt $(j, k, 1)) \star \star 3)$.$* crmtiy$ act $=$ crnthk $(2)+($ ratmod -1.$) *($ startn + starcm $)$ strsmy $=$ w2ymnt $(j, k, 1) *$ axneuy/efmnty+ w2 amfy $(j, k, 1)$ /act

stltny $=\operatorname{ratmod}($ w2yme $(j, k, 1) *$ (wldsty-axneuy) $/$ 
\#

\#

efminty-w2 cmfy (j, $k, 1) / a c t)$

axsney $=$ wldsty/(stltny/stlmod+strsmy/conmod) *

(stltny/stlmod+csstrn) +tencvy (2)

betay $=$ axsney/(axsney-tencvy $(2))$

w2fdpy $(j, k, l)=$ axsney

frcwdy $=$ w2fspy $(j, k, l) *($ stltny/stlmod*betay+csstrn $)$

endif

c..... Y-moments exceed ultimate strength of wall.

$\#$

if (w2ymat $(j, k, 1)$.ge.wlusty. and.w2fdpy $(j, k, 1) .1 t$. conthk (2)) then

w2fdpy $(j, k, I)=\operatorname{cmthk}(2)$

frcwdy $=\operatorname{amin} 1$ ( (stlyld/stlmod+csstrn) *

\# w2fspy $\left.(j, k, 1), 3, e^{-3^{\star}} w 2 \operatorname{fspy}(j, k, 1)\right)$

endif

c..... Calculate cracking due to corrosion once it begins.

$\#$

if (icrflg(2).eq. 1 and. $(j+k+1) \cdot e q \cdot 3)$ call $\operatorname{ccrack}(2$, iyear $)$

c..... Calculate average crack characteristics for second wall. Calculations c..... are performed for an exterior and interior wall. The exterior wall c..... is denoted by a "1" in the second array position; the interior wall c......is denoted by a " 2 " in the second array position.

if (cmthk (2) .eq. 0.) then

do $900 \mathrm{~m}=1,1 \mathrm{yr}$

do $800 n=1,2$

w2aper $(m, n)=0$.

w2frac $(m, n)=0$.

800

continue

900

continue

return

else

$\mathrm{fmax}=.75 *$ cmthk (2)

depth $=\operatorname{amax} 1(w 2 f d p x(j, k, 1), \operatorname{sfrcd} x, \operatorname{crfrcd}(2))$

if (depth.ge. fmax) then

$\operatorname{tmp} 1=0$.

$\operatorname{tm} 2=0$

$\operatorname{tmp} 3=0$.

$\mathrm{krkx}=\mathrm{krkx+1}$

if (w2fspx $(j, k, 1)$.gt. 0.$)$ tmpl $=$ clith/10./w2fspx $(j, k, 1)$

if (crfrcs (2) .gt. 0.) tmp2 = clhght/10./crfics (2)

if (sfrcsx .gt. 0. ) tmp3 $=$ cllth/10./sfrcsx tmp $=t m p 1+t m p 2+t m p 3$

w2aper $(j, 1)=$ w2aper $(j, 1)+($ frcwd $*$ tmp $1+$

crfrcw $(2) * \operatorname{tmp} 2+$ sfrcwx $*$ tmp 3) /tmp

w2aper $(j, 2)=$ w2aper $(j, 2)+\operatorname{crfrcw}(2) * \operatorname{tmp} 2$

w2frac $(j, 1)=w 2 \operatorname{frac}(j, 1)+\operatorname{cmthk}(2) *$ clhght $/ 10$.* (frcwdx*tmp $1+$ sfrcwx* tmp 3 )

endif

$\operatorname{depth}=\operatorname{amax} 1($ w2fdpy $(j, k, 1), \operatorname{sfrcdy}, \operatorname{crfrcd}(2), \operatorname{cfrcdp})$

if (depth.ge. fmax) then 
$\operatorname{tmp1}=0$.
$\operatorname{tmp2}=0$.
tmp3 $=0$.

krky $=k r k y+1$

if (w2fspy $(j, k, 1)$.gt. 0.$)$

$\operatorname{tmpl}=\operatorname{clhght} / 10 . /$ w2fspy $(j, k, 1)$

if (crfrcs(2).gt. 0.$)$ tmp2 = clith/10./crfrcs (2)

if (sfrcsy .gt. 0.) tmp $3=$ clhght/10./sfrcsy

if (cfrcsp .gt. 0.) tmp4 = clhght $/ 10 . /$ cfrcsp

tmp $=$ tmp 1+tmp $2+t m p 3+t m p 4$

w2aper $(j, 1)=$ w2aper $(j, 1)+($ frcwdy $t$ tmp $1+\operatorname{crfrcw}(2)$ * tmp $2+$ sfrcwy tmp $3+c f r c w d^{\star}$ tmp $4 / /$ tmp

if $(\operatorname{tmp} 2+\operatorname{tmp} 4 \cdot g t$. 0.$)$ w2aper $(j, 2)=$

w2aper $(j, 2)+(\operatorname{crfrcw}(2)$ *

tmp2+cfrcwd*tmp4)/(tmp2+tmp4)

$w 2 \operatorname{trac}(j, 1)=\operatorname{wefac}(j, 1)+\operatorname{cmthk}(2) * \operatorname{cllth} / 10 . *$ (frcwdy*tmp 1+ sfrcwy tmp $3+c$ frcwd*tmp 4$)$

$\#$

$w 2 \operatorname{frac}(j, 2)=w 2 \operatorname{frac}(j, 2)+\operatorname{cmthk}(2) * \operatorname{cllth} / 10$ * cfrcwd $\star$ tmp 4

endif

endif

1000

continue

1100 continue

if $(w 2 f r a c(j, 1) . g t .0$. or. $w 2 f r a c(j, 2) \cdot g t .0$.$) icrack (2)=1$ w2frac $(j, 1)=w 2 \operatorname{frac}(j, 1)+\operatorname{crfrac}(2)$ $w 2 \operatorname{frac}(j, 2)=w 2 \operatorname{frac}(j, 2)+\operatorname{crfrac}(2)$

1200 continue

do $1400 j=1,1 \mathrm{yr}$

do $1300 i=1,2$

if (w2frac(j,i) .gt. 0.$)$ then

w2frac $(j, i)=w 2$ frac $(j, i) /(\operatorname{conthk}(2) *$ cllth*clhght $)$ w2aper $(j, i)=w 2 a \operatorname{aper}(j, i) /(k r k x+k r k y) * 2.54$ $i \operatorname{crack}(2)=1$

endif

1300

continue

1400 continue

return

end 
Exhibit D.2. Computer code listing for SOURCE2

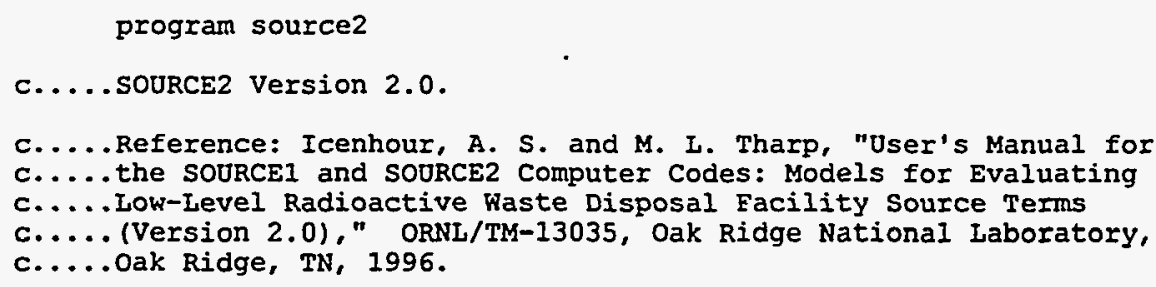

c.....Read input data and perform preliminary calculations for simulation.

call input $(0$, nyears)

c..... Opens the files which have been selected to provide summaries

c..... of the simulation results.

call output $(0$, nyears $)$

c..... Start annual loop.

do 100 iyear $=1$, nyears

c.....Read years when inventories were disposed and associated inventories c..... and updates water infiltration values.

call input (iyear, nyears)

c.... if (mod(iyear, 10$)$.eq. 0$)$ write $(*, *)$ 'year: ', iyear

c..... Calculate time-dependent properties of reinforced concrete.

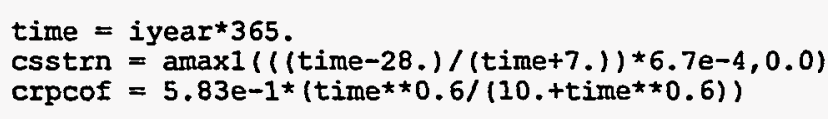

c.....Perform structural analysis for disposal technology.

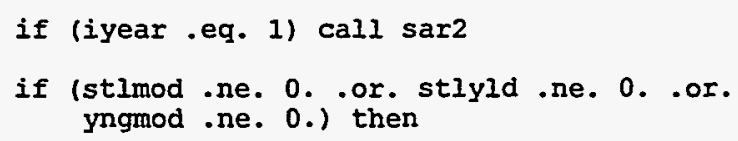

c.....Perform concrete deterioration analysis. Analysis results are c.....used in cracking analysis until silo and/or well have at least c..... one cracked or failed member. Degradation analysis is continued c..... for entire simulation. 
call concrete (iyear)

c.....Perform cracking analysis for silo and well technologies. Analysis c..... is performed until all disposal units have at least one cracked or c..... failed member.

if ((idflag.eq.1 .or. idflag.eq.3) .and. isavel.eq.0) then

$\begin{array}{llll}\text { if (cmthk }(1,1) & \text {.gt. } 0 .) \text { call srf(attk }(1,1), \text { iyear) } \\ \text { if (cmthk }(1,2) & \text {.gt. } 0 .) \text { call swl (attk }(1,2) \text {, iyear) } \\ \text { if (cmthk }(1,3) & \text {.gt. } 0 .) \text { call sfl(attk }(1,3) \text {, iyear) }\end{array}$

endif

else

$i \operatorname{crack}(1)=1$

icrack $(2)=1$

$i \operatorname{crack}(3)=1$

$\operatorname{frac}(1)=0$.

$\operatorname{frac}(2)=0$.

$\operatorname{frac}(3)=0$.

$\operatorname{aper}(1)=0$.

$\operatorname{aper}(2)=0$.

$\operatorname{aper}(3)=0$.

endif

if ((idflag.eq.2 .or. idflag.eq.3) .and. isave2.eq.0) then

call wrf (attk $(2,1)$, iyear)

call wwl

call wfl (attk $(2,3)$, iyear)

endif

c.....Monitor degree to which silo and well have cracked or failed.

$$
\begin{aligned}
& \text { isave } 1=0 \\
& \text { isave2 }=0 \\
& \text { do } 200 \quad i=1,3
\end{aligned}
$$

if (idflag.eq.1 .or. idflag.eq. 3 ) isavel = isave1+icrack(i)

if (idflag .gt. 1) isave 2 = isave $2+2 f a 2 l(i)$

200

continue

c..... Calculate advective and diffusive release rates.

call leach (iyear, nyears)

c..... Output simulation results.

call output (iyear, nyears)

100 continue

stop

end

block data sorbd

common/clcult/annprc, aper (3), attk $(2,3), \operatorname{crfrac}(3), \operatorname{crfrcd}(3)$,

$\begin{array}{ll}\# & \operatorname{crfrcw}(3), \operatorname{crfrcs}(3), \operatorname{crpcof}, \operatorname{csstrn}, \text { frac (3), icl (3), ico2 (3), } \\ \# & \text { icrack (3), icrflg (3), ifail (3), isavel, isave }, i \operatorname{spl}(3), \operatorname{ph}(2,3), \\ \text { slfi,slfo, stlcor (3), xload, xperc (2) }\end{array}$

common/miscel/acoef, bcoef, dpm(12)

data isave 1, isave $2 / 0,0 /$

data attk, icrack, ifail $/ 6 * 1 ., 3 * 0,3 * 0 /$

data icl, ico2, icrflg/9*0/

data $i \mathrm{sp} 1 / 3 \mathbf{0}^{\circ} /$ 
data $\mathrm{dpm} / 31,28.25,31,, 30,, 31,, 30 ., 31 ., 31,30,, 31 ., 30 ., 31 . /$

data annprc/0./

end

subroutine caoh(iyear)

Called by concrete

Calculates loss of concrete strength and reduction in $\mathrm{pH}$ of concrete due to leaching of $\mathrm{Ca}(\mathrm{OH}) 2$.

Calls: none

common/chemcl/c1, co2, 02, so4i, so4o, xmg2, dfalk, dfcaoh, dfcl, dfco2,

\# dfo2, dfso4, casol, crbsol, xmgsol

common/clcult/annprc, aper (3), attk $(2,3), \operatorname{crfrac}(3), \operatorname{crfrcd}(3)$,

\# $\quad \operatorname{crfrcw}(3), \operatorname{crfrcs}(3), \operatorname{crpcof}, \operatorname{csstrn}$, frac (3), icl (3), ico2 (3),

\# icrack (3), icrflg (3), ifail (3), isavel, isave2, ispl $(3), \mathrm{ph}(2,3)$,

\# slfi,sifo, stlcor (3), xload, xperc (2)

common/concrt/ca, cacon, cagw, cap, ccdns, ccon, ccpor, cfa, cfb, clcon,

\# co3, com28d, conpsn, constr, phbeg, si, stlmod, stlyld, wCr, wtcmnt,

\# yngmod

common/hydraul/cck, phgw, sitara, slkr, slk, tds, temp, water(12),

\# iyr1, iyr2

common/silo/cmthk $(2,3), \operatorname{comcvx}(2,3)$, comcvy $(2,3)$, cvrdns, cvrthk,

\# flangl, idflag, ommthk $(2,3)$, ostlrd(3), osttkc, osttkt, otncvx $(2,3)$, otncvy $(2,3)$, silrad, slangl, sldns, slhght, stlrad (3), stlspc (3), sttkcm, sttktn, submod, tencvx $(2,3)$, tencvy $(2,3)$, wstdns, wsthk, wstht

dimension $\operatorname{tlch} 1(2,3), \operatorname{tlch} 2(2,3)$

real*8 az1, az2, derf

data $t \operatorname{lch} 1, t \operatorname{lch} 2 / 6 * 0,, 6 * 0.1$

c...... Calculate retardation factor for $\mathrm{Ca}(\mathrm{OH}) 2$ leaching by diffusion.

if (iyear .eq. 1) then

$r f=1 .+$ ccdns $^{*}$ cacon $/ \operatorname{amin} 1(\operatorname{cas} 01, \mathrm{cap}) /$ ccpor

c..... Calculate Langelier or calcium carbonate saturation index and ionic c..... concentrations of $\mathrm{Ca}(\mathrm{OH}) 2, \mathrm{Mg2++}$, and $\mathrm{CO}^{-}$.

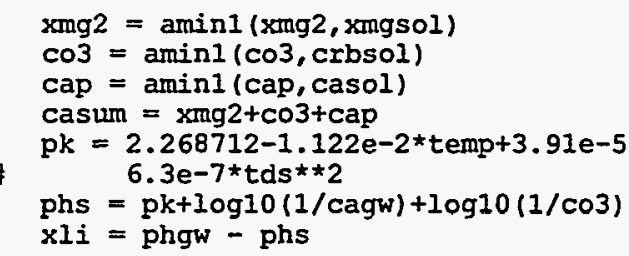

endif

c..... If initial $\mathrm{pH}$ is greater than 12.5, calculate rate of loss of NaOH c..... and $\mathrm{kOH}$ and consequent decline in $\mathrm{pH}$. Pore liquid and solid conc......centrations are assumed to be equal.

if(idflag.eq.1 .or. idflag.eg.3) then

do $3001=1,3$

if $(\mathrm{ph}(1,1) \cdot \mathrm{gt} \cdot 12.5)$ then

c..... Calculate fraction of alkalis remaining in concrete following c..... leaching by advection.

if (ommthk $(1,1)$.ne. 0. ) then 
$\operatorname{tlch} 1(1,1)=\operatorname{amin} 1(1, \operatorname{tlch} 1(1,1)+\operatorname{annprc} /$ 2.54 /omnthk $(1,1))$

else

$\operatorname{tich} 1(1,1)=0$.

endif

$x I \operatorname{ch} 1=1 .-t \operatorname{lch} 1(1,1)$

c......Calculate fraction of alkalis remaining in concrete following c.....leaching by diffusion.

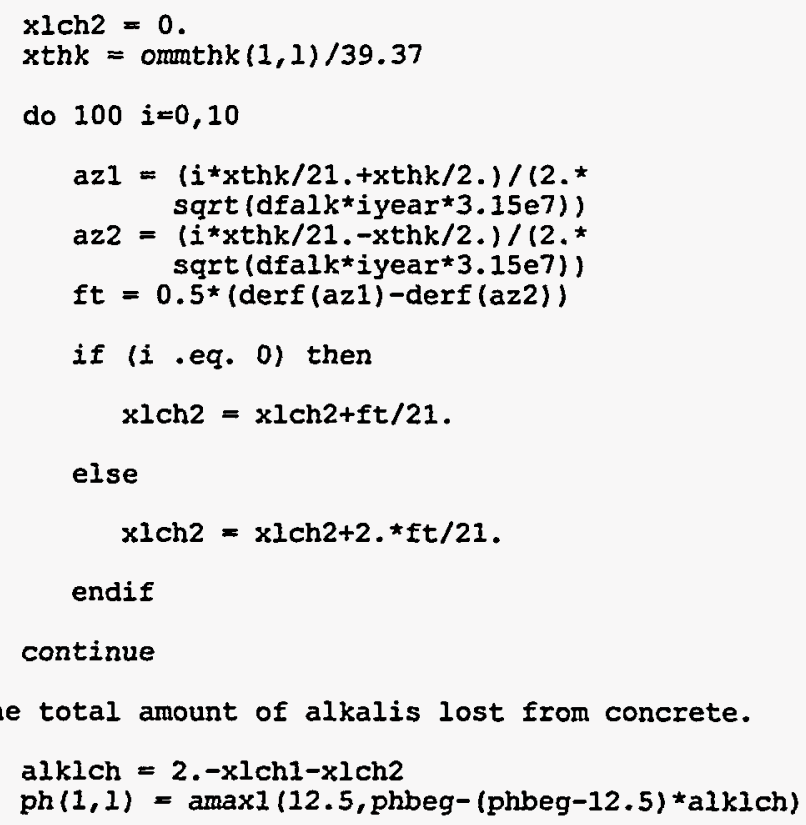

alklch $=2 .-x l c h 1-x l c h 2$

$\mathrm{ph}(1,1)=\operatorname{amax} 1(12.5, \mathrm{phbeg}-(\mathrm{phbeg}-12.5) \star \mathrm{a} 1 \mathrm{klch})$

c..... Determine total amount of alkalis lost from concrete.

else

c..... Calculate fraction of $\mathrm{Ca}(\mathrm{OH}) 2$ remaining in concrete following c..... leaching by advection. Groundwater leaching is assumed only if c....the langelier index is negative, indicating the water is capable c..... of dissolving $\mathrm{Ca}(\mathrm{OH}) 2$.

if (xIi .lt. 0.) then

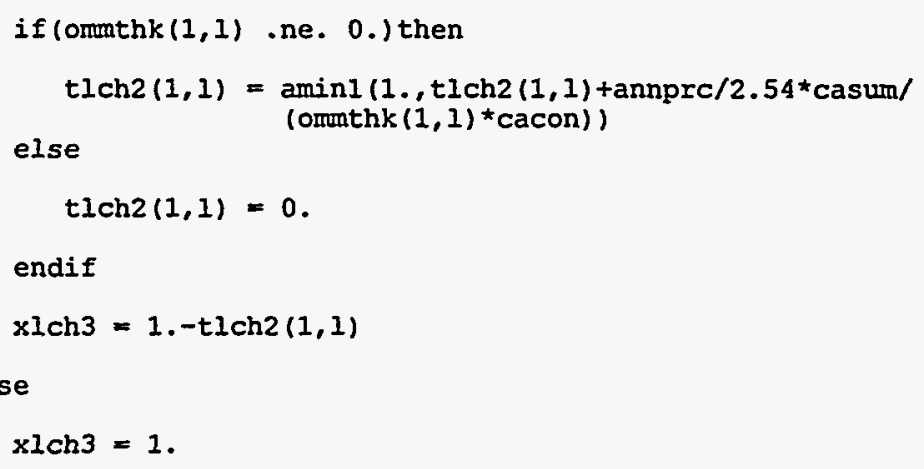


xthk $=\operatorname{omathk}(1,1) / 39.37$

do $200 i=0,10$

\#

\#

continue

c..... Determine total amount of $\mathrm{Ca}$ lost from concrete.

$\operatorname{calch}=2 .-x \operatorname{lch} 3-x \operatorname{lch} 4$

c.....Adjust $\mathrm{Ca}$ concentration and recalculate Ca:Si ratio

$$
\begin{aligned}
& c a=c a c o n *(1 .-c a l c h) \\
& c a \_s i=c a / s i
\end{aligned}
$$

c..... Calculate average $\mathrm{pH}$ for concrete as a function of Ca:Si following c.....the loss of $\mathrm{NaOH}$ and $\mathrm{KOH}$.

\#

$$
\operatorname{ph}(1,1)=\underset{\left.c a \_s i * * 2\right)}{\operatorname{amin} 1\left(12.5,8.83533+3.143848 * c a \_s i-0.6617 *\right.}
$$

c..... Calculate loss in strength for concrete members due leaching. If c..... concrete member thickness goes to zero, strength is set to zero.

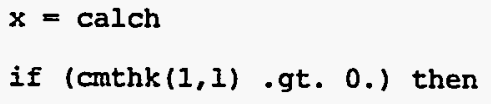

c..... Calculate fraction of alkalis remaining in concrete following c......leaching by advection.

$$
\operatorname{tlch} 1(2,1)=\operatorname{amin} 1(1,, \operatorname{tlch} 1(2,1)+\operatorname{annprc} / 2.54 / \operatorname{mmnthk}(2,1))
$$

c.....Calculate fraction of alkalis remaining in concrete following c.....leaching by diffusion. 


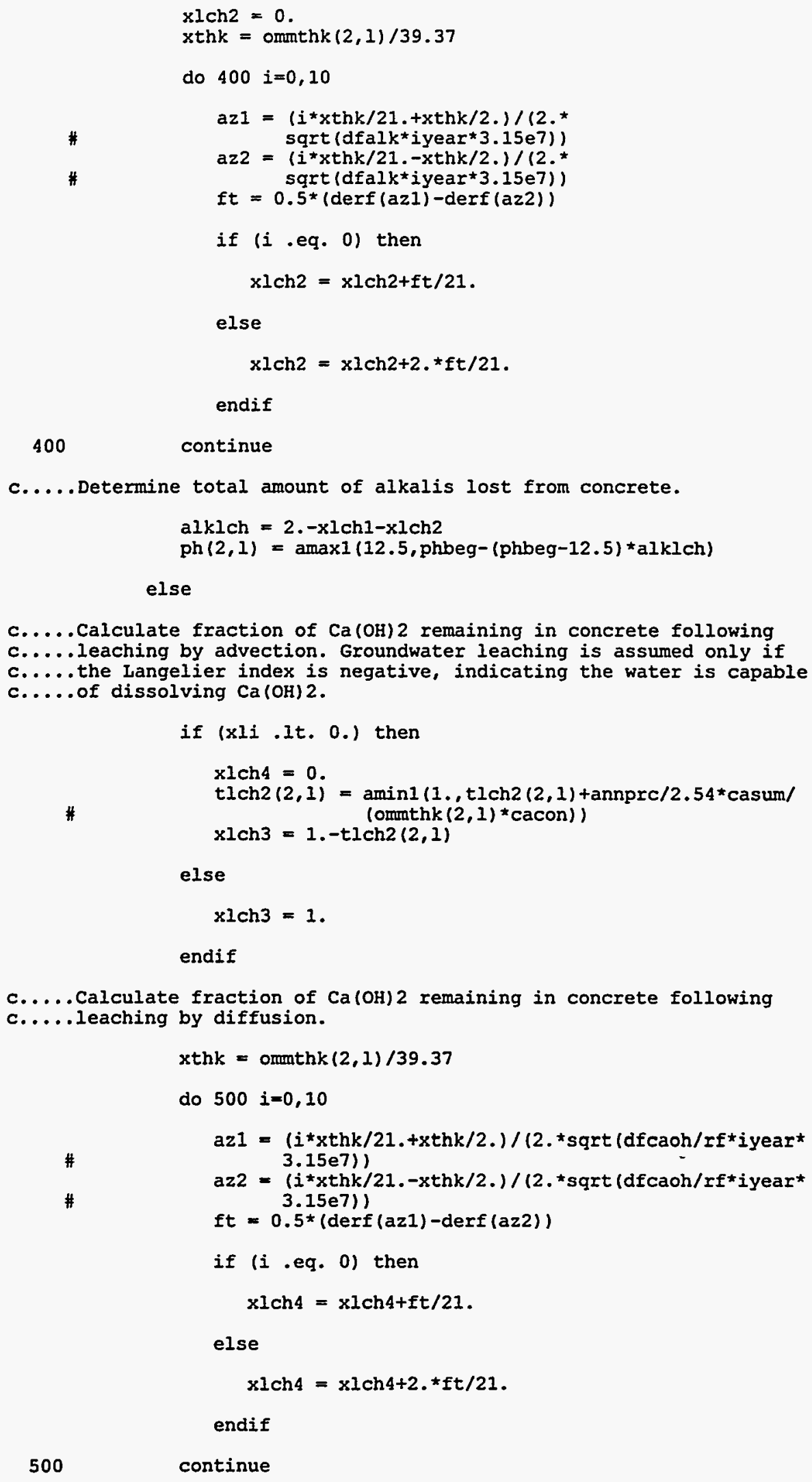


c..... Determine total amount of ca lost from concrete.

$$
\text { calch }=2 \cdot-x l c h 3-x i c h 4
$$

c.....Adjust $\mathrm{Ca}$ concentration and recalculate $\mathrm{Ca}: \mathrm{Si}$ ratio

$$
\begin{aligned}
& \mathrm{ca}=\mathrm{cacon} \star(1 .-\mathrm{cal} \mathrm{ch}) \\
& \mathrm{ca} \text { _si }=\mathrm{ca} / \mathrm{si}
\end{aligned}
$$

c..... Calculate average $\mathrm{pH}$ for concrete as a function of Ca:Si following c.....the loss of $\mathrm{NaOH}$ and $\mathrm{KOH}$.

$\#$

$$
\operatorname{ph}(2,1)=\underset{\text { ca_si }}{\operatorname{aminl}(12)}(1,8.83533+3.143848 * \mathrm{ca} \text { _si-0.6617* }
$$

c.....Calculate equivalent depth of $\mathrm{Ca}(\mathrm{OH}) 2$ loss and loss in strength for c....roof, floor, and internal and external walls.

$$
\begin{aligned}
& x=\text { calch } \\
& \text { if }(\text { cmthk }(2,1) \text {.gt. } 0 .) \text { then } \\
& \text { attk }(2,1)=\operatorname{amax} 1\left(0, .1 .-0.015^{\star} \times 10.01\right)
\end{aligned}
$$$$
\text { if }(\operatorname{attk}(2,1) \text {.eq. } 0.1 \text { cmthk }(2,1)=0 \text {. }
$$

else

$$
\operatorname{attk}(2,1)=0 .
$$

endif

endif

600 continue

endif

return

end

subroutine ccrack(i, iyear)

c Called by: source2
c Calculates cracking due to corrosion of reinforcing steel.
c
c Calls: none

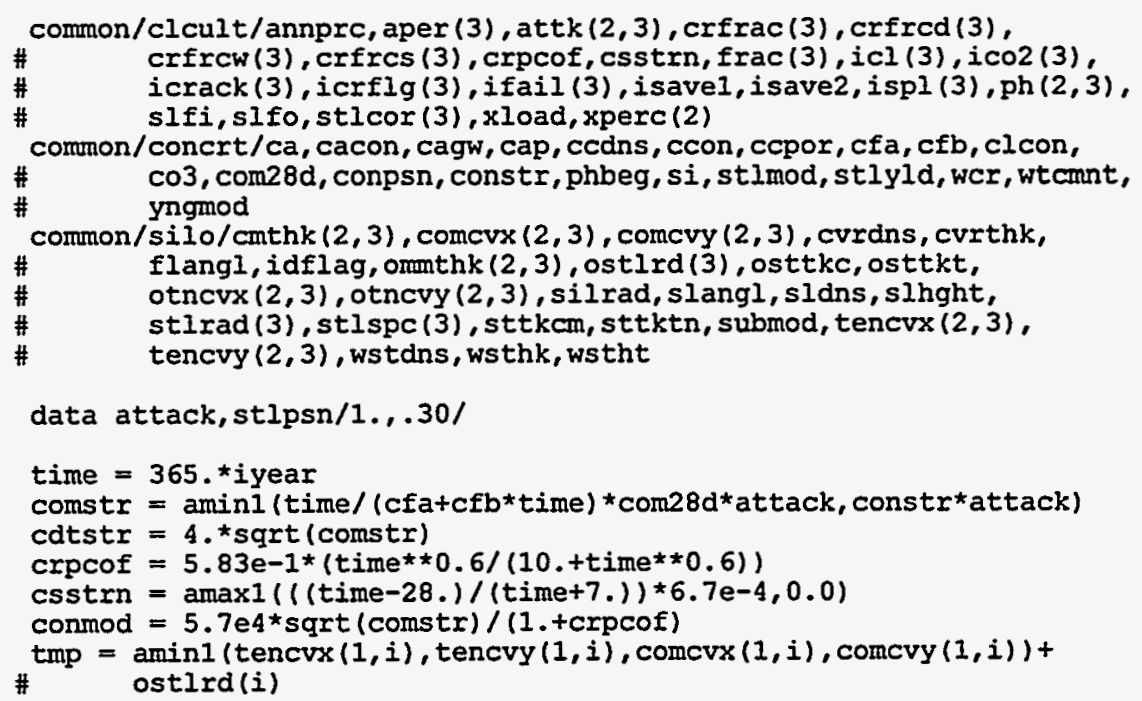


if (tmp .le. stlrad(i)+stlcor(i)) return

c.....Calculate internal pressure due to corrosion.

pstl $=(\operatorname{stl} \operatorname{rad}(i)+s t l \operatorname{cor}(i)-0$ th $l \mathrm{rd}(i)) /$ ostlrd $(i) \star 1.1$

\# $\quad(1 .-$ stlpsn $) /$ stlmod $+(1$. - conpsn $) *$ ostlrd $(i) * * 2+$

\# $(1 .+$ conpsn $) \star t m p * \star 2) /(\operatorname{conmod} \star($ tmp $* \star 2-0 s t 1 r d(i) \star \star 2)))$

c......Calculate maximum stress.

conrad $=s t l r a d(i)+s t l \operatorname{cor}(i)-p s t l * o s t l r d(i) *(1 .-s t l p s n) / s t l m o d$

ctstrs $=4 . *$ pst $1 *$ conrad $* \star 2 /($ tmp $* * 2-\operatorname{conrad} \star \star 2)$

ststrs $=$ psti $*($ tmp $* \star 2+$ conrad $* \star 2) /($ tmp $* \star 2-\operatorname{conrad} * \star 2)$

$x z$ ero $=\operatorname{amax} 1\left(0.5^{\star}\right.$ stlspc(i), sqgrt $(t m p \star \star 2-$ ostlrd $\left.(i) \star \star 2)\right)$

c..... Determine whether spalling has occurred. If it has, all of the

c..... concrete cover is assumed to be destroyed and all steel is exposed.

if (ctstrs.gt.cdtstr . and. ststrs.gt.cdtstr, and.

\# ctstrs.gt.ststrs) then

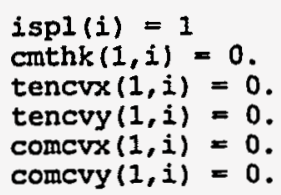

c......cracking extends through concrete cover to steel along steel members.

elseif (ctstrs.gt. cdtstr) then

$\operatorname{crfrcd}(i)=\operatorname{conthk}(1, i)-2 . \star \operatorname{stlrad}(i)$

$\operatorname{crfrcw}(i)=2{ }^{*} x z e r 0^{*}(\operatorname{cdtstr} /$ conmod+csstrn)

$\operatorname{crfrcs}(i)=\operatorname{stlspc}(i)$

ttllth $=0$.

do $100 i=1$, int(silrad/stlspc(i)) +1

ttllth $=$ ttllth+2.*sqrt $(\operatorname{silrad} * 2-((1-1)=\operatorname{stlspc(i))\star \star 2)}$

100

continue

$\operatorname{crfrac}(i)=\operatorname{crfrcw}(i) * \operatorname{crfrcd}(i) * t t 11 t h$

c..... Calculate potential for cracking through concrete cover versus

c.....internal cracking only (i.e., not through the entire concrete cover).

elseif (ststrs .gt. cdtstr) then

$\operatorname{rrr}=\operatorname{sgrt}((\operatorname{conrad} * \star 2 \star t m p * \star 2 * p s t 1) /(\operatorname{cdtstr} *(t \mathrm{mp} * \star 2-$ conrad $\star \star 2$ )-conrad $\star \star 2 \star$ pst 1 )

if (rrr-conrad .ge. $0.5^{\star}($ tmp-conrad $\left.)\right)$ then

$\operatorname{crfrcd}(i)=\operatorname{cmthk}(1, i)-2{ }^{\star} \operatorname{stl} \operatorname{rad}(i)$

$\operatorname{crfrcw}(i)=2 .{ }^{*} \times z$ ero* (cdtstr/conmod+csstrn)

$\operatorname{crfrcs}(i)=\operatorname{stlspc}(i)$

ttlith $=0$

do $200 i=1$, int (silrad/stlspc(i))+1

ttllth $=$ ttllth+2.*sqrt $(\operatorname{silrad} * 2-((i-1) * s t l s p c(i)) * \star 2)$

200

continue

$\operatorname{crfrac}(i)=\operatorname{crfrcw}(i) * \operatorname{crfrcd}(i) * t t l l t h$

endif

endif 
return

end

subroutine concrete(iyear)

Called by: source 2

Calculates degradation of concrete with time.

Calls: caoh, corrode, sulfate

c.....Calculate loss of concrete strength and changes in $\mathrm{pH}$ of concrete

c..... structure due to leaching of Ca(OH)2.

call caoh(iyear)

c.....Calculate loss of concrete due to sulfate attack.

call sulfate (iyear)

c......Calculate corrosion of steel reinforcement.

call corrode (iyear)

return

end

subroutine corrode (iyear)

called by concrete
c Calculates rate of corrosion of steel reinforcement in concrete, and
c rates of loss of corrugated steel in silo and iron wall in well.
c Calls: none

common/chemcl/cl, co2, 02, so4i, so40, xmg2, dfalk, dfcaoh, dfcl, dfco2, \# dfo2, dfso4, casol, crbsol, xmgsol

common/clcult/annprc, aper (3), attk $(2,3), \operatorname{crfrac}(3), \operatorname{crfrcd}(3)$,

\# crfrcw (3), crfics (3), crpcof, csstrn, frac (3), icl (3), ico2 (3),

\# icrack (3), icrflg (3), ifail (3), isavel, isave $2, i \operatorname{spl}(3), \mathrm{ph}(2,3)$,

\# $\quad$ slfi, slfo, stlcor (3), xload, xperc (2)

common/concrt/ca, cacon, cagw, cap, ccdns, ccon, ccpor, cfa, cfb, clcon,

\# co3, com28d, conpsn, constr, phbeg, si, stlmod, stlyld, wcr, wtcmnt,

\# yngmod

comon/failure/eft1, deft, wftl, dwft, xlft1, dlft

common/silo/cmthk $(2,3)$, comcvx $(2,3)$, comcvy $(2,3)$, cvrdns, cvrthk,

\# flangl, idflag, ommthk $(2,3)$, ostlrd (3), osttkc, osttkt,

\# otncvx $(2,3)$, otncvy $(2,3)$, silrad, slangl, sldns, slhght,

\# stlrad (3), stlspc (3), sttkcm, sttktn, submod, tencvx $(2,3)$,

\# tencry $(2,3)$, wstdns, wsthk, wstht

common/well/stldns, stlpsn, wlhght, wlrad, wlstr

dimension corvol (3)

real*8 az, derf

data crbcof, eff,pi/0.,0.,3.141592653589793/

c..... Calculate thickness of corrugated steel liner in silo and well wall.

if (idflag.eq.1 .or. idflag.eq.3) then

if (dlft.gt. 0) then

$\operatorname{aux}=$ float (iyear)

if (aux.gt.xlftl .and. aux.le.xlftl+dlft) then 
sttkcm $=\operatorname{amax} 1(0$, osttkc* $(1 .-($ iyear-xlftl $) / \mathrm{dlft}))$

sttktn $=\operatorname{amax} 1(0 ., \operatorname{osttkt*}(1 .-($ iyear-xlftl $) /$ dIft $))$

endif

endif

endif

if(idflag .gt. 1) then

if (dwft.gt. 0 ) then

aux $=$ float $($ iyear $)$

if (aux.gt.wft1 .and. aux.le.wft1+dwft) then

$\operatorname{amthk}(2,2)=\operatorname{amax} 1(0, \operatorname{ommthk}(2,2) *(1 .-($ iyear-wft 1$) / \mathrm{dwft}))$

endif

endif

endif

c..... Current configuration of containment wells does not require completion c..... of rest of corrosion analysis unless we are dealing with multiple

c..... containment wells. In that case, the steel reinforcement calculations

c.....are performed for the silo only.

if(idflag .ne. 2) then

c......Calculate failure function of epoxy coating on steel reinforcement. c..... If no failure has occurred, corrosion does not occur.

if (deft .gt. 0 ) then

aux $=$ float $($ iyear $)$

if(aux .gt. eft1) then

eff $=\operatorname{amin} 1(1 .,(\operatorname{aux}-$ eft 1$) / \operatorname{def} t)$

else

return

endif

else

eff $=1$

endif

c...... Determine depth of concrete carbonation based on Crank formulation.

if (crbcof .eq. 0.) then

dhydr $=0.4+0.5 *$ wer

ccon $=$ ccon*dhydr

$\mathrm{c} 1=\mathrm{co} 2+\mathrm{ccon}$

crbcof $=\operatorname{sqrt}((c 1 / \operatorname{ccon}-1.) \star 4 . \star d f c 02 * 3.15 e 7 / \operatorname{sqrt}(p i))$

endif

aux=iyear

dpcrb $=$ crbcof*sqrt $(a u x)$

c......Check carbonation depth and concrete cover thickness for structural c...... components.

do $100 i=1,3$ 
if (stirad(i) .gt. 0.) then

$\#$

$\operatorname{tmp}=(\operatorname{amin} 1(\operatorname{comcvx}(1, i), \operatorname{tencvx}(1, i), \operatorname{comcvy}(1, i)$, tencvy $(1, i))$ tostlrd(i))/39.37

if (dpcrb.ge.tmp .and. icrflg(i) .eq. 0 .and. eff.gt.0.) then

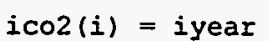

endif

c..... Calculate [OH-] in pore solution based on concrete $\mathrm{pH}$.

poh $=14 \cdot-$ ph $(1, i)$

oh $=1 . / 10 . \star *$ poh

c.....Calculate chloride ion concentration at steel reinforcement. If c.....ratio of chloride concentration to hydroxide ion concentration c.....exceeds 0.61 corrosion is initiated (Hausman).

$$
\text { if(icrflg(i) .eq. } 0 \text { ) then }
$$

\#

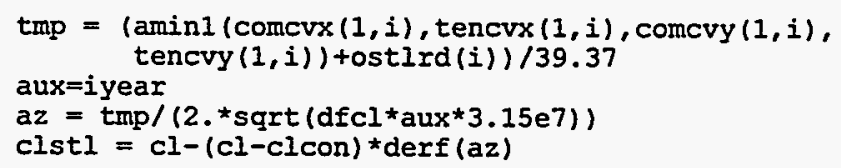

endif

c..... Upon de-passivation, the rate of corrosion is determined by the c..... rate of 02 diffusion to steel. If concrete cover is gone, corrosion c..... is assumed to proceed at a rate of $.025 \mathrm{~cm} / \mathrm{yr}$. Densities of steel c..... and corrosion product $(f e 0)$ are 7.86 and $5.70 \mathrm{~g} / \mathrm{cm}^{\star \star} 3$, respectively.

if (icrflg(i).eq.I and. $\operatorname{stl} \operatorname{rad}(i) . g t .0$.$) then$

$\#$

$\operatorname{tmp}=\operatorname{amin} 1(\operatorname{comcvx}(1, i), \operatorname{tencvx}(1, i), \operatorname{comcvy}(1, i)$, tencry $(1, i))$ tostlird (i)

if (tmp . Ie. ostlrd(i)) then

if (stlrad(i) .gt. .01) then

volfe $=3.142 *(.02 *$ stl $\operatorname{rad}(i)-.0001)$

$\operatorname{stlrad}(i)=\operatorname{stl} \operatorname{rad}(i)-0.01$

else

volfe $=3.142 \star s t l r a d(i) \star \star 2$

$\operatorname{stl} \operatorname{rad}(i)=0$.

endif

elseif (stlrad(i) .gt. 0.) then

c.....Calculate oxygen flux at the steel reinforcement.

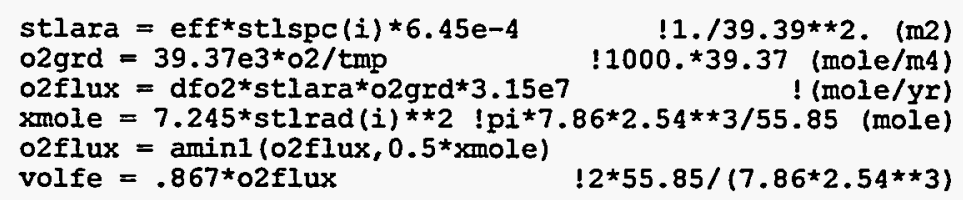


$\#$

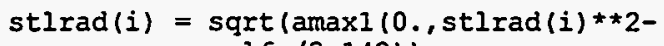

endif

$\operatorname{corvol}(i)=\operatorname{corvol}(i)+1.77 *$ volfe $!(7.86 / 5.7) *(71.85 / 55.85)$

$\#$ $\operatorname{stlcor}(i)=\operatorname{sqrt}($ stlrad $(i) \star \star 2+\operatorname{corvol}(i) / 3.142)-$ stlrad(i)

endif

endif

100 continue

endif

return

end

function $\operatorname{derf}(z)$

$\begin{array}{ll}c & \text { Called by: caoh } \\ c & \text { Function used in } \mathrm{KOH}, \mathrm{NaOH}, \text { and Ca }(\mathrm{OH}) 2 \text { diffusion calculations. Series } \\ \mathrm{c} & \text { expansion for erf }(z) \text { found in Abramowitz \& Stegun } \# 7.1 .5 . \\ \mathrm{c} & \text { Calls: derfc }\end{array}$

implicit real*8 $(a-h, 0-z)$

if(dabs (z).1t.2.) go to 10

$\operatorname{derf}=1 .-\operatorname{derfc}(z)$

go to 50

10 sum $=0$.

if (z.eq.0.) go to 40

$z 2=z$ * $z$

zpowr $=2$

fac $=1$.

$\mathrm{n} 2 \mathrm{p} 1=1$

term=z

do $20 i=1,30$

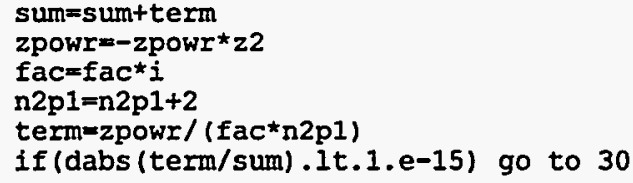

20 continue

30 sum $=$ sum+term

40 derf $=1.128379167095513 *$ sum

50 return

end

function $\operatorname{derfc}(z)$

Called by:. derf

Function used in $\mathrm{KOH}, \mathrm{NaOH}$, and $\mathrm{Ca}(\mathrm{OH}) 2$ diffusion calculations. based on continued fraction from Abramowitz \& Stegun \#7.1.14. 


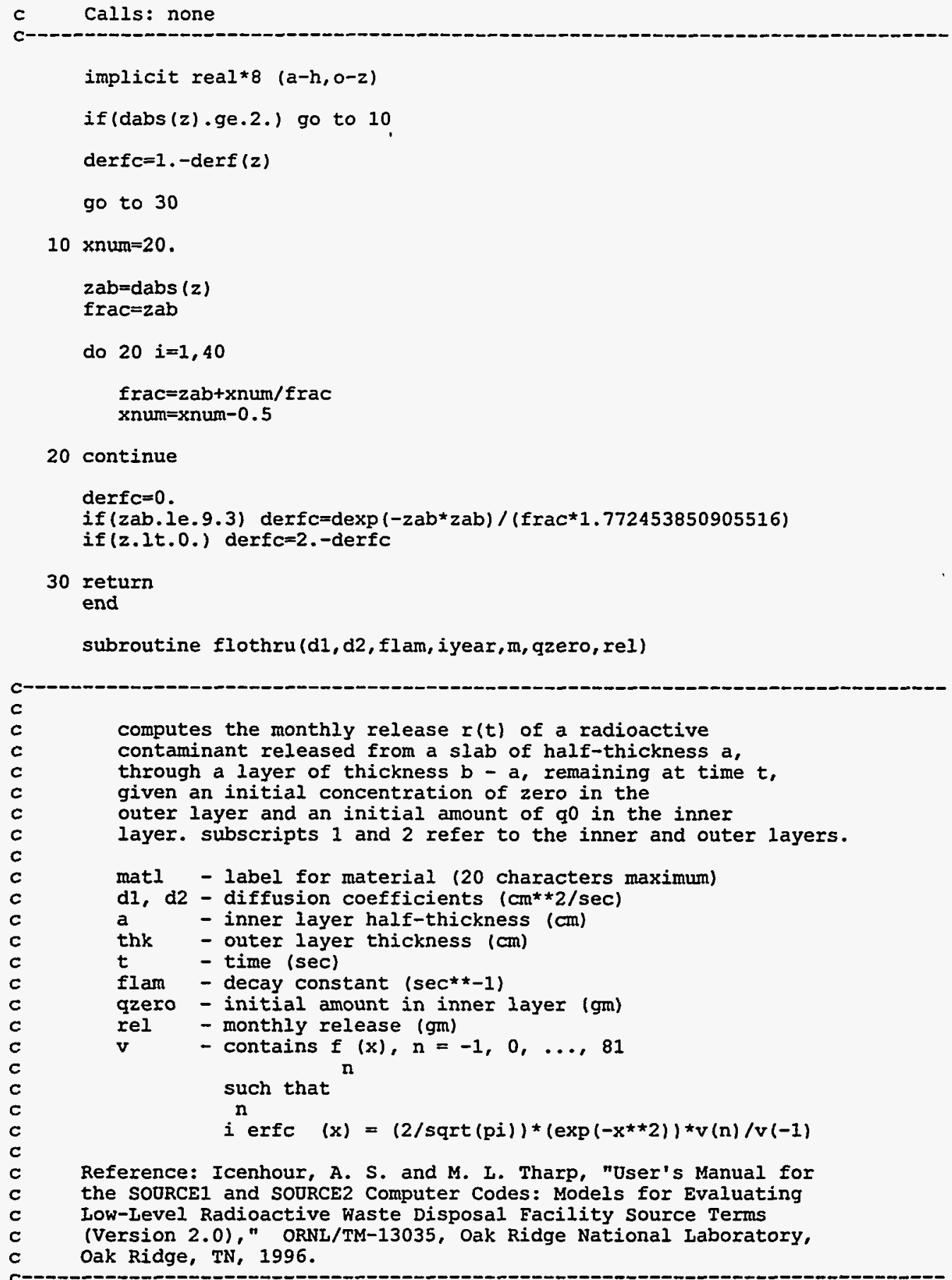

implicit double precision $(a-h, 0-z)$

parameter (maxnuc $=10$ )

parameter (r12=1.d0/12.d0)

common/miscel/acoef, bcoef, dpm (12)

dimension $v(-1: 81), f f(30), f \times 2(30)$, save(3), \# rel (maxnuc, 12), resave (maxnuc)

save resave 
real 4 acoef, bcoef, dpm, d1, d2, flam, qzero, rel

data tosrpi/1.128379167095513d0/

data pi/3.141592653589793d0/

data secpyr/3.15576d7/

data resave /maxnuc*0.do/

$a=$ acoef

thk $=$ bcoef

xkap $=\mathrm{d} 2 / \mathrm{d} 1$

xkap $=$ dsqrt (xkap)

$t k=$ xkap + xkap

alfa $=$ thk $/\left(\right.$ xkap*a $\left.^{*}\right)$

apk $=$ alfa $+x k a p$

$b=a+t h k$

boa $=b / a$

c..... Compute first 30 roots of transcendental equation.

$c 1=((a l f a * x k a p+3 . d 0) \star a l f a+(x k a p * 3 . d 0)) \star a l f a+1 . d 0$

$c 2=((a l f a+(x k a p \star 3 . d 0)) \star a l f a+3 . d 0) \star a l f a+x k a p$

gam $=\operatorname{dsqrt}(((a) f a \star \star 2+1 . d 0) \star x k a p+a l f a+a l f a) / x k a p)$

$\mathrm{x} 1=0.5 \mathrm{~d} 0 * \mathrm{pi} / \mathrm{gam}$

$x=x 1$

do $100 i=1,30$

$\mathrm{n}=\mathbf{0}$

50

continue

call fxcal (x, alfa, xkap, $f, f p$ )

$x 2=x-f / f p$

if (abs $((x 2-x) /(x 2)$.gt. 5.d-9) then

$\mathrm{n}=\mathrm{n}+\mathrm{I}$

$x=x 2$

if (n.1e. 20) go to 50

write $(*, '(1 x, a) ')$ 'not converged after 20 iterations'

endif

$f \times 2(i)=d 1 *(x / a) * \star 2$

$a x=a l f a \star x$

$c=\cos (x)$

$s=\sin (x)$

$c a=\cos (a x)$

$\operatorname{sa}=\sin (a x)$

ff(i) $=s /\left(\left(a p k^{\star} c a^{\star} s+b o a^{\star} s a^{\star} c\right)^{\star} x^{\star \star} 2\right)$

f3 $=c 1 c^{\star} s a+c 2 s^{*} c a$

gam $=-f 3 / f p$

if (gam.1t. $0 . d 0)$ then

write $(*, *)$ ' $f p$ and $f 3$ have same sign' return

endif

$x=x+p i / d s q r t(g a m)$

100 continue

c......set a few constants.

ropk $=1 . \mathrm{d} 0 /(1 . \mathrm{d} 0+\mathrm{xkap})$

$\mathrm{c3}=$ ropk + ropk

$f a c 1=(c 3+c 3) / a$

fxk $=($ xkap $-1 . d 0) *$ ropk

if (resave (m) . It. $0 . d 0$ ) resave $(m)=0 . d 0$

resold $=$ resave $(m)$ 


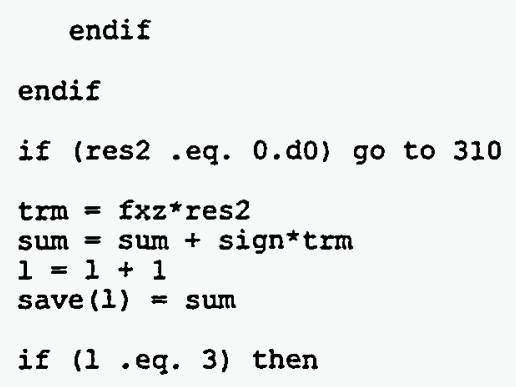

c.....Aitken Delta-Squared extrapolation: .

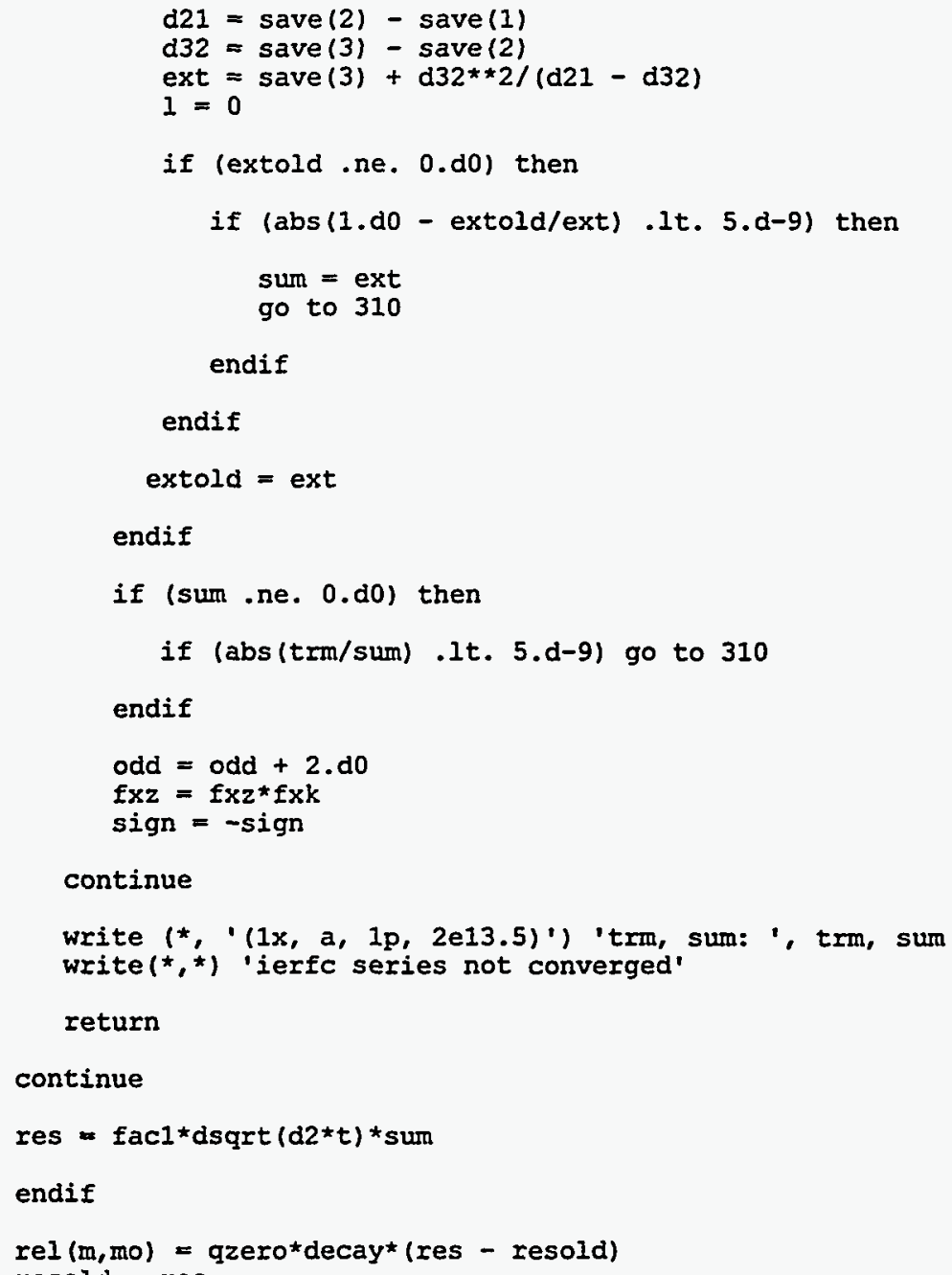




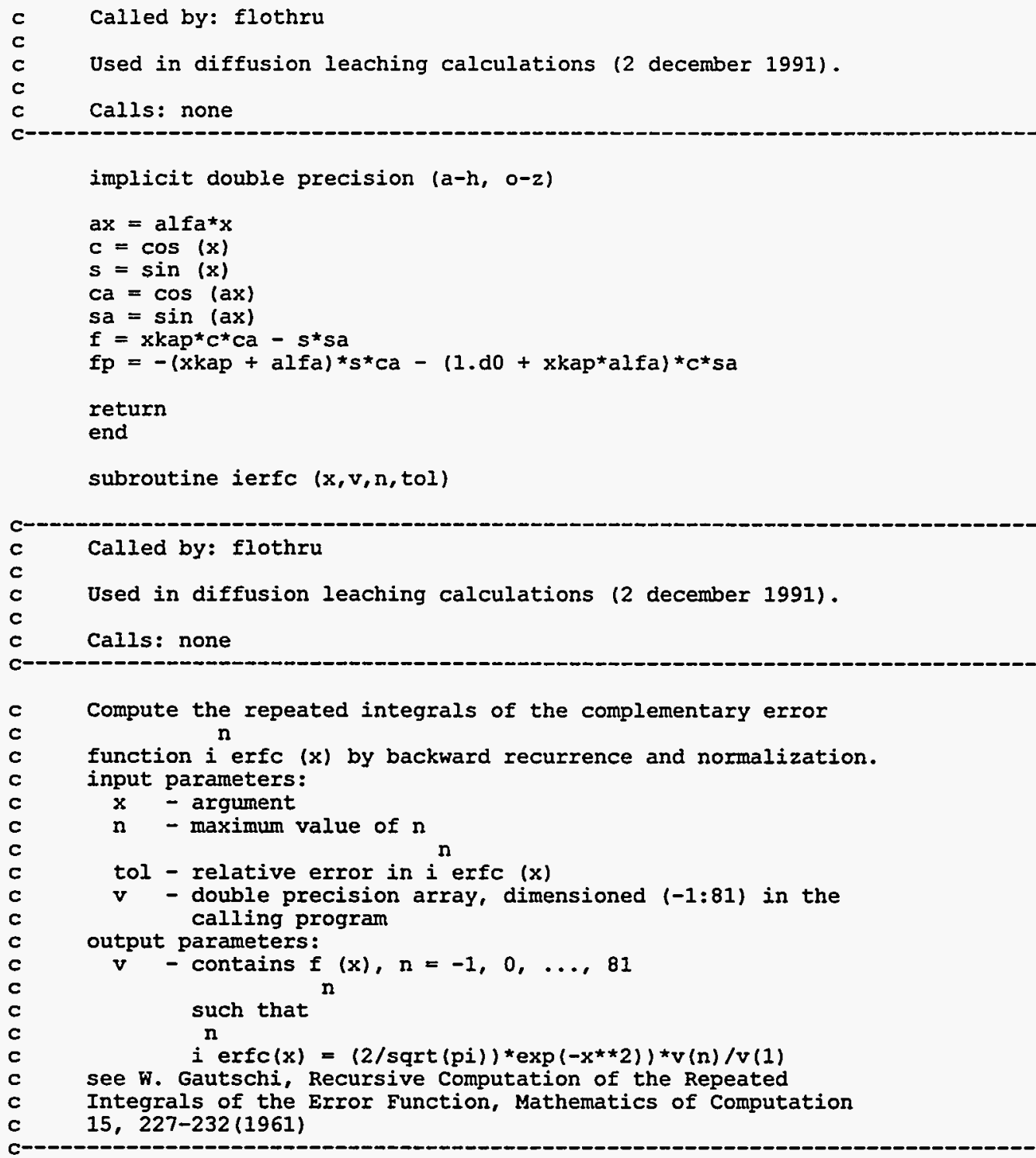

implicit double precision $(a-h, 0-2)$

common/numb/max

dimension $v(-1: 81), \operatorname{st}(21)$

$x s q=x \star \star 2$

$1=0$

do $200 \mathrm{~m}=21,81,5$

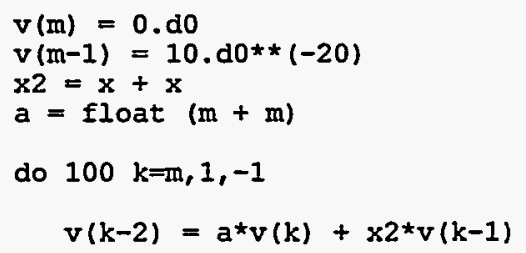

c..... Watch growth in backward recurrence. Scale down if needed. c.....this works for $n=1$ only. 
if $(v(k-2)$.gt. 1.d20) then

if $(k . g t .1)$ then

$\mathrm{v}(\mathrm{k}-1)=\mathrm{v}(\mathrm{k}-1) / \mathrm{v}(\mathrm{k}-2)$

$v(k-2)=1 . d 0$

endif

endif

$a=a-2 . d 0$

100

continue

$1=1+1$

$x t(1)=v(n) / v(-1)$

if (1 .gt. 1) then

if (abs (xt (1)/xt(1-1) - 1.d0) .1t. tol) go to 210

endif

200 continue

write (*, '(1x, a, i2, 1x, a, 1p, e11.3)')

$i_{m}=81$ not enough for $n=1, n, 1 x=1, x$

$=81$

write (*, ' $(1 x, 1 p, 4 e 15.7)$ ') $(x t(n), n=1,1)$

210 continue

$\operatorname{mmax}=\mathrm{m}$

return

end

subroutine input(iyear, nyears)

Called by source 2

Reads and checks input data, prints summary, and performs initial calculations.

Calls: none

parameter (maxnuc $=10, \operatorname{maxy} r=9999999$ )

common/chemcl/cl, co2, o2, so4i, so40, xmg2, dfalk, dfcaoh, dfcl, dfco2, $\#$ dfo2, dfso4, casol, crbsol, xmgsol

common/clcult/annprc, aper (3), attk $(2,3), \operatorname{crfrac}(3), \operatorname{crfrcd}(3)$,

\# $\quad \operatorname{crfrcw}(3), \operatorname{crfrcs}(3), \operatorname{crpcof}, \operatorname{csstrn}, \operatorname{frac}(3), i \operatorname{cl}(3), i \operatorname{co} 2(3)$, icrack (3), icrflg (3), ifail (3), isavel, isave 2 , ispl $(3), \mathrm{ph}(2,3)$, slfi, slfo, stlcor (3), xload, xperc(2)

common/concrt/ca, cacon, cagw, cap, ccdns, ccon, ccpor, cfa, cfb, clcon,

\# co3, com28d, conpsn, constr, phbeg, si, stlmod, stlyld, wer, wtcmnt,

\# yngmod

comon/dump/ndump, refyear

common/failure/eft1, deft, wft 1 , dwft, xlft1, dlft

common/files/iprint, fname, iprn1, ifrq1, iprn2, ifrq2, iprn3, ifrq3

\# iprn4, ifrq4, iprn5, ifrq5, filenam (7)

common/hydraul/cck, phgw, sitara, slkr, slk, tds, temp, water (12),

\# iyr1, iyr2

comon/miscel/acoef, bcoef, dpm(12)

comon/nuclide/noncld, nuclid (maxnuc), am (maxnuc),

\# dfcon (maxnuc), dfwst (maxnuc),

hlife (maxnuc), xllch (maxnuc), qsw (maxnuc),

rlch (maxnuc), sol (maxnuc),

xkd (maxnuc), xleach (maxnuc)

common/runid/title 


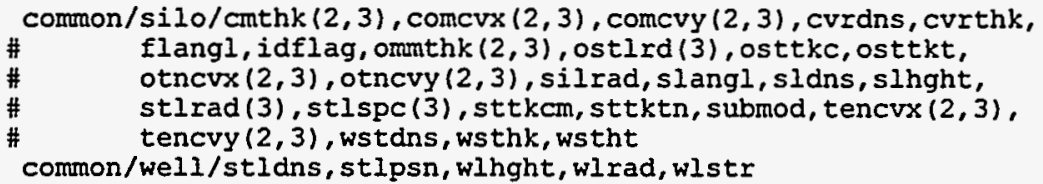

dimension gswsav (maxnuc), qswlast (maxnuc), ext (7)

integer refyear,bgndump, enddump character fname $* 16$, filenam $* 20$, ext $\star 4$ character $\star 8$ nuclid character $\star 80$ title character $* 60$ wat_inp $* 60$

data ext/'.inp','.con', '.1ch','.rch', '.lat', '.sum', '.h20'/ data iyr $2 / 0 /$, ndump $/ 1 /$, refyear $/ 1 /$,

$\#$ bgndump $/ 0 /$, enddump $/ 0 /$

if (iyear .eq. 0 ) then

c..... Input filename of input file for the simulation.

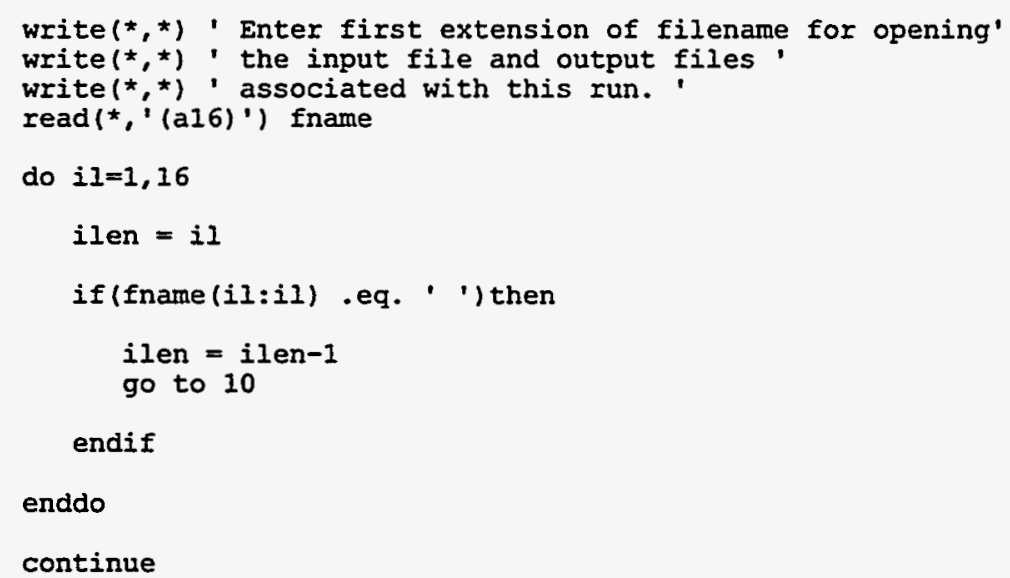

10 continue

c..... Create filenames for all input and output files.

do ifile $=1,7$

filenam(ifile) $=$ fname $(1:$ ilen $) / / \operatorname{ext}($ ifile $)$

enddo

c..... Open input file with name "fnamen.inp.

c..... Open input data set.

open (unit $=1$, file $=$

\# filenam(1), status='old')

c.... Read input data set; read title of simulation and simulation options.

$\operatorname{read}\left(1, \cdot(a 80)^{\prime}\right)$ title

read $(1, \cdot(i 10, i 5, i 2,5(i 2, i 5))$ ') nyears, idflag, iprint,

\# iprn1,ifrq1,iprn2,ifrq2,

$\# \quad$ iprn3, ifrq3, iprn4, ifrq4, iprn5, ifrq5

c.....set default for output files to print every year.

if (iprn1 .eq. 0 .and. ifrq1 .eq. 0 ) ifrq1 $=1$
if (iprn2 .eq. 0 .and. ifrq2 .eq. 0 ) ifrq2 $=1$
if (iprn3 .eq. 0 .and. ifrq3 .eq. 0 ) ifrq3 $=1$
if (iprn4 .eq. 0 .and. ifrq4 .eq. 0 ) ifrq4 $=1$
if(iprn5 .eq. 0 .and. ifrq5 .eq. 0 ) ifrq5 $=1$ 
c.....silo dimensions and design specifications.

if(idflag.eq.1 .or. idflag.eq.3) then

read(1,' (2e10.3)') slhght, silrad

read $(1, '(3 e 10.3)$ ') ( $\operatorname{cmthk}(1, i), i=1,3)$

$\operatorname{read}(1, \cdot(6 \mathrm{e} 10,3) \cdot)(\operatorname{tencrx}(1, i), \operatorname{tencvy}(1, i), i=1,3)$

read $(1, '(2 e 10.3)$ ') sttkcm, sttktn

read $(1, '(6 \mathrm{e} 10,3)$ ') (stlrad(i), stlspc(i), $i=1,3)$

endif

c..... Fell dimensions and design specifications.

if(idflag .gt. 1) then

read (1,'(2e10.3)') wihght, wlrad

read $(1, '(3 e 10.3)$ ') (cmthk $(2, i), i=1,3)$

read $(1, '(6 e 10.3)$ ') (tencrx $(2, i), \operatorname{tencvy}(2, i), i=1,3)$

read $(1$, '(3e10.3)') wlstr, stlpsn, stldns

endif

$\operatorname{read}(1$, ' $(4 \mathrm{e} 10.3)$ ') submod, flangl, sldins, slangl

read (1, '(4e10.3)') cvrthk, cvrdns, wstdns, wstht

c......Concrete and steel specifications.

$\operatorname{read}(1, \cdot(7 e 10.3)$ ') ccdns, ccpor, conpsn, com28d, wcr, phbeg, wtcmnt

read $(1$, ' $(4 \mathrm{e} 10.3)$ ') clcon, ccon, cfa, cfb

read $(1$, ' (3e10.3),' stimod, stiyld, yngmod

read $(1, '(3 e 10.3)$ ') cacon, cap, si

c......Chemical exposure conditions, diffusion coefficients, groundwater c.....properties, and solubilities.

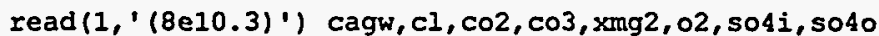

read (1,' (6e10.3)') dfalk, dfcaoh, dfcl, dfco2, dfo2, dfso4

read $(1, \cdot(3 \mathrm{e} 10.3)$ ') phgw, tds, temp

read (1, '(3e10.3)') casol, crbsol, xmgsol

c......Metal failure function data.

if(idflag.eg. 1 .or. idflag.eq.3) then

$\operatorname{read}(1, '(4 \mathrm{e} 10.3)$ ') eft1, deft,xlft1, dlft

endif

if(idflag .gt. 1) then

$\operatorname{read}\left(1, \cdot(2 e 10.3)^{\prime}\right)$ wft 1, dwft

endif

c.....Hydraulic parameters.

$\operatorname{read}(1, \cdot(4 \mathrm{e} 10.3)$ ') sitara,slkr,slk, cck

c..... Input name of file containing water seepage data.

$\operatorname{read}\left(1,{ }^{\prime}(a) '\right)$ wat $i n p$

open (unit $=4$, file $=$ wat_inp, status $=$ 'old')

c..... Radionuclide-specific data.

$\operatorname{read}(1, \cdot(i 5)$ ') noncld

if (noncld .gt. maxnuc) then

write

$\#$ write $(*, 1$ ("The value of the variable noncld is greater' ')') 
write(*, '(" than the value specified for maxnuc on the' ')') write

$(*$, (' ' parameter statements. Increase the value of' ')') write(*,' ("' maxnuc. ' ")')

stop

endif

do $100 i=1$, noncld

$\operatorname{read}(1, '(a 8,7 e 10.3) ') \operatorname{nuclid}(i), \operatorname{am}(i), \operatorname{hlife}(i)$, sol(i),

$\#$ $x k d(i), q s w(i), \operatorname{dfwst}(i), \operatorname{dfcon}(i)$

if (qsw (i) .le. 0. ) ndump $=0$

100

continue

if (ndump .ne. 1) then

$\operatorname{read}(1$, '(i10)') refyear

read $(1, '(2$ i10, $10 \mathrm{e} 10.3)$ ')

\# bgndump, enddump, (qSw(i), $i=1$, noncld)

ndump $=$ bgndump

do $i=1$, noncld

qswlast $(i)=q s w(i)$

enddo

endif

c..... Calculate or initialize various parameters for silo or well. The c..... characteristic dimensions used in diffusion leaching calculations c..... are based, initially, on the assumption that the releases occur c.....through the roof and floor of the silo or well.

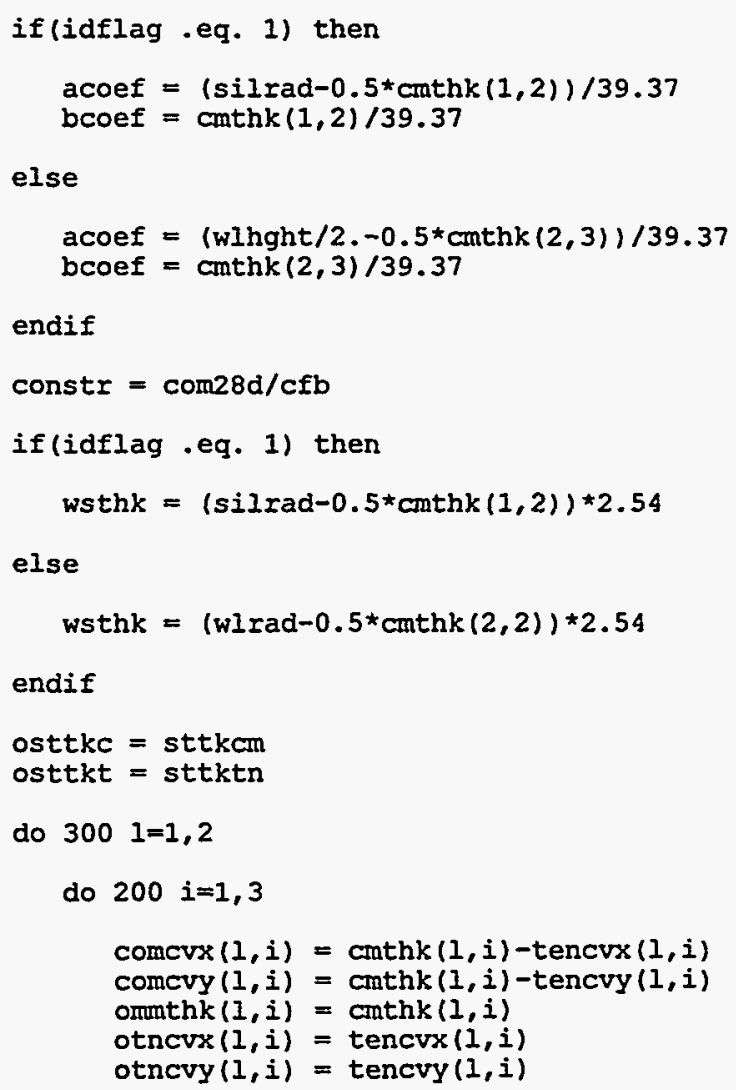




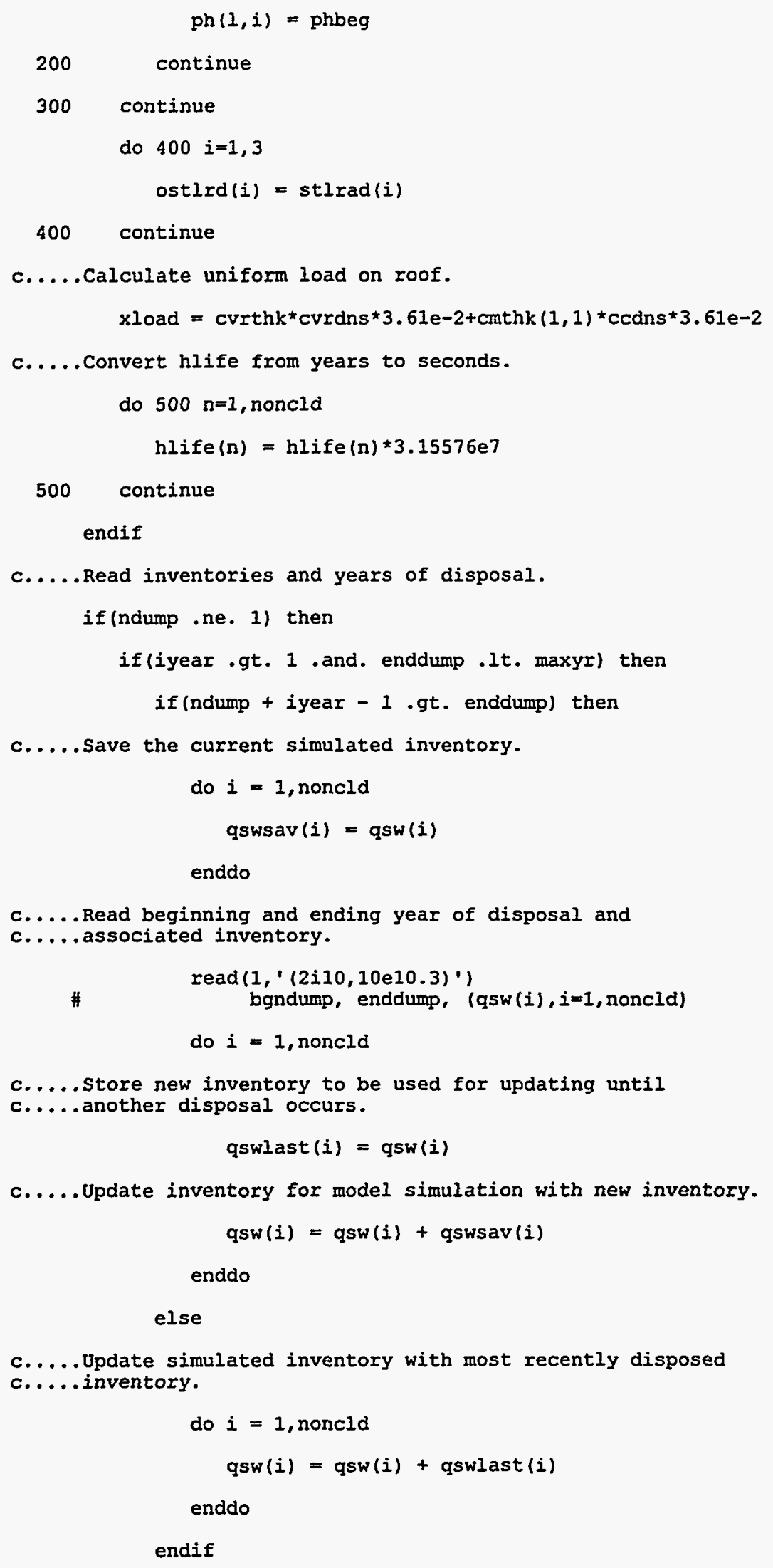


endif

endif

c..... Update water seepage values.

if (iyear .gt. iyr2) then

$\operatorname{read}\left(4, '(2 i 10,12 f 5.2)^{\prime}\right)$ iyr1, iyr2, (water(i), $\left.i=1,12\right)$

c......Calculate annual percolation rate through intact concrete.

annprc $=0$.

do $m o=1,12$

annprc $=\operatorname{annprctaminI}\left(c k^{\star} 8.64 \mathrm{e} 4 \star \operatorname{dpm}(\mathrm{mo})\right.$, water $\left.(\mathrm{mo})\right)$

endio

endif

return

end

subroutine leach (iyear, nyears)

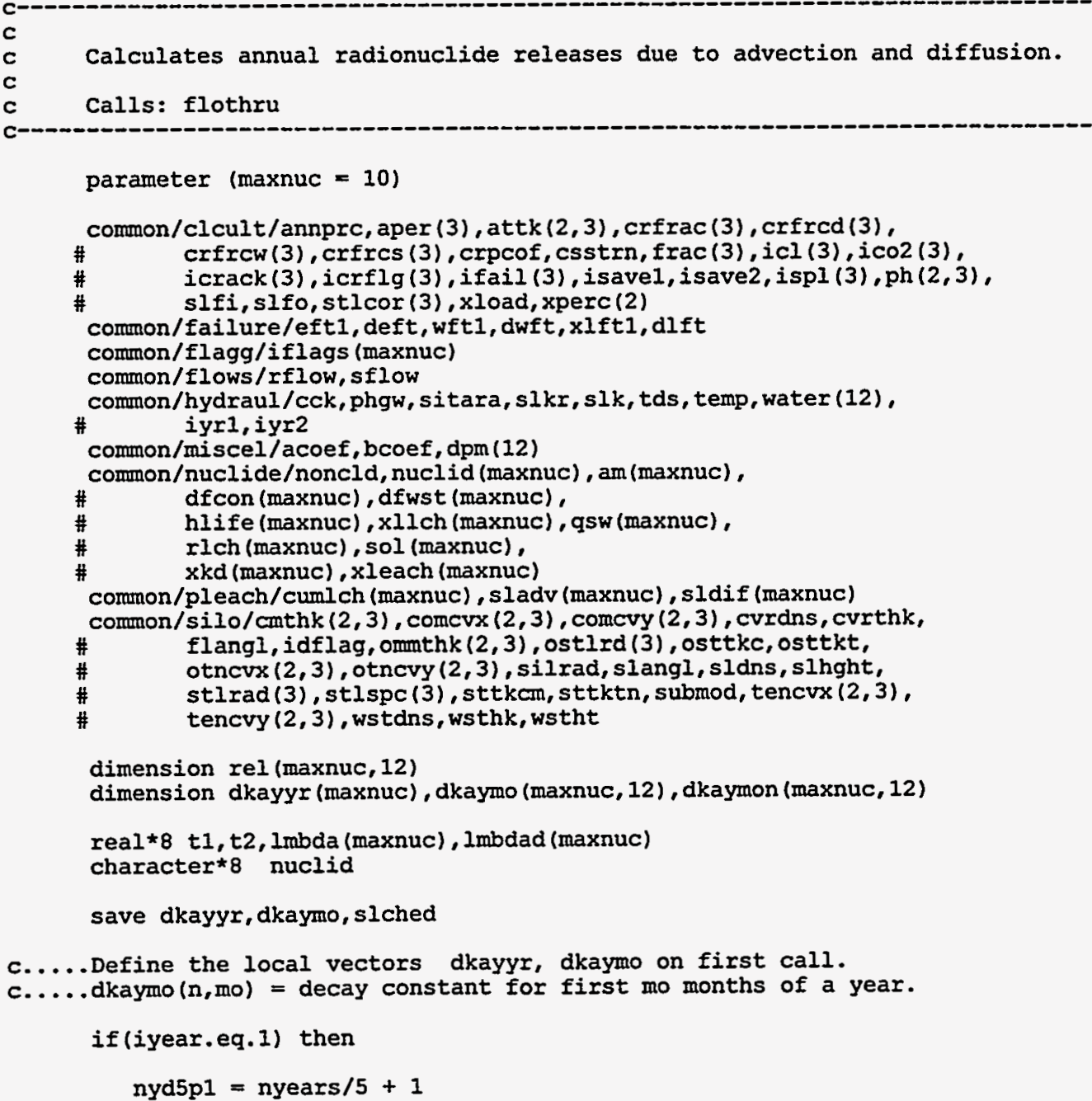




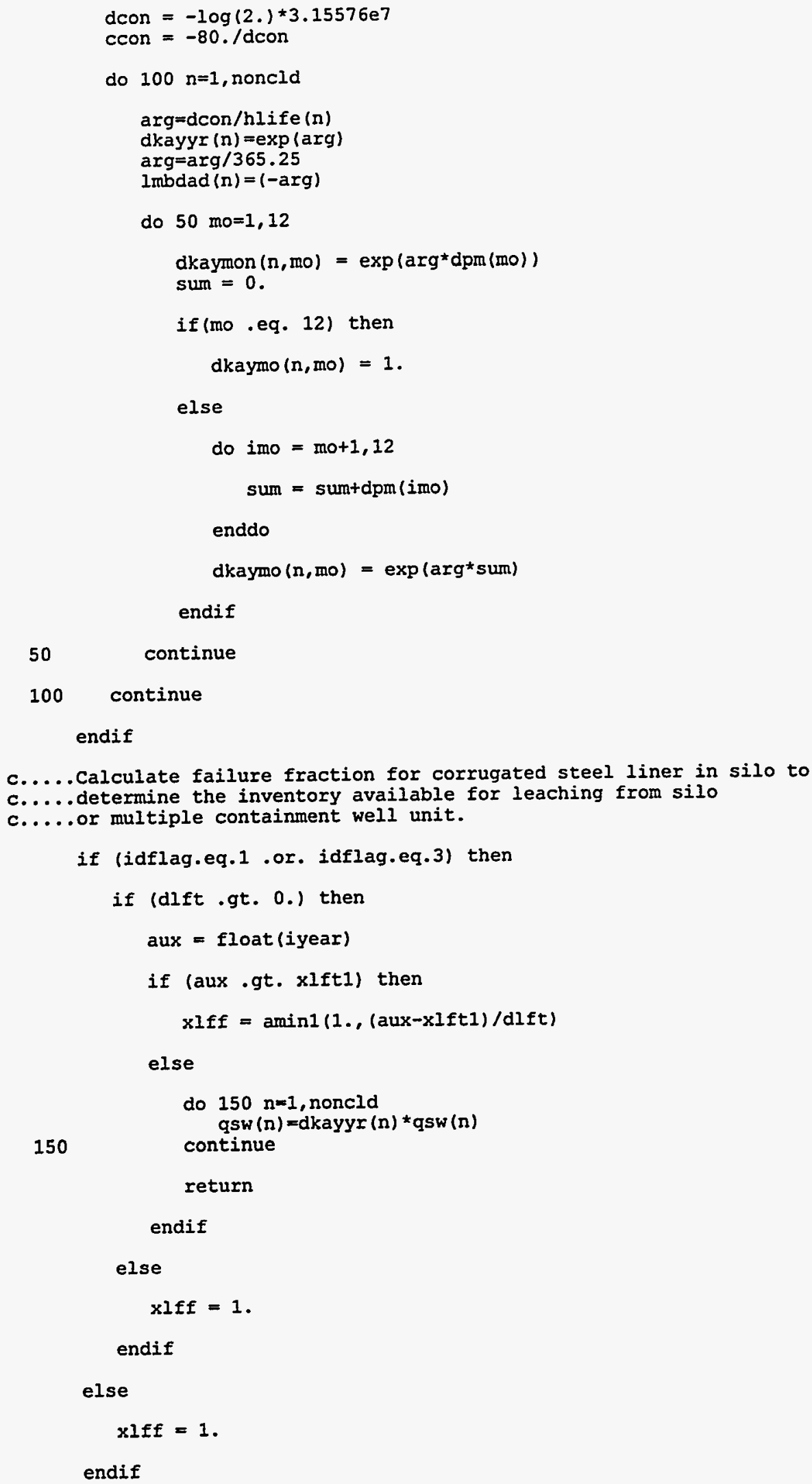


do $200 \mathrm{n}=1$, noncld

$\operatorname{sladv}(\Omega)=0$. $\operatorname{sldif}(n)=0$.

200 continue

c..... Determine which xperc() to use.

$i d x=2$

if (idflag.eq.3) then

if (isavel.eq. 0 .or. isave2.eq. 0 ) $i d x=1$

else

if (isave1.eq. 0 .and. isave2.eq. 0 ) idx=1

endif

Iflow $=0$.

sflow $=0$.

do $\mathfrak{n}=1$, noncld

c...... Set very small inventory values to zero to prevent numerical c.....problems in the leaching calculations.

if(qsw(n) .1t. 1.e-25) qsw(n) $=0$.

endido

do mo $=1,12$

do $1=1$, noncld

$\operatorname{rel}(1, \mathrm{mo})=0$.

enddo

endio

c..... Begin monthly loop

$t 1=1$.

do 500 mo=1, 12

$t 2=t 1+\operatorname{dpm}(\mathrm{mo})-1$.

ttlwat $=$ water $(\mathrm{mo}) / 100 .{ }^{*}$ sitara

$\operatorname{xperc}(1)=\operatorname{aminl}\left(c c k \star 8.64 \mathrm{e}^{\star} \star \operatorname{dpm}(\mathrm{mo})\right.$, water $\left.(\mathrm{mo})\right)$

$\operatorname{xperc}(2)=\operatorname{aminl}(s l k * 8.64 \mathrm{e} 4 * \mathrm{dpm}(\mathrm{mo})$, water $(\mathrm{mo}))$

c.....Partition flow into a vertical and lateral component

$\operatorname{tmp}=\operatorname{amin} 1(1 ., s 1 \mathrm{kr} * 8.64 \mathrm{e} 4 * \mathrm{dpm}(\mathrm{mo}) /$ water $(\mathrm{mo}))$

rflow $=$ rflow+tmp*water $(\mathrm{mo})$

sflow $=$ sflow $(1 .-$ tmp $) *$ water $(m o)$

c.....Begin nuclide loop

do $3001=1$, noncld

c..... Calculate monthly leach rates due to advection.

c..... Advective releases are based on percolation rates for intact and c.....cracked/failed disposal units. In the case of multiple containment c.....wells, it is assumed that the higher percolation rate applies only c..... when both the silo and well have failed.

c..... Calculate leach rate constant.

Imbda $(1)=x$ perc $(i d x) /\left(\right.$ wsthk* $\left(\right.$ wstht + wstdns $\left.\left.{ }^{\star} x k d(1)\right)\right)$

$1 \mathrm{mbda}(I)=1 \mathrm{mbda}(1) / \mathrm{dpm}$ (mo) 
c.....Calculate monthly release (integrated) due to advection.

xieach $(1)=((1 \operatorname{mbda}(1) \star q s w(1)) /(1 \operatorname{mbda}(1)+1 \operatorname{mbdad}(1))) *$

\# $\quad(\operatorname{dexp}(-t 1 *(1 \operatorname{mbda}(1)+1 \operatorname{mbdad}(1)))-$

c..... Calculate monthly leach rates due to diffusion for entire year c.....using the flothru computer code and initialize leach fractions c.....for recharge and lateral flow components.

if (mo .eq. 1) then

if (qsw(l) .ne. 0. )

call flothru(dfwst(1), dfcon(1), hlife(1)

iyear, 1, gsw $(1)$, rel)

$\operatorname{rlch}(1)=0$.

$\operatorname{xllch}(1)=0$.

endif

c..... Sum diffusive and advective releases and correct for portion of c......corrugated steel liner still present.

$x l e a c h(1)=(x l e a c h(I)+\operatorname{rel}(1$, mo $)) * x l f f$

$\operatorname{rel}(1, \mathrm{mo})=\operatorname{rel}(1, \mathrm{mo}) \star x l f f$

300

continue

c..... Check calculated releases against solubility limits using the total c..... amount of water passing through the disposal unit.

call maxlch (xperc(idx)/100. * sitara)

do $4001=1$, noncld

gsw $(1)=\operatorname{amax} 1(0$, dkaymon $(1$, mo $) \star q s w(1)-x l$ each $(1))$

c.....Partition release into lateral flow and recharge components assuning c.....same contaminant concentration in each component. Decay partitioned c......releases to end of current year.

$\operatorname{rlch}(1)=\operatorname{rlch}(1)+x l e a c h(1) *$ tmp*dkaymo $(1$, mo $)$

if (tmp .1t. 1.) xllch(1) $=x 11 \mathrm{ch}(1)+x \operatorname{leach}(1)$

\#

(1. -tmp) *dkaymo $(1$, mo)

c..... Sum leaching due to advection and diffusion.

$\operatorname{sladv}(1)=\operatorname{sladv}(1)+\mathrm{dkaymo}(1, \mathrm{mo}) *(x \operatorname{leach}(1)-\operatorname{rel}(1, \mathrm{mo}))$

sldif $(1)=\operatorname{sldif}(1)+$ dkaymo $(1, \mathrm{mo}) * \operatorname{rel}(1, \mathrm{mo})$

400

continue

$t 1=t 2+1$.

500 continue

c..... Determine total annual release for output to sumary file.

do $6001=1$, noncld

$\operatorname{xleach}(1)=\operatorname{rlch}(1)+x \operatorname{llch}(1)$

c...... Determine cumulative amount leached.

if (iyear.eq. 1 ) then

$\operatorname{cumlch}(1)=x l e a c h(1)$

else

$\operatorname{cumlch}(1)=\operatorname{cumlch}(1)+x l e a c h(1)$

endif 
600 continue

c.... Reset negative diffusion values.

do $n=1$, noncld

if (sldif(n) .lt. 0$) \operatorname{sldif}(n)=-\operatorname{sldif}(n)$

enddo

return

end

subroutine maxlch(ttlwat)

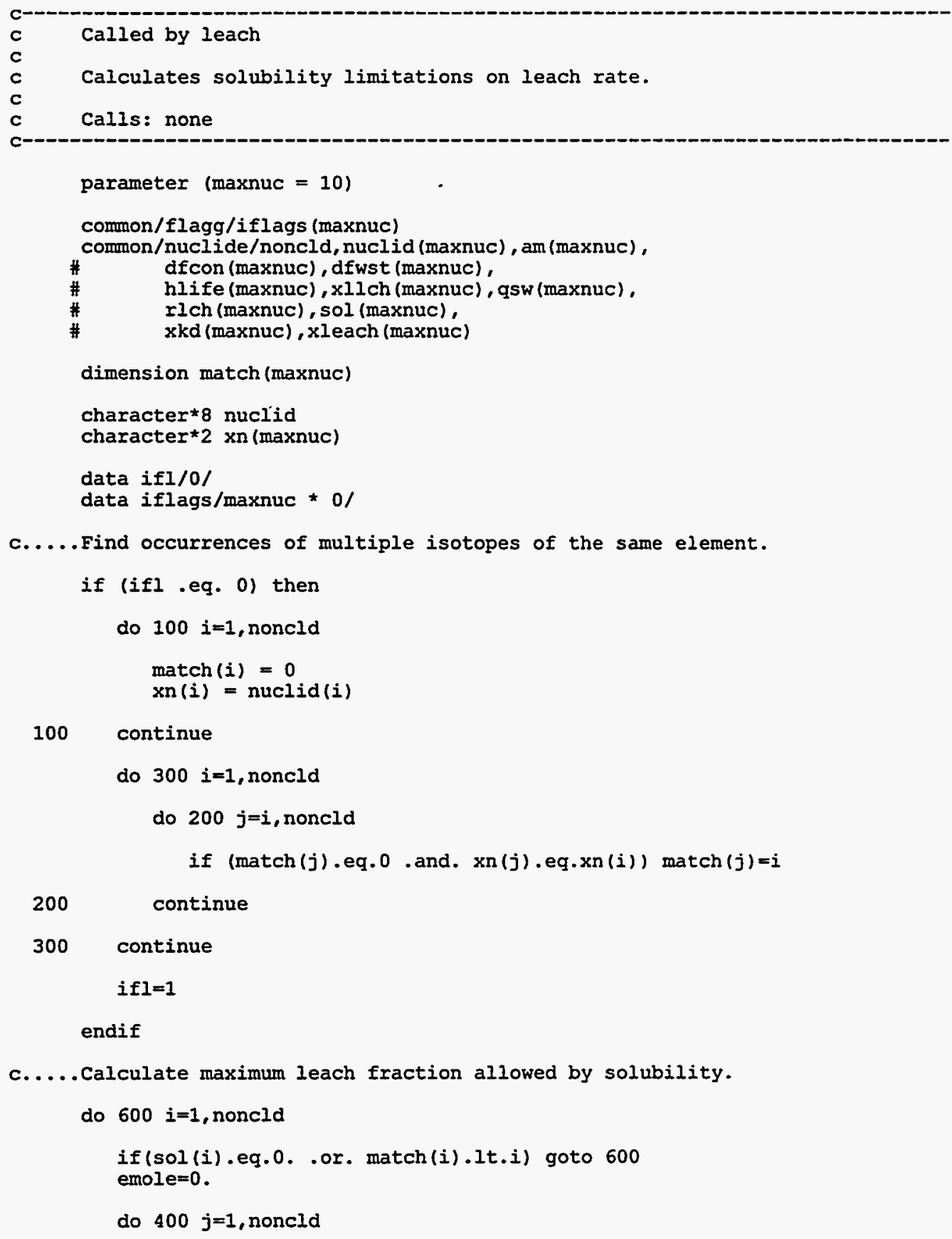


if $($ match $(j)$.eq. i) emole=emoletqsw $(j) / a m(j)$

continue

if (emole .eq. 0.) goto 600

xImax $=1000 * \operatorname{sol}_{(i) * t t \text { lwat } / \text { emole }}$

do $500 j=1$, noncld

if (match $(j) . e q . i)$ then

if $(x \operatorname{leach}(j)$.gt. (qsw $(j) \star x \operatorname{lmax}))$

iflags $(j)=$ iflags $(j)+1$

$\#$

$x l e a c h(j)=\operatorname{aminl}(g s w(j) \star x l m a x, x l e a c h(j))$

endif

500

continue

600 continue

return

end

subroutine output (iyear, nyears)

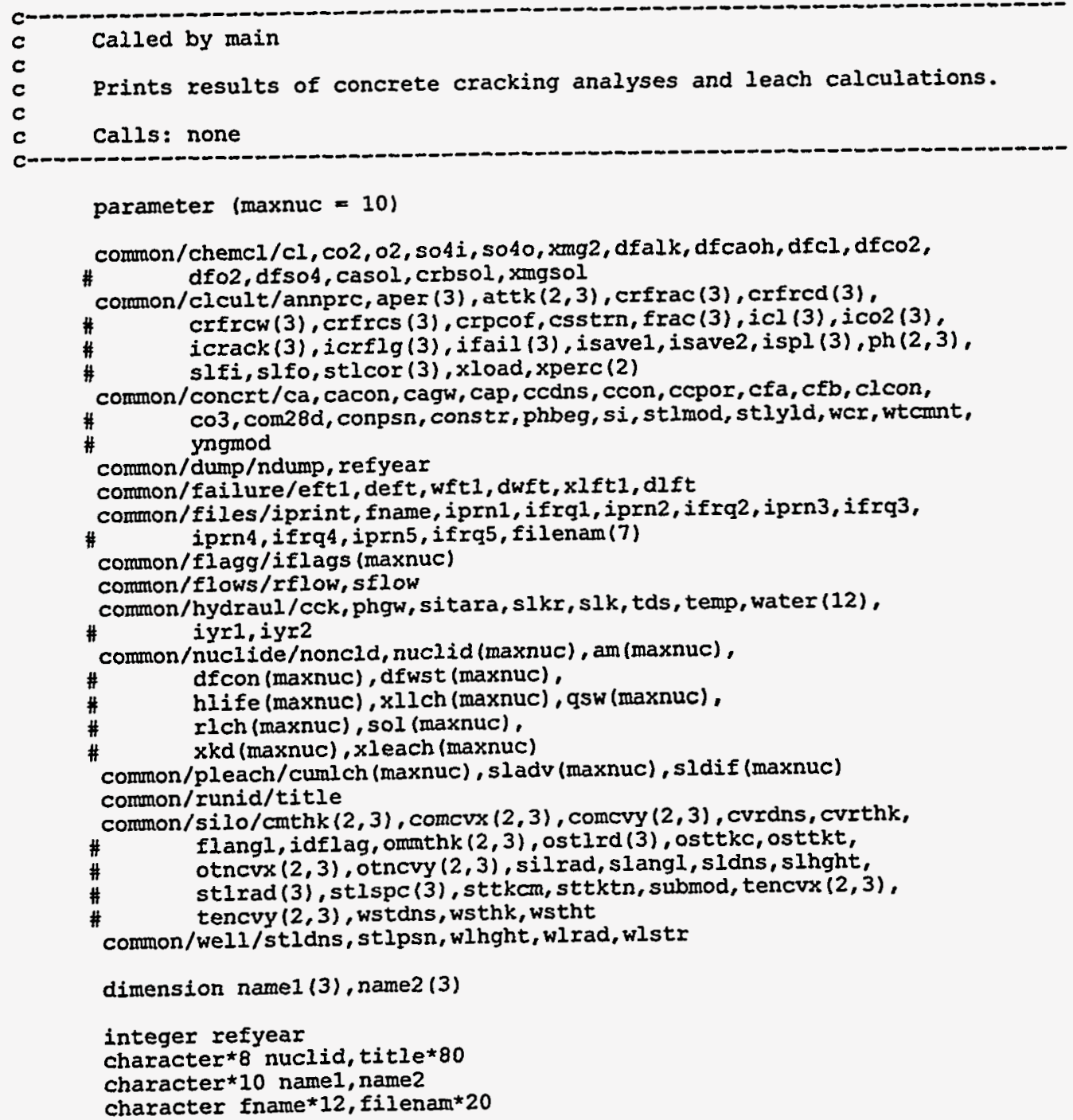




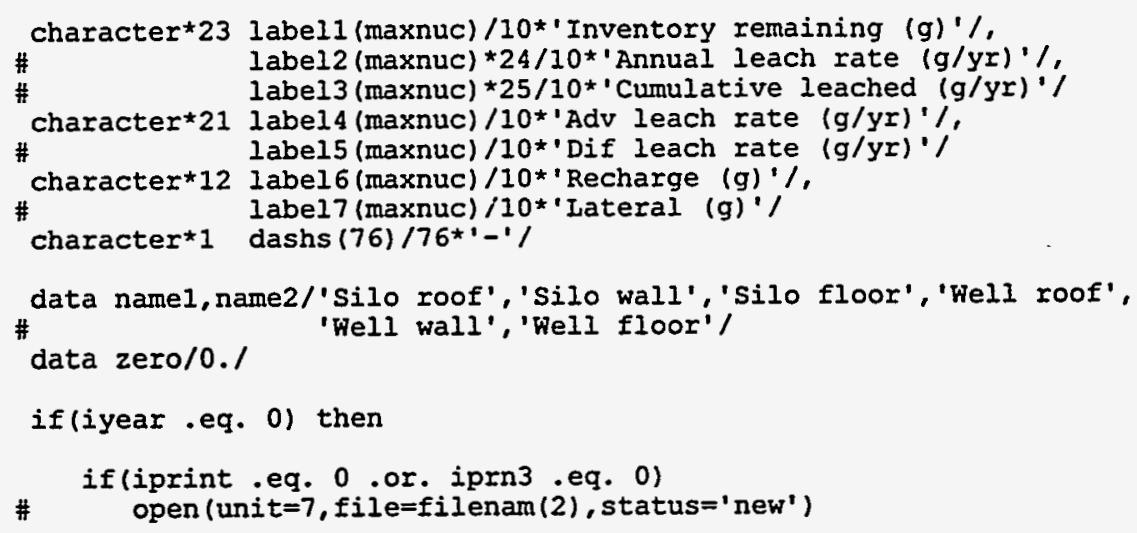

c..... Open file for input data summary and concrete analysis c...... with name "fname".con.

if (iprint .eq. 0) then

$\begin{array}{ll}\text { write }(7,1000) & \text { title } \\ \text { write }(7,1025) & \\ \text { write }(7,1125) & \text { nyears } \\ \text { write }(7,1060) & \text { ifrq3 }\end{array}$

if(idflag .eq. 1) then

write $(7,1050)$

elseif(idflag .eq. 2) then

write $(7,1075)$

elseif(idflag .eq. 3) then

write $(7,1100)$

endif

write $(7,1150)$ sitara, tds, temp, phgw, slkr, slk, cck

write (7,1175) cagw, cl, c03, xmg2, so4i, s040, 02

write $(7,1200)$ casol, crbsol, xmgsol

write $(7,1225)$ cacon, cap, ccon, clcon, si

write $(7,1250)$ com $28 d^{\star} 7.04 \mathrm{e}-2$, conpsn, stlmod* $7.04 \mathrm{e}-2$, stlyld $\star 7.04 \mathrm{e}-2$, submod $\star 7.04 \mathrm{e}-2$, yngmod $\star 1.02 \mathrm{e}-5$, wcr, ccdns, ccpor, wtcmnt, phbeg

if (idflag . gt. 1) write $(7,1275)$ stldns, stipsn, wlstr write $(7,1300)$ dfalk, dfcaoh, dfcl, dfco2, dfo2, dfso4 if (idflag.eq. 1 .or. idflag.eq.3) write $(7,1325)$

silrad/39.37, slhght/39.37, (conthk $(1, i) \star 2.54, i=1,3),(\operatorname{stl} \operatorname{rad}(i)$ *

$2.54, i=1,3),(\operatorname{stl} \operatorname{spc}(i) \star 2.54, i=1,3)$, sttkcm $\star 2.54$, sttktn $\star 2.54$, (tencvx $(1, i) \star 2.54$, tencvy $(1, i) \star 2.54$, $i=1,3$ )

if(idflag .gt. 1) write $(7,1350)$ wlrad $\star 2.54$, wlhght $\star 2.54$, (cmthk $(2, i) * 2.54, i=1,3)$, (tencrx $(2, i) * 2.54$,

tencry $(2, i) \star 2.54, i=1,3,21$

write $(7,1375)$ xload $* 7.04 \mathrm{e}-2$

write $(7,1400)$ curthk/39.37, cvrdns, flangl, slangl, sldns, wstdns, wstht

write $(7,1425)$

if(idflag.eq.1 .or. idflag.eq.3) write(7,1450) eftl,deft, xlft1, dlft

if(idflag.gt. 1) write $(7,1475)$ wftl, dwft

write $(7,1500)$

write ( 7,1525 ) (nuclid(i), hlife(i)/3.15576e7, sol(i), xkd(i), dfwst (i), dfcon(i), qsw (i), $i=1$, noncld)

endif 
if(iprn1 .eq. 0) then

c..... Open file for recharge components with name "fname".rch.

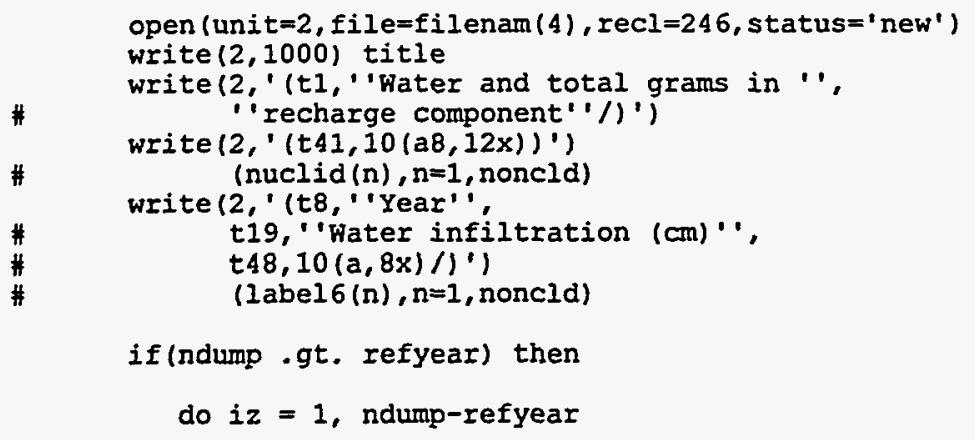

\# write $(2, '(i 10,10 x, 1$ pe16.8,8x, $10(1 \mathrm{pe} 16.8,4 \mathrm{x}))$ ') (refyeartiz-1), zero, (zero, $n=1$, noncld)

enddo

endif

endif

if(iprn2 .eq. 0) then

c..... open file for lateral flow with name "fname".lat.

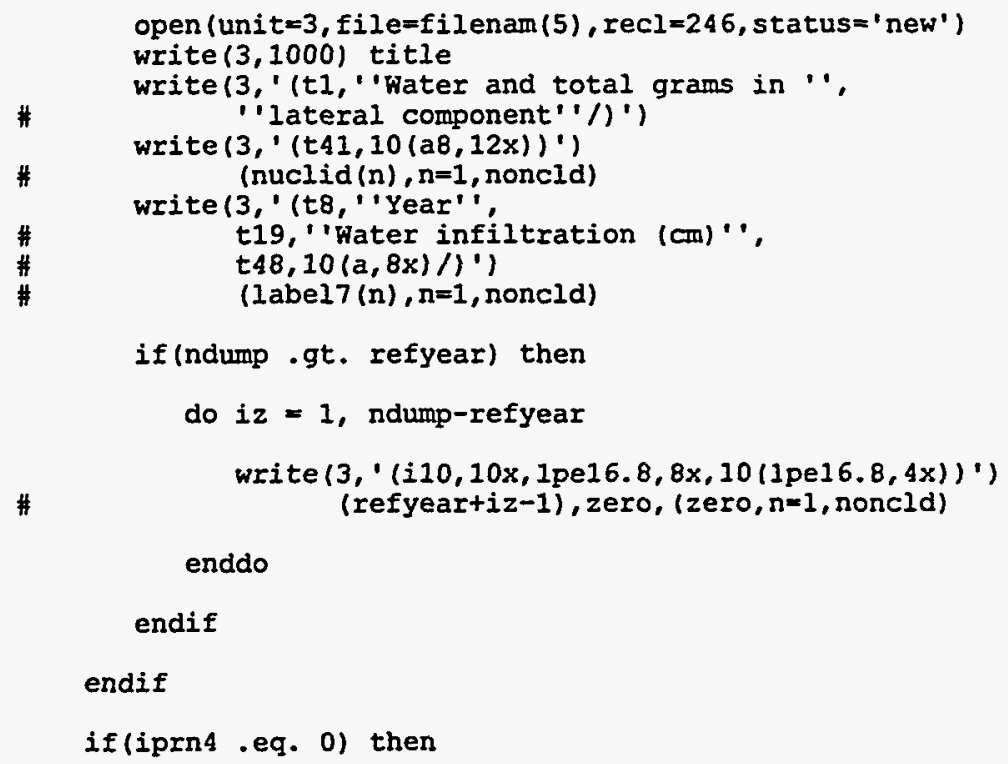

c..... Open file for output summary information

c...... with name "fname". sum.

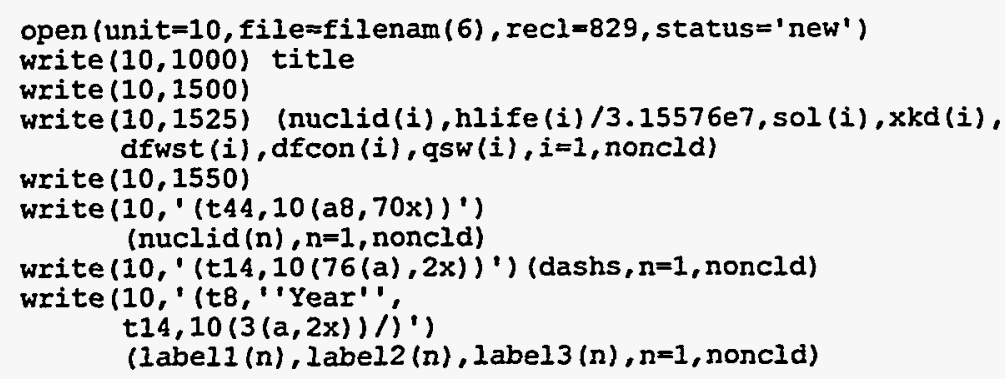


endif

if(iprn5 .eq. 0) then

c..... Open file for annual advective loss, diffusive loss, and total loss c..... with name "fname".1ch.

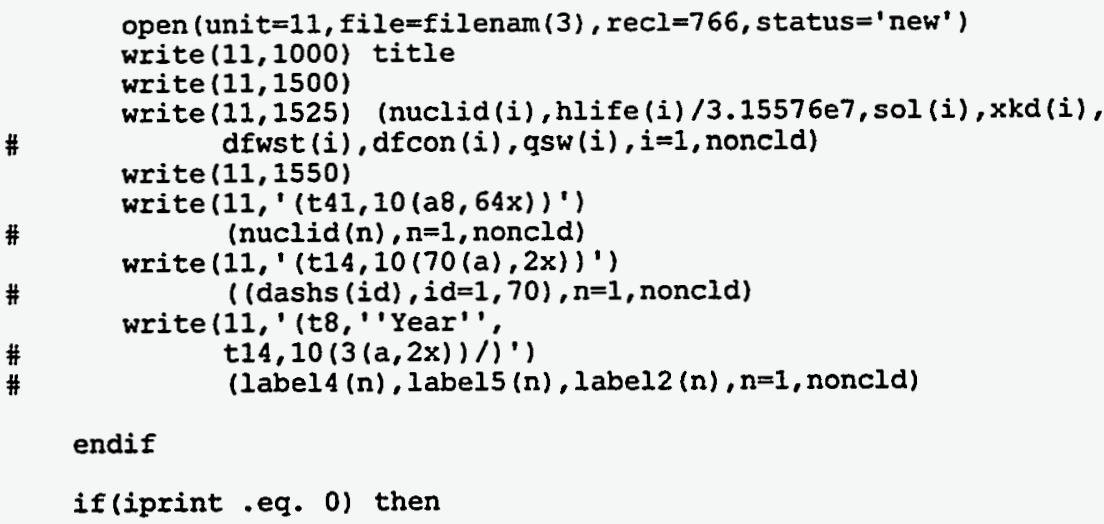

c..... Open file for water infiltration sumary information

c..... with name "fname".h2o.

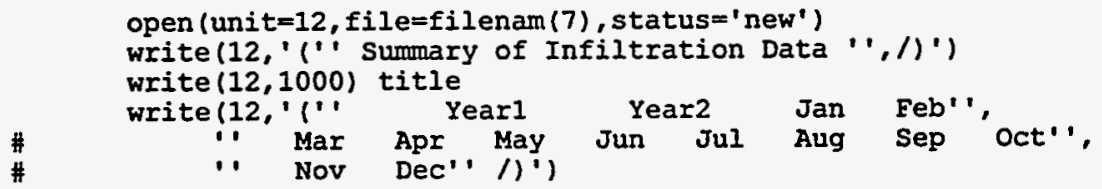

endif

return

endif

if ((iprn3 .eq. 0 .and. $\bmod ($ iyear, ifrq3) .eq. 0$)$.or.

\# (iyear .eq. 1 .and. iprn3 .eq. 0)) then

if (iyear .eq. 1) then

write $(7,2000)$ ndump

else

if (ndump .gt. 1) then

write $(7,2000)$ ndumptiyear

else

write $(7,2000)$ iyear

endif

endif

c.....Print concrete degradation.

write $(7,2005)$

if(idflag.eq.1 .or. idflag.eq.3) then

if(idflag .eq. 3) write $(7,2010)$

write $(7,2015)$ (namel $(i), \operatorname{cmthk}(1, i) \star 2.54, i=1,3)$, (name1 (i),

\# amin1 (ommthk $(1, i)$, iyear* $($ slfi+slfo)) $* 2.54, i=1,3$ ),

\# (namel $(i), 1,-\operatorname{attk}(1, i), i=1,3)$ 


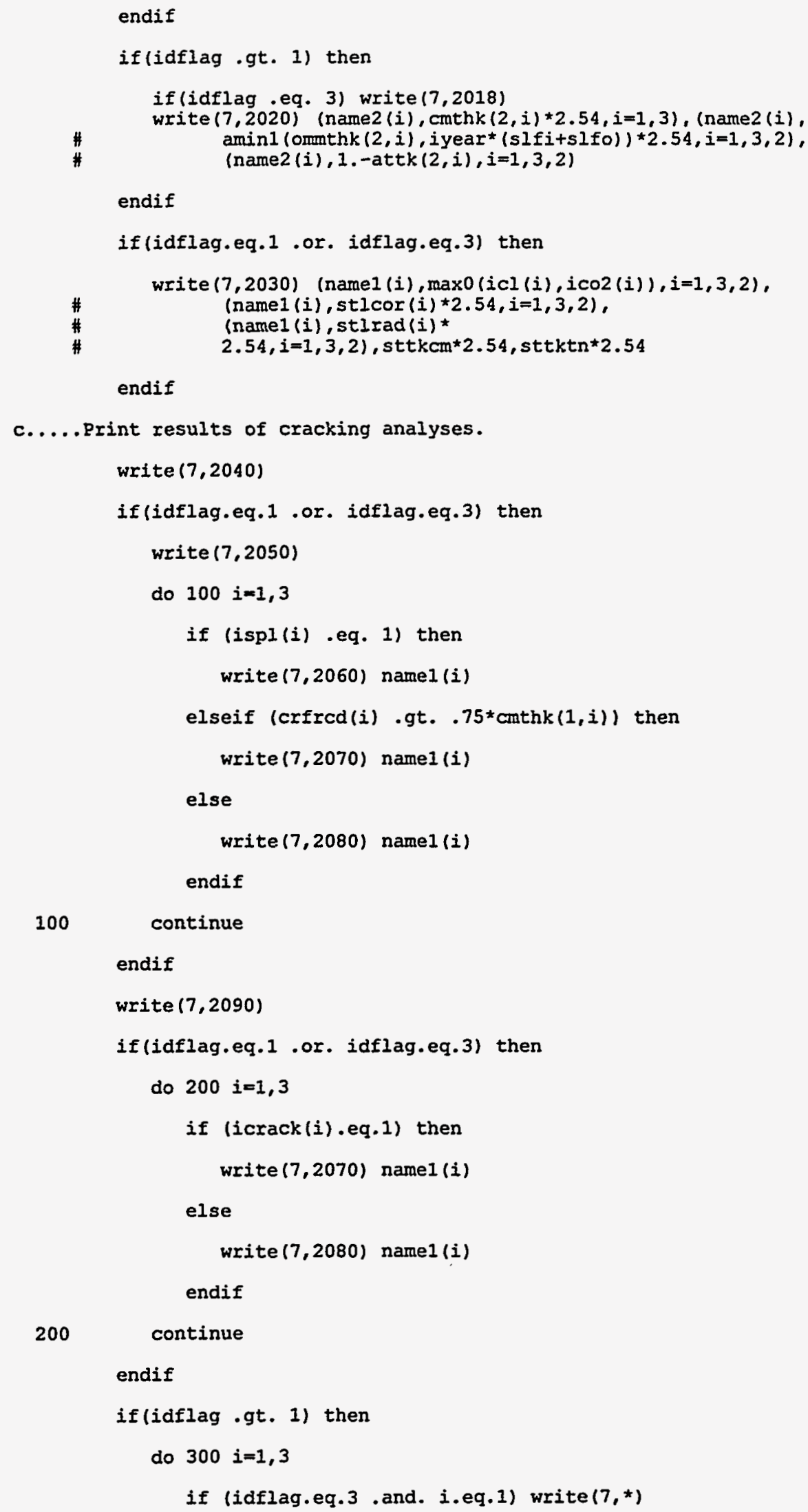


if (ifail(i).eq.1) then

write $(7,2070)$ name2(i)

else

write $(7,2080)$ name2 (i)

endif

300 continue

endif

if(idflag.eq.1 .or. idflag.eq.3) then

if (isavel .gt. 0) write $(7,2130)$

do $400 i=1,3$

if (aper(i) .gt. 0.) then

write $(7,2140)$ namel(i), aper(i)

write $(7,2150)$ frac(i)

endif

400

continue

endif

c.....Print radionuclide release rates.

write $(7,2160)$

write $(7,2170)$ (nuclid(i), xleach(i), $i=1$, noncld)

endif

c..... Output summary values for inventory and leaching.

if(iprn4 .eq. 0 .and. $\bmod (i$ year, ifrq4) .eq. 0 )

\# write (10,' (i10,t18,10(1pe12.4,14x,1pe12.4,14x,

\# 1pe12.4,14x)' ')

\# ndumptiyear-1, (qsw (n), xleach $(\Omega)$,

\# $\quad \operatorname{cumlch}(n), n=1$, noncld)

c..... Output values for leaching.

if(iprn5 .eq. 0 .and. mod(iyear, ifrq5) .eq. 0$)$

\# write (11, (i10,t17,10(1pe12.4,11x,1pe12.4,13x,

\# 1pe12.4,12x);')

\# ndump+iyear $-1,(\operatorname{sladv}(n), \operatorname{sldif}(n), x l e a c h(n), n=1, \operatorname{noncld})$

c..... Output results of solubility check.

if (iyear .ge. nyears) then

do $\mathrm{n}=1$, noncld

if(iflags $(n)$.ne. 0 ) then

if(iprn4 .eq. 0)write $(10,702)$ nuclid(n)

if (iprn5 .eq. 0) write $(11,702)$ nuclid(n)

702 format $(/ / /$ ' The solubility constraints were exceeded',

\# for ', a)

else

if(iprn4 .eq. 0)write $(10,703)$ nuclid(n)

if (iprn5 .eq. 0) write $(11,703)$ nuclid(n)

703 format (/// The solubility constraints were not',

\# 'exceeded for ', a) 
endif

endio

endif

c.....Frite annual releases to lateral and recharge component files.

if (iprn1 .eq. 0 .and. mod(iyear, ifrq1) .eq. 0 )

\# write $(2, '(i 10,10 x, 1$ pe16.8,8x,10(1pe16.8,4x))')

\# (ndumptiyear-1), rflow, $(\operatorname{rlch}(n), n=1$, noncld)

if (iprn2 .eq. 0 .and. $\bmod ($ iyear, ifrq2) .eq. 0)

\# write $(3, '(i 10,10 x, 1$ pe16.8,8x,10(1pe16.8,4x) ')

\# (ndumptiyear-1), sflow, $(x 11 \mathrm{ch}(n), n=1$, noncld)

if (iyear .eq. iyr2 .or. iyear .eq. nyears) then

if (iprint .eq. 0)

\# write(12, '(1h , i10,1x,i10,3x,12f6.2)') iyr1, iyr2,

(water(i), $i=1,12$ )

endif

return

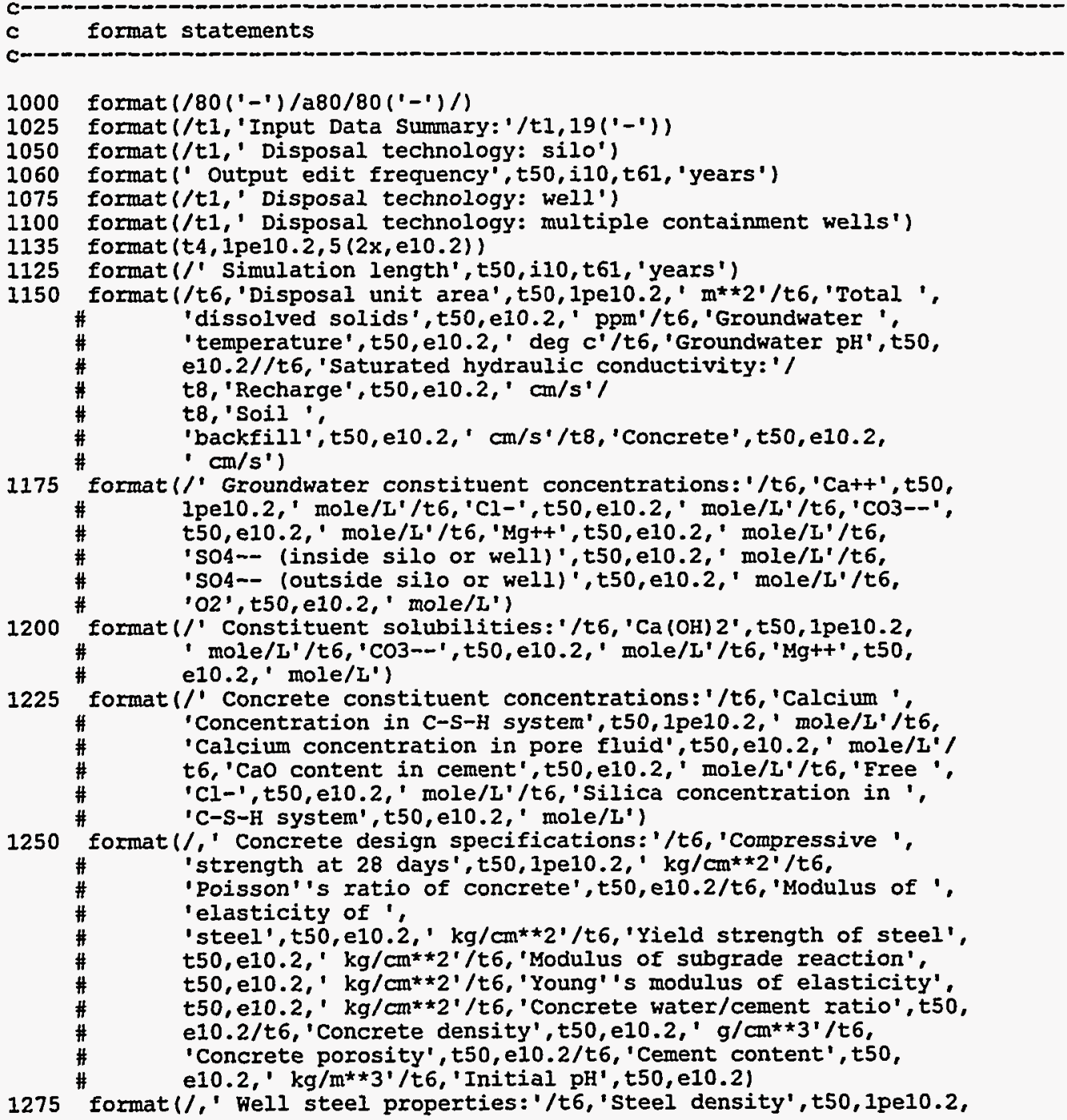




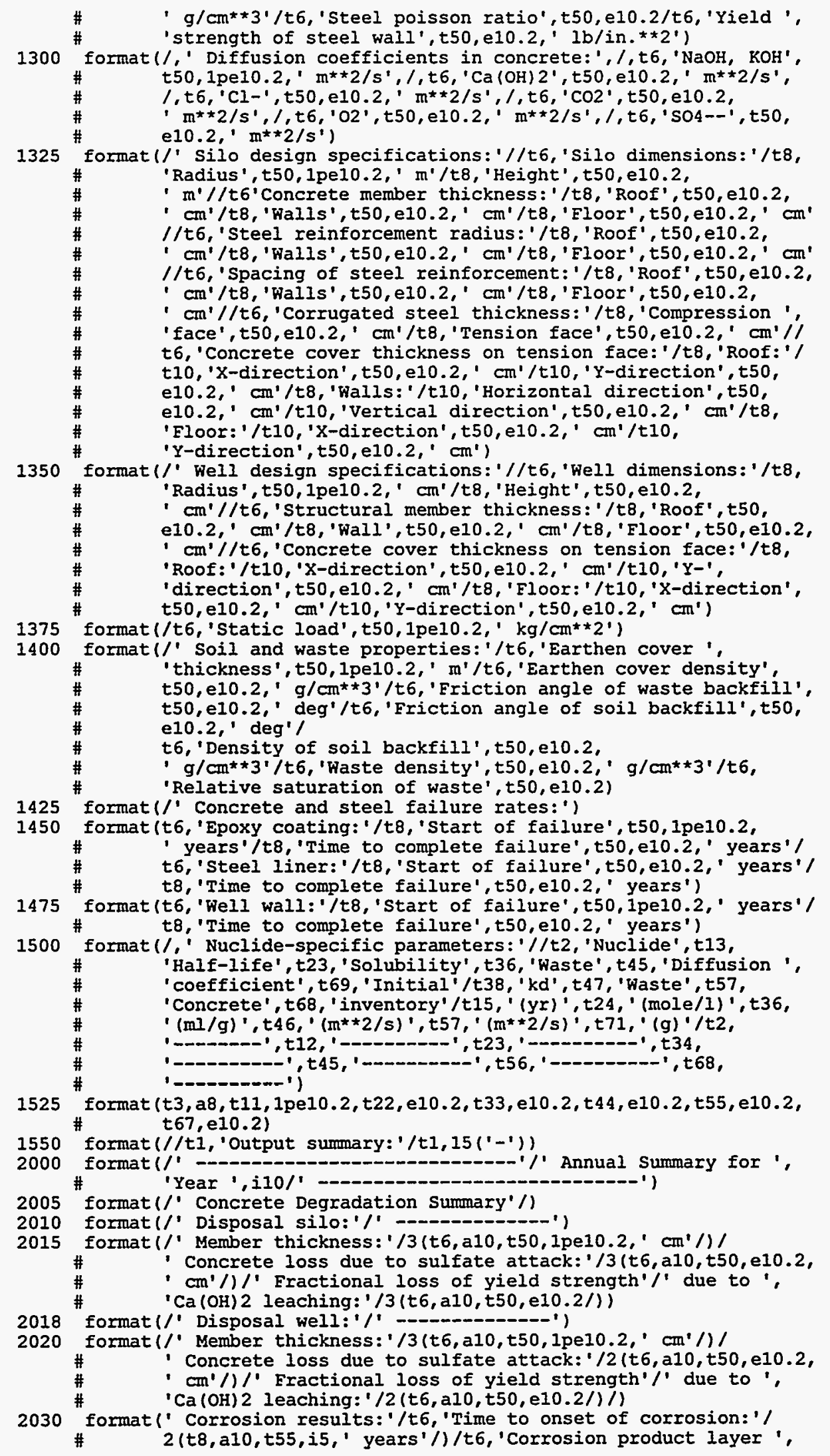




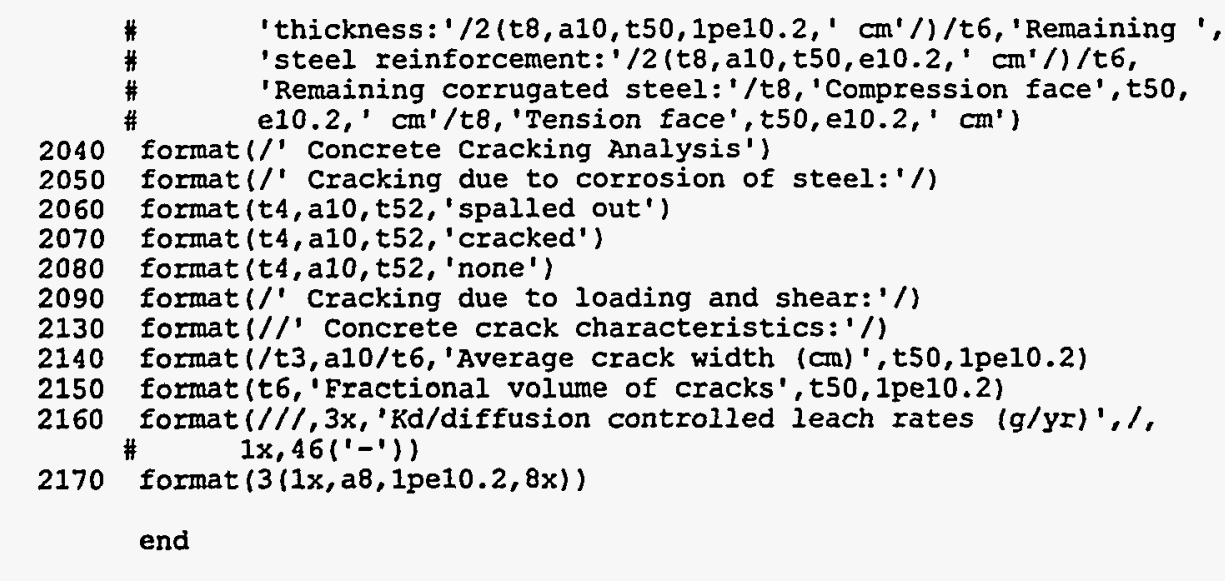

subroutine sar2

$\begin{array}{ll}c & \text { Called by source } \\ c & \text { Performs structural analysis of silos and wells. } \\ c & \text { Calls: none } \\ c & \end{array}$

common/clcult/annprc, aper (3), attk $(2,3), \operatorname{crfrac}(3), \operatorname{crfrcd}(3)$,

\# crfrcw (3), crfrcs (3), crpcof, csstrn, frac (3), icl (3), ico2 (3),

\# icrack (3), icrflg (3), ifail (3), isavel, isave $2, i \operatorname{spl}(3), \operatorname{ph}(2,3)$, slfi, slfo, stlcor (3), xload, xperc (2)

common/concrt/ca, cacon, cagw, cap, ccdns, ccon, ccpor, cfa, cfb, clcon,

\# co3, com28d, conpsn, constr, phbeg, si, stlmod, stlyld, wer, wtennt, yngmod

common/moment/rfxunt $(11,11)$, rfymat $(11,11)$, Iwxant $(11,11)$.

\# rwymnt $(11,11)$, flxment $(11,11)$, flym $(11,11)$, fwxant $(11,11)$.

\# fwymant (11,11), wlyme (11), wwyme (11)

comon/shear/rfshr, rfwshr, flshr, flwshr, wlyshr (11), wwyshr (11)

comon/silo/cmthk $(2,3)$, comevx $(2,3)$, comcvy $(2,3)$, cvrdins, cvrthk,

* flangl, idflag, ommthk $(2,3)$, ostlrd (3), osttkc, osttkt,

otncvx $(2,3)$, otncvy $(2,3)$, silrad, slangl, sldns, slinght,

stlrad (3), stlspc (3), sttkcm, sttktn, submod, tencvx $(2,3)$, tencvy $(2,3)$, wstdns, wsthk, wstht

common/well/stldns, stlpsn, wlhght, wlrad,wlstr

common/wlforc/wlcmfr(11), wlxrc(11), wlwxrc(11), wwcmfr(11)

real*8 alpha, beta

data pi/3.141592653589793/

c..... Calculate modulus of elasticity of concrete for use in structural c..... analysis of floor.

time $=365$

comstr $=\operatorname{amin} 1$ (time/(cfa+cfb*time)*com28d, constr)

conmod $=5.7 e^{*}$ sqrt $($ comstr $) /(1 .+$ crpcof $)$

c......Begin roof structural analysis.

c..... Calculate maximum shear and reaction for roof.

if(idflag.eq.1 .or. idflag.eq.3) then

$\operatorname{rfshr}=x$ load* $(\operatorname{silrad}-\operatorname{cmthk}(1,2) / 2 .-\operatorname{conthk}(1,1)-\operatorname{tencvx}(1,1)) / 2$.

rfxxn $=$ xload*silrad $/ 2$.

endif

if(idflag .gt. 1) then 
Ifwshr $=x l o a d^{\star}($ wlrad-cmthk $(2,2) / 2,-\operatorname{cmthk}(2,1)-\operatorname{tencvx}(2,1)) / 2$.

rfwrXn $=\mathrm{xload} * \mathrm{wl} \mathrm{rad} / 2$.

endif

c.....Calculate $\mathrm{x}$ - and $\mathrm{y}$-direction moments, and shear and reaction for silo c.....roof. Moment curves are discretized into eleven segments, over any c..... one of which the moment is constant.

if(idflag.eq. 1 .or. idflag.eq.3) then

do $200 \mathrm{k}=0,5$

do $100 \quad 1=0,5$

if (1 .gt. 0.) then

theta $=\operatorname{atan}(k \star 0.2 * \operatorname{sil} \mathrm{rad} /(1 * 0.2 * \operatorname{sil} \mathrm{rad}))$

elseif (1.eq. 0 . and. k.gt.0) then

theta $=p i / 2$.

else

theta $=0$.

endif

$I=\operatorname{sqrt}\left(\left(0.2 k^{\star} \operatorname{silrad}\right) \star \star 2+(0.2 \star l * \operatorname{silrad}) * \star 2\right)$

if ( $x$.le. silrad) then

$\operatorname{tmpl}=\mathrm{r} / \mathrm{sil \textrm {rad }}$

tmp2 $=$ xload*silrad $\star \star 2 / 16 . *(3 .+$ conpsn $) *(1 .-\operatorname{tmp} 1 * \star 2)$

tmp $3=x$ load*silrad $* * 2 / 16 . *(3 .+$ conpsn $-(1 .+3 . *$ conpsn) *tmp $1 * \star 21$

Ifxmnt $(k+6-k \star 2,1+6)=$ abs $(\operatorname{tmp} 2 *(\cos ($ theta $)) \star 2+$ $\operatorname{tmp} 3 \star(\sin ($ theta $)) \star \star 2)$

$\#$

$\#$

$\operatorname{rfymnt}(k+6-k \star 2,1+6)=\operatorname{abs}(\operatorname{tmp} 2 *(\sin ($ theta $)) \star \star 2+$

tmp $3 *(\cos ($ theta $)) \star \star 2)$

rfxint $(k+6-k * 2,6-1)=\operatorname{rfxmnt}(k+6-k \star 2,1+6)$

rfymint $(k+6-k * 2,6-1)=\operatorname{rfymnt}(k+6-k * 2,1+6)$

rfxint $(k+6,1+6)=\operatorname{rfxmnt}(k+6-k \star 2,1+6)$

rfyment $(k+6,1+6)=\operatorname{rfymnt}(k+6-k \star 2,1+6)$

rfxint $(k+6,6-1)=\operatorname{rfxmnt}(k+6-k * 2,1+6)$

Ifyment $(k+6,6-1)=\operatorname{rfy} \operatorname{mint}(k+6-k \star 2,1+6)$

endif

100 continue

200 continue

endif

c.....Calculate $x$ - and $y$-direction moments, and shear and reaction for c......well roof. Moment curves are discretized into eleven segments, over c..... any one of which the moment is constant.

if(idflag .gt. 1) then

do $400 \mathrm{k}=0,5$

do $3001=0,5$

if (1.gt. 0.) then

theta $=\operatorname{atan}\left(k * 0.2{ }^{*} \mathrm{wl} \mathrm{rad} /\left(1 * 0.2{ }^{*} \mathrm{wlrad}\right)\right)$

elseif (1.eq. 0 .and. k.gt.0) then

theta $=\mathrm{pi} / 2$. 
else

theta $=0$.

endif

$r=\operatorname{sqrt}((0.2 \star k \star w l \mathrm{rad}) \star \star 2+(0.2 \star l * w 1 \mathrm{rad}) \star \star 2)$

if ( $r$.le. wlrad) then

$\operatorname{tmpl}=r / w 1 \mathrm{rad}$

$\operatorname{tmp2}=x$ load*wl rad $\star \star 2 / 16 . *(3 .+$ conpsn $) *(1 .-\operatorname{tmp} 1 * \star 2)$

$\operatorname{tmp} 3=x 10 a d *$ wl rad $* * 2 / 16 . *(3 .+$ conpsn $-(1 .+3 . *$ conpsn) *tmp $1 * \star 2$ )

rwxont $(k+6-k * 2,1+6)=\operatorname{abs}(\operatorname{tmp} 2 *(\cos ($ theta $)) \star \star 2+$

$\operatorname{tmp} 3 *(\sin ($ theta $)) * \star 2)$

rwymnt $(k+6-k \star 2,1+6)=\operatorname{abs}($ tmp $2 *($ sin $($ theta $)) \star \star 2+$ $\operatorname{tmp} 3 *(\cos ($ theta $)) * \star 2)$

rwxmnt $(k+6-k \star 2,6-1)=\operatorname{rwxmnt}(k+6-k \star 2,1+6)$

rwymnt $(k+6-k * 2,6-1)=$ rwymnt $(k+6-k * 2,1+6)$

rwxint $(k+6,1+6)=\operatorname{rwxmant}(k+6-k \star 2,1+6)$

rwyment $(k+6,1+6)=$ rwymnt $(k+6-k * 2,1+6)$

rwxmnt $(k+6,6-1)=$ rwxont $(k+6-k * 2,1+6)$

rwymnt $(k+6,6-1)=\operatorname{rwymnt}(k+6-k * 2,1+6)$

endif

300 continue

400 continue

endif

c.....Begin wall structural analysis.

c......Calculate ring compression, moments, and shears due to uniform c....load for silo wall.

if(idflag.eq.1 .or. idflag.eq.3) then

flarg $=1 .-\sin ($ flangl*pi/180.)

slarg $=1 .-\sin ($ slangl $* \mathrm{pi} / 180$.

$\mathrm{d}=\operatorname{conmod}^{\star} \operatorname{cmthk}(1,3) \star \star 3 /(12 . \star(1 .-$ conpss $* \star 2))$

beta $=(3 *(1 .-$ conpsn**2)/(silrad $* 2 * \operatorname{cmthk}(1,2) \star \star 2)) \star * 0.25$

alpha $=$ beta*slhght $/ 2$.

$\#$

unfld $=\operatorname{sldns}{ }^{*} 3.61 \mathrm{e}-2 \star(\operatorname{cvrthk}+0.5 * \operatorname{cmthk}(1,1)) * \operatorname{slarg}+0.5 *$ slhght* (sldns*3.61e-2*slarg-wstdns*3.61e-2*flarg)

hydrld $=0.5 *$ slhght* (sldns*3.61e-2*slarg-wstdns*3.61e-2*flarg)

c..... Calculate compressive forces for vertical direction.

do $500 \mathrm{~m}=0,10$

$\#$

wlcmfr $(m+1)=\operatorname{amax} 1(0$, Ifrxn+cmthk $(1,2) * m \star s \operatorname{lnght} / 10 . *$ ccdns $* 3.61 \mathrm{e}-21$

500 continue

c..... Calculate ring compression for horizontal direction.

do $600 \mathrm{k}=5,-5,-1$

$\#$

templa $=\left(2{ }^{*} \sin (\right.$ alpha $){ }^{\star} \sinh$

(alpha))/(cos (2.*alpha)+dcosh (2.*alpha))*sin

(beta*k*sihght/10.)*dsinh (beta* $k$ *sihght/10.)

temp $1 b=\left(2{ }^{\star} \cos (\right.$ alpha $){ }^{\star}$ dcosh $($ alpha $\left.)\right) /\left(\cos \left(2{ }^{\star}\right.\right.$ alpha $)+$ $\operatorname{dcosh}(2 . \star a l p h a)) \star \cos \left(\right.$ beta* $k^{\star}$ slhght $\left./ 10.\right) * \cosh$ (beta*k*slhght/10.)

temp1 $=1 \cdot-$ templa-templb

w $1 \times x c(6+k-k \star 2)=$ unfld*silrad*templ 
c.....Calculate moments and shears for vertical direction.

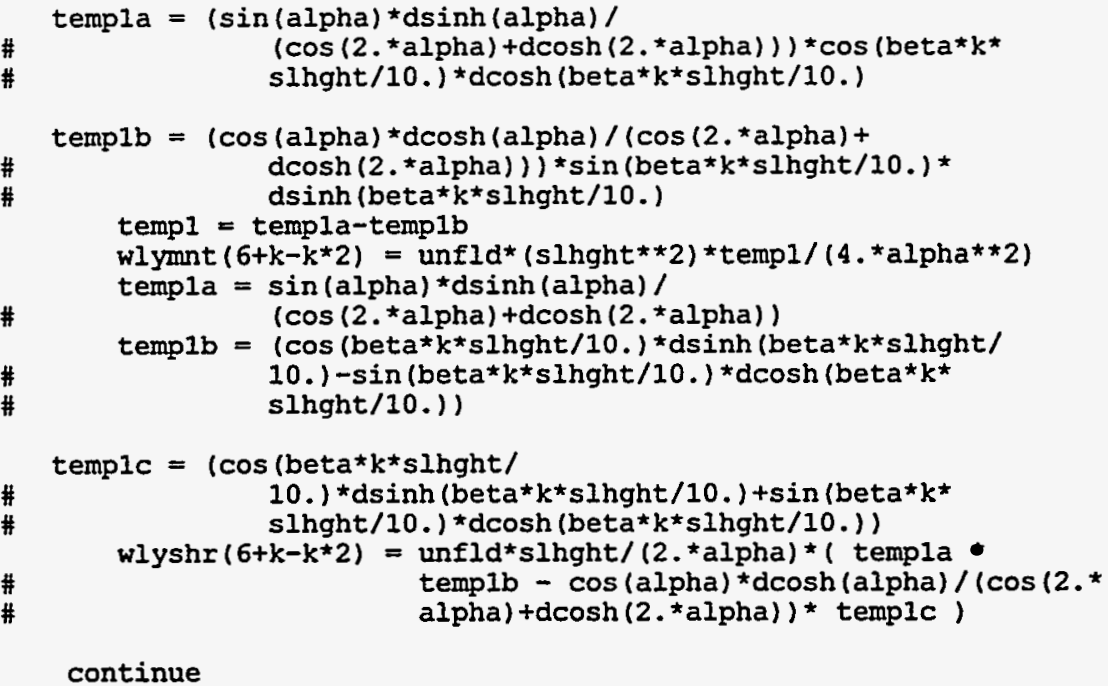

c.....Calculate ring compression, moments, and shears due to hydrostatic c.....load for silo wall. Start with ring compression for horizontal c.....direction. combine results for uniform and hydrostatic loads.

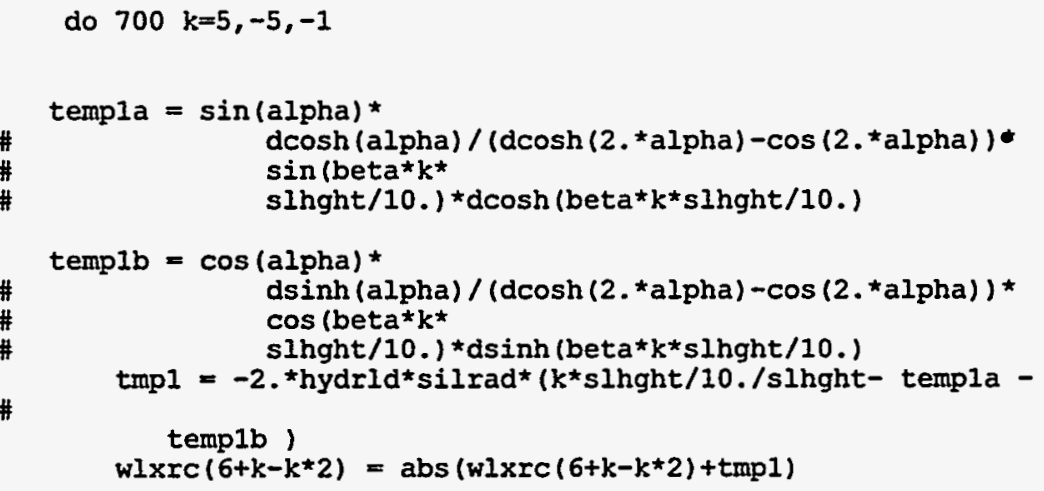

c..... Calculate moments and shears for vertical direction.

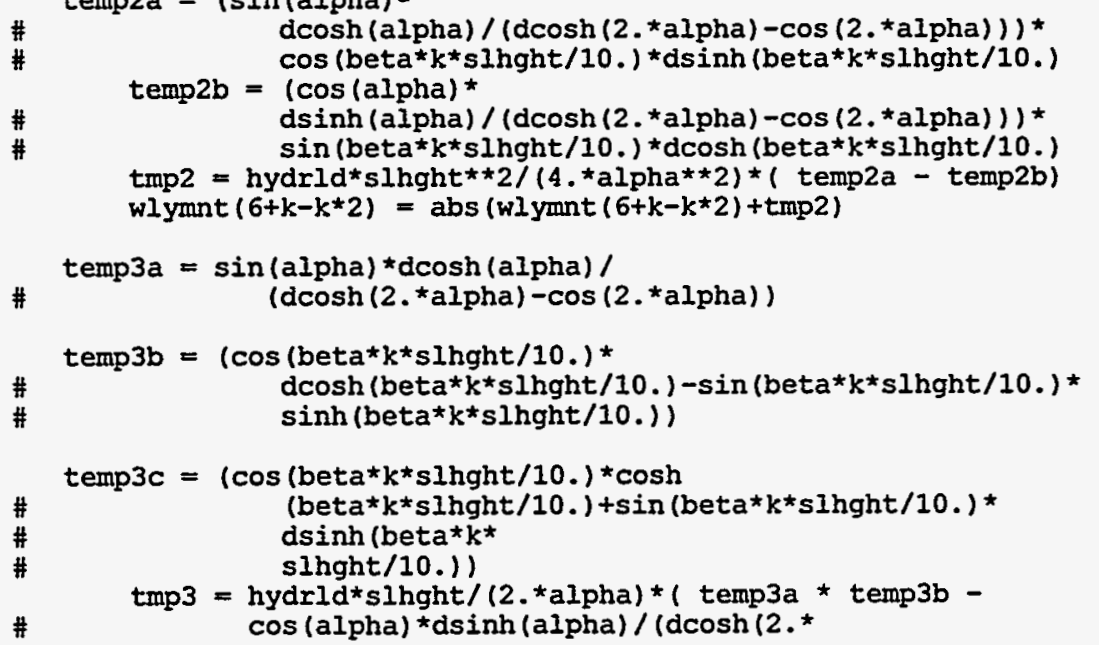


endif

c...... Calculate ring compression, moments, and shears due to c..... uniform load for well wall.

if(idflag .gt. 1) then

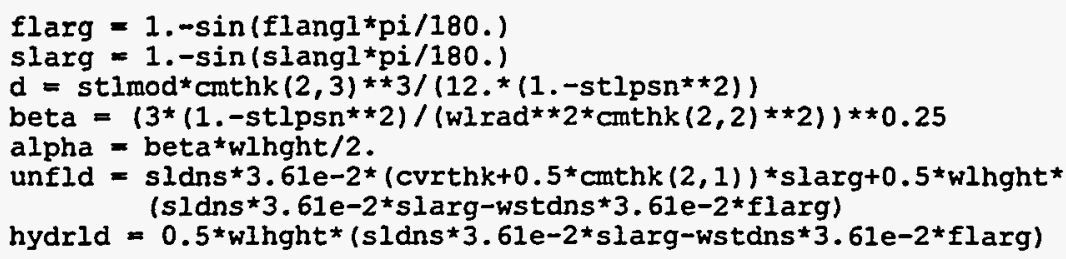

c..... Calculate ring compression for horizontal direction.

do $900 k=5,-5,-1$

$\#$

templa $=\left(2 .{ }^{*} \sin (a) \text { pha }\right)^{\star} \sinh$

(alpha) $) /\left(\cos \left(2{ }^{\star}\right.\right.$ alpha $\left.)+d \cosh (2, \star a l p h a)\right) \star \sin$

(beta* $k *$ wlhght $/ 10) *. d \sinh$ (beta* $k *$ wlhght/10.)

\#

templb $=\left(2 .{ }^{*} \cos (a) \text { pha }\right)^{\star}$ dcosh $\left.(a l p h a)\right) /(\cos (2 . * a l p h a)+$ dcosh $(2 . * a l p h a)) * \cos ($ beta*k*wlhght/10.)* $\cosh$ (beta*k*wlhght/10.)

temp1 = 1.-templa-temp1b

wlwxrc $(6+k-k * 2)=$ unfld*wlrad*templ

c..... Calculate moments and shears for vertical direction.

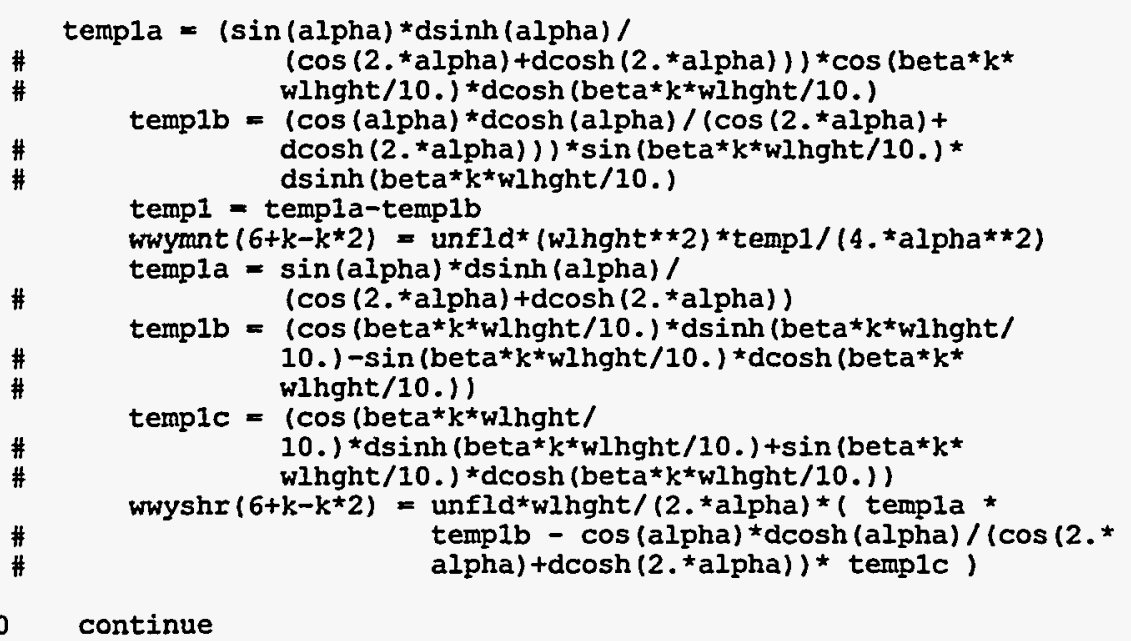

c..... Calculate ring compression, moments, and shears due to hydrostatic c.....load. start with ring compression for horizontal direction. combine c..... results for uniform and hydrostatic loads. 
do $1000 k=5,-5,-1$

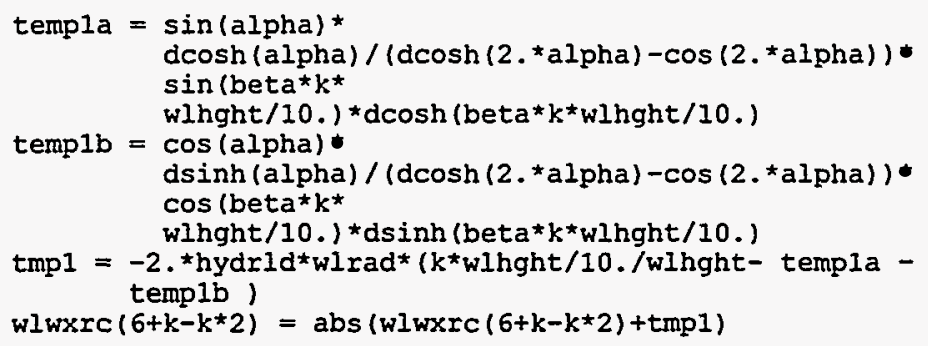

c.....Calculate moments and shears for vertical direction.

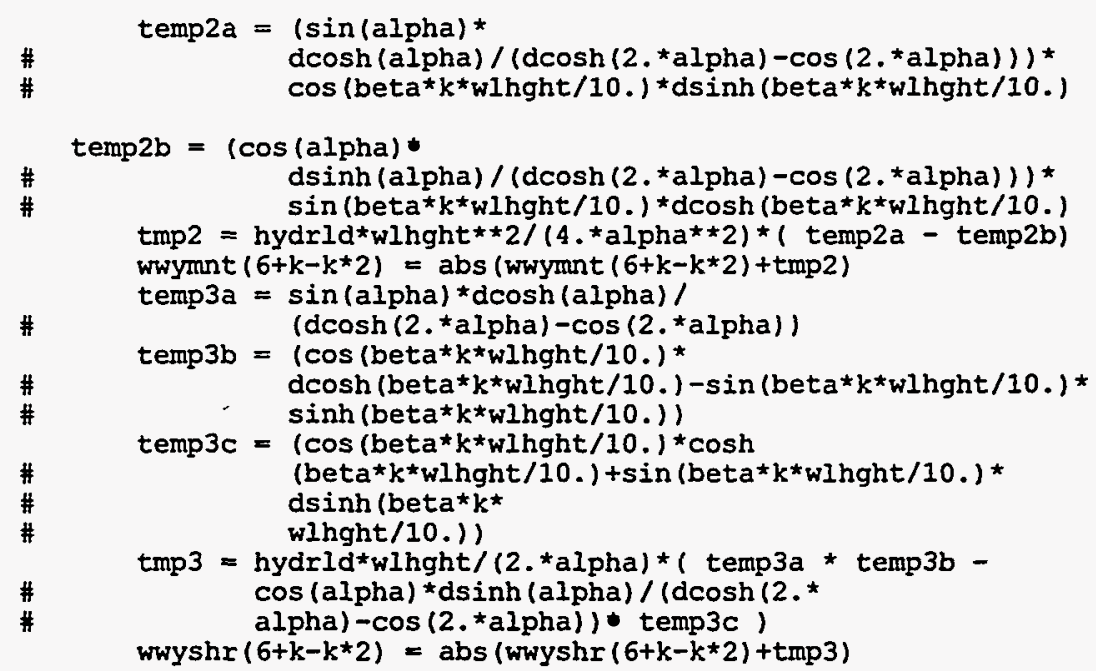

1000

continue

endif

c......Begin floor structural analysis.

c..... Calculate maximum shear for silo floor.

if(idflag.eq.1 .or. idflag.eq.3) then

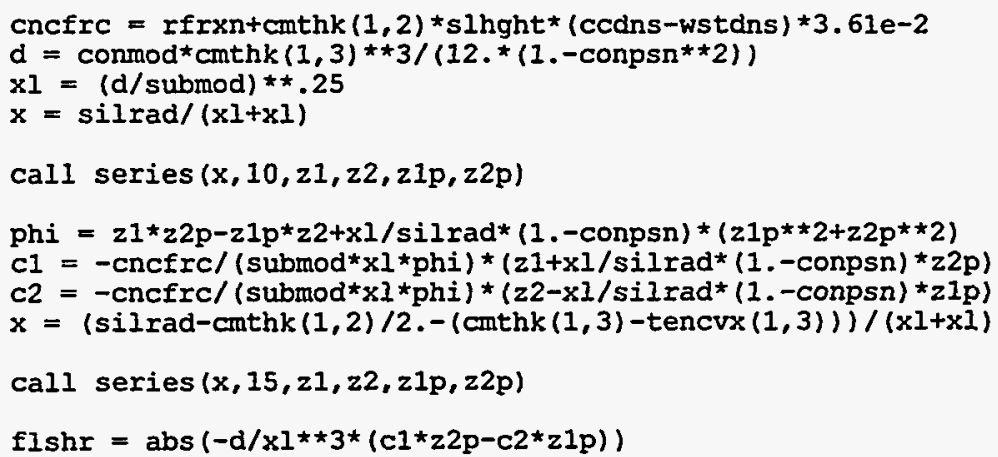

c......Calculate $\mathrm{x}$ - and $\mathrm{y}$-direction moments, shear and reaction for silo c....floor. Moment curves are discretized into eleven segments, over any c..... one of which the moment is constant.

do $1200 \mathrm{k}=0,5$

$$
\text { do } 11001=0,5
$$


if ( $1 . g t .0)$ then

theta $=\operatorname{atan}(k \star 0.2 \star \operatorname{sil} \mathrm{rad} /(0.2 \star 1 \star \operatorname{silrad}))$

elseif (1.eq. 0 .and. k.gt.0) then

theta $=\mathrm{pi} / 2$.

else

theta $=0$.

endif

$I=\operatorname{sqrt}\left(\left(0.2^{\star} k^{\star} \operatorname{silrad}\right) \star \star 2+\left(0.2^{\star} l^{\star} \operatorname{silrad}\right) \star \star 2\right)$

if ( 1 .le. silrad) then

$x=r /(x I+x I)$

call series $(x, 15,21,22,21 p, z 2 p)$

if (r.gt. 0. ) then

$\operatorname{tmp} 2=-d / x I^{\star \star} 2^{\star}\left(c 1 * z 2-c 2 \star z 1-x 1 / r^{\star}(1 .-c o n p s n) *\right.$ $(c 1 * z 1 p+c 2 \star z 2 p))$

$\operatorname{tmp} 3=-d / x 1 \star \star 2 *\left(\operatorname{conpsn}{ }^{*}(c 1 * z 2-c 2 \star z 1)+x 1 / I *\right.$

else

$(1 .-$ conpsn $) \star(c 1 \star z 1 p+c 2 \star z 2 p))$

$\operatorname{tmp} 2=d /(2 . * x 1 * \star 2) \star c 2 *(1 .+\operatorname{conpsn})$

$\operatorname{tmp} 3=d /(2 . \star x I \star \star 2) \star c 2 *(1 .+$ conpsn $)$

endif

flxmint $(k+6-k * 2,1+6)=\operatorname{abs}(\operatorname{tmp} 2 *(\cos ($ theta $)) * \star 2+$ $\operatorname{tmp} 3 *(\sin ($ theta $)) \star \star 2)$

flymant $(k+6-k * 2,1+6)=\operatorname{abs}(\operatorname{tmp} 2 *(\sin ($ theta $)) \star \star 2+$

$\operatorname{tmp} 3 *(\cos ($ theta $)) \star \star 2)$

flxmant $(k+6-k * 2,6-1)=$ flxmnt $(k+6-k * 2,1+6)$

flymant $(k+6-k \star 2,6-1)=$ flymnt $(k+6-k \star 2,1+6)$

flxmnt $(k+6,1+6)=$ flxmnt $(k+6-k * 2,1+6)$

flymont $(k+6,1+6)=$ flymnt $(k+6-k \star 2,1+6)$

flxmnt $(k+6,6-1)=f l x \operatorname{mint}(k+6-k \star 2,1+6)$

flymant $(k+6,6-1)=f l y \operatorname{mant}(k+6-k \star 2,1+6)$

endif

1100

continue

1200

continue

endif

c.....Calculate maximum shear for well floor.

if(idflag .gt. 1) then

cncfrc $=$ rfwrsn+cmthk $(2,2) *$ wlhght* (stldns-wstdns $) \star 3.61 \mathrm{e}-2$ $\mathrm{d}=\operatorname{conmod} \star \operatorname{cmthk}(2,3) \star \star 3 /\left(12 . \star\left(1 .-\operatorname{conpsn}{ }^{\star} * 2\right)\right)$

$x I=(d /$ submod $) \star \star .25$

$x=\mathrm{wIrad} /(\mathrm{xl}+\mathrm{xI})$

call series $(x, 10, z 1, z 2, z 1 p, z 2 p)$

phi $=z 1 * z 2 p-z 1 p \star z 2+x l / w 1 r a d *(1 .-$ conpsn $) \star(z 1 p \star \star 2+z 2 p \star \star 2)$

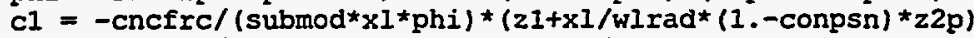

$c 2=-\operatorname{cncfrc} /(\operatorname{submod} \star x I * p h i) *(z 2-x l / w l r a d \star(1 .-c o n p s n) * z l p)$

$x=($ wlrad-cmthk $(2,2) / 2 .-(\operatorname{cmthk}(2,3)-\operatorname{tencvx}(2,3))) /(x 1+x 1)$

call series $(x, 15, z 1, z 2, z 1 p, z 2 p)$

flwshr $=a b s(-d / x 1 * * 3 *(c 1 * z 2 p-c 2 * z 1 p))$ 
c..... Calculate $\mathrm{x}$ - and $\mathrm{y}$-direction moments, shear and reaction for well

c....floor. Moment curves are discretized into eleven segments, over any c..... one of which the moment is constant.

do $1400 \mathrm{k}=0,5$

do $13001=0,5$

if ( 1 .gt. 0 ) then

theta $=\operatorname{atan}(k \star 0.2 * w l r a d /(0.2 * 1 * w l r a d))$

elseif (1.eq.0 and. k.gt.0) then

theta $=\mathrm{pi} / 2$.

else

theta $=0$.

endif

$I=\operatorname{sqrt}\left(\left(0.2 \star k^{\star}\right.\right.$ wlrad $) \star \star 2+(0.2 \star I *$ wlrad $\left.) \star \star 2\right)$

if (r.le. wlrad) then

$x=r /(x l+x l)$

call series $(x, 15, z 1, z 2, z 1 p, z 2 p)$

if ( $r$.gt. 0.) then

tmp2 $=-d / x 1 * \star 2 *(c 1 * z 2-c 2 * 21-x 1 / r *(1,-c o n p s n) *$ $(c 1 * z 1 p+c 2 * z 2 p))$

$\operatorname{tmp} 3=-d / x 1 * \star 2 *(\operatorname{conpsn} *(c 1 * z 2-c 2 * z 1)+x 1 / r *$

(1. - conpsn $) \star(c 1 * z 1 p+c 2 \star z 2 p))$

else

tmp2 $=\mathrm{d} /(2 . \star x I \star \star 2) \star c 2 \star(1 .+\operatorname{conpsn})$

tmp3 $=d /(2 . \star x I \star \star 2) * c 2 *(1 .+$ conps $n)$

endif

\#

fwxmnt $(k+6-k \star 2,1+6)=\operatorname{abs}(\operatorname{tmp} 2 \star(\cos ($ theta $)) \star \star 2+$

tmp $3 *(\sin ($ theta $)) \star \star 2)$

fwymnt $(k+6-k \star 2,1+6)=\operatorname{abs}(t m p 2 *(\sin ($ theta $)) \star * 2+$

$\operatorname{tmp} 3 *(\cos ($ theta $)) \star \star 2)$

fwxmnt $(k+6-k \star 2,6-1)=$ fwxmnt $(k+6-k \star 2,1+6)$

fwymnt $(k+6-k \star 2,6-1)=$ fwymnt $(k+6-k * 2,1+6)$

fwxmnt $(k+6,1+6)=$ fwxmnt $(k+6-k \star 2,1+6)$

fwymant $(k+6,1+6)=$ fwymnt $(k+6-k \star 2,1+6)$

fwxmnt $(k+6,6-1)=$ fwxmnt $(k+6-k \star 2,1+6)$

fwymnt $(k+6,6-1)=$ fwymnt $(k+6-k \star 2,1+6)$

endif

1300

continue

1400 continue

endif

return

end

subroutine series $(x, \operatorname{nmax}, z 1, z 2, z 1 p, z 2 p)$

Called by sar2

This series approximated in several places in sar2. 
c

Calls: none

$c$

c....use $x=r /(21)$ and these relations:

c..... $21 x(n)=-z 1 r(n-1) * x * \star 4 /(2 n(2 n-1)) * \star 2, \quad 21 r(0)=1, n=1, \ldots$

c..... $21 r^{\prime}(n)=(2 n / x) * 21 r(n)$

c.... $22 r(n)=(2 n / x) * \pm 2 * 21 r(n)$

c..... $22 x^{\prime}(n)=((2 n-1) / x) * 22 x(n)$

$z 1=0$.

$\mathrm{z} 1 \mathrm{p}=0$.

$\mathrm{z} 2=0$.

$z 2 p=0$

if (x.eq.0.) go to 200

$x 4 m=-x^{\star \star}$

$\mathrm{a} 2 \mathrm{n}=0$.

$21 r n=1$.

do $100 n=1, n \max$

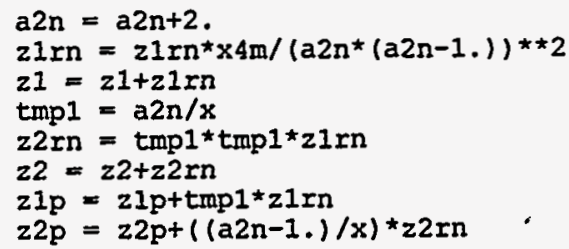

100 continue

$20021=21+1$.

return

end

subroutine sfl (attack, iyear)

Called by: source2
c
c

common/clcult/annprc, aper (3), attk $(2,3), \operatorname{crfrac}(3), \operatorname{crfrcd}(3)$,

\# $\quad \operatorname{crfrcw}(3), \operatorname{crfrcs}(3)$, crpcof, csstrn, frac (3), icl (3), ico2 (3)

\# icrack (3), icrflg (3), ifail (3), isave1, isave2, ispl $(3), \operatorname{ph}(2,3)$, slfi, slfo, stlcor (3), xload, xperc(2)

common/concrt/ca, cacon, cagw, cap, ccdis, ccon, ccpor, cfa, cfb, clcon,

\# co3, com28d, conpsn, constr, phbeg, si, stimod, stiyld, wcr, wtcmnt,

\# yngmod

common/moment/rfxmnt $(11,11)$, rfymnt $(11,11)$, rwxmnt $(11,11)$

\# rwymnt $(11,11)$, flxme $(11,11)$, flymnt $(11,11)$, fwxmnt $(11,11)$,

\# fwymnt (11,11), wlymint (11), wwymn (11)

common/shear/rfshr, rfwshr, flshr, flwshr, wlyshr (11), wwyshr (11)

common/silo/cmthk $(2,3)$, comcvx $(2,3)$, comcvy $(2,3)$, cvrdns, cvrthk,

* flangl, idflag, ommthk $(2,3)$, ostlrd (3), osttkc, osttkt,

\# otncvx $(2,3)$, otncry $(2,3)$, silrad, slangl, sldns, slhght,

\# stlrad (3), stlspc (3), sttkcm, sttktn, submod, tencvx $(2,3)$,

\# tencvy $(2,3)$, wstans, wsthk, wstht

dimension flfdpx $(11,11)$, flfdpy $(11,11)$, flfspx $(11,11)$, flfspy $(11,11)$

data $\mathrm{pi} / 3.141592653589793 /$

data strred/.9/

c..... Calculate time-dependent parameters used in cracking analysis.

time $=$ iyear $* 365$

comstr $=\operatorname{amin} 1($ time $/(c f a+c f b \star t i m e) \star c o m 28 d * a t t a c k$, constr*attack) 
conmod $=5.7 e 4^{\star}$ sqrt $($ comstr $) /(1 .+$ crpcof $)$

ratmod $=\mathrm{stlmod} /$ conmod

rupmod $=7.5 *$ sqrt $($ comstr $)$

fldstx $=\operatorname{cmthk}(1,3)-$ tencvx $(1,3)$

fldsty $=\operatorname{cmthk}(1,3)$-tencvy $(1,3)$

starcm $=0$

startn $=\operatorname{stlrad}(3) \star \star 2 * p i / s t l s p c(3)$

comnti $=$ cmthk $(1,3) * * 3 / 12$.

crkmtf $=$ cnmnti $/(0.5 * \operatorname{cmthk}(1,3)) *$ rupmod

c.....Calculate ultimate strength for floor.

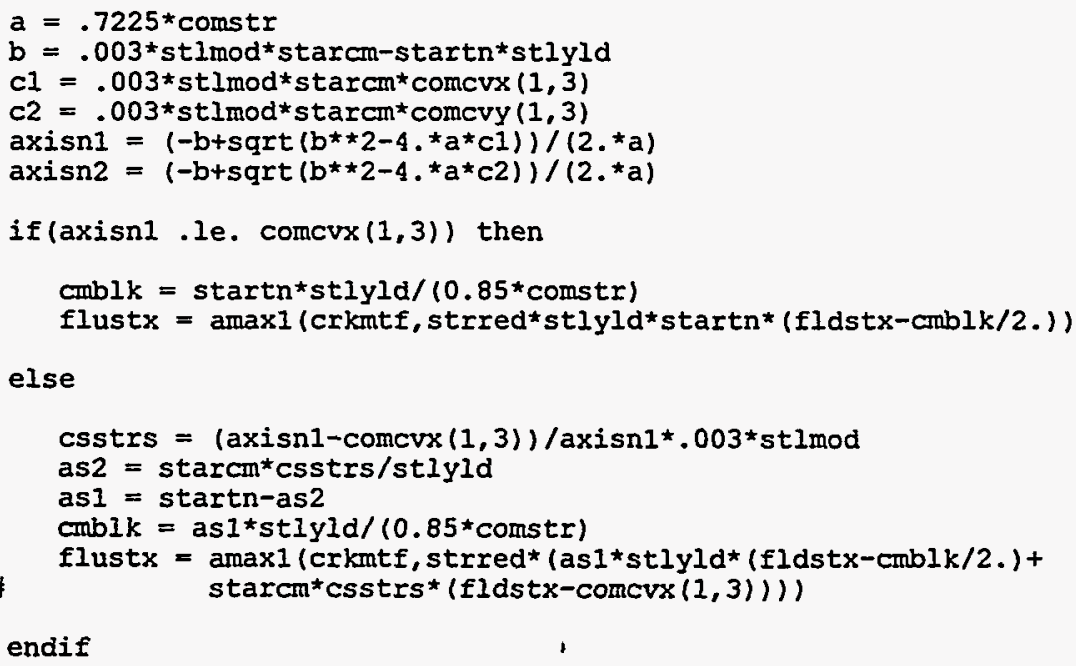

if(axisnl .le. comcrx $(1,3))$ then

cmblk = startn*stlyld $/\left(0.85^{\star}\right.$ comstr $)$

flustx $=$ amaxl (crkmtf, strred*stlyld*startn* (fldstx-cmblk/2.))

else

csstrs $=(\operatorname{axisn} 1-\operatorname{comcvx}(1,3)) / \operatorname{axisn} 1 * .003 *$ stlmod

as2 = starcmcsstrs/stlyld

as1 = startn-as 2

cmblk $=$ as $1 * s t l y l d /(0.85 *$ comstr $)$

flustx $=\operatorname{amax} 1$ (crkmtf, strred* (as1*stlyld* (fldstx-cmblk/2.) + starcm*csstrs* $(f 1 d s t x-\operatorname{comcvx}(1,3)))$

endif

\#

if(axisn2 . Ie. comcvy $(1,3)$ ) then

cmblk $=$ startn*stlyld/ $(0.85 *$ comstr $)$

flusty $=\operatorname{amax} 1($ crkmtf, strred*stlyld*startn*(fldsty-cmblk/2.))

else

csstrs $=(\operatorname{axisn} 2-\operatorname{comcvy}(1,3)) / \operatorname{axisn} 2 * .003 * s t 3 \bmod$

as2 = starcm ${ }^{\star}$ csstrs/stlyld

as1 $1=$ startn-as2

cmblk $=$ as $1 * s t l y l d /(0.85 *$ comstr $)$

\#

flusty $=\operatorname{amax} 1$ (crkmtf, strred* (as $1^{*}$ stlyld* (fldsty-cmblk/2.) +

endif

c..... Calculate cracking moment of inertia for floor for $x$ and $y$ directions.

$\mathrm{aa}=0.5$

$\mathrm{bb}=$ starcm* $($ ratmod -1.$)+$ startn*ratmod

$c c x=\operatorname{comcvx}(1,3) * \operatorname{starcm} *($ ratmod -1.$)-$ fldstx*ratmod*startn

$c c y=$ comcvy $(1,3) *$ starcm* $($ ratmod -1.$)$-fldsty*ratmod*startn

rtt1x $=(-b b+5 q r t(b b * \star 2-4 \cdot * a a * c c x)) /(2 . * a a)$

rtt1y $=\left(-b b+\right.$ sqrt $\left.\left(b b * \star 2-4 \cdot{ }^{\star} a a^{\star} c c y\right)\right) /(2 . \star a a)$

rtt $2 x=(-b b-s q r t(b b * \star 2-4 . \star a a * c c x)) /(2 . \star a a)$

rtt2y $=\left(-b b-s q r t\left(b b * \star 2-4 .{ }^{*} a a^{\star} c c y\right)\right) /(2 . \star a a)$

axneux $=\operatorname{rtt} 1 \mathrm{x}$

axneuy $=$ rttly

crmtix $=0.333 *$ axneux $* * 3+\operatorname{starcm} *($ ratmod-1.)*(axneux-comcvx $(1,3))$

\# $\quad \star \star 2+$ ratmod*startn* (fldst $x$-axneux) $* \star 2$

crmtiy $=0.333^{*}$ axneuy $* * 3+\operatorname{starcm} *($ ratmod-1. $) *($ axneuy-comcvy $(1,3))$

\# $\quad \star \star 2+$ ratmod*startn* (fldsty-axneuy) $* * 2$

c.... Calculate cracking due to shear for floor of silo.

$\mathrm{xk}=(1.6+2.4 *($ sil rad $/ \mathrm{sil} \mathrm{rad}-0.5)) * 0.29$

shrstx $=1.7 *$ sqrt $($ comstr) $*$ fldstx

shrsty $=1.7 * \operatorname{sqrt}($ comst $r) *$ fldsty 


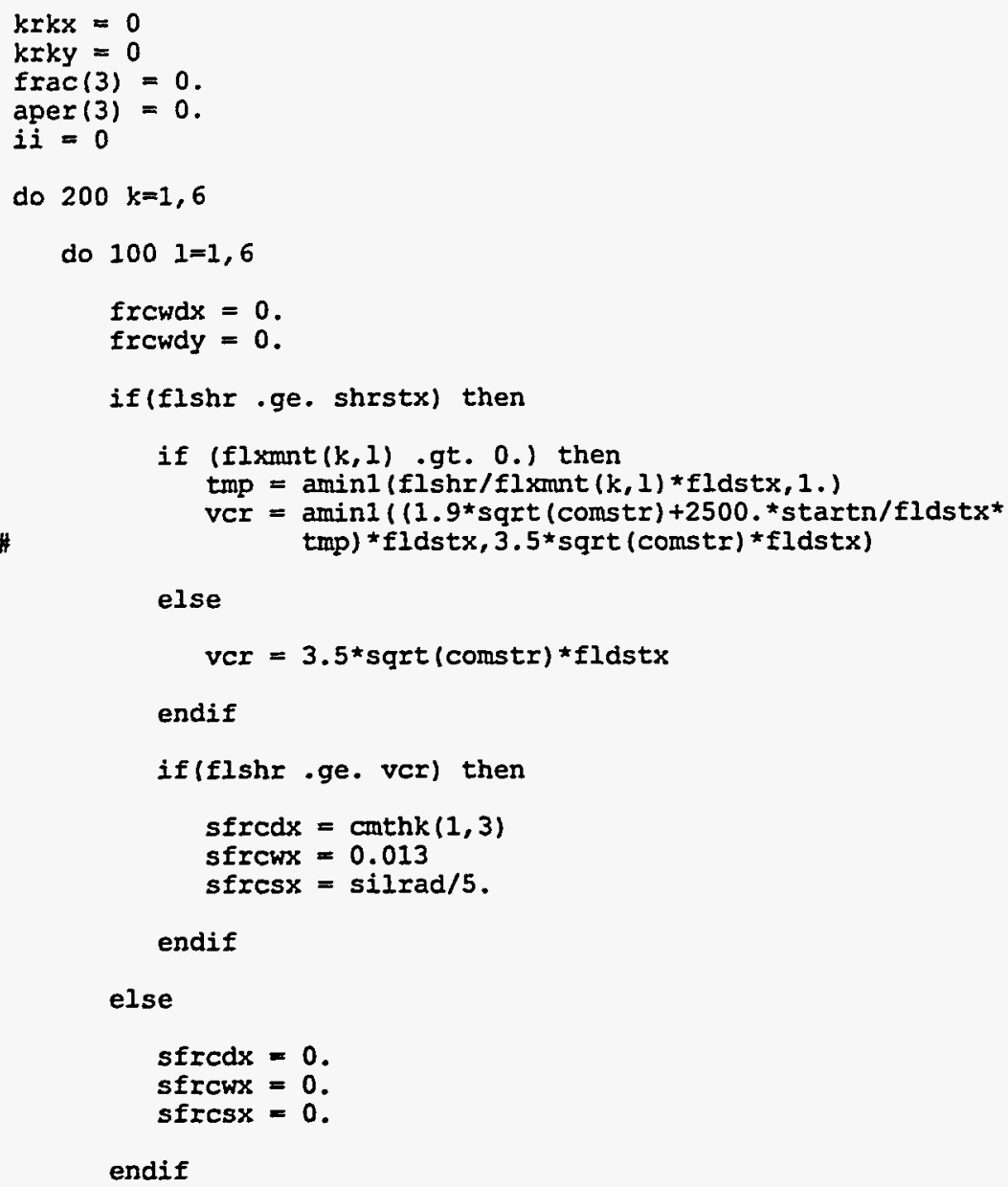

elseif (stlrad(3).1t.1.e-15 .and. flfspx $(k, 1)$.eq. 0.$)$ then

$q=\operatorname{ostlrd}(3) \star \star 2 * 1.571 /(\operatorname{stlspc}(3) * \operatorname{tencvx}(1,3))$

elseif (tencvx $(1,3)$.gt. 0 . .and. stlrad(3) .ge. $1 . e-15)$ then

$\mathrm{g}=\operatorname{stlrad}(3) \star \star 2 \star 1.571 /(\operatorname{stl} \operatorname{spc}(3) * \operatorname{tencvx}(1,3))$

endif

if (stlrad(3) .ge. 1.e-15) then

frspce $=0.5{ }^{*} x k^{*} \operatorname{sqrt}\left(2 .{ }^{*} \operatorname{stl} \operatorname{rad}(3) * \operatorname{stlspc}(3) / q\right)$

elseif (stlrad(3).1t.1.e-15 . and. flfspx (k,1).eq.0.) then

Erspce $=0.5{ }^{*} x k^{\star} \operatorname{sqrt}\left(2 .{ }^{*} \operatorname{ostlrd}(3) * \operatorname{stlspc}(3) / q\right)$

endif

if $(f l f s p x(k, 1)$.eq.0. .or. $f l f s p x(k, 1)$.ge.2.*frspce) 
endif

c.....x-moments exceed cracking moment but not ultimate strength of floor.

if (flxmnt $(k, 1)$.ge.crkmtf .and. flxment $(k, 1) .1 t$.flustx) then

$\#$

efmntx $=(\operatorname{crkmtf} / f l x m n t(k, 1)) \star \star 3 * \operatorname{cnmnti+(1.-(crkmtf)}$ flxmant $(k, 1)) \star \star 3) \star c r m t i x$

strsmx $=$ flxmnt $(k, 1) \star a x n e u x /$ efmntx

stItnx $=$ ratmod $\star f l x m n t(k, l) *$ (fldstx-axneux) $/$ efmntx

\#

axsnex $=\mathrm{fldstx} /($ stltnx/stlmod+strsmx/conmod $) *($ stltnx $/$ stlmod+csstrn) +tencvx $(1,3)$

betax $=\operatorname{axsnex} /(\operatorname{axsnex}-\operatorname{tencvx}(1,3))$

flfdpx $(k, 1)=$ axsnex

frcwdx $=\operatorname{flfspx}(k, 1) *($ stltnx/stlmod*betax+csstrn $)$

endif

c.....x-moments exceed ultimate strength of floor.

if ( $f$ lxmnt $(k, 1)$.ge.flustx . and.

$\# \quad$ flfdpx $(k, 1)$.it.cinthk $(1,3))$ then

flfdpx $(k, 1)=\operatorname{conthk}(1,3)$

\#

frcwdx $=\operatorname{amin} 1(($ stlyld/stlmod+csstrn $) \star f l f s p x(k, 1), 3 \cdot e-3 *$ flfspx $(k, 1))$

endif

c.....Perform calculations for $y$ direction of floor. Start with shear c.....cracking calculations.

if (flshr.ge. shrsty) then

if (flymnt $(k, 1) . g t$. 0. ) then

tmp $=\operatorname{amin} 1($ flshr $/$ flymnt $(k, 1) *$ fldsty, 1.$)$

vcr $=\operatorname{amin} 1((1.9 *$ sqrt $($ comstr $)+2500$. startn/fldsty*

\# tmp) * fldsty, $3.5 *$ sqrt (comstr) * fldsty)

else

vcr $=3.5^{\star} \operatorname{sqrt}($ comstr $) \star f l d s t y$

endif

if (flshr.ge. vcr) then

sfrcdy $=$ cmthk $(1,3)$

sfrcwy $=0.013$

sfrcsy $=$ silrad $/ 5$.

endif

else

$$
\begin{aligned}
& \text { sfrcdy }=0 . \\
& \text { sfrcwy }=0 . \\
& \text { sfrcsy }=0 .
\end{aligned}
$$

endif

c..... Calculate fracture characteristics for $y$ direction.

if (flymnt $(k, 1)$.ge. crkmtf) then

if (tencvy $(1,3)$.eq.0. .and. flfspy $(k, 1)$.eq.0.) then

$\mathrm{q}=\operatorname{stl} \mathrm{rad}(3) \star \star 2 \star 1.571 /(\operatorname{stl} \operatorname{spc}(3) \star \operatorname{otncvy}(1,3))$

$\#$

if (stlrad(3). .1t. 1.e-15) q $=\operatorname{ostl} \operatorname{rd}(3) \star \star 2 \star 1.571$ / (stlspc $(3)$ otncvy $(1,3)$ ) 
elseif (stlrad(3).It.1.e-15 .and. flfspy $(k, 1) \cdot$ eq.0.) then

$q=\operatorname{ostlrd}(3) * * 2 * 1.571 /(\operatorname{stlspc}(3) *$ tencvy $(1,3))$

elseif (tencvy $(1,3) . g t .0$. and. $\operatorname{stl} \operatorname{lad}(3) \cdot g e \cdot 1 . e-15$ ) then

$q=\operatorname{st} 1 \operatorname{rad}(3) * \star 2 * 1.571 /(\operatorname{stl} \operatorname{spc}(3) * \operatorname{tencvy}(1,3))$

endif

if (stlrad(3) .ge. 1.e-15) then

frspce $=0.5 * x k * \operatorname{sqrt}\left(2 .{ }^{*} \operatorname{stl} \operatorname{rad}(3) * \operatorname{stlspc}(3) / q\right)$

elseif (stlrad(3).1t.1.e-15 .and. flfspy $(k, 1)$ eq.0.) then

frspce $=0.5 * x k * \operatorname{sgrt}\left(2 .{ }^{*} \operatorname{ostlrd}(3) * \operatorname{stlspc}(3) / q\right)$

endif

$\#$

if (flfspy $(k, 1)$ eq.0. .or. flfspy $(k, 1) \cdot g e .2 . * f r s p c e)$

flfspy $(k, l)=$ frspce

endif

c.....y-moments exceed cracking moment but not ultimate strength of floor.

if (flymnt $(k, 1)$.ge.crkmtf .and. flymnt $(k, 1)$.1t.flusty) then

efmnty $=($ crkmtf $/ f 1 y \operatorname{mnt}(k, 1)) \star \star 3 \star c n m n t i+(1 .-($ crkmtf $/$

flymnt $(k, 1)) * \star 3) \star$ crmtiy

strsmy $=$ flymnt $(k, 1) * a x n e u y /$ efmnty

stltny = ratmod*flymnt $(k, 1) *($ fldsty-axneuy $) / e f m n t y$

axsney $=$ fldsty $/($ stltny/stlmod+strsmy/conmod)* (stltny/

\# $\quad$ stimod+csstrn)+tencvy $(1,3)$

betay $=$ axsney $/($ axsney-tencvy $(1,3))$

flfdpy $(k, I)=$ axsney

frcwdy $=$ flfspy $(k, 1) *($ stltny/stlmod*betay+csstrn $)$

endif

c.....y-moments exceed ultimate strength of floor.

if (flymint $(k, 1)$.ge.flusty .and.

\# $\quad$ Elfdpy $(k, 1)$.it.cmthk $(1,3))$ then

flfdpy $(k, 1)=\operatorname{cmthk}(1,3)$

frcwdy $=\operatorname{aminl}(($ stlyld/stlmod+csstrn $) \star f l f \operatorname{spy}(k, 1), 3 \cdot e-3 *$

\# $\quad$ flfspy $(k, 1))$

endif

c...... Calculate cracking due to corrosion once it begins.

if (icrflg(3).eq.1 and. (k+1).eq.2) call $\operatorname{ccrack}(3$, iyear)

c..... Calculate average crack characteristics for floor.

if (anthk $(1,3)$.eq. 0.$)$ then

aper $(3)=0$.

$\operatorname{trac}(3)=0$.

return

else

$f \max =.75^{\star} \operatorname{cmthk}(1,3)$

depth $=\operatorname{amax} 1(\operatorname{flfdpx}(k, 1), \operatorname{sfrcdx}, \operatorname{crfrcd}(3))$

if (depth .ge. fmax) then

tmp1 $=0$.

$\operatorname{tmp} 2=0$

$\operatorname{tmp} 3=0$.

$k r k x=k r k x+1$

if $(f \operatorname{lspx}(k, 1)$.gt. 0.) tmpl $=\operatorname{silrad} / 5 . / f l f s p x(k, 1)$ 
if (crfrcs (3) .gt. 0.) tmp $2=\operatorname{silrad} / 5 . / \operatorname{crfrcs}(3)$

if (sfrcsx .gt. 0. ) tmp3 = silrad/5./sfresx

$\operatorname{tmp}=\operatorname{tmp} 1+\operatorname{tmp} 2+\operatorname{tmp} 3$

aper $(3)=\operatorname{aper}(3)+($ frcwdx $* \operatorname{tmp} 1+\operatorname{crfrcw}(3) * \operatorname{tmp} 2+\operatorname{sfrcw} *$ tmp3)/tmp

$\operatorname{frac}(3)=\operatorname{frac}(3)+2 . * \operatorname{cmth} k(1,3) *\left(\operatorname{frcwdx} x^{*} \operatorname{silrad} / 5 . *\right.$ tmpl+sfrcwx*pi*silrad*tmp3)

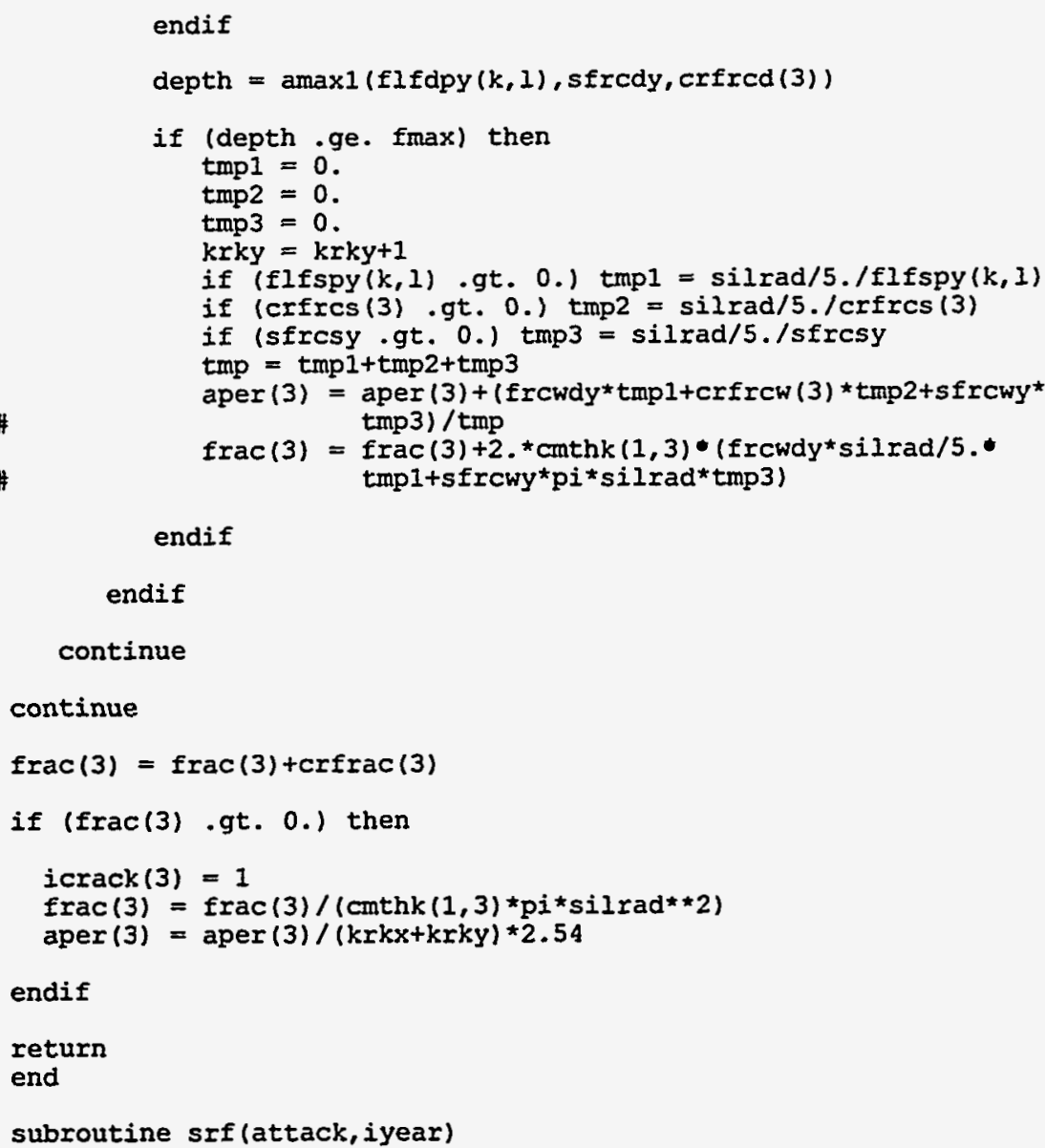

endif

endif

continue

$\operatorname{frac}(3)=\operatorname{frac}(3)+\operatorname{crfrac}(3)$

if ( $\operatorname{frac}(3)$.gt. 0.) then

icrack $(3)=1$

$\operatorname{frac}(3)=\operatorname{frac}(3) /(\operatorname{cmthk}(1,3) * p i * \operatorname{silrad} * * 2)$

$\operatorname{aper}(3)=\operatorname{aper}(3) /(k r k x+k r k y) * 2.54$

endif

return

end

subroutine srf(attack, iyear)

200 continue

Called by: source2
c
c Performs cracking analysis for silo roof.
Calls: ccrack

common/clcult/annprc, aper (3), attk (2,3), crfrac (3), crfrcd (3),

\# $\quad \operatorname{crfrcw}(3), \operatorname{crfrcs}(3)$, crpcof, csstrn, frac (3), icl (3), ico2 (3) ,

\# icrack (3), icrflg (3), ifail (3), isavel, isave 2 , ispl $(3), \mathrm{ph}(2,3)$, slfi,slfo, stlcor (3), xload, xperc (2)

common/concrt/ca, cacon, cagw, cap, ccdns, ccon, ccpor, cfa, cfb, clcon,

\# co3, com28d, conpsn, constr, phbeg, si, stlmod, stlyld, wCr, wtcmnt,

\# yngmod

common/moment/rfxmnt $(11,11), \operatorname{rfymnt}(11,11)$, Iwxmant $(11,11)$.

\# rwymnt $(11,11)$, flxmnt $(11,11)$, flymnt $(11,11)$, fwxmnt $(11,11)$,

\# fwyment (11,11), wlymat (11), wwyment (11)

comon/shear/rfshr, rfwshr, flshr, flwshr, wlyshr (11), wwyshr (11)

common/silo/cmthk $(2,3)$, comcvx $(2,3)$, comcvy $(2,3)$, cvrdns, cvrthk,

\# flangl, idflag, omnthk $(2,3)$, ostlrd ( 3$)$, osttkc, osttkt,

\# otncrx $(2,3)$, otncry $(2,3)$, silrad, slangl, sldns, slhght,

\# stlrad (3), stlspc (3), sttkcm, sttktn, submod, tencrx $(2,3)$.

\# tencry $(2,3)$, wstdns, wsthk, wstht 
dimension $\operatorname{rffdpx}(11,11), \operatorname{rffdpy}(11,11), \operatorname{rffspx}(11,11), \operatorname{Iffspy}(11,11)$

data pi/3.141592653589793/

data strred/.9/

c..... Calculate time-dependent parameters used in cracking analysis.

time $=$ iyear $* 365$.

comstr $=$ aminl (time/ (cfa+cfb*time)*com28d*attack, constr*attack)

conmod $=5.7 \mathrm{e} 4^{*} \mathrm{sqrt}($ comstr $) /(1 .+$ crpcof $)$

ratmod $=s t l m o d /$ conmod

rupmod $=7.5^{\star}$ sqrt (comstr)

rfdstx $=\operatorname{cmthk}(1,1)-$ tencrx $(1,1)$

rfdsty $=\operatorname{cmthk}(1,1)-$ tencvy $(1,1)$

starcm $=0$.

startn $=\operatorname{stl} \operatorname{rad}(1) * * 2 * p i / s t 1 \operatorname{spc}(1)$

cnmnti $=\operatorname{cmthk}(1,1) \star \star 3 / 12$.

crkmtr $=$ cnmnti $/(0.5 * \operatorname{cmthk}(1,1)) *$ rupmod

c..... Calculate ultimate strength for roof.

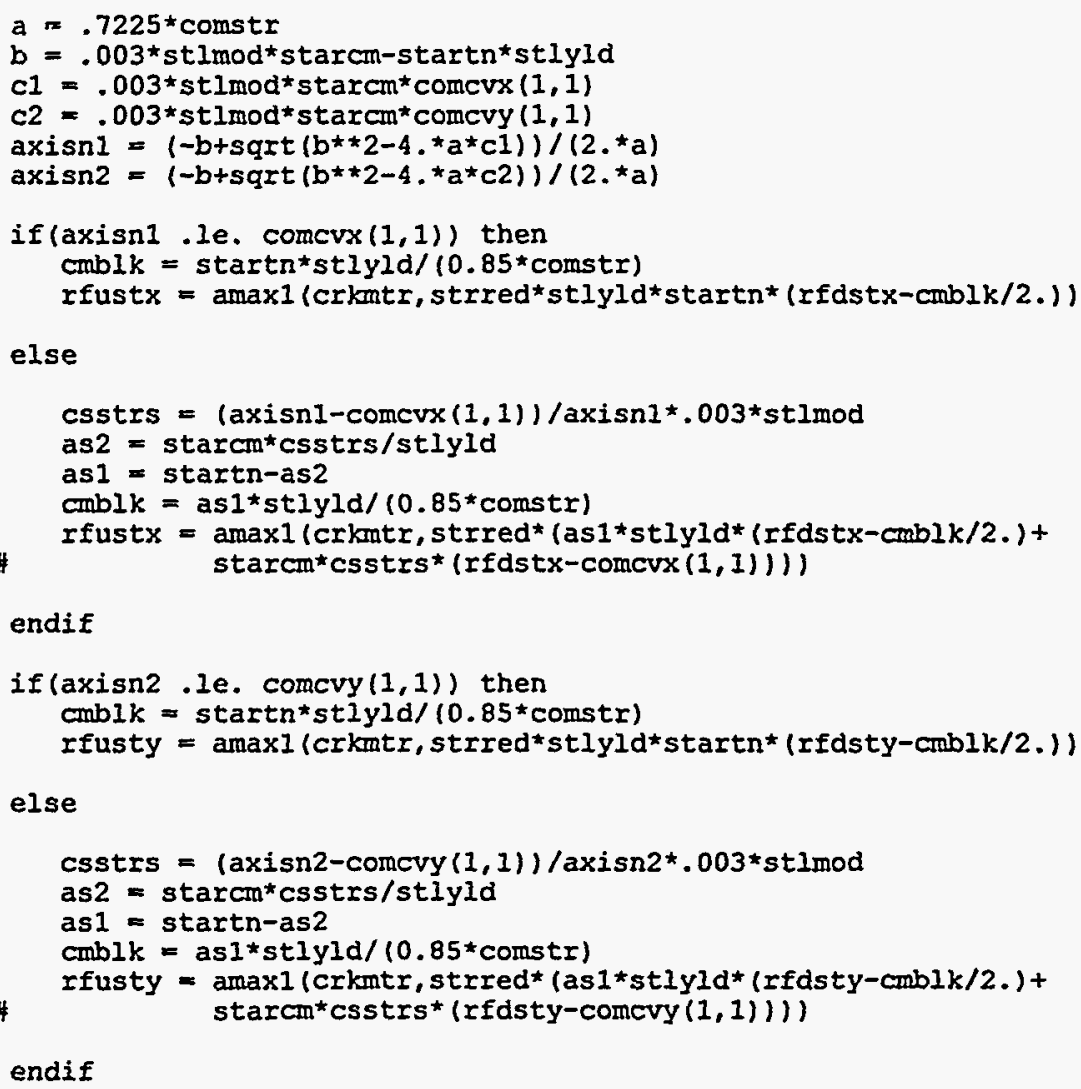

c..... Calculate cracking moment of inertia for roof for $x$ and $y$ directions.

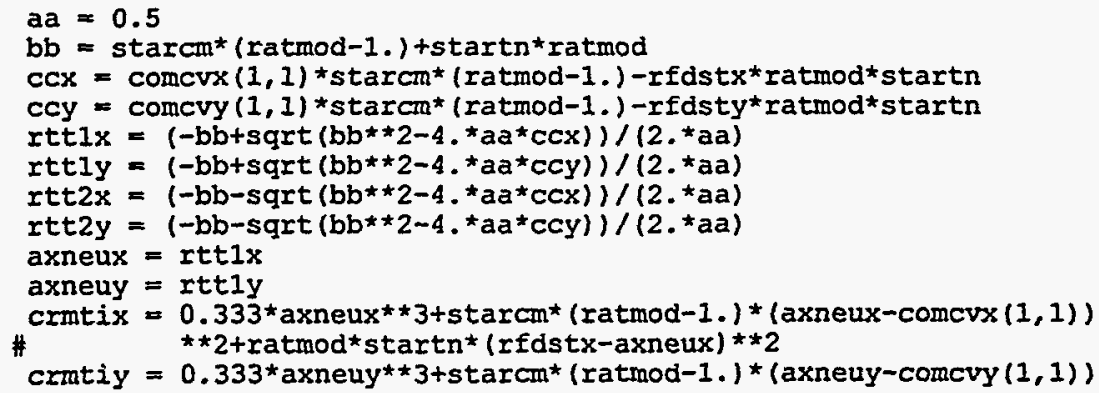


c......Calculate cracking due to shear for roof of silos.

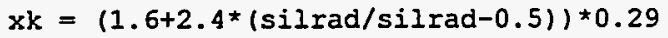

shrstx $=1.7 *$ sqrt (comstr) ${ }^{*}$ ffdstx

shrsty $=1.7 *$ sqrt $($ comstr $) *$ rfdsty

$k r k x=0$

krky $=0$

$\operatorname{frac}(1)=0$.

aper $(1)=0$.

do $200 k=1,6$

do $1001=1,6$

frcwdx $=0$.

frcwdy $=0$.

if (rfshr .ge. shrstx) then

if (rfxunt $(k, 1)$.gt. 0.) then

tmp $=\operatorname{amin} 1\left(\right.$ rfshr/rfxmit $\left.(k, 1){ }^{*} r f d s t x, 1.\right)$

vcr $=\operatorname{aminl}\left(\left(1.9^{\star}\right.\right.$ sqrt $($ comstr $)+2500$. *startn $/ \mathrm{rfdstx}$ * trap) * Ifdstx, 3.5*sqrt (comstr) * rfdstx)

$\#$

else

$v c r=3.5^{\star} \operatorname{sqrt}($ comstr $){ }^{*} r d s t x$

endif

if (rfshr.ge. vcr) then

$\operatorname{sfrcdx}=\operatorname{cmthk}(1,1)$

sfrcwx $=0.013$

$\operatorname{sfrcs} x=\operatorname{silrad} / 5$.

endif

else

$\operatorname{sfrcdx}=0$.

sfrchx $=0$.

$\operatorname{sfrcs} x=0$.

endif

c..... Calculate fracture characteristics for roof due to bending.

if (rfxmnt $(k, 1)$.ge. crkmtr) then

if (tencvx $(1,1)$.eq.0. .and. $\operatorname{rffspx}(k, 1)$.eq.0.) then

if (stlrad(1) .1t. 1.e-15) then

$q=\operatorname{ostlrd}(1) \star \star 2 \star 1.571 /(\operatorname{stlspc}(1) \star \operatorname{otncvx}(1,1))$

else

$q=\operatorname{stl} \operatorname{rad}(1) \star \star 2 \star 1.571 /(\operatorname{stlspc}(1) \star \operatorname{otncvx}(1,1))$

endif

elseif (stlrad(1).1t.1.e-15 .and. $\operatorname{rffspx}(k, 1)$.eq.0.) then

$q=\operatorname{ostlrd}(1) * \star 2 \star 1.571 /(\operatorname{stlspc}(1) * \operatorname{tencrx}(1,1))$

elseif (tencvx $(1,1) . g t .0$. .and. stlrad(1).ge.1.e-15) then

$q=\operatorname{stlrad}(1) \star \star 2 \star 1.571 /(\operatorname{stl} \operatorname{spc}(1) * \operatorname{tencvx}(1,1))$

endif 
if (stlrad(1) ge. 1.e-15) then

frspce $=0.5^{*} x k^{\star} \operatorname{sqrt}\left(2 .{ }^{*} \operatorname{st} l \operatorname{rad}(1) * \operatorname{stlspc}(1) / q\right)$

elseif ( $\operatorname{stl} \operatorname{rad}(1), 1 t \cdot 1, e-15$.and. $\operatorname{rffspx}(k, 1)$.eq.0.) then

frspce $=0.5^{\star} x k^{\star} \operatorname{sqrt}\left(2 .{ }^{*} \operatorname{ostlrd}(1)^{\star} \operatorname{stl} \operatorname{spc}(1) / q\right)$

endif

if $(\operatorname{rffspx}(k, 1)$.eq.0. .or. $\operatorname{rffspx}(k, 1) \cdot g e .2 . \star f r s p c e)$

$\#$ $\operatorname{rffspx}(k, 1)=$ irspce

endif

c.....x-moments exceed cracking moment but not ultimate strength of roof.

if ( $r$ fxmnt $(k, 1)$.ge.crkmtr .and. Ifxmnt $(k, 1), 1 t$.rfustx) then

\#

efmntx $=($ crkmtr $/$ rfxmnt $(k, 1)) * * 3 *$ cnmnt $i+(1 .-($ crkmtr $)$ rfxmnt $(k, 1)) * \star 3) *$ crmtix

strsmx $=$ rfxmnt $(k, 1) *$ axneux/efmntx

stltnx $=$ ratmod*rfxant $(k, 1) *($ rfdstx-axneux $) /$ efmntx

axsnex $=\mathrm{rfdstx} /($ stltnx/stlmod+strsmx/conmod $) *(s t l t n x /$

\# $\quad$ betax $=\operatorname{stlmod+\operatorname {csstrn})+\operatorname {tencvx}(1,1)}$

$\operatorname{rffdpx}(k, 1)=\operatorname{axsnex}$

frcwdx $=\operatorname{Iffspx}(k, I) \star\left(\right.$ stltnx $/$ stlmod ${ }^{*}$ betax+csstrn $)$

endif

c.....x-moments exceed ultimate strength of roof.

if (rfxmnt $(k, 1)$.ge.rfustx .and. $\operatorname{rffdpx}(k, 1) .1 t$. cmthk $(1,1)$ ) then

$\operatorname{rffdpx}(k, 1)=\operatorname{cmthk}(1,1)$

frcwdx $=\operatorname{amin} 1\left((\right.$ stlyld/stlmod+csstrn $){ }^{*} \operatorname{rffspx}(k, 1)$,

\#

$$
\left.3 . e-3^{*} \operatorname{Iffspx}(k, 1)\right)
$$

endif

c.....Perform calculations for $y$ direction of roof. Start with shear c.....cracking calculations.

if (rfshr .ge. shrsty) then

if (rfyment $(k, 1)$.gt. 0.$)$ then

tmp $=\operatorname{amin} 1($ rfshr/Ifymnt $(k, 1) * r f d s t y, 1$.

vcr $=\operatorname{aminl}\left(\left(1.9^{\star}\right.\right.$ sqrt (comstr) +2500 . $^{\star}$ startn $/ r f d s t y *$ tmp) *rfdsty, 3.5*sqrt (comstr) * rfdsty)

else

$v c r=3.5^{\star} s q r t($ comstr $) \star r f d s t y$

endif

if (rfshr .ge. var) then

sfrcdy $=\operatorname{cmthk}(1,1)$

sfrcwy $=0.013$

sfrcsy $=$ silrad $/ 5$.

endif

else

sfrcdy $=0$.

sfrcwy $=0$.

sfrcsy $=0$. 
endif

c..... Calculate fracture characteristics for $y$ direction.

if (rfymnt $(k, 1)$.ge. crkmtr) then

if (tencvy $(1,1)$.eq. 0 . and. $\operatorname{rffspy}(k, 1)$.eq.0.) then

$\mathrm{q}=\operatorname{stl} \mathrm{rad}(1) \star \star 2 * 1.571 /(\operatorname{stlspc}(1) \star \operatorname{otncvy}(1,1))$

\#

if (stlrad(1) .It. 1.e-15) $q=\operatorname{ostlrd}(1) * * 2 \star 1.571 /$ (stlspe (1)*otncvy $(1,1)$ )

elseif (stlrad(1).1t.1.e-15 .and. rffspy $(k, 1)$.eq.0.) then

$\mathrm{q}=\operatorname{ostlrd}(1) \star \star 2 \star 1.571 /(\operatorname{stl} \operatorname{spc}(1) \star \operatorname{tencvy}(1,1))$

elseif (tencvy $(1,1) . g t .0$. .and. stlrad(1).ge.1.e-15) then

$q=\operatorname{stl} \operatorname{rad}(1) \star \star 2 \star 1.571 /(\operatorname{stl} \operatorname{spc}(1) \star \operatorname{tencvy}(1,1))$

endif

if (stlrad(1) .ge. 1.e-15) then

frspce $=0.5^{*} x k^{*} \operatorname{sqrt}\left(2 .{ }^{*} \operatorname{stl} \operatorname{rad}(1)^{*} \mathrm{stlspc}(1) / q\right)$

elseif (stlrad(1).1t.1.e-15 .and. rffspy $(k, 1) . e q .0$.$) then$

frspce $=0.5^{*} x k^{*} \operatorname{sgrt}\left(2 .{ }^{*}\right.$ ostlrd (1)*stlspc(1)/q)

endif

if $(\operatorname{rffspy}(k, 1)$.eq.0. .or. Iffspy $(k, 1) \cdot g e .2 . \star$ frspce)

$\operatorname{rffspy}(k, 1)=$ frspce

endif

c..... Y-moments exceed cracking moment but not ultimate strength of roof.

if (rfymnt $(k, 1)$.ge.crkmtr .and. rfymnt $(k, 1) .1 t$.rfusty) then

efmnty $=($ crkmtr/rfymnt $(k, 1)) * * 3 *$ cnmnti+(1. - (crkmtr $/$ Ifymnt $(k, 1)) * \star 3) *$ crmtiy

strsmy $=$ rfymnt $(k, 1) *$ axneuy/efmnty

stltny $=$ ratmod*rfymnt $(k, 1) *$ (rfdsty-axneuy) /efmnty

axsney $=\mathrm{rfdsty} /($ stltny/stlmod+strsmy/conmod $) *($ stitny/

\# stimod+csstrn)+tencry $(1,1)$

betay $=$ axsney $/(\operatorname{axsney}-\operatorname{tencvy}(1,1))$

$\operatorname{rffdpy}(k, 1)=$ axsney

frcwdy $=\operatorname{Iffspy}(k, 1) *($ stltny/stlmod*betay+csstrn $)$

endif

c..... Y-moments exceed ultimate strength of roof.

if (rfymnt $(k, 1)$.ge.rfusty .and.

\# $\quad$ rffdpy $(k, 1) \cdot i t$. cmthk $(1,1))$ then

$\operatorname{rffdpy}(k, 1)=\operatorname{conthk}(1,1)$

frcwdy $=\operatorname{amin} 1(($ stlyld $/$ stlmod+csstrn $) \star \operatorname{rfspy}(k, 1)$,

$\#$ 3.e-3*rffspy $(k, 1))$

endif

c.....Calculate cracking due to corrosion once it begins.

if (icrfig(1).eq. 1 and. $(k+1) . e q .2)$ call ccrack(1,iyear)

c..... Calculate average crack characteristics for roof.

if (cmthk $(1,1)$.eq. 0.$)$ then

$\operatorname{frac}(1)=0$. 
$\operatorname{aper}(1)=0$.

return

else

$f \max =.75^{\star} \operatorname{conthk}(1,1)$

depth $=\operatorname{amaxl}(\operatorname{Iffdpx}(k, I), \operatorname{sfrcdx}, \operatorname{crfrcd}(1))$

if (depth .ge. fmax) then

tmp1 $=0$.

tmp2 $=0$.

$\operatorname{tmp} 3=0$.

$k r k x=k r k x+1$

if $(\operatorname{rffspx}(k, 1)$.gt. 0.) tmpl $=\operatorname{silrad} / 5 . / \operatorname{rffspx}(k, 1)$

if (crfrcs(1) .gt. 0.) tmp2 = silrad/5./crfrcs (1)

if (sfrcsx .gt. 0.$)$ tmp $3=\operatorname{silrad} / 5$. $/$ sfrcs $x$

tmp $=$ tmp $1+t m p 2+\operatorname{tmp} 3$

$\operatorname{aper}(1)=\operatorname{aper}(1)+($ frcwdx $\star \operatorname{tmp} 1+\operatorname{crfrcw}(1) \star \operatorname{tmp} 2+\operatorname{sfrcwx}$ * tmp3) / tmp

$\operatorname{frac}(1)=\operatorname{frac}(1)+2 .{ }^{*} \operatorname{cmthk}(1,1) *(\operatorname{frcwdx} * \operatorname{silrad} / 5 . *$ tmp $1+$ sfrcwx*pi*silrad*tmp 3 )

endif

depth $=\operatorname{amax} 1(\operatorname{rffdpy}(k, 1), \operatorname{sercdy}, \operatorname{crfrcd}(1))$

if (depth .ge. fmax) then

tmpl $=0$.

$\operatorname{tmp} 2=0$.

$\operatorname{tmp} 3=0$.

$k x k y=k x k y+1$

if $($ Iffspy $(k, 1)$.gt. 0.$)$ tmpl $=\operatorname{silrad} / 5 . / \operatorname{rffspy}(k, 1)$

if (crercs(1) .gt. 0.) tmp2 $=\operatorname{silrad} / 5$./crfrcs (1)

if (sfrcsy .gt. 0.) tmp $3=$ silrad/5./sfresy

$\operatorname{tmp}=\operatorname{tmp} 1+\operatorname{tmp} 2+t m p 3$

aper $(1)=\operatorname{aper}(1)+($ frcwdy*tmp $1+\operatorname{crfrcw}(1) * \operatorname{tmp} 2+\operatorname{sfrcwy} *$ $\operatorname{tmp} 3) / \operatorname{tmp}$

$\operatorname{frac}(1)=\operatorname{frac}(1)+2 .{ }^{*} \operatorname{coth} k(1,1) \bullet($ frcwdy*silrad/5.* tmp $1+$ sfrcwy*pi*silrad*tmp 3$)$

endif

endif

100 continue

200 continue

$\operatorname{frac}(1)=\operatorname{frac}(1)+\operatorname{crfrac}(1)$

if (frac(1) .gt. 0.) then

icrack $(1)=1$

$\operatorname{frac}(1)=\operatorname{Erac}(1) /\left(\operatorname{cmthk}(1,1) \star \mathrm{pi}^{\star} \operatorname{silrad} * \star 2\right)$

$\operatorname{aper}(1)=\operatorname{aper}(1) /(k r k x+k r k y) \star 2.54$

endif

return

end

subroutine sulfate(iyear)

\section{Called by concrete}

Calculates loss of concrete thickness due to sulfate attack.

Calls: none

common/chemcl/cl, co2, 02, so4i, so40, xmg2, dfalk, dfcaoh, dfcl, dfco2, 
\# dfo2, afso4, casol, crbsol, xngsol

common/clcult/annprc, aper (3), attk (2,3), crfrac (3), crfrcd (3),

\# crfrcw (3), crfrcs (3), crpcof, csstrn, frac (3), icl (3), ico2 (3),

\# icrack (3), icrflg (3), ifail (3), isavel, isave2, ispl (3), ph (2, 3), slfi, slfo, stlcor (3), xload, xperc (2)

common/concrt/ca, cacon, cagw, cap, ccdns, ccon, ccpor, cfa, cfb, clcon,

\# co3, com28d, conpsn, constr, phbeg, si, stlmod, stlyld, wcr, wtcmnt,

\# yngmod

common/silo/cmthk $(2,3)$, comcvx $(2,3)$, comcvy $(2,3)$, cvrdns, cvrthk

\# flangl, idflag, ommthk $(2,3)$, ostlrd (3), osttkc, osttkt,

\# $\quad$ otncvx $(2,3)$, otncvy $(2,3)$, silrad, slangl, sldns, slhght,

stlrad (3), stlspc (3), sttkcm, sttktn, submod, tencvx $(2,3)$ tencvy $(2,3)$, wstans, wsthk, wstht

c.....Rate of degradation calculated as per Atkinson and Hearne.

if (iyear.eq. 1) then

c.....Begin outside disposal facility calculations.

$\operatorname{tmp}=1.24$

so40 $=5040 * 1000$.

100 continue

c.....Estimate ettringite concentration.

$c e=$ wtcmint $\star t m p$

c..... Calculate reaction zone thickness at which spalling occurs.

xspl $=2 . * 1 . * 10 . *(1-\operatorname{conpsn}) /($ yngmod* $(1.8 \mathrm{e}-6 * \operatorname{ce}) * 2)$

c.....Calculate time when spalling occurs.

$\operatorname{tspl}=x s p l * \star 2 * \mathrm{ce} /(2, * \mathrm{dfso} 4 * s 040)$

$t=10 . \star \star(\operatorname{tmp} / .32-a \log 10(5040)+a \log 10(3577)+.a \log 10(12.2))$

$\operatorname{tmp}=\operatorname{tmp} * .99$

if(tspl.1t.t) go to 100

c..... Concrete loss from outside of disposal facility.

slfo $=x \operatorname{spl} \star 39.37 /$ tspl $\ 3.15 e 7$

c..... Begin inside disposal facility calculations.

$\operatorname{tmp}=1.24$

so4i $=$ so4i $\star 1000$.

200

continue

c..... Estimate ettringite concentration.

ce $=$ wtcmnt $\star \operatorname{tmp}$

c..... Calculate reaction zone thickness at which spalling occurs.

xspl $=2 . \star 1 . \star 10 . \star(1-$ conpsn $) /($ yngmod $*(1.8 e-6 \star c e) \star \star 2)$

c..... Calculate time when spalling occurs.

$\operatorname{tspl}=x \operatorname{spl}{ }^{\star *} 2 * \mathrm{ce} /\left(2 .{ }^{*} \mathrm{dfs} 04^{\star} \mathrm{so4i}\right)$

$t=10 . \star \star(\operatorname{tmp} / .32-a \log 10($ so4i) $+a \log 10(3577)+.\operatorname{alog} 10(12.2))$

tmp $=t_{m p} .99$

if(tspl.1t.t) go to 200

c..... Concrete loss from inside of disposal facility.

slfi $=x s p l * 39.37 /$ tspl $13.15 \mathrm{e} 7$

endif 


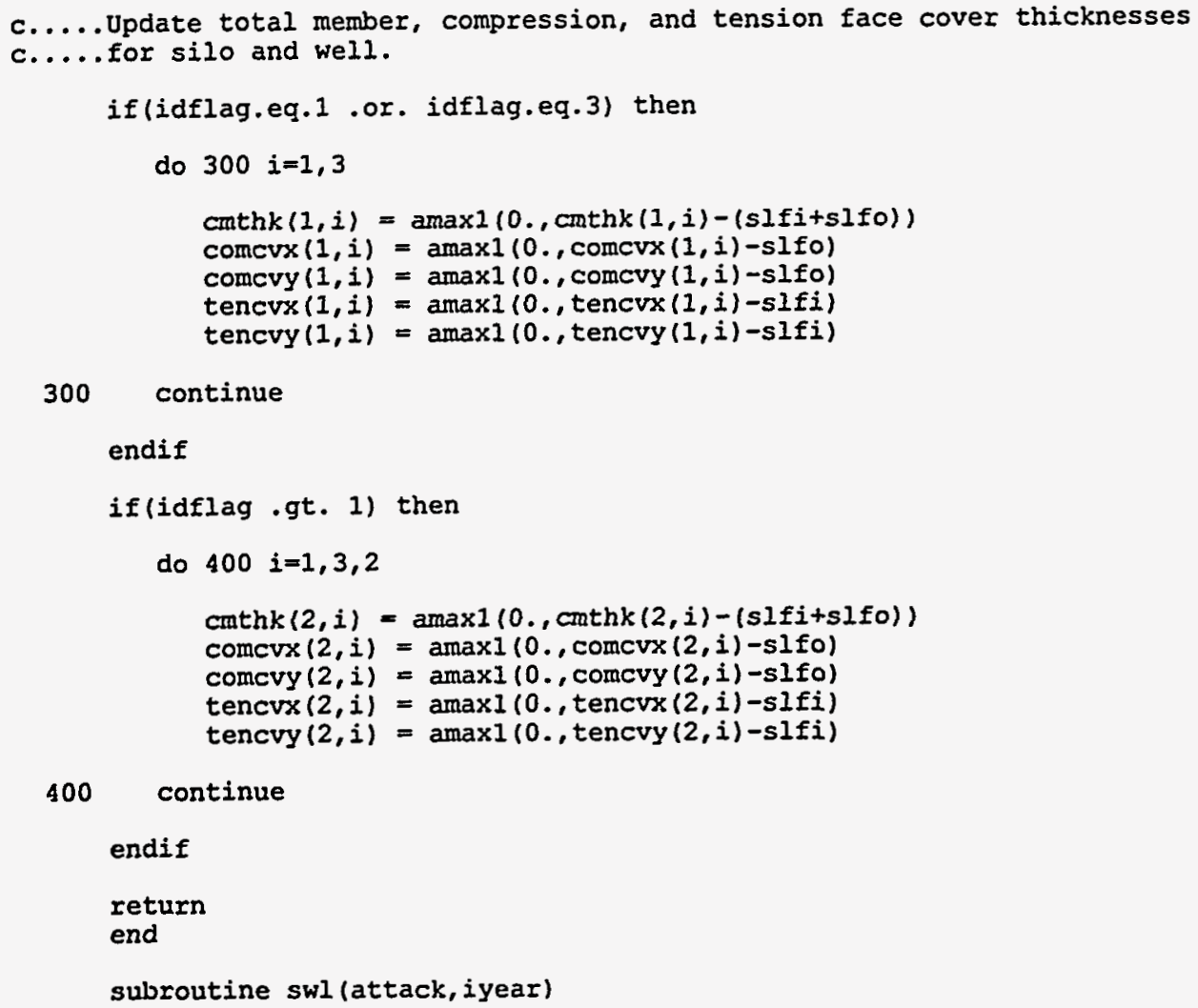


wldsty $=\operatorname{cmthk}(1,2)-\operatorname{tencvy}(1,2)$

starcm $=0$.

startn $=0$.

if (sttktn .gt. 0. ) then

rupmod $=7.5^{\star}$ sqrt $($ comstr)

else

rupmod $=3.25 *$ sqrt (comstr)

sstred $=.65$

endif

comnti $=$ cmthk $(1,2) \star \star 3 / 12$.

crkmtw $=$ cnmti $/(0.5 \star$ cmthk $(1,2)) \star$ rupmod

c..... Calculate ultimate strength for silo wall.

$a=.7225 *$ comstr

$\mathrm{b}=$ sttkcm*stlyld+.003*stlmod*starcm-startn*stlyld-sttktn*stlyld

$c=.003^{*}$ stlmod*starcm* comcvx $(1,2)$

axsneu $=(-b+\operatorname{sqrt}(b * \star 2-4 . * a * c)) /(2, \star a)$

if (axsneu . 1e. comcrx $(1,2)$ ) then

cmblk = (startn*stlyld+sttktn*stlyld-sttkcm*stlyld)/ (.85*comstr)

templ = sstred* (stlyld*startn* (wldstx-cmblk/2.) + sttktn*stlyld*(cmthk $(1,2)+$ sttktn/2.-cmblk/2.)+sttkcm* stlyld* (cmblk/2.+sttkcm/2.))

wlustx $=\operatorname{amaxl}($ crkmtw, templ)

else

csstrs $=($ axsneu-comcvx $(1,2)) /$ axsneu*.003*stimod

as2 = starcm ${ }^{\star}$ csstrs/stlyld

as1 = startn-as2

cmblk $=$ as $1 *$ stlyld $/(0.85 *$ comstr $)$

temp1 = sstred* (as1*stlyld* (wldstx-cmblk/2. $)+$

starcm*csstrs* (wldstx-comcvx $(1,2))+$ sttktn*stlyld* (cmthk $(1,2)+$ sttktn/2.-cmblk/2.) +sttkcm*stlyld* (cmblk/

2.+sttkcm/2.))

wlustx $=\operatorname{amax} 1$ (crkmtw, templ)

endif

c...... Calculate cracking moment of inertia for walls for $x$ and $y$ directions.

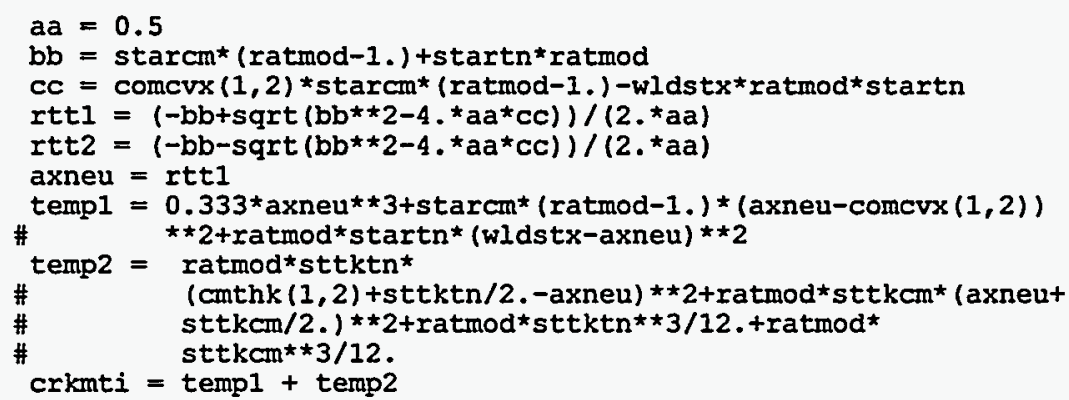

c..... Calculate stability force for use in ring compression cracking analysis.

$\operatorname{tmp} 1=0.85 * 0.7 *$ comstr* $($ cmthk $(1,2)-($ starcm + startn $))+$ stlyld*

\# (starcm+startn)

tmp2 $=$ conmod ${ }^{*} \operatorname{cmthk}(1,2) \star \star 3 /(12 . *(1-\operatorname{conpsn} * \star 2))$

tmp5 $=0$.

nsave $=1$

do $100 \mathrm{n}=2,10$ 


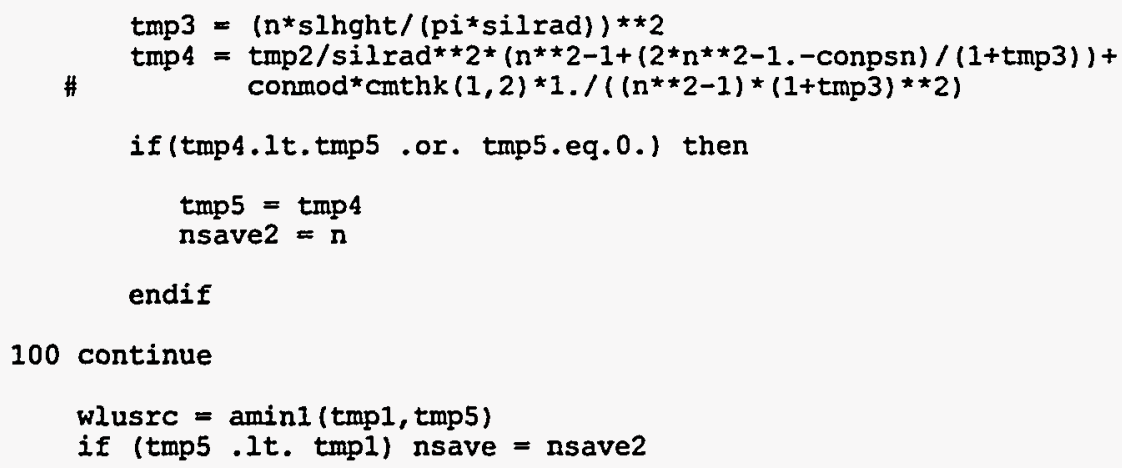

c.....Calculate compression strength for compression cracking analysis c.....for vertical wall.

$\operatorname{tmpl}=0.55 * 0.7 * \operatorname{conthk}(1,2) *$ comstr tmp4 $=0$.

do $200 \mathrm{~m}=1,5$

$\#$

tmp3 $=\operatorname{tmp} 2 / \operatorname{singht}{ }^{\star \star} 2 \star m \star \star 2 * p i \star \star 2+\operatorname{conmod} * \operatorname{cm} t h k(1,2) \star$

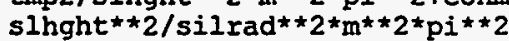

if (tmp3.1t.tmp4 .or. tmp4.eq.0.) tmp4 $=\operatorname{tmp} 3$

200 continue

wlustc $=\operatorname{amin} 1(\operatorname{tmp} 1, \operatorname{tmp} 4)$

c......Begin cracking analysis.

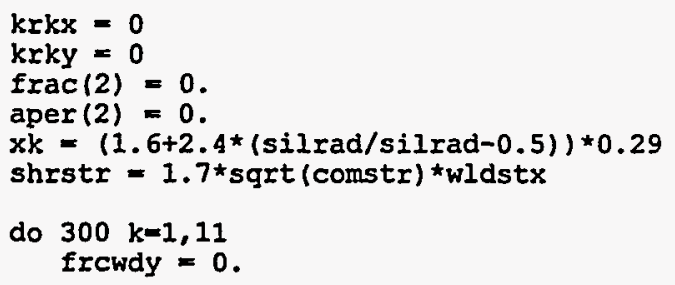

c..... Cracking analysis due to ring compression and compression of c.....vertical wall.

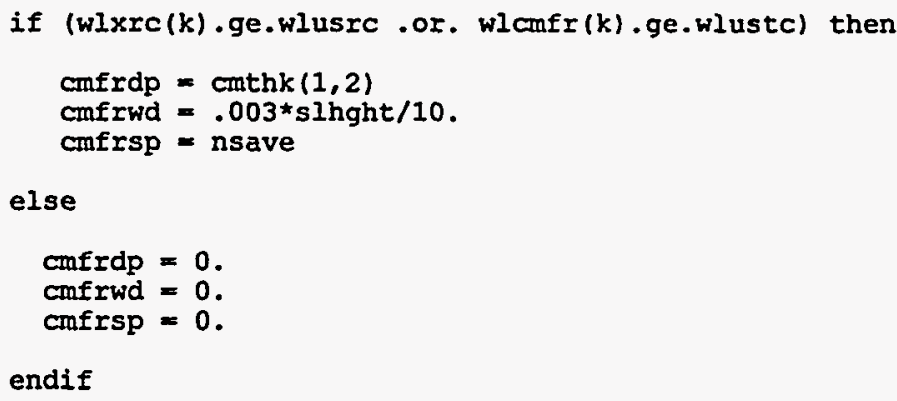


endif

if (wlyshr(k) .ge. vcr) then

sfrcdy $=\operatorname{cmthk}(1,2)$

sfrcwy $=0.013$

sfresy $=$ slhght $/ 10$.

else

sfrcdy $=0$.

sfrcwy $=0$.

sfresy $=0$.

endif

c..... Calculate fracture characteristics for horizontal $(x)$ direction due to c......bending.

if (wlymnt (k) .ge. crkmtw) wlfrsp(k) = slhght $/ 10$.

c......Moments exceed cracking moment but not ultimate strength of wall.

if (wlymnt(k).ge.crkmtw .and. wlymant(k).lt.wlustx) then

$\#$

efmnt $=(c r k m t w / w l y m n t(k)) \star \star 3 *$ cnmnti+(1.-(crkmtw) wlymnt $(k)) \star \star 3) \star c r k m t i$

strsm $=$ wiymnt $(k) \star a x n e u / e f m n t$

stltn $=$ ratmod*wlymnt $(k) *$ (wldstx-axneu) $/$ efmnt

\#

axsnex $=$ wldstx/(stltn/stlmod+strsm/conmod $) *($ stltn/stlmod + csstrn) +tencux $(1,2)$

betax $=$ axsnex $/(\operatorname{axsnex}-\operatorname{tencvx}(1,2))$

wlfrdp $(k)=$ axsnex

frcwdy $=$ wlfrsp $(k) *($ stltn/stlmod*betax+csstrn)

endif

c.....Moments exceed ultimate strength of wall.

if (wlymnt(k).ge.wlustx .and. wlfrap (k).1t.cmthk $(1,2)$ ) then

wlfrdp $(k)=\operatorname{cmthk}(1,2)$

\#

frcwdy $=\operatorname{aminl}\left((s t l y l d / s t l m o d+c s s t r n) * w l f r s p(k), 3 \cdot e-3^{*}\right.$ wlfrsp $(k))$

endif

c..... Calculate average fracture characteristics.

if $(\operatorname{cmthk}(1,2)$.eq. 0.$)$ then

$\operatorname{aper}(2)=0$.

$\operatorname{frac}(2)=0$.

return

else

fmax $=.75 * \operatorname{conthk}(1,2)$

depth $=\operatorname{amax} 1(w)$ frdp $(k)$, sfrcdy, cmfrdp)

if (depth .ge. fmax) then

$\operatorname{tmp} 1=0$.

$\operatorname{tinp2}=0$.

$\operatorname{tmp} 3=0$.

$k r k y=k r k y+1$

if (wlfrsp (k) .gt. 0.$)$ tmpl $=$ slhght/10./wlfrsp $(k)$

if (sfrcsy.gt. 0.) tmp2 = singht/10./sfrcsy

if (cmfrsp .gt. 0.) tmp $3=$ cmfrsp

tmp $=$ tmp $1+$ tmp $2+$ tmp 3

$\#$

aper $(2)=\operatorname{aper}(2)+($ frcwdy*tmp $1+$ sfrcwy*tmp $2+$

cmfrwd*tmp3) /tmp

$\operatorname{frac}(2)=\operatorname{frac}(2)+2{ }^{\star} \operatorname{silrad}{ }^{*} \mathrm{pi} * \operatorname{cmthk}(1,2) *($ frcwdy*tmp $1+$ 
$\#$

sfrcwy*tmp2)

if (tmp3 .eg. nsave2) then

$\operatorname{frac}(2)=\operatorname{frac}(2)+\operatorname{slhght} / 10 \cdot{ }^{*} \operatorname{cmthk}(1,2){ }^{*} \operatorname{cmfrwd}{ }^{*} \operatorname{tmp} 3$

else

$\operatorname{frac}(2)=\operatorname{frac}(2)+2 .{ }^{*} \operatorname{silrad}{ }^{*} p i * \operatorname{cmth} k(1,2) * \operatorname{cmfrwd} * \operatorname{tmp} 3$

endif

endif

endif

300 continue

if $(\operatorname{frac}(2) . g t .0$.$) icrack(2) =1$

do $400 j=1,2$

if (frac(2) .gt. 0.) then

\#

$\operatorname{frac}(2)=\operatorname{frac}(2) /\left(\operatorname{slhght} p^{*}\left(\left(\operatorname{silrad}+0.5^{\star} \operatorname{cmthk}(1,2)\right)\right.\right.$

$\star \star 2-(\operatorname{silrad}-0.5 * \operatorname{coth} k(1,2)) \star \star 2))$

$\operatorname{aper}(2)=\operatorname{aper}(2) /(k r k x+k r k y) * 2.54$

endif

400 continue

return

end

function sxierfc ( $x$ )

Called by: flothru

Function used in diffusion leaching calculations (2 december 1991).

Calls: none

implicit double precision $(a-h, 0-z)$

common/numb/mmax

data rsspi / 5.641895835477563d-1/

$x s q=x * \star 2$

$u=\operatorname{rsrpi} i^{\star} x s q$

sum $=$ rsrpi $-x+u$

$d=6.20$

$e=9 . d 0$

thm $2 \mathrm{~m}=-1 . \mathrm{do}$

do $100 \mathrm{~m}=2,30$

$\max =\mathrm{m}$

$u=u * x s q *$ thm $2 m / d$

$\operatorname{sum}=\operatorname{sum}+u$

if (abs (u/sum) .1t. 5.d-9) go to 110

$d=d+e$

$e=e+4 . d 0$

$\operatorname{thm} 2 m=\operatorname{thm} 2 m-2 . d 0$

100 continue

write $(*, *)$ 'sxierfc: series did not converge' 
110 continue

sxierfc $=$ sum

return

end

subroutine wfl (attack, iyear)

$\begin{array}{ll}\text { c } & \text { Called by: source } 2 \\ \text { c } & \text { Performs cracking analysis for silo floor } \\ \text { c } & \text { Calls: none }\end{array}$

common/clcult/annprc, aper (3), attk $(2,3), \operatorname{crfrac}(3), \operatorname{crfrcd}(3)$,

\# $\quad \operatorname{crfrcw}(3), \operatorname{crfrcs}(3)$, crpcof, csstrn, frac (3), icl (3), ico2 (3),

$\#$ icrack (3), icrflg (3), ifail (3), isave1, isave 2, ispl $(3), \operatorname{ph}(2,3)$,

\# slfi,slfo, stlcor (3), xload, xperc (2)

common/concrt/ca, cacon, cagw, cap, ccdns, ccon, ccpor, cfa, cfb, clcon,

\# co3, com28d, conpsn, constr, phbeg, si, stlmod, stlyld, wcr, wtcmnt,

\# yngmod

common/moment/rfxmnt $(11,11)$, rfymnt $(11,11)$, rwxmnt $(11,11)$,

\# rwymnt $(11,11)$, flxment $(11,11)$, flymnt $(11,11)$, fwxant $(11,11)$.

* fwymnt $(11,11)$, wlymnt (11), wwymnt (11)

common/shear/rfshr, rfwshr, flshr, flwshr, wlyshr (11), wwyshr (11)

common/silo/cmthk $(2,3)$, comcvx $(2,3)$, comcvy $(2,3)$, curdns, cvrthk,

\# flangl, idflag, omthk $(2,3)$, ostlrd (3), osttkc, osttkt,

\# otncvx $(2,3)$, otncvy $(2,3)$, silrad, slangl, sldns, slhght,

\# stlrad (3), stispc (3), sttkcm, sttktn, submod, tencvx $(2,3)$,

* tencvy $(2,3)$, wstdns, wsthk, wstht

common/well/stldns, stlpsn, wlhght, wlrad, wlstr

data wstred/.65/

c..... Calculate time-dependent parameters used in cracking analysis.

time $=$ iyear $\$ 365$.

comstr $=\operatorname{amin} 1$ (time $/(c f a+c f b * t i m e) * \operatorname{com} 28 d * a t t a c k$, constr*attack)

conmod $=5.7 e 4 * \operatorname{sqrt}($ comstr) $/(1 .+$ crpcof $)$

ratmod $=\mathrm{stlmod} /$ conmod

rupmod $=7.5 *$ sqrt (comstr)

fldst $x=$ conthk $(2,3)$-tencvx $(2,3)$

fldsty $=$ cmthk $(2,3)$-tencvy $(2,3)$

starcm $=0$.

startn $=0$.

cominti $=\operatorname{coth} k(2,3) \star \star 3 / 12$

crkmtf $=$ cnmnti $/\left(0.5^{\star}\right.$ cmthk $\left.(2,3)\right) \star$ rupmod

c..... Calculate ultimate strength for floor.

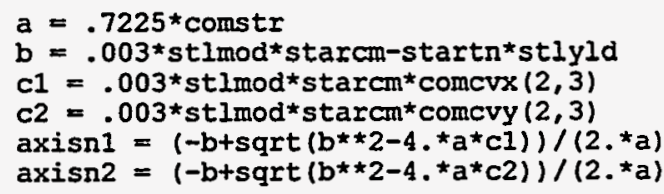

if (axisn 1 . Ie. comcrx $(2,3))$ then

cmbIk $=$ startn*stlyld $/\left(0.85^{\star}\right.$ comstr $)$

flustx $=\operatorname{amax} 1($ crkmtf, wstred*stlyld*startn*(fldstx-cmblk/2.))

else

csstrs $=(\operatorname{axisn} 1-\operatorname{comcvx}(2,3)) / \operatorname{axisn} 1 * .003^{*}$ st $l \bmod$

as $2=$ starcm ${ }^{\star}$ csstrs/stlyld

as1 = startn-as2

cmblk = as $1 *$ stlyld $/\left(0.85^{\star}\right.$ comst $\left.x\right)$

flustx $=\operatorname{amax} 1($ crkmtf, wstred* (as $1 * \operatorname{stlyld*}($ fldstx-cmblk/2.)+ 
endif

if (axisn2 .1e, comcry $(2,3))$ then

cmblk = startn*stlyld $/(0.85 *$ comstr $)$

flusty $=\operatorname{amaxl}($ crkmtf, wstred*stlyld*startn*(fldsty-cmblk/2.))

else

csstrs $=($ axisn2-comcry $(2,3)) /$ axisn2*.003*stlmod

as2 $=$ starcm ${ }^{\star}$ csstrs/stiyld

as 1 = startn-as2

cmblk = as $1 * s t l y l d /(0.85 *$ comstr $)$

$\#$

flusty $=$ amaxl (crkmtf, wstred* (as1*stlyld* (fldsty-cmblk/2.) +

endif

c..... Calculate cracking moment of inertia for floor for $x$ and $y$ directions.

$a a=0.5$

$b b=\operatorname{starcm} *(\operatorname{ratmod}-1)+.s t a r t n *$ ratmod

ccx $=\operatorname{comcvx}(2,3) \star \operatorname{starcm}($ ratmod -1.$)$-fldstx*ratmod*startn

ccy $=\operatorname{comcvy}(2,3) * s t a r c m *($ ratmod -1.$)$-fldsty* ratmod*startn

rttlx $=\left(-b b+\operatorname{sgrt}\left(b b \star \star 2-4 .{ }^{*} a a^{\star} c c x\right)\right) /(2 . \star a a)$

rttly $=\left(-b b+\operatorname{sqrt}\left(b b^{\star *} 2-4 .{ }^{*} a a^{*} c c y\right)\right) /(2 . \star a a)$

$\operatorname{rtt} 2 x=(-b b-\operatorname{sqrt}(b b * \star 2-4 . * a a * c c x)) /(2, * a a)$

$r t t 2 y=(-b b-s q r t(b b \star \star 2-4 . \star a a * c c y)) /(2 . \star a a)$

axneux $=\operatorname{rtt} 1 \mathrm{x}$

axneuy $=$ rtt1y

crmtix $=0.333 * \operatorname{axneux} * * 3+\operatorname{starcm} *(\operatorname{ratmod}-1) *.(\operatorname{axneux}-\operatorname{comcvx}(2,3))$

$\#$ $\star \star 2+$ ratmod*startn* (fldst $x-$ axneux $) \star \star 2$

crmtiy $=0.333 *$ axneuy $* * 3+\operatorname{starcm} *($ ratmod -1.$) *($ axneuy $-\operatorname{comcvy}(2,3))$

$\#$ $\star \star 2+$ ratmod $\star$ start $\approx \star($ fldsty-axneuy $) \star \star 2$

c.....Calculate shear cracking.

$x k=(1.6+2.4 *($ wl rad $/$ wl rad -0.5$)) * 0.29$

shrstx $=1.7 *$ sqrt (comstr) $*$ fldstx

shrsty $=1.7 *$ sqrt (comstr) *fldsty

do $200 \mathrm{k}=1,6$

do $1001=1,6$

if (flwshr .ge. shrstx) then

if (fwxmant $(k, 1)$.gt. 0. ) then

tmp $=\operatorname{amin} 1$ (flwshr/fwxant $(k, 1) \star f l d s t x, 1$.

ver $=\operatorname{amin} 1\left(1.9^{*}\right.$ sqrt $($ comstr $)+2500$.*startn/fldstx*

$\#$ tmp) *fldstx, $3.5 * s q r t($ comstr) $*$ fldstx)

else

vcr $=3.5 * s q r t($ comstr $) \star f l d s t x$

endif

if(flwshr.ge. vcr) ifail(3) $=1$

endif

c.....x-moments exceed cracking moment but not ultimate strength of floor.

if (fwxmnt $(k, 1)$.ge.crkmtf .and. fwxmnt $(k, 1)$.1t.flustx) then

$\#$

efmntx $=($ crkmtf $/$ fwxmnt $(k, 1)) \star * 3 *$ cnmnti+(1.- $($ crkmtf $)$

fwxmnt $(k, 1)) * * 3) *$ crmtix

strsmx $=$ fwxmnt $(k, 1) *$ axneux/efmntx

stltnx $=$ ratmod*fwxmnt $(k, 1) *($ fldstx-axneux $) /$ efmntx

axsnex $=\mathrm{fldstx} /($ stItnx/stlmod+strsmx/conmod $) \star(s t l t n x)$

stlmod+csstrn)+tencvx $(2,3)$ 
betax $=$ axsnex $/(\operatorname{axsnex}-$ tencvx $(2,3))$

depth = axsnex

if (depth .ge. cmthk $(2,3))$ ifail $(3)=1$

endif

c.....x-moments exceed ultimate strength of floor.

if (fwxmnt $(k, I)$.ge. flustx) ifail(3) $=1$

c..... Perform shear cracking calculations for $y$ direction of floor.

if (flwshr.ge. shrsty) then

if (fwymnt $(k, 1)$.gt. 0.) then

tmp $=\operatorname{amin} 1(f l w s h r / f w y m n t(k, 1) * f l d s t y, 1$.

vcr $=\operatorname{aminl}\left(\left(1.9^{*}\right.\right.$ sqrt (comstr) $+2500 .{ }^{*}$ startn $/$ fldsty*

\# tmp) * fldsty, $3.5 *$ sqrt $($ comstr) $*$ fldsty)

else

ver $=3.5^{\star}$ sgrt $($ comstr $) \star$ fldsty

endif

if(flwshr .ge. vcr) ifail (3) $=1$

endif

c..... Y-moments exceed cracking moment but not ultimate strength of floor.

if (fwymnt $(k, 1)$.ge.crkmtf .and. fwymnt $(k, 1) .1 t$.flusty) then

\#

efmnty $=($ crkmtf $/$ fwymnt $(k, 1)) * * 3 *$ cnmnti $+(1,-($ crkmtf $)$ fwymnt $(k, 1)) \star \star 3) \star c r m t i y$

strsmy $=$ fwymnt $(k, 1) *$ axneuy/efmnty

stltny $=$ ratmod $\star$ fwymnt $(k, 1) \star($ fldsty-axneuy $) /$ efmnty

axsney $=$ fldsty/(stitny/stimod+strsmy/conmod $) *($ stitny $/$

\# betay = $\quad$ axsney/(axsney-tencvy $(2,3)$

depth = axsney

if (depth .ge. cmthk $(2,3))$ ifail $(3)=1$

endif

c.....Y-moments exceed ultimate strength of floor.

if (fwymnt $(k, 1)$.ge. flusty) ifail $(3)=1$

100 continue

200 continue

return

end

subroutine wrf(attack, iyear)

\footnotetext{
Called by: source 2

c Performs cracking analysis for well roof.

C Calls: none

c--o-n--

common/clcult/annprc, aper (3), attk $(2,3), \operatorname{crfrac}(3), \operatorname{crfrcd}(3)$,

\# crfrcw (3), crfrcs (3), crpcof, csstrn, frac (3), icl (3), ico2 (3),

\# icrack (3), icrflg (3), ifail (3), isavel, isave, ispl $(3), \mathrm{ph}(2,3)$,

\# slfi,slfo, stlcor(3), xload, xperc (2)

common/concrt/ca, cacon, cagw, cap, ccdns, ccon, ccpor, cfa, cfb, clcon,

\# $\quad \operatorname{co3}$, com28d, conpsn, constr, phbeg, si, stimod, stlyld, wcr, wtcmnt,
} 
\# yngmod

common/moment/rfxmnt $(11,11)$, rfymnt $(11,11)$, rwxmnt $(11,11)$,

\# rwymnt $(11,11)$, flxmnt $(11,11)$, flymnt $(11,11)$, fwxmnt $(11,11)$,

\# fwymnt $(11,11)$, wlymnt (11), wwymnt (11)

common/shear/Ifshr, rfwshr, flshr, flwshr, wlyshr (11), wwyshr (11)

common/silo/cmthk $(2,3), \operatorname{comcvx}(2,3)$, comcvy $(2,3)$, cvrdns, cvrthk,

\# flangl, idflag, ommthk (2,3), ostlrd(3), osttkc, osttkt,

\# otncvx $(2,3)$, otncvy $(2,3)$, silrad, slangl, sldns, slight,

\# $\quad$ stlrad (3), stlspc (3), sttkcm, sttktn, submod, tencvx $(2,3)$,

\# tencvy $(2,3)$, wstans, wsthk, wstht

common/well/stldns, stlpsn, wlhght, wirad, wlstr

data wstred/.65/

c..... Calculate time-dependent parameters used in cracking analysis.

time $=$ iyear $\star 365$.

comstr $=$ amin1 (time $/\left(\right.$ cfa+cfb*time) ${ }^{\star}$ com28d*attack, constr*attack)

conmod $=5.7 e 4 * s q r t($ comstr $) /(1 .+\operatorname{crpcof})$

ratmod $=$ stlmod/conmod

rupmod $=7.5^{\star}$ sqrt (comstr)

rfdstx $=$ cmthk $(2,1)-$ tencvx $(2,1)$

rfdsty $=\operatorname{cmthk}(2,1)-\operatorname{tencvy}(2,1)$

starcm $=0$

startn $=0$.

cnmnti $=$ cmthk $(2,1) \star \star 3 / 12$

if $($ cmthk $(2,1)$.ne. 0.0$)$ crkmtr $=\operatorname{cnmnti} /\left(0.5^{*} \mathrm{cmthk}(2,1)\right)^{\star}$ rupmod

c..... Calculate ultimate strength for roof.

$a=.7225^{\star}$ comstr

$b=.003 * s t l m o d * s t a r c m-s t a r t n * s t l y l d$

$c 1=.003^{\star}$ stlmod*starcm*comcvx $(2,1)$

$c 2=.003^{\star} s$ t lmod*starcm* comcvy $(2,1)$

$\operatorname{axisn} 1=\left(-b+s q r t\left(b * * 2-4 \cdot{ }^{*} a * c 1\right)\right) /\left(2,{ }^{\star} a\right)$

axisn $2=(-b+\operatorname{sqrt}(b * \star 2-4 . \star a \star c 2)) /(2 . \star a)$

if $(\operatorname{axisn} 1$. Ie. $\operatorname{comcvx}(2,1))$ then

cmblk = startn*stlyld/(0.85* comstr $)$

rfustx $=\operatorname{amax} 1$ (crkmtr, wstred*stlyld*startn*(Ifdstx-cmblk/2.))

else

csstrs $=(\operatorname{axisn} 1-\operatorname{comcvx}(2,1)) / \operatorname{axisn} 1 * .003 *$ st $1 \bmod$

as2 = starcm*csstrs/stlyld

as1 = startn-as2

$\mathrm{cmblk}=\mathrm{as} I^{*} \mathrm{stlyld} /\left(0.85^{*}\right.$ comstr $)$

$\#$

rfustx $=\operatorname{amaxl}$ (crkmtr,wstred*(as $1 * s t$ lyld*(rfdstx-cmblk/2.) +

endif

if(axisn2. Ie. comcry $(2,1))$ then

cmblk = startn*stlyld $/(0.85 *$ comstr $)$

rfusty $=\operatorname{amax} 1$ (crkmtr, wstred*stlyld*startn* (rfdsty-cmblk/2.))

else

csstrs $=(\operatorname{axisn} 2-\operatorname{comcvy}(2,1)) / \operatorname{axisn2*} .003 *$ st $1 \mathrm{mod}$

as2 = starcm*csstrs/stlyld

as1 = startn-as2

cmblk $=a s 1^{\star} s t l y l d /\left(0.85^{\star}\right.$ comstr $)$

$\#$

rfusty $=\operatorname{amax} I$ (crkmtr, wstred* (as $1 *$ stlyld* (rfdsty-cmblk/2.) +

endif

c..... Calculate cracking moment of inertia for roof for $x$ and $y$ directions.

$a a=0.5$

$\mathrm{bb}=$ starcm* $($ ratmod-1.)+startn*ratmod 


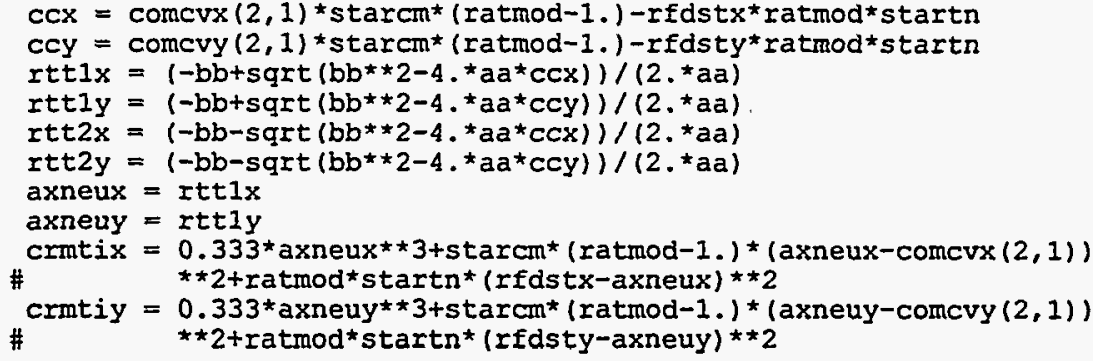

c..... Calculate cracking due to shear for roof of silos.

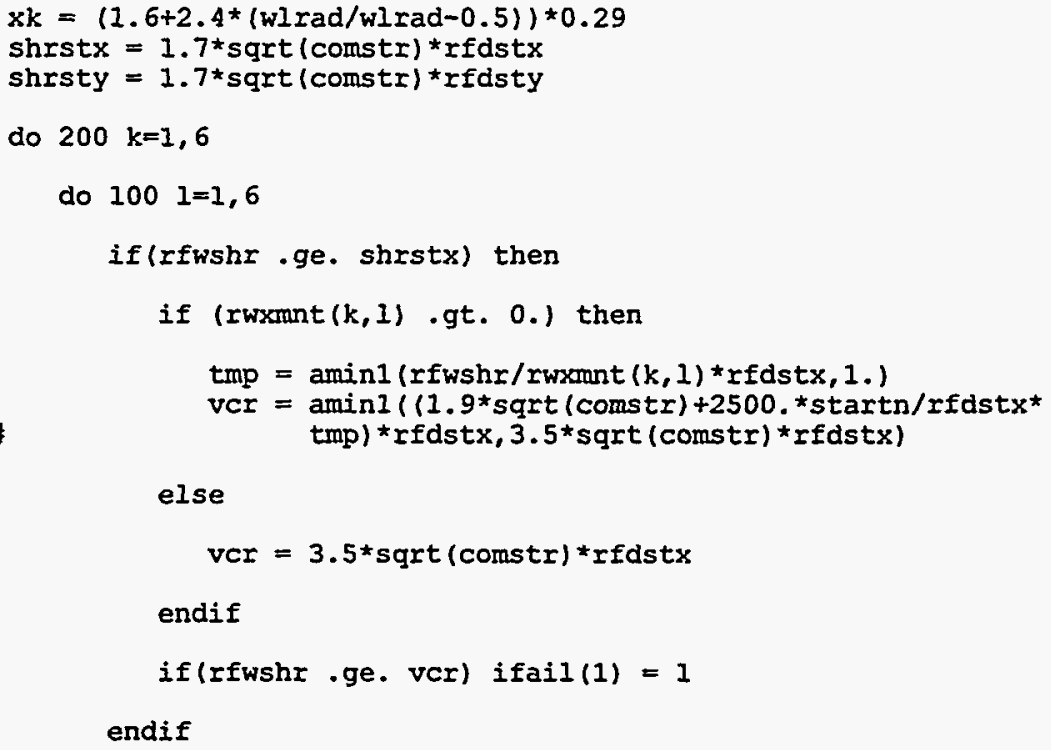

c.....x-moments exceed cracking moment but not ultimate strength of roof.

if (rwxmnt $(k, 1) \cdot g e . c r k m t r$.and. rwxmnt $(k, 1) .14$. .rfustx) then

\#

efmntx $=($ crkmtr $/$ rwxmnt $(k, 1)) * \star 3^{*}$ cnmnti+(1.- (crkmtr) Iwxmnt $(k, 1)) \star \star 3) \star c$ cmtix

strsmx $=$ rwxmnt $(k, 1) *$ axneux/efmntx

stltnx $=$ ratmod*rwxmnt $(k, 1) *($ rfdstx-axneux $) /$ efmntx

axsnex $=$ rfdstx/(stltnx/stlmod+strsmx/conmod) (stltnx/

\# $\quad$ betax $=$ axsnex $/($ axsnex-tencrx $(2,1))$

depth $=$ axsnex

if (depth .ge. $0.75^{\star}$ cmthk $(2,1)$ ) ifail $(1)=1$

encif

c.....X-moments exceed ultimate strength of roof.

if (rwxmnt $(k, 1)$.ge. rfustx) ifail $(1)=1$

c.....Perform calculations for y direction of roof. Start with shear c.....cracking calculations.

if (rfwshr .ge. shrsty) then

if (rwymnt $(k, 1)$.gt. 0.) then

tmp $=\operatorname{amin} 1(r$ fwshr/rwymnt $(k, 1) *$ rfdsty, 1.)

vcr $=\operatorname{amin} 1\left(\left(1.9 *\right.\right.$ sqrt $($ comstr $)+2500 .{ }^{*} \operatorname{startn} / r$ fdsty*

\# tmp) * rfdsty, 3.5*sqrt (comstr) *rfdsty)

else 
ver $=3.5^{\star}$ sqrt $($ comstr $){ }^{\star} r f d s t y$

endif

if (rfwshr .ge. var) ifail $(1)=1$

endif

c...... Y-moments exceed cracking moment but not ultimate strength of roof.

if (rwymnt $(k, 1)$.ge.crkmtr .and. rwymnt $(k, 1) .1 t$.rfusty) then

\#

efmnty $=($ crkmtr $/$ rwymnt $(k, 1)) * * 3 *$ cnmnti $+(1 .-($ crkmtr $)$

strsmy $=$ rwymnt $(k, 1)) \star \star 3) \star$ crmtiy

stitny $=$ ratmod*rwymnt $(k, 1) *($ rfdsty-axneuy $) /$ efmnty

\#

axsney $=\mathrm{rfdsty} /(\text { stltny/stimod+strsny/conmod })^{\star}($ stltny $/$ stlmod+csstrn)+tencvy $(2,1)$

betay $=$ axsney $/($ axsney-tencry $(2,1))$

depth = axsney

if (depth .ge. cmthk $(2,1)$ ) ifail(1) $=1$

endif

c..... Y-moments exceed ultimate strength of roof.

if (rwymnt $(k, 1)$.ge. rfusty) ifail (1) $=1$

100

continue

200 continue

return

end

subroutine wwl

c Called by: source 2
c Performs cracking analysis for silo wall.
c Calls: none

common/clcult/annprc, aper (3), attk $(2,3), \operatorname{crfrac}(3), \operatorname{crfrcd}(3)$,

\# $\quad \operatorname{crfrcw}(3), \operatorname{crfrcs}(3), \operatorname{crpcof}, \operatorname{csstrn}$, frac (3), icl (3), ico2 (3),

\# icrack (3), icrflg (3), ifail (3), isavel, isave $2, i s p l(3), p h(2,3)$,

\# slfi,slfo, stlcor (3), xload, xperc (2)

common/concrt/ca, cacon, cagw, cap, ccdns, ccon, ccpor, cfa, cfb, clcon,

\# co3, com28d, conpsn, constr, phbeg, si, stlmod, stlyld, wcr, wtcmnt,

\# yngmod

common/moment/rfxmet $(11,11)$, Ifyment $(11,11)$, rwxomt $(11,11)$,

\# $\quad$ rwymnt $(11,11)$, flxmnt $(11,11)$, flymnt $(11,11)$, fwxmnt $(11,11)$,

\# fwymnt $(11,11)$, wlymant (11), wwymnt (11)

common/shear/rfshr, rfwshr, flshr, flwshr, wlyshr (11), wwyshr (11)

common/silo/cmthk $(2,3)$, comcvx $(2,3)$, comcvy $(2,3)$, cvrdns, cvrthk,

\# flangl, idflag, ommthk $(2,3)$, ostlrd (3), osttkc, osttkt,

\# otncvx $(2,3)$, otncvy $(2,3)$, silrad, slangl, sldns, slhght,

\# stlrad (3), stlspc (3), sttkcm, sttktn, submod, tencvx $(2,3)$,

\# tencvy $(2,3)$, wstdns, wsthk, wstht

common/well/stldins, stlpsn, wlhght, wlrad, wlstr

common/wlforc/wlcmfr(11), wlxrc (11), wlwxrc(11), wwcmfr(11)

c.....Calculate ultimate strength of well under ring compression and c..... allowable stress in tension.

pusrc $=\operatorname{aminl}\left(2 .{ }^{\star} \operatorname{cmthk}(2,2) \star 2 . e^{\star} \operatorname{cm} t h k(2,2) /\right.$ wlrad*abs $\left(1 .-33.333^{\star}\right.$

\# cmthk $(2,2) /$ wlrad), $3 . e^{*}$ cathk $(2,2)$ )

pipshr $=0.4 * 1.7 *$ Cmthk $(2,2) \star$ wlstr

c...... Compare calculated ring compressions and shears to ultimate strength c..... and allowable stress. 
do $100 k=1,11$

if (wlwxrc(k),ge.pusrc .or. wwyshr(k).ge.pipshr) ifail(2) $=1$

c..... Calculate maximum stress due to axial compression and bending, and c......check for failure.

if (cmthk $(2,2)$.gt. 0.$)$ then

pustr $=$ wwcmfr $(k) /$ cmthk $(2,2)+6$. *wwymnt $(k) /$ cmthk $(2,2) \star \star 2$

if (pustr.ge. wlstr) ifail (2) $=1$

else

ifail $(2)=1$

endif

100 continue

return

end 


\section{INTERNAL DISTRIBUTION}

1. J. M. Begovich

2. G. R. Cunningham

3. D. L. Daugherty

4. J. R. Forgy, Jr.

5-10. A. S. Icenhour

11. J. A. Klein

12. D. C. Kocher

13. D. W. Lee

14. S. L. Loghry

15. R. J. Luxmoore

16. L. E. McNeese

17. D. E. Reichle
18. R. Salmon

19. T. F. Scanlan

20. R. W. Sharpe

21. R. D. Spence

22. S. N. Storch

23. F. J. Sweeney

24. J. D. Tauxe

25. M. L. Tharp

26. M. W. Tull

27. M. W. Yambert

28-29. Central Research Library

30. ORNL Laboratory Records, RC

\section{EXTERNAL DISTRIBUTION}

31. H. W. Godbee, 104 Tidewater Lane, Oak Ridge, TN 37830

32. L. F. Miller, University of Tennessee, Department of Nuclear Engineering, Pasqua Engineering Bldg., Knoxville, TN 37996-2300

33. R. Shuman, Rogers \& Associates Engineering Corporation, 21124 E. Lakeshore Road, Big Fork, MT 59911

34. Office of Assistant Manager, Energy Research and Development, DOE-OR, P.O. Box 2001, Oak Ridge, TN 37831

35. Office of Scientific and Technical Information, P.O. Box 62, Oak Ridge, TN 37831 
